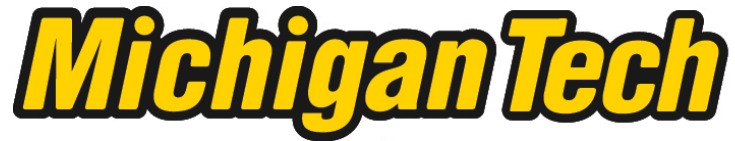 \\ Michigan Technological University Create the Future Digital Commons @ Michigan Tech
}

Dissertations, Master's Theses and Master's Reports - Open

Dissertations, Master's Theses and Master's

Reports

2009

\section{Capacity optimization of a prestressed concrete railroad tie}

Russell H. Lutch

Michigan Technological University

Follow this and additional works at: https://digitalcommons.mtu.edu/etds

Part of the Civil and Environmental Engineering Commons

Copyright 2009 Russell H. Lutch

\section{Recommended Citation}

Lutch, Russell H., "Capacity optimization of a prestressed concrete railroad tie", Master's Thesis, Michigan Technological University, 2009.

https://doi.org/10.37099/mtu.dc.etds/254

Follow this and additional works at: https://digitalcommons.mtu.edu/etds

Part of the Civil and Environmental Engineering Commons 


\title{
CAPACITY OPTIMIZATION
}

OF

\section{A PRESTRESSED CONCRETE RAILROAD TIE}

\author{
By: \\ RUSSELL H. LUTCH
}

\begin{abstract}
A THESIS
Submitted in partial fulfillment of the requirements

For the degree of

MASTER OF SCIENCE IN CIVIL ENGINEERING
\end{abstract}

MICHIGAN TECHNOLOGICAL UNIVERSITY

2009

Copyright (C) Russell H. Lutch 
This thesis, "Capacity Optimization of A Prestressed Concrete Railroad Tie", is hereby approved in partial fulfillment of the requirements for the Degree of MASTER OF SCIENCE IN CIVIL ENGINEERING.

DEPARTMENT:

Civil and Environmental Engineering

Signatures:

Thesis Advisor

Dr. Devin K. Harris

Department Chair

Dr. William Bulliet

Date 


\begin{abstract}
Today the use of concrete ties is on the rise in North America as they become an economically competitive alternative to the historical industry standard wood ties, while providing performance which exceeds its competition in terms of durability and capacity. Similarly, in response to rising energy costs, there is increased demand for efficient and sustainable transportation of people and goods. One source of such transportation is the railroad. To accommodate the increased demand, railroads are constructing new track and upgrading existing track. This update to the track system will increase its capacity while making it a more reliable means of transportation compared to other alternatives. In addition to increasing the track system capacity, railroads are considering an increase in the size of the typical freight rail car to allow larger tonnage. An increase in rail car loads will in turn affect the performance requirements of the track.
\end{abstract}

Due to the increased loads heavy haul railroads are considering applying to their tracks, current designs of prestressed concrete railroad ties for heavy haul applications may be undersized. In an effort to maximize tie capacity while maintaining tie geometry, fastening systems and installation equipment, a parametric study to optimize the existing designs was completed. The optimization focused on maximizing the capacity of an existing tie design through an investigation of prestressing quantity, configuration, stress levels and other material properties.

The results of the parametric optimization indicate that the capacity of an existing tie can be increased most efficiently by increasing the diameter of the prestressing and concrete strength. However, researchers also found that current design specifications and procedures do not include consideration of tie behavior beyond the current tie capacity limit of cracking to the first layer of prestressing. In addition to limiting analysis to the cracking limit, failure mechanisms such as shear in deep beams at the rail seat or pullout failure of the prestressing due to lack of development length were absent from specified design procedures, but discussed in this project. 


\section{ACKNOWLEDGEMENTS}

First, I would like to express my gratitude to the faculty members at Michigan Technological University for their support during both my graduate and undergraduate studies. Without their encouragement I would have never considered further education beyond my undergraduate career. In particular I would like to express my appreciation to Dr. Devin Harris for his assistance and direction during the course of my research labors. It was an honor to be his first graduate student and I hope that those who follow me appreciate his efforts and participation in their academic endeavors as much as I have. I would like to thank Dr. Theresa Ahlborn for serving on my committee and providing continual support during the completion of this research and in the classroom. Dr. Ahlborn was influential in my decision to attend Michigan Technological University for graduate school and helped to initiate my graduate studies by allowing me to work as an undergraduate research assistant on the project which became the foundation of my graduate research.

My project would not have been possible without the participation of L.B. Foster CXT ${ }^{\circledR}$, specifically Pelle Duong and Vince Petersen. They provided both the inspiration for the research and guidance during its completion.

Most of all I would like to thank my family for their support, especially my grandfather, who passed away during my graduate studies and was one of my biggest supporters and inspirations.

\section{DISCLAIMER}

The content of this report reflects the views of the authors, who are responsible for the facts and accuracy of the information presented herein. 


\section{Table of Contents}

ABSTRACT

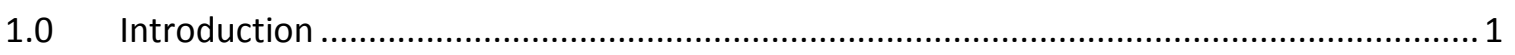

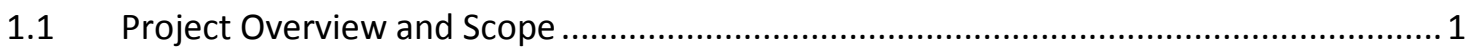

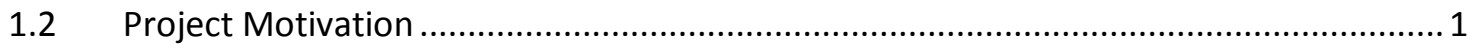

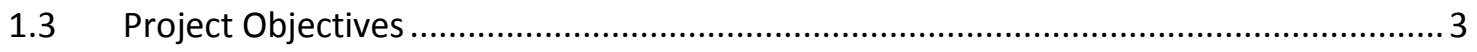

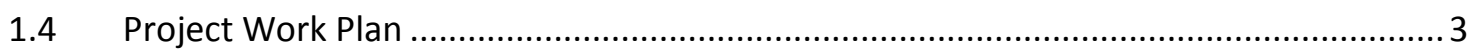

1.4.1 Phase I: Design/Analysis Validation .................................................................... 3

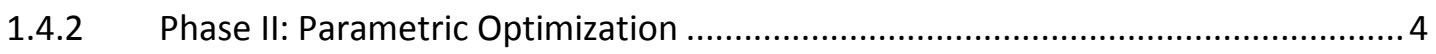

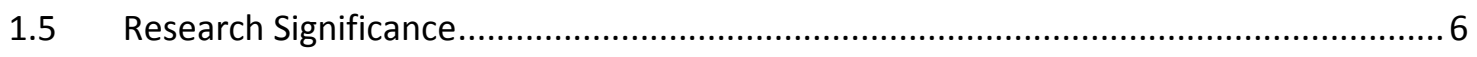

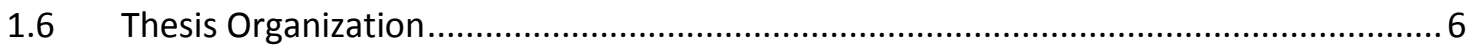

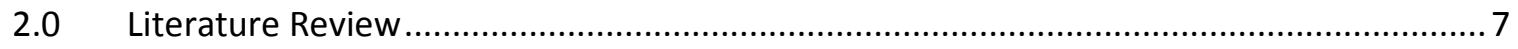

2.1 Overview of Prestressed Concrete Railroad Ties ........................................................

2.1.1 Introduction to Concrete Railroad Ties............................................................ 7

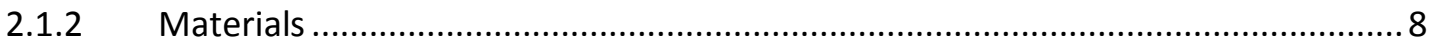

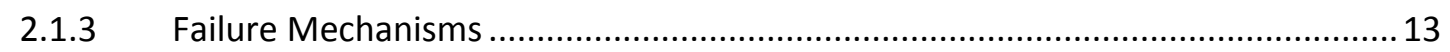

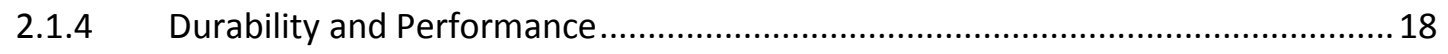

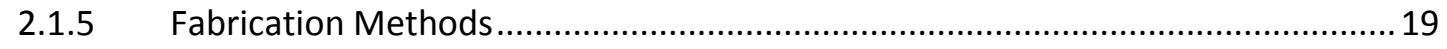

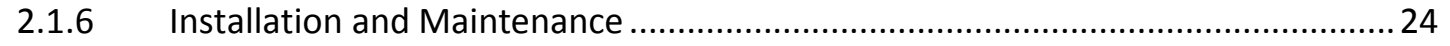

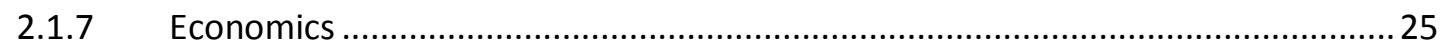

2.2 Prestressed Concrete Railroad Tie Design ............................................................ 26

2.2.1 Design Considerations and Load Development .................................................26

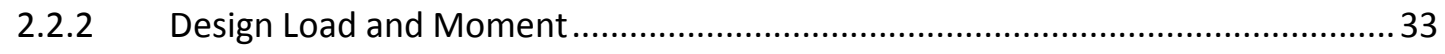

2.2.3 Load Cases and Critical Sections ......................................................................... 35 


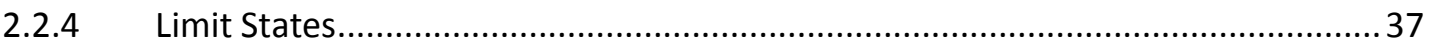

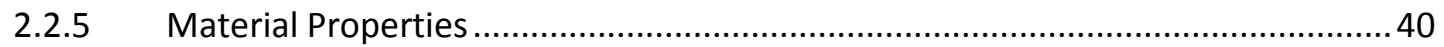

2.2.6 Anchorage of Prestressing in End Zone (Bursting)............................................. 44

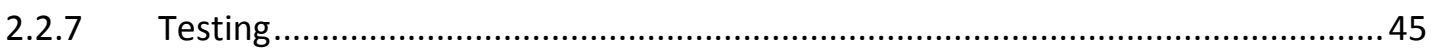

2.2.8 Performance Requirements and Tolerances .................................................. 47

2.2.9 Existing Prestressed Concrete and Railroad Specifications .................................. 49

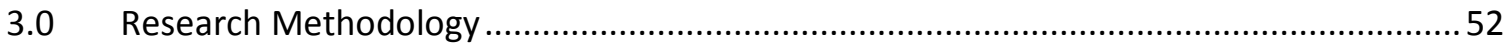

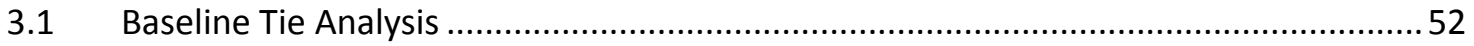

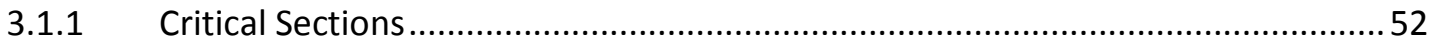

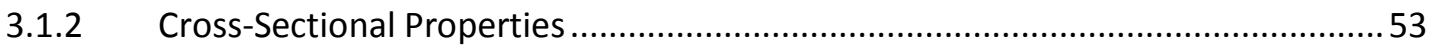

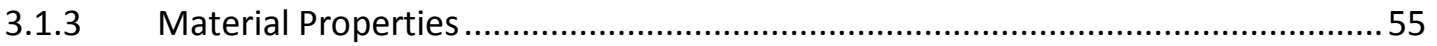

3.1.4 Prestressing Forces and Losses ...................................................................... 58

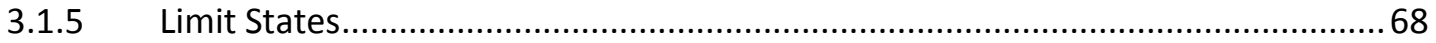

3.1.6 Nominal Flexural Capacity Using Strain Compatibility......................................... 70

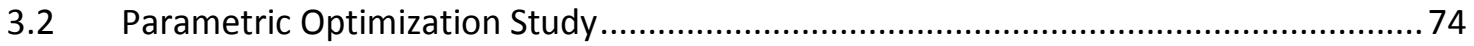

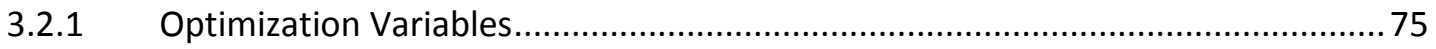

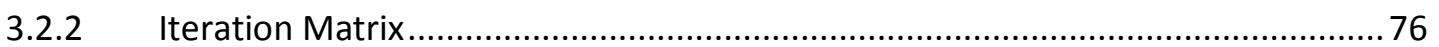

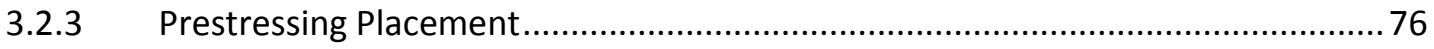

3.2.4 Baseline and Optimized Tie Analysis Similarities ................................................. 78

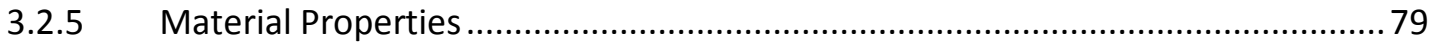

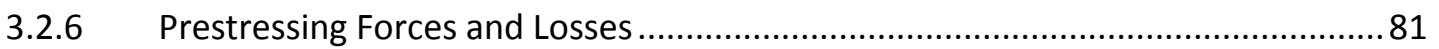

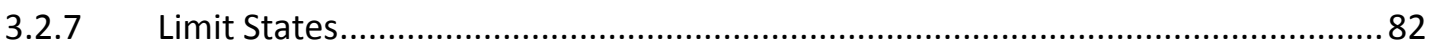

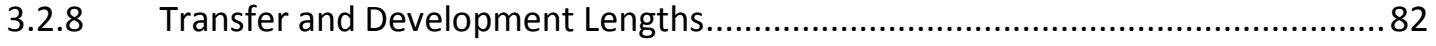

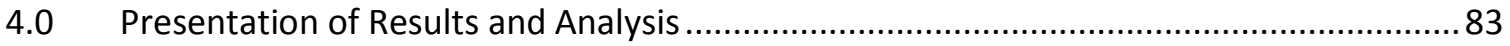

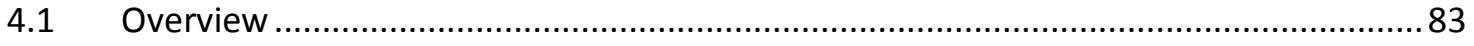

4.2 Numerical Analysis: Baseline Tie Design Results (Phase I) ......................................... 83

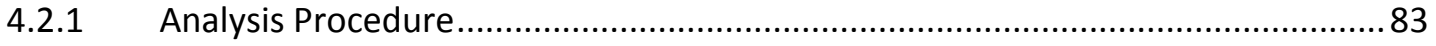

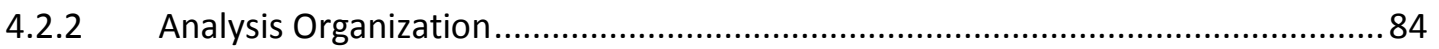

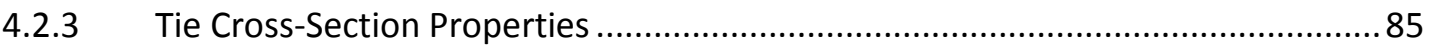




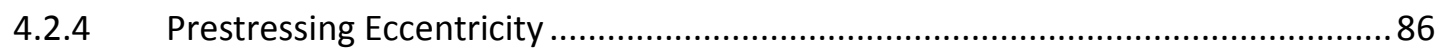

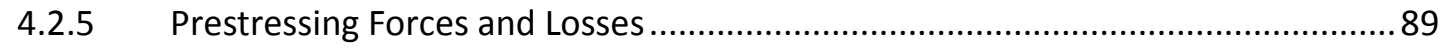

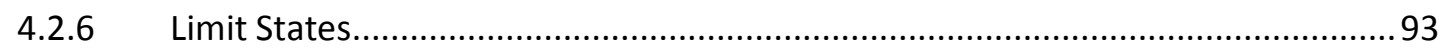

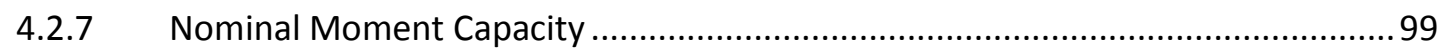

4.2.8 Comparison of Calculated to Manufacturer Values............................................. 106

4.3 Numerical Analysis: Parametric Optimization Results (Phase II) ............................... 113

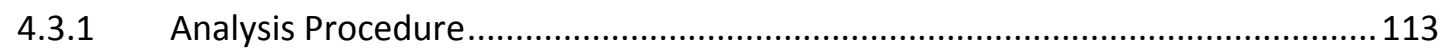

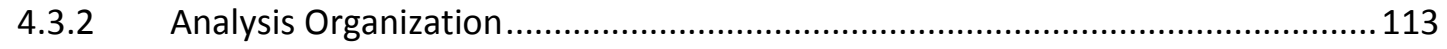

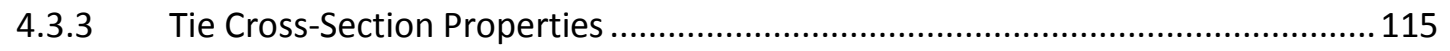

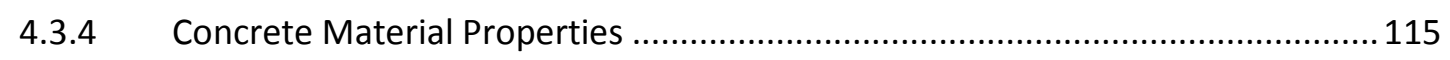

4.3.5 Prestressing Properties and Placement ........................................................... 117

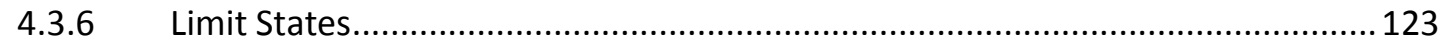

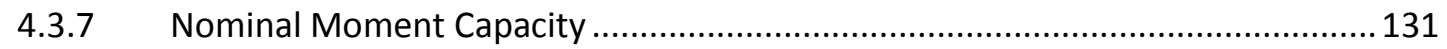

5.0 Summary, Conclusions and Recommendations....................................................... 139

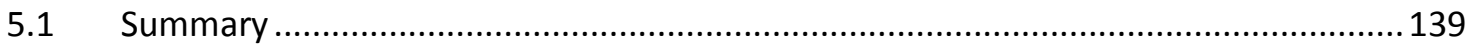

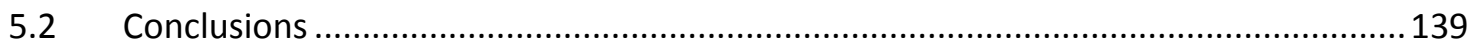

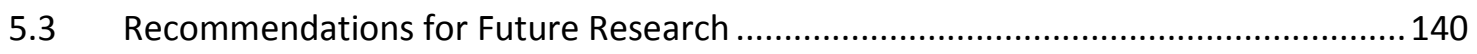

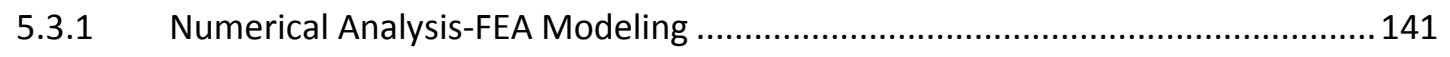

5.3.2 Validation Testing-Optimized Tie Designs .......................................................... 141

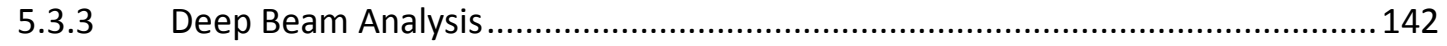

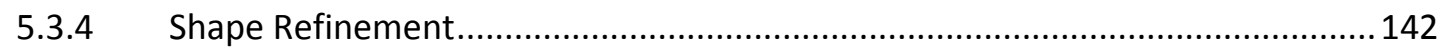

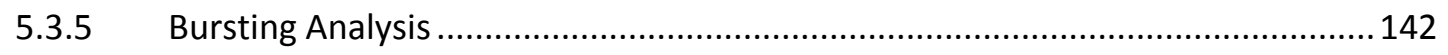

5.3.6 ASTM Material Testing for Creep and Shrinkage ............................................. 143

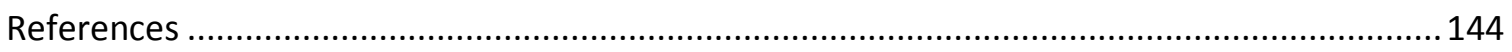

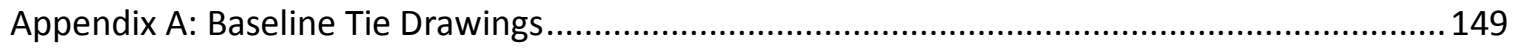

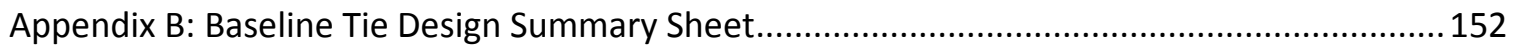

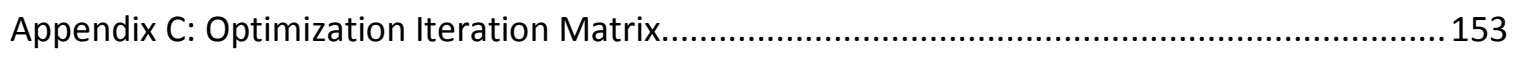

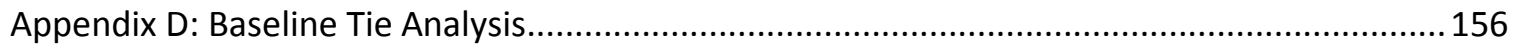

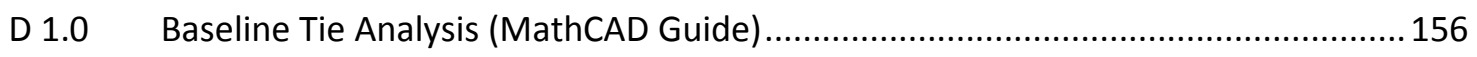

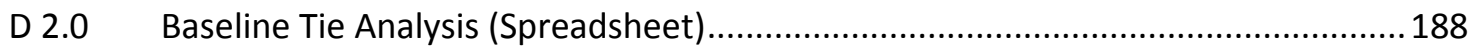




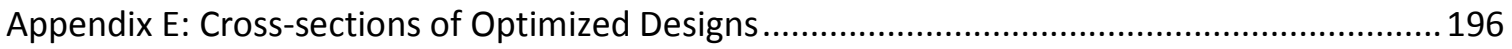

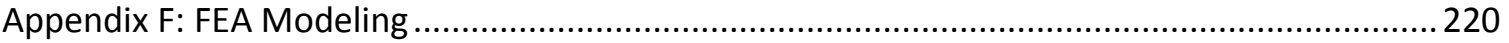

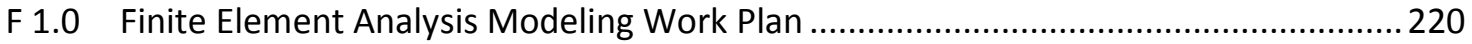

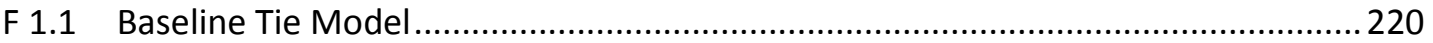

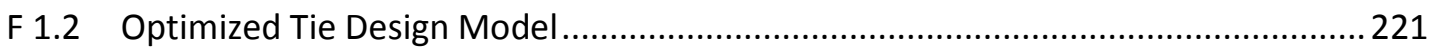

F 2.0 Modeling Prestressed Concrete Ties Using Finite Element Analysis ..........................2221

F 2.1 Introduction to the Application of FEA to Prestressed Concrete ...........................221

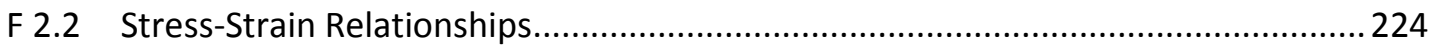

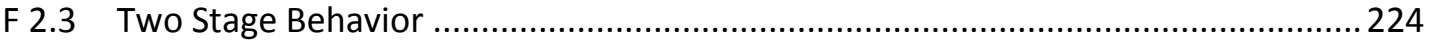

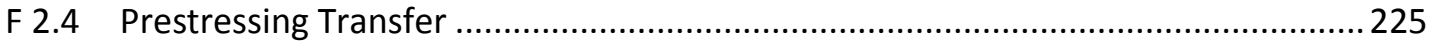

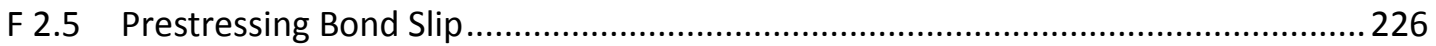

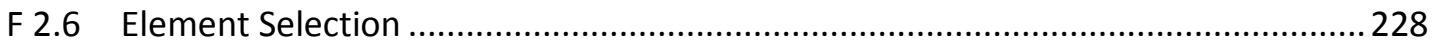

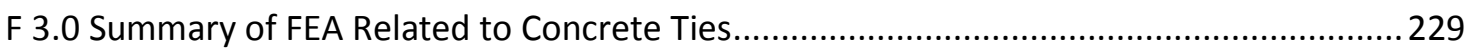

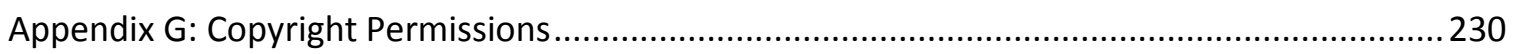




\section{LIST OF FIGURES}

Figure 1: Alaska Canada Rail Link (ACRL) route map .............................................................. 2

Figure 2: Generic concrete tie shape and dimensions............................................................ 7

Figure 3: Typical concrete maturity chart for an early high strength mixture used in prestressed

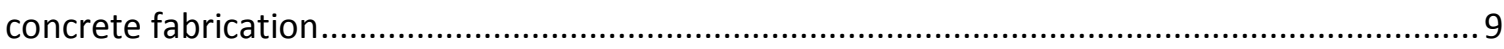

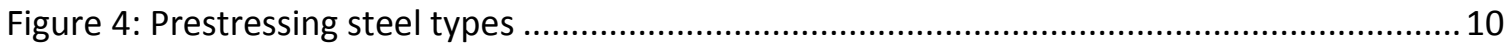

Figure 5: Embedded cast iron shoulder for PANDROL E-CLIP fastening system........................... 12

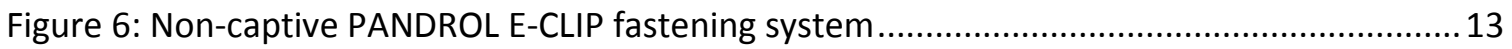

Figure 7: Captive PANDROL SAFELOK III fastening system ..................................................... 13

Figure 8: Rail seat abrasion where cement paste has been removed leaving an uneven aggregate

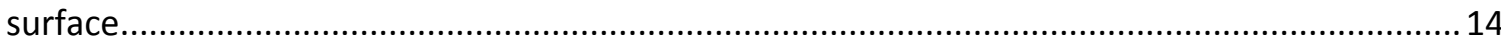

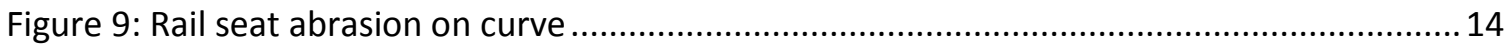

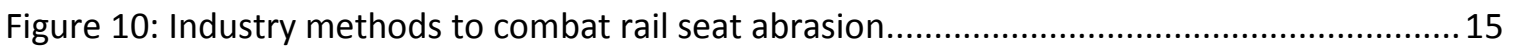

Figure 11: Center-binding support and void configuration ..................................................... 16

Figure 12: Rail fastener components effected by fatigue......................................................... 17

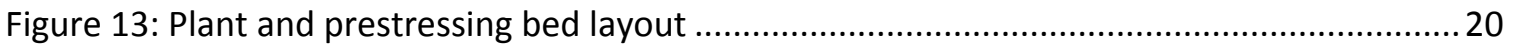

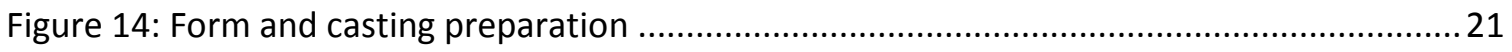

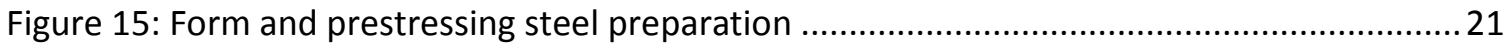

Figure 16: Prestressing set and jacking configuration ............................................................ 22

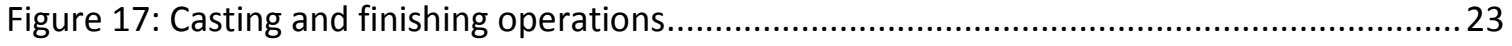

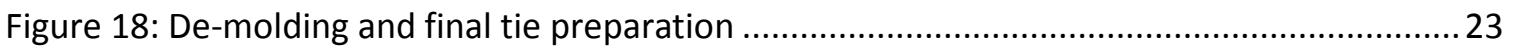

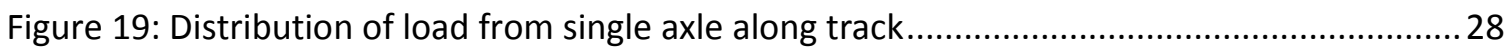

Figure 20: Estimated distribution of loads based on tie spacing ...............................................29

Figure 21: First round of tamping, consolidation restricted to rail seat region............................ 30

Figure 22: Ballast support distribution configurations ............................................................. 31

Figure 23: Lateral force applied to rail which tie must transfer to ballast as train navigates curves

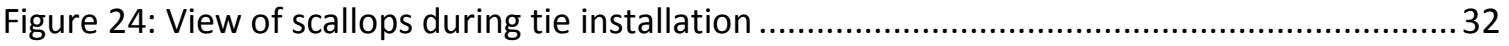

Figure 25: Cooper E 80 load configuration corresponding to a 315 kip car ................................ 33

Figure 26: AREMA load factor charts for speed and tonnage ................................................... 35 
Figure 27: Load Case 1: After installation and tamping, ballast support limited to rail seat region producing positive moment in rail seat section .36

Figure 28: Load Case 2: Over time settlement and ballast degradation lead to uniform ballast support inducing negative moment at center section and continued positive moment at railseat

Figure 29: Flexural critical sections for generic concrete tie (a) rail seat section (b) center section

Figure 30: Load/deflection curve for flexural prestressed concrete member showing cracking and maximum loads.

Figure 31: Prestressed concrete beam failure corresponding to Figure 30, showing flexural cracking and crushing of the compression zone. 39

Figure 32: Failures due to excessive tensile force in anchorage zone. 44

Figure 33: Positive rail seat moment test configuration as outlined in AREMA 4.9.1 Design Test of Monoblock Ties 45

Figure 34: Negative rail seat moment test configuration as outlined in AREMA 4.9.1 Design Test of Monoblock Ties. 46

Figure 35: Positive center moment test configuration as outlined in AREMA 4.9.1 Design Test of Monoblock Ties. 46

Figure 36: Negative center moment test configuration as outlined in AREMA 4.9.1 Design Test of Monoblock Ties .46

Figure 37: Workers checking rail cant and gauge of tie form using jig equipped with dial gauges

Figure 38: AREMA unfactored positive bending moment at centerline of railseat based on 315 kip car and Cooper E80 load configuration .48

Figure 39: Positive rail seat bending moment reduction according to EN 13230 ..... 50 Figure 40: Computed positive rail seat design moment based on same design load from AREMA and European specifications..... 51 Figure 41: Division of tie cross sections into standard shape components for use in parallel axis theorem .53

Figure 42: Sign convention for prestressing eccentricity. .55

Figure 43: Plot of effective prestressing with respect to time for baseline tie design .68 
Figure 44: Load configurations corresponding to the transfer limit state 69

Figure 45: Strain diagram at rail seat section showing three strain increments. 72

Figure 46: Screen capture of prestressing placement design aid used to evaluate baseline tie... 78 Figure 47: Division of tie cross sections into standard shape components for use in parallel axis theorem 85

Figure 48: Prestressing configuration schematic. 87

Figure 49: Sign convention for prestressing eccentricity. 88

Figure 50: Regions of prestressing eccentricity along the length of the tie .89

Figure 51: Cross-section of baseline design prestressing configuration 89

Figure 52: Effective prestressing stress with respect to time for rail seat and center section of baseline tie. .92

Figure 53: Loading configurations for stresses in concrete at transfer .94

Figure 54: Concrete stress distributions at transfer and service for rail seat section corresponding to large positive prestressing eccentricity.

Figure 55: Concrete stress distributions at transfer and service for center section corresponding to small negative prestressing eccentricity 97

Figure 56: Deep beam effect at rail seat region in AREMA test configuration 100

Figure 57: Concrete maturity chart for baseline tie (provided by baseline tie manufacturer) ... 109 Figure 58: Predicted positive rail seat capacities at various concrete strengths compared to actual. 109

Figure 59: Predicted negative rail seat capacities at various concrete strengths compared to actual.

Figure 60: Predicted positive center capacities at various concrete strengths compared to actual 110

Figure 61: Predicted negative center capacities at various concrete strengths compared to actual

Figure 62: Allowable concrete compressive stresses at transfer and service based on design concrete strengths 116

Figure 63: Allowable concrete tensile stresses at transfer and service based on design concrete strengths 116

Figure 64: Area of prestressing for positive rail seat moment governing design iterations 119 
Figure 65: Area of prestressing for negative center moment governing design iterations.

Figure 66: Eccentricity at rail seat section for positive rail seat moment governing design iterations.

Figure 67: Eccentricity at center section for negative center moment governing design iterations

Figure 68: Positive rail seat moment capacity defined by AREMA for positive rail seat governed design at 50 years

Figure 69: Negative center moment capacity defined by AREMA for negative center governed design at 50 years

Figure 70: Comparison of optimized capacity vs. baseline capacity for positive rail seat governed designs 127

Figure 71: Comparison of capacity of optimized designs vs. baseline capacity for negative center governed designs

Figure 72: Transfer lengths of prestressing for optimization iterations with limiting end distance to rail seat section.

Figure 73: Positive rail seat nominal moment capacity for positive rail seat governed design at 50 years

Figure 74: Negative center nominal moment capacity for negative center governed design at 50 years

Figure 75: Development lengths of prestressing for optimization iterations with distances to critical sections.

Figure 76: Bilinear relationship between prestressing stress and distance from free end of tendon.

Figure 77: Two-dimensional demonstration of discrete model showing individual components

Figure 78: Steel elements in concrete mesh: (a) regular mesh (b) mesh with shifted edge nodes

Figure 79: Cracking in bottom flange of beam outlined in black marker occurs prior to complete failure of beam. 225

Figure 80: Effect of cracking at interface between steel and concrete. 226

Figure 81: SOLID65 three-dimensional element. 228 
Figure 82: LINK8 bar element displayed with local and global axis ........................................229 


\section{LIST TABLES}

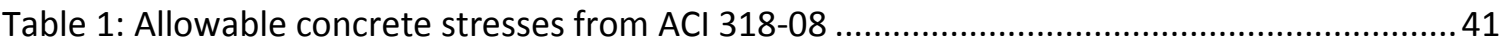

Table 2: Allowable concrete stresses in conjunction with FRP prestressing ................................42

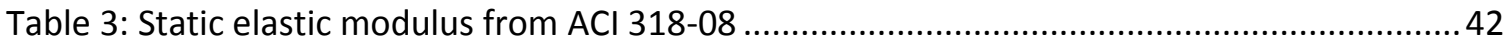

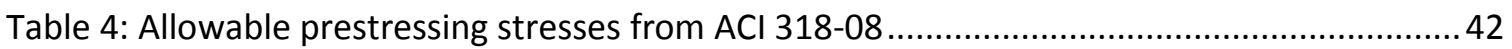

Table 5: Permissible prestressing stresses for carbon FRP ........................................................ 43

Table 6: AREMA unfactored bending moments for tie critical sections based on positive bending moment at centerline of railseat from Figure 38

Table 7: Cross-sectional geometry for rail seat and center sections using parallel axis theorem 54

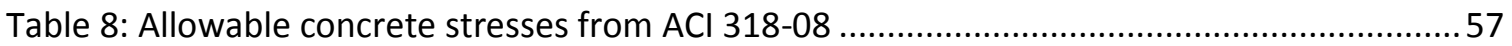

Table 9: Allowable prestressing stresses from ACl 318-08 ........................................................59

Table 10: Recommended relationships for time-dependent properties of concrete ..................64

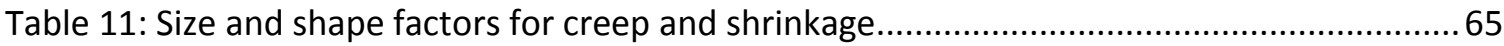

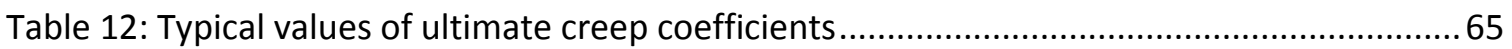

Table 13: Summary of prestressing losses at the rail seat and center sections of baseline tie ....67

Table 14: Optimization study file name abbreviations of iteration parameters .......................... 76

Table 15: Allowable concrete stresses in conjunction with FRP prestressing ............................. 80

Table 16: Prestressing sectional and material properties ............................................................. 81

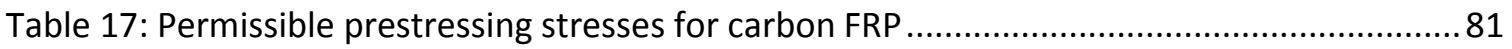

Table 18: Cross-sectional geometry for rail seat and center sections using parallel axis theorem

Table 19: Cross-sectional properties of rail seat and center critical sections ............................... 86

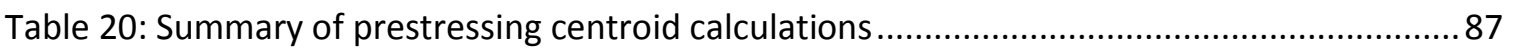

Table 21: Prestressing eccentricities for rail seat and center sections of baseline tie .................. 88

Table 22: Stress in prestressing at jacking and after transfer for baseline tie..............................90

Table 23: Comparison of applied stresses in prestressing to permissible stresses from $\mathrm{ACl}$ 318-08

Table 24: Time-dependent prestress losses at rail seat for baseline tie ....................................92

Table 25: Time-dependent prestress losses at center for baseline tie .........................................92

Table 26: Calculated initial and effective prestressing stresses ................................................93

Table 27: Prestressing lump sum losses at 40 days and 50 years.............................................. 93 
Table 28: Stresses in concrete at transfer due to prestressing and self weight

Table 29: Self weight moments at critical sections corresponding to AREMA flexural test configurations 95

Table 30: Predicted flexural capacity of baseline tie at 40 days, corresponding to Limit State II. 96

Table 31: Flexural capacity of baseline tie at 50 years, corresponding to Limit State II. 99

Table 32: Deep beam criteria variables and definitions 101

Table 33: Nominal moment capacities of baseline tie with effective prestressing at 40 days and 50 years. 104

Table 34: The transfer and development lengths for effective prestressing at 40 days and 50 years. 105

Table 35: Comparison of time-step and lump sum effective prestressing losses at $1000 \mathrm{hrs} . . .106$ Table 36: Theoretical capacities vs. experimental test results for baseline $\left(f^{\prime}{ }_{c}=7,000\right.$ psi at 40 days)

Table 37: Predicted vs. actual capacities for positive bending rail seat condition $\left(f^{\prime}{ }_{c}=7,000\right.$ psi at 40 days) 111

Table 38: Predicted vs. actual capacities for negative bending center condition $\left(f^{\prime}{ }_{c}=7,000\right.$ psi at 40 days) 111

Table 39: Live load moment capacity for baseline tie at 50 years (after all losses) 112

Table 40: Optimization study iteration name nomenclature .114

Table 41: Comparison of concrete optimization parameters to baseline 117

Table 42: Comparison of concrete allowable stresses to baseline 117

Table 43: Comparison of prestressing optimization parameters to baseline prestressing ..........118

Table 44: Transfer lengths for maximum effective prestress from each design iteration ..........130

Table 45: Development length for each prestressing type and comparison to available development distance . 135

Table 46: Allowable prestressing stresses corresponding to provided development length......138 Table 47: Maximum stress in prestressing at ultimate and allowable stress in prestressing based on development 138

Table 48: Baseline tie design summary sheet 152 


\section{NOTATION AND DEFINITIONS}

The terms in this list are used in the numerical analysis performed for this research project and discussed in the research methodology and results sections of this thesis. Multiple notations may exist for the same condition and definition and correspond to the specific code or reference from which they were used.

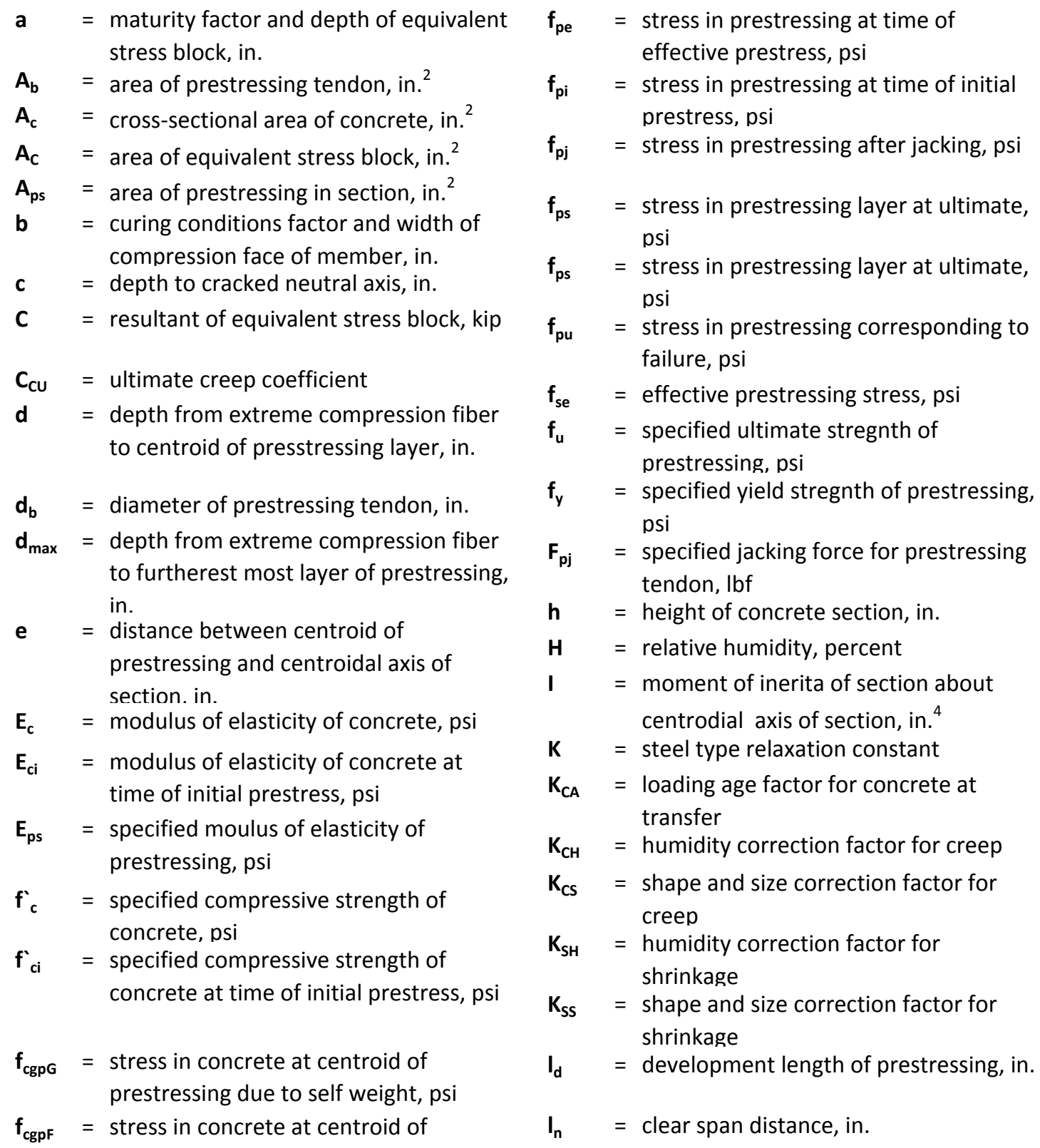




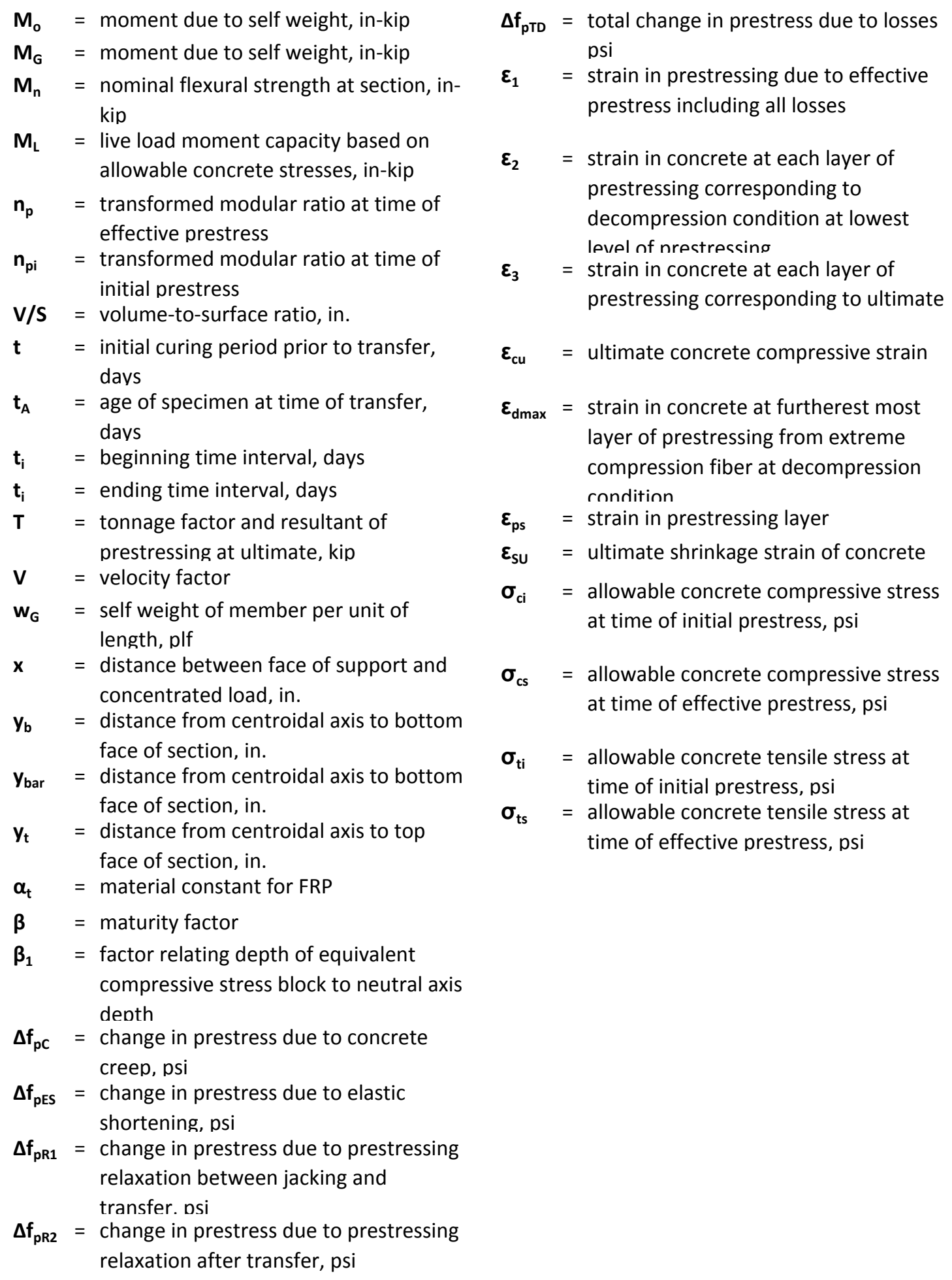




\subsection{Introduction}

\subsection{Project Overview and Scope}

In response to rising energy costs there is increased demand for efficient and sustainable transportation for transit and freight. One source of such transportation is the railroad. To accommodate the increased demand, railroads are constructing new track and upgrading existing track (Freudenstein and Haban 2006). This update to the track system is expected to increase capacity while also providing a more reliable means of transportation when compared to other alternatives such as trucking. In addition to increasing the track system capacity, railroads are considering an increase in the size of the typical freight rail car to allow larger tonnage. This potential increase in rail car loads will in turn effect the performance requirements of the track structure including the rail, ties, and ballast.

As a result of these potential increases in heavy haul, current designs of prestressed concrete railroad ties for heavy haul applications may be undersized. Changes from current designs (specifically size) present a number of challenges related to operations and manufacturing such as:

- Equipment (installation and maintenance) incompatibility,

- Integration of larger ties within existing track,

- Manufacturer equipment set up for current size ties.

In an effort to maximize tie capacity while maintaining tie geometry, fastening systems and installation equipment, a parametric study to optimize an existing tie design was completed in this research program. The optimization focused on maximizing the capacity through an investigation of prestressing quantity, configuration, stress level and concrete strength. To validate the analysis, experimental results for the existing tie design were used.

\subsection{Project Motivation}

An ongoing research project, "Synthesis of Railroad Engineering Best Practices in Deep Seasonal Frost and Permafrost Areas," provided the foundation for this investigation (ALCAN RaiLink Inc. 2007). That project relates to the Alaska Canada Rail Link (ACRL), which is a proposed 1,300 mile expansion of heavy haul mainline track which will link the mineral deposits of interior portions 
of Alaska, the Yukon Territory and British Columbia with ports on the Pacific Rim. A secondary goal of the ACRL is to connect the Alaska Railroad to the continuous forty eight states (ALCAN RaiLink Inc. 2007). A map illustrating the proposed working alignment is shown in Figure 1.

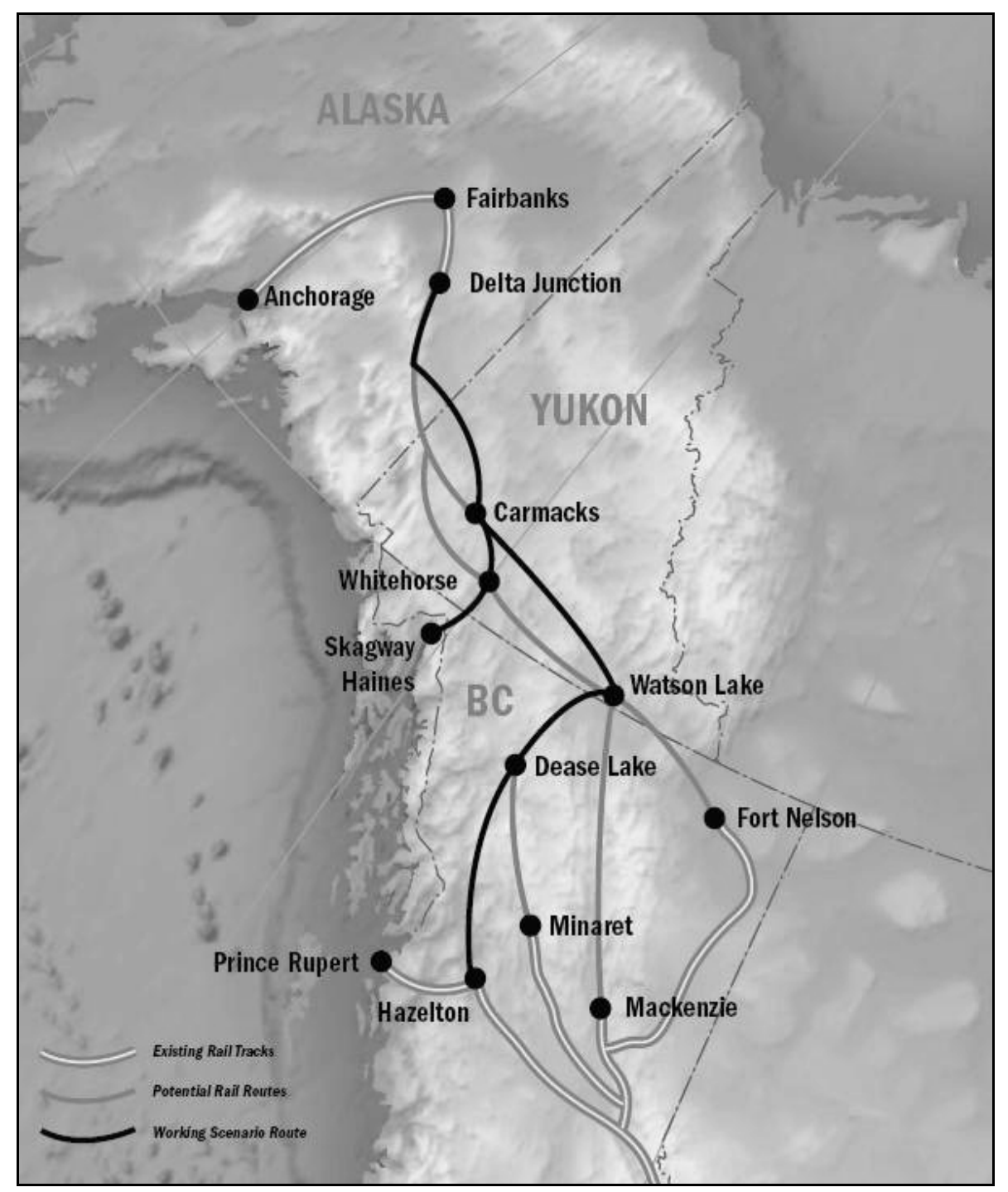

Figure 1: Alaska Canada Rail Link (ACRL) route map (ALCAN RaiLink Inc. 2007)

During the "Synthesis of Railroad Engineering Best Practices in Deep Seasonal Frost and Permafrost Areas" research project, two key issues pertaining to concrete railroad ties were identified including rail seat abrasion, which is the degradation of the concrete in the rail seat region of the tie, and the possible inadequacy of ties for the proposed rail car load increases. This research project addresses the later. 


\subsection{Project Objectives}

This research investigates a variety of options for increasing tie capacity while maintaining the common tie geometry. The end goal of this project is to produce a final tie design which will be capable of withstanding the anticipated loads of heavy haul railways in North America while maintaining current tie geometry.

\subsection{Project Work Plan}

To achieve the objectives described in Section 1.3, the following work plan was developed. The project is broken into three phases consisting of:

Phase I: Design/Analysis Validation

Phase II: Parametric Optimization

Phase III: Validation of Optimization through Experimental Testing (Future)

Design/analysis validation and parametric optimization are completed using historical test data on an existing tie design performed by the tie manufacturer and varying design parameters. Testing of optimized tie designs is beyond the scope of this research, but a template is presented as a third phase discussed in the Future Work section of this report (Section 5.3.2).

\subsubsection{Phase I: Design/Analysis Validation}

The first step in this project was to determine a baseline capacity by analyzing the existing tie design using the standard design codes ( $\mathrm{ACl}$ 2008; AREMA 2003). This analysis consisted of hand calculations performed using MathCAD mathematical software and Excel. Once a benchmark capacity is established, the design optimization took place. To optimize the current design, material properties and prestressing characteristics were varied.

\subsubsection{Existing (Baseline) Tie Design Analysis}

For the benchmark analysis, a commercially available heavy haul concrete tie was selected for comparison. The design drawings for the tie, showing tie geometry, prestressing configuration and other design information are located in Appendix A. The baseline tie incorporates features such as a necked down cross-section in the center region and scallops (extrusions from the longitudinal sides of the tie to increase lateral restraint through increased tie-ballast interaction), which increases the material efficiency and performance of the tie. The success of these features, combined with the expense associated with new forms and industry familiarity 
with the baseline tie, are all reasons why it is desired to maintain the existing tie geometry. However, to optimize the design a baseline of capacity was required.

To determine the capacity of the baseline tie design, information on material properties of the concrete and steel was collected from the tie manufacturer. This information is summarized in Appendix $B$ along with the minimum flexural capacity as specified by AREMA acceptance criteria (AREMA 2003). For material data not available from the manufacturer, assumptions on material properties were selected based on $\mathrm{ACl} 318-08(\mathrm{ACl} 2008)$ design code.

The flexural capacity of the baseline tie was then compared with the minimum flexural capacity criteria in Table 48 (Appendix B) for validation of the analysis procedure. Results for both the cracking capacity and ultimate strength were used for validation. This validation served as both an evaluation of the design process and the assumptions used. Assumptions of design parameters were then refined based on their agreement with actual capacities. From this refined baseline capacity, all other design optimization iterations were compared.

\subsubsection{Validation from Previous Experimental Tests}

To evaluate the accuracy of the numerical analyses of the baseline tie design and design predictions of optimized tie designs, a comparison between numerical results and experimental test results was performed. Experimental results for flexural capacity of the baseline ties were provided by the manufacturer. Tests were performed to determine both cracking capacity (Section 4.2.8).

\subsubsection{Phase II: Parametric Optimization}

After completion of the design/analysis validation of the baseline tie, the design optimization process began using a similar analysis/design process. Because the geometry of the tie is fixed, the optimization focused on variations in the prestressing and concrete properties. A variety of

prestressing configurations, sizes and stress levels were considered to achieve increased capacity, along with changes in steel grade/type and concrete compressive strength. An advantage of the numerical analyses over experimental testing is that a large number of variations (prestressing configurations and material properties) can be analyzed in a short period of time, while also considering the various stages of loading. 
During the design optimization, the two components which were varied were the prestressing (location, type) and the concrete strength. The baseline tie uses high strength drawn wire whereas the optimization considered variations in the type, size and position of prestressing including 7-wire strand and fiber reinforced polymer (FRP). The 7-wire strand is common among prestressed ties and was suggested by the baseline tie manufacturer for consideration. FRP for prestressing has been used in some recent applications, and has advantages over conventional prestressing steel of being corrosion resistant, strong and lightweight. However, FRP has never been used in large scale production of prestressed concrete ties. Therefore, it should be considered as an alternative to the industry standard of high strength steel.

In addition to prestressing configurations, variations in concrete compressive strength were evaluated in this study. The concrete strengths selected were assumed to be feasible for a quality prestressed concrete manufacturer. High strength concrete $\left(f^{\prime}{ }_{c}\right.$ greater than 10,000 psi) is associated with different design standards and material assumptions than conventional normal strength concrete ( $f_{c}{ }_{c}$ less than 10,000 psi). This adds an additional degree of complexity to optimization design calculations as they vary at higher concrete strengths. This additional complexity is justified however by the effect an increase of concrete strength has on delaying the initiation of cracking, which is one definition of failure for concrete ties.

The arrangement of optimization design iterations with varying prestressing and concrete conditions has been organized into an iteration matrix in Appendix C. The matrix contains the various prestressing and concrete properties in each iteration and the file names for the corresponding MathCAD and support files. In total there are 48 iterations included; 24 combinations of prestressing and concrete alternatives and then each alternative has two configurations representing the optimized condition for the two critical support conditions discussed in Section 2.2.3.

\subsubsection{Optimized Tie Design Validation Testing}

The goal of the optimized tie design testing will be similar to that outlined in the existing tie design validation testing. Ties will be tested to failure and again compared to the results of the numerical analyses. However, the production and testing of optimized tie designs is outside the scope of this report and is discussed in the Section 5.2. 


\subsection{Research Significance}

This research was conducted with the intent of increasing the knowledge and utility of prestressed concrete railroad ties in the development of the railroad as a sustainable and efficient transportation mode. It is anticipated that the suggested methods of increasing concrete tie capacity identified in this research, will aid in the proposed transition to higher tonnage applications. The knowledge gained through this research will benefit two groups in particular; prestressed concrete tie manufacturers and the heavy haul Class I railroads.

\subsection{Thesis Organization}

The following chapters are organized to include background information, the adopted research methodology, and results. Chapter 2 provides a thorough overview of prestressed concrete railroad ties and the process used for their design with a concentration on the use and design of ties for heavy haul applications. Chapter 3 discusses the procedure and method of analysis of the baseline tie and specifics of the design optimization. Chapter 4 presents a discussion of the results for the baseline tie design analysis and the optimization study. Also included is a comparison of the results of the numerical analyses with the available experimental test results.

Chapter 5 summarizes the research findings and presents the conclusions and future work identified through the progression of this project. 


\subsection{Literature Review}

\subsection{Overview of Prestressed Concrete Railroad Ties}

\subsubsection{Introduction to Concrete Railroad Ties}

Today the use of concrete ties is on the rise in North America as they become an economically competitive alternative to the historical industry standard wood ties, while providing performance which exceeds its competition in terms of durability and capacity. Problems regarding flexural capacity and concrete durability were experienced during the early years of concrete tie production in North America. However, with the aid of the Portland Cement Association (PCA) suitable designs capable of withstanding the tremendous loads of North American railroads were developed during the 1970's (Hanna 1979). Since this time, concrete ties have developed into an adaptable tie alternative with applications in both transit and heavy haul rail lines. The shape and dimensions of a typical North American concrete tie are illustrated in Figure 2.

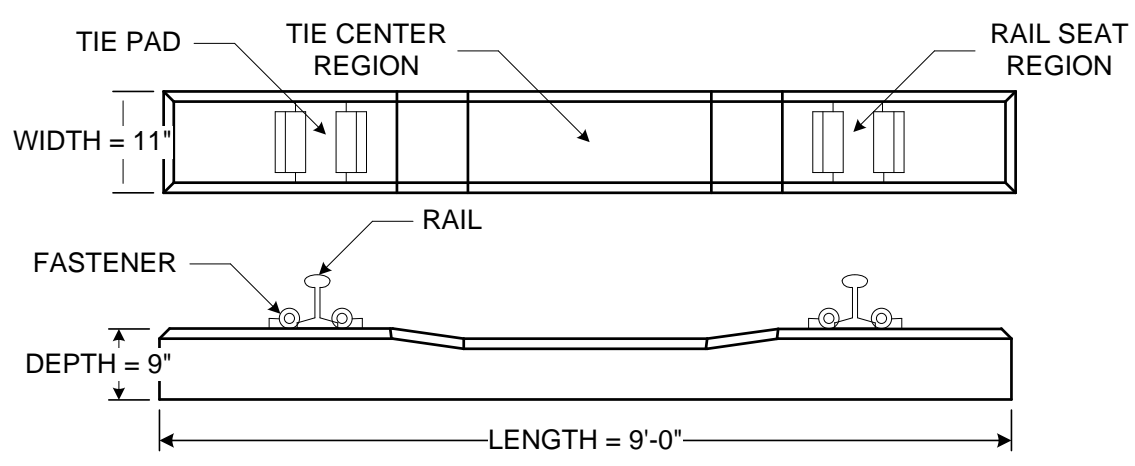

Figure 2: Generic concrete tie shape and dimensions

To achieve the performance exhibited by concrete ties, considerable amounts of engineering have been employed with respect to materials and design. The composite behavior between the concrete and prestressing steel provides the necessary strength to resist the cyclic loading of the trains while concrete provides the protection and rigidity to hold the system together. Initially, this relationship was not well understood and failures were often the result of inadequate development of prestressing steel and insufficient flexural capacity. However, over the last several decades tie failures due to flexure and inadequate development have been nearly 
eliminated (Hanna 1986). Currently, the focus of the rail industry is to improve tie durability and service life. Additionally, the application of concrete ties in unique environments such as permafrost is of interest. The following sections highlight the materials, failure mechanisms, durability, performance, fabrication methods, installation, maintenance and economics related to prestressed concrete railroad ties.

\subsubsection{Materials}

Typical to any prestressed concrete member are high early strength concrete and high tensile strength steel (Heintz 2000). In addition to the concrete and prestressing steel, tie fasteners and pads are integral to the concrete tie. However, it should be noted that the application of these connection devices is dictated by the railroad operators and the connection design is outside of the scope of the tie manufacturer responsibilities. This presents a unique challenge because a component failure is often associated with a tie failure (Remennikov and Kaewunruen 2007).

\subsubsection{Concrete}

The use of higher strength concrete is necessary in the production of concrete ties due to the use of prestressing. It is generally suggested that a minimum compressive strength of 7,000 psi at 28 days be used; however, most manufacturers achieve strengths in excess of 10,000 psi (AREMA 2003; Hanna 1979). It is common for high early strength concrete to reach approximately 80 percent of its 28 day compressive strength in less than 24 hours after casting (Naaman 2004). An example of a high early strength concrete maturity chart is provided in Figure 3. Typical reasons for the use of high early strength concrete include the following (Hanna 1979):

- The prestressing force must be transferred from the stressing bed to the member at an early age with the compressive strength required for prestressing load transfer varying depending on the design; but 4,500 psi is typically considered satisfactory,

- Prestressing beds can be turned over more rapidly due to shorter release times arising from sufficient or high strength at transfer,

- Low water/cement ratios are typical of high early strength concrete; resulting in decreased shrinkage and cracking,

- Unlike conventional reinforced concrete, high strength steel is required to resist the applied prestressing forces. 
Other considerations related to concrete composition include admixtures. In order to achieve early high strength concrete, manufacturers commonly include accelerator and water reducing admixtures. Accelerators increase the rate or cement hydration while water reducers allow for workability of the concrete at the low water-cement ratios necessary for higher strength concretes. For areas with significant freeze-thaw cycles, air-entraining mixtures should be used. This relates to the fact that air voids accommodate the growth of pore water during freezing (Hanna 1979).

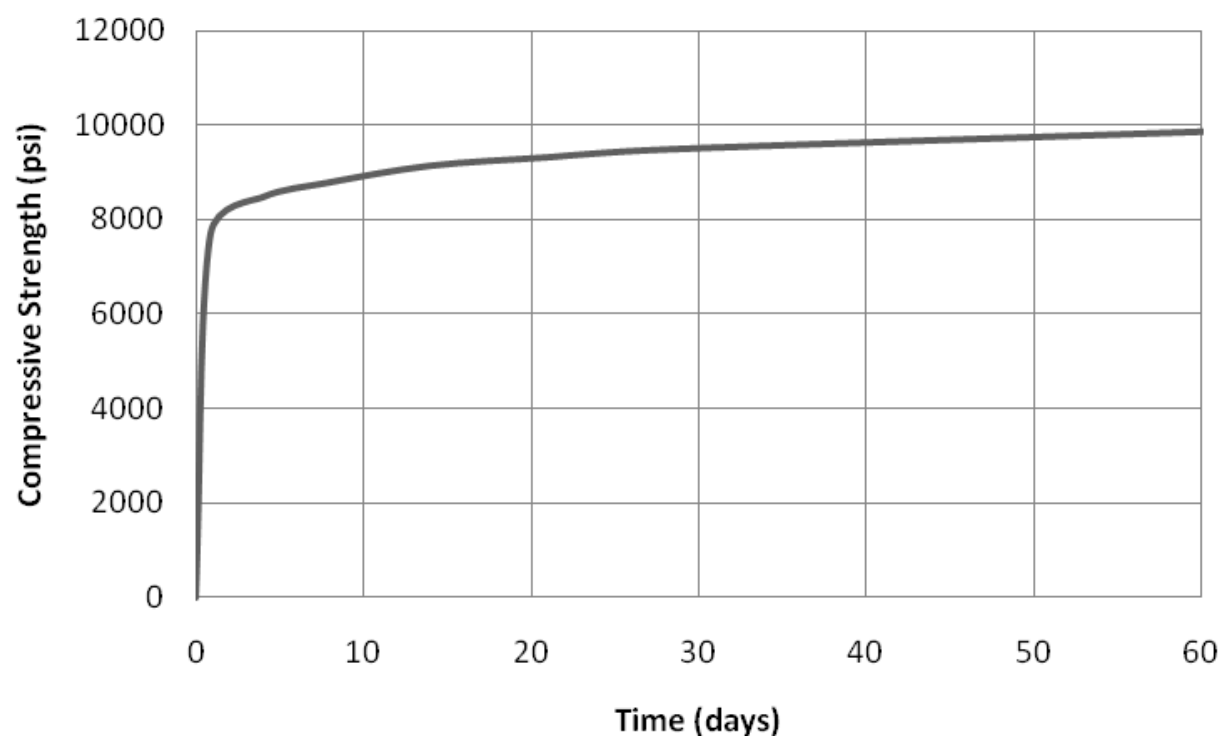

Figure 3: Typical concrete maturity chart for an early high strength mixture used in prestressed concrete fabrication

\subsubsection{Prestressing}

Prestressing tendons provide the necessary tensile resistance to support the flexural loads imparted by the trains. During the initial days of concrete tie fabrication, when the concrete is only at a fraction of its design strength, the most difficult issues to satisfy are prestressing bond and allowable stresses of the concrete in tension. However, bond and stress issues related to concrete ties are typically satisfied by using smaller tendon diameters and larger numbers of tendons set in a uniform pattern to avoid tension stresses induced in the cross-section at prestressing transfer. For this project two prestressing material types will be considered. First, the industry standard of steel prestressing and second the innovative alternative of fiber reinforced polymer (FRP) tendons. 


\subsection{Steel}

Prestressing in concrete ties consist of either the 7-wire strand or steel wire (Figure 4) (AREMA 2003). Dimensions of 7-wire strand vary, but the most common among North American manufacturers is 0.375 in. diameter. The size of wire used over the years in concrete ties has varied from 0.19 in. to $0.21 \mathrm{in}$. (4.80 $\mathrm{mm}$ to $5.32 \mathrm{~mm}$ ). An ultimate strength of $255 \mathrm{ksi}$ is common for wire, whereas 7-wire strand typically has an ultimate strength of $270 \mathrm{ksi}$.

The choice to use either 7-wire strand or individual wire is up to manufacturers and is dictated by design and material efficiency. However, wire prestressing offers several advantages over conventional twisted multi-wire strand. Using wire provides the ability to change the quantity of steel within the tie by smaller increments compared to 7-wire strands, since wire is available in smaller diameters than 7-wire strand. Therefore, the ties can be more efficiently designed to parameters dictated by predicted service loads, decreasing excess material, and in turn decreasing the cost of the tie (Naaman 2004). Wire also requires shorter lengths for transfer and development.

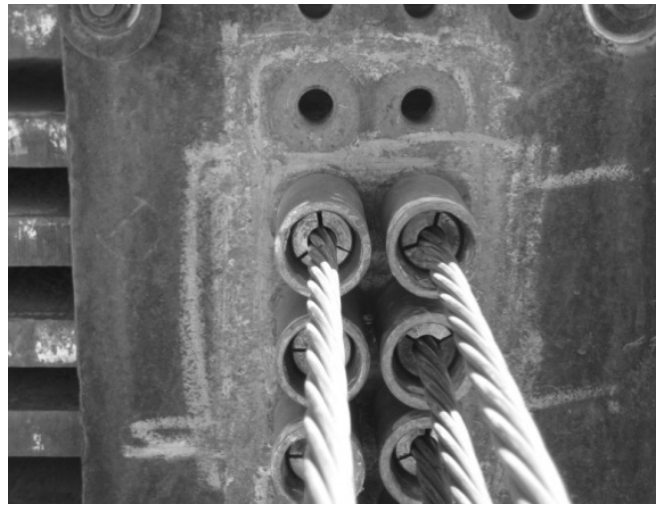

(a)

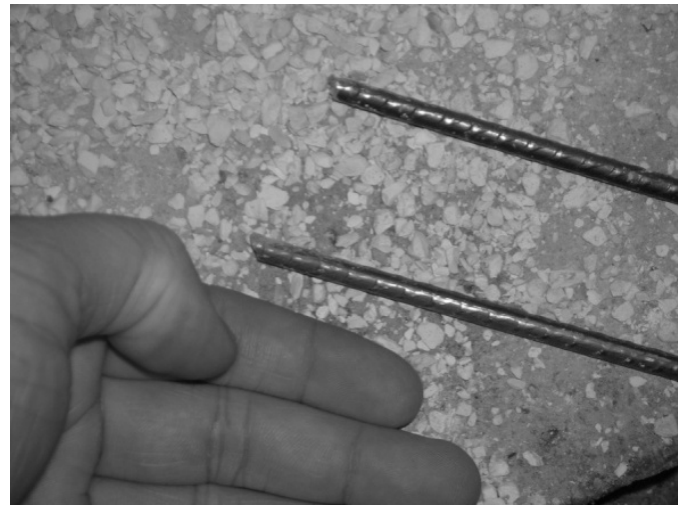

(b)

Figure 4: Prestressing steel types (a) 7-wire strand, 0.5 in. diameter, 270 ksi (b) wire, 0.21 in. diameter, 255 ksi

\subsection{Fiber Reinforced Polymer (FRP)}

While steel remains to be the industry standard for prestressed concrete railroad ties, other alternatives do exist for prestressing materials. One such alternative which provides increased strength and decreased weight in comparison to steel, is fiber reinforced polymer (FRP) 
prestressing tendons. In addition to being stronger and lighter than steel, FRP is a noncorrosive material, which allows it to be utilized in environments which could cause early degradation of the concrete, should steel be used. To date however, FRP has not been used in the large scale production of prestressed concrete railroad ties.

FRP is composed of two components, fibers which provide the tensile strength of the material and resin (polymer) which is used to impregnate and bind the individual fibers together. There are three types of FRP fibers which include aramid, glass, and carbon. Generally aramid and carbon fiber based FRP materials are used for prestressing applications due to their ability to be produced with a wide range of elastic moduli. However, since FRP is relatively new in the prestressed concrete industry, little standardization between the prestressing manufacturers has been completed. The size, strength, modulus, surface texture and therefore bond of individual FRP materials vary greatly from manufacturer to manufacturer. Due to this lack of standardization, the utilization of FRP requires substantial engineering effort with respect to the particular application and FRP material.

In the past, FRP has been used in bridge applications for both internal and external prestressing of girders and as a noncorrosive option for reinforcement in the bridge deck. The application of FRP to concrete railroad ties is considered in this study as an alternative to steel prestressing. The reason for consideration of FRP as an alternative to steel is the possibility of eliminating corrosion of the prestressing should cracking occur. If corrosion is not an issue and fatigue of the prestressing can be handled through design, tie capacity may be able to extend beyond the current cracking limit, ultimately increasing the capacity of the tie.

\subsubsection{Attachment Components}

\subsection{Tie Pads}

Tie pads are installed between the rail and concrete ties to reduce electrical conductivity between rails, and impact and vibration effects on the track structure leading to quieter operation and increased tie life (AREMA 2003). Tie pads come in a variety of materials and configurations with steel and polymers being the most common materials. A typical pad configuration includes a polymer top pad, a steel plate for added rigidity, and a rubber gasket 
between the steel plate and concrete tie to decrease sound and vibration. Pads can also be made solely of steel or polymeric materials. However, pads have the unfortunate effect of trapping water and grit ultimately accelerating the rate of rail seat abrasion beneath them (Remennikov et al. 2006).

\subsection{Fasteners}

In addition to the primary tie components of concrete and steel, fasteners are essential to attach the steel rail to the tie and protect the tie from rail movement. The fastener type used is dictated by the railroad operator and the tie application. Most fasteners are composed of three parts; the ductile iron shoulder (or embed with bolt), spring clip, and insulator. The ductile iron shoulder or embed is cast into the tie during tie fabrication and varies in terms of size and embedment depth depending on the fastening system used and tie application (Figure 5). Spring clips attach to the ductile iron shoulder or embed and apply a restraining force to the rail (Figure 7). Between the spring clip and rail is the insulator to reduce noise, impact forces, vibration, abrasion and electrical conductivity (Figure 7).

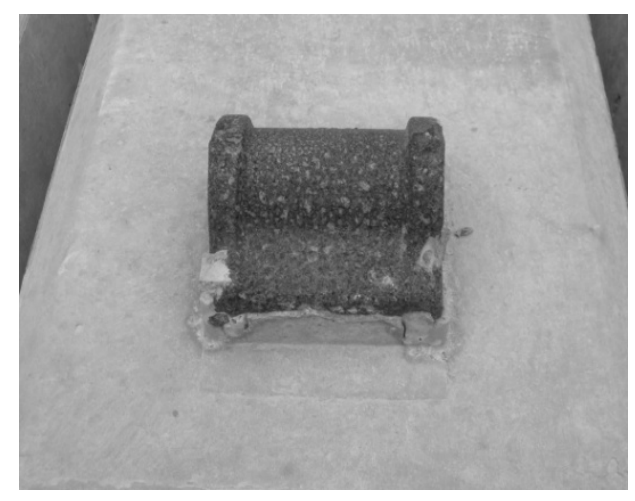

Figure 5: Embedded cast iron shoulder for PANDROL E-CLIP fastening system

Fasteners are divided into two categories; captive and non-captive. The difference is in how and when fastener parts are attached to the tie. Non-captive fasteners include those where only the ductile iron shoulder is attached to the tie prior to shipping and tie installation (Figure 6). Captive systems have all parts (shoulder, spring clip and insulator) installed prior to shipment and installation (Figure 7). Captive systems are at risk of damage to the fastener during transportation and installation, whereas non-captive systems require additional labor and time for component installation once the tie is placed within the track. 


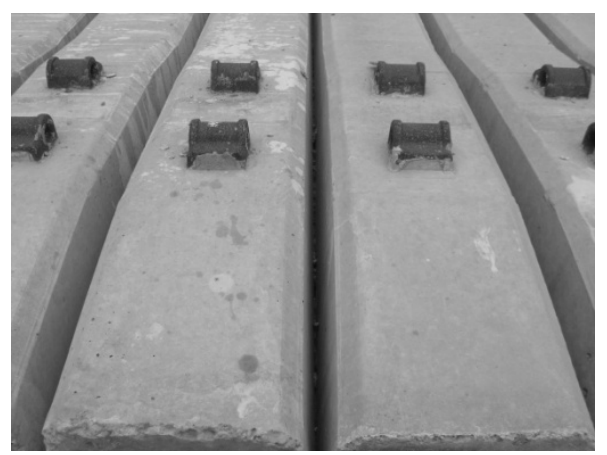

Figure 6: Non-captive PANDROL E-CLIP fastening system

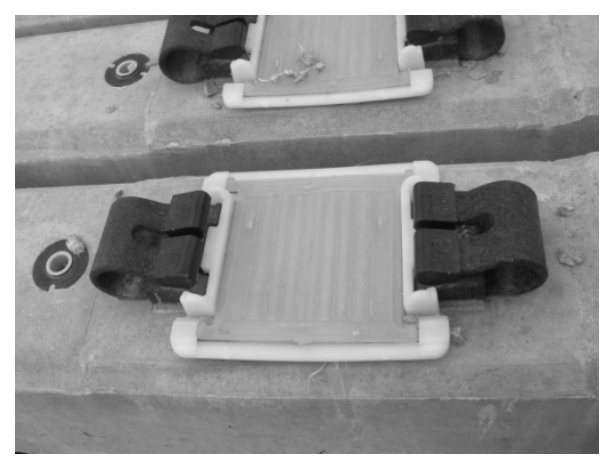

Figure 7: Captive PANDROL SAFELOK III fastening system

\subsubsection{Failure Mechanisms}

The three primary failure mechanisms of concrete ties observed by the rail industry in North America are rail seat abrasion, flexural cracking from center binding and rail fastener failure (Cann 1978; Reinschmidt 1991). Of these three, rail seat abrasion is the most perplexing and difficult to prevent. Failures may be related to concrete tie materials, design, or a combination of the two. Installation and maintenance practices also contribute to a tie's resistance to these failure mechanisms. A discussion of the three primary failure mechanisms is presented in the following sections.

\subsubsection{Rail Seat Abrasion}

AREMA defines rail seat abrasion (RSA) as the gradual wearing away of the cement paste from the concrete, resulting in an uneven aggregate bearing surface beneath the tie pad (Reinschmidt 1991). However, RSA may degrade the concrete uniformly across the entire interface depending on the mechanism causing the deterioration. Figure 8 illustrates the surface of a degraded rail seat which conforms to the AREMA definition, while Figure 9 demonstrates abrasion on a curved 
section of track in which the aggregate and cement paste deteriorated at the same rate. Factors contributing to RSA include: the presence of water, high tonnage (static wheel loads larger than 25,000 lbs), steep track grades, and especially track curves greater than two degrees (Hanna 1979). Regions with freeze-thaw cycles often experience rail seat abrasion at an accelerated rate due to increased cement paste deterioration below the tie pad.

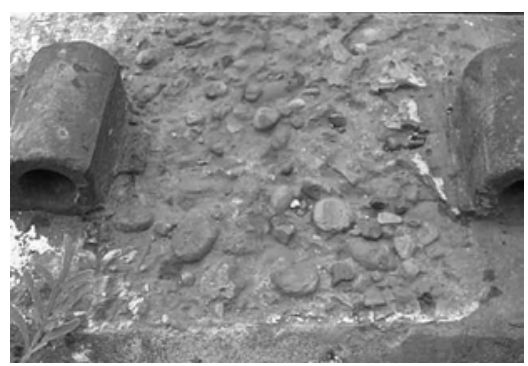

Figure 8: Rail seat abrasion where cement paste has been removed leaving an uneven aggregate surface (Peters and Mattson 2003)

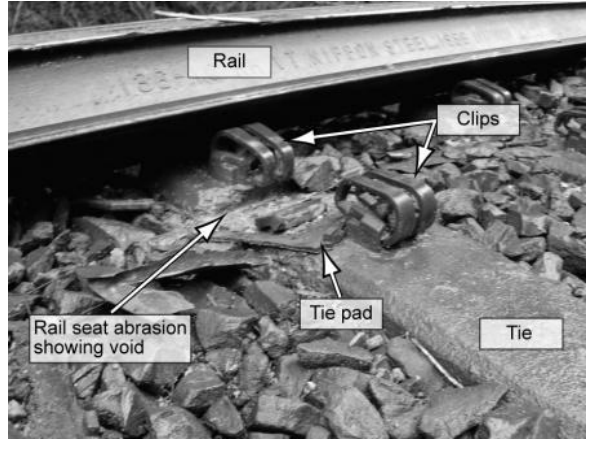

(a)

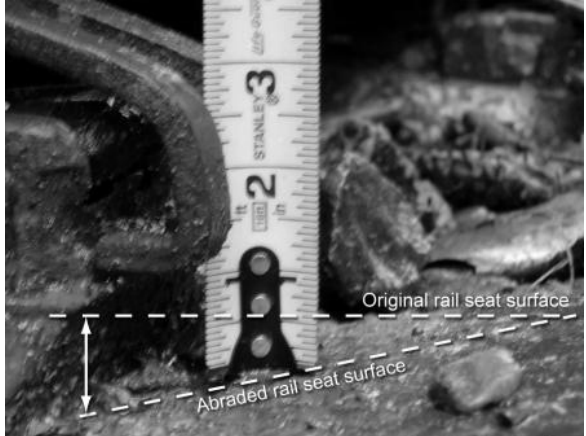

(b)

Figure 9: Rail seat abrasion on curve (a) abrasion allowed rail to roll causing derailment due to widening of track gage, (b) Side view of rail seat abrasion (NTSB 2005)

To prevent RSA and prolong tie life, concrete tie manufacturers have investigated methods to protect concrete in the rail seat region. Research has focused on the application of abrasion resistant materials applied in the rail seat region and some industry techniques used to mitigate RSA to date include:

- Epoxy or polyurethane applied to rail seat shortly after casting (Peters 2007),

- Cast-in-place steel plates (Peters and Mattson 2003),

- Abrasion resistant pad assembly (Peters and Mattson 2003). 


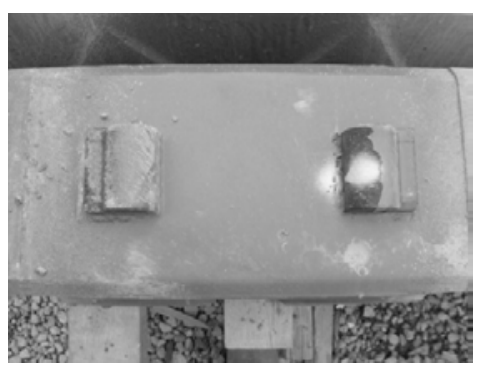

(a)

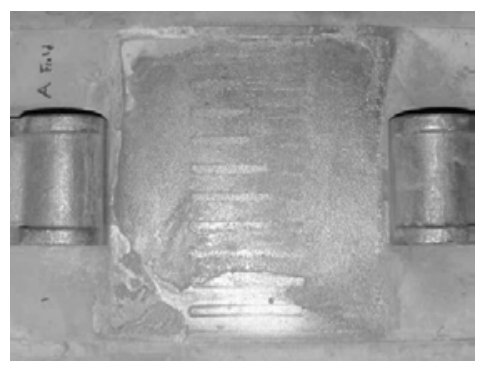

(b)

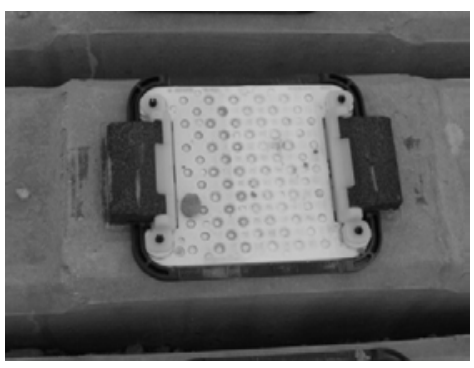

(c)

Figure 10: Industry methods to combat rail seat abrasion (a) epoxy (b) cast-in-place steel plate (Peters and Mattson 2003)(c) tie pad

Of these options, epoxy or polyurethane has shown promising short term results and appears to have gained acceptance among manufacturers and railroads. However, epoxy and polyurethane do wear down over time allowing RSA to take place. For RSA in field repair operations, the application of epoxy is common, but requires specific temperature and also results in costly track closures (Peters 2007; Reiff 1995). Laboratory testing of cast-in-place steel plates has shown no rail seat abrasion at four times the number of cycles required to cause failure of current tie designs. However, issues with water intrusion below the plate and the additional cost of materials and fabrication have limited the use of the cast-in-place steel plate method (Peters and Mattson 2003).

Abrasion resistant pad assemblies remain the industry standard due to lower initial cost and ease of replacement. However, some research has show that tie pads in certain cases may actually exacerbate the abrasion process by creating a path for water intrusion into the rail-tie interface. In addition, the stiffness of the pad material itself has shown correlation to the rate of RSA. Increasing the pad stiffness appears to increase the rate of abrasion, while softer pads wear out faster, ultimately providing decreased electrical insulation, impact dissipation and abrasion resistance. Additional solutions that been explored by tie manufacturers and railroad operators with mixed results include (Hanna 1975):

- Steel fiber reinforced grout applied to the rail seat (Takahashi et al. 2008),

- Steel plates bonded to the tie using epoxy after casting,

- Metallic aggregate in the rail seat region (Wu et al. 2001),

- Variations in strength and porosity of concrete to increase abrasion resistance. 
To date, numerous methods have proven to delay the onset of rail seat abrasion, but issues of cost and repeatability on a high production basis remain a concern.

\subsubsection{Flexural Cracking (Center-Binding)}

While inadequate tie flexural capacity is predominantly an issue of the past, cases of ties cracking at the top center location due to negative moment have been observed on mainline tracks (Figure 11) (Cann 1978; Magee and Ruble 1960; Raymond 1984; Thun et al. 2008). Two factors contribute to the ballast support conditions which cause this center bound condition. First, as the tie develops uniform ballast support in response to ballast consolidation negative moment occurs at the tie center (Freudenstein 2007). Secondly, over time cyclic loading applied to the track causes ties to oscillate and deform vertically within the track structure; this deformation produces pumping action which ultimately allows ballast to abrade the bottom of the tie and pulverize the ballast beneath the tie. The extent of ballast deterioration is unique to concrete ties when compared to that observed with wood ties resulting from the difference in the tie material strength and hardness. A converse scenario can occur with wood ties, where the tie is broken down by the ballast through the same action discussed above (White et al. 1978). Investigations have shown that this failure type results from ballast conditions which are beyond the scope of tie design.

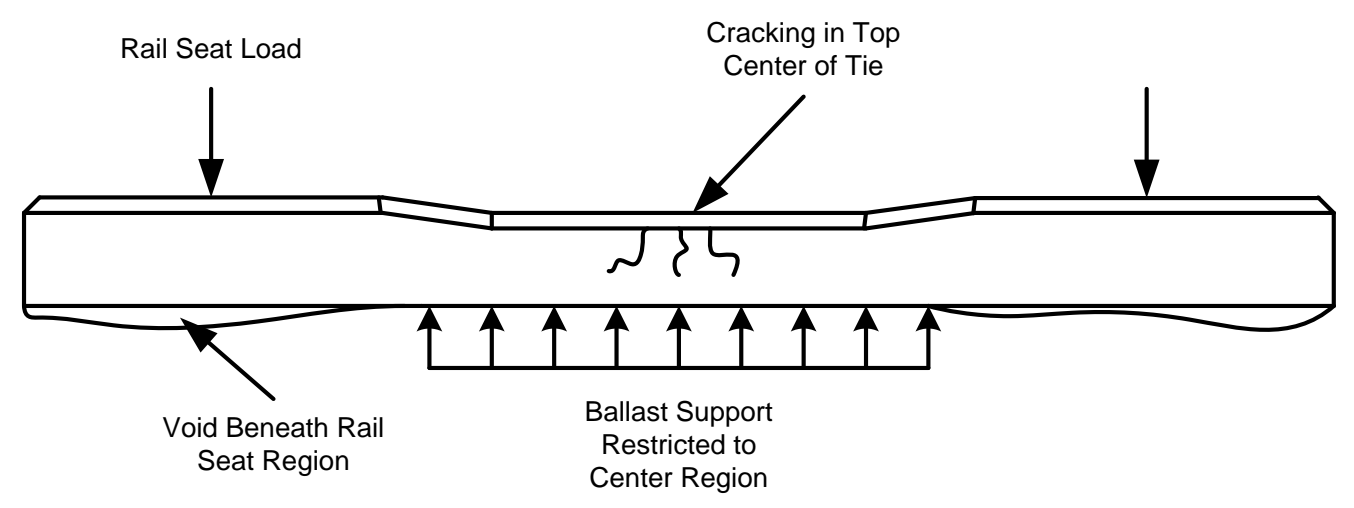

Figure 11: Center-binding support and void configuration

The pulverized ballast is routinely removed from the track and replaced with new ballast during undercutting maintenance operations (Riessberger 1984). However, when undercutting and replacement is not carried out regularly, depressions in the pulverized ballast beneath the ends of the tie may develop, altering the support condition of the tie. The new support condition is a center support where ballast bearing still remains. Based on this support condition, the tie 
cantilevers from the center over the pulverized ballast depression. When loaded, large negative moments occur at the tie center, resulting in cracking and tie failure as the flexural capacity is exceeded. This type of failure is referred to as "center binding". To prevent center binding regular maintenance of ballast must be performed to avoid deterioration of the material leading to unsuitable tie support conditions (Riessberger 1984). The required regularity of ballast maintenance will be dictated by frequency and intensity of loading.

\subsubsection{Fastener Failure}

While many rail fastener configurations exist, a commonality between them is their shared purpose of providing a restraining force known as toe load to the rail. However, over time due to the effect of cyclic loading, fatigue of fastener components such as the spring clip and ductile iron shoulder occurs, allowing movement of the rail, deterioration of pads, and a decrease in the fastener toe load applied to the rail (Figure 12) (Cann 1978; Reiff 2008; Remennikov et al. 2006). In addition to a decreased toe load, polymer insulators located between the rail and spring clip are subjected to abrasion from cyclic loading. Over time this abrasion wears away insulating material, creating voids and allowing for excess movement between the rail-tie interface in the form of rail rocking side-to-side and slip in the longitudinal direction of the rail. This excessive movement and space between the tie and rail further exacerbates the issues related to rail seat abrasion by providing an abrasive motion and allowing for the intrusion of water and abrasive agents such as rail grit or sand (McQueen 2007).

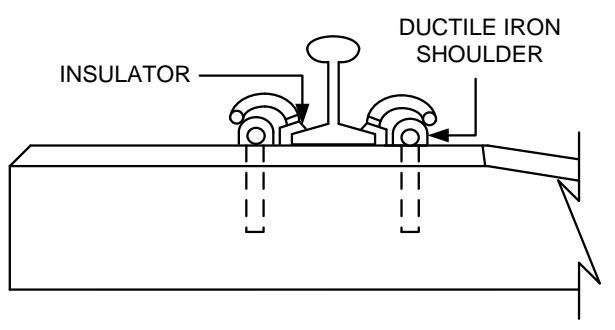

(a)

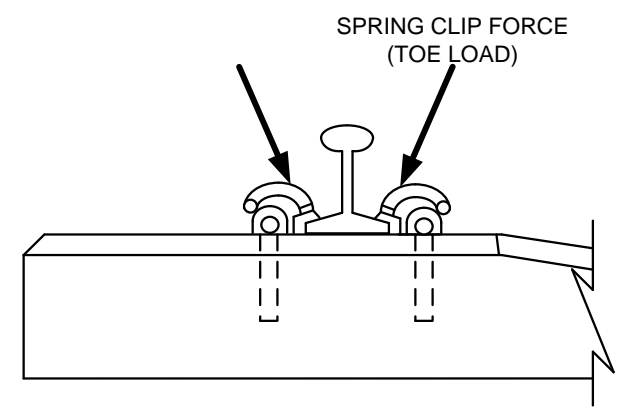

(b)

Figure 12: Rail fastener components effected by fatigue (a) Rail fastener polymer insulator (b) Downward toe load applied by fastener spring clip

To prevent fastener failure or related issues such as rail seat abrasion, regular maintenance of fastener components is essential. The replacement of worn insulators and other components 
can prevent the escalation of related issues before they begin. Fortunately, for maintenance operations component wear is typically uniform along a length of track and can be estimated based on historic performance for a given location knowing the frequency and intensity of loading. Similarly, fastener wear is relatively easy to monitor visually compared to rail seat abrasion which is typically hidden by the rail and ballast (Riessberger 1984).

\subsubsection{Durability and Performance}

One reason railroads utilize concrete railroad ties in their tracks is their increased durability and life span when compared to timber ties. These increases result primarily from the absence of rotting and an increased resistance to climate change (Abbott 1989). Generally, a concrete tie has a lifespan longer than the typical treated timber tie with decreased maintenance requirements. Historically concrete ties will last two to three times longer than wooden ties under the same track, loading and environmental conditions (Zarembski 1999). However, this has not always been the case (Jimenez and LoPresti 2004; Qinhua et al. 1997).

\subsubsection{Concrete Durability}

Like any other concrete product, concrete railroad ties can be affected by changes in temperature and moisture (Sahu and Thaulow 2004; Tourney et al. 2004). Freeze-thaw cycles in particular may cause accelerated deterioration of the concrete if air entrainment is not used (Stark 1976; Stark 1989). Additionally, the durability of concrete ties is largely dependent on the ballast condition, which provides both support and load transfer of wheel loads and drainage of water away from the tie's surface (Riessberger 1984). Sufficient drainage is critical for preventing rail seat abrasion and in regions that experience freeze-thaw cycles. For this reason ballast material is often replaced or cleaned when adequate drainage is no longer achieved.

\subsubsection{Corrosion}

Corrosion is typically a secondary effect of thermal and flexure cracking of the tie. Within any reinforced or prestressed concrete member, the formation of cracking provides a conduit for the ingress of moisture and chemicals, which in turn initiate the corrosion process once the moisture or chemicals reach the internal reinforcement. To prevent corrosion, adequate concrete cover of prestressing steel must be provided in addition to proper drainage around the tie by the ballast. In general, corrosion is not often observed in service because ties are typically replaced due to another failure mechanism such as flexural failure or rail seat abrasion, which 
tend to occur well before corrosion becomes a problem. As for corrosion of the prestressing steel during the fabrication of the tie, AREMA specifies that surface rusting may occur; however, pitting may not (AREMA 2003). Under normal tie manufacturing conditions, prestressing steel is typically turned over well before any significant surface rusting occurs.

\subsubsection{Fabrication Methods}

Concrete tie production is similar to other precast, prestressed concrete members except in terms of the repetition and quantity of concrete ties which are produced during a single casting. Depending on the fabrication method used, hundreds of ties can be cast concurrently. The three methods of fabrication historically used in North America are the long-line method, stress-bench method, and the individual form method (Hanna 1979). The most common fabrication method used today is the long-line method; the other two methods are less common for major manufacturing facilities and are typically used for one off castings such as turnout ties, therefore those fabrication methods will not be presented (Heintz 2000).

\subsubsection{Long-Line Method}

The long-line method describes the process in which ties are produced end to end in a line, with continuous strands of prestressing steel running through the ties. Casting beds containing the forms are stationary and equipment moves along the length of each bed. A variation of this method, in which forms are placed on train cars called lorries, which allows the ties to move between the different production steps, is termed the Grinberg method.

The long-line fabrication process can be highly automated, but still requires a labor force with a size dependent on the number of casting beds in operation and the number of forms in each bed. Workers are typically broken down into crews performing specific tasks which may include utility application, steel layout, casting, sawing, stripping, and final preparation. The various stages of fabrication are illustrated in Figure 13 through Figure 18. A turnaround time of less than 24 hours is typical for this method (Fogarasi et al. 1991).

A typical tie manufacturing facility will consist of a lay down area, casting building occupied by several prestressing beds, and a concrete batch plant. The facility is typically serviced by an over head gantry cranes and interior rail systems to transport completed ties out of facility (Figure 13 
(a)). Prestressing beds support tie forms and ties during curing process while prestressing forces and jacking equipment is supported by "dead men" anchors at ends of beds. Form sections contain several tie cells set side by side, with multiple form sections placed end to end (Figure 13 (b)). For one tie manufacturer visited, the form sections contained 6 tie cells with 60 form sections set in a single prestressing bed; therefore 360 ties could be cast at a single time. Ties were cast upside down for the reasons including:

- Decrease occurrence of air voids and poor concrete consolidation,

- Cast-in-place fastener components can be set in form prior to casting,

- The bottom of a tie tends to be the only flat surface which makes it the easiest to have as a form free surface to provide an opening for concrete placement and finishing.

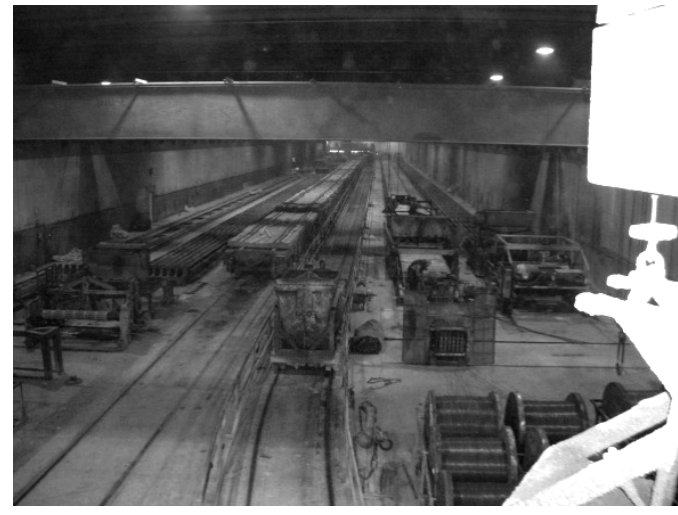

(a)

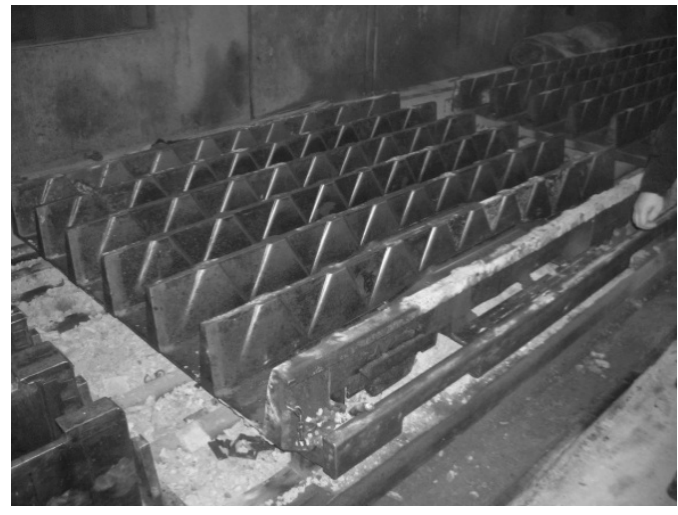

(b)

Figure 13: Plant and prestressing bed layout

The first step in tie production is the form and casting preparation. Forms must be cleaned to remove concrete from previous castings and to apply release agent which aids in the removal of ties during de-molding (Figure 14 (a)). Cast-in-place components such as ductile iron shoulders or polymer embeds, depending on the fastening system used, are placed at this time. Some manufacturers also place information such as the casting date and a serial number using castin-place plastic identification caps (Figure 14 (b)). This information can later be used by the railroad customer and manufacturer to track ties and evaluate performance. 


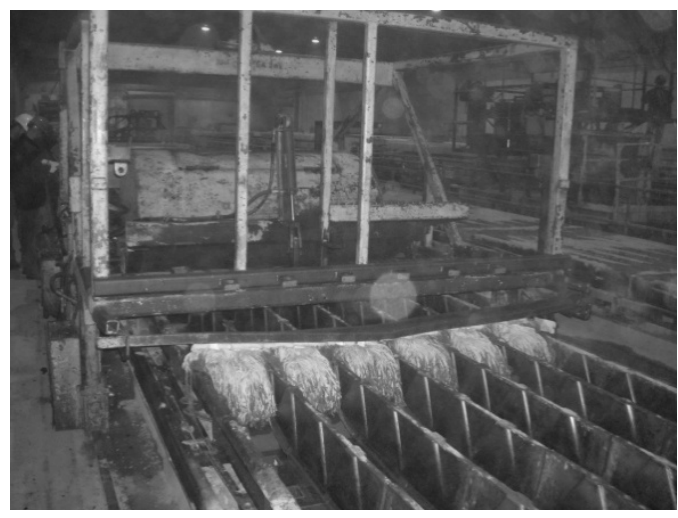

(a)

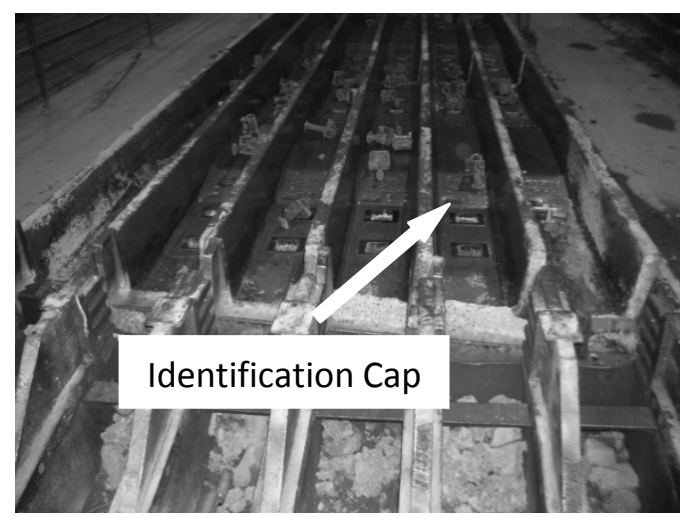

(b)

Figure 14: Form and casting preparation

Once all cast-in-place components have been set within the forms they must be prepared for placement of the prestressing steel. To decrease the amount of concrete which must be cut to separate the individual ties after curing, steel plates are placed between form sections between the horizontal layers of prestressing steel (Figure 15 (a)). Prestressing steel is pulled off rolls set at one end of the bed through a template which distributes the steel throughout the cross section of the tie (Figure 15 (b)).

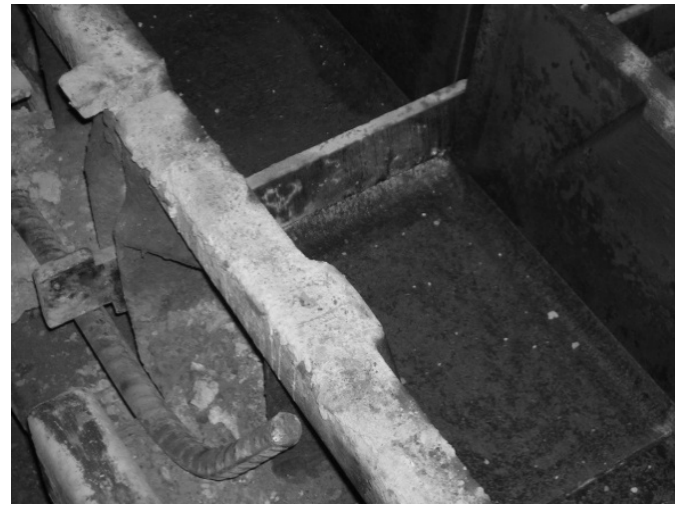

(a)

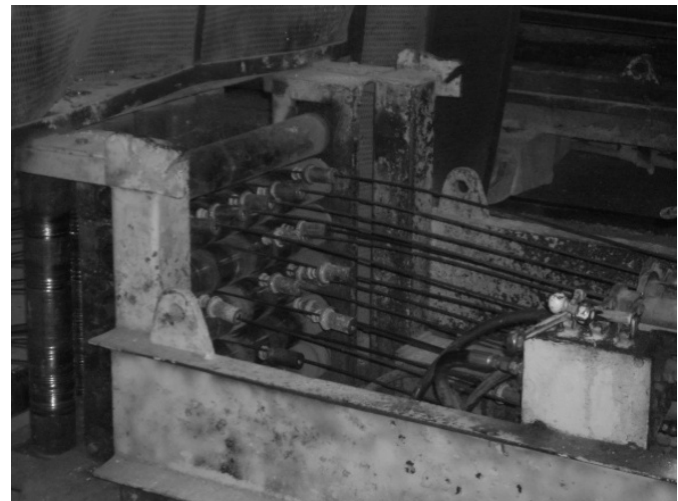

(b)

Figure 15: Form and prestressing steel preparation

Once all prestressing steel for a single line of ties has been run through all the form sections and anchored at the jacking end of the prestressing bed, end plates are placed at the free end; prestressing steel is cut, and the distribution template shown in Figure 15 moves to the next line 
of ties in the prestressing bed (Figure 16 (a)). Once all the prestressing for the bed is set, the steel is stressed (Figure 16 (b)). The level of stressing depends on several factors including:

- Pre-compression force designated by the tie design,

- Type of prestressing steel (stress relieved or low relaxation),

- Elastic elongation of prestressing steel.

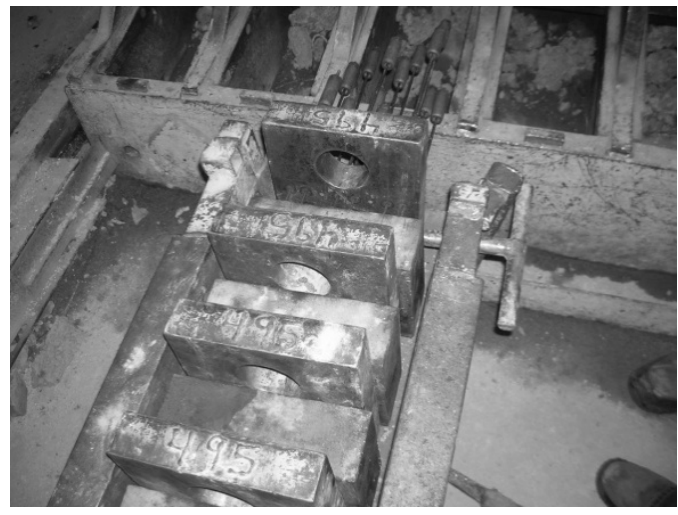

(a)

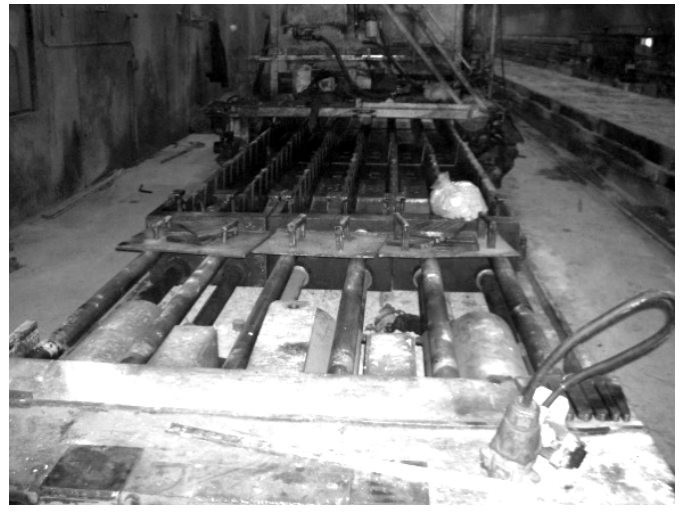

(b)

Figure 16: Prestressing set and jacking configuration

Concrete is typically produced by the tie manufacturer on site to ensure quality and give them control of mix characteristics. Following jacking of prestressing, concrete is batched and placed in the tie forms using a hopper and overhead gantry crane. Finishing of the bottom of the ties is completed by hand before the concrete sets (Figure 17 (a)). To enhance curing, the prestressing beds are capable of controlling the temperature of the ties using heated oil which circulates along the beds. Following a curing period of between 12-24 hours or until the concrete obtains adequate strength to transfer the prestressing force, the jacks are released transferring the prestressing force to the concrete. A saw set over the bed then cuts the prestressing steel at the form sections, separating the ties (Figure 17 (b)). 


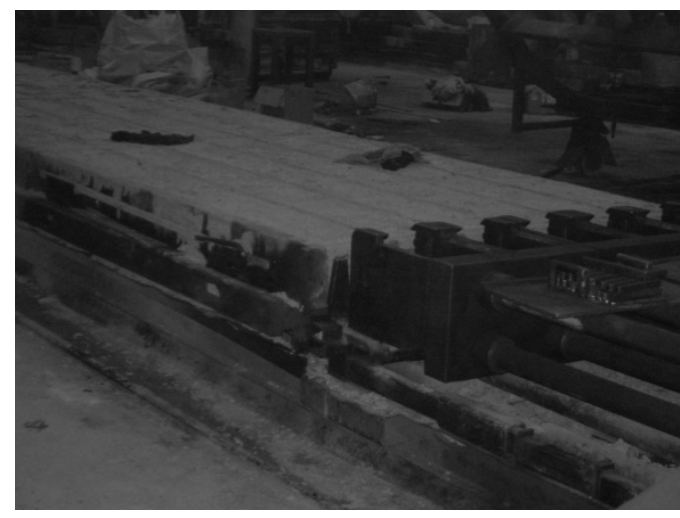

(a)

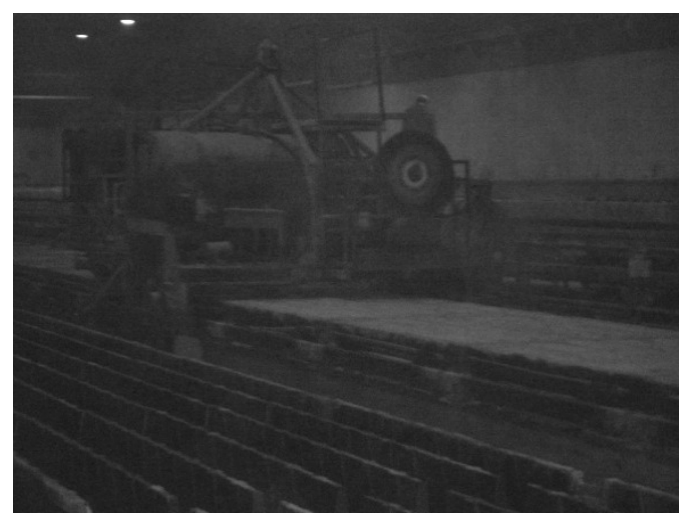

(b)

Figure 17: Casting and finishing operations

The final step in the tie production is de-molding and application of rail seat protectant, if required. De-molding is performed using the apparatus shown in Figure 18 (a) which lifts each form section up from the prestressing bed, allowing access to the tie ends by a hoist equipped with hydraulic clamps. Ties are then removed from the form, rotated 180 degrees and set on rail cars. Once the ties are right side up on the rail car, polyurethane is applied to the rail seat region using a manual sprayer prior to being moved outside for storage or shipment (Figure 18 (b)).

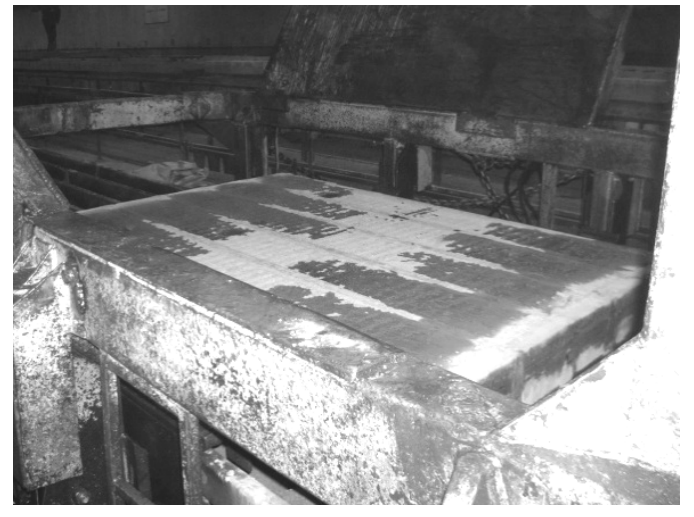

(a)

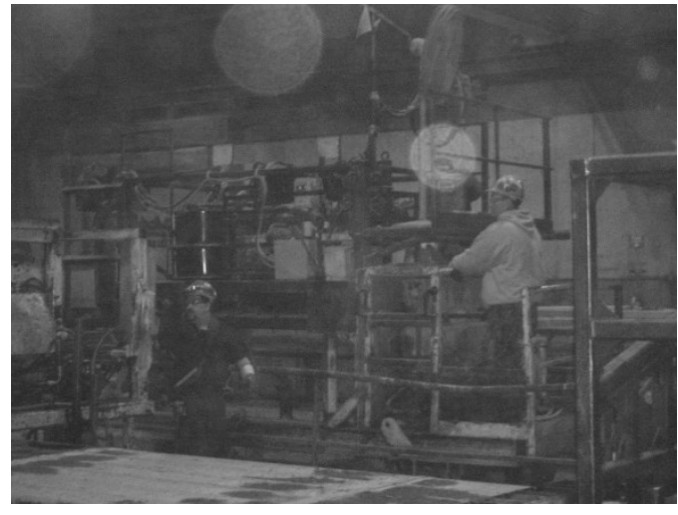

(b)

Figure 18: De-molding and final tie preparation

The fabrication process shown in Figures 13-18 still requires considerable amounts of manual labor when compared to other more recently developed systems, which are also based on the long-line method, but incorporate higher levels of mechanization. However, this process is efficient and has a high production rate compared to other methods. Other advantages of the 
long-line method of concrete tie production include uniform tie quality and few labor hours. Drawbacks to the long-line method are that it requires a large capital investment for forms and space for production. Tie manufacturing facilities vary in size and capacity, but the largest facility in North America is capable of producing around 400,000 to 500,000 ties annually.

\subsubsection{Installation and Maintenance}

The rate at which concrete ties are installed depends on the equipment used. Large railroads tend to use highly mechanized processes with equipment such as the Track Renewal Train (TRT) systems, which are capable of installing 8-9 miles of track in a single day. Whereas smaller contractors may use either tie clamps or chain hoist systems mounted on backhoes, which can install up to 1000 and 500 ties per day, respectively (Cann 1978).

Maintenance is the responsibility of the operating railroads and procedures vary significantly between companies. However, it is generally understood that for concrete ties to last, proper care must be taken to maintain the ballast and fastening systems. This is because the tie acts in conjunction with the rest of the track components, where if one component fails it tends to start a cascade of failures for the remaining components (Abbott 1979; Kramer 1996).

To increase quality control and documentation, some manufacturers have imprinted ties with information including its date and place of fabrication and tie design. Using this information, an in-service tie can be identified and evaluated based on historical manufacturer records.

\subsubsection{Initial Production and Construction Costs}

Concrete ties are an engineered product requiring specialized knowledge, equipment and a substantial capital investment in terms of facilities to produce. In addition, more complicated and expensive fastening systems are required with concrete ties compared to the steel spike used with wood ties. With this in mind, comparing concrete and wood ties in terms of materials and manufacturing, wood ties are cheaper to produce in North America by a small margin. In other regions of the world where sustainable sources of timber are unavailable, concrete is often a cheaper alternative (Gauntt and Zarembski 2000). 
As for North America, the cost disparity between wood and concrete may change as a projected shortage of wood of sufficient size and quality may limit timber tie production (White et al. 1978). Concrete ties could potentially experience a similar rise in price due to increasing energy costs related to cement production and the demand for steel. It can be assumed that the price for both timber and concrete ties will rise, but the rates are subject to speculation (Gauntt and Zarembski 2000).

Similar to their production, concrete and timber ties have very little in common in terms of construction and installation procedures. Crew size and equipment requirements vary depending on installation methods, but generally concrete tie track construction is faster and simpler due to the track gage being set during production rather than during construction as is the case with wood ties (White et al. 1978).

\subsubsection{Long Term Maintenance Costs}

The main advantage of concrete ties over other tie materials is their inert nature. Concrete unlike wood and steel can neither rot nor rust. Concrete ties also tend to wear uniformly over a section of track, whereas the location of timber tie wear is more random. Instead of replacing individual ties over an extended period of time like timber track typically requires, concrete tie tracks are repaired in sections leading to lower overall maintenance costs (Parker 2002). The higher initial capital investment made for concrete ties is typically recouped through the extended lifespan of a tie. This is supported by the fact that there are concrete ties still in service today that were installed 35 year ago. However, concrete ties have not typically endured the originally estimated 50 year service life. In comparison most wooden ties have an estimated lifespan of 20 years (Zarembski and Gauntt 2002). It is important to remember that tie lifespan is dependent on track, loading, maintenance and environmental conditions which may vary widely from location to location, therefore when comparing different tie alternatives, in these conditions must be specified.

\subsubsection{Economics}

To analyze the cost of concrete ties in comparison with traditional wood ties, both initial production and long term maintenance costs must be considered. The cost estimates however are subject to change with respect to the price of steel, portland cement and timber. With rising 
energy costs as well as increased reservations about the harvest of dimensionally suitable timber, the future prices of both concrete and timber ties are uncertain. The following factors have been determined to have the most significant impact on the economic benefits of concrete ties (White et al. 1978):

- Annual tonnage carried on track section, as tonnage increases concrete ties benefit increases due to higher durability,

- Life of concrete ties versus wood ties,

- Savings in train fuel due to more efficient train operation on more rigid concrete tie tracks,

- Future cost of old growth timber,

- Future cost of labor to replace aging wood ties on a more regular basis than concrete ties.

\subsection{Prestressed Concrete Railroad Tie Design}

\subsubsection{Design Considerations and Load Development}

The collective body for railroads in North America is the American Railway Engineering and Maintenance-of-Way Association (AREMA). Within the AREMA Manual for Railway Engineering an entire chapter is dedicated to railroad ties (AREMA 2003). The largest portion of this chapter, (Part 4) pertains to concrete railroad ties, which individual companies can use as a foundation for their own design standards. Design aspects such as loading, material specification, testing requirements and discussion of the relationships between a tie and the surrounding track components (ballast, rail, etc.) are considered. However, to provide their customers with a reliable product, manufacturers tend to design their ties to surpass the requirements set forth by AREMA, usually with additional requirements stipulated by the railroad operators.

The first step in designing a tie begins with discussing the intended service of the tie with its consumer, the railroad operator. Conditions unique to a tie application such as: tie spacing, loading in million gross tons annually (MGT) and operating train speed must be acquired from the railroad operator to indentify the performance requirements of the tie in service (Sikka and Singh 1972). With this information, the tie manufacturer can then design for the various limit states including flexure and durability. 
The flexural capacity of a concrete tie is derived from material properties, tie dimensions and number and type of prestressing wire used. Depending on the application, industrial, transit or heavy haul, cross-section dimensions and quantity of prestressing steel will vary, with heavier loading conditions requiring larger ties with more prestressing steel. When designing a tie, an evaluation of the loads being transferred and their flow through the track structure is essential. Therefore, forces and pressures of interest include the rail seat load, lateral load, and the ballast pressure. The required flexural capacity is determined based on the ballast support conditions (pressure distributions) encountered during the life of a tie and the applied rail seat loads. AREMA has accounted for these various loading and support conditions in the minimum specified positive and negative moments located at the critical sections of the rail seat and tie center.

Similarly, lateral loads are accounted for in tie and fastener design. Fasteners are designed for the transfer of a minimum lateral load to account for those encountered in curved sections of track, while ties must be capable of withstanding lateral loads to maintain horizontal track geometry (AREMA 2003). A further discussion of load analysis and transfer is presented in the following sections.

\subsubsection{Rail Seat Load}

As a train moves along the track, the load from an axle is distributed amongst several ties due to the rigidity of the track (Figure 19)(Hanna 1979). A single tie typically carries between 45 to 55 percent of an axle load directly above it. Factors affecting this load distribution are the tie spacing, fastening system, rail stiffness, and ballast and sub-grade conditions with tie spacing having the largest effect. Typical track design with concrete ties utilize tie spacing between 19 and 27 inches (AREMA 2003). 


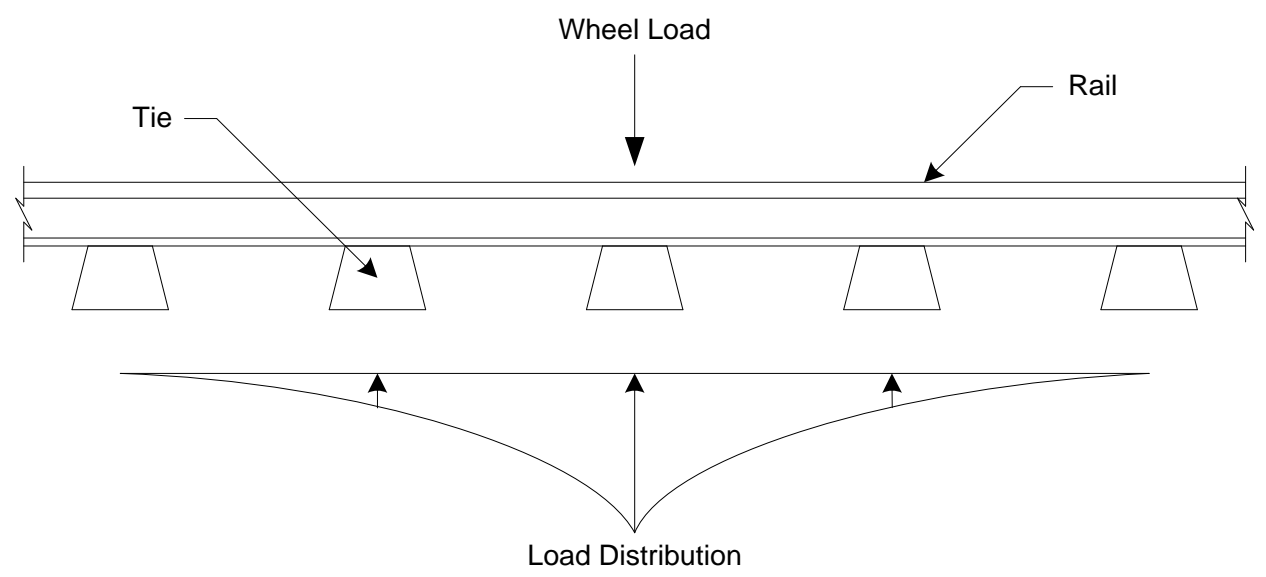

Figure 19: Distribution of load from single axle along track

In the past, equations and variables were used to calculate the rail seat load; however, to simplify the process of calculating rail seat loads, AREMA collected the factors related to the load distribution and created a design aid relating the percentage of a wheel load transferred to a single tie as a function of tie spacing (Figure 20). For example, a tie spacing of 24 in. would correlate to approximately 50 percent of the applied axle load being carried by an individual tie. 


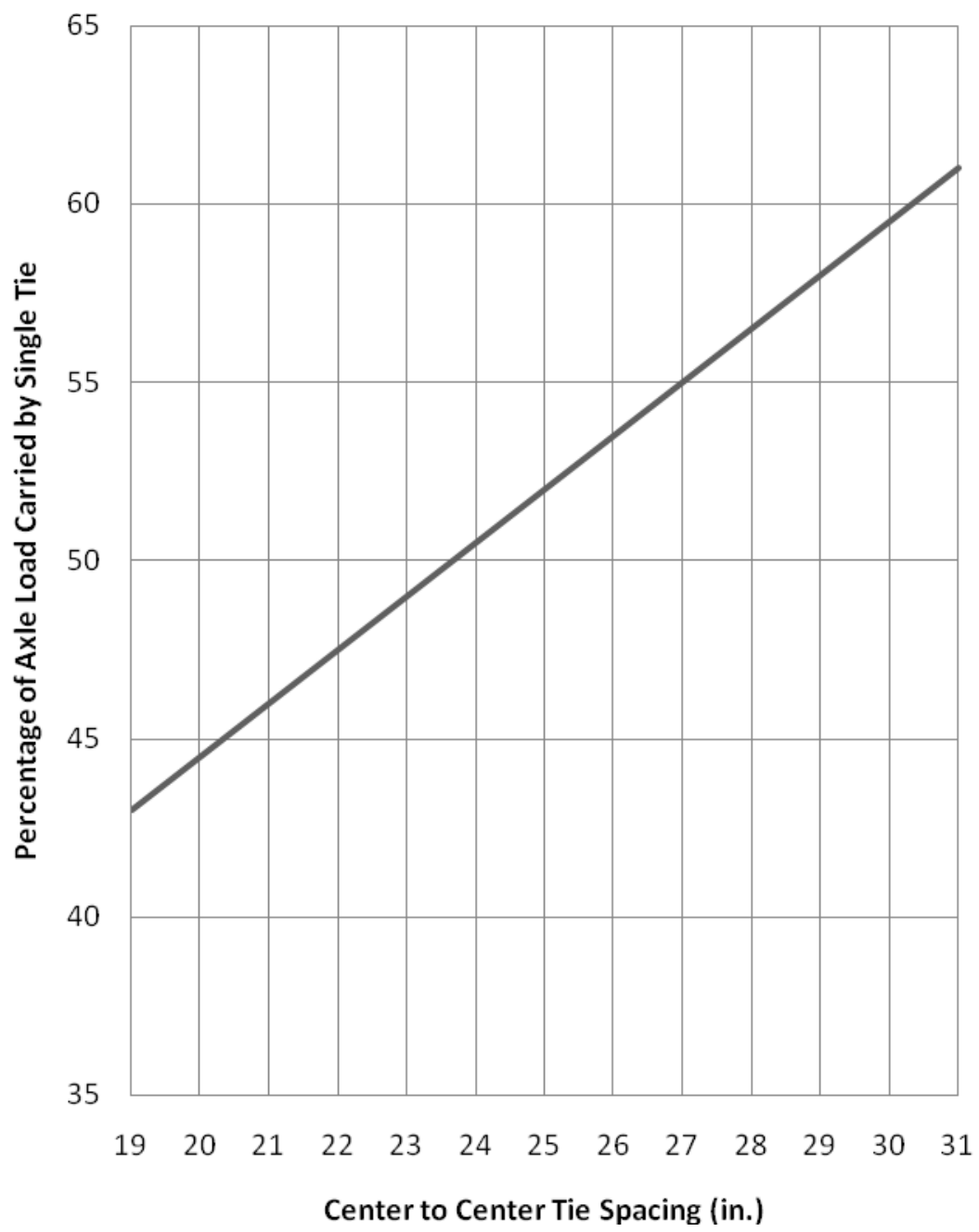

Figure 20: Estimated distribution of loads based on tie spacing (AREMA 2003)

To account for rail irregularities and dynamic wheel load effects, an impact factor is applied. An impact factor of 200 percent is recommended by AREMA for design load determination (AREMA 2003). Research into the effects of impact loads on the ties and fastening components has caused some investigators to question the adequacy of current impact factors. In laboratory tests, impact loads in excess of 400 percent of the static wheel load have been observed from wheel flats and other irregularities (Kaewunruen and Remennikov 2007). However, the frequency at which these impacts are observed varies and is unpredictable. It has been previously stated that tie manufacturers are often held to higher standards than those set by AREMA by the operating railroad consumer who requests a minimum flexural capacity. It is then 
left to the best judgment of the tie designer whether an increased factor of safety is required in regards to impact factors.

\subsubsection{Ballast Support}

Once wheel loads are applied to the tie they must be transferred to the ground through the ballast and sub-ballast material. Ballast support is crucial to a tie's ability to support load. Poor ballast support results in tie cracking and track misalignment (Namura et al. 2004). Following tie placement and tamping operations, ballast support is limited to the areas around the rail seat region leaving the center region of the tie with little to no support (Figure 21 and Figure 22 (b)). Over time due to train traffic the ballast will consolidate to a uniform support distribution along the length of the tie. Figure 22 illustrates the different stages of ballast support (Hanna 1979). However, deterioration of the ballast due to improper maintenance can result in a center support condition as previously discussed. How these support conditions relate to tie design will be discussed in later sections.

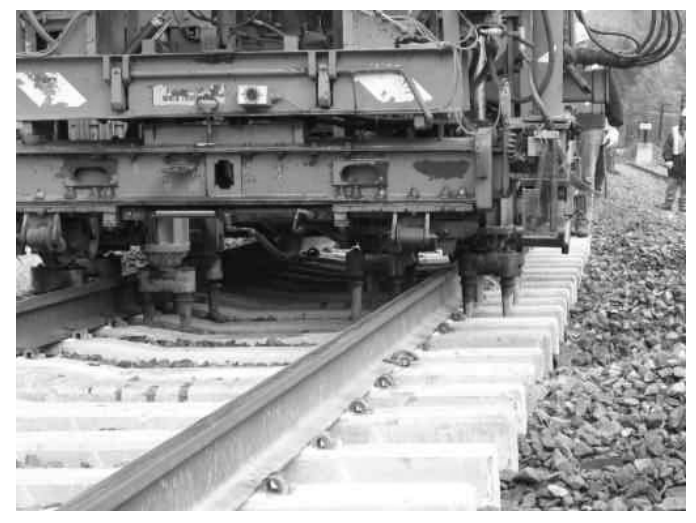

Figure 21: First round of tamping, consolidation restricted to rail seat region (Peters and Mattson 2003)

In reality, pressure between the tie and ballast is not uniform across the bottom of the tie, but an approximation or average is used to limit bearing pressures and prevent excessive depression of the track. This average ballast pressure is a function of the applied axle loads, impact factors, and the bearing area of the tie per AREMA section 4.1.2.5 (AREMA 2003). It is essential that the ballast and sub-ballast are not over stressed to prevent accelerated deterioration to the track and the ballast itself due to excessive depression of the track (Namura et al. 2004). 

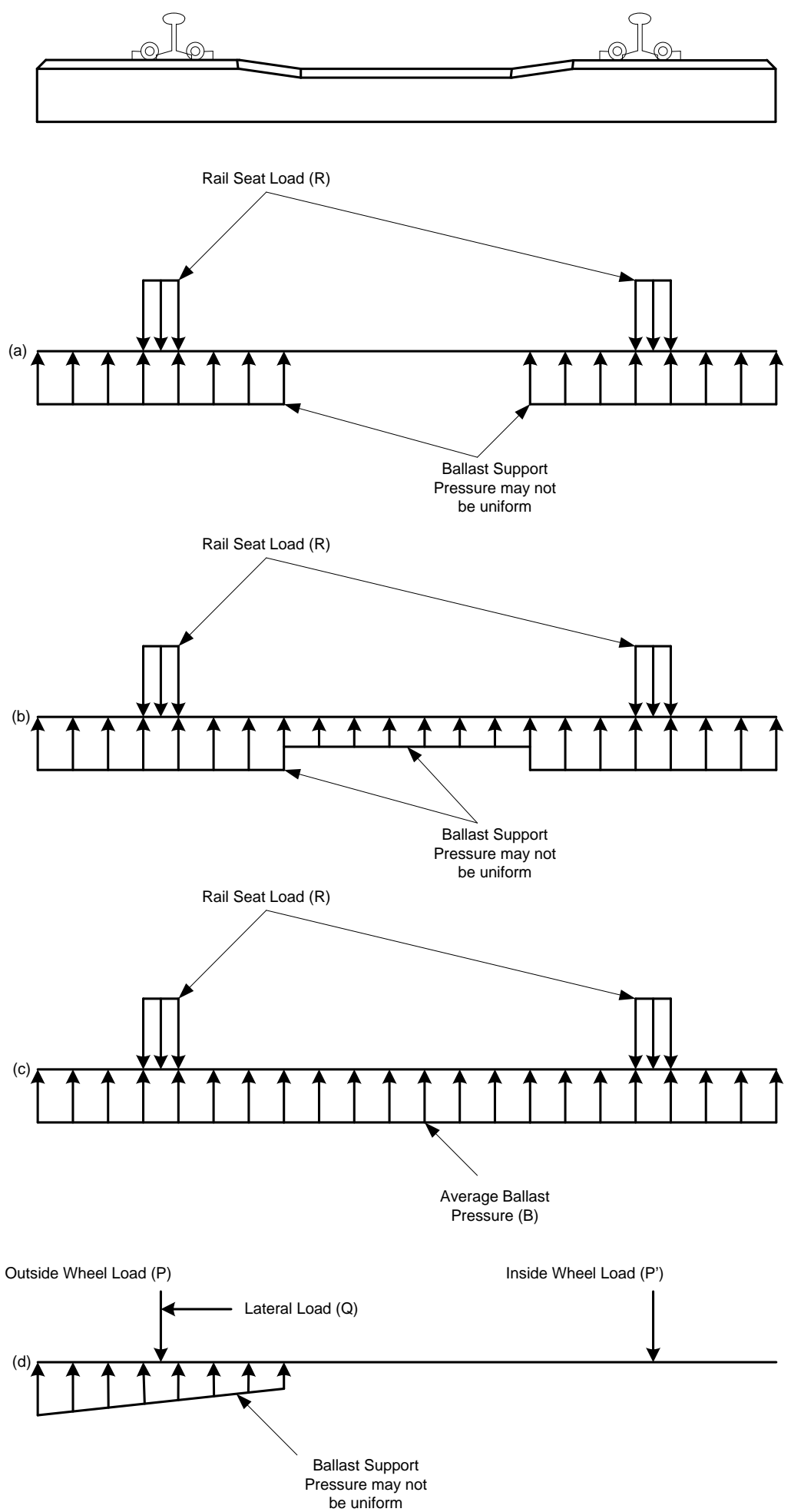

Figure 22: Ballast support distribution configurations (a) ballast support restricted to rail seat region following installation due to tamping only around rail (b) train traffic consolidating ballast, engaging center region (c) extensive train traffic, uniform support condition (d) on curved sections of track non-uniform support 


\subsubsection{Lateral Load}

Along with vertical loads applied from the wheels and ballast, ties are subjected to lateral loads especially on curved sections of track (Figure 23). The ability of a tie to restrict lateral movement is important for maintaining track geometry. To support these lateral loads, ties rely on bearing of their ends against ballast material, friction between tie surfaces and ballast, and gravity. A recent design innovation to increase this resistance to lateral movement has been the addition of scallops to the sides of ties (Figure 24). The scallops are wedges which extend from the sides of the tie to increase the interaction between the tie and ballast; historically tie designs maintained a smooth surface (Peters and Mattson 2003). In addition to the lateral load requirement for ties, AREMA suggests fastener systems have a minimum capacity of 14 kips per linear foot of track to resist lateral wheel to rail loads. This load is then used for the tie fastener anchorage design of the ductile iron shoulder or embed (AREMA 2003).

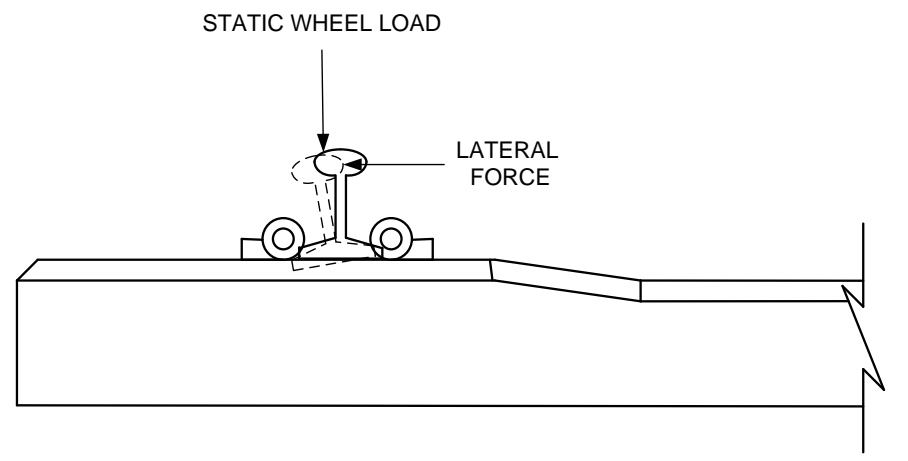

Figure 23: Lateral force applied to rail which tie must transfer to ballast as train navigates curves

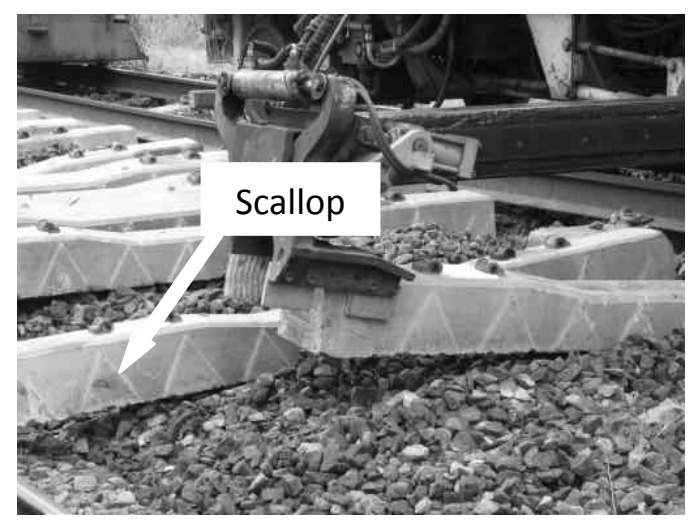

Figure 24: View of scallops during tie installation (Peters and Mattson 2003) 


\subsubsection{Design Load and Moment}

In the previous sections, the forces which are exerted on the tie by train traffic were analyzed and load flow path and distribution were considered. Now that a basic understanding of applied loads on tie has been developed, these loads must be transitioned into design loads and moments which incorporate the effects of train speed and tonnage.

Concrete tie design is based on the rail seat load which is transferred from a single train wheel to the rail seat through the rail, as this load will eventually dictate the applied moment at the critical sections of the tie. The first step in determining the magnitude of the rail seat load is considering the maximum load to be found in service. In the case of heavy haul track this will be the 315 kip car. This is an increase from the industry standard 286 kip car which is being replaced in response to an increased demand for freight rail transportation (Freudenstein 2007).

The 315 kip car is broken down into the axle configuration know as the Cooper E 80 load. This is a common load configuration based on four axles spaced at 60 inches. The 315 kip load is then uniformly distributed between the axles, resulting in each axle transferring a 78 kip static vertical load. Figure 25 displays the loads and axle spacing of the Cooper $\mathrm{E} 80$ load configuration (Freudenstein 2007).

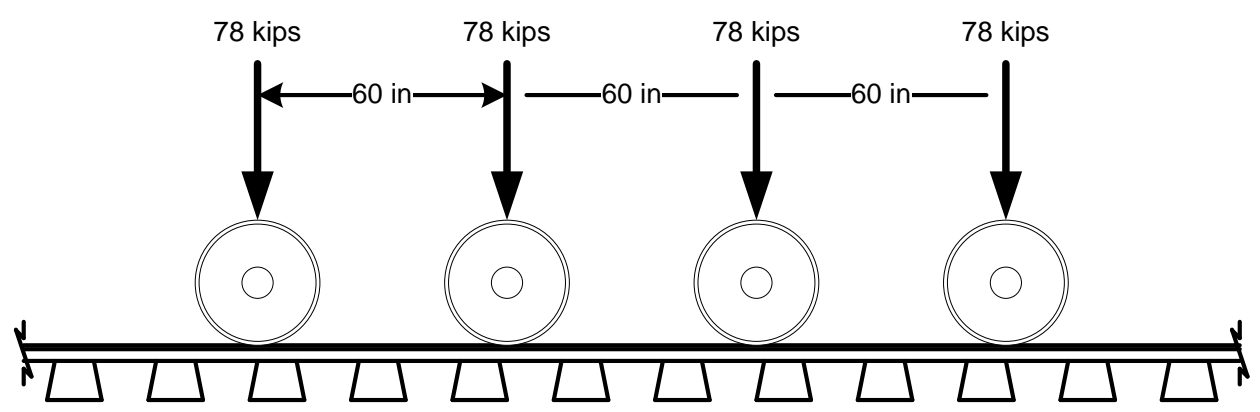

Figure 25: Cooper E 80 load configuration corresponding to a 315 kip car

Assuming symmetry in railcar loading, the maximum single axle load of $78 \mathrm{kip}$ is divided evenly between the two rail seats. Currently the AREMA specification does not include provisions for uneven wheel load conditions which occur in curves or unbalanced loads (AREMA 2003). At slow speeds this simplifying assumption may be inconsequential. However, at higher speeds the 
outside rail on a curved section will observe increased loads. Possible reasons for this absence of provision maybe that the effect of track super elevation and train motion in curved sections of track is negligible when compared to the overall vertical loading. For now, it is common practice to use the same ties designed for tangent sections of track in curved sections. Since no consistent flexural failures have been associated with increased load on outside rail seats of curves there appears to be sufficient additional capacity incorporated into the tie designs. Should train speeds increase substantially, consideration should be given to including uneven load effects in design load determination.

Once the axle load is separated between the individual wheels it must be divided further between the individual ties due to the rigid effects of the track structure as discussed in previous sections. Based on a typical spacing of 24 inches for concrete ties, a single tie will carry approximately 50 percent of the axle load. Finally, incorporating the 200 percent impact factor dictated by AREMA, a rail seat load of 58 kips is calculated as shown below (AREMA 2003).

$$
\begin{aligned}
& P_{\text {Rail seat }}=\frac{\text { Axle Load }}{2} \times \text { Distribution Factor } \times\left(1.0+\frac{\text { Impact Factor }}{100}\right) \\
& P_{\text {Rail seat }}=\frac{78 \text { kips }}{2} \times 0.5 \times\left(1.0+\frac{200}{100}\right)=58 \text { kips }
\end{aligned}
$$

\subsubsection{Load Factors}

In addition to the distribution and impact factors, AREMA accounts for the effects of train speed and tonnage when determining the design load for a tie. Operating speed and tonnage contribute to the cyclical loading effects which are applied to the tie. In an effort to predict these effects long term, AREMA has the additional load factors for train speed (V) and tonnage (T) displayed in load factor charts (Figure 26) (AREMA 2003; Freudenstein 2007). Load factors were derived from testing which studied the correlation between train speed, tonnage and railseat load. For example, using typical values for operating speed and tonnage characteristic of heavy haul freight railroad such as $60 \mathrm{mph}$ with an annual tonnage of 75 MGT the following rail seat design load was determined: 


$$
\begin{aligned}
& P_{\text {Factored }}=P_{\text {Rail seat }} \times V \times T \\
& P_{\text {Factored }}=58 \text { kips } \times 0.9 \times 1.1 \approx 58 \mathrm{kips}
\end{aligned}
$$
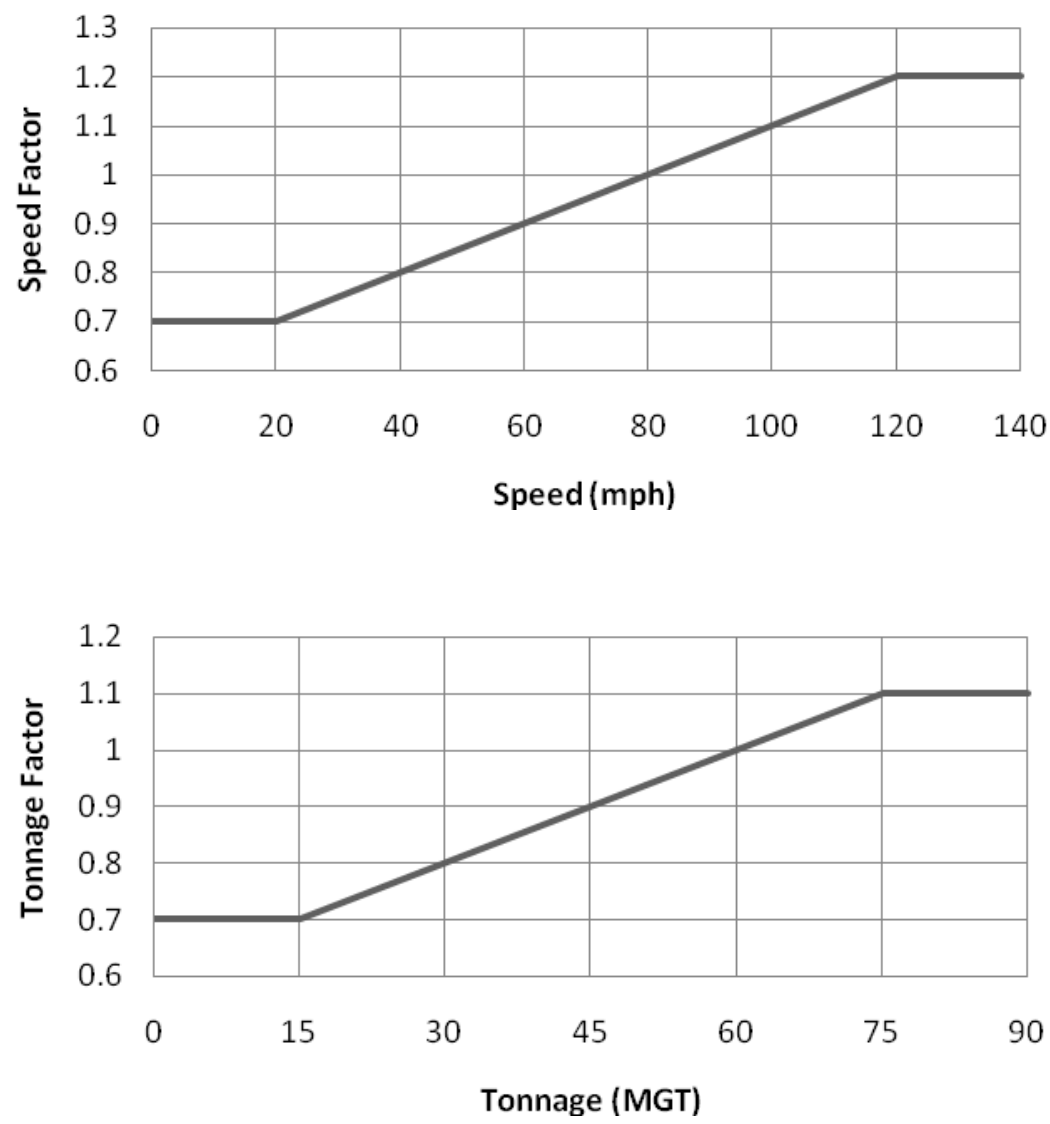

Figure 26: AREMA load factor charts for speed and tonnage (AREMA 2003)

\subsubsection{Load Cases and Critical Sections}

The design rail seat load determined above is used to calculate the design moments. The design moments are a function of the ballast support which varies over the life of the tie. Two load cases characterized by their ballast support conditions are of primary importance.

The first load case occurs immediately after tamping whether it is following tie installation or ballast maintenance procedures. During tamping operations only the ballast near the rail seat is consolidated causing support to be limited to the rail seat. In this case ballast support extends from the rail seat to the end of the tie shoulder and equal distance towards the center of the tie (Figure 27). In most instances the center section has little to no interaction. This support 
configuration causes the maximum moment to occur in the positive direction at the rail seat while the center section experiences only slight positive bending.

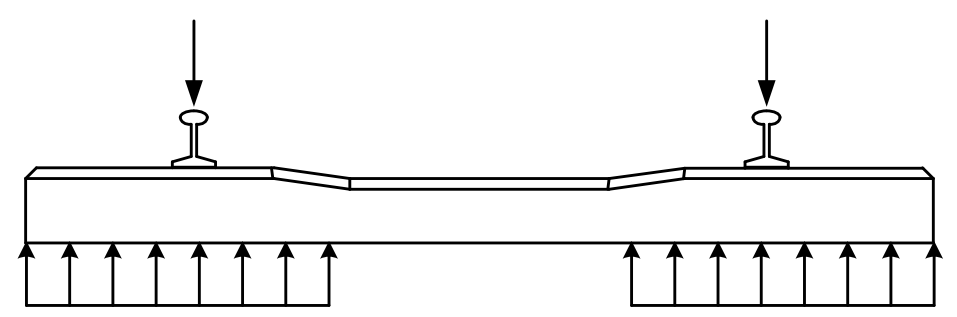

Figure 27: Load Case 1: After installation and tamping, ballast support limited to rail seat region producing positive moment in rail seat section (AREMA 2003; Freudenstein 2007)

The second load case is characteristic of a well trafficked section of track which has received little ballast maintenance. Over time, loading from trains causes movement of the tie along with vibration. This motion consolidates the ballast into more uniform support distribution (Figure 28).This uniform loading produces a decreased positive rail seat moment compared to the first case, but transitions the center of the tie into negative bending. This configuration can lead to the previously discussed failure known as center-binding.

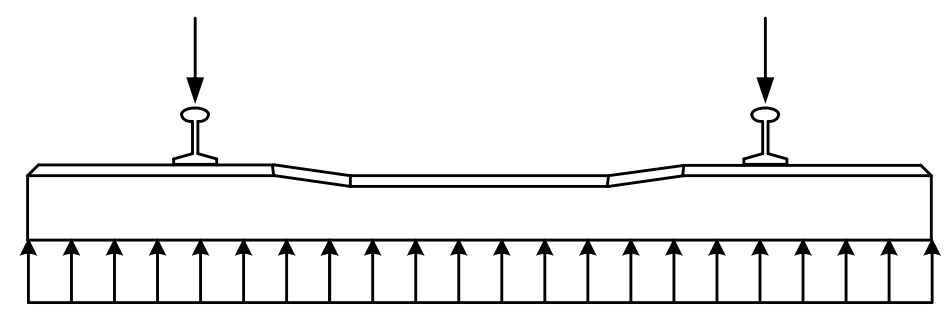

Figure 28: Load Case 2: Over time settlement and ballast degradation lead to uniform ballast support inducing negative moment at center section and continued positive moment at railseat (AREMA 2003; Freudenstein 2007)

The locations of maximum moment from the two load cases are the rail seat and center. When designing the ties for flexure, the rail seat and center critical sections are evaluated for capacity. Typical cross sections at the rail seat and center can are shown in Figure 29. Generally the rail seat section has the largest height and cross-sectional area since it has the largest applied moment, while the center section slims down from the rail seat due to lower applied moment (AREMA 2003). This slimming of the center cross-section also allows for a shift of the eccentricity of the prestressing about the tie's axis of bending, accounting for the variation of positive and negative bending between the two sections, leading to a more efficient design (Freudenstein 2007). 


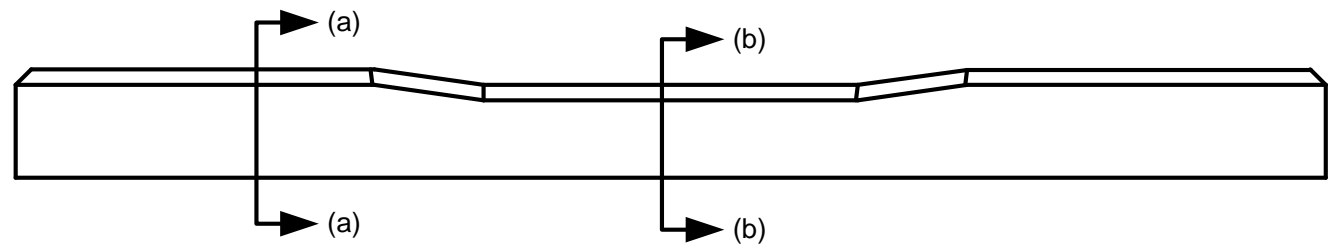

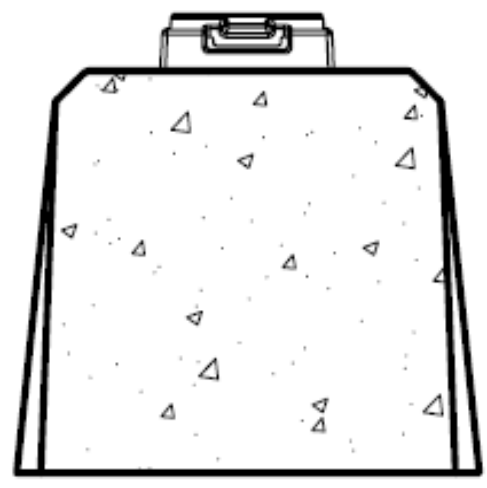

(a)

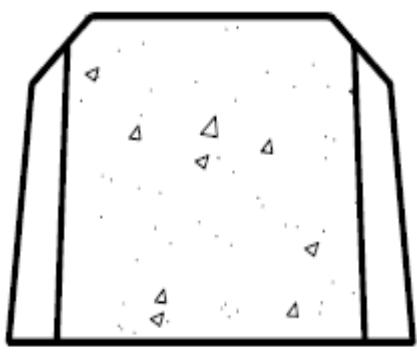

(b)

Figure 29: Flexural critical sections for generic concrete tie (a) rail seat section (b) center section

\subsubsection{Limit States}

The limit state of flexural failure as defined by AREMA for concrete railroad ties is unique compared to the typical prestressed concrete member. For this reason the following section will discuss flexural failure as defined by common prestressed concrete design and then highlight how it differs for prestressed concrete railroad ties.

\subsubsection{Prestressed Concrete Limit States}

In structural concrete design whether it is prestressed or reinforced, it is generally understood that concrete cracks whether it be from loading or temperature change or shrinkage. However cracking does not constitute structural failure. Unlike other structural building materials such as steel and wood, concrete has remaining capacity after cracking that occurs due to the interaction between the prestressing or reinforcement and the concrete ( $\mathrm{ACl} 2005$; Naaman 2004). This can be observed by plot of load versus deflection of a prestressed concrete beam designed and tested by Michigan Tech students for the Precast/Prestressed Concrete Institute's Student Engineering Competition: Big Beam, shown in Figure 30. The plot shows the transition from linear to non-linear behavior as the section begins to crack. Following the transition from 
an uncracked to cracked section, load can continue to be applied until the maximum applied load is reached. At this point two conditions may occur, rupture of the steel or crushing of the extreme compression fiber. Whether rupture or crushing occurs first depends on factors such as the quantity of steel and the strength of the concrete (Naaman 2004).

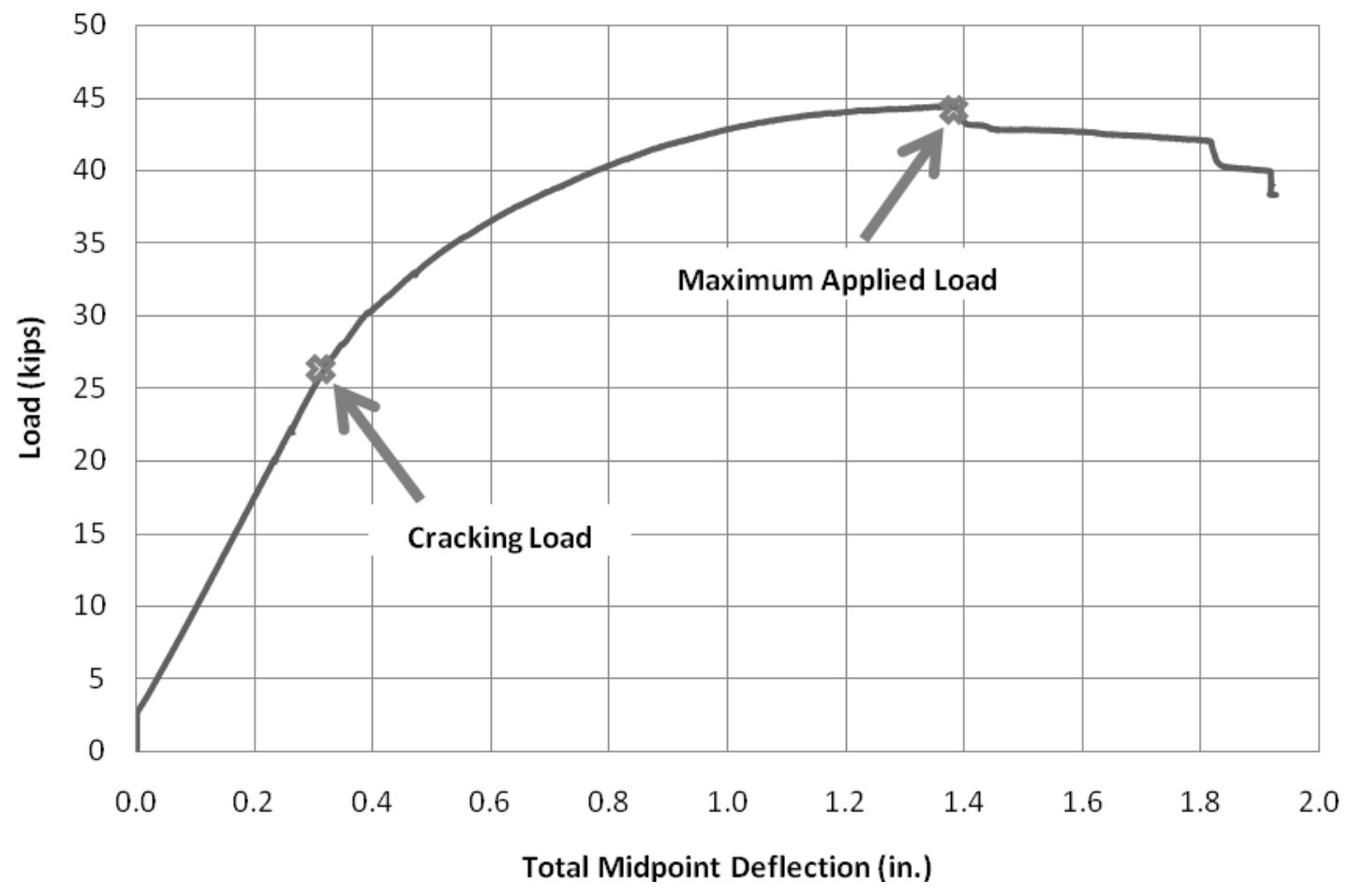

Figure 30: Load/deflection curve for flexural prestressed concrete member showing cracking and maximum loads

Figure 31 is an example of a prestressed concrete beam which has been tested to failure. In this case the beam was over-reinforced causing the extreme fiber to crush prior to rupture of the prestressing steel. Flexural cracking can be observed stretching from the extreme tension fiber into the web of the beam. 


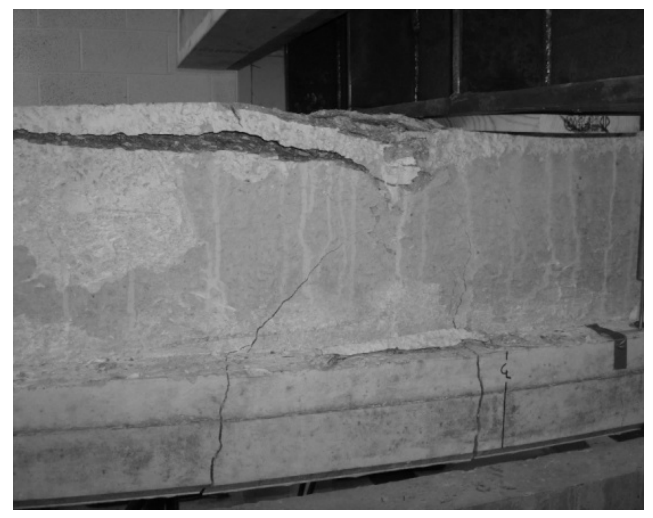

Figure 31: Prestressed concrete beam failure corresponding to Figure 30, showing flexural cracking and crushing of the compression zone

\subsubsection{Limit States of Prestressed Concrete Railroad Ties}

In prestressed concrete tie design the primary limit state is flexural failure. However, unlike typical prestressed concrete design flexural failure in ties is not defined by steel rupture or concrete crushing. Instead failure as defined by AREMA (Section 4.9.1) is the propagation of cracks from the extreme tension fiber of the tie to the first layer of prestressing (AREMA 2003). Even though the tie may have considerable amounts of flexural capacity remaining, for all intensive purposes the tie has failed and requires replacement.

Cracking constitutes flexural failure in prestressed concrete railroad ties for several reasons. Since ties are in direct contact with the ground, sources of water are readily available to cause corrosion of the prestressing steel should a crack allow the infiltration of moisture to the level of prestressing. However, corrosion is actually a secondary consideration in the decision to limit failure to cracking. Cyclic loading is actually the driving motivation for the cracking limit. The application of prestressed concrete to the railroad ties creates unique loading conditions which exacerbate fatigue susceptibility of the prestressed concrete. Since the concrete is repeatedly loaded to high percentages of its design load, a large margin of additional capacity must be left untapped to provide for the effect of fatigue on the steel and concrete components of the tie (Kaewunruen and Remennikov 2008; Remennikov et al. 2007).

If concrete ties were allowed to reach their ultimate capacity as defined by typical prestressed design the expected service life would be miniscule. In order extend their service life and 
provide for the cyclic loading encountered by railroads, ties must be limited to only a fraction of their flexural capacity or service capacity.

In addition to the flexure, ties must be designed for the following limit states (AREMA 2003):

- Bearing failure of the concrete at the rail seat surface (this condition typically controls the minimum top width dimension)

- Shear failure (typically negligible due to the continuous support provided by the ballast)

- Bearing failure of the ballast (dictates the bottom dimensions of the tie)

Serviceability requirements such deflection and vibration of ties are largely absent from typical designs for one of two reasons. Either the serviceability criteria such as vibrations is irrelevant since concrete ties are not utilized like the typical prestressed member (vibration is a limit state in most prestressed design for human comfort rather than safety, not applicable to heavy haul railroad tie design) or it is accounted for by other conditions. In the case of deflections, the ballast bearing capacity will dictate whether or not appropriate deformations have been designed for (AREMA 2003).

\subsubsection{Material Properties}

The material properties of concrete and steel undoubtedly play an important role in the design of a prestressed concrete tie. The strength and stiffness of the materials which comprise the ties dictate their capacity as well as portions of the fabrication process. Therefore, a thorough understanding of their properties is required.

\subsubsection{Concrete}

The purpose of the concrete within the tie is to offer rigidity and resist the prestressing force. To perform these tasks material properties such as allowable stresses and elastic modulus are of importance. For prestressed concrete tie design AREMA references the American Concrete Institute ( $\mathrm{ACl}$ ) Building Code Requirements for Structural Concrete and Commentary ACl 318 to obtain specifications on concrete material properties as well as design procedures $(\mathrm{ACl} 4.4 .2)$ (AREMA 2003). 
The allowable tensile and compressive stresses outlined by $\mathrm{ACl} 318$ have been summarized in Table 1. However, some precaution must be taken when using the material property approximations provided in $\mathrm{ACl} 318$, especially for allowable concrete stresses. These approximations are valid for standard structural concrete and are not necessarily applicable for high strength concrete $(10,000 \mathrm{psi}$ and greater) such as that used in the production of prestressed concrete ties (AREMA 2003). For the design of concrete with compressive strengths greater than 10,000 psi, ACl 363R-92 is referenced ( $\mathrm{ACl}$ 1997). However, $\mathrm{ACl} 363 \mathrm{R}-92$ does not present complete allowable stress limits and therefore, for this project $\mathrm{ACl} 318$ will be used for all concrete strengths considered, above and below 10,000 psi. For allowable concrete stresses tie manufacturers will either use laboratory material test results or other approximations which (Table 48 in Appendix B).

While $\mathrm{ACl} 318$ specifies the allowable concrete stresses for steel prestressing, $\mathrm{ACl}$ 440.4R-04 specifies the allowable concrete stresses for FRP prestressing (Table 2). The only difference between the two specifications is the allowable tensile stress in the concrete at service. Instead of $7.5 f^{\prime}{ }_{c}^{0.5}$ for the allowable tension stress with steel prestressing, FRP has a slightly lower limit of $6 f_{c}{ }_{c}^{0.5}$. Unlike the allowable concrete stresses, the approximation for elastic modulus of the concrete does not change depending on the prestressing type used. The approximation relates concrete strength to the elastic modulus (Table 3).

Table 1: Allowable concrete stresses from $\mathrm{ACl}$ 318-08

\begin{tabular}{|c|c|c|}
\hline $\begin{array}{c}\text { Allowable Concrete } \\
\text { Stresses }\end{array}$ & Stress Case Description & $\begin{array}{c}\text { ACI Code } \\
\text { Specification (psi) }\end{array}$ \\
\hline \multicolumn{3}{|c|}{ Allowable stress at transfer of prestress (before losses) } \\
\hline$\sigma_{\mathrm{ci}}$ & $\begin{array}{l}\text { Extreme fiber stress in compression at prestress } \\
\text { transfer, } \mathrm{ACl} 318-0818.4 .1 \text { (a) }\end{array}$ & $0.6 f_{c i}^{\prime}$ \\
\hline$\sigma_{\mathrm{ti}}$ & $\begin{array}{l}\text { Extreme fiber stress in tension at prestress } \\
\text { transfer, } \mathrm{ACl} 318-0818.4 .1 \text { (b) }\end{array}$ & $3 f_{c}^{\prime} 0.5$ \\
\hline \multicolumn{3}{|c|}{ Allowable stresses under service loads (after losses) } \\
\hline$\sigma_{\mathrm{cs} 1}$ & $\begin{array}{l}\text { Extreme fiber stress in compression at service (P/S } \\
\text { and } \mathrm{SDL}), \mathrm{ACl} 318-08 \text { 18.4.2 (a) }\end{array}$ & $0.45 f_{c}^{\prime}$ \\
\hline$\sigma_{\mathrm{cs} 2}$ & $\begin{array}{l}\text { Extreme fiber stress in compression at serivce (P/S } \\
\text { and total load, } \mathrm{ACl} 318-0818.4 .2 \text { (b) }\end{array}$ & $0.6 f_{c}^{\prime}$ \\
\hline$\sigma_{\mathrm{ts}}$ & $\begin{array}{l}\text { Extreme fiber stress in tension at service, } \mathrm{ACl} 318 \text { - } \\
08 \text { 18.3.3 Class } \mathrm{U}\end{array}$ & $7.5 f_{c}^{\prime}{ }_{c}^{0.5}$ \\
\hline
\end{tabular}


Table 2: Allowable concrete stresses in conjunction with FRP prestressing (ACI Committee 440 2004)

\begin{tabular}{|c|c|c|}
\hline $\begin{array}{l}\text { Allowable Concrete } \\
\text { Stresses }\end{array}$ & Stress Case Description & $\begin{array}{c}\text { ACl Code } \\
\text { Specification (psi) }\end{array}$ \\
\hline \multicolumn{3}{|c|}{ Allowable stress at transfer of prestress (before losses) } \\
\hline$\sigma_{\mathrm{ci}}$ & $\begin{array}{l}\text { Extreme fiber stress in compression at prestress } \\
\text { transfer } \mathrm{ACl} 440.4 \mathrm{R}-04 \text { Table } 3.2 \text { (a) }\end{array}$ & $0.6 f_{c i}^{\prime}$ \\
\hline$\sigma_{\mathrm{ti}}$ & $\begin{array}{l}\text { Extreme fiber stress in tension at prestress transfer, } \\
\mathrm{ACl} 440.4 \mathrm{R}-04 \text { Table } 3.2 \text { (b) }\end{array}$ & $3 f_{c}^{0.5}$ \\
\hline \multicolumn{3}{|c|}{ Allowable stresses under service loads (after losses) } \\
\hline$\sigma_{\mathrm{cs} 1}$ & $\begin{array}{l}\text { Extreme fiber stress in compression at service (P/S } \\
\text { and SDL) ACl 440.4R-04 Table } 3.2 \text { (a) }\end{array}$ & $0.45 f_{c}^{\prime}$ \\
\hline$\sigma_{\mathrm{cs} 2}$ & $\begin{array}{l}\text { Extreme fiber stress in compression at serivce (P/S } \\
\text { and total load) } \mathrm{ACl} 440.4 \mathrm{R}-04 \text { Table } 3.2 \text { (b) }\end{array}$ & $0.6 f_{c}^{\prime}$ \\
\hline$\sigma_{\mathrm{ts}}$ & $\begin{array}{l}\text { Extreme fiber stress in tension at service } \mathrm{ACl} 440.4 \mathrm{R} \\
04 \text { Table } 3.2 \text { (c) }\end{array}$ & $6 f_{c}^{0.5}$ \\
\hline
\end{tabular}

Table 3: Static elastic modulus from ACI 318-08

\begin{tabular}{|c|c|c|}
\hline Concrete Modulus & Case Description & $\begin{array}{c}\text { ACl Code } \\
\text { Specification (ksi) }\end{array}$ \\
\hline $\mathrm{E}_{\mathrm{ci}}$ & Concrete modulus at transfer, $\mathrm{ACl}$ 18.4.1 & $57000 f_{c i}^{0.5}$ \\
\hline $\mathrm{E}_{\mathrm{c}}$ & Concrete modulus at service, $\mathrm{ACl}$ 18.4.1 & $57000 f_{c}^{0.5}$ \\
\hline
\end{tabular}

\subsubsection{Prestressing}

Similar to the specifications for concrete material properties, AREMA references $A C I 318$ as well for the prestressing properties. Properties such as allowable prestressing stress from jacking through service are presented in Table 4. For design of prestressed concrete ties utilizing FRP the use of $\mathrm{ACl} 440.4 \mathrm{R}-04$ (Table 5) is recommended ( $\mathrm{ACl}$ Committee 440 2004).

Table 4: Allowable prestressing stresses from $\mathrm{ACl}$ 318-08

\begin{tabular}{|c|l|c|}
\hline $\begin{array}{c}\text { Allowable Prestressing } \\
\text { Stresses }\end{array}$ & \multicolumn{1}{|c|}{ Stress Case Description } & $\begin{array}{c}\text { ACl Code } \\
\text { Specification (ksi) }\end{array}$ \\
\hline $\mathrm{f}_{\mathrm{pj}}$ & Due to prestressing steel jacking & $0.94 \mathrm{f}_{\mathrm{py}}$ \\
\hline $\mathrm{f}_{\mathrm{pj}}$ & Due to prestressing steel jacking & $0.80 \mathrm{f}_{\mathrm{pu}}$ \\
\hline $\mathrm{f}_{\mathrm{pi}}$ & Immediately after prestress transfer & $0.82 \mathrm{f}_{\mathrm{py}}$ \\
\hline $\mathrm{f}_{\mathrm{pi}}$ & Immediately after prestress transfer & $0.74 \mathrm{f}_{\mathrm{pu}}$ \\
\hline
\end{tabular}


Table 5: Permissible prestressing stresses for carbon FRP (ACI Committee 440 2004)

\begin{tabular}{|l|c|}
\hline \multicolumn{1}{|c|}{ Stress Case Description } & ACI Code Specification \\
\hline Allowable jacking stress, $f_{p j}$ & $0.65 f_{p u}$ \\
\hline Due to prestressing steel jacking, $f_{p i}$ & $0.60 f_{p u}$ \\
\hline
\end{tabular}

\subsubsection{Losses}

Over time the stress in prestressing will decrease, imparting progressively less prestressing force on the tie. However this loss of prestressing occurs at a decreasing rate until it eventually levels off. It is necessary to predict total loss of prestressing to determine the long term capacity of a member. The total prestressing loss is a combination of sources including the fabrication process and material characteristics such as the following (ACl 2005; Naaman 2004):

- Elastic Shortening: As prestressing force is transferred to concrete it is compressed, simultaneously shortening the prestressing steel which has bonded to it. This process occurs immediately following prestressing transfer.

- Relaxation: This process may be considered the equivalent of creep. This is the loss of tension force of time while constant length and temperature are maintained.

- Shrinkage: Occurs over a longer period of time as the free water within the concrete is used during hydration and evaporated allowing shortening of the concrete.

- Creep: In response to long term applied compressive stresses concrete undergoes plastic shortening strain in addition to the elastic strain. Simultaneously, the prestressing steel which had bonded shortens.

- Anchorage Set: In prestressed fabrication, chucks placed around the prestressing steel to maintain tension endure mechanical losses when they "set in".

These sources listed above will each produce losses and are summed together produce the total prestressing loss. Some many occur instantaneously (elastic shortening and anchorage) or over the life of the prestressed member (creep, shrinkage, etc.). Computation of the losses can be performed individually then summed giving the most accurate solution or a lump sum estimate of the losses may be computed.

\subsubsection{Transfer and Development Lengths}

To achieve the nominal moment capacity of a section, the prestressing tendons must maintain the bond between the concrete prestressing tendons up to the stress level associated with 
ultimate capacity. If the tendons are unable to attain the necessary level of stress with the provided anchorage, the tendon will slip or pull out of the concrete before reaching the ultimate capacity of the section. The distance required to obtain the necessary bond or anchorage between the concrete and the prestressing tendons is called the development length and is a function of the maximum applied stress in the tendon and the diameter of the tendon.

In addition to the development length, prestressing requires a length of bond to transfer the prestressing force into the concrete referred to as the transfer length. At the free end of the tie the stress in the concrete due to the prestressing is zero and increases linearly along the length of the tendon up to the effective prestressing stress. In order to have full efficiency of the prestressing the transfer length must be met before the critical section of flexure. In the case of the prestressed concrete railroad tie, the transfer length must be met in the shoulder length to have the full capacity based on the effective prestress by the rail seat section.

\subsubsection{Anchorage of Prestressing in End Zone (Bursting)}

In the end zones of pretensioned and posttensioned concrete members, special consideration is given to the transfer of the prestressing force to the concrete due to the possible development of excessive tensile stresses, known as bursting stresses. The bursting stresses which develop in the concrete due to the prestressing may cause horizontal cracking or spalling. To prevent cracking and spalling due to high tensile stresses, confining steel in the form of spirals or hoops is typically placed in the anchorage zone (region of prestressing force transfer). Other methods of reducing the tensile stresses include, changing the cutting patterns used during the release of the prestressing force or changing the prestressing configuration to reduce areas of stress concentration (ACl 2008; Naaman 2004).

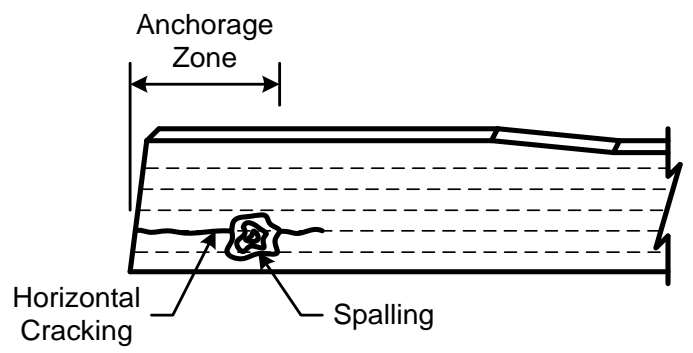

Figure 32: Failures due to excessive tensile force in anchorage zone 
For the design of prestressed concrete railroad ties, bursting stresses are not addressed by AREMA, however ACl 318 is referenced for concrete related design issues (AREMA 2003). ACl 318-08 recommends the following methods for analyzing a prestressed member for bursting stresses $(\mathrm{ACl} 2008)$ :

- Strut-and-tie models,

- Linear stress analysis using finite element analysis,

- Simplified equations where applicable.

Analysis of bursting stresses was not included in this study (see future work Section 5.3)

\subsubsection{Testing}

To gauge tie performance, laboratory testing is performed by tie manufactures to check that ties meet the minimum specified requirements set forth by AREMA and are adequate for the anticipated loads and load frequency. Testing includes both static and dynamic loadings to simulate in service conditions of the ties. Flexural testing includes the rail seat moment test (Figure 33 and Figure 34), center moment test (Figure 35 and Figure 36), bond development test and fatigue testing (AREMA 2003). For the equations shown in Figure 33 through Figure 36, the variables $\mathrm{P}$ and $\mathrm{M}$ represent the unfactored static wheel load and moment, respectively.

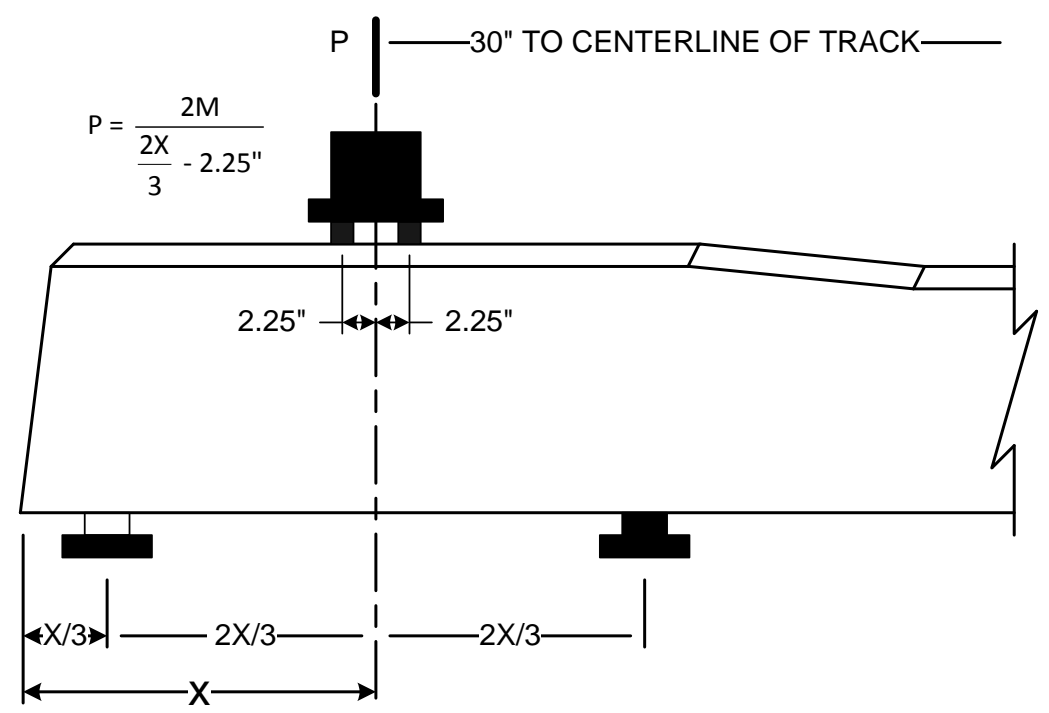

Figure 33: Positive rail seat moment test configuration as outlined in AREMA 4.9.1 Design Test of Monoblock Ties (AREMA 2003) 


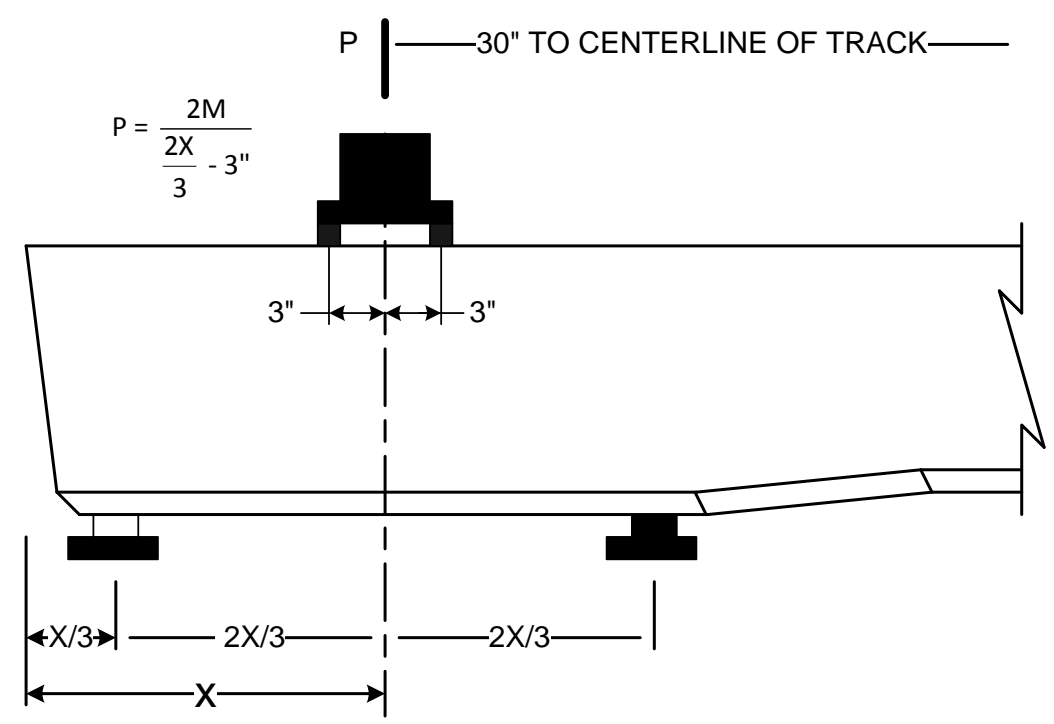

Figure 34: Negative rail seat moment test configuration as outlined in AREMA 4.9.1 Design Test of Monoblock Ties (AREMA 2003)

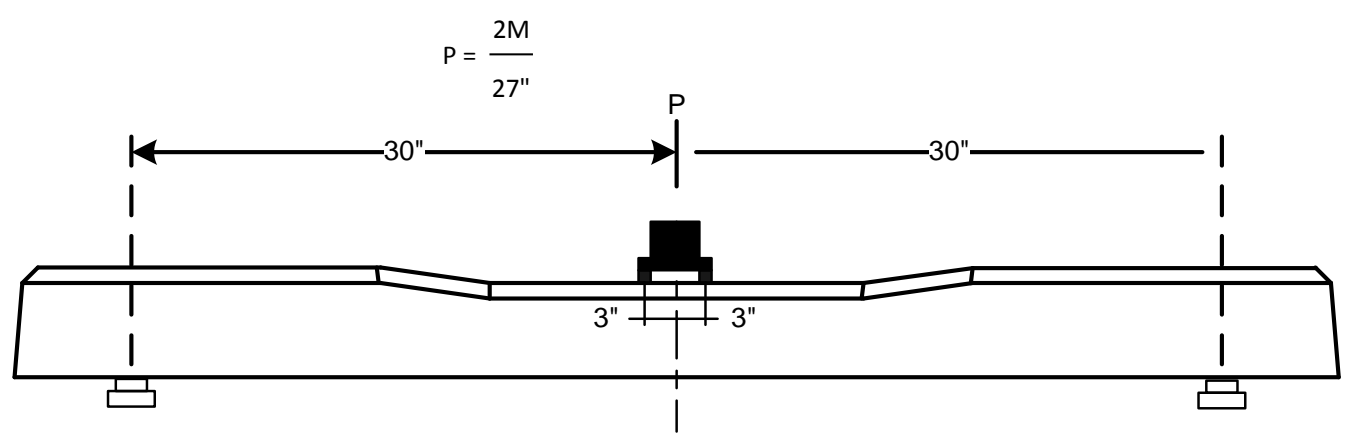

Figure 35: Positive center moment test configuration as outlined in AREMA 4.9.1 Design Test of Monoblock Ties (AREMA 2003)

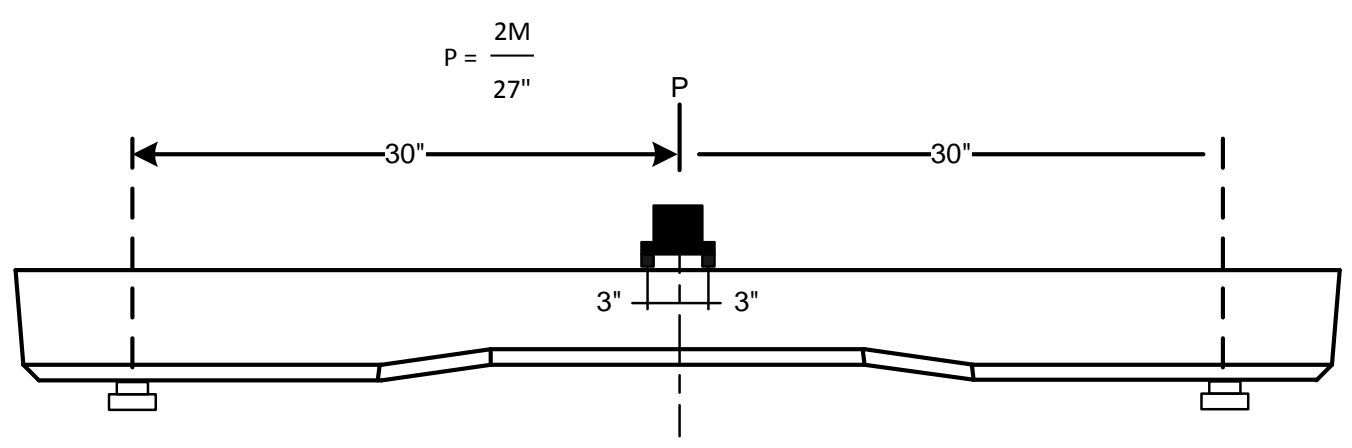

Figure 36: Negative center moment test configuration as outlined in AREMA 4.9.1 Design Test of Monoblock Ties (AREMA 2003) 
Along with flexural testing, simulated track testing performed by railroads is also utilized to determine effects of ballast support and dynamic wheel loading during different stages of tie life. Such testing is often carried out at the Transportation Technology Center, Inc., a jointly operated research facility by the Class 1 railroads of North America or on test sections of track owned by individual railroads (Jimenez and LoPresti 2004).

\subsubsection{Performance Requirements and Tolerances}

To maintain high quality while producing large numbers of ties simultaneously, stringent performance requirements and dimensional tolerances have been set by AREMA, tie manufacturers and the railroad consumers themselves (AREMA 2003). However, the standards set by the manufacturer and railroad consumer supersede those set by AREMA. These requirements and tolerances are checked regularly by the tie manufacturer by selecting ties at random from each casting to ensure quality. Geometric tolerances such as rail cant (slope of tie surface at rail seat) and gauge (distance between rails) are checked regularly to ensure that proper track geometry is achieved once ties are installed.

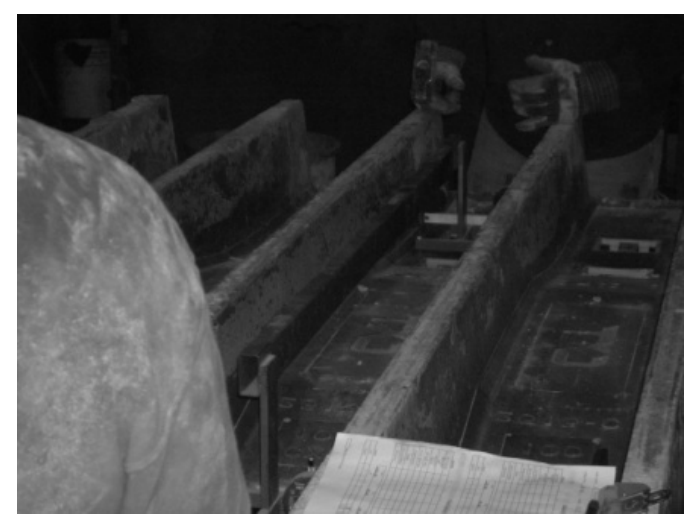

Figure 37: Workers checking rail cant and gauge of tie form using jig equipped with dial gauges

Performance requirements pertain primarily to flexure and are a function of tie length and spacing. The minimum moment capacity performance requirements set by AREMA are derived using the same process described in Section 2.2.2, where design loads based on the Cooper E 80 load configuration and the corresponding applied moments were determined. To simplify the process of determining performance requirements the impact factor and load distribution percent have been condensed and the design load calculation altered to directly calculate the applied moment. Therefore the only variables required to determine a minimum applied 
moment are the tie spacing and length. Given the tie length and spacing, the unfactored positive rail seat moment can be obtain from Figure 38 which is constructed from the simplified applied moment calculation including the impact factor and load distribution percentage. Using Table 6 the remaining moments are determined as a function of the positive bending moment, restoring continuity. Finally, to achieve a factored design moment, the speed and tonnage factors discussed in Section 2.2.2.1 are applied (AREMA 2003; Freudenstein 2007).

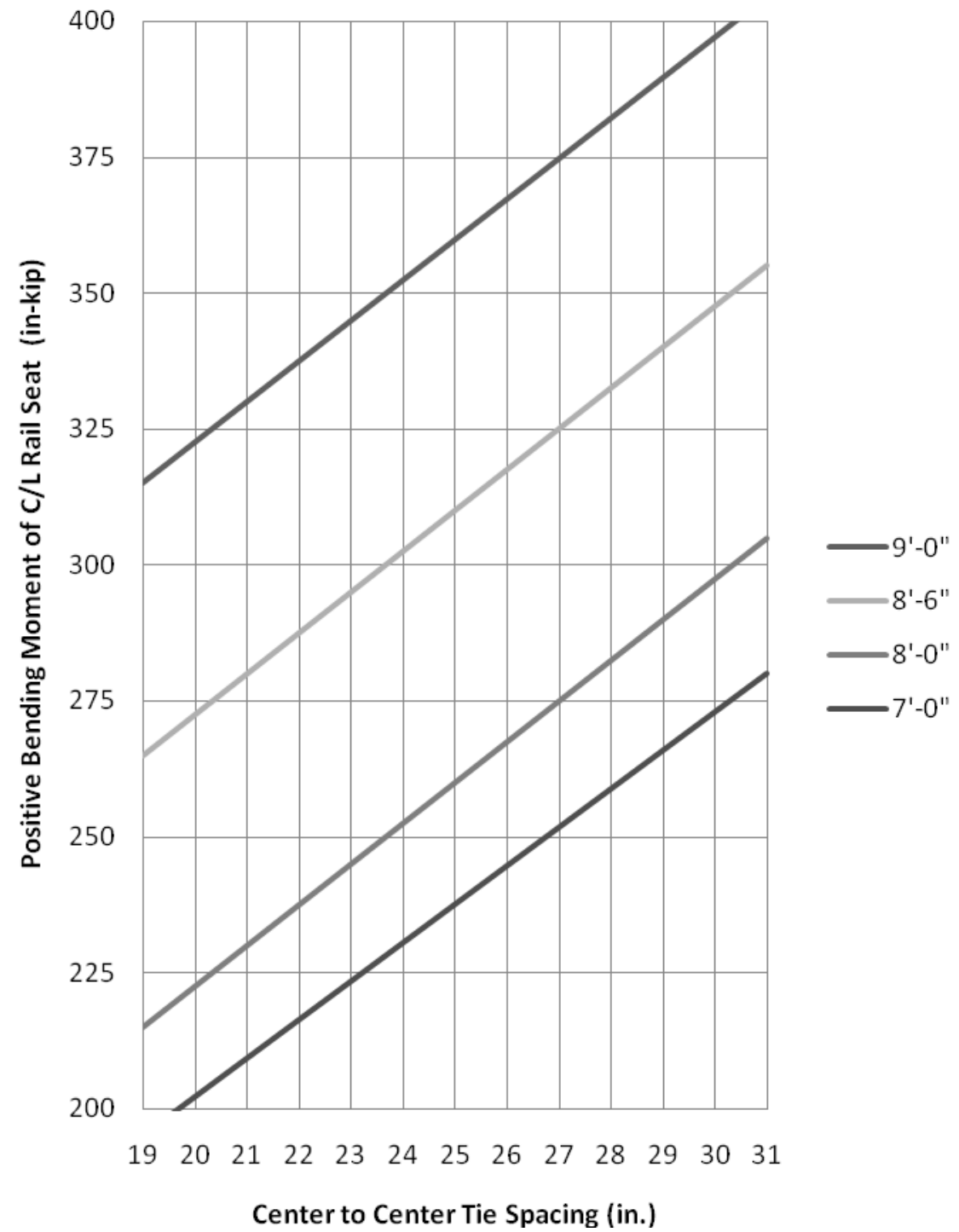

Figure 38: AREMA unfactored positive bending moment at centerline of railseat based on 315 kip car and Cooper E80 load configuration (AREMA 2003) 
Table 6: AREMA unfactored bending moments for tie critical sections based on positive bending moment at centerline of rail seat from Figure 38 (AREMA 2003)

\begin{tabular}{|c|c|c|c|}
\hline Tie Length & $\begin{array}{c}\text { Rail Seat } \\
\text { Negative }\end{array}$ & $\begin{array}{c}\text { Center } \\
\text { Negative }\end{array}$ & $\begin{array}{c}\text { Center } \\
\text { Positive }\end{array}$ \\
\hline $7^{\prime}-9 "$ & $0.72 \mathrm{M}$ & $1.13 \mathrm{M}$ & $0.61 \mathrm{M}$ \\
\hline $8^{\prime}-0 "$ & $0.64 \mathrm{M}$ & $0.92 \mathrm{M}$ & $0.56 \mathrm{M}$ \\
\hline $8^{\prime}-6 "$ & $0.53 \mathrm{M}$ & $0.67 \mathrm{M}$ & $0.47 \mathrm{M}$ \\
\hline $9^{\prime}-0 "$ & $0.46 \mathrm{M}$ & $0.57 \mathrm{M}$ & $0.40 \mathrm{M}$ \\
\hline
\end{tabular}

\subsubsection{Existing Prestressed Concrete and Railroad Specifications}

In previous sections codes and specifications have been referenced for material properties and design processes related to prestressed concrete railroad ties. However, depending on the country which the tie will be in service consideration must be given to the codes of that nation and its governing bodies whether they be prestressed concrete or railroad related. The following sections will discuss the importance and governance of codes and specifications within the United States which have been used for a majority of this review then briefly discuss those found in other areas of the world.

\subsubsection{Prestressed Concrete}

In the United States the governing bodies of prestressed concrete design include the American Concrete Institute (ACl) and the Precast/Prestressed Concrete Institute (PCI). A large majority of the code and specifications for materials and designs are dictated by $\mathrm{ACl}$ and adopted by $\mathrm{PCl}$. The collective body of railroads in North America reference $\mathrm{ACl}$ for prestressed concrete design as well. In other countries similar relationships have been drawn between railroad and concrete organizations (Freudenstein 2007).

\subsubsection{Railroad Specifications}

Railroad organizations are numerous across the world, but their size and authority vary widely. One of the largest is the American Railway Engineering and Maintenance-of-Way Association (AREMA); this organization is responsible for the rail standards of North America. However, the term standards must be used loosely since they are recommendations for best engineering practice, not absolute guidelines or code. In the North America the ultimate authority lies with the tie manufacturers and the railroads themselves. 
In comparison, the European Union has standards set specifically for prestressed concrete ties (EN 13230) created by the European Committee for Standardization with the aid of its governed railroads. In addition to the standard, the International Union of Railways distributes a design supplement (UIC 713) which offers an example tie design using the European standard (Freudenstein 2007). The European standard and the AREMA recommendations serve as two of the most comprehensive specifications for concrete ties in the world. While other smaller organizations produce standards they are infrequently used and are often derived from either of the previously stated specifications.

Several differences do exist between the two codes which deserve mention. The calculation of design loads is where the largest disparities can be found. In the European code, factors for damping, support flaws, and track position flaws are incorporated above and beyond the typical dynamic impact factor which both standards contain. The effects of train speed are considered differently as well. Rather than having a progressive factor system which varies linearly with train speed like AREMA, in accordance with EN 13230 the factors only change for speeds above and below $124 \mathrm{mph}(200 \mathrm{~km} / \mathrm{h})$. The effect of tonnage are absent entirely from EN 13230 as well (Freudenstein 2007).

Finally, the calculation process of the design moment as stipulated by AREMA is far more stringent than that of EN 13230. The European standard allows for a reduction caused by the spreading of the rail seat load across the rail seat surface rather than a point load as in the AREMA specification (Figure 39) (Freudenstein 2007). The effects of this reduction can be seen in Figure 40; given the same design load far different moments are achieved.

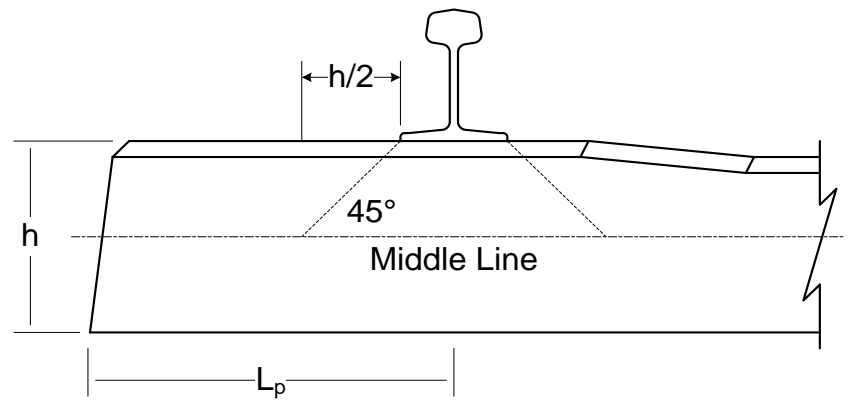

Figure 39: Positive rail seat bending moment reduction according to EN 13230 (Freudenstein 2007) 


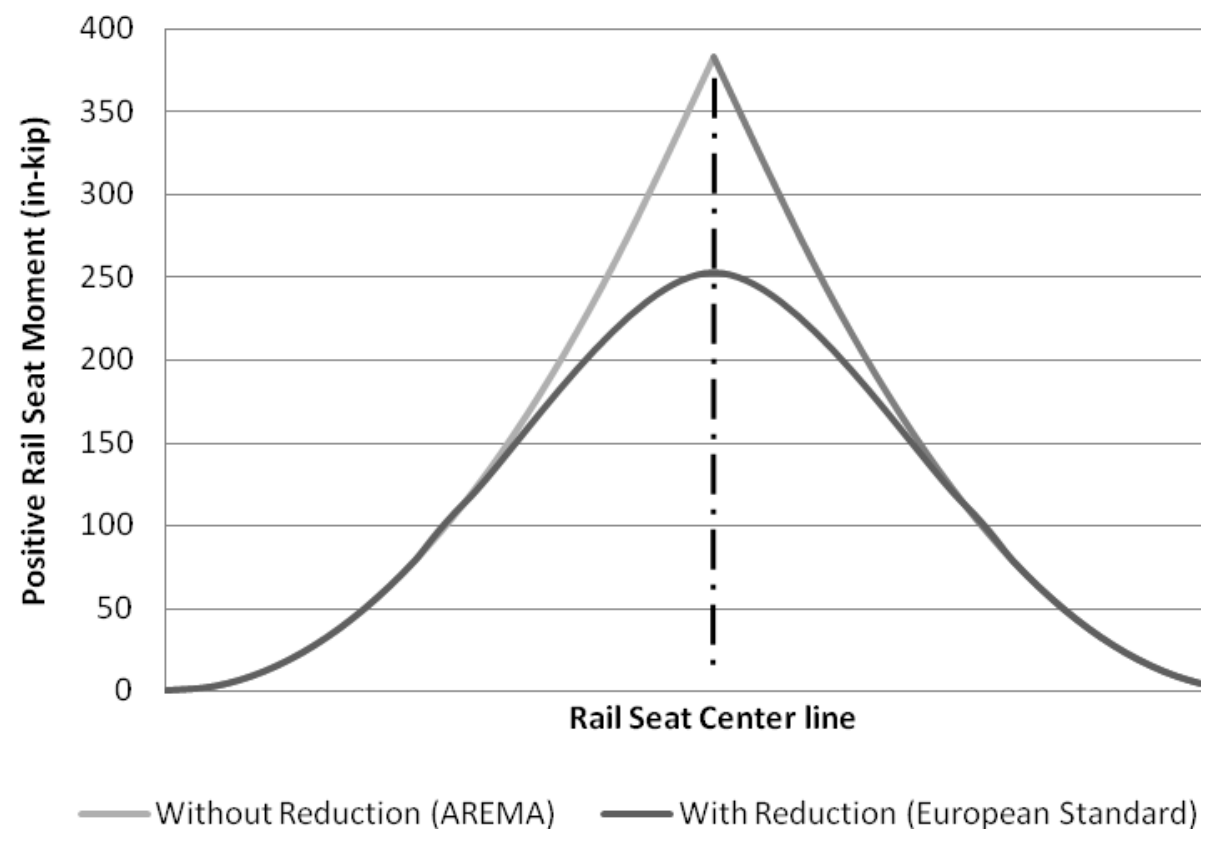

Figure 40: Computed positive rail seat design moment based on same design load from AREMA and European specifications (Freudenstein 2007)

In this review only the standards available in English have been considered. A more complete analysis would require the consideration of the Chinese, Japanese and individual European countries railroad standards. 


\subsection{Research Methodology}

As stated in the work plan (Section 1.4), this project is divided into three phases consisting of a design/analysis validation, parametric optimization and validation of optimization (future). The design/analysis validation consists of the development of a numerical analysis procedure and validation using capacity results of an existing tie design. The same analysis procedure was then extended to perform a parametric optimization study.

\subsection{Baseline Tie Analysis}

To increase the capacity of the baseline tie, the capacity provided by the baseline tie must be determined. This can be done by two methods, numerical analysis and experimental testing. While experimental testing will yield the most accurate results, it is beneficial to have the capability of accurately predicting the capacity using numerical analysis methods since they are inexpensive and easily repeatable.

In addition to determining a baseline capacity, performing an analysis on the baseline tie provides one other incentive. Existing tie designs typically have experimental flexural capacity results which can be used for comparison of predicted capacities determined from the numerical analysis. Through this comparison the accuracy of the approximations and assumptions made during the numerical analysis can be accessed. The procedures and assumptions used in the baseline tie analysis are discussed in the following sections.

\subsubsection{Critical Sections}

In Section 2.2.1.2, the various ballast support conditions that exist during the service life of a tie were identified. Based on these support conditions, two moment distributions along the length of tie are described in Section 2.2.3. The two critical sections that result from these distributions and the corresponding directions of maximum bending are:

- Section at centerline of rail seat with positive bending (top of tie in compression and bottom in tension),

- Section at center of longitudinal tie dimension with negative bending (bottom of tie in compression and top in tension). 
While the directions of maximum bending are positive and negative for the rail seat and center sections respectively, the opposite bending directions will be considered as well. The inclusion of both bending directions in the numerical analysis relates to the reversal of bending direction in the center section depending on the ballast support conditions.

\subsubsection{Cross-Sectional Properties}

\subsubsection{Concrete Cross-Sections}

All necessary cross-sectional properties and dimensions of the baseline tie were provided by the tie manufacturer and summarized in Table 48 (Appendix B), with the exception of the section modulus or moment of inertia. Since these cross-sectional properties are necessary for stress analysis, the moment inertia of the rail seat and center sections have been calculated using the parallel axis theorem; the cross-section was broken up into standard square and triangle components to simplify calculations (Figure 41). Once sectioned into standard shapes the dimensions are placed into a spreadsheet, since this process will be repeated for each section and design iteration. An example of the spreadsheet used for the calculation of cross-sectional properties is shown in Table 7. When calculating the cross sectional properties, the base dimensions provided on the ties drawings (Appendix A) were used without consideration of the casting tolerances associated with each dimension.

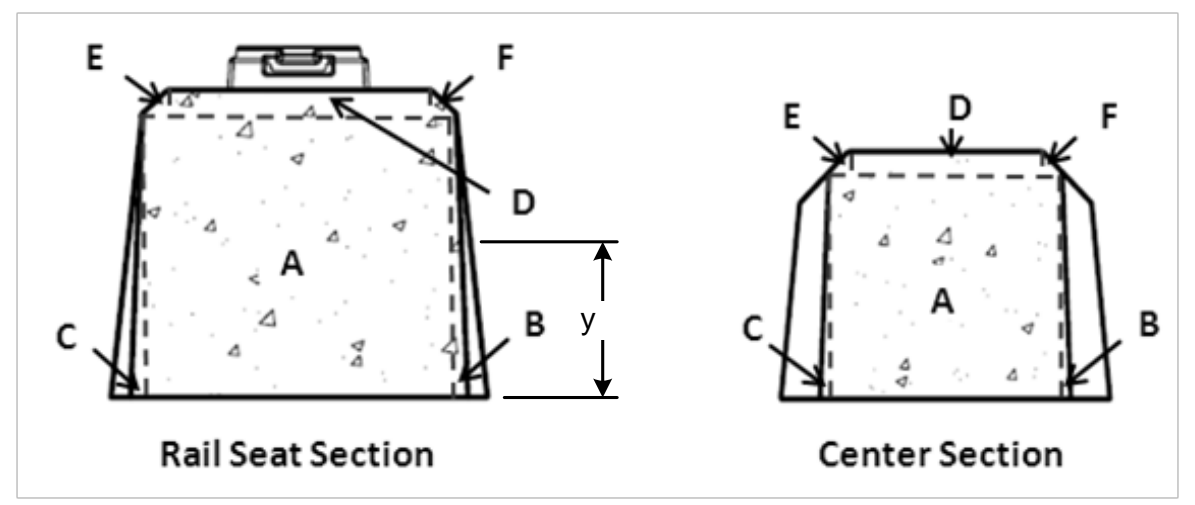

Figure 41: Division of tie cross sections into standard shape components for use in parallel axis theorem 
Table 7: Cross-sectional geometry for rail seat and center sections using parallel axis theorem

\begin{tabular}{|c|c|c|c|c|c|c|c|}
\hline \multicolumn{8}{|c|}{ Rail Seat Section } \\
\hline Component & $\begin{array}{l}\text { Width } \\
\text { b (in) }\end{array}$ & $\begin{array}{l}\text { Height } \\
\mathrm{h} \text { (in) }\end{array}$ & $\begin{array}{l}\text { Area } \\
\text { A }\left(\text { in }^{2}\right)\end{array}$ & $\begin{array}{c}\text { Centroid } \\
\text { Distance } \\
\text { y (in) }\end{array}$ & $\begin{array}{c}\text { Moment of } \\
\text { Inertia } \\
\mathrm{I}_{\mathrm{bar}}\left(\mathrm{in}^{4}\right)\end{array}$ & $\begin{array}{c}\text { Centroid } \\
\text { Difference } \\
\text { d (in) }\end{array}$ & $\begin{array}{l}\text { Parallel Axis } \\
\text { Theorem } \\
\mathrm{I}_{\mathrm{bar}}+\mathrm{Ad}^{2}\left(\mathrm{in}^{4}\right)\end{array}$ \\
\hline A & 9.10 & 8.59 & 78.12 & 4.29 & 479.82 & 0.26 & 485.12 \\
\hline B & 0.39 & 8.59 & 1.65 & 2.86 & 6.77 & 1.69 & 11.49 \\
\hline C & 0.39 & 8.59 & 1.65 & 2.86 & 6.77 & 1.69 & 11.49 \\
\hline $\mathrm{D}$ & 7.69 & 0.71 & 5.42 & 8.94 & 0.22 & -4.38 & 104.46 \\
\hline $\mathrm{E}$ & 0.71 & 0.71 & 0.25 & 8.82 & 0.01 & -4.27 & 4.60 \\
\hline $\mathrm{F}$ & 0.71 & 0.71 & 0.25 & 8.82 & 0.01 & -4.27 & 4.60 \\
\hline Sum & & & 87.35 & & & & 621.76 \\
\hline$y_{b a r}$ & 4.55 & & & & & & \\
\hline
\end{tabular}

\begin{tabular}{|c|c|c|c|c|c|c|c|}
\hline \multicolumn{8}{|c|}{ Center Section } \\
\hline Component & $\begin{array}{l}\text { Width } \\
\text { b (in) }\end{array}$ & $\begin{array}{l}\text { Height } \\
\text { h (in) }\end{array}$ & $\begin{array}{l}\text { Area } \\
\text { A }\left(\text { in }^{2}\right)\end{array}$ & $\begin{array}{c}\text { Centroid } \\
\text { Distance } \\
\text { y (in) }\end{array}$ & $\begin{array}{c}\text { Moment of } \\
\text { Inertia } \\
\mathrm{I}_{\text {bar }}\left(\text { in }^{4}\right)\end{array}$ & $\begin{array}{c}\text { Centroid } \\
\text { Difference } \\
\text { d (in) }\end{array}$ & $\begin{array}{c}\text { Parallel Axis } \\
\text { Theorem } \\
\mathrm{I}_{\text {bar }}+\mathrm{Ad}^{2}\left(\mathrm{in}^{4}\right)\end{array}$ \\
\hline A & 7.75 & 6.88 & 53.28 & 3.44 & 209.86 & 0.28 & 214.14 \\
\hline$B$ & 0.31 & 6.88 & 0.11 & 2.29 & 2.80 & 1.43 & 3.02 \\
\hline C & 0.31 & 6.88 & 0.11 & 2.29 & 2.80 & 1.43 & 3.02 \\
\hline $\mathrm{D}$ & 6.50 & 0.63 & 4.06 & 7.19 & 0.13 & -3.47 & 48.96 \\
\hline $\mathrm{E}$ & 0.63 & 0.63 & 0.20 & 7.08 & 0.00 & -3.36 & 2.21 \\
\hline $\mathrm{F}$ & 0.63 & 0.63 & 0.20 & 7.08 & 0.00 & -3.36 & 2.21 \\
\hline Sum & & & 57.95 & & & & 273.55 \\
\hline $\mathrm{y}_{\mathrm{bar}}$ & 3.72 & & & & & & \\
\hline
\end{tabular}

\subsubsection{Prestressing Centroids and Eccentricities}

The concept of variable eccentricity of prestressing along the length of a prestressed concrete member is not uncommon in prestressed design. Altering the depth of the prestressing and therefore the magnitude of the eccentricity with respect to the moment along the member using harped tendons is common practice for prestressed bridge girders and other flexural members. The baseline tie design takes this concept of variable eccentricity further by accounting for the reversal in bending which occurs in railroad ties due to changing ballast support distribution.

The baseline tie design has eccentricities both above and below the uncracked neutral axis of the cross-sections of the tie. In the rail seat region where positive bending governs, the 
prestressing is below the neutral axis of the tie cross-section. While in the tie center, where negative bending governs, the prestressing is above the uncracked neutral axis of the crosssection. This transition of prestressing from below the neutral axis at the rail seat to above at the center is not achieved by harped tendons. Instead, the cross sectional dimensions of the tie center change to move the neutral axis downward while the prestressing tendons maintain the same distance from the bottom of the tie.

To account for the transition of prestressing eccentricity from below to above the neutral axis, a definition of positive and negative directions with respect to the uncracked neutral axis was developed. By applying a sign convention to the prestressing eccentricity the calculation of stresses within the tie cross section can be simplified by using the same equations regardless of the section of interest. For this project, the sign convention for prestressing eccentricity is as follows and is demonstrated in Figure 42:

- An eccentricity which references a prestressing centroid below the uncracked neutral axis of the concrete cross-section will be referred to as positive,

- An eccentricity which references a prestressing centroid above the uncracked neutral axis of the concrete cross-section will be referred to as negative.

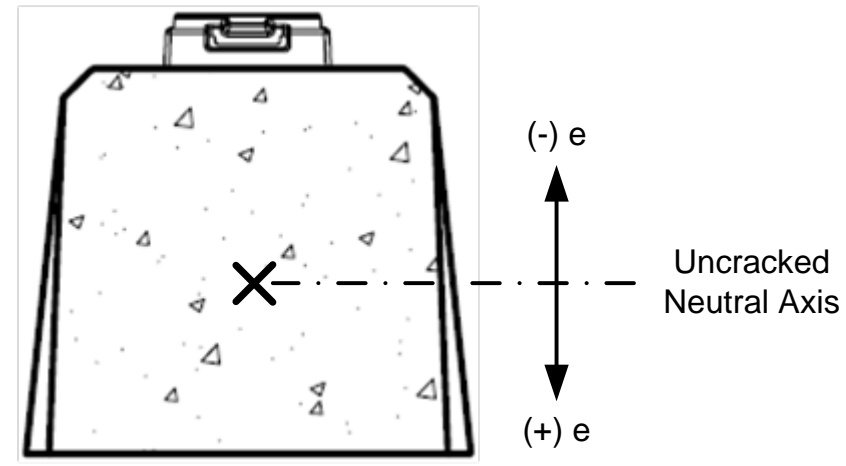

Figure 42: Sign convention for prestressing eccentricity

\subsubsection{Material Properties}

The following sections focus on the assumptions and approximations made for material allowable stresses and behavior for the numerical analysis of the baseline tie. While some information about material properties was available from the tie manufacturer for the concrete 
mixture and prestressing steel, most material properties have been approximated based on existing literature and design specifications. The reasoning behind the assumptions and the sources of approximations will be discussed in the following sections for concrete and prestressing steel.

\subsubsection{Concrete Properties}

\subsection{Compressive Strength}

The concrete mix used in the production of the baseline tie is a high early strength design which is a common characteristic of most prestressed concrete manufacturing facilities. The compressive design strength of the baseline tie is 7,000 psi at 28 days with a minimum required strength at transfer of 4,500 psi. Actual 28 day compressive strengths range from 9,000 to 11,000 psi. Though concrete strengths at service are considerably higher than the design strength, for the purpose of continuity, the baseline tie will be performed with the stated design strength rather than the actual.

\subsection{Modulus of Elasticity}

The modulus of elasticity was not available from the tie manufacturer, therefore an approximation was made. From the literature review it was determined that for concrete with a compressive strength less than 10,000 psi, $\mathrm{ACl} 318$ governs material approximations ( $\mathrm{ACl} 2008)$. $\mathrm{ACl} 318$ is also referenced by AREMA as the source for all concrete related specifications. From $\mathrm{ACl} 318$ the modulus of elasticity for concrete is a function of unit weight. Assuming normal weight concrete the equation is simplified to a relationship between compressive strength and modulus of elasticity (Eqn. 1 and Eqn. 2).

$$
\begin{aligned}
& E_{c i}=57,000 \sqrt{f_{c i}}(p s i) \\
& E_{c}=57,000 \sqrt{f_{c}^{\prime}}(p s i) \\
& f_{c i}=\text { concrete compressive strength at transfer (psi) } \\
& f_{c}=28 \text {-day concrete design compressive strength (psi) }
\end{aligned}
$$

Two values of modulus of elasticity were determined, the modulus at transfer (Eqn. 5) and modulus at service (Eqn. 6) using the $\mathrm{ACl}$ approximation. The initial value corresponds to the modulus of elasticity of the concrete prior to achieving full design compressive strength and was 
based on the minimum specified transfer strength of 4,500 psi. The initial value was used for determining stresses and strains of the concrete at transfer and the prestressing losses during the initial time periods of less than 7 days. The final modulus of elasticity was based on the 28day design strength and used for all capacity analysis and prestressing loss calculations with time intervals greater than 7 days.

\subsection{Allowable Stresses}

For the baseline tie design the allowable concrete stress specified by the manufacturer is the allowable tensile stress set at 800 psi. The method by which this value was determined was unknown and no other allowable concrete stresses derived from experimental results or approximations were available from the manufacturer. Therefore, the stress limits from $\mathrm{ACl} 318$ were used (Table 8).

Table 8: Allowable concrete stresses from $\mathrm{ACl}$ 318-08

\begin{tabular}{|c|c|c|}
\hline $\begin{array}{l}\text { Allowable Concrete } \\
\text { Stresses }\end{array}$ & Stress Case Description & $\begin{array}{c}\text { ACl Code } \\
\text { Specification (psi) }\end{array}$ \\
\hline \multicolumn{3}{|c|}{ Allowable stress at transfer of prestress (before losses) } \\
\hline$\sigma_{\mathrm{ci}}$ & $\begin{array}{l}\text { Extreme fiber stress in compression at prestress } \\
\text { transfer, } \mathrm{ACl} 318-08 \text { 18.4.1 (a) }\end{array}$ & $0.6 f_{\mathrm{ci}}^{\prime}$ \\
\hline$\sigma_{\mathrm{ti}}$ & $\begin{array}{l}\text { Extreme fiber stress in tension at prestress transfer, } \\
\mathrm{ACl} 318-0818.4 .1 \text { (b) }\end{array}$ & $3 f_{c}^{\prime} 0.5$ \\
\hline \multicolumn{3}{|c|}{ Allowable stresses under service loads (after losses) } \\
\hline$\sigma_{\mathrm{cs} 1}$ & $\begin{array}{l}\text { Extreme fiber stress in compression at service (P/S } \\
\text { and } \mathrm{SDL}), \mathrm{ACl} 318-08 \text { 18.4.2 (a) }\end{array}$ & $0.45 f_{c}^{\prime}$ \\
\hline$\sigma_{\mathrm{cs} 2}$ & $\begin{array}{l}\text { Extreme fiber stress in compression at serivce (P/S } \\
\text { and total load, } \mathrm{ACl} 318-0818.4 .2 \text { (b) }\end{array}$ & $0.6 f_{c}^{\prime}$ \\
\hline$\sigma_{\mathrm{ts}}$ & $\begin{array}{l}\text { Extreme fiber stress in tension at service, } \mathrm{ACl} 318 \text { - } \\
08 \text { 18.3.3 Class } U\end{array}$ & $7.5 f_{c}^{0} 0.5$ \\
\hline
\end{tabular}

\subsubsection{Prestressing Properties}

For the baseline tie design, a drawn wire with a diameter of 0.21 in. and an ultimate strength of $250 \mathrm{ksi}$ was used. The $0.21 \mathrm{in}$. diameter drawn wire was assumed to have minimum ultimate and yield strengths of 255 and $230 \mathrm{ksi}$, respectively. For calculations of the prestressing strain above 0.0076 (this corresponds roughly to the yield strain) the approximation provided in the $\mathrm{PCl}$ handbook $6^{\text {th }}$ Edition Design Aid 11.2.5 for 250 ksi strand was used (Eqn. 3 and Eqn. 4) 
(Prestressed/Precast Concrete Institute 2004). The modulus of elasticity for the drawn wire used in the baseline tie was $28,500 \mathrm{ksi}$ and was provided by the tie manufacturer.

$$
\begin{array}{ll}
\varepsilon_{\mathrm{ps}} \leq 0.0076: \mathrm{f}_{\mathrm{ps}}=28500 \varepsilon_{\mathrm{ps}}(\mathrm{ksi}) & \text { Eqn. } 3 \\
\varepsilon_{\mathrm{ps}}>0.0076: \mathrm{f}_{\mathrm{ps}}=250-\frac{0.04}{\varepsilon_{\mathrm{ps}}-0.0064}(\mathrm{ksi}) & \text { Eqn. } 4 \\
\varepsilon_{\mathrm{ps}}=\text { total strain in prestressing steel } & \\
\mathrm{f}_{\mathrm{ps}}=\text { total stress in prestressing steel corresponding to total strain } &
\end{array}
$$

\subsubsection{Prestressing Forces and Losses}

Since this is an existing tie design, the jacking force has already been set and measured values are available for the initial and final prestressing forces which include the measured losses of the prestressing force over time. These measured prestressing forces were used for comparison with those obtained from theoretical methods ( $\mathrm{ACl} 2008)$ in order to select an appropriate prestressing loss calculation process for analysis of the optimization iterations.

\subsubsection{Permissible Stresses in Prestressing Steel}

\subsection{Jacking Force}

From the tie manufacturer, the jacking force of each tendon is set at 7,000 lbf, which corresponds to a stress of approximately $203 \mathrm{ksi}$ per wire. This jacking force was determined to optimize the tendon efficiency by applying the largest amount of force based on the permissible stresses in the prestressing steel set by either the steel manufacturer or the code limits. For the analysis of the baseline tie the jacking force provided was used, and compared to the permissible stresses described in $\mathrm{ACl} 318$.

\subsection{ACI Allowable Stresses}

To avoid permanent plastic deformation and for other reasons related to safety during the fabrication process, the amount of stress imparted on prestressing tendons is limited by either the steel producer or the relevant code. In the case of the baseline tie no limits on permissible stresses of prestressing by the steel producer were available, therefore the limits presented in $\mathrm{ACl}$ 318-08 Section 18.5 were assumed to govern. The $\mathrm{ACl}$ 318-08 permissible stress limits have been summarized in Table 4. The limits for the jacking stress and the initial prestress are based on percentages of the ultimate and yield strengths of the steel. 
Table 9: Allowable prestressing stresses from $\mathrm{ACl}$ 318-08

\begin{tabular}{|c|c|c|}
\hline $\begin{array}{c}\text { Allowable Prestressing } \\
\text { Stresses }\end{array}$ & Stress Case Description & $\begin{array}{c}\text { ACl Code } \\
\text { Specification (ksi) }\end{array}$ \\
\hline $\mathrm{f}_{\mathrm{pj}}$ & Due to prestressing steel jacking & $0.94 \mathrm{f}_{\mathrm{py}}$ \\
\hline $\mathrm{f}_{\mathrm{pj}}$ & Due to prestressing steel jacking & $0.80 \mathrm{f}_{\mathrm{pu}}$ \\
\hline $\mathrm{f}_{\mathrm{pi}}$ & Immediately after prestress transfer & $0.82 \mathrm{f}_{\mathrm{py}}$ \\
\hline $\mathrm{f}_{\mathrm{pi}}$ & Immediately after prestress transfer & $0.74 \mathrm{f}_{\mathrm{pu}}$ \\
\hline
\end{tabular}

\subsubsection{Prestressing Losses Estimation (Tie Manufacturer)}

As discussed in Section 2.2.3.2, over the life of a prestressed member the prestressing force applied to the concrete from the prestressed tendons decreases as a result of several sources including; steel relaxation, elastic shortening, concrete creep and shrinkage. For the baseline tie, the tie manufacturer approximated the losses for each source and presented them as a percentage of the initial prestressing force. Since several of these loss sources are dependent on the member geometry the losses have been calculated for both the rail seat and center sections. The prestressing loss estimations provided by the tie manufacturer are given in Table 48 (Appendix B). The total prestressing losses for the rail seat and center sections were estimated by the tie manufacturer to be:

$$
\begin{aligned}
& \text { Total Losses at Rail Seat }(1000 \mathrm{hrs})=15.2 \% \\
& \text { Total Losses at Center }(1000 \mathrm{hrs})=18.5 \%
\end{aligned}
$$

One important detail of the loss estimation performed by the tie manufacturer is the time interval for which the calculations extend, since creep and shrinkage losses are time-dependent. The tie manufacturer loss estimates are for a time interval of $1000 \mathrm{hrs}$ (approximately 40 days) after transfer of prestressing force. However, prestressing losses tend to require significantly longer durations before they level off and a relatively constant prestressing force is achieved (Naaman 2004). Depending on the concrete mixture and the stress imposed by the prestressing, the losses may require in excess of 5 years to reach their maximum due to creep and shrinkage. Using a time interval less than the one required for full losses yields an overestimation of the prestressing force and therefore inaccurate predictions of service load behavior such as deflections and cracking moment $(\mathrm{ACl}$ 318-08 R18.6.1). This is especially important for prestressed concrete ties since the limit of their flexural capacity is based on cracking. 
For the numerical analysis of the baseline tie completed for this project, the same time interval (1000 hrs) was used for the purpose of comparing computed losses and capacities. However, all other design iterations and analyses used a prestressing loss time interval of 50 years. Using a time interval of this length allows prestressing losses to reach equilibrium and provides the smallest prestressing force which will be imposed on the tie during its service life (estimates of prestressed concrete railroad tie life range from 35-50 years).

\subsubsection{Theoretical Losses}

In addition to the experimental prestressing losses estimates provided by the tie manufacturer, losses were calculated using theoretical methods. Reasons for the additional prestressing loss calculations include:

- Prestressing loss results provided were for a time interval of only $1000 \mathrm{hrs}$ and most likely overestimate the final prestressing force,

- Once prestressing configuration and steel size and type change the provided losses will no longer be valid,

- The more accurate time-step method of loss calculation will be employed versus the lump sum method

For the calculation of prestressing losses $\mathrm{ACl} 318$, does not provide a specific process or set of equations, but rather references several other sources (ACl-ASCE Committee 4231958 (1); ACl Committee 4351963 (2); PCI Committee on Prestress Losses 1975 (4); Zia et al. 1979 (4)). For this project, the time-step method of prestressing loss calculation was selected (4). The timestep method offers several advantages over the other methods of estimating prestressing losses. Unlike the lump sum method which calculates the total prestressing loss regardless of time, the time-step method can be used to determine the rate at which prestressing loss occurs and how much time is required for the losses to stabilize. In the time-step method, the individual loss sources are calculated separately, at specified time intervals, so greater control over material assumptions and load conditions is provided as well.

While the time-step method was chosen for this study due to its accuracy and ability to predict prestressing losses at specific intervals of time, it has yet to be validated. Other methods of prestressing loss estimation could have been used and provided acceptable agreement with 
actual loss values, but the inherent qualities of the time-step method discussed above made it an excellent choice given the requirements of this study. A discussion of each of the prestressing loss sources, their contribution using the time-step method, and the necessary assumptions made are discussed in the following sections.

\subsection{Steel Relaxation}

Unlike the other sources of prestressing loss, steel relaxation occurs both before and after transfer. Therefore, the stresses within the steel for calculation of the relaxation loss are based on the condition (before or after transfer) and the additional loss sources associated with the condition, i.e. anchorage and elastic shortening. For instance, the applied stress within the prestressing prior to transfer is the jacking stress minus the losses from anchorage seating (Eqn. 5). However, after transfer the stress within steel includes the loss due to steel relaxation between jacking and transfer as well as the loss from elastic shortening. This prestressing stress condition is known as the initial prestressing stress $\left(f_{p i}\right)$. For the time step method the initial stress in the prestressing steel at the beginning of each time interval is used (Eqn. 6). The assumption of low-relaxation steel was made for the baseline tie analysis since steel wire is typically low relaxation steel (ACI 2008).

$$
\begin{aligned}
& \Delta f_{p R 1}=\frac{\log (24 t)}{40}\left[\frac{f_{p J 2}}{f_{p y}}-0.55\right] f_{p J 2} \\
& \Delta f_{p R 1}=\text { relaxation loss during initial curing period (ksi) } \\
& t=\text { time estimated from stressing to transfer (days) } \\
& f_{p / 2}=\text { initial stress in tendon after jacking and anchorage losses (ksi) } \\
& f_{p y}=\text { specified yield strength of prestressing steel (ksi) } \\
& \Delta f_{p R}\left(t_{i}, t_{j}\right)=\frac{f_{p}\left(t_{i}\right)}{40}\left[\frac{f_{p}\left(t_{i}\right)}{f_{p y}}-0.55\right] \text { log }\left(\frac{t_{i}}{t_{j}}\right) \\
& \Delta f_{p R}\left(t_{i}, t_{j}\right)=\text { relaxation loss during time interval (ksi) } \\
& t_{i}=\text { beginning of time interval (days) } \\
& t_{j}=\text { ending of time interval (days) } \\
& f_{p}\left(t_{i}\right)=\text { stress in tendon at beginning of time interval (ksi) }
\end{aligned}
$$




\subsection{Elastic Shortening}

As the transfer of force from the prestressing bed to the concrete occurs, it is assumed that the concrete is instantaneously compressed, changing the strain in the concrete and therefore the strain in the steel since the two materials have bonded during the curing time interval. This change in strain is due to a combination of the prestressing force and the self weight of the tie (Eqn. 7). While the effect of the prestressing is known, the stress induced in the concrete by the self weight moment is debatable. It has been assumed that the self weight moment of the tie follows a simply supported condition with a uniformly distributed load to represent the self weight. This would reflect an upward camber of the tie in the form due to the prestressing force as well as the support condition of the tie during the storage on cribbing shortly after transfer.

In addition to the assumption of self weight moment effects, the change in strain is also related to the respective modulus of the concrete and steel. This relationship is accounted for using the transformed modular ratio of steel over concrete modulus. While the steel has a constant modulus, the modulus of the concrete changes as a function of the concrete's compressive strength and therefore increases over time as the compressive strength increases. For the calculation of elastic shortening, the assumed modulus is based on the concrete compressive strength at transfer which is 4,500 psi.

$$
\begin{aligned}
& \Delta f_{p E S}=n_{p i}\left(f_{C g P}\right)_{F+G} \\
& \Delta f_{p E S}=\text { elastic shortening loss at transfer (ksi) } \\
& n_{p i}=\text { transformed modular ratio, }\left(\frac{E_{p s}}{E_{c i}}\right) \\
& E_{p s}=\text { modulus of elasticity for steel (ksi) } \\
& E_{c i}=\text { modulus of elasticity for concrete at transfer (ksi) } \\
& \left(f_{c g p}\right)_{F+G}=\left(f_{c g p}\right)_{F}+\left(f_{c g p}\right)_{G} \\
& \left(f_{c g p}\right)_{F}=\text { stress in the concrete at the centroid of the prestressing } \\
& \quad \text { tendons due to the initial prestressing force }\left(F_{i}\right) \text {, (ksi) } \\
& \left(f_{c g p}\right)_{G}=\text { stress in the concrete at the centroid of the prestressing } \\
& \text { tendons due to the self-weight of the tie (ksi) }
\end{aligned}
$$




\subsection{Creep and Shrinkage}

The remaining prestressing loss sources are creep and shrinkage and will be discussed together since they share several parameters. Of all the loss sources they also required the largest number of assumptions about curing procedures, environmental conditions and material properties. For the curing procedure it has been assumed that the method employed by the tie manufacturer is most accurately represented by a steam-cured operation rather than a moisture-cured. The long-term relative humidity has been set at 50 percent. The assumption of a relative humidity is one of the most difficult since prestressed concrete ties are produced and used in a wide range of climates and environments. For this analysis an average value of relative humidity was used. Considering the curing conditions and relative humidity assumptions, the following creep and shrinkage coefficients and constants have been determined for the baseline tie and presented with the their source:

- Ultimate shrinkage strain $\left(\varepsilon_{s u}\right)$, is based on water content within the concrete mix. Since a value for water content was unknown and will change for future iterations using higher concrete compressive stresses (different mixes), a common value of 0.005 was used for all iterations. This common value was obtained from average values presented in Naaman (2004),

- Humidity correction factor for shrinkage $\left(\mathrm{K}_{\mathrm{SH}}\right)$, from Table 10:

$$
\begin{aligned}
& \mathrm{H}=50 \% \quad \text { Relative Humidity } \\
& \mathrm{K}_{\mathrm{SH}}=1.40-0.01 \mathrm{H} \\
& \mathrm{K}_{\mathrm{SH}}=0.9
\end{aligned}
$$

- Shape and size correction factor for shrinkage $\left(\mathrm{K}_{\mathrm{ss}}\right)$, based on volume-to-surface ratio, use linear interpolation to obtain value from Table 11:

$$
\begin{array}{ll}
\mathrm{K}_{\mathrm{SS}}=0.9826 & \text { Center Section } \\
\mathrm{K}_{\mathrm{SS}}=0.9352 & \text { Rail Seat Section }
\end{array}
$$

- Ultimate creep coefficient $\left(\mathrm{C}_{\mathrm{cu}}\right)$, based upon concrete compressive strength, equal to 2.2 from Table 12, 
- Humidity correction factor for creep $\left(\mathrm{K}_{\mathrm{CH}}\right)$, from Table 10:

$$
\begin{aligned}
& \mathrm{K}_{\mathrm{CH}}=1.27-0.0067 \mathrm{H} \\
& \mathrm{K}_{\mathrm{CH}}=0.935
\end{aligned}
$$

- Shape and size correction factor for creep $\left(K_{\mathrm{cS}}\right)$, based on volume-to-surface ratio, use linear interpolation to obtain value from Table 11:

$$
\begin{array}{ll}
\mathrm{K}_{\mathrm{CS}}=0.9855 & \text { Center Section } \\
\mathrm{K}_{\mathrm{CS}}=0.9377 & \text { Rail Seat Section }
\end{array}
$$

\begin{tabular}{|c|c|c|c|}
\hline \multirow[b]{2}{*}{ Property } & \multirow[b]{2}{*}{ Relationship } & \multicolumn{2}{|c|}{ Equation Constants } \\
\hline & & Moist-cured concrete & Steam-cured concrete \\
\hline $\begin{array}{c}\text { Compressive } \\
\text { strength }\end{array}$ & $\begin{array}{l}\text { For } t \geq 1 \text { day } \\
f^{\prime}{ }_{c}(t)=\left(t f^{\prime}{ }_{c}(28)\right) /(b+c t) \\
\text { Same for normal weight and lightweight } \\
\text { concrete }\end{array}$ & $\begin{array}{l}\text { Type I cement: } \\
b=4 \\
c=0.85 \\
\text { Type III cement: } \\
b=2.30 \\
c=0.92\end{array}$ & $\begin{array}{l}\text { Type I cement: } \\
\text { b }=1 \\
c=0.95 \\
\text { Type III cement: } \\
\text { b }=0.70 \\
c=0.98\end{array}$ \\
\hline Shrinkage strain & $\begin{array}{l}\varepsilon_{s}(t)=\left(t \varepsilon_{S U} K_{S H} K_{S S}\right) /(b+t) \\
\text { for normal weight and lightweight } \\
\text { concretes using Type I or Type III cements. } \\
\mathrm{K}_{S H} \text { humidity correction factor } \\
\mathrm{K}_{S S} \text { shape and size factor }\end{array}$ & $\begin{array}{l}40 \% \leq \mathrm{H} \leq 80 \% \\
\mathrm{~b}=35 \\
\mathrm{t} \geq 7 \text { days } \\
\mathrm{K}_{\mathrm{SH}}=1.40-0.01 \mathrm{H} \\
\mathrm{K}_{\mathrm{SS}}=\text { see Table } 2.10 \\
80 \% \leq \mathrm{H} \leq 100 \% \\
\mathrm{~b}=35 \\
\mathrm{t} \geq 7 \text { days } \\
\mathrm{KSH}=3-0.03 \mathrm{H} \\
\mathrm{KSS}=\text { see Table } 2.10 \\
\text { (Naaman) }\end{array}$ & $\begin{array}{l}40 \% \leq \mathrm{H} \leq 80 \% \\
\mathrm{~b}=55 \\
\mathrm{t} \geq 1 \text { to } 3 \text { days } \\
\mathrm{K}_{\mathrm{SH}}=1.40-0.01 \mathrm{H} \\
\mathrm{K}_{\mathrm{SS}}=\text { see Table } 2.10 \\
80 \% \leq \mathrm{H} \leq 100 \% \\
\mathrm{~b}=55 \\
\mathrm{t} \geq 1 \text { to } 3 \text { days } \\
\mathrm{K}_{\mathrm{SH}}=3-0.03 \mathrm{H} \\
\mathrm{K}_{\mathrm{SS}}=\text { see Table } 2.10 \\
\text { (Naaman) }\end{array}$ \\
\hline $\begin{array}{c}\text { Creep } \\
\text { coefficient }\end{array}$ & $\begin{array}{l}C_{C}(t)=\left(t^{0.60} /\left(10+t^{0.60}\right)\right) C_{C U} K_{C H} K_{C A} K_{C S} \\
\mathrm{~K}_{C H} \text { humidity correction factor } \\
\mathrm{K}_{\mathrm{CA}} \text { age at loading factor } \\
\mathrm{K}_{\mathrm{CS}} \text { shape and size factor } \\
\mathrm{t}_{\mathrm{A}} \text { age at loading }\end{array}$ & $\begin{array}{l}\mathrm{t}, \mathrm{t}_{\mathrm{A}} \geq 7 \text { days and } \mathrm{H} \geq 40 \% \\
\mathrm{KCA}=1.25 \mathrm{t}_{\mathrm{A}}^{-0.118} \\
\mathrm{~K}_{\mathrm{CH}}=1.27-0.0067 \mathrm{H} \\
\mathrm{K}_{\mathrm{CS}}=\text { see Table } 2.10 \\
\text { (Naaman) }\end{array}$ & $\begin{array}{l}\mathrm{t}, \mathrm{t}_{\mathrm{A}} \geq 1 \text { to } 3 \text { days and } \mathrm{H} \geq 40 \% \\
\mathrm{KCA}=1.13 \mathrm{t}_{\mathrm{A}}^{-0.095} \\
\mathrm{~K}_{\mathrm{CH}}=1.27-0.0067 \mathrm{H} \\
\mathrm{K}_{\mathrm{CS}}=\text { see Table } 2.10 \\
\text { (Naaman) }\end{array}$ \\
\hline
\end{tabular}

- Loading age factor $\left(K_{C A}\right)$, accounts for age of concrete at transfer, from Table 10:

$$
\begin{aligned}
& \mathrm{t}_{\mathrm{A}}=1 \text { day age of concrete at transfer } \\
& \mathrm{K}_{C A}=1.13 \mathrm{t}_{\mathrm{A}}^{-0.095} \\
& \mathrm{~K}_{C A}=1.13
\end{aligned}
$$

Table 10: Recommended relationships for time-dependent properties of concrete, adopted from (Naaman 2004) 
Table 11: Size and shape factors for creep and shrinkage, adopted from (Naaman 2004)

\begin{tabular}{|c|c|c|c|}
\hline \multicolumn{2}{|c|}{$\begin{array}{c}\text { Volume-to-surface } \\
\text { ratio }\end{array}$} & \multicolumn{2}{c|}{ Size and shape factor } \\
\hline (in) & (cm) & ${\text { Creep } \mathrm{K}_{\mathrm{CS}}}^{\text {Shrinkage } \mathrm{K}_{\mathrm{SS}}}$ \\
\hline 1 & 2.54 & 1.05 & 1.04 \\
\hline 2 & 5.1 & 0.96 & 0.96 \\
\hline 3 & 7.6 & 0.87 & 0.86 \\
\hline 4 & 10.2 & 0.77 & 0.77 \\
\hline 5 & 12.7 & 0.68 & 0.69 \\
\hline 6 & 15.2 & 0.68 & 0.6 \\
\hline
\end{tabular}

Table 12: Typical values of ultimate creep coefficients, adopted from (Naaman 2004)

\begin{tabular}{|c|c|c|}
\hline \multicolumn{2}{|c|}{ Compressive strength } & $\begin{array}{c}\text { Ultimate creep } \\
\text { coefficient } \mathbf{C}_{\mathrm{CU}}\end{array}$ \\
\hline (psi) & (Mpa) & 3.10 \\
\hline 3,000 & 20.7 & 2.90 \\
\hline 4,000 & 27.6 & 2.65 \\
\hline 5,000 & 34.5 & 2.40 \\
\hline 6,000 & 41.4 & 2.20 \\
\hline 7,000 & 48.3 & 2.00 \\
\hline 8,000 & 55.2 & 1.60 \\
\hline 10,000 & 69 & 1.40 \\
\hline 12,000 & 83 & \\
\hline
\end{tabular}

In addition to the coefficients listed above, the effects of induced strain from long term applied loads such as prestressing and self weight affect creep. Similar to elastic shortening the effects of self weight are uncertain since numerous support distributions occur over the service life of the tie. For the calculation of creep, the same self weight moment as that determined for elastic shortening was used. Using the values discussed above the incremental shrinkage (Eqn. 8) and creep (Eqn. 9) losses for each time interval were obtained.

$$
\begin{aligned}
& \Delta \mathrm{f}_{p s}\left(\mathrm{t}_{\mathrm{i}}, \mathrm{t}_{\mathrm{j}}\right)=\mathrm{E}_{\mathrm{ps}} \varepsilon_{\mathrm{su}} \mathrm{K}_{\mathrm{sH}} \mathrm{K}_{\mathrm{sS}} \frac{\mathrm{b}\left(\mathrm{t}_{\mathrm{i}}-\mathrm{t}_{\mathrm{j}}\right)}{\left(\mathrm{b}+\mathrm{t}_{\mathrm{i}}\right)\left(\mathrm{b}+\mathrm{t}_{\mathrm{j}}\right)} \\
& \Delta \mathrm{f}_{\mathrm{pS}}\left(\mathrm{t}_{\mathrm{i}}, \mathrm{t}_{\mathrm{j}}\right)=\text { shrinkage loss during time interval (ksi) } \\
& \varepsilon_{\mathrm{sU}}=\text { ultimate shrinkage strain (in/in) } \\
& \mathrm{K}_{\mathrm{sH}}=\text { humidity correction factor } \\
& \mathrm{K}_{\mathrm{sS}}=\text { size and shape correction factor } \\
& \mathrm{b}=\text { curing conditions factor }
\end{aligned}
$$




$$
\begin{aligned}
& \Delta \mathrm{f}_{p c}\left(\mathrm{t}_{\mathrm{i}}, \mathrm{t}_{\mathrm{j}}\right)=\mathrm{n}_{\mathrm{p}} \mathrm{C}_{\mathrm{cu}} \mathrm{K}_{\mathrm{CH}} \mathrm{K}_{\mathrm{CS}} \mathrm{K}_{\mathrm{CA}} \mathrm{f}_{\mathrm{cgp}}\left(\mathrm{t}_{\mathrm{i}}\right)\left[\frac{\mathrm{t}_{\mathrm{j}}^{0.60}}{10+\mathrm{t}_{\mathrm{j}}^{0.60}}-\frac{\mathrm{t}_{\mathrm{i}}^{0.60}}{10+\mathrm{t}_{\mathrm{i}}^{0.60}}\right] \\
& \Delta \mathrm{f}_{\mathrm{pC}}\left(\mathrm{t}_{\mathrm{i}}, \mathrm{t}_{\mathrm{j}}\right)=\text { creep loss during time interval (ksi) } \\
& \mathrm{n}_{\mathrm{p}}=\text { transformed modular ratio } \\
& \mathrm{C}_{\mathrm{cu}}=\text { ultimate creep coefficient } \\
& \mathrm{K}_{\mathrm{cH}}=\text { humidity correction factor } \\
& \mathrm{K}_{\mathrm{cS}}=\text { size and shape correction factor } \\
& \mathrm{K}_{\mathrm{CA}}=\text { age at loading factor } \\
& \mathrm{f}_{\mathrm{cgp}}\left(\mathrm{t}_{\mathrm{i}}\right)=\text { stress in concrete at the centroid of the prestressing } \\
& \quad \text { tendons due to prestressing force and self-weight }
\end{aligned}
$$

\subsubsection{Time Intervals Considered}

Considering the sources of prestressing loss, some occur instantaneously such as anchorage or elastic shortening while others are time-dependent such as relaxation, creep, and shrinkage. Typically, time-dependent losses follow an exponentially decreasing trend to a maximum loss at which the final prestressing force is achieved (Naaman 2004). Performing the time-step method requires the determination of time intervals to which calculation of the losses for each source are determined. Considering the trends of time-dependent losses, shorter time intervals should be used at the early stages of member life while longer intervals should be used as the age of the member increases. For losses which occur instantaneously, such as elastic shortening, the instant of loss application (i.e. transfer) should constitute a time interval boundary.

Considering the criteria for interval determination and the interval of experimental losses from the tie manufacturer, the time intervals used for the computation of prestressing losses are; 1 , $3,7,28,40,365,1,825$ (5 years), and 18,250 days (50 years). The time begins at zero corresponding to jacking of prestressing and the initiation of steel relaxation. Day one served as the assumed time of transfer while 3, 7, and 28 days served as intermediate points for the purpose of plotting final prestressing force versus time. Forty days served as the point at which theoretical estimates for losses from this study and the tie manufacturer were compared. The interval of 5 years corresponds the time required for creep and shrinkage effects to typically reach their maximum ( $\mathrm{ACl} 318-08$ R9.5.2.5). The 50 year time interval corresponds to the estimated service life of a prestressed concrete tie. 


\subsubsection{Prestressing Losses Spreadsheet Organization}

A spreadsheet was developed to document the prestressing losses for the different critical sections. While the time-step method is accurate, one disadvantage is that it is computationally intensive; computation of losses must be repeated for each interval of time. Organization of the prestressing losses spreadsheet is based on the individual sources of loss. Constants for the cross-section geometry and material properties of each critical section are defined while the calculation of each loss source is done separately then summarized in a general table presenting the losses due to individual sources and the sum of those sources with respect to time. From this table the stress in the prestressing steel at each interval of time is shown. The final prestress can then be plotted on semi-log plot to show the relationship between prestressing force and time. Examples of the prestressing loss spreadsheets and plot of prestressing versus time for the baseline tie design are shown in Table 13 and Figure 41.

Table 13: Summary of prestressing losses at the rail seat and center sections of baseline tie

\begin{tabular}{|c|c|c|c|c|c|c|c|c|c|c|}
\hline \multicolumn{11}{|c|}{ Prestessing Losses Based on Rail Seat Section Properties } \\
\hline $\begin{array}{l}\text { Time } \\
\text { (days) }\end{array}$ & $\Delta f_{p R 1}(k s i)$ & $\begin{array}{l}\Delta f_{\text {pES }} \\
\text { (ksi) }\end{array}$ & $\begin{array}{c}f_{p i} \\
\text { (ksi) }\end{array}$ & $\Delta f_{p R 2}(k s i)$ & $\begin{array}{l}\Delta \mathrm{f}_{\mathrm{ps}} \\
\text { (ksi) }\end{array}$ & $\begin{array}{l}\Delta \mathrm{f}_{\mathrm{pc}} \\
\text { (ksi) }\end{array}$ & $\begin{array}{l}f_{\mathrm{pe}} \\
(\mathrm{ksi})\end{array}$ & $\begin{array}{l}\Delta \mathrm{f}_{\mathrm{pTD}} \\
(\mathrm{ksi})\end{array}$ & $\begin{array}{l}\text { Total Loss } \\
\text { (ksi) }\end{array}$ & $\begin{array}{c}\text { Actual Prestress } \\
\text { (ksi) }\end{array}$ \\
\hline 1 & 2.34 & 12.45 & 188.37 & 0.00 & 0.00 & 0.00 & 188.37 & 0.00 & 14.79 & 188.37 \\
\hline 3 & 2.34 & 12.45 & 188.37 & 0.61 & 0.41 & 1.81 & 185.55 & 2.82 & 17.61 & 185.55 \\
\hline 7 & 2.34 & 12.45 & 188.37 & 1.07 & 1.14 & 3.86 & 182.31 & 6.06 & 20.85 & 182.31 \\
\hline 28 & 2.34 & 12.45 & 188.37 & 1.81 & 3.83 & 7.48 & 175.24 & 13.13 & 27.92 & 175.24 \\
\hline 40 & 2.34 & 12.45 & 188.37 & 2.00 & 4.84 & 8.52 & 173.01 & 15.36 & 30.15 & 173.01 \\
\hline 365 & 2.34 & 12.45 & 188.37 & 3.17 & 10.21 & 14.31 & 160.68 & 27.69 & 42.48 & 160.68 \\
\hline 1,825 & 2.34 & 12.45 & 188.37 & 4.00 & 11.43 & 16.68 & 156.26 & 32.10 & 46.90 & 156.26 \\
\hline 18,250 & 2.34 & 12.45 & 188.37 & 5.16 & 11.74 & 18.03 & 153.44 & 34.93 & 49.72 & 153.44 \\
\hline
\end{tabular}

\begin{tabular}{|c|c|c|c|c|c|c|c|c|c|c|}
\hline \multicolumn{10}{|c|}{ Prestessing Losses Based on Center Section Properties } \\
\hline $\begin{array}{c}\text { Time } \\
(\text { days })\end{array}$ & $\begin{array}{c}\Delta f_{p R 1} \\
(\mathbf{k s i})\end{array}$ & $\begin{array}{c}\Delta \mathbf{f}_{p E S} \\
(\mathbf{k s i})\end{array}$ & $\begin{array}{c}\mathbf{f}_{\mathrm{pi}} \\
(\mathbf{k s i})\end{array}$ & $\begin{array}{c}\Delta \mathbf{f}_{\mathrm{pR} 2} \\
(\mathbf{k s i})\end{array}$ & $\begin{array}{c}\Delta \mathbf{f}_{\mathrm{ps}} \\
(\mathbf{k s i})\end{array}$ & $\begin{array}{c}\Delta \mathbf{f}_{\mathrm{pc}} \\
(\mathbf{k s i})\end{array}$ & $\begin{array}{c}\mathbf{f}_{\mathrm{pe}} \\
(\mathbf{k s i})\end{array}$ & $\begin{array}{c}\Delta \mathbf{f}_{\mathrm{pTD}} \\
(\mathbf{k s i})\end{array}$ & $\begin{array}{c}\text { Total Loss } \\
(\mathbf{k s i})\end{array}$ & $\begin{array}{c}\text { Actual Prestress } \\
(\mathbf{k s i})\end{array}$ \\
\hline 1 & 2.34 & 17.89 & 182.96 & 0.00 & 0.00 & 0.00 & 182.96 & 0.00 & 20.23 & 182.96 \\
\hline 3 & 2.34 & 17.89 & 182.96 & 0.54 & 0.43 & 2.65 & 179.35 & 3.62 & 23.85 & 179.35 \\
\hline 7 & 2.34 & 17.89 & 182.96 & 0.95 & 1.20 & 5.64 & 175.18 & 7.78 & 28.02 & 175.18 \\
\hline 28 & 2.34 & 17.89 & 182.96 & 1.61 & 4.03 & 10.90 & 166.42 & 16.54 & 36.77 & 166.42 \\
\hline 40 & 2.34 & 17.89 & 182.96 & 1.78 & 5.08 & 12.39 & 163.71 & 19.25 & 39.48 & 163.71 \\
\hline 365 & 2.34 & 17.89 & 182.96 & 2.81 & 10.73 & 20.69 & 148.73 & 34.23 & 54.46 & 148.73 \\
\hline 1,825 & 2.34 & 17.89 & 182.96 & 3.55 & 12.01 & 24.02 & 143.39 & 39.57 & 59.80 & 143.39 \\
\hline 18,250 & 2.34 & 17.89 & 182.96 & 4.58 & 12.34 & 25.90 & 140.14 & 42.82 & 63.05 & 140.14 \\
\hline
\end{tabular}




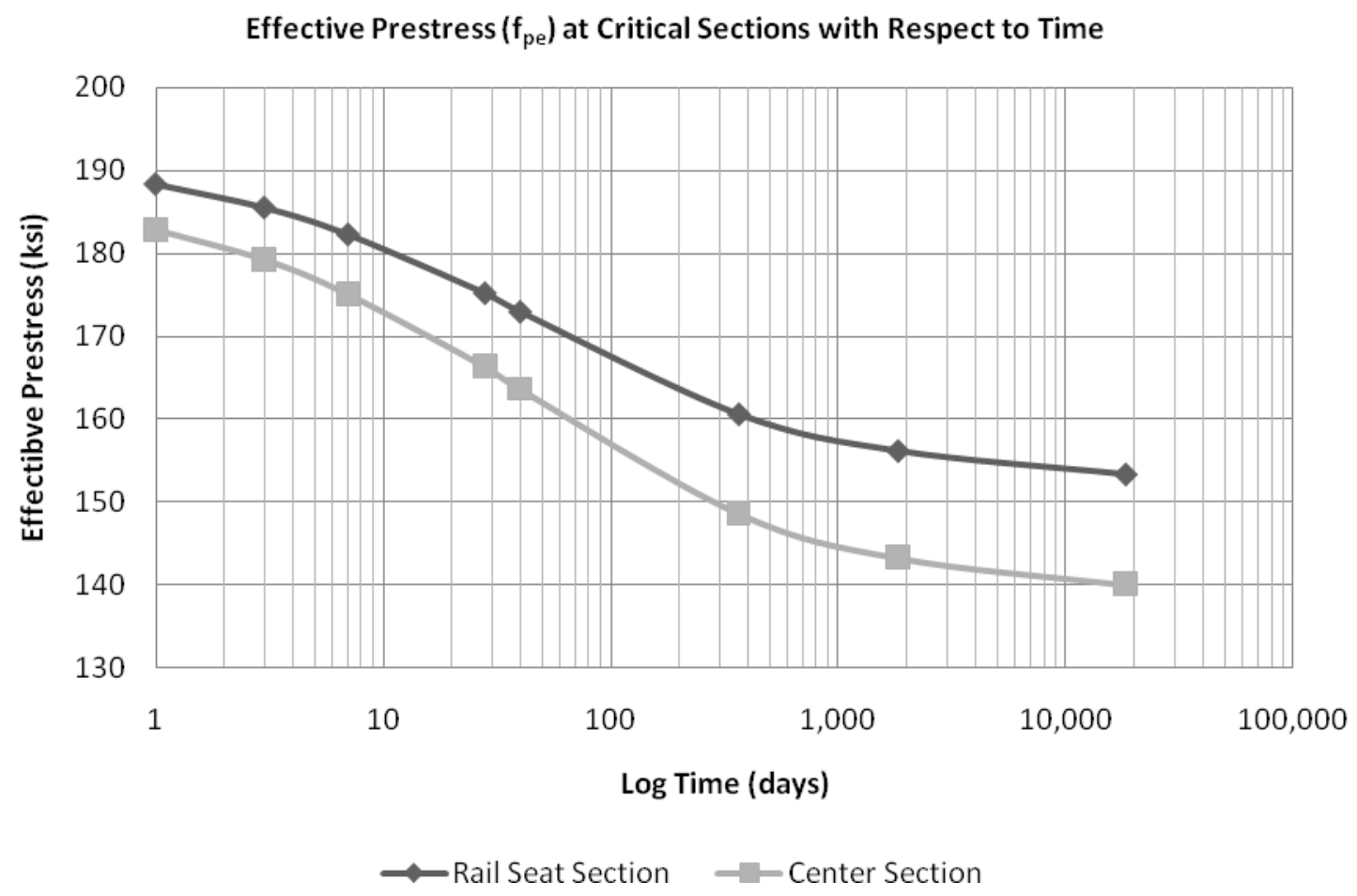

Figure 43: Plot of effective prestressing with respect to time for baseline tie design

\subsubsection{Limit States}

\subsubsection{Limit State I: Stresses at Transfer}

At transfer the prestressing is released and the force transferred to the concrete. Losses included at transfer are anchorage seating, initial steel relaxation and elastic shortening. Once the prestressing force including these losses was determined, the induced stresses in the concrete from the prestressing and the self weight of the tie were computed. During the process of calculating the theoretical prestressing losses it was determined that the self weight would be analyzed as a uniformly distributed load in a simply supported condition at transfer. The applied stresses were then compared to allowable concrete stresses from $\mathrm{ACl}$ 318-08.

Concrete ties produced using the long-line method are cast upside down. Therefore, at transfer the tie will be upside down, but quickly rotated to right side up after de-molding (Figure 44). Since this rotation occurs almost immediately after transfer both load configurations were checked against allowable stresses. 

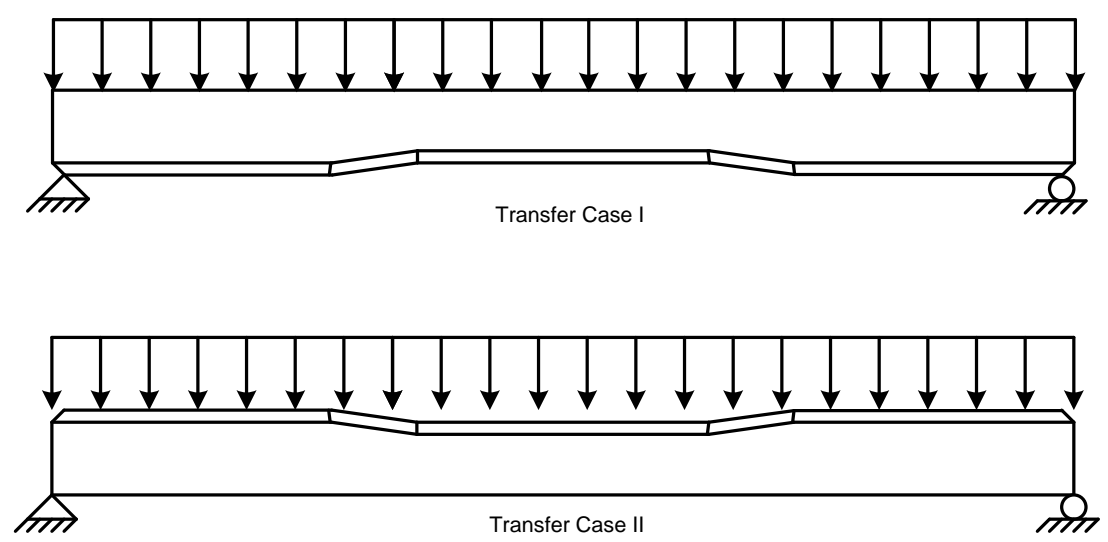

Figure 44: Load configurations corresponding to the transfer limit state

\subsubsection{Limit State II: Stresses at Service (AREMA Defined Flexural Capacity)}

At the service load limit state the tie is subjected to the prestressing force minus all losses, both instantaneous and time-dependent which have occurred up to that time and the applied loads from the train and ballast. Prestressed concrete railroad ties do not follow the conventional definition of failure for prestressed concrete, since their capacity is limited to the load which produces the first structural crack to reach the outermost layer of steel. However, for the prediction of flexural capacity using theoretical methods the applied moment which corresponds to the first crack to the outer most layer of prestressing will not be determined. Instead, once the stress in the extreme tension or compression fiber reaches either of the allowable concrete stresses as specified in $\mathrm{ACl} 318$ for service, the tie will be considered failed.

Experimental test results were provided by the tie manufacturer in the form of applied loads corresponding to failure as defined by AREMA. The testing configurations corresponding to the load values are illustrated in Figure 33 through Figure 36. Using the equations relating the applied point load for the test to the applied moment in Figure 33 through Figure 36, the experimental moment capacities for the critical sections in the positive and negative directions were determined. It was assumed that the prestressing force applied to the tie corresponds to that including losses at $1000 \mathrm{hrs}$ (40 days).

Since the experimental results appear to correspond to a prestressing force including the losses at $1000 \mathrm{hrs}$, the prestressing force used in the theoretical capacity prediction were based on the 
comparable theoretical losses at 1000 hrs (40 days) as well. However, for all further analyses and designs the prestressing force included all theoretical prestressing losses at a time duration of 50 year. The moment due to self weight were calculated using the boundary conditions corresponding to the test configurations in Figure 33 through Figure 36 . If the difference between the applied moment causing failure and self weight moment is many orders of magnitude, the self weight may be considered negligible.

\subsubsection{Transfer Length}

Transfer length is the distance of bond between the prestressing and concrete required to transfer the force in the prestressing to the surrounding concrete. The distance required for the force transfer is a function of the effective prestress and the diameter of the prestressing tendon. For the drawn wire steel prestressing used in the baseline tie, the equation for transfer from $\mathrm{ACl}$ 318-08 was used (Eqn. 10).

$$
\begin{aligned}
& \mathrm{I}_{t}=\left(\frac{\mathrm{f}_{\mathrm{se}}}{3}\right) \mathrm{d}_{\mathrm{b}} \\
& \mathrm{I}_{\mathrm{t}}=\text { transfer length (in) }
\end{aligned}
$$

\subsubsection{Nominal Flexural Capacity Using Strain Compatibility}

While the flexural capacity as defined by AREMA is governed by cracking, the ultimate load capacity of the tie design will be determined for comparative purposes. The nominal moment capacity will also demonstrate the actual capacity of the section or potential reserve capacity should the section be allowed to crack. The process of strain compatibility with respect to the baseline tie is described in the following sections.

\subsubsection{Division of Prestressing Layers}

Typical prestressed flexural members only have prestressing steel located in the tension zone of the member during service. However, prestressed concrete railroad ties have prestressing throughout their entire cross-section which can actually reduce their capacity. The initial compressive stress imparted by the prestressing in the compression region of the tie during bending may lead to the allowable concrete compressive stress to be reached at lower levels of externally applied loads. The main reason for this possibly detrimental uniformly prestressed section is the reversal in bending direction which occurs in the center of the tie in response to 
changes in the ballast support distribution. To account for bending in both directions, prestressing must be provided both above and below the neutral axis of the cross-section.

With respect to strain compatibility, the calculation process is made slightly more complicated by having prestressing in the compression region. Rather than being able to calculate strains of the prestressing tendons as a whole at the centroid of the steel, each prestressing layer must have their strains calculated separately. This is due to the effect of bending on the strain in the prestressing steel. If the prestressing layer is located in the compression zone the strain in the steel will decrease as the applied moment increases. Inversely, the strain in prestressing located in the tension zone will increase. An advantage to calculating the strain in each level of prestressing is the ability to then plot the strain in each layer producing strain diagrams for verification purposes.

\subsubsection{Strain Components}

To determine the flexural capacity of the tie, the stress in the prestressing steel must be determined. During casting, the concrete is bonded to the steel, therefore as the concrete is loaded and strained, the prestressing steel will encounter the same change in strain. By determining the increments of strain which correspond to each loading condition and summing them, the total strain in the steel at failure is determined. The three increments of strain are; strain due to effective prestress $\left(\varepsilon_{1}\right)$, strain in the concrete surrounding the prestressing layer corresponding to the decompression load condition $\left(\varepsilon_{2}\right)$, and the strain in the concrete surrounding the prestressing layer corresponding to failure of the compression fiber $\left(\varepsilon_{3}\right)$. Figure 45 illustrates the strain increments as they appear in the strain diagram for the rail seat section. 


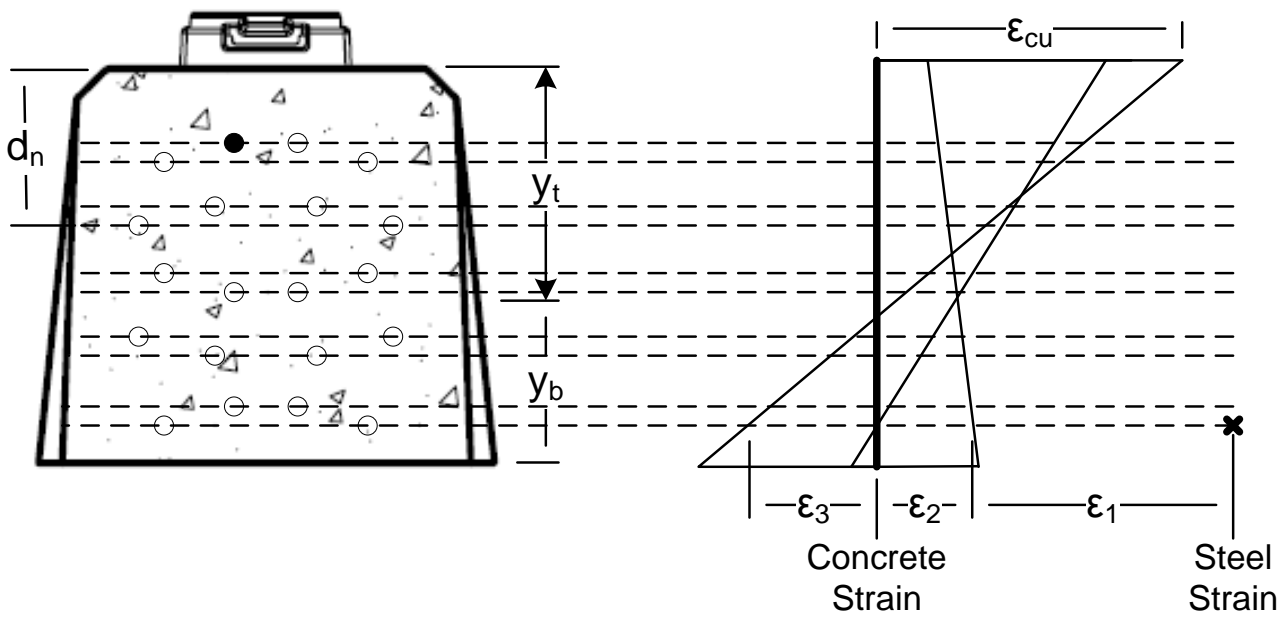

Figure 45: Strain diagram at rail seat section showing three strain increments

\subsection{Strain due to Effective Prestress $\left(\varepsilon_{1}\right)$}

The first increment of strain in the prestressing steel is that due to the effective prestress (i.e. the prestress including all losses). Assuming that the effective prestress is the same in all tendons and therefore the strain due to the effective prestress is the same for all tendons. It is possible that the strain due to effective prestress varies from tendon to tendon due to camber of the tie, but for sake for simplifying the calculations it will be assume that the effective prestressing force is constant across the cross-section. However, the strain due to effective prestress does vary depending on the section since prestressing losses vary depending on the section.

\subsection{Decompression Strain $\left(\varepsilon_{2}\right)$}

The second strain increment is the change in strain corresponding to decompression. Decompression is the condition in which external load is applied causing the concrete surrounding the bottom layer of prestressing to reach zero strain. Based on decompression condition the determination of the strain change in the bottom layer or prestressing is simplified since the strain the concrete surrounding the tendons is zero. For the remaining prestressing layers the change is strain is determined using the assumption of constant curvature, with the neutral axis based on uncracked elastic section properties. Assuming constant curvature the strain in the remaining levels of prestressing corresponding to decompression can be determined using similar triangles. 


\subsection{Strain Corresponding to Failure $\left(\varepsilon_{3}\right)$}

The third and final strain increment is the strain corresponding to failure. Assuming a maximum concrete compressive strain of 0.003 , the strain in the concrete at the level of each prestressing layer can be determined based on similar triangles once again. However, at this point it is assumed that section is cracked and the neutral axis has shifted towards the extreme compression fiber. This will require a guess of the new distance to the neutral axis, (c). Steel that was previously located in the compression zone may transition into the tension zone.

\subsection{Strain Component Summation}

Even though $\varepsilon_{2}$ and $\varepsilon_{3}$ are increments of strain in the concrete at the level of the prestressing layer, based on the assumption of fully bonded tendons, the changes in strain for the steel are the same as those calculated in the concrete. Summing the individual components will provide the strain in the prestressing steel at each layer corresponding to failure. When summing the strain components special attention must be paid to the location of the prestressing layer with respect to the neutral axis during the specific load case (i.e. decompression or failure). If the prestressing layer is above the neutral axis, $\varepsilon_{2}$ and $\varepsilon_{3}$ are subtracted from $\varepsilon_{1}$. If the prestressing layer is located below the neutral axis, $\varepsilon_{2}$ and $\varepsilon_{3}$ are added to $\varepsilon_{1}$.

\subsection{Resultant Force Determination}

Once the summation of the stain increments is completed the total strain in each layer of prestressing is available. Using the stress-strain relationship presented in Section 3.1.3.2.1, the corresponding total stress is determined. Based on the area of steel in each layer the prestressing force and applied moment about the uncracked neutral axis is determined for each layer. Similarly the resultant compressive force for the compression block is determined based on the approximate depth of the compression block. For equilibrium to be achieved the sum of all the tensile prestressing forces must equal the resultant compressive force. If this is true the correct depth to the cracked neutral axis is found. If the two resultant forces are not equal, a new depth to the cracked neutral axis must be assumed and the process above repeated. If the resultant compression force is larger than the resultant tension force, the assumed depth to the cracked neutral axis is too large and if the resultant tension force is larger the assumed depth is to shallow. 


\subsubsection{Strain Compatibility Spreadsheet Organization}

Since strain compatibility is inherently a trial and error process the analysis procedure was organized into a spreadsheet dependent on a single variable, the depth to the cracked neutral axis, (c). Then a solver was used to perform the iterative process until the resultant compressive and tension forces converge. All other variables are set as constants which are specific to the specific section and load condition of interest. An example of the full analysis is presented in Appendix $\mathrm{D}$ in the form of a MathCAD file; however, all analyses were performed in Excel.

\subsubsection{Development Length}

To achieve the nominal moment capacity calculated using strain compatibility the prestressing tendon must be securely anchored in the concrete. The anchorage is developed by the bond between the concrete and the prestressing. The bond must be capable of supporting the stress in the prestressing at ultimate capacity. Equation 11 from $\mathrm{ACl} 318$ is used for calculating the required length of bond to develop the stress at ultimate in the drawn wire of the baseline tie.

$$
\begin{aligned}
& \mathrm{I}_{d}=\left(\frac{f_{s e}}{3}\right) d_{b}+\left(f_{p s}-f_{s e}\right) d_{b} \\
& I_{d}=\text { develpment length (in) } \\
& f_{s e}=\text { effective prestressing (ksi) } \\
& f_{p s}=\text { stress in prestressing corresponding to failure (ksi) } \\
& d_{b}=\text { diameter of prestressing tendon (in) }
\end{aligned}
$$

\subsection{Parametric Optimization Study}

The purpose of the parametric optimization study was to determine which design variables such as concrete strength, prestressing type and configuration offer the most efficient and largest gains in flexural capacity over the baseline tie while maintaining the current concrete geometry. Since the concrete tie geometry remains constant a large majority of the calculations and assumptions made for the baseline tie analysis will remain the same. However, one portion of the process which will change dramatically is the determination of prestressing configuration and eccentricity. Similarly the prestressing type and concrete strength used in the design iterations will vary. The following sections will summarize the characteristics unique to the optimization process and identify those similar to the baseline analysis. 


\subsubsection{Optimization Variables}

The following sections will outline the optimization parameters of concrete compressive strength and prestressing type and size.

\subsubsection{Concrete Compressive Strength}

The concrete compressive strength is the controlling factor for allowable concrete stresses at transfer and service. Therefore increasing the compressive design strength will increase the allowable stresses for the two stress related limit states. This will in turn allow for an increase in eccentricity or the applied prestressing force, ultimately increasing the capacity of the tie. The four concrete compressive strengths which will be used for the optimization study are; the current design strength of 7,000 psi, the actual average strength of 9,500 psi which is currently achieved by the manufacturer and 12,000 and 15,000 psi, which a precast manufacturer can typically achieve. The means of determining the mechanical properties corresponding to these four compressive design strengths will be discussed in later sections.

\subsubsection{Prestressing Type and Size}

With increases in compressive strength it was expected that the maximum applied prestressing force or eccentricity could be increased. In addition to these properties pertaining to configuration and jacking of the prestressing, different types and sizes of prestressing were of interest as well. While the current prestressing type, 0.21 in. diameter drawn wire, will continue to be evaluated. Various sizes of 7-wire strand and fiber reinforced plastic (FRP) strand will be considered as well. At the request of the industry partner, the use of 0.375 in. 7 -wire strand will be evaluated since it is the predominate prestressing choice in the North American prestressed concrete tie industry. Smaller diameters of 7-wire strand, 0.25 and $0.3125 \mathrm{in}$. were used as well.

As for FRP, this is an idea which originated from the research team. One of the factors limiting concrete capacity to the onset of cracking is the fear of corrosion of the prestressing, should cracking occur, allowing water to migrate into the section. If a material such as FRP which does not corrode were used, the flexural capacity may then exceed the cracking limit ultimately increasing the capacity of the tie. The material properties of the 7-wire strand and FRP will be discussed in later sections. 


\subsubsection{Iteration Matrix}

To organize the various design iterations composed of the different combinations of concrete compressive strength and prestressing type, an optimization iteration matrix was developed and presented in Appendix C. The material properties corresponding to each design iteration are included for quick reference as well as the base file names for the calculation support files in MathCAD and Excel. The iteration matrix also serves a summary table for the limit state values of the design iterations. To organize the design iteration calculations a file naming system was developed based on the optimization parameters; prestressing type (PT), prestressing tendon diameter (PD) and concrete strength (CS). Table 14 shows the abbreviations and their placement within the base file name used for all calculation support files.

Table 14: Optimization study file name abbreviations of iteration parameters

\begin{tabular}{|c|c|c|}
\hline Optimization Parameter & $\begin{array}{c}\text { File Name } \\
\text { Abbreviation }\end{array}$ & $\begin{array}{c}\text { Abbreviation Location in } \\
\text { File Name }\end{array}$ \\
\hline \multicolumn{3}{|c|}{ Prestressing Type (PT) } \\
\hline Drawn Wire & W & $\mathbf{W}(\mathrm{PT})-\mathrm{XX}(\mathrm{PD})-\mathrm{XX}(\mathrm{CS})$ \\
\hline 7-Wire Strand & $\mathrm{S}$ & $\mathbf{S}(\mathrm{PT})-\mathrm{XX}(\mathrm{PD})-\mathrm{XX}(\mathrm{CS})$ \\
\hline FRP & FRP & FRP(PT)-XX(PD)-XX(CS) \\
\hline \multicolumn{3}{|c|}{ Presstressing Diameter (PD) } \\
\hline $0.21 \mathrm{in.}$ & 0.21 & $X X(P T)-0.21(P D)-X X(C S)$ \\
\hline 0.25 in. & 0.25 & $X X(P T)-0.25(P D)-X X(C S)$ \\
\hline 0.3125 in. & 0.3125 & $X X(P T)-0.3125(P D)-X X(C S)$ \\
\hline $0.375 \mathrm{in}$. & 0.375 & $\mathrm{XX}(\mathrm{PT})-0.375(\mathrm{PD})-\mathrm{XX}(\mathrm{CS})$ \\
\hline \multicolumn{3}{|c|}{ Concrete Strength (CS) } \\
\hline 7,000 psi & 7 & $X X(P T)-X X(P D)-7(C S)$ \\
\hline 9,500 psi & 95 & $X X(P T)-X X(P D)-95(C S)$ \\
\hline $12,000 \mathrm{psi}$ & 12 & $X X(P T)-X X(P D)-12(C S)$ \\
\hline 15,000 psi & 15 & $\mathrm{XX}(\mathrm{PT})-\mathrm{XX}(\mathrm{PD})-\mathbf{1 5}(\mathrm{CS})$ \\
\hline
\end{tabular}

\subsubsection{Prestressing Placement}

The placement of prestressing within the geometric envelope was based on permissible cover and spacing. The position of tendons was selected to achieve the maximum eccentricity while remaining within the allowable prestressing and concrete stresses. The following sections outline the detailing constraints for prestressing placement and the design aid created using drafting software for determining dimensions to prestressing layers. 


\subsubsection{Detailing Constraints}

Detailing constraints for the optimization study were from ACl 318 (ACl 2008). AREMA has a minimum cover specification of 0.75 in., however it was decided to use the minimum cover specified in ACl 318-08 (AREMA 2003). For cover, the prestressed concrete tie is a precast member which is exposed to earth and weather with prestressing $0.625 \mathrm{in}$. diameter or less. Per $\mathrm{ACl}$ 318-08 Section 7.7.3 (a) the minimum cover is $1.25 \mathrm{in}$. Spacing requirements for the prestressing from $\mathrm{ACl} 318$ Section 7.6.7 are the following:

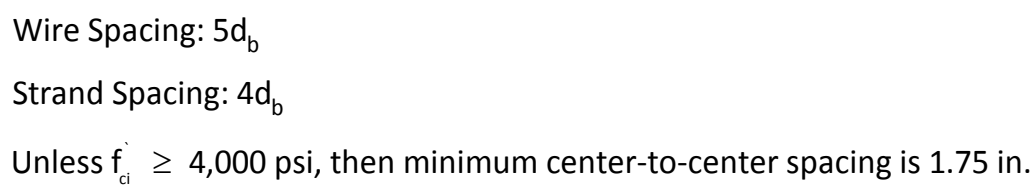

The third criteria based on concrete compressive stress will control for all iterations. The minimum value of concrete compressive stress at transfer for all iterations is 4,500 psi. In addition to the $\mathrm{ACl} 318$ detailing criteria, it was decided that no more than three tendons may be placed in the same layer. The restriction on the number of tendons per layer is done in an effort to reduce the availability of failure planes within the section and stagger the prestressing tendons.

\subsubsection{Prestressing Placement Design Aid}

To aid in the process of prestressing placement the envelope of allowable placement area set using the cover constraints discussed above was illustrated in a CAD program. Prestressing was placed within the drawing with their own envelopes modeling the required spacing. A snap grid was situated over the drawing with a spacing of 0.125 in. to provide a consisted spacing and avoid obscure dimensions. An example of the prestressing placement aid illustrating the baseline tie can be seen in Figure 46.

Detailing constraints were modeled as dashed lines shown in Figure 46. The straight dashed line shows the minimum cover envelope, while the dashed circles around the prestressing (solid circles) designate the minimum spacing. If no prestressing is outside the dashed line, cover requirements have been met. If no dashed circles overlap, spacing requirements have been met. This design aid offered quick visual verification of whether or not the detailing requirements according to $\mathrm{ACl} 318$ have been satisfied. In addition to detailing constraint envelops, the aid 
provided dimensions to the centerline of prestressing layers which were used for eccentricity calculations.

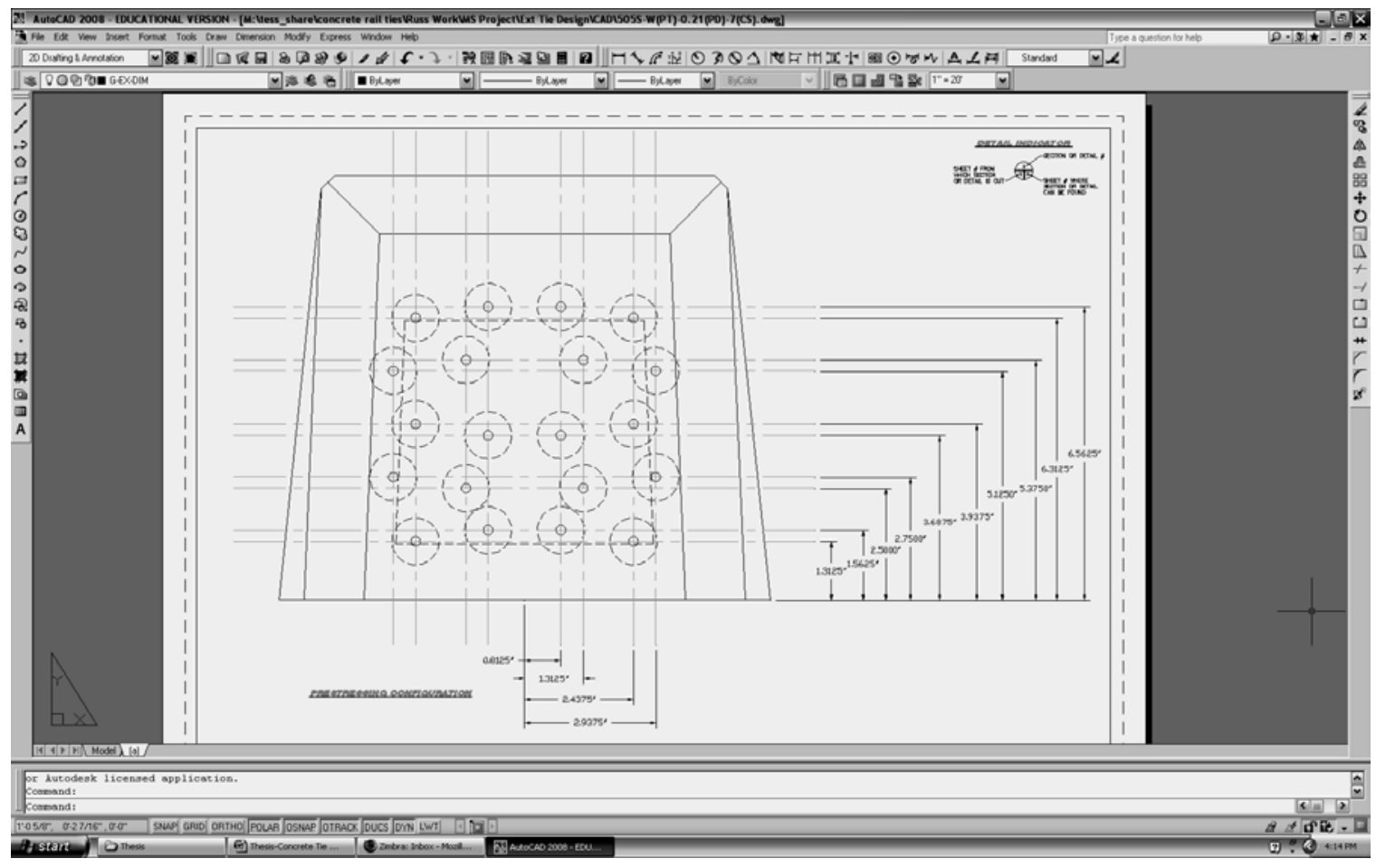

Figure 46: Screen capture of prestressing placement design aid used to evaluate baseline tie

\subsubsection{Baseline and Optimized Tie Analysis Similarities}

Since this optimization study was based on an existing tie design whose external dimensions will remain unchanged, several aspects of the design process will be the same for the optimization study when compared to the process described in the previous section 3.1. Tie characteristics that remained the same for the optimized study include:

- External tie geometry (i.e. the concrete section),

- Fabrication process (i.e. un-harped prestressing tendons, same load conditions),

- Self weight effects,

- Limit states of allowable stresses at transfer, allowable stresses at service (AREMA defined failure), and nominal capacity (corresponds to crushing of concrete or rupture of prestressing) still apply. 
Any changes to limit state conditions with respect to the analysis process will be discussed in later sections of this chapter.

\subsubsection{Material Properties}

\subsubsection{Concrete Properties}

\subsection{Compressive Strength}

The design compressive strengths used in the optimization study were 7,000, 9,500, 12,000, and 15,000 psi. To determine the corresponding compressive strengths at transfer the maturity relationship (Eqn. 12) presented in ACl 209R-92 ( $\mathrm{ACl}$ Committee 209 1992) was used for all design compressive strengths unless specified otherwise (for 7,000 psi iterations used the currently specified 4,500 psi). This equation relates the 28-day compressive strength with respect to time and was used to determine the compressive strength at a specified time. The use of this equation requires assumptions about the curing procedures to determine constants contained within Table 2.2.1 of ACl 209R. For this project it was assumed that transfer occurs after 24 hours and the concrete is maintained under a steam cured condition. An example of the maturity relationship for a 28-day design compressive strength of 9,500 psi to determine the compressive strength at transfer is shown below.

$$
\begin{aligned}
& f_{c i}=\frac{t}{a+\beta t} f_{c}^{\prime}=\frac{1}{(0.70)+(0.98) 1} 9,500 p s i=5,655 \text { psi } \\
& t=1 \quad \text { initial curing period (days) prior to transfer } \\
& a=0.70 \text { constant from ACl 209R Table 2.2.1 (steam cured \& Type III Cement) } \\
& \beta=0.98 \text { constant from ACl 209R Table 2.2.1 (steam cured \& Type III Cement) }
\end{aligned}
$$

$\mathrm{ACl}$ 363R-92, the design specification for concrete with compressive strengths greater than 10,000 psi does not have a maturity equation to approximate concrete strength based on 28day design strength. Therefore, the approximation described in ACl $209 \mathrm{R}-92$ was used for all iterations excluding those for 7,000 psi concrete. The effect of specifying transfer at a specific time (24hours) rather than the minimum allowable concrete strength at transfer of 4,500 psi by AREMA, is higher concrete strengths at transfer and therefore higher stresses can be applied by the prestressing ( $\mathrm{ACl}$ 2008; AREMA 2003). 


\subsection{Modulus of Elasticity}

When calculating the modulus of elasticity for all iterations the relationship described in Section 3.1.3.1.2 was used (Eqn. 1 and Eqn. 2). This relationship between design compressive strength and elastic modulus is from $\mathrm{ACl} 318-08$ which is limited to concrete with a compressive strength less than 10,000 psi; however, $\mathrm{ACl} 363 \mathrm{R}$ which covers concrete with compressive strengths greater than 10,000 psi does not have a specification for elastic modulus which differs considerably from that found in $\mathrm{ACl} 318-08$. Additionally, the approximation found in $\mathrm{ACl} 318-08$ is more up-to-date with current material behavior assumptions.

\subsection{Allowable Stresses}

For allowable concrete stresses, the limits presented in $\mathrm{ACl} 318-08$ will continue to govern regardless of the compressive design strength. However, for FRP the allowable concrete stresses at service conditions for tension was slightly less than those corresponding to conventional steel (Table 15).

Table 15: Allowable concrete stresses in conjunction with FRP prestressing (ACl Committee 440 2004)

\begin{tabular}{|c|c|c|}
\hline $\begin{array}{l}\text { Allowable Concrete } \\
\text { Stresses }\end{array}$ & Stress Case Description & $\begin{array}{l}\text { ACl Code } \\
\text { Specification (psi) }\end{array}$ \\
\hline \multicolumn{3}{|c|}{ Allowable stress at transfer of prestress (before losses) } \\
\hline$\sigma_{\mathrm{ci}}$ & $\begin{array}{l}\text { Extreme fiber stress in compression at prestress } \\
\text { transfer } \mathrm{ACl} 440.4 \mathrm{R}-04 \text { Table } 3.2 \text { (a) }\end{array}$ & $0.6 f_{\mathrm{ci}}^{\prime}$ \\
\hline$\sigma_{\mathrm{ti}}$ & $\begin{array}{l}\text { Extreme fiber stress in tension at prestress transfer, } \\
\mathrm{ACl} 440.4 \mathrm{R}-04 \text { Table } 3.2 \text { (b) }\end{array}$ & $3 f_{c}^{0.5}$ \\
\hline \multicolumn{3}{|c|}{ Allowable stresses under service loads (after losses) } \\
\hline$\sigma_{\mathrm{cs} 1}$ & $\begin{array}{l}\text { Extreme fiber stress in compression at service (P/S } \\
\text { and SDL) ACl 440.4R-04 Table } 3.2 \text { (a) }\end{array}$ & $0.45 f_{c}^{\prime}$ \\
\hline$\sigma_{\mathrm{cs} 2}$ & $\begin{array}{l}\text { Extreme fiber stress in compression at serivce (P/S } \\
\text { and total load) } \mathrm{ACl} 440.4 \mathrm{R}-04 \text { Table } 3.2 \text { (b) }\end{array}$ & $0.6 f_{c}^{\prime}$ \\
\hline$\sigma_{\mathrm{ts}}$ & $\begin{array}{l}\text { Extreme fiber stress in tension at service } \mathrm{ACl} 440.4 \mathrm{R} \\
04 \text { Table } 3.2 \text { (c) }\end{array}$ & $6 f_{c}^{\prime 0.5}$ \\
\hline
\end{tabular}

\subsubsection{Prestressing Properties}

Prestressing properties will change depending on the design parameters relevant to the specific iteration. For 0.21 in. diameter drawn wire the material properties described in Section 3.1.3.2 still govern. For 7-wire strand material properties such as ultimate and yield strengths as well as elastic modulus will be specified by ASTM A 416/A416M-06 (Table 16) (ASTM International 
2006). Material properties for carbon FRP have been collected from ACl 440.4R-04 (Table 16) ( $\mathrm{ACl}$ Committee 440 2004). FRP does not have a defined yield strength because the stress-strain curve remains linear up to failure.

Table 16: Prestressing sectional and material properties

\begin{tabular}{|c|c|c|c|c|c|}
\hline Prestressing Type & $\begin{array}{c}\text { Tendon } \\
\text { Diameter } \\
(\mathbf{i n})\end{array}$ & $\begin{array}{c}\text { Tendon } \\
\text { Area } \\
\left(\mathbf{i n}^{2}\right)\end{array}$ & $\begin{array}{c}\text { Ultimate } \\
\text { Strength } \\
(\mathbf{k s i})\end{array}$ & $\begin{array}{c}\text { Yield } \\
\text { Strength } \\
(\mathbf{k s i})\end{array}$ & $\begin{array}{c}\text { Elastic } \\
\text { Modulus } \\
(\mathbf{k s i})\end{array}$ \\
\hline Drawn Wire (W) (Baseline) & 0.21 & 0.03445 & 255 & 230 & 28,500 \\
\hline 7-Wire Strand (S) & 0.25 & 0.036 & 250 & 225 & 28,500 \\
\hline 7-Wire Strand (S) & 0.3125 & 0.058 & 250 & 225 & 28,500 \\
\hline 7-Wire Strand (S) & 0.375 & 0.085 & 270 & 243 & 28,500 \\
\hline Carbon FRP (FRP) & 0.25 & 0.049 & 425 & NA & 18,000 \\
\hline Carbon FRP (FRP) & 0.375 & 0.11 & 425 & NA & 18,000 \\
\hline
\end{tabular}

\subsubsection{Prestressing Forces and Losses}

The permissible prestressing stresses presented in Section 3.1.4.1.2 still govern for steel wire and strand while the permissible stresses for FRP were obtained from $\mathrm{ACl} 440.4 \mathrm{R}-04(\mathrm{ACl}$ Committee 440 2004). To avoid creep-rupture, a prestressing failure unique to FRP, a maximum limit well below the creep-rupture value is placed on the FRP prestressing force. For this project it has been assumed that carbon FRP tendons will be used. The permissible stresses for carbon FRP are given in Table 17.

Table 17: Permissible prestressing stresses for carbon FRP (ACI Committee 440 2004)

\begin{tabular}{|c|c|}
\hline Stress Case Description & ACI Code Specification \\
\hline Allowable jacking stress, $\mathrm{f}_{\mathrm{pj}}$ & $0.65 \mathrm{f}_{\mathrm{pu}}$ \\
\hline Due to prestressing steel jacking, $\mathrm{f}_{\mathrm{pi}}$ & $0.60 \mathrm{f}_{\mathrm{pu}}$ \\
\hline
\end{tabular}

The process of calculating prestressing losses for the optimization study will depend on the prestressing type. The properties of the prestressing change from wire to strand to FRP. For 7wire strand the process was exactly the same as that described in Section 3.1.4.3 with the only changes being the material property constants. The process of calculating theoretical losses of FRP vary in terms of the relaxation component of losses. In general, carbon FRP strands have smaller relaxation losses than normal steel strands exposed to the same loading ( $\mathrm{ACl}$ Committee 440 2004). ACl 440 recommends an approximation of the prestressing loss for carbon FRP due 
to relaxation to be approximately 1.5 percent of the jacking stress during the initial curing period and another 1.5 percent after transfer ( $\mathrm{ACl}$ Committee 440 2004).

\subsubsection{Limit States}

All processes related to the previously defined limit states will be the same during the optimization study as those presented in Sections 3.1.5 and 3.1.6 with the following exceptions:

- The limit states of allowable stresses at service and nominal capacity will be derived using the effective prestressing value taken at a time of 50 years to include all prestressing losses calculated using the theoretical time-step method,

- Changes related to the variation in concrete or prestressing materials

\subsubsection{Transfer and Development Lengths}

For the design iterations utilizing steel prestressing, Equations 10 and 11 from Section 3.1 were used to determine the required transfer and development length. However, for iterations using FRP, the equations from $\mathrm{ACl} 318$ no longer apply. Since FRP does not bond to concrete the same as steel due to variations in the surface texture and material properties, different equations for transfer and development lengths were required. The transfer length for FRP is defined by Equation 13 from $\mathrm{ACl}$ 440.4R-04. The development length for FRP is defined by Equation 14 from $\mathrm{ACl}$ 440.4R-04.

$$
\begin{aligned}
& I_{t}=\frac{f_{p e} d_{b}}{\alpha_{t} f_{c}^{0.67}} \\
& I_{t}=\text { transfer length of FRP prestressing (in) } \\
& f_{p e}=\text { effective prestressing (psi) } \\
& d_{b}=\text { diameter of prestressing tendon (in) } \\
& \alpha_{t}=\text { material constant for FRP, use } 11.2 \text { for carbon FRP (in) } \\
& f_{c}=28 \text {-day concrete design strength (psi) } \\
& I_{d}=\left(\frac{1}{3}\right) f_{p e} d_{b}+\left(\frac{3}{4}\right)\left(f_{p u}-f_{p e}\right) d_{b} \\
& I_{d}=\text { development length of FRP prestressing (in) } \\
& f_{p u}=\text { effective prestressing (ksi) }
\end{aligned}
$$




\subsection{Results and Discussion}

\subsection{Overview}

This section summarizes the results of the baseline tie analysis and the parametric optimization study. The capacity predictions for the baseline tie obtained from the numerical analysis process developed in the first phase of the project are compared to actual values collected during experimental testing. Based on the comparison of predicted to actual values, improvements to the analysis procedure and assumptions are suggested. The results of the parametric optimization are presented, demonstrating the effects of various prestressing and concrete combinations on the flexural capacity of prestressed concrete railroad ties.

\subsection{Numerical Analysis: Baseline Tie Design Results (Phase I)}

Performing a numerical analysis on a baseline tie has several functions with respect to this optimization study. First, the predicted capacities obtained from the analysis will serve as a baseline for the remaining design iterations performed in the optimization process. Secondly, an advantage of the existing tie design is the experimental results which are available to be used in comparison with the predicted values. This comparison offers the opportunity to evaluate the accuracy of assumptions, material approximations and the numerical analysis process as a whole. In the following sections the numerical process developed to analyze an baseline tie will be presented and the accuracy evaluated in a comparison with actual values obtained from experimental testing performed by the tie manufacturer.

\subsubsection{Analysis Procedure}

With respect to the computation processes completed during the course of this project, the most critical component was the development of the baseline tie numerical analysis due to the impact it would have on the remainder of the optimization design iterations. The capacity predictions developed during the baseline tie numerical analysis served as the benchmark for the study, so it was essential that a high level of accuracy be achieved. In addition to being accurate, a goal of the numerical analysis was to make the process universally applicable to a variety of tie designs. Since this was an optimization study, a compilation of tie designs utilizing a variety of concrete strengths, prestressing types and configurations were developed. 
Therefore, the process must be capable of adapting to a wide range conditions whether they be material or process based.

\subsubsection{Analysis Organization}

To achieve an adaptive capacity analysis procedure which could be used for the baseline tie analysis and later optimization iterations, it was important to develop a process which was capable of remaining effective after changes in material properties and other design parameters such as prestressing configuration. Assembling the analysis method with the material properties of the prestressing and concrete, along with the prestressing configuration as variables, the desired versatility was accomplished. For example, the sign conventions for stresses and prestressing eccentricities discussed in Chapter 3 were chosen so that the analysis procedure would be applicable regardless of changes to the inputs. The consideration of the analysis inputs prior to the development of the procedure produced a system which can efficiently evaluate a design in terms of time and reduce the possibility of errors, since the analysis method was independent of the inputs.

To perform the procedure effectively in terms of accuracy and time, careful consideration was given to the computer software used to complete the analyses. To document and clearly convey the methodology behind processes and assumptions, the first analysis of the baseline tie was completed using the math computation software MathCAD (Appendix D). An advantage of MathCAD is the ability to complete the necessary computations while documenting the process using the word processor application of the software. Therefore, the analysis is presented in a step-by-step manner with supporting discussion of the procedure and assumptions used. The goal of this first analysis completed using MathCAD was to develop a guide for the remaining iterations as well as perform the preliminary analysis of the baseline tie design.

However, MathCAD does have some disadvantages which make it unsuitable for the optimization phase of this project. For repetitious analysis such as the optimization study, MathCAD is bulky and difficult to evaluate quickly, since all text and equations are displayed, rather than simply the outputs of the desired information. To reduce the bulk of text and equations to a digestible level in the design iterations and decrease the time required for evaluation of results, the analysis procedure developed in MathCAD was transferred to a 
spreadsheet format for all other analyses. To verify the conversion of the analysis procedure between the two applications, the baseline tie analysis was completed using both systems. One advantage of the spreadsheet computation method is the ability to quickly evaluate the results of the analysis and make changes accordingly. This became especially important during the optimization phase of the project. A disadvantage of the spreadsheet computation method was the lack of discussion compared to the MathCAD system. However, since the procedure did not change between the two systems, the original MathCAD analysis of the baseline tie served as a guide to the remaining iterations completed using Excel.

\subsubsection{Tie Cross-Section Properties}

The first step in developing the numerical analysis method was identifying the cross-sectional properties of the baseline tie. One simplifying condition of this project was that the concrete tie geometry remained constant for all design iterations and analyses. For the baseline tie, as-built drawings and material data sheets were furnished by the tie manufacturer (Appendix $A$ ). However, several properties required calculation or approximation, such as the moment of inertia of the rail seat and center critical sections. Using the parallel axis theorem, values for the moment of inertia of the sections were obtained (Figure 47 and Table 18). The cross-sectional properties for the rail seat and center sections are summarized in Table 19.

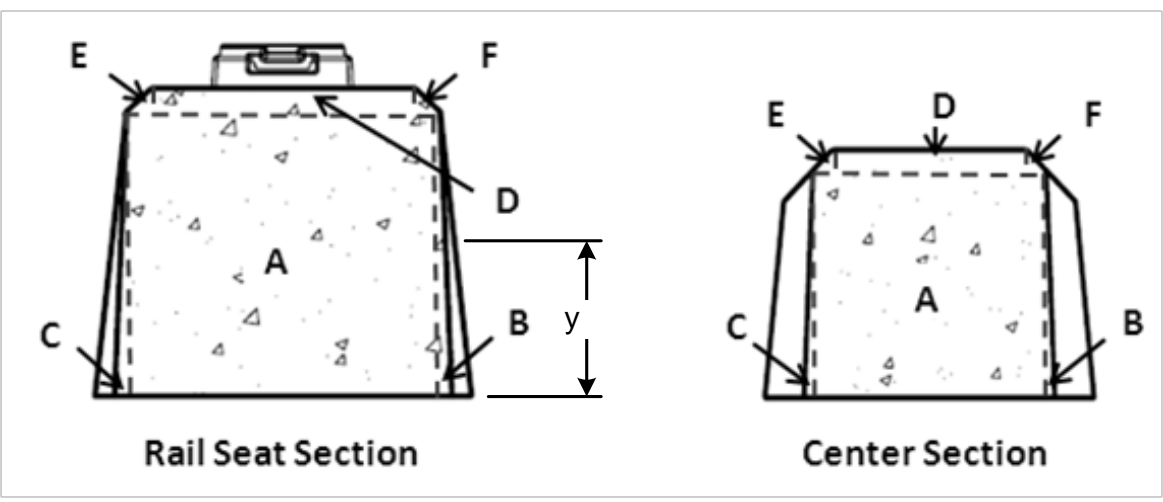

Figure 47: Division of tie cross sections into standard shape components for use in parallel axis theorem 
Table 18: Cross-sectional geometry for rail seat and center sections using parallel axis theorem

\begin{tabular}{|c|c|c|c|c|c|c|c|}
\hline \multicolumn{8}{|c|}{ Rail Seat Section } \\
\hline Component & $\begin{array}{l}\text { Width } \\
\text { b (in) }\end{array}$ & $\begin{array}{l}\text { Height } \\
\text { h (in) }\end{array}$ & $\begin{array}{l}\text { Area } \\
\text { A }\left(\mathrm{in}^{2}\right)\end{array}$ & $\begin{array}{c}\text { Centroid } \\
\text { Distance } \\
\text { y (in) }\end{array}$ & $\begin{array}{c}\text { Moment of } \\
\text { Inertia } \\
\mathrm{I}_{\text {bar }}\left(\text { in }^{4}\right)\end{array}$ & $\begin{array}{l}\text { Centroid } \\
\text { Difference } \\
\text { d (in) }\end{array}$ & $\begin{array}{c}\text { Parallel Axis } \\
\text { Theorem } \\
\mathrm{I}_{\text {bar }}+\mathrm{Ad}^{2}\left(\mathrm{in}^{4}\right)\end{array}$ \\
\hline$A$ & 9.10 & 8.59 & 78.12 & 4.29 & 479.82 & 0.26 & 485.12 \\
\hline B & 0.39 & 8.59 & 1.65 & 2.86 & 6.77 & 1.69 & 11.49 \\
\hline C & 0.39 & 8.59 & 1.65 & 2.86 & 6.77 & 1.69 & 11.49 \\
\hline $\mathrm{D}$ & 7.69 & 0.71 & 5.42 & 8.94 & 0.22 & -4.38 & 104.46 \\
\hline $\mathrm{E}$ & 0.71 & 0.71 & 0.25 & 8.82 & 0.01 & -4.27 & 4.60 \\
\hline $\mathrm{F}$ & 0.71 & 0.71 & 0.25 & 8.82 & 0.01 & -4.27 & 4.60 \\
\hline Sum & & & 87.35 & & & & 621.76 \\
\hline$y_{\text {bar }}$ & 4.55 & & & & & & \\
\hline
\end{tabular}

\begin{tabular}{|c|c|c|c|c|c|c|c|}
\hline \multicolumn{8}{|c|}{ Center Section } \\
\hline Component & $\begin{array}{l}\text { Width } \\
\text { b (in) }\end{array}$ & $\begin{array}{l}\text { Height } \\
\text { h (in) }\end{array}$ & $\begin{array}{l}\text { Area } \\
\text { A }\left(\text { in }^{2}\right)\end{array}$ & $\begin{array}{c}\text { Centroid } \\
\text { Distance } \\
\text { y (in) }\end{array}$ & $\begin{array}{c}\text { Moment of } \\
\text { Inertia } \\
I_{\text {bar }}\left(\text { in }^{4}\right)\end{array}$ & $\begin{array}{l}\text { Centroid } \\
\text { Difference } \\
\text { d (in) }\end{array}$ & $\begin{array}{c}\text { Parallel Axis } \\
\text { Theorem } \\
\text { I bar }+\mathrm{Ad}^{2}\left(\mathrm{in}^{4}\right)\end{array}$ \\
\hline$A$ & 7.75 & 6.88 & 53.28 & 3.44 & 209.86 & 0.28 & 214.14 \\
\hline$B$ & 0.31 & 6.88 & 0.11 & 2.29 & 2.80 & 1.43 & 3.02 \\
\hline C & 0.31 & 6.88 & 0.11 & 2.29 & 2.80 & 1.43 & 3.02 \\
\hline $\mathrm{D}$ & 6.50 & 0.63 & 4.06 & 7.19 & 0.13 & -3.47 & 48.96 \\
\hline $\mathrm{E}$ & 0.63 & 0.63 & 0.20 & 7.08 & 0.00 & -3.36 & 2.21 \\
\hline $\mathrm{F}$ & 0.63 & 0.63 & 0.20 & 7.08 & 0.00 & -3.36 & 2.21 \\
\hline Sum & & & 57.95 & & & & 273.55 \\
\hline $\mathrm{y}_{\mathrm{bar}}$ & 3.72 & & & & & & \\
\hline
\end{tabular}

Table 19: Cross-sectional properties of rail seat and center critical sections

\begin{tabular}{|c|c|c|}
\hline \multicolumn{3}{|c|}{ Section Properties Summary } \\
\hline Geometry Constant & Rail Seat & Center \\
\hline Area, A $\left(\right.$ in $^{2}$ ) & 87.35 & 57.95 \\
\hline Moment of Inertia, I (in ${ }^{4}$ ) & 621.76 & 273.55 \\
\hline Bottom disatnce to CG, $\mathrm{y}_{\mathrm{b}}$ (in) & 4.55 & 3.72 \\
\hline Top distance to $\mathrm{CG}, \mathrm{y}_{\mathrm{t}}$ (in) & 4.74 & 3.78 \\
\hline
\end{tabular}

\subsubsection{Prestressing Eccentricity}

Once the cross-sectional properties of the concrete section had been defined, the prestressing configuration was input into a spreadsheet to calculate the prestressing eccentricities. The spreadsheet is arranged based on the layers of prestressing in the section. Assuming the same size prestressing tendons were used throughout the tie, the number of tendons per layer and 
the distance of each layer from the bottom of the tie were input into the spreadsheet. The layer was referenced from the bottom of the tie because this was the only dimension which remained constant along the length of the tie (Figure 48). The output for the spreadsheet was the distance from the bottom of the tie to the centroid of the prestressing steel (Table 20).

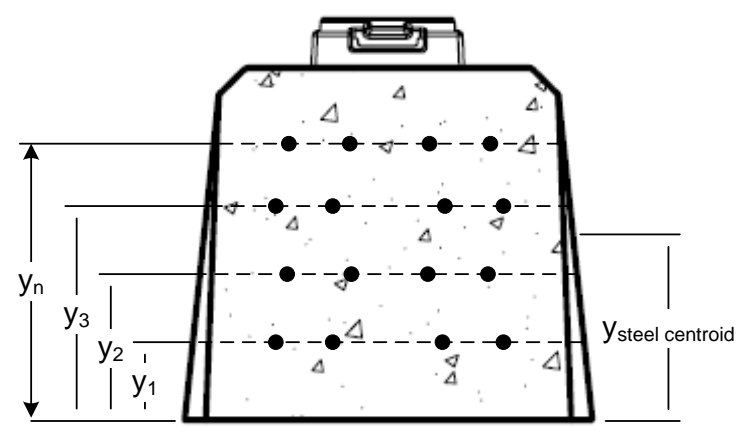

Figure 48: Prestressing configuration schematic

Table 20: Summary of prestressing centroid calculations

\begin{tabular}{|c|c|c|c|c|}
\hline \multicolumn{5}{|c|}{ Prestressing Centroid Calculator } \\
\hline Layer Number & $\begin{array}{c}\text { Number of } \\
\text { Tendons in Layer }\end{array}$ & $\begin{array}{l}\text { Area of Tendons } \\
\text { in Layer } \\
\text { (A) }\left(\mathrm{in}^{2}\right)\end{array}$ & $\begin{array}{c}\text { Distance of Layer } \\
\text { From Bottom } \\
\text { (y) (in.) }\end{array}$ & Ay \\
\hline 1 & 2 & 0.07 & 1.3125 & 0.09 \\
\hline 2 & 2 & 0.07 & 1.5625 & 0.11 \\
\hline 3 & 2 & 0.07 & 2.5 & 0.17 \\
\hline 4 & 2 & 0.07 & 2.75 & 0.19 \\
\hline 5 & 2 & 0.07 & 3.6875 & 0.25 \\
\hline 6 & 2 & 0.07 & 3.9375 & 0.27 \\
\hline 7 & 2 & 0.07 & 5.125 & 0.35 \\
\hline 8 & 2 & 0.07 & 5.375 & 0.37 \\
\hline 9 & 2 & 0.07 & 6.3125 & 0.43 \\
\hline 10 & 2 & 0.07 & 6.5625 & 0.45 \\
\hline 11 & 0 & 0.00 & 0 & 0.00 \\
\hline 12 & 0 & 0.00 & 0 & 0.00 \\
\hline 13 & 0 & 0.00 & 0 & 0.00 \\
\hline 14 & 0 & 0.00 & 0 & 0.00 \\
\hline 15 & 0 & 0.00 & 0 & 0.00 \\
\hline Totals & 20 & 0.69 & & 2.70 \\
\hline & & & Ysteel centroid $_{\text {(in.) }}$ & 3.91 \\
\hline
\end{tabular}


Given the distance between the bottom of the tie and the prestressing centroid the eccentricity at any section along the length of the tie could be determined. The sign convention used was positive for a prestressing centroid below the uncracked neutral axis and negative for above the uncracked neutral axis (Section 3.1.2.2) (Figure 49). For the rail seat and center sections the eccentricities for the baseline tie designs are given in Table 21.

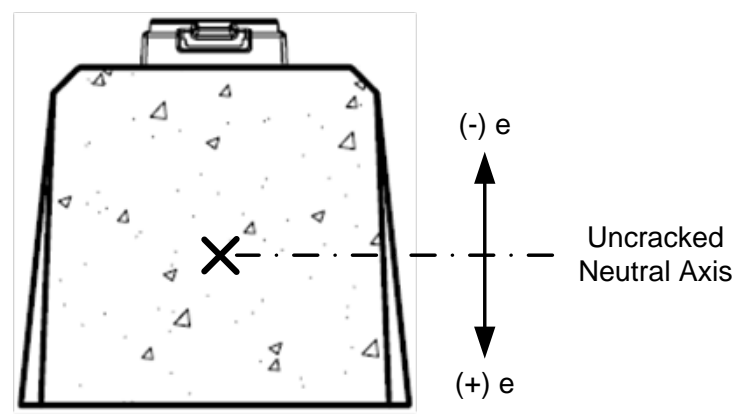

Figure 49: Sign convention for prestressing eccentricity

Table 21: Prestressing eccentricities for rail seat and center sections of baseline tie

\begin{tabular}{|c|c|c|}
\hline \multicolumn{3}{|c|}{ Eccentricity Calculator } \\
\hline $\begin{array}{c}\text { Eccentricity } \\
\text { Location }\end{array}$ & $y_{\text {concrete centroid }} \quad$ (in.) & $\begin{array}{c}\text { Eccentricity } \\
\text { (in.) }\end{array}$ \\
\hline Rail Seat $\left(\mathrm{e}_{\mathrm{RS}}\right)$ & 4.55 & 0.64 \\
\hline Center $\left(\mathrm{e}_{\mathrm{C}}\right)$ & 3.72 & -0.19 \\
\hline
\end{tabular}

The baseline tie design experiences a shift in the prestressing eccentricity with respect to the uncracked neutral axis along the length of the tie. This shift in prestressing eccentricity is not due to harped tendons, but rather a change in tie geometry which lowers the center of gravity of the concrete section at the center section compared to the rail seat. At the rail seat section and the surrounding shoulder and necked down regions, the prestressing eccentricity is below the uncracked neutral axis, while the eccentricity shifts to above the uncracked neutral axis in the center region (Figure 50). This shift in prestressing eccentricity is a design feature in response to the maximum applied moments experience by the tie over its service life. Due to the consolidation of the ballast, support conditions change over time, altering the maximum moments applied to the tie. At the tie center, a reversal in bending direction from positive to negative occurs, which requires a negative prestressing eccentricity to resist the induced negative bending. 


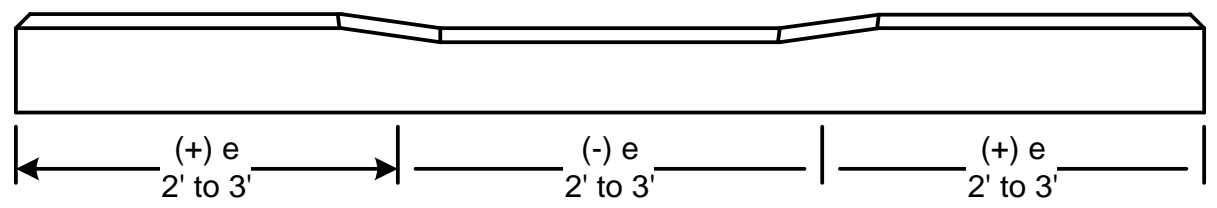

Figure 50: Regions of prestressing eccentricity along the length of the tie

Another design aspect which relates to the placement of the prestressing and eccentricities of the baseline tie design is the detailing requirements of cover and spacing. The cover requirement of 0.75 in. specified by AREMA has been met at every section of the baseline tie, but the larger cover specification of 1.25 in. by $\mathrm{ACl} 318-08$, which will be used for the optimization study, has not been satisfied by the center section (Figure 51). The spacing of prestressing provided in the baseline tie design was however, adequate for the $\mathrm{ACl}$ 318-08 limits (minimum of $\left.5 d_{b}\right)$.
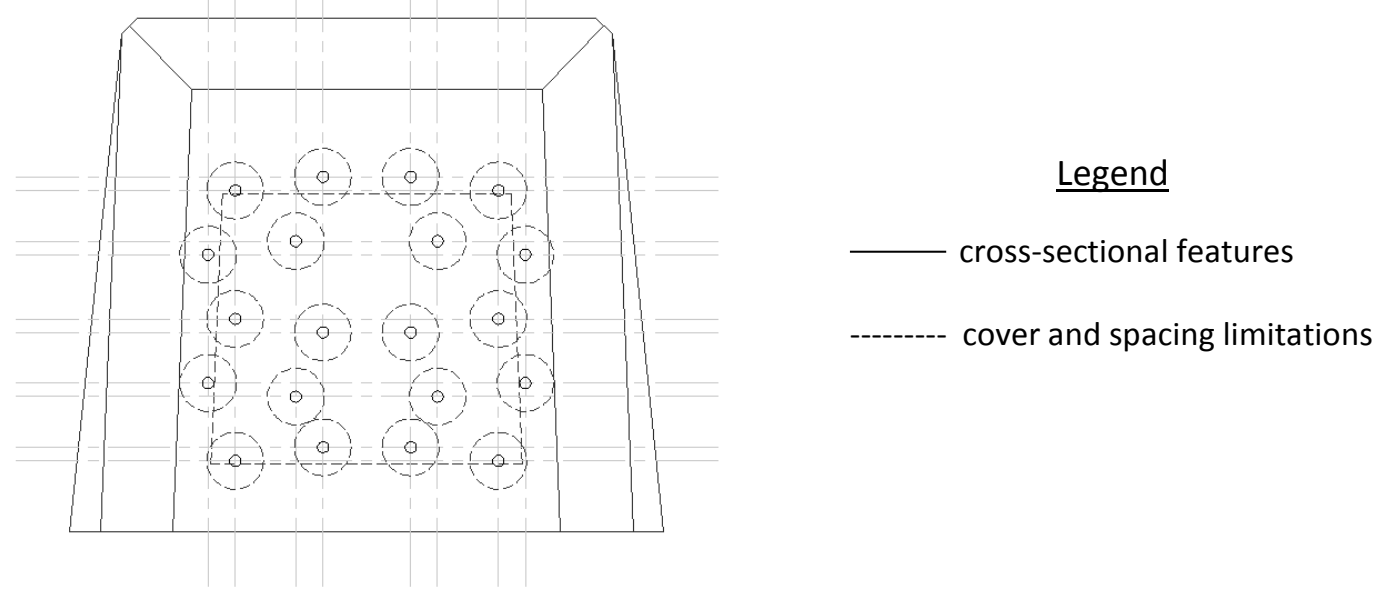

Figure 51: Cross-section of baseline design prestressing configuration

\subsubsection{Prestressing Forces and Losses}

The jacking force per prestressing tendon $\left(F_{p j}\right)$ and the initial prestressing force $\left(F_{p i}\right)$, which include losses from anchorage set, steel relaxation, and elastic shortening, were provided by the manufacturer (Table 48). The stresses in each wire are summarized in Table 22. Comparing the stresses in each tendon to the permissible stresses specified in $\mathrm{ACl} 318-08$, it was determined that the applied stresses were within the acceptable limits (Table 23). However, it was observed that the stresses in the tendons were close to the limits and careful consideration must be given 
to the jacking stress in future iterations utilizing the drawn wire as not to exceed the permissible stress limits. The initial prestressing stress at the rail seat has been calculated to be less than a quarter of a percent higher than the permissible value from $\mathrm{ACl}$ 318-08.

Table 22: Stress in prestressing at jacking and after transfer for baseline tie

\begin{tabular}{|c|c|c|}
\hline $\begin{array}{c}\text { Applied Prestressing } \\
\text { Stress Case }\end{array}$ & Stress Case Description & $\begin{array}{c}\text { Calculated Stress } \\
\text { (ksi) }\end{array}$ \\
\hline $\mathrm{f}_{\mathrm{pj}}=\mathrm{F}_{\mathrm{pj}} / \mathrm{A}_{\mathrm{b}}$ & Due to prestressing steel jacking & 203 \\
\hline $\mathrm{f}_{\mathrm{pi} \mathrm{RS}}=\mathrm{F}_{\mathrm{pi}} / \mathrm{A}_{\mathrm{b}}$ & $\begin{array}{c}\text { Immediately after prestress transfer @ Rail } \\
\text { Seat Section }\end{array}$ & 189 \\
\hline $\mathrm{f}_{\mathrm{pi} \mathrm{C}}=\mathrm{F}_{\mathrm{pi}} / \mathrm{A}_{\mathrm{b}}$ & $\begin{array}{c}\text { Immediately after prestress transfer @ } \\
\text { Center Section }\end{array}$ & 188 \\
\hline
\end{tabular}

Table 23: Comparison of applied stresses in prestressing to permissible stresses from $\mathrm{ACl}$ 318-08

\begin{tabular}{|c|c|c|c|c|c|c|}
\hline $\begin{array}{c}\text { Allowable } \\
\text { Prestressing } \\
\text { Stresses }\end{array}$ & $\begin{array}{c}\text { Stress Case } \\
\text { Description }\end{array}$ & $\begin{array}{c}\text { ACl Code } \\
\text { Specification } \\
\mathbf{( k s i )}\end{array}$ & $\begin{array}{c}\text { Permissible } \\
\text { Stress } \\
(\mathbf{k s i})\end{array}$ & $\begin{array}{c}\text { Maximum } \\
\text { Calculated } \\
\text { Stress } \\
\mathbf{( k s i )}\end{array}$ & $\begin{array}{c}\text { Percent Difference } \\
\text { 100(Calculated - Allowable) } \\
\text { /Allowable }\end{array}$ & $\begin{array}{c}\text { Applied } \\
\text { vs. } \\
\text { Allowable }\end{array}$ \\
\hline $\mathrm{f}_{\mathrm{pj}}$ & $\begin{array}{c}\text { Due to prestressing } \\
\text { steel jacking }\end{array}$ & $0.94 \mathrm{f}_{\mathrm{py}}$ & 216 & 203 & $6.06 \%$ & OK \\
\hline $\mathrm{f}_{\mathrm{pj}}$ & $\begin{array}{c}\text { Due to prestressing } \\
\text { steel jacking }\end{array}$ & $0.80 \mathrm{f}_{\mathrm{pu}}$ & 204 & 203 & $0.66 \%$ & OK \\
\hline $\mathrm{f}_{\mathrm{pi}}$ & $\begin{array}{c}\text { Immediately after } \\
\text { prestress transfer }\end{array}$ & $0.82 \mathrm{f}_{\mathrm{py}}$ & 189 & 189 & $-0.26 \%$ & NG \\
\hline $\mathrm{f}_{\mathrm{pi}}$ & $\begin{array}{c}\text { Immediately after } \\
\text { prestress transfer }\end{array}$ & $0.74 \mathrm{f}_{\mathrm{pu}}$ & 189 & 189 & $0.01 \%$ & OK \\
\hline
\end{tabular}

While estimates for prestressing losses of the baseline tie have been provided by the manufacturer, the loss estimates calculated in this investigation were used instead. The reason for using the estimates calculated in this study was continuity. Since the optimization study varied prestressing and concrete parameters, the estimates determined by the tie manufacturer would not apply. To maintain continuity between the analysis procedure of the baseline tie design and the optimization iterations, the loss estimation conducted during this investigation was used for both analyses. Furthermore, the estimation of prestressing losses conducted by the tie manufacturer only covered a time period of 40 days. Limiting the prestressing losses to 40 days overestimated the effective prestressing force and therefore the tie capacity, since time dependent losses, such as prestressing relaxation, creep and shrinkage continue to cause losses long after 40 days. 
The time-step method outlined in Section 3.1.4.3 was used to determine losses. Prestressing losses are dependent on cross-sectional properties; as a result the losses vary between the rail seat and center critical sections. The time-dependent prestressing losses for the critical sections are summarized in Table 24 and Table 25 and illustrated in Figure 52. From Figure 52 it is observed that a majority of the prestressing losses occur during the first year and then level off as time increases out to 50 years.

A comparison of the prestressing loss estimations conducted in this analysis and by the tie manufacturer is provided in Section 4.2.8.1. When comparing the two loss estimations, the comparison was made at 40 days since this was the time interval which corresponds to the estimation made by the tie manufacturer. However, the baseline tie capacity was evaluated at 50 years, which corresponds to the estimated service life of the tie and the time required for the total prestressing losses to approach a constant value. The initial and effective prestressing stresses at 40 days and 18,250 days (50 years) for the rail seat and center critical sections are shown in Table 26. Using the effective prestressing stress at 50 years will provide the lowest capacity for the baseline tie over the service life; whereas the effective prestressing at 40 days would overestimate the capacity long term. The percent difference between the effective prestressing at 40 days and 50 years is given in Table 26.

The total time-dependent prestressing losses between jacking and the effective prestressing at 40 days and 50 years at the rail seat and center sections are summarized in Table 27. As expected the losses accrued at the center section are larger than those at the rail seat due to the decreased cross-sectional area to resist the same prestressing force. The smaller crosssectional area of the center section increases the stress in the concrete due to the prestressing and in turn increases elastic shortening, creep and shrinkage losses which are a function of the stress in the concrete. 
Table 24: Time-dependent prestress losses at rail seat for baseline tie

\begin{tabular}{|c|c|c|c|c|c|c|c|c|c|c|}
\hline \multicolumn{11}{|c|}{ Prestessing Losses Based on Rail Seat Section Properties } \\
\hline $\begin{array}{c}\text { Time } \\
\text { (days) }\end{array}$ & $\begin{array}{l}\Delta \mathrm{f}_{\mathrm{pR} 1} \\
\text { (ksi) }\end{array}$ & $\begin{array}{l}\Delta \mathrm{f}_{\mathrm{pEs}} \\
(\mathrm{ksi})\end{array}$ & (ksi) & $\begin{array}{l}\Delta \mathrm{f}_{\mathrm{pR} 2} \\
\text { (ksi) }\end{array}$ & $\begin{array}{l}\Delta \mathrm{f}_{\mathrm{ps}} \\
\text { (ksi) }\end{array}$ & $\begin{array}{l}\Delta \mathrm{f}_{\mathrm{pc}} \\
\text { (ksi) }\end{array}$ & $\begin{array}{c}f_{p e} \\
\text { (ksi) }\end{array}$ & $\begin{array}{l}\Delta \mathrm{f}_{\mathrm{pTD}} \\
\text { (ksi) }\end{array}$ & $\begin{array}{c}\text { Total Loss } \\
\text { (ksi) }\end{array}$ & $\begin{array}{c}\text { Actual Prestress } \\
\text { (ksi) }\end{array}$ \\
\hline 1 & 2.34 & 12.43 & 188.42 & 0.00 & 0.00 & 0.00 & 188.42 & 0.00 & 14.78 & 188.42 \\
\hline 3 & 2.34 & 12.43 & 188.42 & 0.61 & 0.41 & 1.81 & 185.60 & 2.82 & 17.59 & 185.60 \\
\hline 7 & 2.34 & 12.43 & 188.42 & 1.07 & 1.14 & 3.85 & 182.36 & 6.06 & 20.83 & 182.36 \\
\hline 28 & 2.34 & 12.43 & 188.42 & 1.81 & 3.83 & 7.48 & 175.30 & 13.12 & 27.90 & 175.30 \\
\hline 40 & 2.34 & 12.43 & 188.42 & 2.00 & 4.84 & 8.51 & 173.07 & 15.35 & 30.13 & 173.07 \\
\hline 365 & 2.34 & 12.43 & 188.42 & 3.17 & 10.21 & 14.30 & 160.74 & 27.68 & 42.45 & 160.74 \\
\hline 1825 & 2.34 & 12.43 & 188.42 & 4.00 & 11.43 & 16.66 & 156.33 & 32.09 & 46.86 & 156.33 \\
\hline 18250 & 2.34 & 12.43 & 188.42 & 5.16 & 11.74 & 18.00 & 153.51 & 34.91 & 49.68 & 153.51 \\
\hline
\end{tabular}

Table 25: Time-dependent prestress losses at center for baseline tie

\begin{tabular}{|c|c|c|c|c|c|c|c|c|c|c|}
\hline \multicolumn{11}{|c|}{ Prestessing Losses Based on Center Section Properties } \\
\hline $\begin{array}{c}\text { Time } \\
\text { (days) }\end{array}$ & $\begin{array}{l}\Delta f_{p R 1} \\
(k s i)\end{array}$ & $\begin{array}{l}\Delta \mathrm{f}_{\mathrm{pES}} \\
(\mathrm{ksi})\end{array}$ & (ksi) & $\begin{array}{l}\Delta \mathbf{f}_{\mathrm{pR} 2} \\
(\mathrm{ksi})\end{array}$ & $\begin{array}{l}\Delta \mathbf{f}_{\mathrm{ps}} \\
(\mathrm{ksi})\end{array}$ & $\Delta f_{p c} \quad(k s i)$ & $\begin{array}{r}\mathbf{f}_{\mathrm{pe}} \\
(\mathrm{ksi})\end{array}$ & $\begin{array}{l}\Delta \mathbf{f}_{\text {pTD }} \\
(\mathbf{k s i})\end{array}$ & $\begin{array}{c}\text { Total Loss } \\
\text { (ksi) }\end{array}$ & $\begin{array}{c}\text { Actual Prestress } \\
\text { (ksi) }\end{array}$ \\
\hline 1 & 2.34 & 17.89 & 182.96 & 0.00 & 0.00 & 0.00 & 182.96 & 0.00 & 20.23 & 182.96 \\
\hline 3 & 2.34 & 17.89 & 182.96 & 0.54 & 0.43 & 2.65 & 179.35 & 3.62 & 23.85 & 179.35 \\
\hline 7 & 2.34 & 17.89 & 182.96 & 0.95 & 1.20 & 5.64 & 175.18 & 7.78 & 28.02 & 175.18 \\
\hline 28 & 2.34 & 17.89 & 182.96 & 1.61 & 4.03 & 10.90 & 166.42 & 16.54 & 36.77 & 166.42 \\
\hline 40 & 2.34 & 17.89 & 182.96 & 1.78 & 5.08 & 12.39 & 163.71 & 19.25 & 39.48 & 163.71 \\
\hline 365 & 2.34 & 17.89 & 182.96 & 2.81 & 10.73 & 20.69 & 148.73 & 34.23 & 54.46 & 148.73 \\
\hline 1825 & 2.34 & 17.89 & 182.96 & 3.55 & 12.01 & 24.02 & 143.39 & 39.57 & 59.80 & 143.39 \\
\hline 18250 & 2.34 & 17.89 & 182.96 & 4.58 & 12.34 & 25.90 & 140.14 & 42.82 & 63.05 & 140.14 \\
\hline
\end{tabular}

Actual Prestress vs. Time

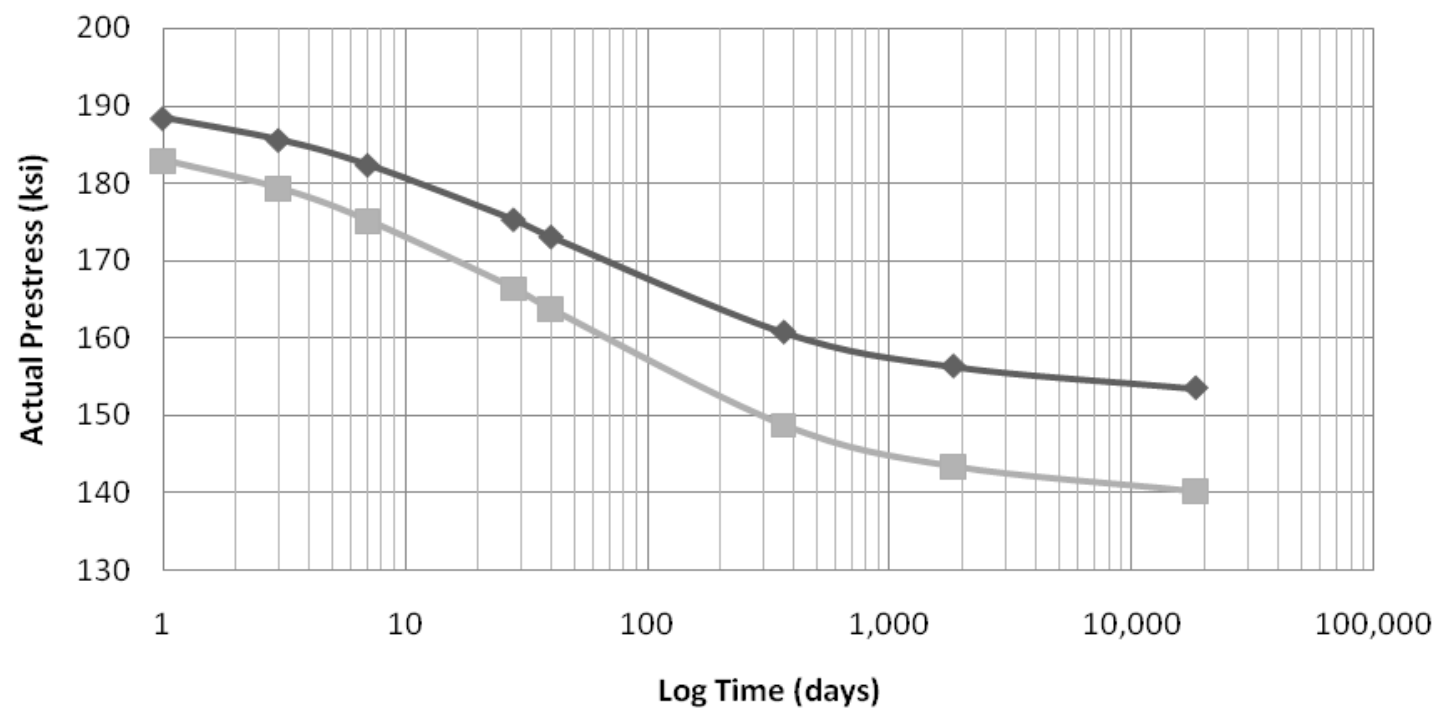

$\longrightarrow$ Rail Seat Section Losses $\quad \longrightarrow$ Center Section Losses

Figure 52: Effective prestressing stress with respect to time for rail seat and center section of baseline tie 
Table 26: Calculated initial and effective prestressing stresses

\begin{tabular}{|c|c|c|c|c|}
\hline $\begin{array}{l}\text { Critical } \\
\text { Section }\end{array}$ & $\begin{array}{c}\text { Initial } \\
\text { Prestressing } \\
\text { Stress, } \mathbf{f}_{\mathrm{pi}} \\
\text { (ksi) }\end{array}$ & $\begin{array}{c}\text { Effective } \\
\text { Prestressing Stress } \\
\text { @ } \mathbf{4 0} \text { days, } \mathrm{f}_{\mathrm{pe}} \\
\text { (ksi) }\end{array}$ & $\begin{array}{c}\text { Effective } \\
\text { Prestressing Stress } \\
@ 50 \text { years , } f_{\text {pe }} \text { (ksi) }\end{array}$ & $\begin{array}{c}\text { Percent Difference } \\
100 \text { (40 days - } 50 \text { years) / } \\
40 \text { days }\end{array}$ \\
\hline Rail Seat & 188 & 173 & 154 & $11 \%$ \\
\hline Center & 183 & 164 & 140 & $14 \%$ \\
\hline
\end{tabular}

Table 27: Prestressing lump sum losses at $\mathbf{4 0}$ days and $\mathbf{5 0}$ years

\begin{tabular}{|c|c|c|c|c|}
\hline $\begin{array}{c}\text { Critical } \\
\text { Section }\end{array}$ & $\begin{array}{c}\text { Total Prestressing } \\
\text { Losses at } \mathbf{4 0} \text { days } \\
(\mathbf{k s i})\end{array}$ & $\begin{array}{c}\text { Lump Sum Losses } \\
\text { at } \mathbf{4 0} \text { days } \\
\mathbf{( \% )}\end{array}$ & $\begin{array}{c}\text { Total Prestressing } \\
\text { Losses at } \mathbf{5 0} \text { years } \\
\mathbf{( k s i )}\end{array}$ & $\begin{array}{c}\text { Lump Sum Losses } \\
\text { at } \mathbf{5 0} \text { years } \\
\text { (\%) }\end{array}$ \\
\hline Rail Seat & 30.13 & 14.83 & 49.68 & 24.45 \\
\hline Center & 39.48 & 19.43 & 63.05 & 31.03 \\
\hline
\end{tabular}

\subsubsection{Limit States}

Using the values for initial and effective prestressing in Table 26, the baseline tie was evaluated for the limit states of concrete stresses at transfer (Limit State I Section 3.1.5.1) and concrete stresses at service (Limit State II Section 3.1.5.2). ACl 318-08 allowable concrete stress limits served as the boundaries for these limit states (Section 3.1.3.1.3).

\subsubsection{Limit State I: Concrete Stress at Transfer}

For the concrete stress at transfer, two load configurations were evaluated which relate to the orientation of the tie during the fabrication process (Figure 53). In the first configuration the tie is upside down in the form at the instance of prestressing transfer. The second configuration takes place almost immediately after transfer when the tie is de-molded and rotated right side up. The reason for considering both loading configurations is the short time frame following transfer in which they both occur. Since prestressing transfer takes place between 12 and 24 hours after casting, the concrete has only had time to obtain a fraction of its design strength. In the case of the baseline tie design, 4,500 psi was considered to be the minimum allowable compressive concrete strength to permit prestressing transfer. Based on the concrete strength of 4,500 psi the allowable concrete stresses at transfer per ACl 318-08 were 201 psi in tension and 2,700 psi in compression. At transfer the only forces acting on the tie are the prestressing and self weight. The applied stresses from these forces for the two load configurations are summarized in Table 28. 

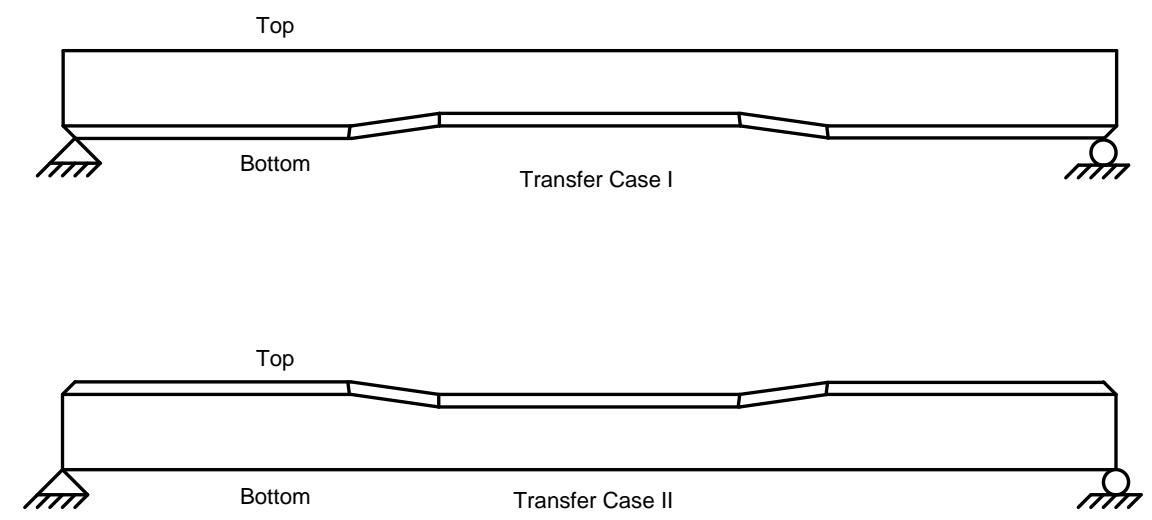

Figure 53: Loading configurations for stresses in concrete at transfer

Table 28: Stresses in concrete at transfer due to prestressing and self weight

\begin{tabular}{|c|c|c|c|}
\hline \multicolumn{4}{|c|}{ Rail Seat } \\
\hline Load Condition & Location & $\begin{array}{c}\text { Concrete Stress } \\
\text { (psi) }\end{array}$ & $\begin{array}{c}\text { Allowable } \\
\text { Check }\end{array}$ \\
\hline \multirow{2}{*}{ Transfer Case 1} & Top & 2165 & OK \\
\hline & Bottom & 834 & OK \\
\hline \multirow{2}{*}{ Transfer Case 2} & Top & 903 & OK \\
\hline & Bottom & 2046 & OK \\
\hline \multicolumn{4}{|c|}{ Center } \\
\hline Load Condition & Location & $\begin{array}{c}\text { Concrete Stress } \\
\text { (psi) }\end{array}$ & $\begin{array}{c}\text { Allowable } \\
\text { Check }\end{array}$ \\
\hline \multirow{2}{*}{ Transfer Case 1} & Top & 1970 & OK \\
\hline & Bottom & 2378 & OK \\
\hline \multirow{2}{*}{ Transfer Case 2} & Top & 2640 & OK \\
\hline & Bottom & 1718 & OK \\
\hline
\end{tabular}

Due to the relatively small eccentricities of the baseline design, the entire tie remains in compression at transfer with the largest stresses in the bottom of the tie at the rail seat section and in the top at the center section. The stresses in the concrete at transfer due to prestressing and self weight for both loading conditions were within allowable concrete stresses specified by $\mathrm{ACl} 318-08$ for a minimum concrete strength of 4,500 psi. While the applied stresses are within allowable limits, the stress in the top center of the tie does approach the compressive limit in loading configuration 2 (right side up), when the self weight and prestressing cause bending in the same direction. 


\subsubsection{Limit State II: Concrete Stress at Service}

For this project, Limit State II corresponds to the flexural capacity of the tie as specified by AREMA. The stresses in the concrete at service are a function of the prestressing, self weight and the live load applied by the train. In this case the known forces are the prestressing and the self weight. The live load caused by the train an unknown and was solved for by setting the applied stress equal to the allowable concrete stresses specified in $\mathrm{ACl}$ 318-08. Rearranging the equation for concrete stress at the extreme fibers, the maximum applied live load moment can be determined. The maximum moment corresponds to the flexural capacity. At service the allowable tensile and compressive stresses specified by $\mathrm{ACl} 318-08$ are 627 and 4,200 psi, respectively for the baseline tie with 28 -day strength of 7,000 psi.

The boundary conditions for the calculation of service stresses correspond to the flexural testing configurations from AREMA are presented in Figure 33 through Figure 36 . The self weight moments at the rail seat and center critical sections based on the boundary conditions of test configurations are given in Table 29. The representation of the self weight has been simplified as a uniformly distributed load (total weight divided by member length), neglecting the variable cross-section. Comparing the minimum calculated live load moments to the self weight moments it was determined that the moments due to self weight were negligible and were omitted from the flexural capacity calculation.

Table 29: Self weight moments at critical sections corresponding to AREMA flexural test configurations

\begin{tabular}{|l|c|}
\hline \multicolumn{1}{|c|}{$\begin{array}{c}\text { Critical } \\
\text { Section }\end{array}$} & $\begin{array}{c}\text { Self Weight Moment, } \mathbf{M}_{\mathbf{0}} \\
\text { (in-kip) }\end{array}$ \\
\hline Rail Seat & 0.33 \\
\hline Center & 1.65 \\
\hline
\end{tabular}

To determine the live load moment based on the $\mathrm{ACl} 318-08$ allowable stresses required consideration of both the compressive and tensile stresses. Even though the AREMA definition of tie failure focuses on the tension stress and the subsequent cracking, the compressive stress limit at service is considered as well in this project. Therefore, for each bending condition (i.e. positive and negative) at the rail seat and center critical sections, two live load moment capacities corresponding to the allowable tension and compression stresses were determined. The capacity of the tie for the specific bending condition will be the lower of the two calculated 
live load moments. For the baseline tie, Table 30 shows the live load moment capacities based on the allowable tension and compression stresses for positive and negative bending at the rail seat and center sections. The governing live load moment and the corresponding stress condition are given as well. The live load moment capacities in Table 30 are determined using the effective prestressing at 40 days and were used in the comparison between predicted and actual capacities.

Table 30: Predicted flexural capacity of baseline tie at $\mathbf{4 0}$ days, corresponding to Limit State II

\begin{tabular}{|c|c|c|c|c|}
\hline \multicolumn{5}{|c|}{ Rail Seat } \\
\hline Load Condition & Location & $\begin{array}{c}\text { Live Load } \\
\text { Moment } \\
\text { (kip-in) }\end{array}$ & $\begin{array}{c}\text { Governing } \\
\text { Moment } \\
\text { (in-kip) }\end{array}$ & $\begin{array}{l}\text { Governing } \\
\text { Stress } \\
\text { Condition }\end{array}$ \\
\hline \multirow{2}{*}{ (+) Bending } & Top & 448 & \multirow{2}{*}{348} & \multirow{2}{*}{ Tension } \\
\hline & Bottom & 348 & & \\
\hline \multirow{2}{*}{ (-) Bending } & Top & 186 & \multirow{2}{*}{186} & \multirow{2}{*}{ Tension } \\
\hline & Bottom & 311 & & \\
\hline \multicolumn{5}{|c|}{ Center } \\
\hline Load Condition & Location & $\begin{array}{c}\text { Live Load } \\
\text { Moment } \\
\text { (kip-in) }\end{array}$ & $\begin{array}{c}\text { Governing } \\
\text { Moment } \\
\text { (in-kip) }\end{array}$ & $\begin{array}{l}\text { Governing } \\
\text { Stress } \\
\text { Condition }\end{array}$ \\
\hline \multirow{2}{*}{ (+) Bending } & Top & 141 & \multirow{2}{*}{141} & \multirow{2}{*}{ Compression } \\
\hline & Bottom & 168 & & \\
\hline \multirow{2}{*}{ (-) Bending } & Top & 208 & \multirow{2}{*}{187} & \multirow{2}{*}{ Compression } \\
\hline & Bottom & 187 & & \\
\hline
\end{tabular}

The flexural capacity of the baseline tie with an effective prestress at 40 days was limited by allowable concrete tension stress at the rail seat for both positive and negative bending. Conversely, the allowable concrete compressive stress governs for both positive and negative bending in the center section. The reason for the tension governance in the rail seat section and compression in the center is the eccentricity of the prestressing in the respective sections. In the rail seat section there is a larger eccentricity than the center, which in the case of positive bending (top of tie in compression and bottom in tension), produces a larger pre-compression stress in the tension zone of the tie. As live load from the train is applied, the tension zone previously in compression due to the prestressing, transitions to tension. Due to the large precompression stress, a larger force is required to reach the allowable tension stress limit. 
Inversely, the compression zone experiences a smaller pre-compression stress due to the eccentricity and requires a larger force to reach the allowable compression stress (Figure 54).

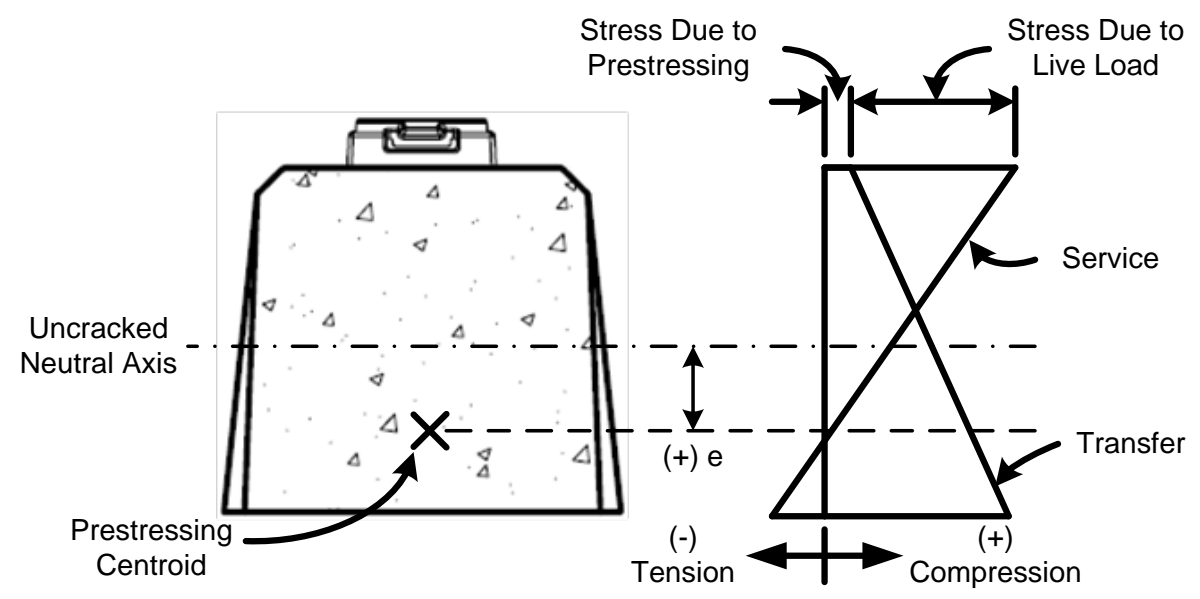

Figure 54: Concrete stress distributions at transfer and service for rail seat section corresponding to large positive prestressing eccentricity

Unlike the rail seat section, the center section has very little prestressing eccentricity and therefore a more uniform pre-compression stress distribution across the concrete section. The effect of a uniform compression stress distribution is increased pre-compression stress in the compression region of the tie during loading, compared to a section with larger eccentricity. The increased compression stress prior to applying live load decreases the amount of live load required to cause the compression zone to reach the stress limit and in turn decreases the capacity of the section (Figure 55).

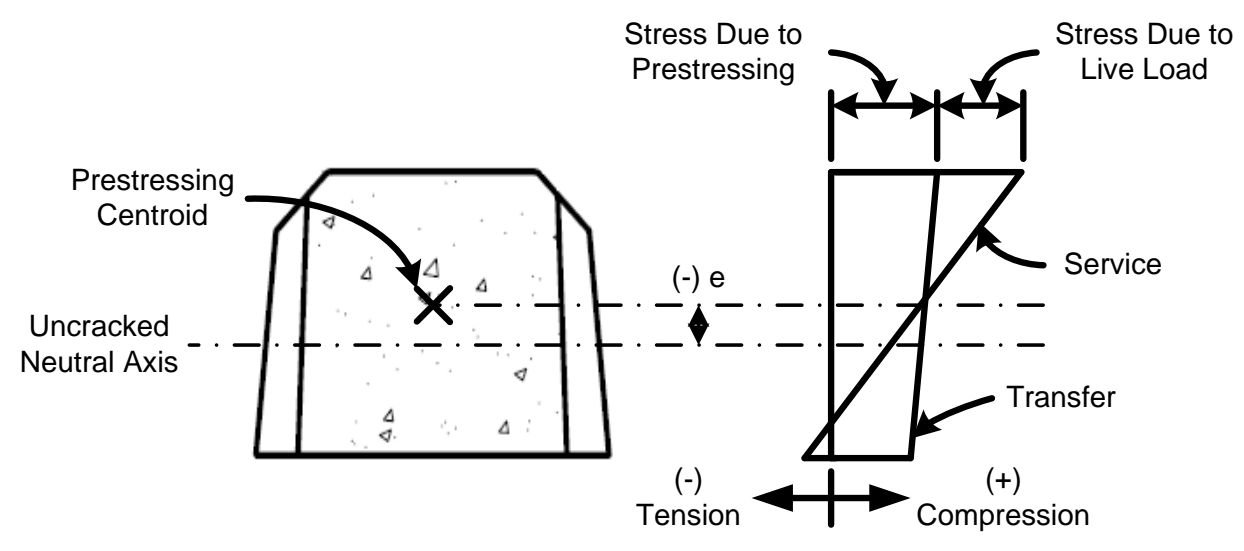

Figure 55: Concrete stress distributions at transfer and service for center section corresponding to small negative prestressing eccentricity 
For the baseline tie live load moment capacity, the same process of solving for moments based on allowable concrete stresses was repeated, but with the effective prestress at 50 years, to include total prestressing losses and determine the long term capacity of the tie (Table 31). Comparing the flexural capacities at 40 days and 50 years, several notable changes were observed. Due to the decreased pre-compression stress, both positive and negative bending for the rail seat and center sections are governed by the allowable tension stress of the concrete, where as the shorter duration was controlled by compression at the center section.

The change from compression to tension control as the age of the tie increases is associated with the decreasing pre-compression stress as a result of the increasing prestressing losses. The decrease in pre-compression stress allows for a larger live load stresses to be applied and the allowable tension stress to be reached before the allowable compressive stress. In addition to the change in the governing stress condition in the center section, the transition from compression control to tension control actually increases the baseline flexural capacity in the positive bending direction of the center section, even though the pre-compression stress has decreased. While the concept of increasing the flexural capacity while decreasing the prestressing force appears to be a paradox; for the positive bending center section condition, the eccentricity of the prestressing works additively with the live load moment to reach the allowable compression limit. Therefore, by decreasing the pre-compressive force a larger quantity of stress may be applied by the live load prior to reaching the allowable compressive stress limit of the concrete. 
Table 31: Flexural capacity of baseline tie at 50 years, corresponding to Limit State II

\begin{tabular}{|c|c|c|c|c|}
\hline \multicolumn{5}{|c|}{ Rail Seat } \\
\hline Load Condition & Location & $\begin{array}{c}\text { Live Load } \\
\text { Moment } \\
\text { (kip-in) }\end{array}$ & $\begin{array}{c}\text { Governing } \\
\text { Moment } \\
\text { (in-kip) }\end{array}$ & $\begin{array}{c}\text { Governing } \\
\text { Stress } \\
\text { Condition }\end{array}$ \\
\hline \multirow{2}{*}{ (+) Bending } & Top & 460 & \multirow{2}{*}{318} & \multirow{2}{*}{$\begin{array}{c}\text { Tension @ } \\
\text { Bottom }\end{array}$} \\
\hline & Bottom & 318 & & \\
\hline \multirow{2}{*}{ (-) Bending } & Top & 174 & \multirow{2}{*}{174} & \multirow{2}{*}{$\begin{array}{c}\text { Tension @ } \\
\text { Top }\end{array}$} \\
\hline & Bottom & 341 & & \\
\hline \multicolumn{5}{|c|}{ Center } \\
\hline Load Condition & Location & $\begin{array}{c}\text { Live Load } \\
\text { Moment } \\
\text { (kip-in) }\end{array}$ & $\begin{array}{l}\text { Governing } \\
\text { Moment } \\
\text { (in-kip) }\end{array}$ & $\begin{array}{c}\text { Governing } \\
\text { Stress } \\
\text { Condition }\end{array}$ \\
\hline \multirow{2}{*}{ (+) Bending } & Top & 165 & \multirow{2}{*}{150} & \multirow{2}{*}{$\begin{array}{c}\text { Tension @ } \\
\text { Bottom }\end{array}$} \\
\hline & Bottom & 150 & & \\
\hline \multirow{2}{*}{ (-) Bending } & Top & 185 & \multirow{2}{*}{185} & \multirow{2}{*}{$\begin{array}{c}\text { Tension @ } \\
\text { Top }\end{array}$} \\
\hline & Bottom & 205 & & \\
\hline
\end{tabular}

\subsubsection{Nominal Moment Capacity}

The nominal moment capacity of a prestressed member is defined as the maximum load which a member can support. This is typically controlled by either crushing of the extreme compression fiber or rupture of the prestressing. While these types of failure do not define prestressed concrete tie failure, the nominal moment capacity was determined in this project for several reasons including the following:

- Allows for the determination of development length, which is based on the stress in the prestressing at ultimate capacity,

- Provides capacity data for prestressed concrete ties should their failure limits ever be extended past cracking.

To calculate the nominal moment capacity of the baseline tie and all other optimization iterations, strain compatibility was used. Compared to other methods for calculating the nominal moment capacity of prestressed members such as the $\mathrm{ACl}$ approximation method $(\mathrm{ACl}$ 2008), strain compatibility provides increased accuracy and the ability to evaluate the nominal moment capacity of prestressed members with prestressing located in the compression zone of the section. However, this procedure is not applicable for sections that behave as deep beams. 


\subsubsection{Deep Beam Effect}

A unique situation which exists for flexural members with short spans and comparatively large beam depths is the condition known as deep beams. Due to short spans and the height of the member, deep beams are capable of producing compression struts between the point of loading and the support (Figure 56). The effect of the compression strut is a decrease in stress due to bending as the differential stress is transferred to the support through compression in the strut, similar to a column. The decrease in bending stress corresponds to a decrease in stress of the prestressing, and the delay of flexural cracking and crushing of the extreme compression fiber. The end result of the deep beam condition is an increase in capacity over the calculated nominal moment capacity based on the properties of the beam section for pure flexure ( $\mathrm{ACl} 2008)$.

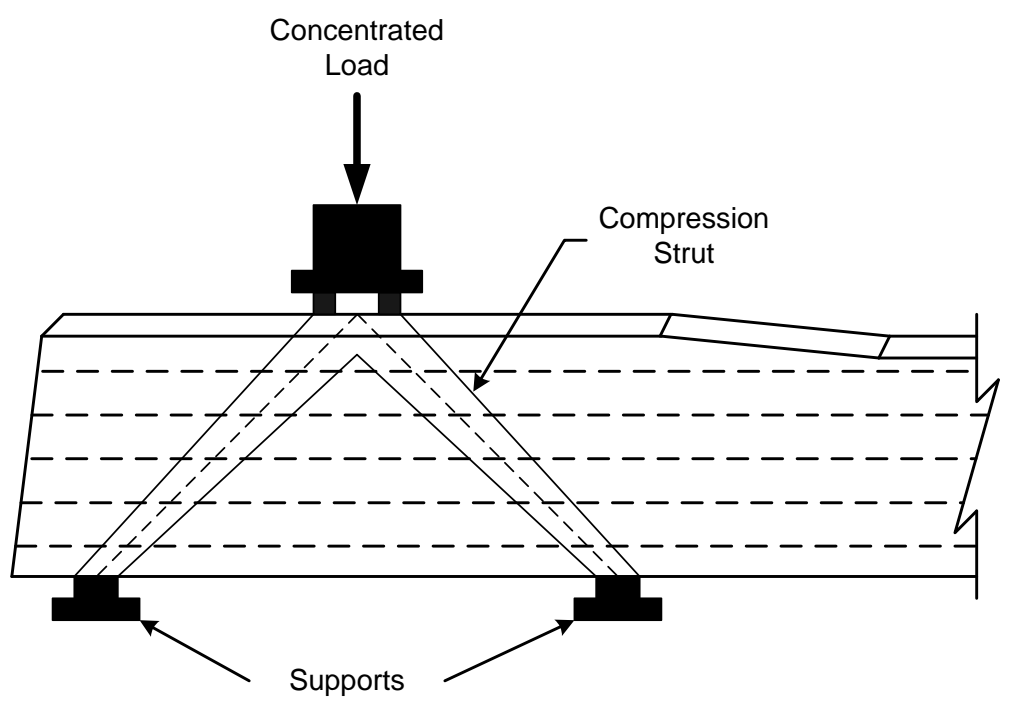

Figure 56: Deep beam effect at rail seat region in AREMA test configuration

The importance of assessing the baseline tie for the deep beam conditions relates to the accuracy of nominal moment capacity predictions. If the concrete tie is categorized as a deep beam, it is expected that the actual capacity of the tie would be larger than the predicted value assuming pure flexure. To calculate the capacity of a deep beam, $\mathrm{ACl}$ 318-08 suggests either using the strut-and-tie model approach presented in Appendix A of $\mathrm{ACl} 318-08$ or a nonlinear distribution of strain. While either of these methods could be used to calculate the nominal capacity of the baseline tie if the deep beam condition applies, they will not be considered in 
this project. However, the nominal moment capacity will be determined assuming pure flexure for all critical sections regardless of the deep beam criteria.

It is also important to note that the deep beam condition does not only affect the nominal moment capacity of the tie. The deep beam condition may also explain a portion of the underestimation of the capacity of the tie under AREMA defined failure based on allowable concrete stresses at service calculated in Section 4.2.6. Again however, the application of the deep beam condition to the determination of the tie capacity is outside the scope of this project and will be discussed during the future work section of this paper should the tie design meet the criteria of a deep beam. To determine whether or not the baseline tie is considered a deep beam, the span-to-depth ratio is used. Criteria for the deep beam condition are defined in Section 10.7 of $\mathrm{ACl}$ 318-08. To be considered a deep beam a flexural member must meet either of the two following conditions:

(a) The clear span $\left(I_{n}\right)$, of the member must be equal to or less than four times the overall depth of the member (Table 32),

(b) The member must support regions of concentrated load within twice the member depth from the face of the nearest support (Table 32).

Table 32: Deep beam criteria variables and definitions

\begin{tabular}{|c|c|}
\hline $\begin{array}{c}\text { Deep Beam } \\
\text { Parameter }\end{array}$ & Parameter Discription \\
\hline$I_{n}$ & clear span distance (in.) \\
\hline$h$ & height of section in direction of bending (in.) \\
\hline $\mathrm{x}$ & distance between face of support and concentrated \\
\hline
\end{tabular}

For this project the clear spans are from the AREMA flexural test configurations in Figure 33 through Figure 36. Since the cross-sectional geometry and support conditions for flexural testing of the baseline tie is not constant, the tie was compared against the deep beam criteria at both rail seat and center sections. The first section to be evaluated for the deep beam condition was the rail seat section. The height of the rail seat region is not constant therefore the height is taken at the centerline of the rail seat which corresponds to the center of the clear span 
according to the testing configuration. The clear span of the testing configuration is a function of the shoulder length of the baseline tie (shoulder length is the distance from the centerline of the rail seat to the end of the tie). Below, the rail seat section height and span parameters have been compared against the deep beam criteria.

$$
\begin{aligned}
& \text { Shoulder Length }=21.17 \text { in } \\
& I_{n}=2\left(\frac{2}{3}\right) 21.17=28.23 \text { in } \\
& h=9.5 \text { in } \\
& x=\left(\frac{2}{3}\right) 21.17=14.11 \text { in }
\end{aligned}
$$

The rail seat section meets both provisions of a deep beam and therefore it was assumed that the calculated nominal moment capacity derived using strain compatibility will underestimate the actual capacity of the rail section for both positive and negative bending. The additional capacity related to the deep beam condition will be achieved due to the development of compression struts between the concentrated load at the rail seat load and the supports. Even though it has been shown that the rail seat section and the corresponding bending conditions are a deep beam, the nominal moment capacity were still be calculated using strain compatibility to provide a gauge on the nominal capacity. For further discussion of the implications of the deep beam condition on the capacity of the rail seat section see Section 5.3.

The parameters of the center section are different than the railseat due to the changes in geometry and testing configuration. The height of the center section is smaller than the railseat, which reduces the chances for a compression strut to form. The clear span of the testing configuration is not dependent on tie geometry like the rail seat, but the geometry of the track, specifically the distance between load application points of the rail seats (distance between rail 
seat centerlines). Below the center section height and span parameters have been compared against the deep beam criteria.

$$
\begin{aligned}
& \text { Clear Span }=60 \text { in } \\
& \mathrm{I}_{\mathrm{n}}=\text { Clear Span }=60 \mathrm{in} \\
& \mathrm{h}=7.5 \mathrm{in} \\
& \mathrm{x}=\left(\frac{\text { Clear Span }}{2}\right)=30 \mathrm{in}
\end{aligned}
$$

Deep Beam Criteria Check:

$\mathrm{I}_{\mathrm{n}}<4 \mathrm{~h} \rightarrow 60$ in $<4(7.5 \mathrm{in})=30$ in ( Not Deep Beam)

$\mathrm{x}<2 \mathrm{~h} \rightarrow 30 \mathrm{in}<2(7.5 \mathrm{in})=15$ in (Not Deep Beam)

The center section does not meet either of the deep beam provisions and therefore pure flexure applies. The nominal moment capacity calculated using strain compatibility should offer adequate predictions of capacity.

\subsubsection{Strain Compatibility Results}

In the previous section the rail seat and center sections were evaluated for the flexural member categorization of deep beam. The results of the evaluation revealed that the rail section demonstrates the behavior of a deep beam while the center section exhibits pure flexure behavior. Considering these categorizations it was decided to continue with evaluating both sections under pure flexure conditions, using strain compatibility to determine the nominal moment capacities. Consideration was given to the assumption of pure flexure for the rail seat section when comparing the predicted nominal moment capacity against the actual value from experimental results. Using the strain compatibility method of nominal moment capacity analysis presented in Section 3.1.6, the predictions of nominal moment capacity with the assumption of pure bending behavior were determined for the baseline tie with effective prestress at 40 days and 50 years (Table 33 ). 
Table 33: Nominal moment capacities of baseline tie with effective prestressing at $\mathbf{4 0}$ days and $\mathbf{5 0}$ years

\begin{tabular}{|c|c|c|}
\hline Load Case/Critical Section & $\begin{array}{c}\text { Nominal Moment Capacity w/ } \\
\text { Effective Prestressing @ 40 Days } \\
\mathbf{M}_{\mathbf{n}} \text { (kip-in) }\end{array}$ & $\begin{array}{c}\text { Nominal Moment Capacity w/ } \\
\text { Effective Prestressing @ 50 Years } \\
\mathbf{M}_{\mathbf{n}} \text { (kip-in) }\end{array}$ \\
\hline Positive Bending/Rail Seat & 610 & 598 \\
\hline Negaitive Bending/Rail Seat & 412 & 405 \\
\hline Positive Bending/Center & 334 & 327 \\
\hline Negaitive Bending/Center & 385 & 376 \\
\hline
\end{tabular}

Comparing the nominal moment capacities corresponding to effective prestressing at 40 days and 50 years, the nominal moment capacity at 50 years decreases slightly. The source of the decrease in capacity between 40 days and 50 years is the additional prestressing losses which occur over the time period. The decreased effective prestressing causes a lower initial strain in the concrete and steel due to effective prestress $\left(\varepsilon_{1}\right)$. However, the remaining strain components associated to the conditions of decompression $\left(\varepsilon_{2}\right)$ and failure $\left(\varepsilon_{3}\right)$, experience a change in value, but the summations of all three strain components are fairly similar over time, since the same limit of ultimate concrete strain, $\left(\varepsilon_{c}\right)$ governs the capacity. Summarizing the relationship between nominal moment capacity and effective prestressing, the capacity will decrease over time as the total prestressing loss increases.

\subsubsection{Transfer and Development Lengths}

To achieve the nominal moment capacities presented in the previous section, the prestressing tendons must maintain the bond between the concrete prestressing tendons up to the stress level associated with ultimate capacity. If the tendons are unable to attain the necessary level of stress with the provided anchorage, the tendon will slip or pull out of the concrete before reaching the ultimate capacity. The distance required to obtain the necessary bond or anchorage between the concrete and the prestressing tendons is called the development length and is a function of the maximum applied stress in the tendon and the diameter of the tendon.

In addition to the development length, prestressing requires a length of bond to transfer the prestressing force into the concrete referred to as the transfer length. The transfer length is the length of bond required to transfer the full effective prestressing force from the tendon to the surrounding concrete. At the free end of the tie the stress in the concrete due to the prestressing is zero and increases linearly along the length of the tendon up to the effective 
prestress. To have full efficiency of the prestressing, the transfer length must be met before the critical section. In the case of prestressed concrete railroad ties, the transfer length must be met in the shoulder length to have the full capacity at the rail seat section. Similar to development length, the transfer length is a function of the effective prestressing force and the diameter of the tendon.

Once the nominal moment capacity has been calculated the development and transfer lengths can be checked based on the prestress found using strain compatibility. The required development and transfer lengths for the baseline tie were calculated for effective prestressing at 40 days and 50 years (Table 34 ).

Table 34: The transfer and development lengths for effective prestressing at $\mathbf{4 0}$ days and $\mathbf{5 0}$ years

\begin{tabular}{|c|c|c|c|c|c|}
\hline $\begin{array}{c}\text { Time } \\
\text { Interval }\end{array}$ & $\begin{array}{l}\text { Tendon } \\
\text { Diameter } \\
\text { (in) }\end{array}$ & $\begin{array}{l}\text { Maximum } \\
\text { Effective } \\
\text { Prestress } \\
\text { (ksi) }\end{array}$ & $\begin{array}{c}\text { Stress in Prestressing } \\
@ \text { Nominal Strength } \\
\text { (1) } \\
\text { (ksi) }\end{array}$ & $\begin{array}{l}\text { Required } \\
\text { Transfer } \\
\text { Length }^{(2)} \\
\text { (in) }\end{array}$ & $\begin{array}{l}\text { Required } \\
\text { Development } \\
\text { Length }^{(3)} \\
\text { (in) }\end{array}$ \\
\hline 40 Days & 0.21 & 173.07 & 244.2 & 12.11 & 27.05 \\
\hline 50 Years & 0.21 & 153.51 & 238.1 & 10.75 & 28.51 \\
\hline
\end{tabular}

\footnotetext{
(1) The stress in the prestressing at nominal moment is the maximum stress computed of all the layers in a cross-section determined using strain compatibility.

(2) The transfer length of the prestressing is determined using the first component of the method described in $\mathrm{ACl}$ 318-08 Section 12.9 Development of prestressing strand Equation (12-4).

(3) The development length of the prestressing is determined using the method described in $\mathrm{ACl}$ 318-08 Section 12.9 Development of prestressing strand Equation (12-4).
}

The maximum transfer length for the baseline tie is $12.11 \mathrm{in.}$ and corresponds to the effective prestressing at 40 days. Since transfer length is a function of effective prestressing, theoretically, the transfer length will be the largest after casting and decrease as the effective prestressing decreases due to prestressing losses. The computed maximum transfer length in Table 34 is less than the shoulder length; therefore full transfer of prestressing force can be achieved by the rail seat section and subsequently the center. The maximum development length is 28.51 inches and corresponds to the effective prestressing at 50 years. Since development length is a function of the difference between the effective prestressing and the maximum stress in the prestressing at failure, the maximum development length will occur at the lowest value effective 
prestress. Comparing the maximum development length computed in Table 34 to the available distance to the first critical section (i.e. shoulder length) the development length exceeds the distance provided to the rail seat section, while full development is achieved at the center section. Since the prestressing does not achieve development by the rail seat section, the actual nominal moment capacity will be lower than the capacity presented in Table 33 . However, in Section 4.2.7.1 it was determined that the rail seat section is considered to be a deep beam and nominal moment capacity calculated using strain compatibility will not predict flexural capacity, but rather provide a lower bound estimate of the ultimate capacity.

\subsubsection{Comparison of Calculated to Manufacturer Results}

One advantage to working with an existing tie design is the availability of experimental results and other design data. The experimental results include flexural capacities as defined by AREMA and nominal moment capacities. The comparison of theoretical and experimental values is presented in the following sections.

\subsubsection{Prestressing Losses}

To determine whether the assumptions used during the process of calculating the theoretical losses were accurate, the predicted effective prestressing at $1000 \mathrm{hrs}$ (40 days) for the rail seat and center sections were compared to those provided by the tie manufacturer (Table 35). The percent difference between the two loss estimations was used an indicator of the correlation of the two values.

Table 35: Comparison of time-step and lump sum effective prestressing losses at $\mathbf{1 0 0 0} \mathrm{hrs}$

\begin{tabular}{|c|c|c|c|}
\hline \multirow{2}{*}{$\begin{array}{c}\text { Critical } \\
\text { Section }\end{array}$} & \multicolumn{2}{|c|}{$\begin{array}{c}\text { Effective Prestressing Losses at 1000 } \\
\text { hrs }\end{array}$} & $\begin{array}{c}\text { Percent Difference } \\
100 \text { (Lump Sum - Time-Step) } \\
\text { / Lump Sum }\end{array}$ \\
\hline Rail Seat & $14.8 \%$ & Lump Sum & $2.4 \%$ \\
\hline Center & $19.4 \%$ & $15.2 \%$ & $-5.0 \%$ \\
\hline
\end{tabular}

The prestressing loss estimate completed in this study for the rail seat and center sections were within 5 percent of the values provided by the tie manufacturer and therefore show adequate similarity to demonstrate the accuracy of the theoretical prestressing loss computation procedure. However, the rail seat estimation from this study is less than the value provided by the manufacturer which could lead to an overestimation of the effective prestressing stress. It should be noted that neither estimation method has been validated with experimental results. 


\subsubsection{AREMA Defined Flexural Capacity}

Similar to the process described above for the comparison of prestressing losses, the predicted flexural capacities corresponding to the second limit state of concrete stresses at service were compared to actual values provided by the baseline tie manufacturer. Percent difference was again used as the method of comparison. Table 36 presents a comparison between predicted values of flexural capacity and the experimental results provided by the tie manufacturer. The experimental results provided by the manufacturer only include load capacities for the governing bending conditions (positive bending at rail seat and negative bending at center). For the remaining bending conditions (negative bending at rail seat and positive bending at center) flexural testing is completed on purely a pass/fail basis with no values recorded. For a tie to pass, it must withstand the minimum moment provided by the AREMA performance specification (Section 2.2.8). For the experimental capacities provided, the values presented corresponds to the minimum values recorded for the flexure testing of the baseline tie completed in June 2009.

Table 36: Theoretical capacities vs. experimental test results for baseline ( $f_{c}^{\prime}=7,000$ psi at 40 days)

\begin{tabular}{|c|c|c|c|}
\hline $\begin{array}{c}\text { Moment } \\
\text { Direction/Location }\end{array}$ & $\begin{array}{c}\text { Theoretical } \\
\text { Moment Capacity } \\
\text { (kip-in) }\end{array}$ & $\begin{array}{c}\text { Experimental } \\
\text { Moment Capacity } \\
\text { (kip-in) }\end{array}$ & $\begin{array}{c}\text { Percent Difference } \\
\mathbf{1 0 0} \text { (Exp. - Theo.) } \\
\text { / Exp. }\end{array}$ \\
\hline Positive/Rail Seat & 348 & 397 & $12.44 \%$ \\
\hline Negative/Rail Seat & 186 & NA & NA \\
\hline Positive/Center & 141 & NA & NA \\
\hline Negative/Center & 187 & 230 & $18.52 \%$ \\
\hline
\end{tabular}

Comparing the predicted flexural capacity values to the actual in Table 36, it appears there was considerable underestimation of the flexural capacity. The percent difference for the two critical sections and their bending cases varies from approximately 12-19 percent. The source of this difference can likely be attributed to the following:

- The design compressive strength of 7,000 psi for the baseline tie numerical analysis is lower than the actual concrete compressive strength during service and at the time of the experimental testing (more likely between 9,500 and 12,000 psi) (Figure 57), 
- The theoretical prestressing loss for the center section was calculated to be larger than the estimate of the manufacturer, therefore the effective prestressing stress used in analysis may be smaller than the actual value, decreasing the predicted capacity,

- The rail seat section was classified as a deep beam and therefore theoretical predictions based on pure flexure are no longer applicable and likely underestimate the capacity of the section,

- The theoretical procedure limits the capacity of the tie to the moment which causes the stress in the extreme tension fiber of the section to reach the allowable value based on $\mathrm{ACl}$ 318-08; therefore no cracking is accounted for in the tension stress condition unlike the AREMA definition of failure which allows cracking to the outermost layer of prestressing,

- AREMA test procedures do not consider an allowable concrete compressive stress limit in the failure definition, only cracking the limit corresponding to tension stress is defined. The $\mathrm{ACl}$ 318-08 allowable concrete compressive limit, which was considered in the theoretical capacity prediction, may be exceeded and the test continued until cracking failure is achieved, causing an increase in the experimental capacity result compared to the theoretical capacity. This would affect the center section theoretical capacity comparison since it was predicted that compressive stress would govern.

While a majority of the suspected causes of the difference between the predicted and actual moment capacities discussed above would require changes to the numerical procedure, the effects of the design compressive strength would not and the impact was evaluated by repeating the analysis procedure at various compressive strengths while maintaining all other variables. Completing this process for same concrete strengths which were used in the optimization study of 9,500, 12,000 and 15,000 psi, the flexural capacities of the baseline tie was determined. Figure 58 through Figure 61 compare the actual flexural capacities of the baseline design versus the predicted capacities at concrete strengths of 7,000 (baseline case), 9,500, 12,000 , and 15,000 psi for the bending conditions of the critical sections. The percent difference between the actual capacity and the predicted for the various concrete strengths is provided in Table 37 through Table 38. 


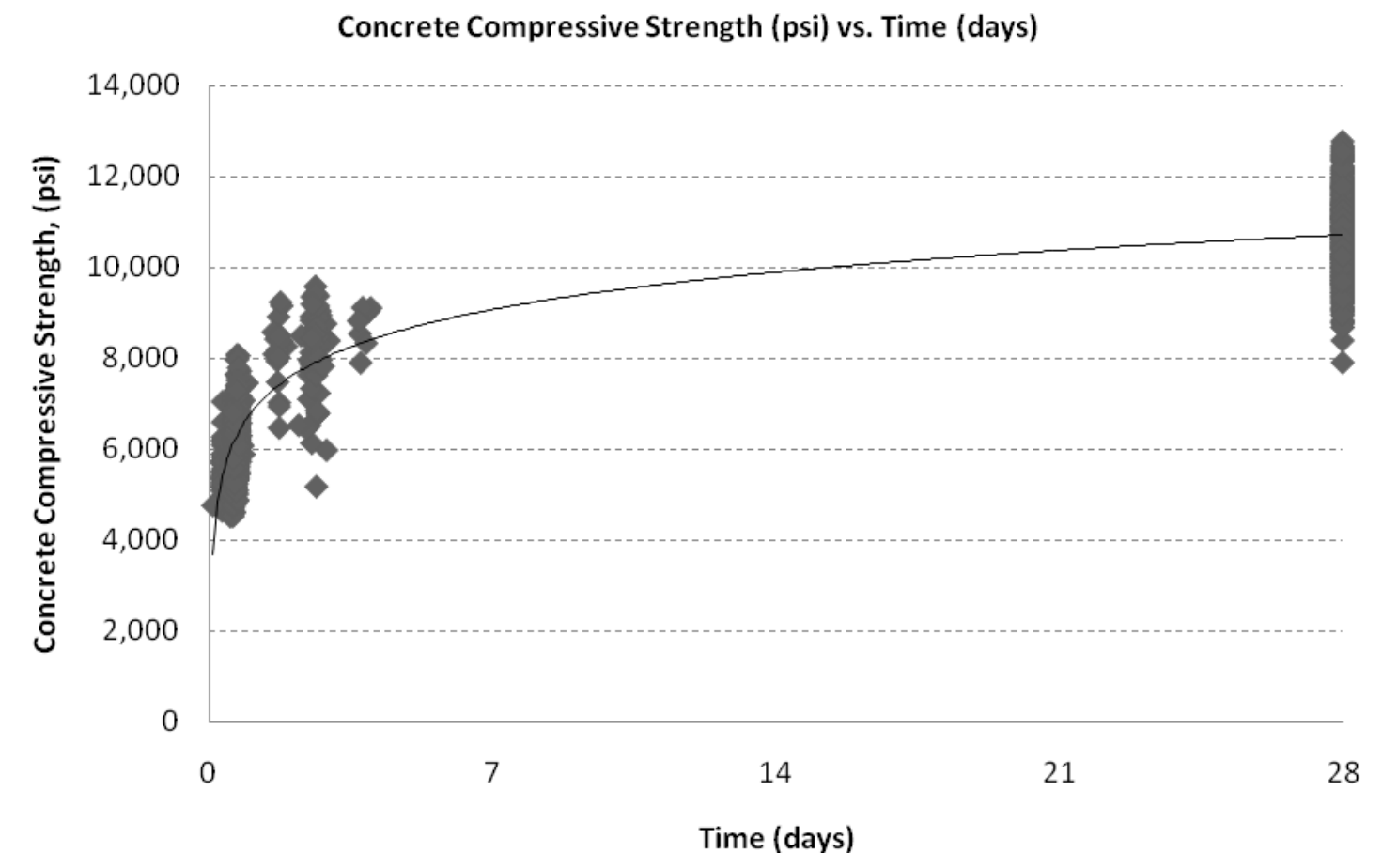

Figure 57: Concrete maturity chart for baseline tie (provided by baseline tie manufacturer)

Predicted Positive Rail Seat Live Load Moment Capacity at Various Concrete Strengths Compared to Actual Capacity

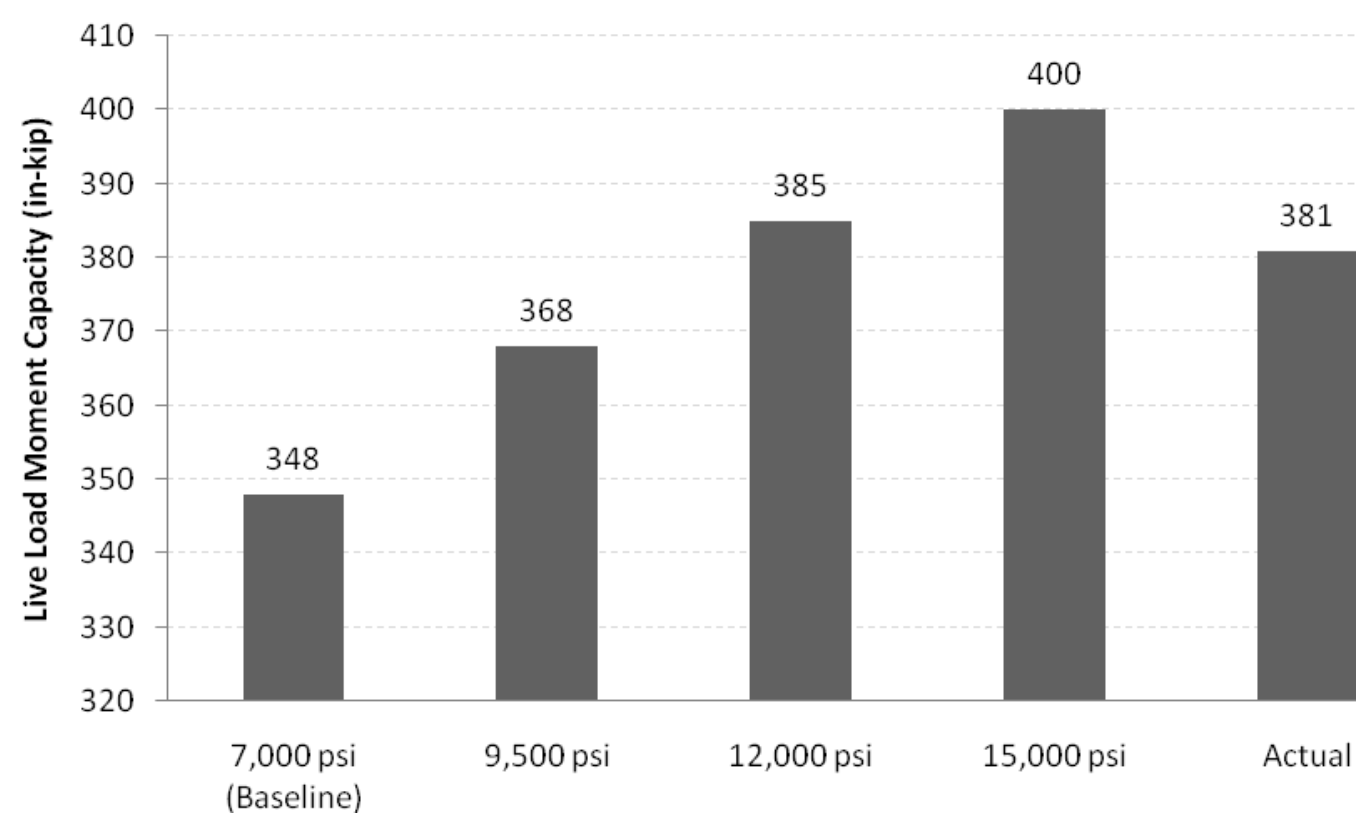

Figure 58: Predicted positive rail seat capacities at various concrete strengths compared to actual 
Predicted Naegative Rail Seat Live Load Moment Capacity at Various Concrete Strengths Compared to Actual Capacity

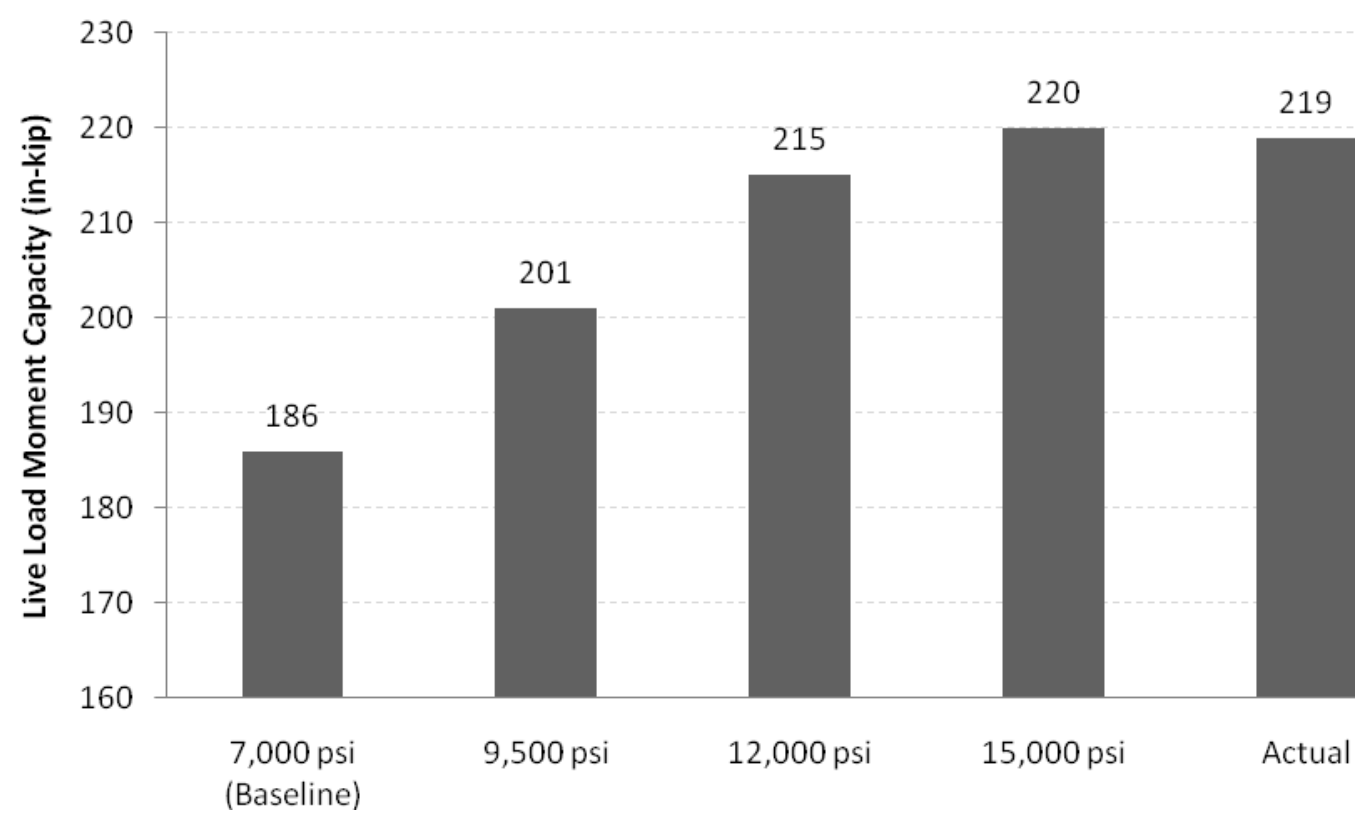

Figure 59: Predicted negative rail seat capacities at various concrete strengths compared to actual

Predicted Positive Center Live Load Moment Capacity at Various Concrete Strengths Compared to Actual Capacity

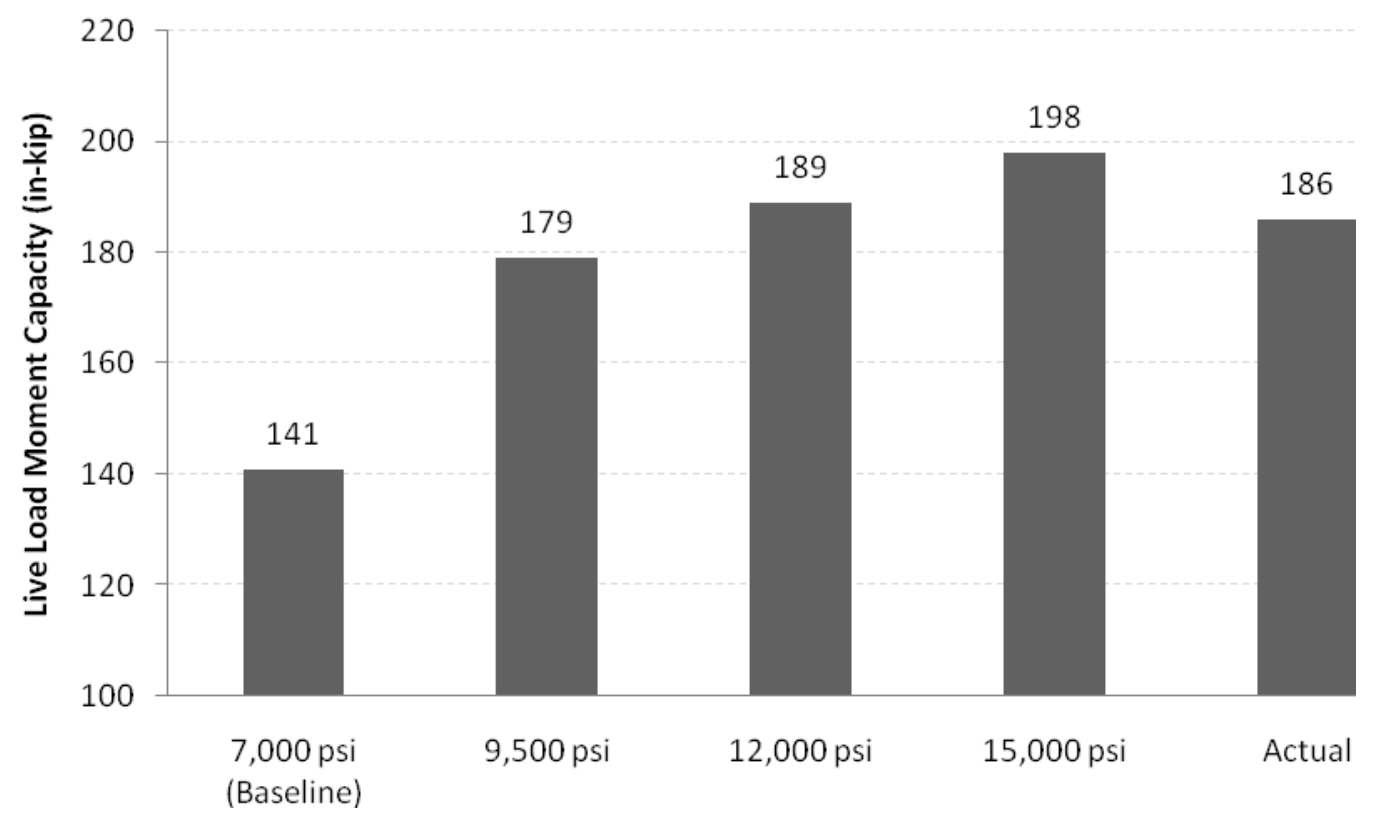

Figure 60: Predicted positive center capacities at various concrete strengths compared to actual 
Predicted Negative Center Live Load Moment Capacity at Various Concrete Strengths Compared to Actual Capacity

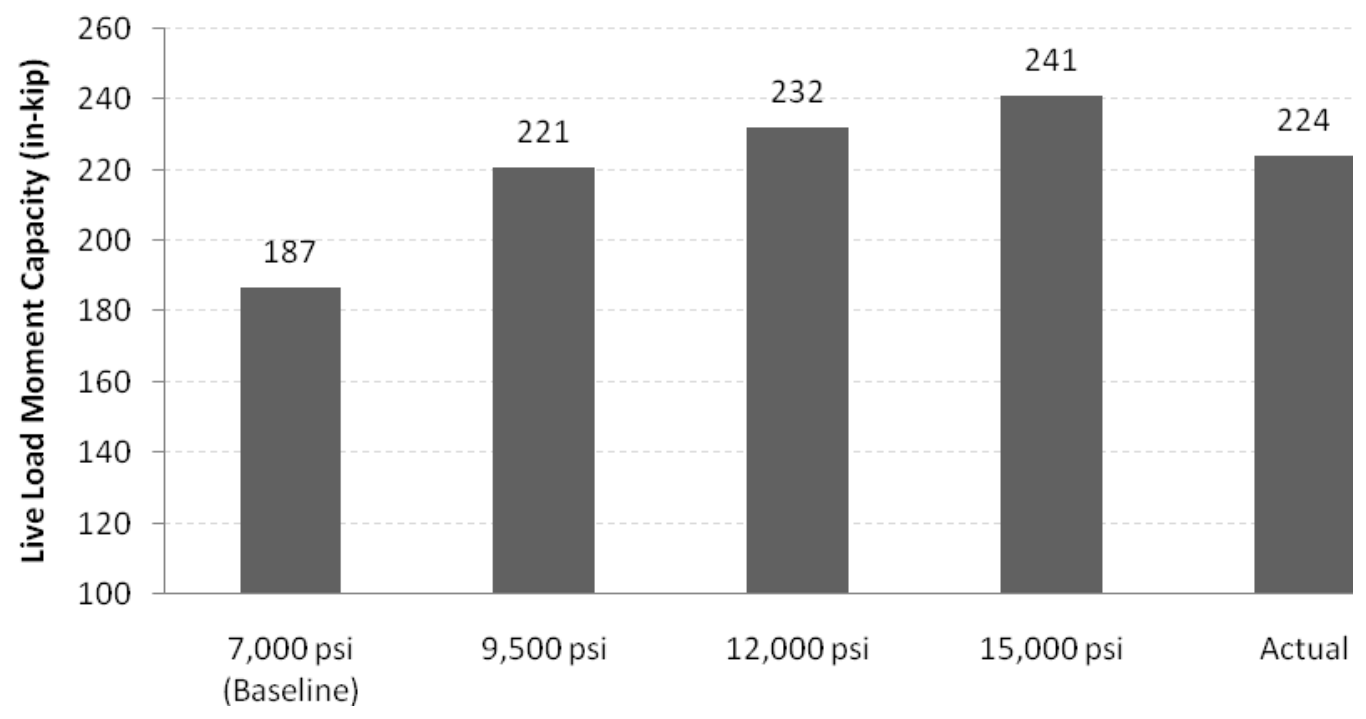

Figure 61: Predicted negative center capacities at various concrete strengths compared to actual

Table 37: Predicted vs. actual capacities for positive bending rail seat condition $\left(f_{c}{ }_{c}=7,000\right.$ psi at 40 days)

\begin{tabular}{|c|c|c|}
\hline \multicolumn{3}{|c|}{ Positive Bending Rail Seat Condition } \\
\hline Moment Case & $\begin{array}{c}\text { Live Load Moment } \\
\text { (in-kip) }\end{array}$ & Percent Difference $^{\text {(1) }}$ \\
\hline Actual & 397 & - \\
\hline 7,000 psi (Baseline) & 348 & $12.34 \%$ \\
\hline 9,500 psi & 368 & $7.30 \%$ \\
\hline 12,000 psi & 385 & $3.02 \%$ \\
\hline 15,000 psi & 400 & $-0.76 \%$ \\
\hline
\end{tabular}

(1) The percent diffence is: 100 (compared value - Actual) / Actual

Table 38: Predicted vs. actual capacities for negative bending center condition $\left(f^{\prime}{ }_{c}=7,000\right.$ psi at 40 days)

\begin{tabular}{|c|c|c|}
\hline \multicolumn{3}{|c|}{ Negative Bending Center Condition } \\
\hline Moment Case & $\begin{array}{c}\text { Live Load Moment } \\
\text { (in-kip) }\end{array}$ & Percent Difference $^{(1)}$ \\
\hline Actual & 230 & - \\
\hline 7,000 psi (Baseline) & 187 & $18.70 \%$ \\
\hline 9,500 psi & 221 & $3.91 \%$ \\
\hline 12,000 psi & 232 & $-0.87 \%$ \\
\hline 15,000 psi & 241 & $-4.78 \%$ \\
\hline
\end{tabular}

(1) The percent diffence is: 100 (compared value - Actual) / Actual 
As expected, increasing the concrete strength $\left(f_{c}{ }_{c}\right)$ in the numerical analysis to values closer to the concrete strength at service and testing causes the predicted capacity values to increase. For both the controlling load cases, the predicted capacity matches the actual for a concrete strength between 9,500 and 12,000 psi. Therefore, it can be reasoned that a large portion of the error in the numerical analysis capacity predictions is due to the underestimation of the design concrete strength. It must be noted that the capacities presented in this section were all based on effective prestressing at 40 days. The capacities, both predicted and actual, would be lower than the values presented once all prestressing losses have been incorporated.

\subsubsection{Baseline Capacity}

Based on the comparison between the predicted and actual values of the baseline tie capacity, the numerical analysis procedure developed adequately predicts the capacity of the prestressed concrete tie. However, up to this point a majority of the analysis was performed at an effective prestress corresponding to the losses at 40 days after casting. If the baseline capacity of this study were calculated using an effective prestress at 40 days, the long term capacity of the baseline tie would be overestimated since only a fraction of the total prestressing losses would be incorporated. To avoid the overestimation of tie capacity, the baseline tie was evaluated at a time interval of 50 years to include all applicable prestressing losses which would occur over the service life of the tie. The baseline live load moment capacities for the four flexure cases of; positive bending rail seat section, negative bending rail seat section, positive bending center section and negative bending center section, at a time interval of 50 years to include all prestressing losses, are presented in Table 39.

Table 39: Live load moment capacity for baseline tie at 50 years (after all losses)

\begin{tabular}{|c|c|}
\hline \multicolumn{2}{|c|}{ Baseline Capacity } \\
\hline $\begin{array}{c}\text { Moment } \\
\text { Direction/Location }\end{array}$ & $\begin{array}{c}\text { Live Load Moment } \\
\text { (in-kip) }\end{array}$ \\
\hline Positive/Rail Seat & 318 \\
\hline Negative/Rail Seat & 174 \\
\hline Positive/Center & 150 \\
\hline Negative/Center & 185 \\
\hline
\end{tabular}




\subsection{Numerical Analysis: Parametric Optimization Results (Phase II)}

The purpose of the parametric optimization study was to determine which prestressed concrete design components such as concrete strength, prestressing type and configuration offer the most efficient use of materials and largest gains in flexural capacity while maintaining the current concrete geometry. The following sections summarize the outcome of the optimization study, while presenting the steps in the numerical analysis project and discussing the effect of changing various design parameters on the flexural capacity of the tie design.

\subsubsection{Analysis Procedure}

The numerical analysis procedure developed for the baseline tie was done so with the intent of transitioning the procedure over to the optimization study. Therefore, the material and crosssectional properties of the tie were organized as inputs independent from the rest of the analysis procedure. At the beginning of each design iteration the material properties of the prestressing and concrete were set while the remainder of the process remains the same for all iterations unless specific changes were required for a parameter such as prestressing losses dependent on material type (i.e. steel or fiber reinforced polymer). Besides changes related to the design parameters, the overall procedure developed during the numerical analysis of the baseline tie remained the same for the design iterations completed during optimization study.

Due to the large quantity of data collected during the study an iteration matrix was constructed to organize the input parameters for the design iterations and the corresponding results of each numerical analysis. The iteration matrix containing the results of the optimization study and the baseline tie design analysis is included in Appendix C.

\subsubsection{Analysis Organization}

The first step in organizing the optimization study was the development of a nomenclature system based on the design parameters which was used for both naming of the calculation files as well as presentation of the results for the remainder of this section. The system was based on abbreviations of the optimization parameters themselves. The three basic categories of abbreviations are prestressing type (PT), prestressing diameter (PD), and concrete strength (CS); contained within each abbreviation category are the individual component options. For example, the baseline tie contains the following parameter components; drawn wire (W), 0.21 
in. diameter (0.21), and 7,000 psi concrete (7). Assembling these components into the nomenclature system the base name for the baseline tie is $W(P T)-0.21(P D)-7(C S)$. The nomenclature for the remaining parameter options is presented in Table 40.

In addition to the design parameter components, additional detail could be added to identify a specific age of the tie. For instance if the capacity result under consideration occurred at $\mathbf{4 0}$ days after casting, the additional abbreviation of $(40)$ to the end of the base name would designate a time after casting in days. The two time designations which will be used in the following sections are $(40)$ and $(18,250)$ which correspond to 40 days (time at which manufacturer data is available for baseline tie) and 50 years (estimated service life of tie and time required to achieve to total prestressing losses).

Table 40: Optimization study iteration name nomenclature

\begin{tabular}{|c|c|c|}
\hline Optimization Parameter & $\begin{array}{c}\text { Optimization Parameter } \\
\text { Abbreviation }\end{array}$ & $\begin{array}{c}\text { Parameter Location in } \\
\text { Name System }\end{array}$ \\
\hline \multicolumn{3}{|c|}{ Prestressing Type (PT) } \\
\hline Drawn Wire (baseline) & W & $\mathbf{W}(\mathrm{PT})-\mathrm{XX}(\mathrm{PD})-\mathrm{XX}(\mathrm{CS})$ \\
\hline 7-Wire Strand & $S$ & $\mathbf{S}(\mathrm{PT})-\mathrm{XX}(\mathrm{PD})-\mathrm{XX}(\mathrm{CS})$ \\
\hline FRP & FRP & FRP(PT)-XX(PD)-XX(CS) \\
\hline \multicolumn{3}{|c|}{ Presstressing Diameter (PD) } \\
\hline 0.21 in. (baseline) & 0.21 & $\mathrm{XX}(\mathrm{PT})-0.21(\mathrm{PD})-\mathrm{XX}(\mathrm{CS})$ \\
\hline 0.25 in. & 0.25 & $\mathrm{XX}(\mathrm{PT})-0.25(\mathrm{PD})-\mathrm{XX}(\mathrm{CS})$ \\
\hline 0.3125 in. & 0.3125 & $\mathrm{XX}(\mathrm{PT})-\mathbf{0 . 3 1 2 5}(\mathrm{PD})-\mathrm{XX}(\mathrm{CS})$ \\
\hline $0.375 \mathrm{in}$. & 0.375 & $\mathrm{XX}(\mathrm{PT})-\mathbf{0 . 3 7 5}(\mathrm{PD})-\mathrm{XX}(\mathrm{CS})$ \\
\hline \multicolumn{3}{|c|}{ Concrete Strength (CS) } \\
\hline 7,000 psi (baseline) & 7 & $\mathrm{XX}(\mathrm{PT})-\mathrm{XX}(\mathrm{PD})-7(\mathrm{CS})$ \\
\hline 9,500 psi & 95 & XX(PT)-XX(PD)-95(CS) \\
\hline 12,000 psi & 12 & $X X(P T)-X X(P D)-12(C S)$ \\
\hline $15,000 \mathrm{psi}$ & 15 & $\mathrm{XX}(\mathrm{PT})-\mathrm{XX}(\mathrm{PD})-\mathbf{1 5}(\mathrm{CS})$ \\
\hline
\end{tabular}

As with the baseline tie, the numerical analysis for the optimization study was completed using the analysis procedure developed in a spreadsheet form. The spreadsheet was developed from the baseline tie analysis and augmented accordingly to accept the changes of various design parameters during the optimization study. 


\subsubsection{Tie Cross-Section Properties}

One aspect of this project that significantly simplified the optimization process was the concrete cross-sectional properties remaining constant for all design iterations. This provided the ability to single out one design parameter per iteration for manipulation. By only altering a single design parameter, comparisons of iterations became more manageable and made trends more apparent.

\subsubsection{Concrete Material Properties}

The first tie parameter under consideration was the 28-day concrete design strength. Currently, the baseline tie has specified concrete design strength of 7,000 psi. However, the manufacturer routinely achieves concrete compressive strengths between 9,000 and 11,000 psi within 28 days. This was cited as one of the reasons for error in the comparison between the predicted and actual moment capacities of the baseline tie in the previous section. Since the manufacturer is already capable of achieving concrete strengths in excess of the 7,000 psi design strength, it was of interest to see the effect of concrete strength on the capacity of the tie.

Increasing the compressive strength of the concrete affects two components of the design procedure in particular. First, increasing the compressive strength will cause an increase in the allowable concrete stresses as specified by $\mathrm{ACl}$ 318-08 (Figure 62 and Figure 63). Increased allowable stresses in the concrete directly affect both limit states at transfer and service. Increased allowable stresses at transfer, allows increases in both the applied prestressing force and eccentricity and therefore the flexural capacity. Similarly, increased allowable stresses at service, allows the application of larger live loads prior to meeting the compression and tension limits which define failure. The second effect of higher concrete strengths is decreased prestressing losses. The prestressing losses of creep shrinkage and elastic shortening all have components which are a function of the concrete design strength. Increasing the design strength has the inverse effect of decreasing the total prestressing losses over time. 


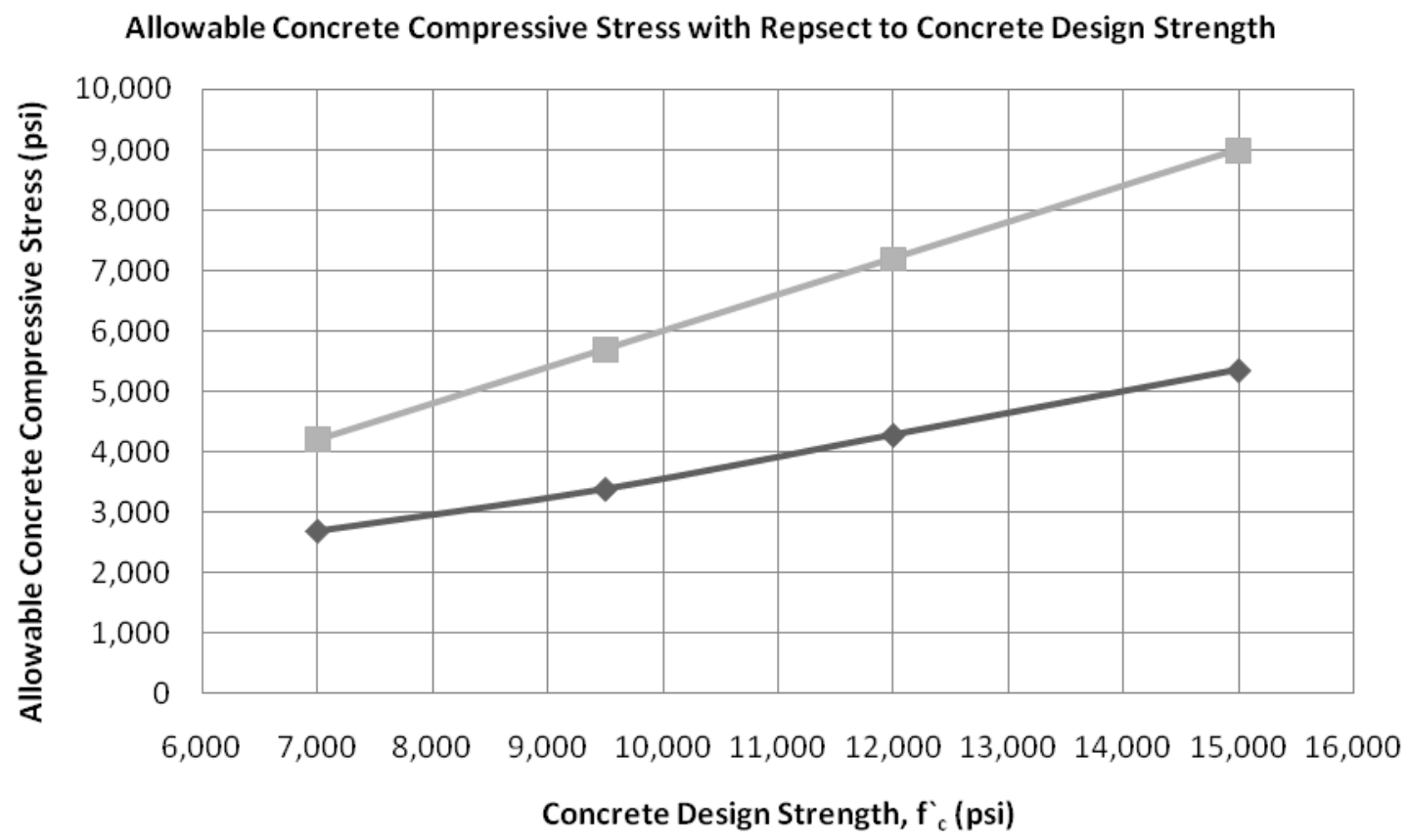

$\multimap$ Allowable Compressive Stress at Transfer $\_$-Allowable Compressive Stress at Service

Figure 62: Allowable concrete compressive stresses at transfer and service based on design concrete strengths

Allowable Concrete Tesnsile Stress with Repsect to Concrete Design Strength

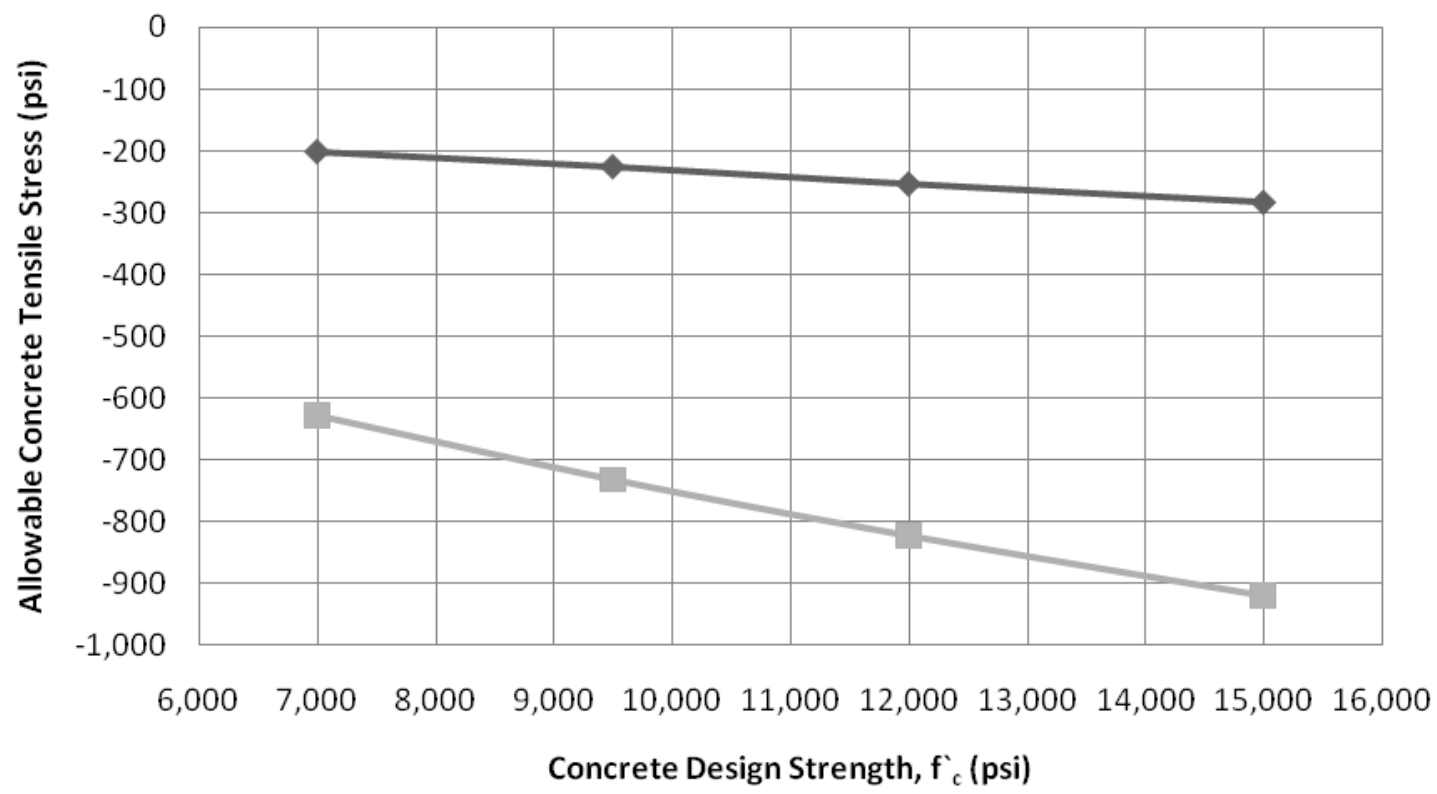

$\longrightarrow$ Allowable Tensile Stress at Transfer $\quad \longrightarrow$ Allowable Tensile Stress at Service

Figure 63: Allowable concrete tensile stresses at transfer and service based on design concrete strengths 
As a measure of the increase in concrete compressive strength and the associated allowable stresses, Table 41 and Table 42 present the percent increases in the related design parameters for the four concrete strength levels of 7,000 and $9,500,12,000$, and 15,000 psi used in the optimization study. A comparison between the flexural capacities related to the individual concrete strengths is presented in the limit states section of this chapter.

Table 41: Comparison of concrete optimization parameters to baseline

\begin{tabular}{|c|c|c|c|c|}
\hline $\begin{array}{c}\text { Concrete Design } \\
\text { Strength } \\
\text { (psi) }\end{array}$ & $\begin{array}{c}\text { 28-Day Concrete } \\
\text { Design Strength, } \\
f_{c}(p s i)\end{array}$ & $\begin{array}{c}\text { Percent } \\
\text { Difference } \\
\text { Design }^{(1)}\end{array}$ & $\begin{array}{c}\text { Concrete } \\
\text { Strength @ } \\
\text { Transfer, } \\
\mathbf{f}_{\text {ci }}(p s i)\end{array}$ & $\begin{array}{c}\text { Percent } \\
\text { Difference } \\
\text { Transfer }^{(1)}\end{array}$ \\
\hline 7,000 (Baseline) & 7,000 & - & 4,500 & - \\
\hline 9,500 & 9,500 & $35.7 \%$ & 5,655 & $25.7 \%$ \\
\hline 12,000 & 12,000 & $71.4 \%$ & 7,143 & $58.7 \%$ \\
\hline 15,000 & 15,000 & $114.3 \%$ & 8,929 & $98.4 \%$ \\
\hline
\end{tabular}

(1) The percent diffence is: 100 (compared value - Baseline) / Baseline

Table 42: Comparison of concrete allowable stresses to baseline

\begin{tabular}{|c|c|c|c|c|c|c|c|c|c|}
\hline \multirow[b]{2}{*}{$\begin{array}{c}\text { 28-Day Concrete } \\
\text { Design Strength, } \\
f_{c}^{\prime}(p s i)\end{array}$} & \multirow{2}{*}{$\begin{array}{l}\text { Concrete } \\
\text { Strength at } \\
\text { Transfer, } \\
f_{\text {ci }}(p s i)\end{array}$} & \multicolumn{4}{|c|}{ Allowable Concrete Tensile Strengths (psi) } & \multicolumn{4}{|c|}{ Allowable Concrete Compressive Strengths (psi) } \\
\hline & & Transfer & $\begin{array}{c}\text { Percent } \\
\text { Difference } \\
\text { Transfer }^{(1)}\end{array}$ & Service & $\begin{array}{c}\text { Percent } \\
\text { Difference } \\
\text { Service }^{(1)}\end{array}$ & Transfer & $\begin{array}{c}\text { Percent } \\
\text { Difference } \\
\text { Transfer }^{(1)} \\
\end{array}$ & Service & $\begin{array}{c}\text { Percent } \\
\text { Difference } \\
\text { Service }^{(1)}\end{array}$ \\
\hline 7,000 & 4,500 & 201 & - & 627 & - & 2,700 & - & 4,200 & - \\
\hline 9,500 & 5,655 & 226 & $12.1 \%$ & 731 & $16.5 \%$ & 3,393 & $25.7 \%$ & 5,700 & $35.7 \%$ \\
\hline 12,000 & 7,143 & 254 & $26.0 \%$ & 822 & $30.9 \%$ & 4,286 & $58.7 \%$ & 7,200 & $71.4 \%$ \\
\hline 15,000 & 8,929 & 283 & $40.9 \%$ & 919 & $46.4 \%$ & 5,357 & $98.4 \%$ & 9,000 & $114.3 \%$ \\
\hline
\end{tabular}

${ }^{(1)}$ The percent diffence is: 100 (compared value - value corresponding to 7,000 psi) / value corresponding to 7,000 psi

\subsubsection{Prestressing Properties and Placement}

In addition to altering the material properties of the concrete, the prestressing is also a viable source for increasing the flexural capacity of the tie. However, the prestressing offers multiple means of increasing the tie capacity such as higher strength materials, increased diameter of tendons, and the ability to optimize prestressing placement and eccentricity with respect to the constant concrete cross-section. The effects of altering the prestressing material and crosssectional properties are discussed in the following sections. The cross-sections of the optimized designs are included in Appendix E.

\subsubsection{Comparison of Prestressing Properties}

Unlike concrete, which has a single variable for manipulation for this project, the design compressive strength, prestressing offers considerably more diversity and freedom in terms of 
parameter variation. Not only can the strength of the prestressing be changed, but the size and type as well. For this project three different prestressing types were selected for evaluation; drawn wire, 7-wire strand, and carbon fiber reinforced polymer (FRP). All three prestressing types have their own advantages and disadvantages, but in general all three prestressing types are capable of achieving increased flexural capacities over the baseline case. The properties of the prestressing which were under evaluation were the diameter and the strength. The comparisons of the prestressing properties for the various design iterations to the baseline tie of 255 ksi steel 0.21 inch diameter drawn wire are summarized in Table 43.

Table 43: Comparison of prestressing optimization parameters to baseline prestressing

\begin{tabular}{|c|c|c|c|c|c|c|c|c|}
\hline Prestressing Type & $\begin{array}{c}\text { Tendon } \\
\text { Diameter } \\
\text { (in) }\end{array}$ & $\begin{array}{c}\text { Percent } \\
\text { Difference } \\
\text { Diameter }^{(2)}\end{array}$ & $\begin{array}{c}\text { Tendon } \\
\text { Area } \\
\left(\text { in }^{2}\right)\end{array}$ & $\begin{array}{c}\text { Percent } \\
\text { Difference } \\
\text { Area }^{(2)} \\
\end{array}$ & $\begin{array}{c}\text { Ultimate } \\
\text { Strength } \\
\text { (ksi) }\end{array}$ & $\begin{array}{c}\text { Percent } \\
\text { Difference }^{(2)} \\
\text { Ultimate }^{(2)}\end{array}$ & $\begin{array}{c}\text { Yield } \\
\text { Strength } \\
\text { (ksi) }\end{array}$ & $\begin{array}{c}\text { Percent } \\
\text { Difference } \\
\text { Yield }^{(2)}\end{array}$ \\
\hline Drawn Wire (W) (Baseline) & 0.21 & - & 0.03445 & - & 255 & - & 230 & - \\
\hline 7-Wire Strand (S) & 0.25 & $19.0 \%$ & 0.03600 & $4.5 \%$ & 250 & $-2.0 \%$ & 225 & $-2.2 \%$ \\
\hline 7-Wire Strand (S) & 0.3125 & $48.8 \%$ & 0.05800 & $68.4 \%$ & 250 & $-2.0 \%$ & 225 & $-2.2 \%$ \\
\hline 7-Wire Strand (S) & 0.375 & $78.6 \%$ & 0.08500 & $146.7 \%$ & 270 & $5.9 \%$ & 243 & $5.7 \%$ \\
\hline Carbon FRP (FRP) & 0.25 & $19.0 \%$ & 0.04900 & $42.2 \%$ & 425 & $66.7 \%$ & $N A^{(1)}$ & NA \\
\hline Carbon FRP (FRP) & 0.375 & $78.6 \%$ & 0.11000 & $219.3 \%$ & 425 & $66.7 \%$ & NA & NA \\
\hline
\end{tabular}

${ }^{(1)}$ FRP does not have a defined yield strength since the stress-strain curve remains linear up to failure

${ }^{(2)}$ The percent diffence is: 100 (compared value - value corresponding to baseline) / value corresponding to baseline)

A relationship which became apparent during the optimization study was the connection between concrete design strength and the area of prestressing within the section. As concrete design strength increased, the area of prestressing tendons in the section increased to enable the application of a larger prestressing force. With the prestressing tendons in the tie already tensioned to their permissible stress limits, the only means of increasing the prestressing force was to add more tendons to the section. However, the number of tendons which could be fit within the cross-section was limited by the detailing requirements of cover and spacing. The detailing limitations on the prestressing within the section act in conjunction with the allowable concrete stresses from $\mathrm{ACl} 318-08$ to dictate the prestressing quantity and configuration. Figure 64 and Figure 65 illustrate the relationship between area of prestressing and concrete design strength. 
Area of Prestressing $\left(A_{p s}\right)$ With Positve Rail Seat Moment Governing Design for all Concrete Strengths

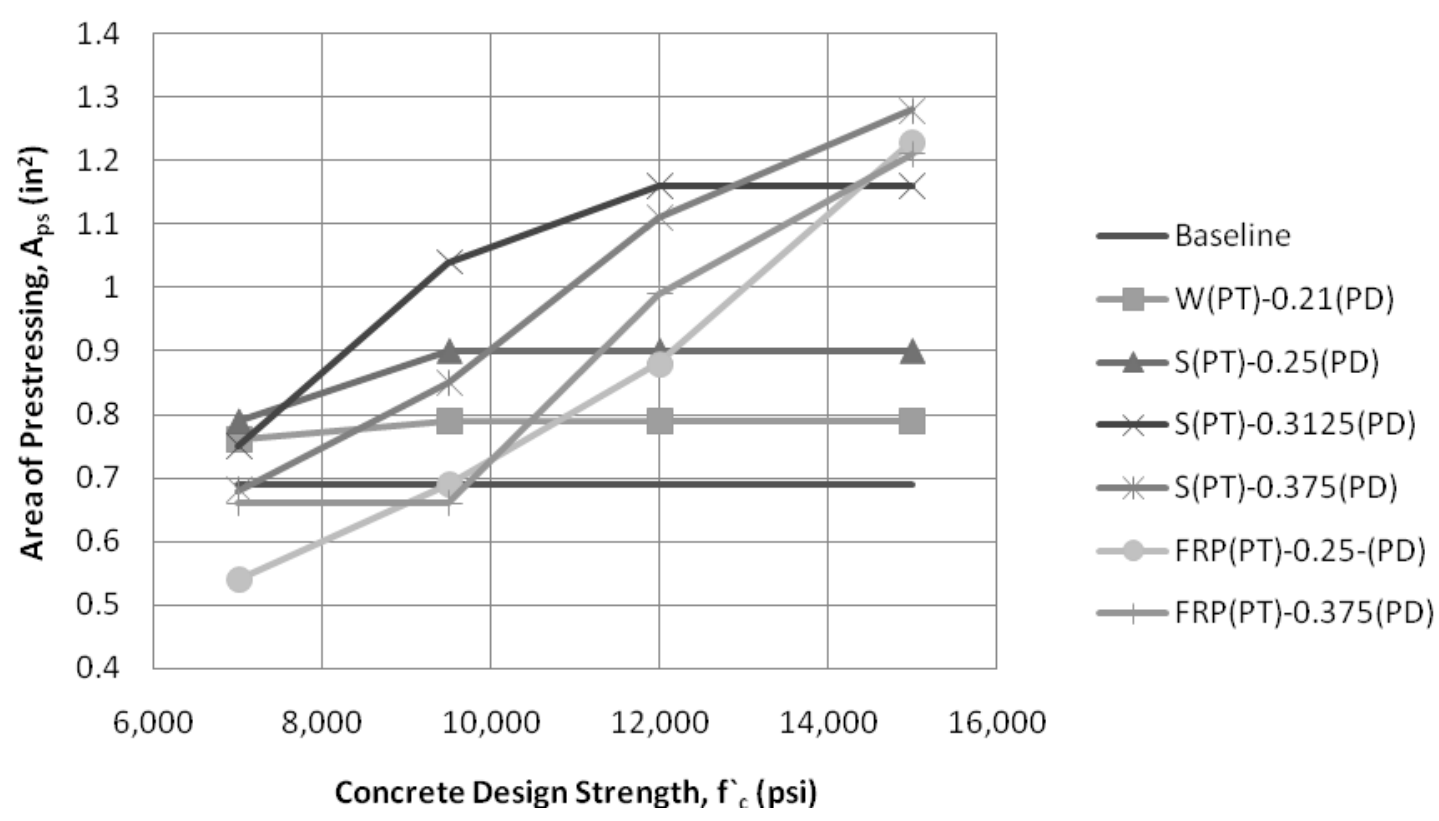

Figure 64: Area of prestressing for positive rail seat moment governing design iterations

Area of Prestressing $\left(A_{p s}\right)$ With Negative Center Moment Governing Design for all Concrete Strengths

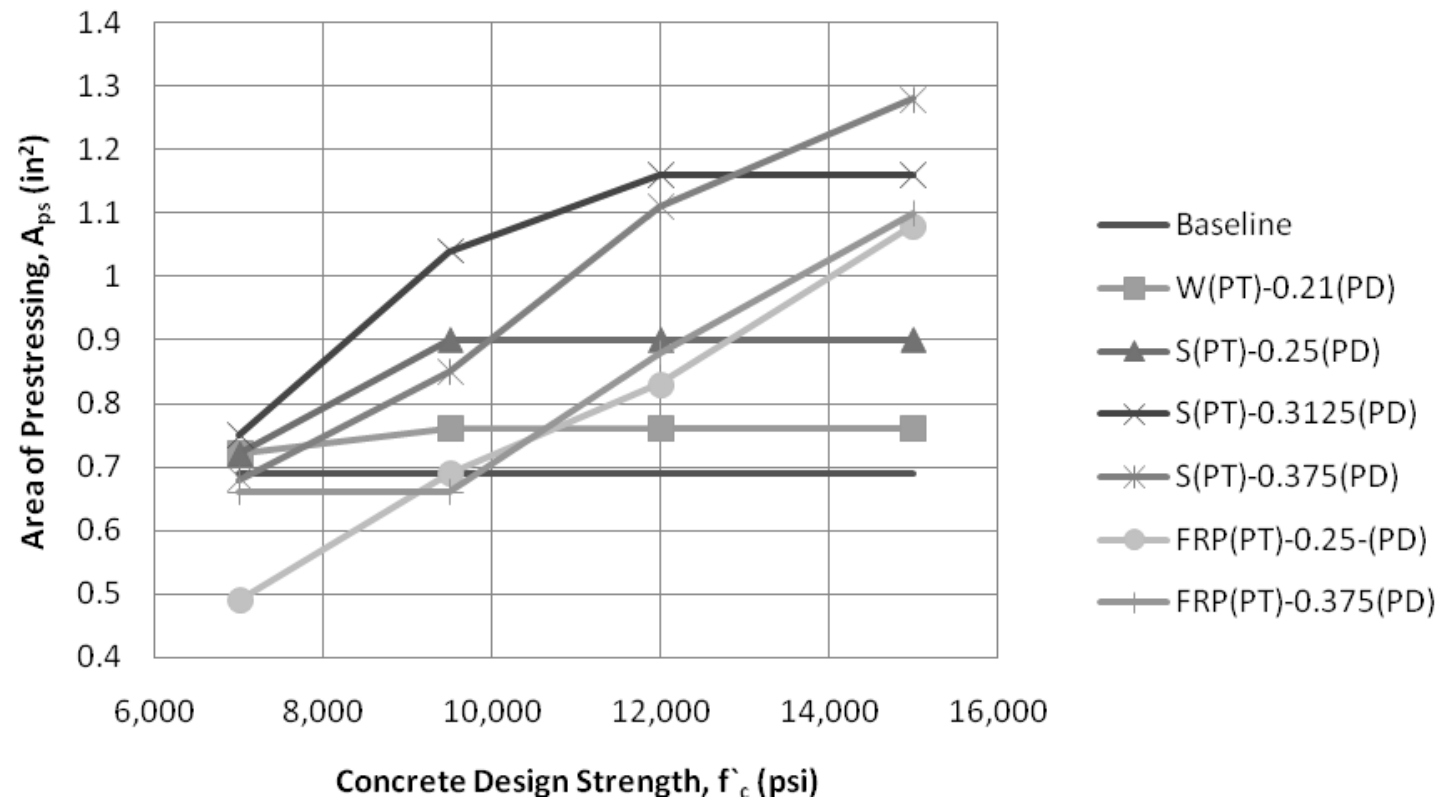

Figure 65: Area of prestressing for negative center moment governing design iterations 
Figure 64 and Figure 65 shows the area of prestressing for each iteration, given the specific prestressing type and diameter versus the concrete design strength for that particular iteration. The following summarizes the trends observed in Figure 64 and Figure 65 between the increase of concrete strength and the area of prestressing in each optimized design iteration:

- The "Baseline" case had a constant area of prestressing for all concrete strengths because the configuration remained unchanged for the parametric optimization study,

- $\quad W(P T)-0.21(P D)$ and $S(P T)-0.25(P D)$ cases had a small increase in area of prestressing corresponding to an increase in concrete design strength $\left(f_{c}{ }_{c}\right)$ from 7,000 psi to 9,500 psi. For the rest of the concrete strength increases the area of prestressing remained constant,

- $\mathrm{S}(\mathrm{PT})-0.3125(\mathrm{PD})$ had an increase in prestressing from 7,000 psi to 12,000 psi, but leveled off from 12,000 psi to 15,000 psi,

- The three remaining prestressing combinations, $\mathrm{S}(\mathrm{PT})-0.375(\mathrm{PD}), \mathrm{FRP}(\mathrm{PT})-0.25(\mathrm{PD})$, and FRP(PT)-0.375(PD) experienced increases in the area of prestressing throughout the entire range of concrete strengths considered.

The reason why the area of prestressing levels off for $W(P T)-0.21(P D)$ and $S(P T)-0.25(P D)$ at 9,500 psi is because of a transition in the governing criteria for the design. Below 9,500 psi the number of prestressing tendons and the corresponding prestressing force applied to the tie was governed by the allowable concrete stresses defined by $\mathrm{ACl} 318-08$. However, as the concrete strength increased, the number of prestressing tendons and therefore the magnitude of the prestressing force was able to increase. This increase in area of prestressing continues until the section cannot accommodate anymore tendons based on the detailing restrictions of cover and spacing. For the prestressing cases of $W(P T)-0.21(P D)$ and $S(P T)-0.25(P D)$ the sections were unable to hold more prestressing at the concrete strength level of 9,500 psi. For the S(PT)$0.3125(P D)$ prestressing case, the detailing limitation was encountered at a concrete strength of 12,000 psi.

Unlike the smaller diameter prestressing cases such as W(PT)-0.21(PD), S(PT)-0.25(PD) and $S(P T)-0.3125(P D)$, the larger diameter and stronger prestressing cases of $S(P T)-0.375(P D)$, FRP(PT)-0.25(PD), and FRP(PT)-0.375(PD) are capable of increasing the area of prestressing throughout the range of concrete strengths considered. Larger diameter and stronger 
prestressing materials provided the ability to apply the same prestressing force to the tie while using fewer tendons. Therefore, the detailing limitations which affected the smaller prestressing diameter combinations did not apply to the larger cases, which continued to be governed by the allowable concrete stresses throughout the range of concrete strengths considered.

Summarizing this relationship, the two smallest diameter prestressing iterations, consisting of $W(P T)-0.21(P D)$ and S(PT)-0.25(PD), reach the detailing limit at a concrete strength of 9,500 psi. The remaining iterations based on larger prestressing diameters and higher strengths continue to allow for increased areas of prestressing throughout the range of concrete strengths evaluated. Except for S(PT)-0.3125(PD) which reaches the detailing limit at a concrete strength of 12,000 psi. From this relationship it can be concluded that in order to maintain full material efficiency at higher concrete strengths larger diameter prestressing tendons must be used to achieve the necessary area of prestressing to continue the governance of allowable concrete stresses rather than detailing.

\subsubsection{Prestressing Placement and Eccentricity}

Similar to increasing the area of prestressing, increasing the eccentricity of the prestressing can also increase the pre-compression force. However, increasing the eccentricity while maintaining the same area of prestressing simply reorganizes the applied stress into a different distribution, which may cause in an increase in capacity in one flexure condition while decreasing another. Figure 66 and Figure 67 illustrate the effect of variations in the concrete strength on the eccentricities for the governing load cases of positive bending at the rail seat section and negative bending at the center section, respectively. The objective of this variable optimization wass to increase the eccentricity of the prestressing while maintaining the applied stresses on the concrete within the acceptable limits. The effect of this variation is more apparent at the rail seat section than the center section, because the center section has smaller eccentricities due to the reduced cross-section compared to the rail seat section. 
Eccentricity at the Rail Seat ( $e_{\mathrm{RS}}$ ) With Positive Rail Seat Moment Governing Design for all Concrete Strengths

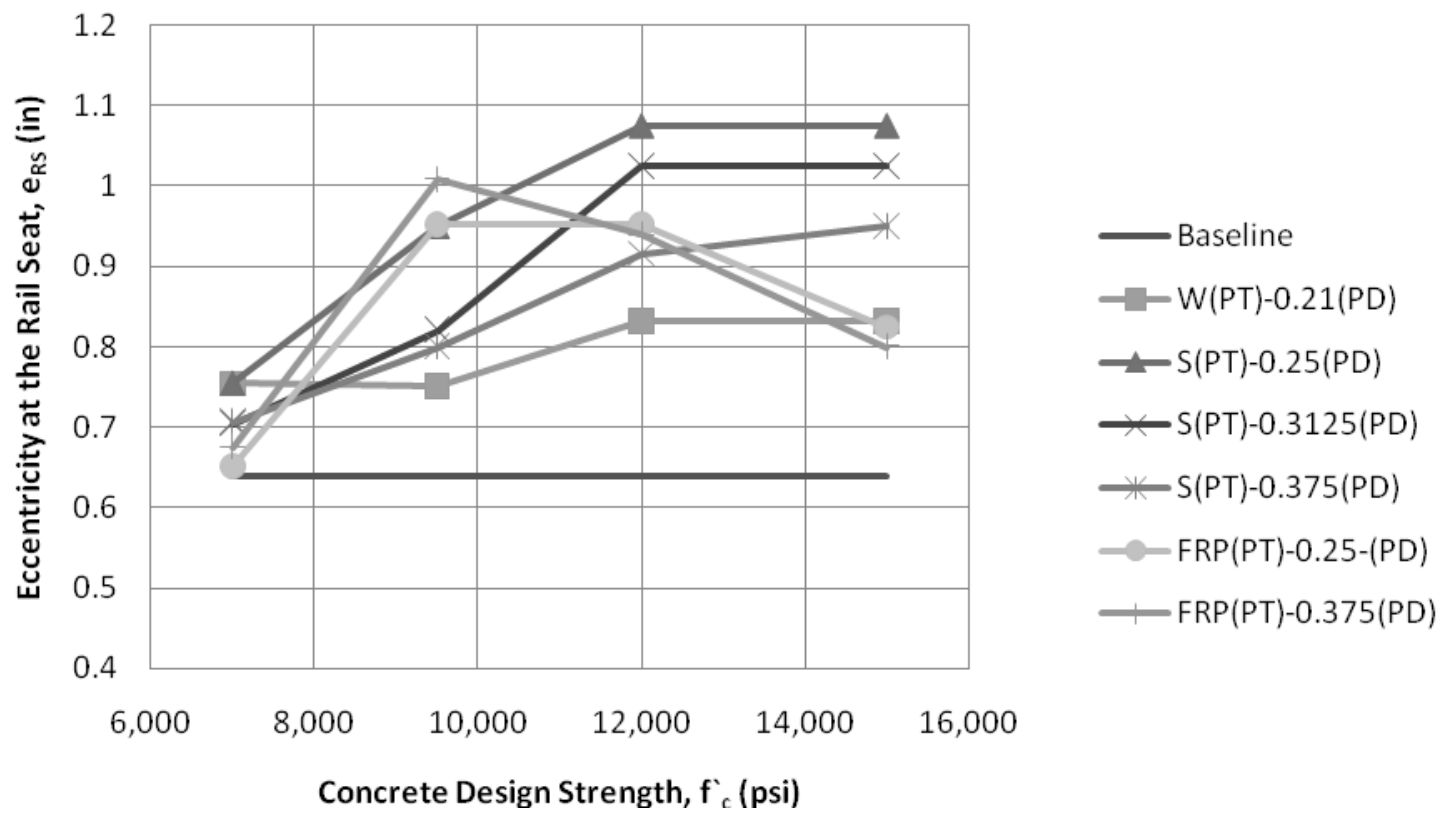

Figure 66: Eccentricity at rail seat section for positive rail seat moment governing design iterations
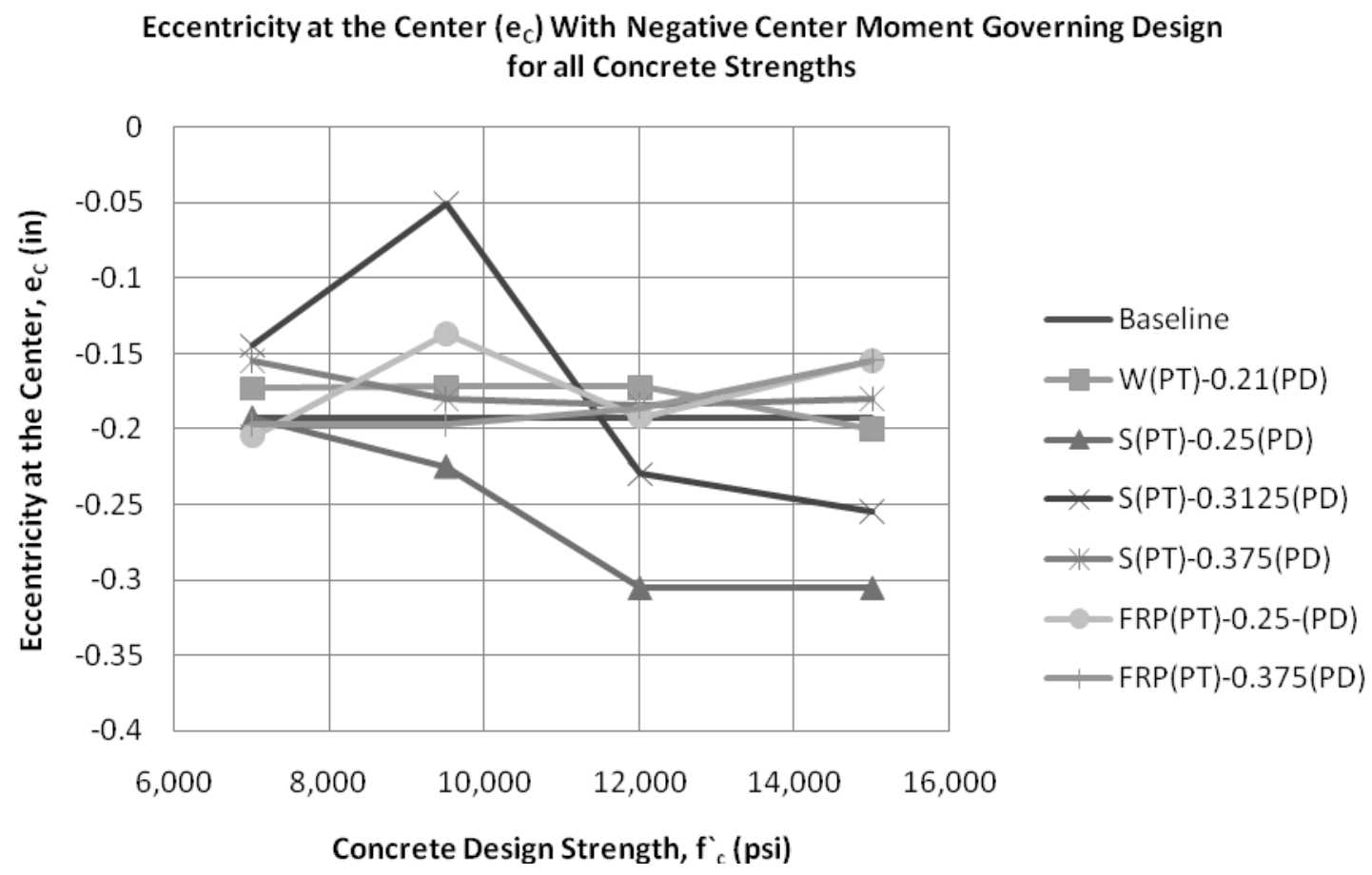

Figure 67: Eccentricity at center section for negative center moment governing design iterations 
Similar to the area of prestressing and concrete strength relationship, eccentricity generally increases as concrete strength increases. The increase in eccentricity is in response to the increased allowable concrete stresses. The exception to this observation seen in Figure 66, are the FRP cases which experience a decrease in eccentricity with respect to concrete strengths greater than 9,500 psi. The reason for the decrease in FRP eccentricities is the jacking stress which is applied to the tendons. At a concrete strength of 9,500 psi or less, the FRP tendons could not be stresses to their full potential due to the allowable concrete strengths. As the concrete strength increased above 9,500 psi the FRP tendons were jacked to a higher initial stress and the eccentricity was reduced.

To summarize the remainder of the prestressing cases, the eccentricities in the rail seat region increase as concrete strengths increase. In contrast, the eccentricity in the center region remains essentially constant as concrete strength increases, with the exception of slight variations which are result to changes in the area of prestressing (to change the amount of prestressing in a section, the configuration typically must change, changing the eccentricity).

\subsubsection{Limit States}

The same limits states discussed for the baseline tie apply for the optimization study. However, Limit State I, concrete stresses at transfer is somewhat inconsequential since all iterations were designed with the intention of achieving the maximum allowable stress in the concrete at transfer in order to have full efficiency in terms of the materials used and the largest possible moment capacities for the governing load case of the iteration.

\subsubsection{Limit State II: Stresses at Service (AREMA Defined Capacity)}

For Limit State II, concrete stress at service, Figure 68 and Figure 69 illustrate the moment capacities for the design governing conditions of positive bending at the rail seat section and negative bending at the center section. All capacities presented in the figures correspond to effective prestressing including all losses at 50 years. In addition to the optimization iterations, the capacity of the baseline tie is included as well. 


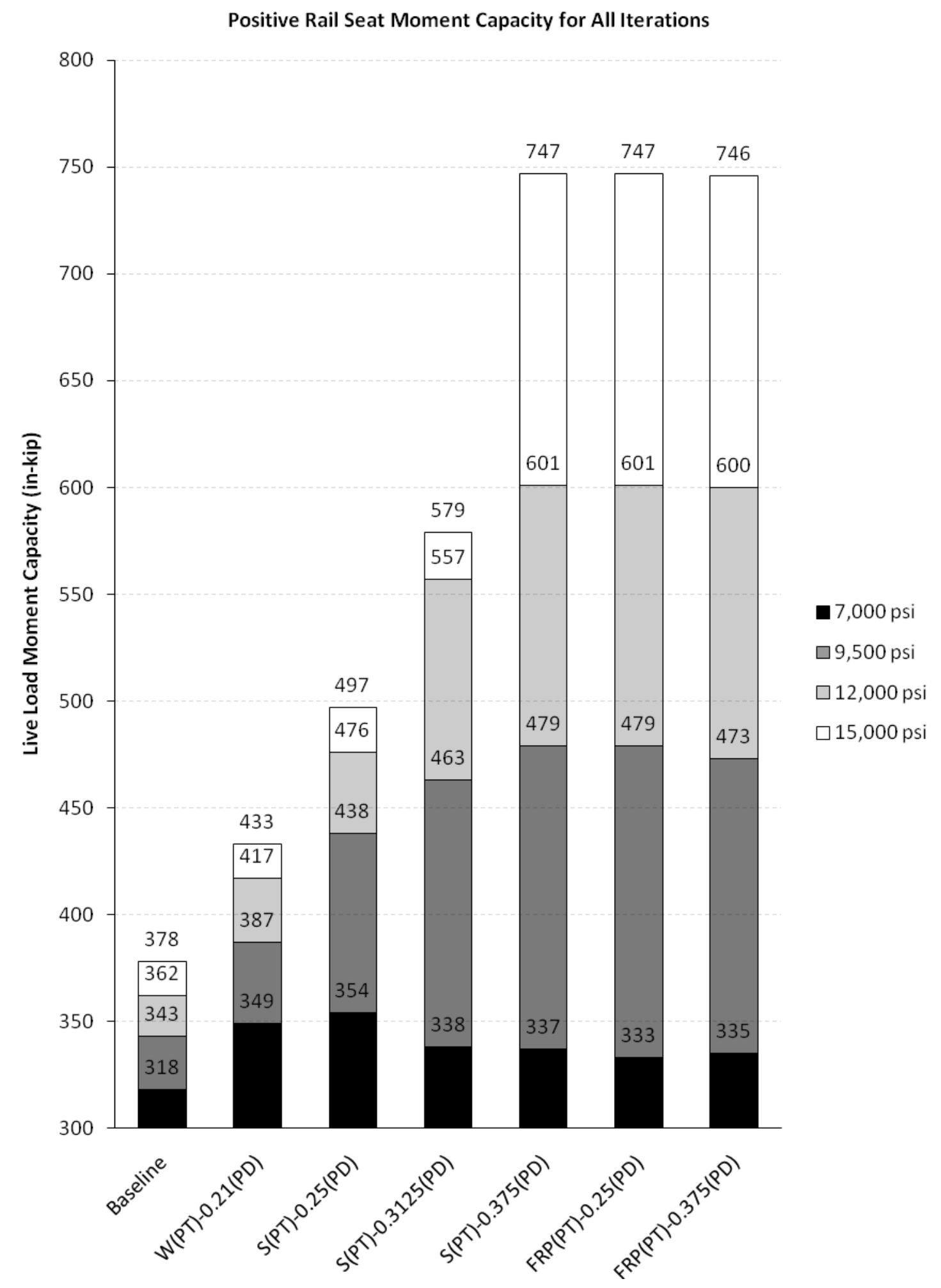

Figure 68: Positive rail seat moment capacity defined by AREMA for positive rail seat governed design at 50 years 


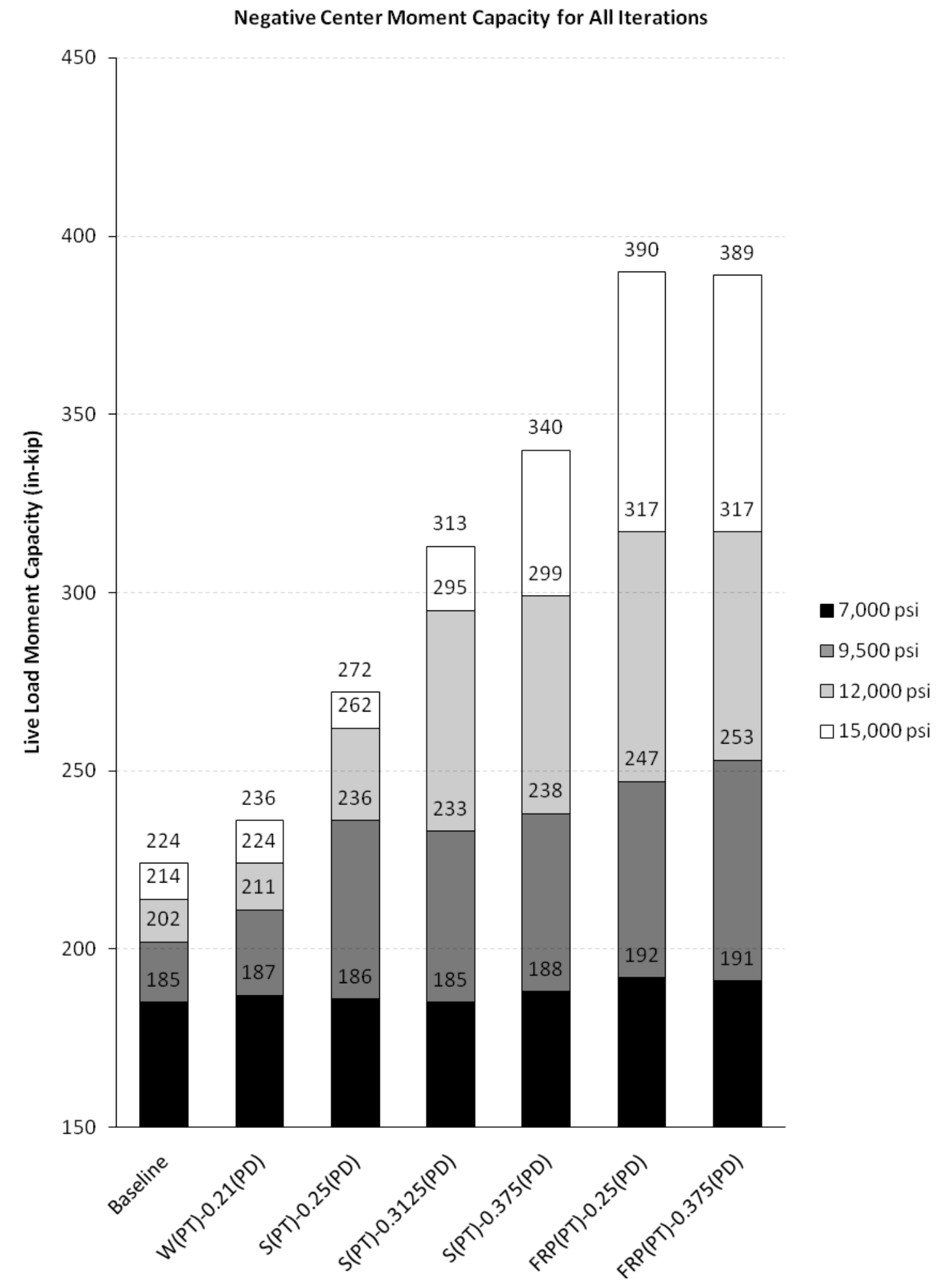

Figure 69: Negative center moment capacity defined by AREMA for negative center governed design at 50 years 
The goal of this research project was to increase the capacity of an existing tie design by varying parameters related to the prestressing and concrete components. Once the designs using the various combinations of design parameters were completed, they were compared to one another to determine which yields the largest gains in capacity. The comparison is based on the tie capacity defined by the service cracking limit not nominal capacity. The tie designs were completed with the intention of increasing the capacity defined by the service cracking limit regardless of what the nominal capacity was. Since multiple variables such as prestressing type, size and concrete strength were varied simultaneously the comparison of optimization iterations was conducted by comparing iterations using the same concrete strength while prestressing parameters varied. These comparisons are illustrated in Figure 70 and Figure 71, which correspond to the capacities of the optimized designs for the positive rail seat and negative center bending conditions. 
Optimized Capacity vs. Baseline Capacity for Given Concrete Strength, Positive Rail Seat Governed Designs

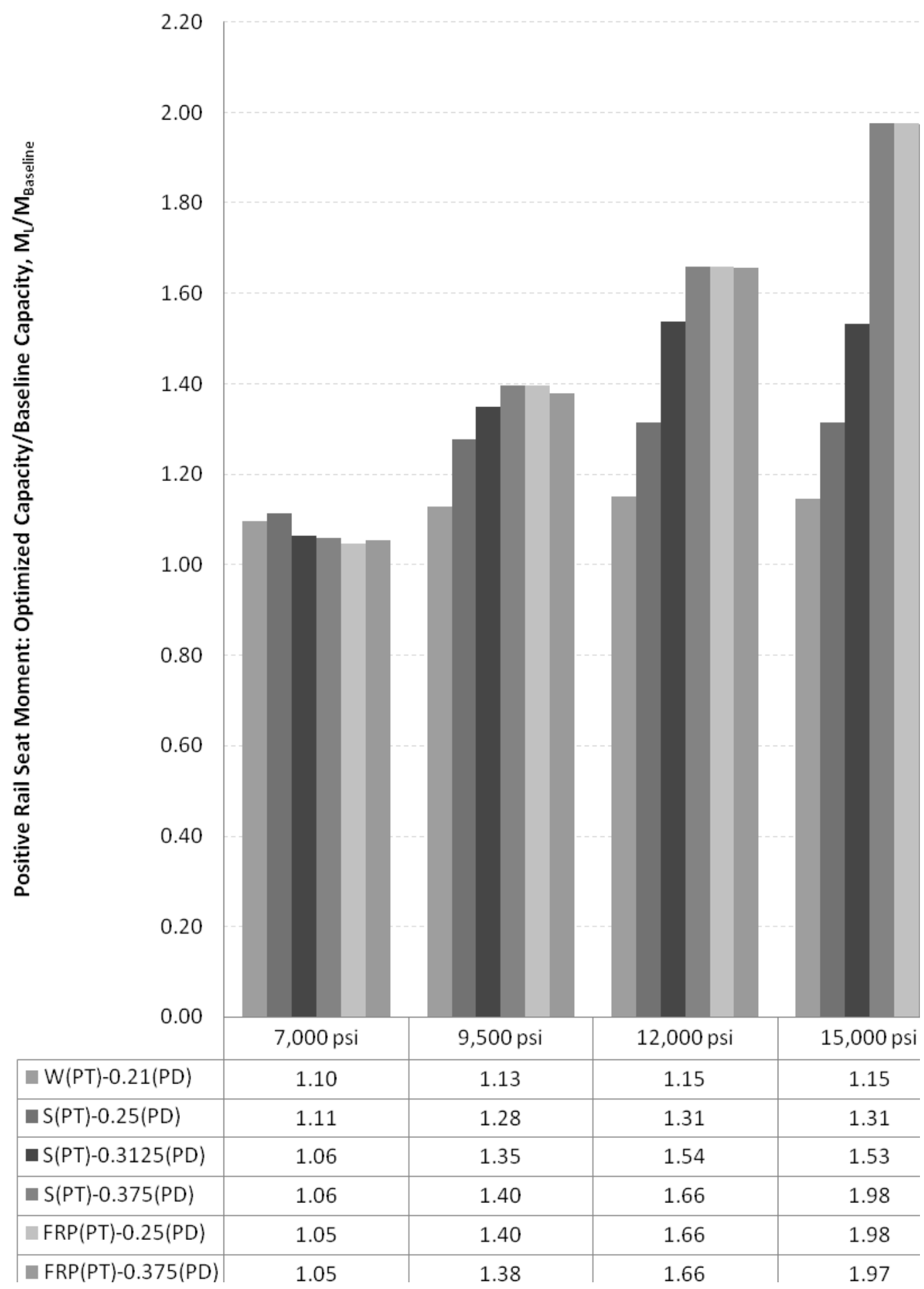

Figure 70: Comparison of optimized capacity vs. baseline capacity for positive rail seat governed designs 
Optimized Capacity vs. Baseline Capacity for Given Concrete Strength, Negative Center Governed Designs

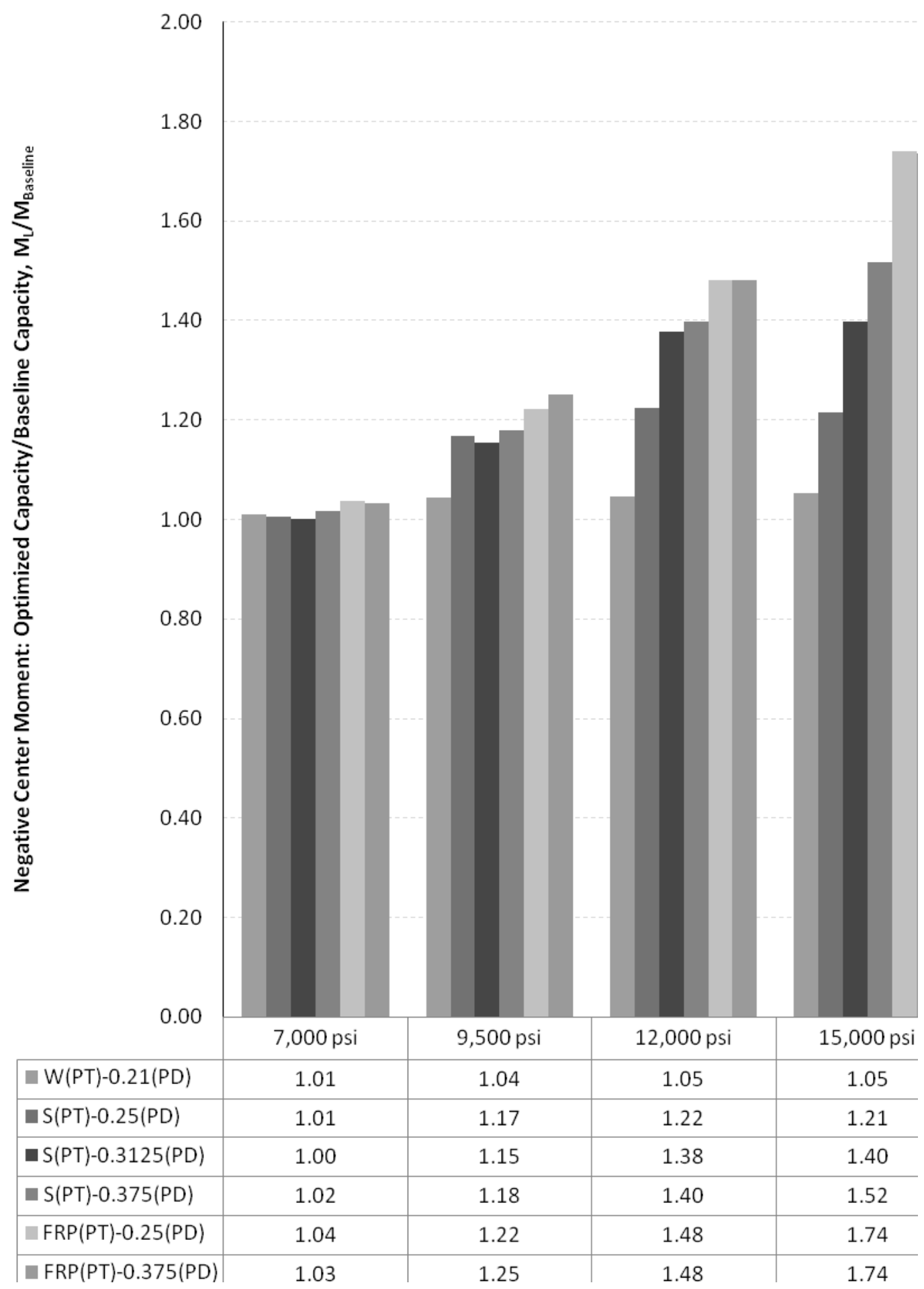

Figure 71: Comparison of capacity of optimized designs vs. baseline capacity for negative center governed designs 
Evaluating the results of the flexural capacity optimization study, the following conclusions can be made about the effects of specific iteration parameters on the AREMA defined flexural capacity of prestressed concrete railroad ties:

- For lower levels of concrete strength, capacity is governed by the allowable concrete stresses,

- As concrete strength increases, the governing factor of the tie capacity transitions from concrete stress to the quantity of prestressing which can be placed in the tie, while maintaining adequate spacing and cover,

- Smaller diameter prestressing tendons reach the governing limit of detailing before the larger tendon diameters, due to the larger number of tendons required to achieve the same prestressing force,

- The order of prestressing types and diameters in terms of tie capacity from lowest to highest is generally: W(PT)-0.21(PD), S(PT)-0.25(PD), S(PT)-0.3125(PD), S(PT)-0.375(PD), FRP(PT)-0.375(PD), FRP(PT)-0.25(PD),

- Tie capacity increases as concrete design strength increases.

Selecting which optimized design is the best and offers the greatest gain in capacity is difficult since no clear plateau or limit in capacity appears to exist for the material parameter values considered. However, for the same concrete strength, larger diameter steel prestressing tendons have larger strength gains than smaller diameter tendons. This becomes particularly evident when detailing becomes the limiting factor in design rather than allowable stresses at transfer at higher concrete strengths. Based on this observation, the prestressing case S(PT)0.375(PD) appears to provide the largest gains for steel prestressing, while FRP prestressing appears to be unaffected by changes in diameter. This is a result of the higher strength associated with FRP which allows concrete stresses at transfer to remain the governing factor in design.

\subsubsection{Transfer Lengths}

Based on Equation 10 in Section 3.1.5.3 the transfer length for all steel prestressing has been calculated. For FRP, the transfer length was found using Equation 13 from Section 3.2.8. The reason for multiple equations for calculating transfer length with respect to the prestressing material type, is the differences in bond between the two materials. However, the basis of the 
transfer length equations is the same. For both the steel and FRP prestressing, transfer length is a function of tendon diameter. Therefore, as the diameter of the tendon increases so does the required transfer length. The required transfer lengths for the steel and FRP prestressing optimization iterations were calculated and are presented in Table 44. The required transfer lengths from Table 44 are plotted in Figure 72 with respect to concrete design strength.

Table 44: Transfer lengths for maximum effective prestress from each design iteration

\begin{tabular}{|c|c|c|c|c|}
\hline Prestressing Type & $\begin{array}{l}\text { Tendon } \\
\text { Diameter } \\
\text { (in) }\end{array}$ & $\begin{array}{c}\text { Concrete } \\
\text { Strength, } f_{c}^{\prime} \\
\text { (psi) }\end{array}$ & $\begin{array}{c}\text { Maximum Effective } \\
\text { Prestress } \\
\text { (1) } \\
\text { (ksi) }\end{array}$ & $\begin{array}{l}\text { Transfer } \\
\text { Length }^{(2)} \\
\text { (in) }\end{array}$ \\
\hline \multirow{4}{*}{$\begin{array}{c}\text { Drawn Wire (W) (Baseline) } \\
\text { W(PT)-0.21(PD) }\end{array}$} & \multirow{4}{*}{0.21} & 7,000 & 173.1 & 12.1 \\
\hline & & 9,500 & 177.1 & 12.4 \\
\hline & & 12,000 & 179.7 & 12.6 \\
\hline & & 15,000 & 181.2 & 12.7 \\
\hline \multirow{4}{*}{$\begin{array}{l}\text { 7-Wire Strand (S) } \\
\text { S(PT)-0.25(PD) }\end{array}$} & \multirow{4}{*}{0.25} & 7,000 & 149.2 & 12.4 \\
\hline & & 9,500 & 151.4 & 12.6 \\
\hline & & 12,000 & 156.4 & 13.0 \\
\hline & & 15,000 & 157.6 & 13.1 \\
\hline \multirow{4}{*}{$\begin{array}{l}\text { 7-Wire Strand (S) } \\
\text { S(PT)-0.3125(PD) }\end{array}$} & \multirow{4}{*}{0.3125} & 7,000 & 147.9 & 15.4 \\
\hline & & 9,500 & 146.3 & 15.2 \\
\hline & & 12,000 & 150.5 & 15.7 \\
\hline & & 15,000 & 153.5 & 16.0 \\
\hline \multirow{4}{*}{$\begin{array}{l}\text { 7-Wire Strand (S) } \\
\text { S(PT)-0.375(PD) }\end{array}$} & \multirow{4}{*}{0.375} & 7,000 & 163.1 & 20.4 \\
\hline & & 9,500 & 165.8 & 20.7 \\
\hline & & 12,000 & 164.7 & 20.6 \\
\hline & & 15,000 & 163.7 & 20.5 \\
\hline \multirow{4}{*}{$\begin{array}{l}\text { Carbon FRP (FRP) } \\
\text { FRP(PT)-0.25(PD) }\end{array}$} & \multirow{4}{*}{0.25} & 7,000 & 232.2 & 13.8 \\
\hline & & 9,500 & 231.2 & 11.2 \\
\hline & & 12,000 & 233.8 & 9.7 \\
\hline & & 15,000 & 232.6 & 8.3 \\
\hline \multirow{4}{*}{$\begin{array}{l}\text { Carbon FRP (FRP) } \\
\text { FRP(PT)-0.375(PD) }\end{array}$} & \multirow{4}{*}{0.375} & 7,000 & 180.1 & 16.0 \\
\hline & & 9,500 & 231.7 & 16.8 \\
\hline & & 12,000 & 222.0 & 13.7 \\
\hline & & 15,000 & 227.7 & 12.1 \\
\hline
\end{tabular}

(1) Use the maximum effective prestress from the rail seat and center governed designs and critical sections.

${ }^{(2)}$ For calculation of transfer length for steel prestressing use method described in $\mathrm{PCl}$ Handbook 6th Edition Section 4.2.3 Prestress Transfer and Strand Development. For FRP used method described in ACl 440.4R-04 Section 6.2 Transfer Length Equation (6-1). 
Transfer Lengths of Prestressing Types and Sizes with Respect to Concrete Strength

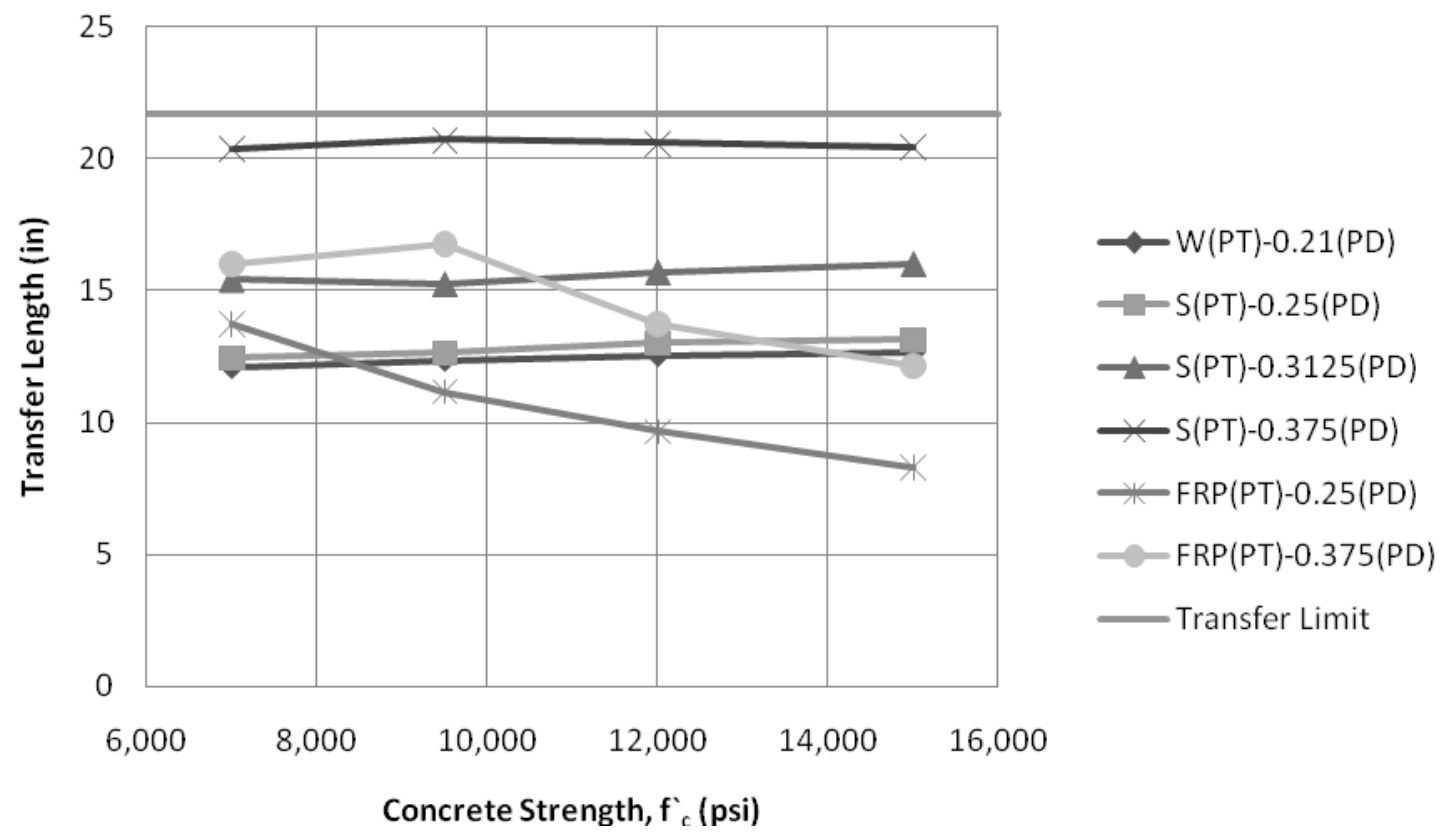

Figure 72: Transfer lengths of prestressing for optimization iterations with limiting end distance to rail seat section It appears that FRP and steel react differently to changes in concrete strength as transfer lengths increase for steel and decrease for FRP as the concrete strength is increased (Figure 72). The difference is a result of the inclusion of concrete strength in the calculation of FRP transfer lengths; FRP has an inverse relationship with concrete strength for transfer, causing transfer length to decrease as concrete strength increases. Comparing the required transfer lengths to the available distance (shoulder length) full transfer of the effective prestress is achieve by the rail seat section for all prestressing types and sizes.

\subsubsection{Nominal Moment Capacity}

The nominal moment capacity results of the optimization study follow similar trends to those observed in the AREMA defined flexural capacity. However, the consideration of the deep beam condition and development length has a significant impact on the nominal moment capacity of the optimized design iterations. The results for the nominal capacity of the optimized tie designs are presented in the following sections, along with discussion of the effects of the deep beam condition and the development length of the prestressing. 


\subsubsection{Deep Beam Effect}

Since the overall tie geometry remained constant throughout the optimization study, the rail seat section still qualifies as a deep beam. For continuity, the nominal moment capacity assuming pure flexure for the rail seat section, is presented along with the nominal moment capacity of the center section, which does not qualify as a deep beam.

\subsubsection{Strain Compatibility Results}

The nominal moment capacity results using strain compatibility, assuming pure flexure and full development of the prestressing for both the rail seat and center governed design iterations are presented in Figure 73 and Figure 74. The design configurations were not optimized for the nominal moment capacity, but maintained from the optimization which was performed based on Limit State II. Should the failure definition for prestressed concrete railroad ties ever change to extend the capacity to ultimate, optimization based on the nominal capacity would have be completed.

The nominal moment capacities presented in Figure 73 for the rail seat section are lower-bound estimates of the actual capacities since the deep beam condition governs; they are shown only for comparison reasons and continuity with the rest of the numerical process. Even though the rail seat would not exhibit pure bending behavior, the maximum stress in the prestressing derived using strain compatibility was used to determine the required development length. This value served as a prediction of what the actual required development length may be.

The nominal moment capacities presented in Figure 74 for the center section are the predicted ultimate capacities since the center section does not qualify as a deep beam. The calculated effective and maximum prestressing stresses are used in the next section to calculate the required development lengths for the design iterations and determine whether or not the provided distance is adequate. 
(+) Rail Seat Nominal Moment Capacity for All Iterations

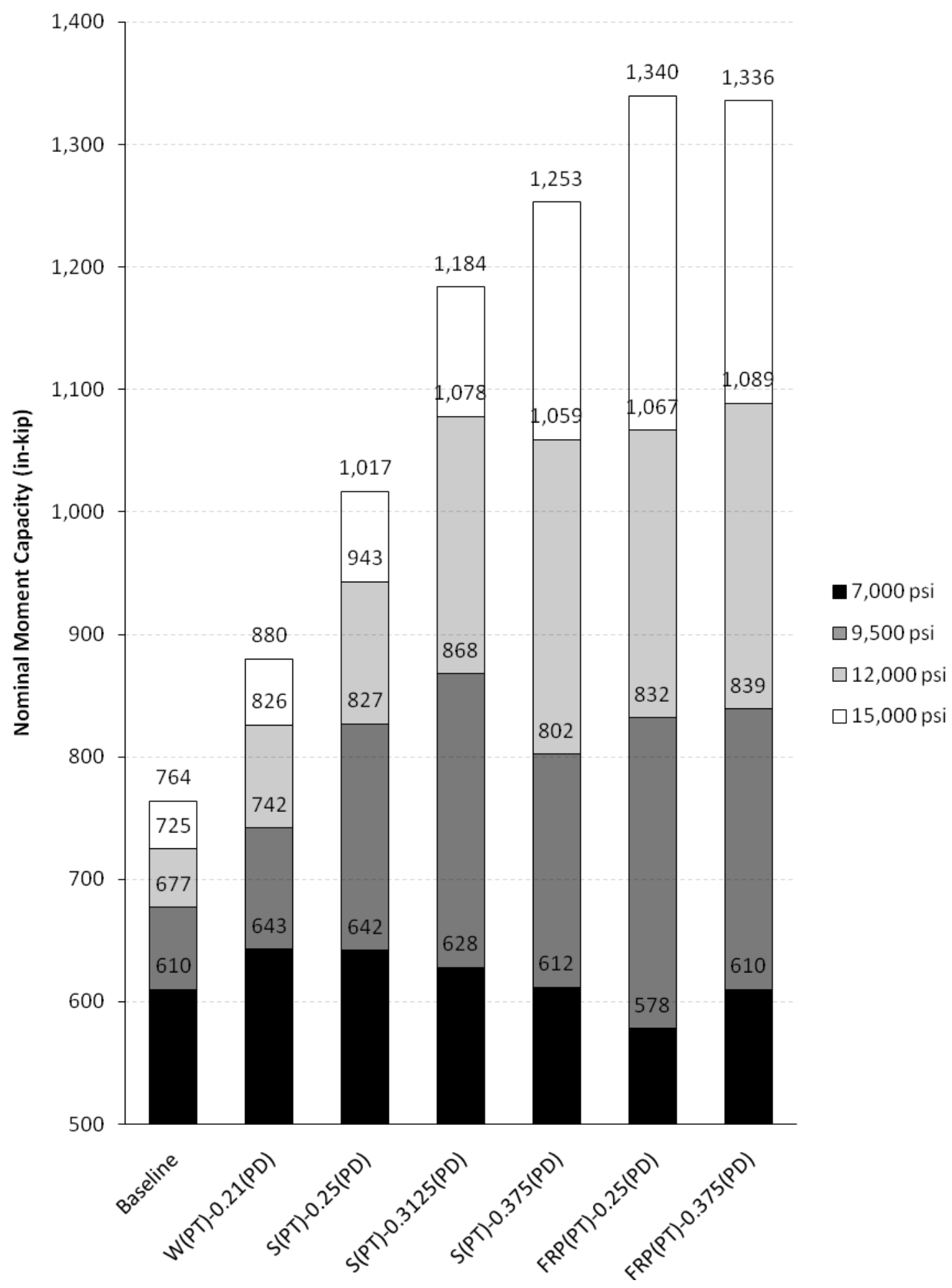

Figure 73: Positive rail seat nominal moment capacity for positive rail seat governed design at 50 years 
(-) Center Nominal Moment Capacity for All Iterations

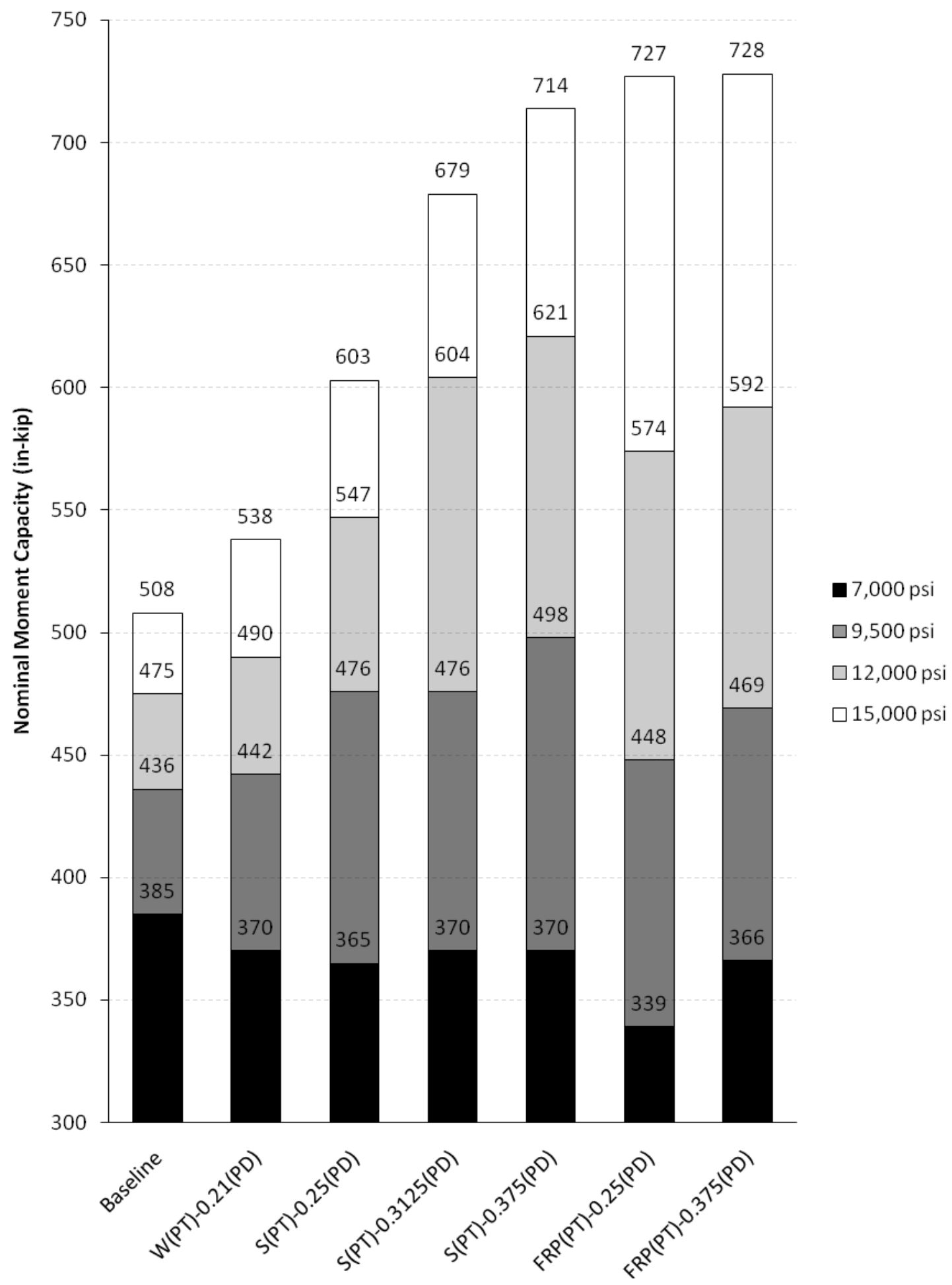

Figure 74: Negative center nominal moment capacity for negative center governed design at 50 years 
Evaluating the results of the nominal moment capacity the following conclusions can be made about the effects of iteration parameters on the nominal moment capacity of prestressed concrete railroad ties:

- Sections with larger diameter and stronger prestressing tendons achieve higher nominal moment capacities,

- The order of prestressing types and diameters in terms of nominal moment capacity from lowest to highest, follow the same trends as the tie capacity as defined by AREMA (limit state II),

- Nominal moment capacity increases as concrete strength increases.

\subsubsection{Development Length}

Similar to the transfer length, development length is a function of the prestressing diameter and applied stress in the prestressing. To determine the required development lengths of the steel prestressing cases, Equation 11 from Section 3.1.6.4 was used. For the FRP prestressing cases Equation 14 from Section 3.2.8 was used. Table 45 summarizes the required development lengths which correspond to the optimization design iterations. The required development lengths are then plotted with respect to the available distances for development in Figure 75.

Table 45: Development length for each prestressing type and comparison to available development distance

\begin{tabular}{|c|c|c|c|c|}
\hline Prestressing Type & $\begin{array}{c}\text { Tendon } \\
\text { Diameter } \\
\text { (in) }\end{array}$ & $\begin{array}{l}\text { Required } \\
\text { Development } \\
\text { Length }^{(2)} \\
\text { (in) } \\
\end{array}$ & $\begin{array}{c}\text { Percentage of } \\
\text { Development Length } \\
\text { Obtained by Rail Seat } \\
\text { Section }\end{array}$ & $\begin{array}{c}\text { Percentage of } \\
\text { Development Length } \\
\text { Obtained by Center } \\
\text { Section }\end{array}$ \\
\hline Drawn Wire (W) (Baseline) & 0.21 & 25.92 & $83.72 \%$ & Development Obtained \\
\hline 7-Wire Strand (S) & 0.25 & 34.34 & $63.20 \%$ & Development Obtained \\
\hline 7-Wire Strand (S) & 0.3125 & 42.83 & $50.66 \%$ & Development Obtained \\
\hline 7-Wire Strand (S) & 0.375 & 48.33 & $44.90 \%$ & Development Obtained \\
\hline Carbon FRP (FRP) & 0.25 & 55.33 & $39.22 \%$ & $92.17 \%$ \\
\hline Carbon FRP (FRP) & 0.375 & 83.33 & $26.04 \%$ & $61.20 \%$ \\
\hline
\end{tabular}

${ }^{(1)}$ The stress in the steel prestressing at nominal moment is the maximum stress computed of all the layers in a cross-section determined using strain compatibility.

(2) The development length of steel prestressing is determined using the method discribed in $\mathrm{ACl} 318-08$ Section 12.9 Development of prestressing strand Equation (12-4). The development length of carbon FRP prestressing is determined using the method in $\mathrm{ACl} 440.4 \mathrm{R}-04$ Section 6.3 Flexural bond length Equation (6-2). 
Maximum Calculated Development Lengths of Prestressing Types with Respect to Prestressing Diameter

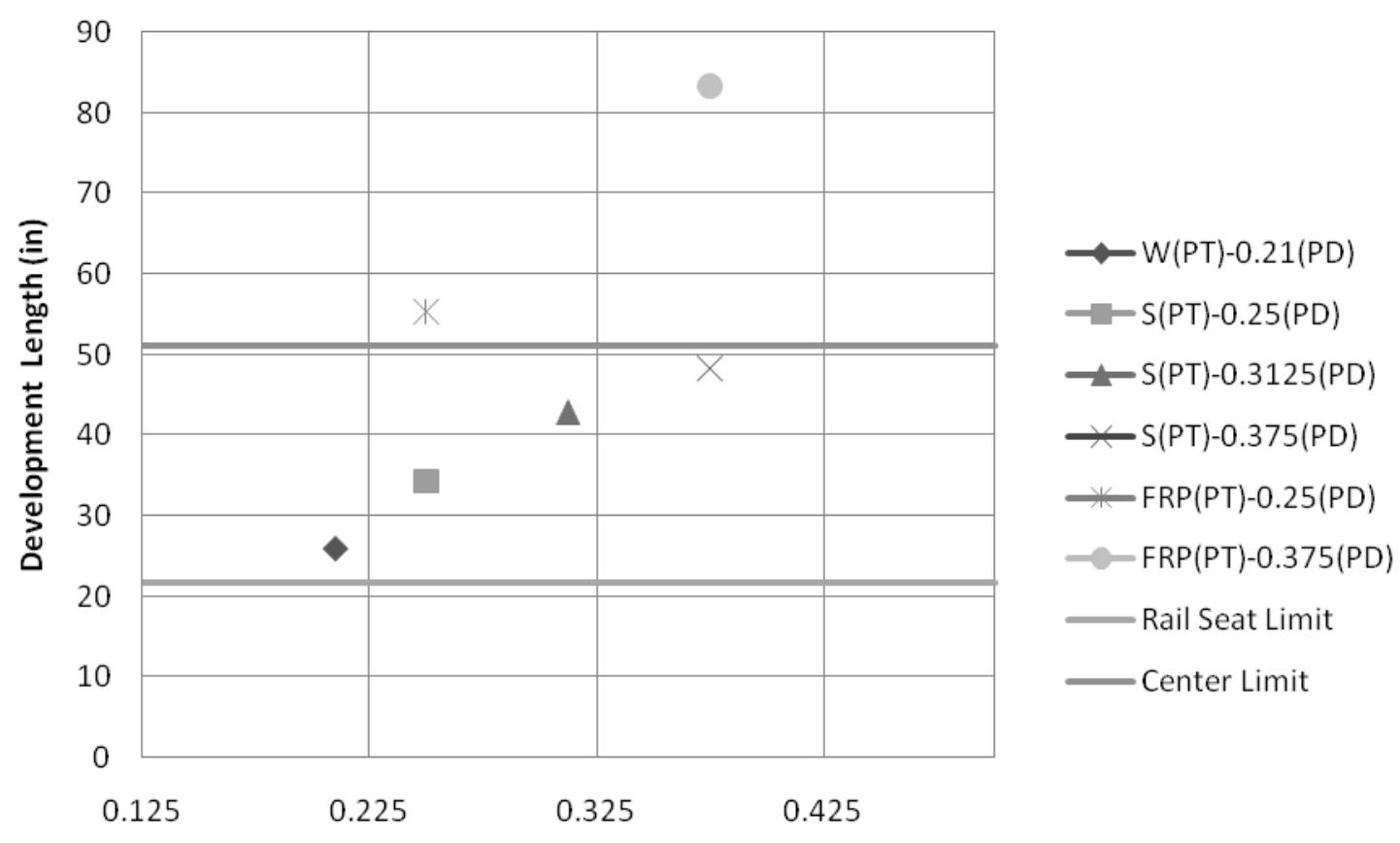

Prestressing Tendon Diameter, $\mathrm{db}$ (in)

Figure 75: Development lengths of prestressing for optimization iterations with distances to critical sections

For the rail seat section none of the prestressing combinations are capable of achieving full development. However, at the center section all steel prestressing combinations obtain full development while, FRP does not. For the prestressing combinations which did not achieve full development in the provided distance, the percentage of development obtained has been provided in Table 45. For the rail seat section the calculated required development length serves as an estimate since the calculated nominal moment capacity is a lower bound of the actual due to the deep beam condition. As for the center section, prestressing combinations which result in required development lengths larger than those available, require recalculation of the nominal moment capacity based on the maximum stress which can be developed given the provided distance. The only prestressing cases which did not achieve full development in the provided distance were the FRP iterations.

When development is not achieved by a critical section the stress in prestressing steel must be limited to the stress which can be achieved given the available development distance. To 
determine the allowable stress corresponding to the available development length, Equation 14 from Section 3.2.8 was rewritten to solve for the stress in the FRP prestressing at failure based on the distance between the section and the end of the tie (Eqn. 15). The bilinear relationship between prestressing stress and development length is illustrated in Figure 76. For the FRP prestressing combinations which did not achieve full development, using Equation 15, the maximum prestressing stress corresponding to the available development distance with effective prestressing at 50 years is given in Table 46. The maximum stress in the FRP tendons at ultimate capacity assuming full development for each design iteration is summarized in Table 47 and compared to the allowable prestressing stress based on the available development distance.

$$
\begin{aligned}
& f_{p s}=\left(\frac{4}{3}\right)\left(\frac{l_{d}}{d_{b}}-\frac{f_{s e}}{3}\right)+f_{s e} \\
& f_{p s}=\text { stress in prestressing corresponding to failure (ksi) } \\
& I_{d}=\text { available length for develpment of prestressing (in) } \\
& d_{b}=\text { diameter of prestressing tendon (in) } \\
& f_{s e}=\text { effective prestressing (ksi) }
\end{aligned}
$$

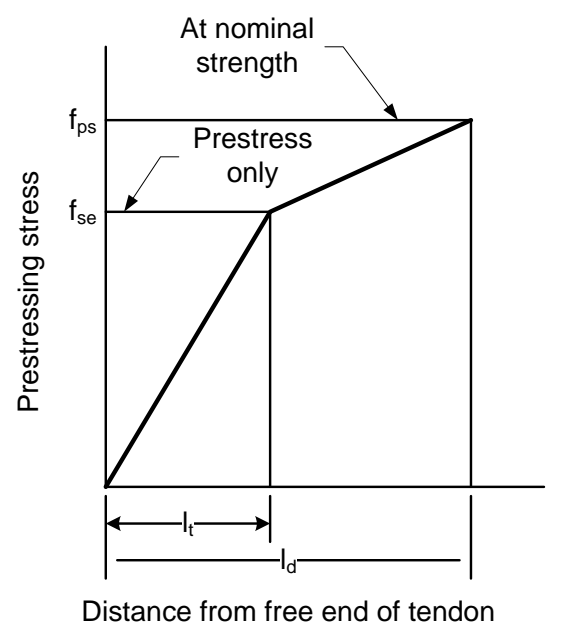

Figure 76: Bilinear relationship between prestressing stress and distance from free end of tendon 
Table 46: Allowable prestressing stresses corresponding to provided development length

\begin{tabular}{|c|c|c|c|c|}
\hline Prestressing Case & $\begin{array}{c}\text { Tendon } \\
\text { Diameter } \\
\text { (in) }\end{array}$ & $\begin{array}{c}\text { Maximum Effective } \\
\text { Prestress, } \mathbf{f}_{\text {pe }} \\
\text { (ksi) }\end{array}$ & $\begin{array}{c}\text { Available } \\
\text { Development Length } \\
\text { (in) }\end{array}$ & $\begin{array}{c}\text { Allowable Stress in } \\
\text { Prestressing, } \mathbf{f}_{\mathrm{ps}} \\
\text { (ksi) }\end{array}$ \\
\hline FRP(PT)-0.25(PD) & 0.25 & 233.8 & 51.0 & 401.9 \\
\hline FRP(PT)-0.375(PD) & 0.375 & 231.7 & 51.0 & 310.0 \\
\hline
\end{tabular}

Table 47: Maximum stress in prestressing at ultimate and allowable stress in prestressing based on development

\begin{tabular}{|c|c|c|}
\hline Prestressing Case & $\begin{array}{c}\text { Allowable Stress in } \\
\text { Prestressing, } \mathbf{f}_{\mathrm{ps}} \\
\text { (ksi) }\end{array}$ & $\begin{array}{c}\text { Maximum Stress in } \\
\text { Prestressing at Ultimate } \\
(\mathbf{k s i})\end{array}$ \\
\hline FRP(PT)-0.25(PD) & 401.9 & 280.6 \\
\hline FRP(PT)-0.375(PD) & 310.0 & 280.8 \\
\hline
\end{tabular}

Comparing the allowable stress in the FRP prestressing corresponding to the provided development length, to the stress calculated from strain compatibility based on full development at ultimate, it appears that the development provided is capable of achieving the required stress limits. Even though the prestressing will not be fully developed given the available development distance, the section can still achieve nominal capacity. This is because the nominal capacity is based on the maximum concrete strain of 0.003 not rupture of the prestressing. 


\subsection{Summary, Conclusions and Recommendations}

\subsection{Summary}

In response to the proposed increase in the applied loads to the railroad track structure in North America, this research project has been completed to evaluate and identify the design parameters of prestressed concrete railroad ties which offer the largest increases in flexural capacity while maintaining the baseline tie geometry. Design parameters which were considered include concrete compressive strength, prestressing type, strength, size and configuration. The investigation began with the design/analysis of an existing tie design which was considered to be the baseline capacity for the study. Following the validation of the analysis procedure developed during the baseline study with experimental results provided by the baseline tie manufacturer, a parametric optimization of concrete tie parameters was completed. The results of the parametric optimization suggest that an increase in concrete compressive strength, in combination with an increase in the diameter of prestressing tendons would provide considerable increases in the tie capacity.

\subsection{Conclusions}

Conclusions which were developed during the execution of the research project, about the design/analysis procedure of a prestressed concrete railroad ties and the design parameters which offer the greatest possibility of capacity increase include the following:

- The design compressive strength of 7,000 psi for the baseline tie numerical analysis underestimates the actual concrete compressive strength during service and at the time of the experimental testing which is likely between 9,500 and 12,000 psi,

- The theoretical prestressing loss for the center section was calculated to be larger than the experimental values, therefore the effective prestressing stress used in capacity calculation may be smaller than the actual value, decreasing the predicted capacity,

- The rail seat section has been determined to be a deep beam and therefore theoretical predictions based on pure flexure are no longer applicable and will likely underestimate the capacity of the section, 
- For lower levels of concrete strength, flexural capacity is governed by the allowable concrete stresses,

- As concrete strength increases, the governing factor of the tie capacity transitions from concrete stress to the quantity of prestressing which can be placed in the tie, while maintaining adequate spacing and cover,

- Smaller diameter prestressing tendons reach the governing limit of detailing before the larger tendon diameters due to the increase in the number of tendons required to achieve the same prestressing force,

- The order of prestressing types and diameters in terms of tie capacity from lowest to

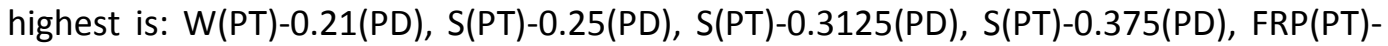
0.375(PD), FRP(PT)-0.25(PD),

- The anticipated tie capacity increases as concrete design strength increases,

- The first optimized tie design that should be tested is the S(PT)-0.375(PD)-7(CS), since the 0.375 in. diameter 7-wire strand is common prestressing type and size among other tie manufacturers and provides the largest increase in flexural capacity for all steel prestressing types considered by this study. This maintains the existing concrete mix design.

\subsection{Recommendations for Future Research}

Considering the work completed during this research project and the direction of future related work. A few topics of particular interest to the evaluation of prestressed concrete railroad ties which warrant further investigation include:

1) Finite element analysis of prestressed concrete tie behavior,

2) The construction and testing of the tie designs completed during the parametric optimization study,

3) Deep beam analysis of the rail seat region,

4) Capacity optimization including shape refinement of the cross-section,

5) Bursting stresses analysis of tie anchorage zone,

6) ASTM testing for creep and shrinkage values. 


\subsubsection{Numerical Analysis-FEA Modeling}

During the early stages of this research project the scope included the modeling of the baseline tie design and the designs developed during the parametric optimization using finite element analysis (FEA). The purpose of using FEA to model the ties was, first to have a second numerical method for comparison with experimental results for the baseline tie design and second, to provide a means of analyzing the nonlinear behavior of the tie designs. However, it quickly became apparent during the initial model development that the creation of a prestressed concrete tie model is remarkably complicated due to the following:

- The model must be capable of differentiating when the concrete elements have reached the allowable concrete stress conditions which correspond to failure.

- The model must be capable of operating within the nonlinear range of behavior to capture the ultimate capacity of the tie.

- The connection between the concrete and prestressing elements should be able to account for bond slip, transfer and development.

- Concrete railroad ties have variable boundary conditions due to the changing ballast support distributions.

Considering the above criteria the development of a prestressed concrete tie FEA is a project in itself and could simply not be completed during this project time frame. The initial findings of literature review related to modeling of prestressed concrete members using finite element analysis is presented in Appendix $\mathrm{E}$.

\subsubsection{Validation Testing-Optimized Tie Designs}

The next logical step in this project would be to construct the designs competed during the parametric optimization study and test them for validation of the analysis/design. The reason for the exemption of this phase from the scope of this project is cost of construction and testing and the lack of facilities to fabricate the ties. The testing of optimized tie designs should evaluate the following parameters:

- Losses,

- Transfer length,

- Development length,

- Allowable stresses (transfer and service-cracking), 
- Ultimate capacity.

In addition to testing of the various design parameters above, testing the capacities of ties at different ages is of interest, since the capacity of concrete ties changes as they age. The change in capacity is a result of concrete strength gain and prestressing losses over time. Therefore, testing of ties with ages ranging from days after castings to years later will provide an idea of the variation in capacity during the service life of the tie. This concept of capacity versus time could be made even more fascinating if ties exposed to service loads and fatigue effects were tested. The testing of the ties exposed to service would offer insight into the effect of loadings on long term capacity of a tie.

\subsubsection{Deep Beam Analysis}

During the evaluation of the rail seat section to determine the flexural capacity it was identified that the section is classified as a deep beam. The deep beam condition is a unique flexural member requiring a specific calculation procedure in order to determine the flexural capacity. In this project it was assumed that pure flexure governed all capacity analysis, however for the rail seat section this resulted in inaccurate results. To properly determine the flexural capacities both at service and ultimate for the rail seat section this portion of the project must be repeated, accounting for the deep beam condition.

\subsubsection{Shape Refinement}

This project focused on the optimization of only the prestressing properties and concrete strength of the prestressed concrete railroad tie while maintaining constant tie geometry. To provide a complete optimization of the prestressed concrete railroad tie however, variations in the shape of the tie should be considered as well. Shape optimization will focus on the length of the tie as well as the cross-sectional dimensions along the length of the tie. Optimizing the tie shape may lead to a more efficient design in terms of material placement and weight.

\subsubsection{Bursting Analysis}

The analysis completed in this study for the baseline tie and the optimized tie designs did not include consideration of bursting stresses in the anchorage zone of the tie ends. Future work should consider the effect of bursting stresses on prestressed concrete railroad ties. If bursting stresses due to the pre-compression forces appear to exceed allowable tensile stresses, solutions such as confining steel in the anchorage zone or possible cutting patterns at release 
should be analyzed. It should be noted however, that the baseline tie design does not include confining transverse reinforcement. Transverse reinforcement is impractical in the design of prestressed concrete ties due to the long-line fabrication method which is common among tie manufacturers. Therefore, it is of interest what changes to design or the fabrication process, other than confining reinforcement, can be made to reduce or cope with bursting stresses.

\subsubsection{ASTM Material Testing for Creep and Shrinkage}

For the development of theoretical prestressing loss predictions in this study, assumptions and approximations based on code specifications were made for the material properties of the prestressing and concrete ( $\mathrm{ACl}$ 2008; ACl Committee 440 2004; ASTM International 2006). A majority of such assumptions and approximations deal with the losses due to creep and shrinkage of the concrete. In an effort to achieve higher accuracy in the predictions of prestressing losses related to concrete creep and shrinkage; it is suggested that the results of experimental testing of the actual concrete mixes used in the fabrication of the ties be used to determine the material properties. Using ASTM tests for concrete creep and shrinkage, the material properties related to prestressing losses will be determined. 


\section{References}

Abbott, R. A. (1979). "Matching tie life to replacement cycle." Railway Track \& Structures, 75(7), 3.

Abbott, R. A. (1989). "Concrete Ties vs. Wood Ties: The Debate Continues." Railway Track and Structures, 85(3), 2.

ACI-ASCE Committee 423. (1958). "Tentative Recommendations for Prestressed Concrete." ACI Journal, 54(7), 545-578.

ACl. (1997). "State-of-the-Art Report on High-Strength Concrete (ACI 363R-92)." ACI 363R-92, $\mathrm{ACl}$, ed.

ACl. (2005). "Building Code Requirements for Structural Concrete (ACI 318-05) and Commentary (ACl 318R-05)." ACl 318-05, ACl, ed.

ACI. (2008). "Building Code Requirements for Structural Concrete (ACI 318-08) and Commentary (ACl 318R-08)." ACl, ed.

ACl Committee 209. (1992). "Prediction of Creep, Shrinkage, and Temperature Effects in Concrete Structures (ACl 209R-92)(Reapproved 1997)." American Concrete Institute.

ACl Committee 435. (1963). "Deflections of Prestressed Concrete Members (ACl 435.1R63)(Reapproved 1989)." ACl Journal, 60(12), 1697-1728.

ACI Committee 440. (2004). "Prestressing Concrete Structures with FRP Tendons." American Concrete Institute.

ALCAN RaiLink Inc. (2007). "Executive Report: Rails to Resources to Ports: The Alaska Canada Rail Link Project Phase 1 Feasibility Study." Yukon Government/State of Alaska, Whitehorse, YK.

AREMA. (2003). "AREMA Manual for Railway Engineering Part 4 Chapter 30 Concrete Ties." A. R. E. a. M.-o.-W. Association, ed., AREMA.

ASTM International. (2006). "ASTM Standard A 416/A416M-06 "Standard Specification for Steel Strand, Uncoated Seven-Wire for Prestressed Concrete"." DOI: 10.1520/A0416_A0416M-06 ASTM International, West Conshohocken, PA.

Cann, J. L. (1978). "CN Experience With Concrete Sleepers." Railway Gazette International, 134(2), 4. 
Fogarasi, G. J., Nijhawan, J. C., and Tadros, M. K. (1991). "World Overview of Flow Line Pretensioning Method." PCl Journal, 36(2), 18.

Freudenstein, S. (2007). "Concrete Ties Designed for High Dynamic Loads." AREMA Conference, Chicago, IL.

Freudenstein, S., and Haban, F. (2006). "Prestressed-Concrete Sleepers." European Railway Review(4), 73-79.

Gauntt, J. C., and Zarembski, A. M. (2000). "Analysis of Wood Cross-Tie Price Sensitivities." AREMA Conference, Dallas, TX, 40.

Hanna, A. N. (1975). "Railway Track Research-Theoretical and Experimental." Portland Cement Association.

Hanna, A. N. (1979). "Prestressed Concrete Ties for North American Railroads." PCl Journal, 24(5), 29.

Hanna, A. N. (1986). "Concrete Ties for U.S. Railroads-An Update." Portland Cement Association, Skokie, Illinois.

Heintz, J. (2000). "Prestressed Concrete Tie Production-Summary of the World wide most common used prestressed Concrete Tie Production Systems." AREMA Conference, Dallas, TX.

Jimenez, R., and LoPresti, J. (2004). "Performance of alternative tie material under heavy-axleload traffic." Railway Track and Structures, 100(1), 16(3).

Kaewunruen, S., and Remennikov, A. M. (2007). "Relationships between wheel/rail interface impact and railseat flexural moment of railway prestressed concrete sleepers." 2007 SEM Annual Conference and Exposition on Experimental and Applied Mechanics, Springfield, Massachusetts, USA, 3.

Kaewunruen, S., and Remennikov, A. M. (2008). "Experimental study of crack propagations in prestressed concrete sleepers in railway track systems subjected to severe impact loads." University of Wollongong.

Kramer, J. (1996). "Demanding the best: Track maintenance in severe environments." Railway Track \& Structures, 92(1), 3.

Logan, D. L. (2007). A First Course in the Finite Element Method, Nelson, Toronto. 
Lykidis, G. C., and Spiliopoulos, K. V. (2008). "3D Solid Finite-Element Analysis of Cyclically Loaded RC Structures Allowing Embedded Reinforcement Slippage." Journal of Structural Engineering, 134(4), 629-638.

Magee, G. M., and Ruble, E. J. (1960). "Progress Report: Service tests of prestressed concrete ties." Railway Track and Structures, 56(9), 33-36,82,84,88.

Mario, E. R., Juan, C. B., and Jaime, V. (1999). "Cyclic Stress-Strain Behavior of Reinforcing Steel Including Effect of Buckling." Journal of Structural Engineering, 125(6), 605-612.

McQueen, P. J. (2007). "Railseat Abrasion of Concrete Ties." Portland Cement Association, Skokie, Illinois.

Naaman, A. E. (2004). Prestressed Concrete Analysis and Design Fundamentals, Techno Press 3000, Ann Arbor.

Namura, A., Kohata, Y., and Miura, S. (2004). "Effect of Sleeper Size on Ballasted Track Settlement." Railway Technical Research Institute.

Nasreddin, E.-M., and Ergin, C. (1991). "Finite Element Analysis of Prestressed and Reinforced Concrete Structures." Journal of Structural Engineering, 117(10), 2851-2864.

NTSB. (2005). "Derailment of Amtrak Passenger train No. 27." National Transportation Safety Board.

Parker, L. (2002). "BNSF Tie Inspection System." AREMA Conference, 8.

PCl Committee on Prestress Losses. (1975). "Recommendations for Estimating Prestress Losses." Journal of the Prestressed Concrete Institute, 20(4), 43-75.

Peters, N., and Mattson, S. R. (2003). "CN 60E Concrete Tie Development ", Canadian National.

Peters, S. R. (2007). "Abrasion Testing of Epoxy-Coated Concrete Ties (Using Symons Product No. 301 Epoxy)." J.A. Cesare \& Associates, Inc.

Prestressed/Precast Concrete Institute. (2004). "PCI Design Handbook: Precast and Prestressed Concrete." PCl, ed.

Qinhua, J., Weiqing, L., and Liang, T. (1997). "Investigations on concrete railway ties suffering from alkali-silica reaction." Cement and Concrete Research, 27(1), 107-113.

Raymond, G. P. (1984). "Track Support Must be Right if Concrete Sleepers are to Survive." Railway Gazette International, 140(7), 3. 
Reiff, R. (1995). "An Evaluation of Remediation Technology for Concrete Tie Railseat Deterioration in the FAST Environment." Bulletin - American Railway Engineering Association, 96(753), 406-418.

Reiff, R. (2008). "Improved Performance Rail Insulators for Concrete Ties Field Testing Progress Report." Railway Track and Structures, 104(9), 35-37.

Reinschmidt, A. J. (1991). "Rail-seat abrasion: Cause and the search for the cure." Railway Track and Structures, 87, 2.

Remennikov, A. M., and Kaewunruen, S. (2007). "Resistance of railway concrete sleepers to impact loading." 7th International Conference on Shock \& Impact Loads on Structures, Beijing, China, 9.

Remennikov, A. M., Kaewunruen, S., and Ikaunieks, K. (2006). "Deterioration of dynamic rail pad characteristics." Conference of Railway Engineering, Melbourne, Australia.

Remennikov, A. M., Murray, M. H., and Kaewuruen, S. (2007). "Conversion of AS1085.14 for prestressed concrete sleepers to limit states design format." AusRAIL PLUS 2007, Sydney, Australia, 18.

Riessberger, K. (1984). "Treat Them Right and Concrete Sleepers Will Last Half-A-Century." Railway Gazette International, 140(7), 3.

Sahu, S., and Thaulow, N. (2004). "Delayed ettringite formation in Swedish concrete railroad ties." Cement and Concrete Research, 34(9), 1675-1681.

Sikka, N. K., and Singh, S. P. (1972). "Some Aspects of Design of Monoblock Prestressed Concrete Sleepers." Indian Railway Technical Bulletin, 185, 12.

Stark, D. (1976). "Characteristics of and Utilization of Coarse Aggregates Associated with DCracking." Portland Cement Association, Skokie, Illinois, USA.

Stark, D. (1989). "Effect of Length of Freezing Period on Durability of Concrete." Portland Cement Association, Skokie, Illinois.

Takahashi, T., Sekine, E., Horiike, T., Matsuoka, S., and Hoshiro, H. (2008). "Study on the Applicability of Short Fiber Reinforced Concrete to Precast Concrete Slabs for Slab Track." Railway Technical Research Institute.

Thun, H., Utsi, S., and Elfgren, L. (2008). "Load carrying capacity of cracked concrete railway sleepers." International Federation for Structural Concrete. 
Tourney, P. G., Marchand, J., and Maltais, Y. (2004). "Service Life Prediction of High Performance Concrete Mixture." IS601, Portland Cement Association.

White, D. W., Arnlund, R. C., and Prause, R. H. (1978). "Economics of Concrete and Wood Tie Track Construction." U.S. Department of Transportation, Washington D.C.

Wu, K., Yan, A., Yao, W., and Zhang, D. (2001). "Effect of metallic aggregate on strength and fracture properties of HPC." Cement and Concrete Research, 31, 6.

Zarembski, A. M. (1999). "Use of Track Strength in the Determination of Future Crosstie Requirements." AREMA Conference, Chicago, IL, 22.

Zarembski, A. M., and Gauntt, J. C. (2002). "Development of a Tie Usage Index for Matching Wood Performance and Operating Conditions." Railway Tie Association.

Zia, P., Preston, H. K., Scott, N. L., and Workman, E. B. (1979). "Estimating Prestress Losses." Concrete International: Design \& Construction, 1(6), 32-38. 
Appendix A: Baseline Tie Drawings 


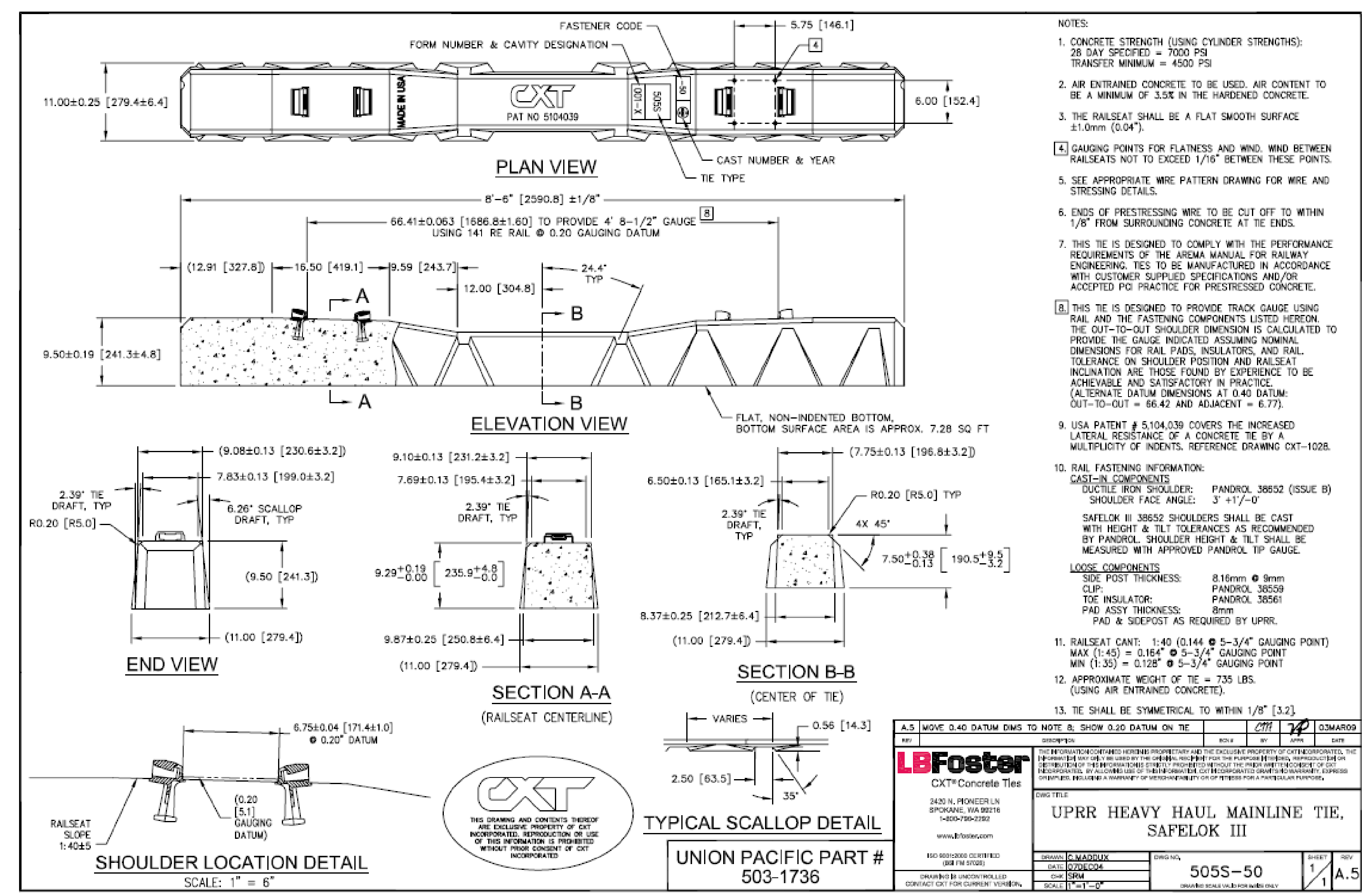




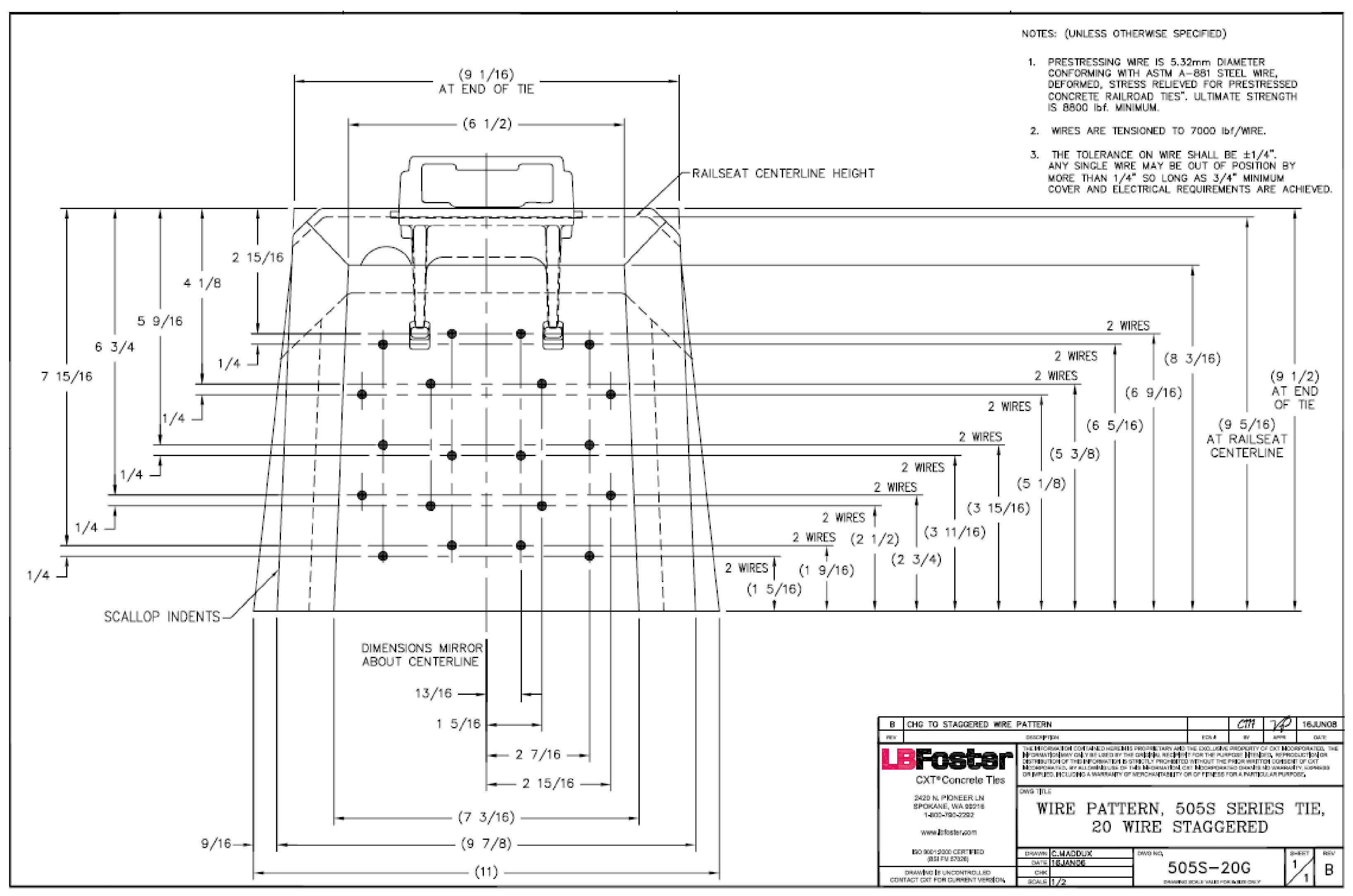




\section{Appendix B: Baseline Tie Design Summary Sheet}

Table 48: Baseline tie design summary sheet

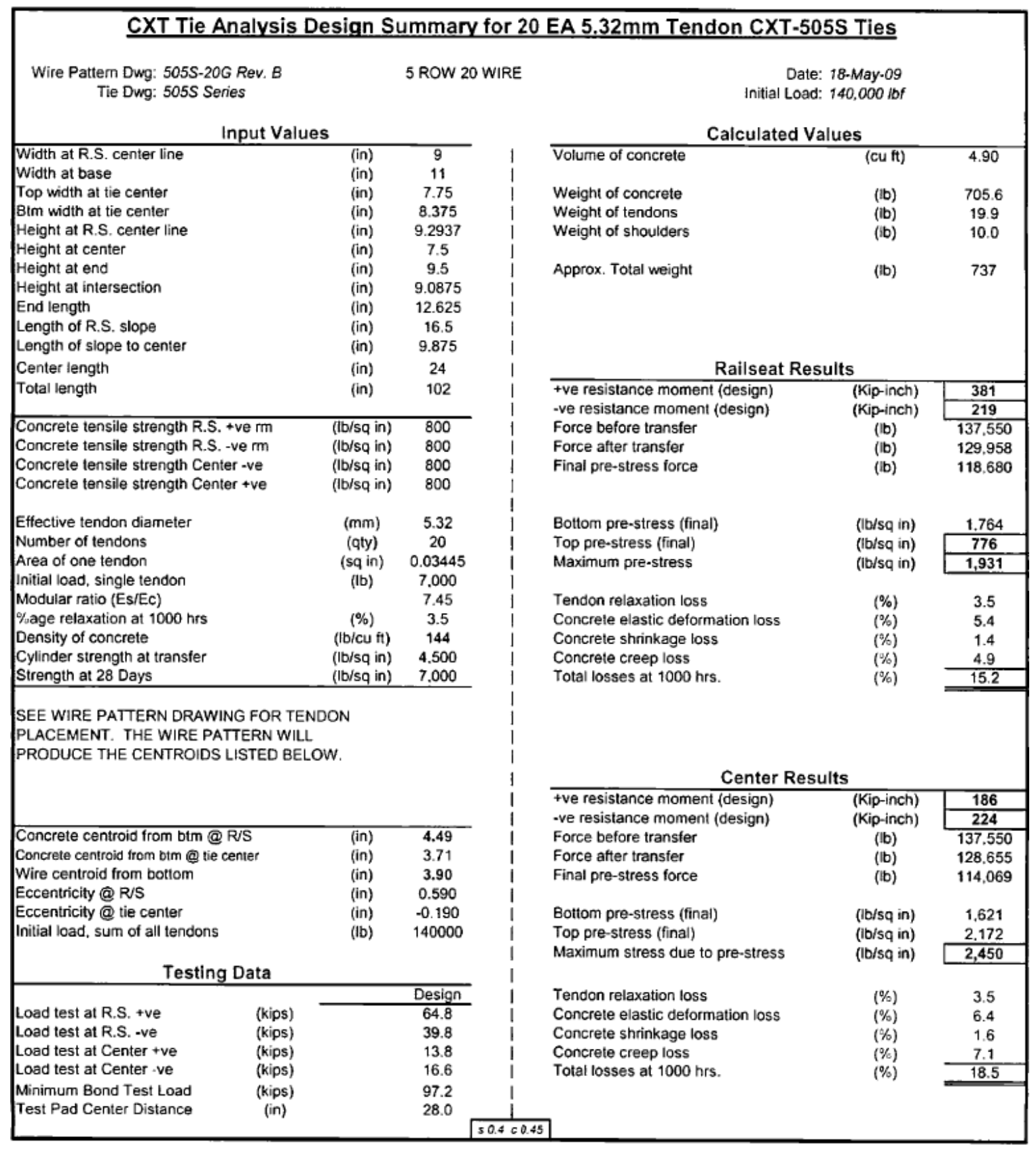


Appendix C: Optimization Iteration Matrix 



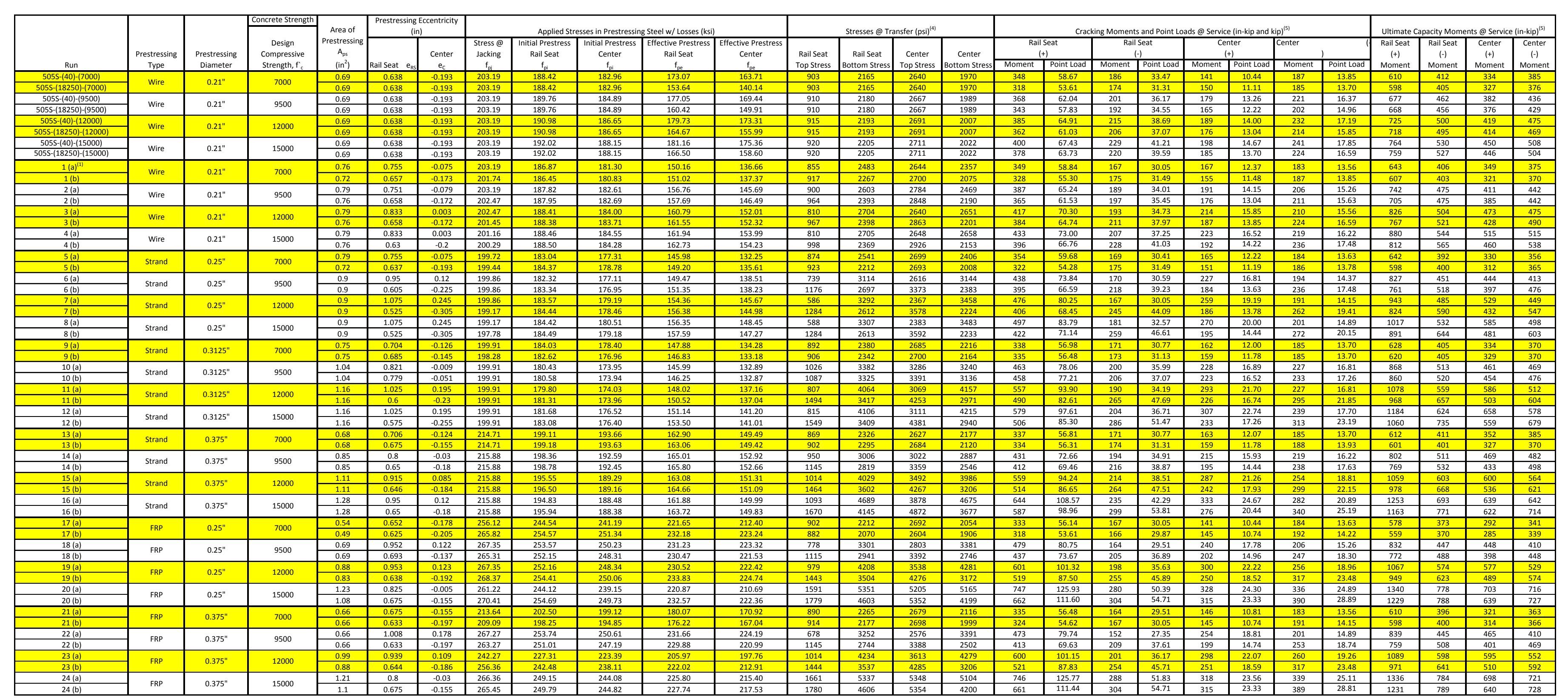




\title{
Appendix D: Baseline Tie Analysis
}

\section{1.0 Baseline Tie Analysis (MathCAD Guide)}

\author{
W(PT)-0.21(PD)-7(CS)-Baseline
}

\section{Objective}

Determine the positive and negative moment capacities for the critical sections identified in the 2003 AREMA Manual (center and rail seat regions). This information will then be compared to experimental data.

\section{Additional Design/Analysis Information}

- Use AREMA 2003, ACI 318-08, ACI Manual of Concrete Practice 2002 and PCI Handbook 6th Edition for analysis.

- Information provided by tie manufacturer in referenced drawings of exisitng tie design (Drawing Numbers: $505 \mathrm{~S}-20 \mathrm{G}, 505 \mathrm{~S}-50$ ) contained in Appendix A and design summary sheet in Appendix B.

- Information provided in metric units will be converted to standard units to match design codes utilized in analysis.

\section{Gritical Section Views}
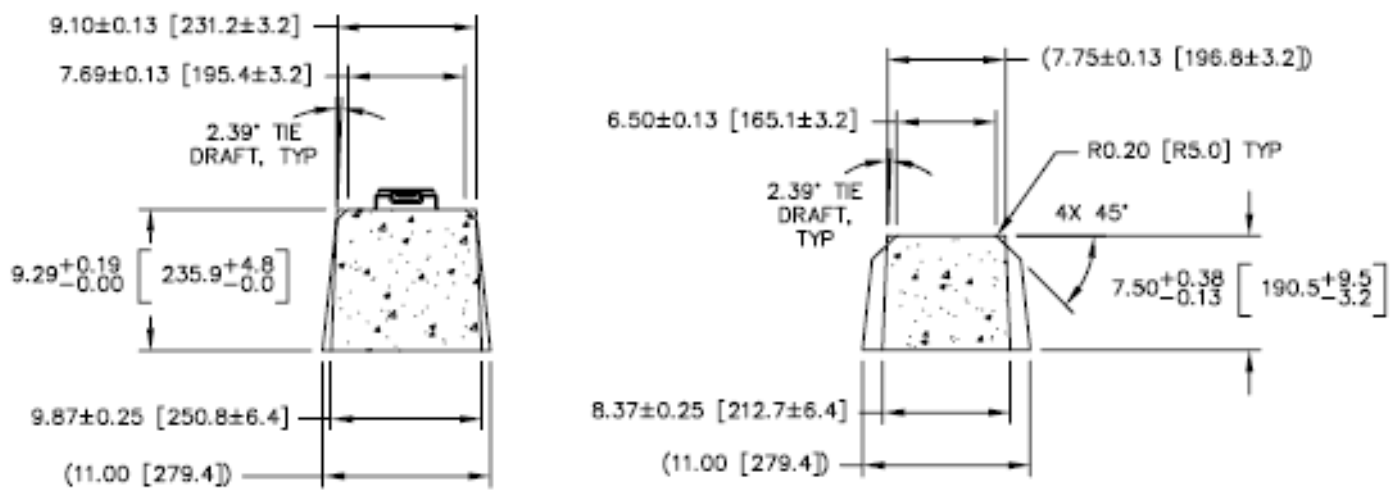


\section{Cross-Section Details}

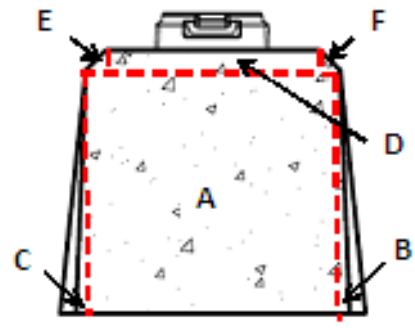

Rail Seat Section

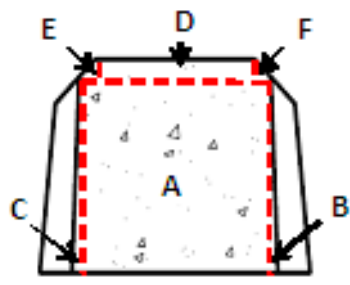

Center Section

\begin{tabular}{|c|c|c|c|c|c|c|c|c|}
\hline \multicolumn{9}{|c|}{$\mathrm{I}_{\mathrm{x}}$ Rail Seat Section } \\
\hline Component & b & $\mathrm{h}$ & $\mathrm{A}$ & $\mathrm{y}$ & Ay & $\mathrm{I}_{\mathrm{ber}}$ & d & $\mathrm{I}_{\mathrm{ber}}+\mathrm{Ad}^{2}$ \\
\hline A & 9.10 & 8.59 & 78.12 & 4.29 & 335.35 & 479.82 & 0.26 & 485.12 \\
\hline B & 0.39 & 8.59 & 1.65 & 2.86 & 4.73 & 6.77 & 1.69 & 11.49 \\
\hline C & 0.39 & 8.59 & 1.65 & 2.86 & 4.73 & 6.77 & 1.69 & 11.49 \\
\hline D & 7.69 & 0.71 & 5.42 & 8.94 & 48.45 & 0.22 & -4.38 & 104.46 \\
\hline$E$ & 0.71 & 0.71 & 0.25 & 8.82 & 2.22 & 0.01 & -4.27 & 4.60 \\
\hline$F$ & 0.71 & 0.71 & 0.25 & 8.82 & 2.22 & 0.01 & -4.27 & 4.60 \\
\hline Sum & & & 87.35 & & 397.70 & & & 621.76 \\
\hline$V_{b a r}$ & 4.55 & & & & & & & \\
\hline
\end{tabular}

\begin{tabular}{|l|c|c|c|c|c|c|c|c|}
\hline \multicolumn{7}{|c|}{$\mathrm{I}_{\mathbf{x}}$ Center Section } \\
\hline Component & $\mathbf{b}$ & $\mathrm{h}$ & $\mathrm{A}$ & $\mathrm{y}$ & $\mathrm{Ay}$ & $\mathrm{I}_{\text {ber }}$ & $\mathrm{d}$ & $\mathrm{I}_{\text {ber }}+\mathrm{Ad}^{2}$ \\
\hline A & 7.75 & 6.88 & 53.28 & 3.44 & 183.15 & 209.86 & 0.28 & 214.14 \\
\hline B & 0.31 & 6.88 & 0.11 & 2.29 & 0.24 & 2.80 & 1.43 & 3.02 \\
\hline C & 0.31 & 6.88 & 0.11 & 2.29 & 0.24 & 2.80 & 1.43 & 3.02 \\
\hline D & 6.50 & 0.63 & 4.06 & 7.19 & 29.20 & 0.13 & -3.47 & 48.96 \\
\hline E & 0.63 & 0.63 & 0.20 & 7.08 & 1.38 & 0.00 & -3.36 & 2.21 \\
\hline F & 0.63 & 0.63 & 0.20 & 7.08 & 1.38 & 0.00 & -3.36 & 2.21 \\
\hline Sum & & & 57.95 & & 215.61 & & & 273.55 \\
\hline Ybar & 3.72 & & & & & & &
\end{tabular}

\section{Tie Geometry Constants}
$\mathrm{A}_{\text {c_RS }}:=87.35 \mathrm{in}^{2}$
$I_{x \_R S}:=621.76 \operatorname{in}^{4}$
$\mathrm{yb}_{\mathrm{B}} \mathrm{RS}:=4.55 \mathrm{in}$
$\mathrm{A}_{\mathrm{c}_{-} \mathrm{C}}:=57.95 \mathrm{in}^{2}$
$I_{x_{-} C}:=273.55 \operatorname{in}^{4}$
$\mathrm{y}_{\mathrm{b}} \mathrm{C}:=3.72 \mathrm{in}$
$\mathrm{y}_{\mathrm{t} \_\mathrm{RS}}:=9.29 \mathrm{in}-\mathrm{y}_{\mathrm{b} \_\mathrm{RS}} *$
$\mathrm{y}_{\mathrm{t} \_\mathrm{RS}}=4.74 \mathrm{in}$
$\mathrm{y}_{\mathrm{t} \_\mathrm{C}}:=7.50 \mathrm{in}-\mathrm{y}_{\mathrm{b} \_\mathrm{C}} *$
$\mathrm{y}_{\mathrm{t} \_\mathrm{C}}=3.78 \mathrm{in}$ 


\section{Prestressing Centroid and Eccentricities}

Inidividual prestressing tendon diameter and area:

$$
\begin{aligned}
& \mathrm{d}_{\text {tendon }}:=5.32 \mathrm{~mm} \\
& \text { A }_{\text {tendon }}:=0.03445 \mathrm{in}^{2}
\end{aligned}
$$

The total area of prestressing in a cross-section:

$$
\begin{aligned}
& \text { number_of_tendons }:=20 \\
& \text { Aps }_{\mathrm{ps}}:=\text { number_of_tendons } \cdot \text { A }_{\text {tendon }} \\
& \text { A }_{\mathrm{ps}}=0.689 \mathrm{in}^{2}
\end{aligned}
$$

The distance from the bottom of the tie to the centroid of the prestressing:

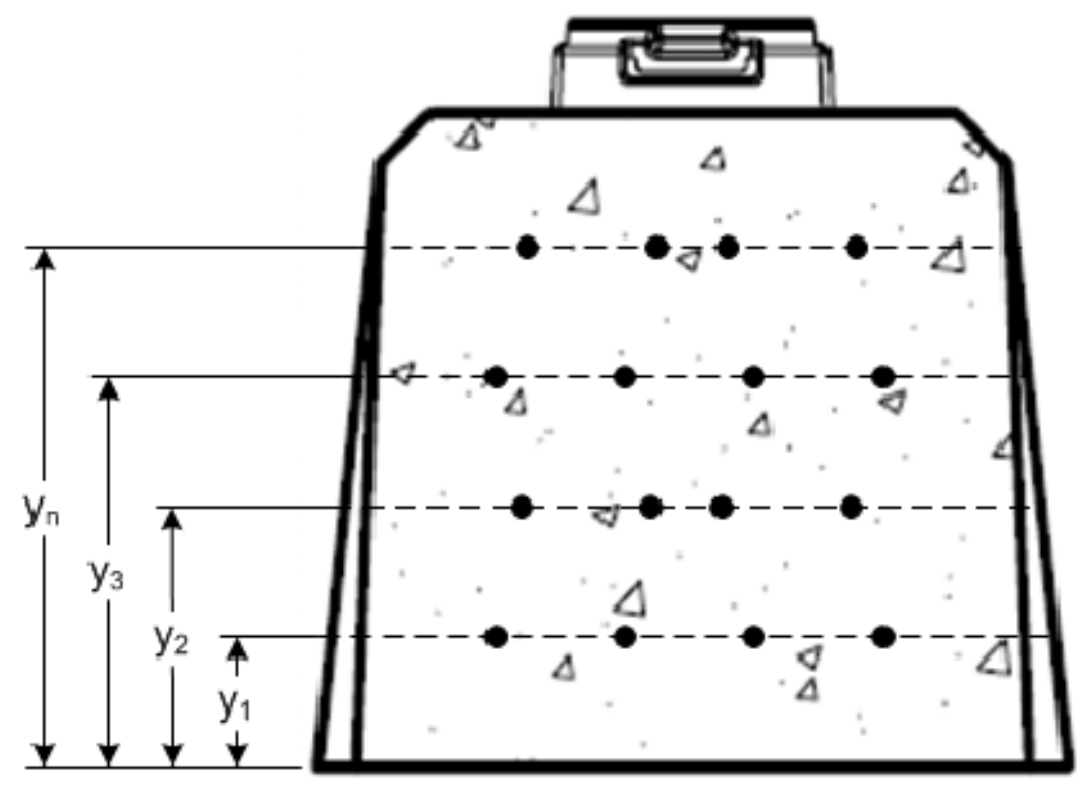




\begin{tabular}{|c|c|c|c|c|}
\hline \multicolumn{5}{|c|}{ Prestressing Centroid Calculator } \\
\hline Layer Number & $\begin{array}{l}\text { Number of } \\
\text { Tendons in } \\
\text { Layer }\end{array}$ & $\begin{array}{c}\text { Area of Tendons in } \\
\text { Layer } \\
\text { (A) }\left(\mathrm{in}^{2}\right) \\
\end{array}$ & $\begin{array}{l}\text { Distance of Layer } \\
\text { From Bottom } \\
\text { (y) (in.) }\end{array}$ & Ay \\
\hline 1 & 2 & 0.07 & 1.3125 & 0.09092 \\
\hline 2 & 2 & 0.07 & 1.5625 & 0.108238 \\
\hline 3 & 2 & 0.07 & 2.5 & 0.17318 \\
\hline 4 & 2 & 0.07 & 2.75 & 0.190498 \\
\hline 5 & 2 & 0.07 & 3.6875 & 0.255441 \\
\hline 6 & 2 & 0.07 & 3.9375 & 0.272759 \\
\hline 7 & 2 & 0.07 & 5.125 & 0.35502 \\
\hline 8 & 2 & 0.07 & 5.375 & 0.372338 \\
\hline 9 & 2 & 0.07 & 6.3125 & 0.43728 \\
\hline 10 & 2 & 0.07 & 6.5625 & 0.454598 \\
\hline 11 & 0 & 0.00 & 0 & 0 \\
\hline 12 & 0 & 0.00 & 0 & 0 \\
\hline 13 & 0 & 0.00 & 0 & 0 \\
\hline 14 & 0 & 0.00 & 0 & 0 \\
\hline 15 & 0 & 0.00 & 0 & 0 \\
\hline Totals & 20 & 0.69 & & 2.710272 \\
\hline & & & $\mathrm{y}_{\text {steel centroid }}$ (in.) & 3.9125 \\
\hline
\end{tabular}

Since the bottom of the tie is flat, this value is constant for all sections. Therefore the eccentricities with respect to the critical sections are (assume eccentricity below concrete centroid to be positive):

\begin{tabular}{|c|c|c|}
\hline \multicolumn{3}{|c|}{ Prestressing Eccentricity Calculator } \\
\hline $\begin{array}{c}\text { Eccentricity } \\
\text { Location }\end{array}$ & $\begin{array}{c}y_{\text {concrete centroid }} \\
\text { (in.) }\end{array}$ & $\begin{array}{c}\text { Eccentricity } \\
\text { (in.) }\end{array}$ \\
\hline Rail Seat $\left(e_{\mathrm{RS}}\right)$ & 4.55 & 0.6375 \\
\hline Center $\left(\mathrm{e}_{\mathrm{C}}\right)$ & 3.72 & -0.1925 \\
\hline
\end{tabular}

$$
\begin{aligned}
& { }^{\mathrm{e}_{\mathrm{RS}}}:=0.637 \mathrm{sin} \\
& \mathrm{e}_{\mathrm{C}}:=-0.1925 \mathrm{in}
\end{aligned}
$$




\section{Concrete Properties}

All concrete strengths are based on assumed 28 day design strength as stated within interation matrix (Appendix C). Strength of concrete at transfer has been calculated using maturity equation (2-1) from $\mathrm{ACI}$ $209 \mathrm{R}-92$ unless specified otherwise (for 7000 psi iterations use $4500 \mathrm{psi}$ ). ACI 363R-92, the design specification for concrete with a compressive strength greater than $10000 \mathrm{psi}$ does not have a maturity equation to approximate concrete strength based on a 28 day design strength. Therefore, the approximation discribed in ACI $209 \mathrm{R}$ will be used for all iterations excluding those for $7000 \mathrm{psi}$ strength concrete.

$$
\begin{array}{ll}
\mathrm{f}_{\mathrm{c}}:=7000 \mathrm{psi} & \mathrm{f}_{\mathrm{c}}=7000 \mathrm{psi} \\
\mathrm{E}_{\mathrm{c}}:=57000 \cdot \sqrt{\mathrm{psi}} \cdot \sqrt{\mathrm{f}_{\mathrm{c}}} & \mathrm{E}_{\mathrm{c}}=4768.96215 \mathrm{ksi} \\
\mathrm{f}_{\mathrm{ci}}:=4500 \mathrm{psi} & \mathrm{f}_{\mathrm{ci}}=4500 \mathrm{psi} \\
\mathrm{E}_{\mathrm{ci}}:=57000 \cdot \sqrt{\mathrm{psi}} \cdot \sqrt{\mathrm{f}_{\mathrm{ci}}} & \mathrm{E}_{\mathrm{ci}}=3823.67624 \mathrm{ksi}
\end{array}
$$

Allowable concrete stresses per ACI 318-08 code specifications for all compressive concrete design strengths. Even though ACI 318-08 is only applicable to concrete compressive strength less than 10000 $\mathrm{psi}$, it will be used for all iterations (for all calculations tension is negative and compression is positive).

Extreme fiber stress in tension (0) transfer, ACI 318-08 18.4.1(b):

$$
\sigma_{\mathrm{ti}}:=-3 \cdot \sqrt{\mathrm{psi}} \cdot \sqrt{\mathrm{f}_{\mathrm{ci}}}
$$$$
\sigma_{\mathrm{ti}}=-201.24612 \mathrm{psi}
$$

Extreme fiber stress in tension (0) service, ACI 318-08 18.3.3 Class U:

$$
\sigma_{\mathrm{ts}}:=-7.5 \cdot \sqrt{\mathrm{psi}} \cdot \sqrt{\mathrm{f}_{\mathrm{c}}} \quad \sigma_{\mathrm{ts}}=-627.49502 \mathrm{psi}
$$

Extreme fiber stress in compression (d) transfer, ACI 318-08 18.4 .1 (a):

$$
\sigma_{\mathrm{ci}}:=0.6 \cdot \mathrm{f}_{\mathrm{ci}} \quad \sigma_{\mathrm{ci}}=2700 \mathrm{psi}
$$

Extreme fiber stress in compression (0) service (P/S \& SDL), ACI 318-08 18.4.2 (a):

$$
\sigma_{\mathrm{cs}}:=0.45 \cdot \mathrm{f}_{\mathrm{c}} \quad \sigma_{\mathrm{cs}}=3150 \mathrm{psi}
$$

Extreme fiber stress in compression (0) service (P/S \& total load), ACI 318-08 18.4.2 (b):

$$
\sigma_{\mathrm{cs} 2}:=0.6 \cdot \mathrm{f}_{\mathrm{c}} \quad \sigma_{\mathrm{cs} 2}=4200 \mathrm{psi}
$$




\section{Steel Properties}

Ultimate strength specified by prestressing manufacture:

$$
\begin{aligned}
& \mathrm{P}_{\text {ultimate }}:=8800 \mathrm{lbf} \\
& \mathrm{f}_{\mathrm{pu}}:=\frac{\mathrm{P}_{\text {ultimate }}}{\mathrm{A}_{\text {tendon }}}
\end{aligned}
$$$$
\mathrm{f}_{\mathrm{pu}}=255.44267 \mathrm{ksi}
$$

Yield strength specified by prestressing manufacture:

$$
\begin{aligned}
& \mathrm{P}_{\text {yield }}:=79201 \mathrm{bf} \\
& \mathrm{f}_{\mathrm{py}}:=\frac{\mathrm{P}_{\text {yield }}}{\mathrm{A}_{\text {tendon }}}
\end{aligned}
$$

$f_{p y}=229.8984 k s i$

Elastic modulus specified by prestressing manufacture:

$$
\mathrm{E}_{\mathrm{ps}}:=28500 \mathrm{ksi}
$$

\section{Prestressing Forces/Losses:}

The initial jacking force/stress prior to anchorage losses should be set to use the full capacity of each prestressing tendon. Change the prestressing jacking force to the maximum with respect to ACI 318-08 permissible stressses in prestressing. For this iteration the prestressing jacking force has been set by tie manufacturer since this is an existing tie design being analyzed.

$$
\begin{aligned}
& F_{p j}:=70001 b f \\
& f_{p j}:=\frac{F_{p j}}{A_{\text {tendon }}}
\end{aligned}
$$

$$
\mathrm{f}_{\mathrm{pj}}=203.19303 \mathrm{ksi}
$$

For this iteration since it is an analysis of an existing tie design with experimental results for inital prestressing force, the experimental result for inital prestressing force will be compared with that obtained by caluclating the prestressing losses using theoretical methods.This will help determine the assumptions made for the remaining iterations related to prestressing loss. Losses at the rail seat and center sections will vary since the cross-sectional geometry changes. The average total prestressing force measured by tie manufacturer after losses due to anchorage, short term relaxation (initial curing period), and elastic shortening is:

$$
\begin{aligned}
& P_{\text {i_RS }}:=129.958 \mathrm{kip} \\
& P_{\text {i_C }}:=128.655 \mathrm{kip} \\
& f_{\mathrm{pi} \text { RS }}:=\frac{\mathrm{P}_{\mathrm{i} \_\mathrm{RS}}}{\mathrm{A}_{\mathrm{ps}}} \\
& \mathrm{f}_{\mathrm{pi} \_\mathrm{C}}:=\frac{\mathrm{P}_{\mathrm{i} \_\mathrm{C}}}{\mathrm{A}_{\mathrm{ps}}}
\end{aligned}
$$

$$
\begin{aligned}
& \mathrm{f}_{\mathrm{pi} \_\mathrm{RS}}=188.61829 \mathrm{ksi} \\
& \mathrm{f}_{\mathrm{pi} \_\mathrm{C}}=186.72714 \mathrm{ksi}
\end{aligned}
$$


Based on the experimental initial prestressing force result, the corresponding initial stress losses between jacking and after transfer are:

$$
\begin{array}{ll}
\Delta \mathrm{f}_{\mathrm{pi} \_\mathrm{RS}}:=\mathrm{f}_{\mathrm{pj}}-\mathrm{f}_{\mathrm{pi} \_\mathrm{RS}} & \Delta \mathrm{f}_{\mathrm{pi} \_\mathrm{RS}}=14.57475 \mathrm{ksi} \\
\Delta \mathrm{f}_{\mathrm{pi} \_\mathrm{C}}:=\mathrm{f}_{\mathrm{pj}}-\mathrm{f}_{\mathrm{pi} \_\mathrm{C}} & \Delta \mathrm{f}_{\mathrm{pi} \_\mathrm{C}}=16.46589 \mathrm{ksi}
\end{array}
$$

Check permissible stresses in prestressing steel, ACI 318-08 18.5.

The tensile stress in prestressing steel shall not exceed the following:

(a) Due to prestressing steel jacking force:

$$
0.94 \mathrm{f}_{\mathrm{py}}=216.1045 \mathrm{ksi} \quad \mathrm{f}_{\mathrm{pj}}<0.94 \mathrm{f}_{\mathrm{py}} \quad \text { O.K. }
$$

but not greater than the lesser of $0.80 \mathrm{f}_{\mathrm{pu}}$ and the maximum value recommended by the manufacturer of prestressing or ancorage devices.

$$
0.8 \cdot \mathrm{f}_{\mathrm{pu}}=204.35414 \mathrm{ksi}
$$$$
\mathrm{f}_{\mathrm{pj}}<0.80 \mathrm{f}_{\mathrm{pu}}
$$

O.K.

No manufacturer limitations have been provided.

(b) Immediately after prestress transfer (includes anchorage, short term relaxation and elastic shortening losses):

$$
0.82 \cdot f_{\mathrm{py}}=188.51669 \mathrm{ksi} \quad \mathrm{f}_{\mathrm{pi}}<0.82 \cdot \mathrm{f}_{\mathrm{py}}
$$

but not greater than:

$$
0.74 \cdot \mathrm{f}_{\mathrm{pu}}=189.02758 \mathrm{ksi}
$$$$
\mathrm{f}_{\mathrm{pi}}<0.74 \cdot \mathrm{f}_{\mathrm{pu}}
$$

Lump sum losses of 15.2 and 18.5 percent for the time dependent losses at the rail seat and center respectively have been obsevered in test specimens after 1000 hours. Therefore, the final stress in the prestressing steel is:

$$
\begin{array}{ll}
\eta_{\mathrm{RS}}:=1-0.152 * & \eta_{\mathrm{RS}}=0.848 \\
\eta_{\mathrm{C}}:=1-0.185 * & \eta_{\mathrm{C}}=0.815 \\
\mathrm{f}_{\mathrm{pe} \_\mathrm{RS}}:=\eta_{\mathrm{RS}} \cdot \mathrm{f}_{\mathrm{pj}} & \mathrm{f}_{\mathrm{pe} \_\mathrm{RS}}=172.30769 \mathrm{ksi} \\
\mathrm{f}_{\mathrm{pe} \_\mathrm{C}}:=\eta_{\mathrm{C}} \cdot \mathrm{f}_{\mathrm{pj}} & \mathrm{f}_{\mathrm{pe} \_\mathrm{C}}=165.60232 \mathrm{ksi}
\end{array}
$$

To calaculate the prestress losses using theoreteical methods, the time step technique outlined in Naaman 2004 is used (reference can be found in reference section of report). This process is similar to that discribed by the PCI Design Handbook which is referenced by ACI 318-08 since no method is presented in the ACI 318-08 manual for calculating prestressing losses. The time step method is more accurate than a lump sum estimate since cause and relationship effects between loss sources are considered (Naaman 2004).

Calculate losses at 40 days (approximately 1000 hours) since this is the time interval at which prestressing loss experimental results have been provided by the tie manufacturer. Since the tie cross-section is not unifrom, losses will vary along length of the tie. Calculate the total prestressing losses at both rail seat and center sections. 


\section{Theoretical Prestress Loss at Rail Seat}

All references to equations, tables and figures are from Naaman 2004 for the determination of losses.

Use Table 2.9 to determine humidity correction factors for creep and shrinkage, assume an age at transfer of $t_{\mathrm{A}}=1$ day. Assume a relative humidity of 50 percent and steam-cured conditions.

$$
\begin{array}{ll}
\mathrm{t}_{\mathrm{A}}:=1 \quad \text { unitless in constant equations } & \\
\mathrm{H}:=50 \quad \text { H must be given in percent } & \\
\mathrm{K}_{\mathrm{CH}}:=1.27-0.0067 \cdot \mathrm{H} * & \mathrm{~K}_{\mathrm{CH}}=0.935 \\
\mathrm{~K}_{\mathrm{CA}}:=1.13 \cdot \mathrm{t}_{\mathrm{A}}^{-0.095 *} & \mathrm{~K}_{\mathrm{CA}}=1.13 \\
\mathrm{~K}_{\mathrm{SH}}:=1.40-0.01 \cdot \mathrm{H} * & \mathrm{~K}_{\mathrm{SH}}=0.9
\end{array}
$$

From Table 2.10 determine size and shape factors for creep and shrinkage based on the volume-to-surface ratio.

$$
\begin{aligned}
& \text { Perimeter_RS }:=38.86 \mathrm{in} \\
& \text { Lateral_Surface_Per_Unit_Length_RS }:=1 \cdot \text { in.Perimeter_RS }
\end{aligned}
$$

Use linear interpolation to calculate values corresponding to volume to-to-surface ratio.

$$
\mathrm{K}_{\mathrm{SS}}:=0.93
$$

Given

$$
\frac{0.96-\mathrm{K}_{\mathrm{SS}}}{0.96-0.86}=\frac{2 \text { in }- \text { V_S }}{2 \mathrm{in}-3 \text { in }}
$$

$$
\begin{aligned}
& \mathrm{K}_{\mathrm{SS}}:=\operatorname{Find}\left(\mathrm{K}_{\mathrm{SS}}\right) \\
& \mathrm{K}_{\mathrm{CS}}:=0.93 \\
& \text { Given } \\
& \qquad \frac{0.96-\mathrm{K}_{\mathrm{CS}}}{0.96-0.87}=\frac{2 \operatorname{in}-V_{-}}{2 \operatorname{in}-3 \operatorname{in}} \\
& \mathrm{K}_{\mathrm{CS}}:=\operatorname{Find}\left(\mathrm{K}_{\mathrm{CS}}\right)
\end{aligned}
$$$$
\mathrm{K}_{\mathrm{SS}}=0.93522
$$$$
\mathrm{K}_{\mathrm{CS}}=0.9377
$$ 
Time intervals for the computation of losses are; $1,3,7,28,40,365,1825$ ( 5 years), 18250 days ( 50 years).

Losses before and during stress transfer:

The interval of time which these losses take place is $0-24$ hours ( 1 day). The stress at hour zero after jacking and anchorage set is the following:

$$
\mathrm{f}_{\mathrm{pj}}=203.19303 \mathrm{ksi} \quad \text { provided by tie manufacturer }
$$

The relaxation losses during the inital curing period $\left(\Delta f_{\mathrm{pr}}\right)$ of 24 hours $(1$ day) according to Equation 8.17 is (low relaxation steel):

$$
\begin{aligned}
& \mathrm{K}:=40 \quad \text { low relaxation steel } \\
& \Delta \mathrm{f}_{\mathrm{pr} 1}:=\frac{\log \left(24 \cdot \mathrm{t}_{\mathrm{A}}\right)}{\mathrm{K}} \cdot\left(\frac{\mathrm{f}_{\mathrm{pj}}}{\mathrm{f}_{\mathrm{py}}}-0.55\right) \cdot \mathrm{f}_{\mathrm{pj}} * \quad \Delta \mathrm{f}_{\mathrm{pr} 1}=2.34062 \mathrm{ksi}
\end{aligned}
$$

The losses due to elastic shortening is given by Equation 8.21. For the self-weight moment assume a simply supported condition (this is consistent with the tie being stored in stacks shortly after transfer, seperated with cribbing at the ends of the ties as well as cambering of the tie inside the form).

Self-weight moment acting on tie during elastic shortening period:

$$
\begin{aligned}
& \mathrm{L}:=8.5 \mathrm{ft} \\
& \text { Tie_Weight }:=7351 \mathrm{bf} \\
& \mathrm{w}_{\mathrm{G}}:=\frac{\text { Tie_Weight }}{\mathrm{L}} \quad \text { distance of rail seat section from end of tie } \\
& \mathrm{x}:=21.7 \mathrm{in} \quad \mathrm{w}_{\mathrm{G}}=86.47059 \mathrm{plf} \\
& \mathrm{M}_{\mathrm{G}}:=\frac{\mathrm{w}_{\mathrm{G}} \cdot \mathrm{x}}{2}(\mathrm{~L}-\mathrm{x}) \quad \mathrm{M}_{\mathrm{G}}=6.27816 \mathrm{in} \cdot \mathrm{kip}
\end{aligned}
$$

The stress in the concrete at the centroid of the prestressing steel due to the self-weight of the tie is:

$$
f_{\text {cgpG }}:=\frac{M_{G_{G}} \cdot e_{\mathrm{RS}}}{I_{x_{-} R S}} \quad f_{\text {cgpG }}=0.00644 k s i
$$

Determine the stress in the concrete due to the prestressing force. The prestressing force including the losses due to the initial prestressing relaxation is:

$$
\begin{array}{ll}
\mathrm{F}_{\mathrm{i}}:=\left(\mathrm{f}_{\mathrm{pj}}-\Delta \mathrm{f}_{\mathrm{pr} 1}\right) \cdot \mathrm{A}_{\mathrm{ps}} & \mathrm{F}_{\mathrm{i}}=138.38731 \mathrm{kip} \\
\mathrm{f}_{\mathrm{cgpF}}:=\frac{\mathrm{F}_{\mathrm{i}}}{\mathrm{A}_{\mathrm{C} \_ \text {RS }}}+\frac{\mathrm{F}_{\mathrm{i}} \cdot \mathrm{e}_{\mathrm{RS}}}{\mathrm{I}_{\mathrm{x} \_\mathrm{RS}}} & \mathrm{f}_{\mathrm{cgpF}}=1.67474 \mathrm{ksi}
\end{array}
$$


The loss of prestressing force due to elastic shortening $\left(\Delta f_{\mathrm{PS}}\right)$ is:

$$
\begin{array}{ll}
\mathrm{n}_{\mathrm{pi}}:=\frac{\mathrm{E}_{\mathrm{ps}}}{\mathrm{E}_{\mathrm{ci}}} & \mathrm{n}_{\mathrm{pi}}=7.45356 \\
\Delta \mathrm{f}_{\mathrm{pES}}:=\mathrm{n}_{\mathrm{pi}}\left(\mathrm{f}_{\mathrm{cgpF}}-\mathrm{f}_{\mathrm{cgpG}}\right) & \Delta \mathrm{f}_{\mathrm{pES}}=12.4348 \mathrm{ksi}
\end{array}
$$

Therefore, the initial prestressing stress including all instantaneous losses is:

$$
\mathrm{f}_{\mathrm{pi}}:=\mathrm{f}_{\mathrm{pj}}-\Delta \mathrm{f}_{\mathrm{pr} 1}-\Delta \mathrm{f}_{\mathrm{pES}} \quad \mathrm{f}_{\mathrm{pi}}=188.41762 \mathrm{ksi}
$$

Time dependent losses after transfer:

The force in the prestressing steel at the begining of each time interval is equal to the force at the end of the preceding time interval. During the first time interval (0-24 hours) 1 day, creep and shrinkage did not occur. However, creep and strinkage begin after transfer and continue while eponentially decreasing over the remainder of the intervals. Computation of creep, shrinkage and relaxation for the second to thrid (1 day to 3 days) intervals is shown below.

The stress in the concrete at the centroid of the prestressing steel at the end of the first interval (1 day) is:

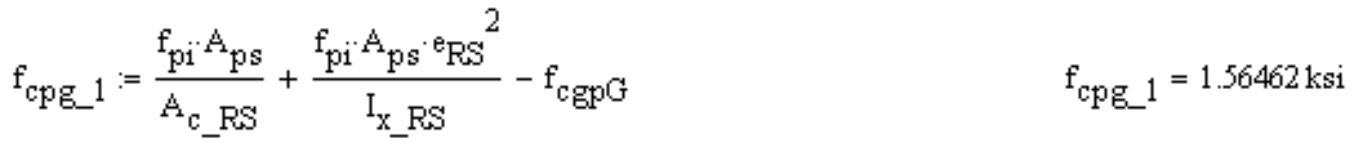

To estimate the loss due to creep $\left(\Delta \mathrm{f}_{\mathrm{p}} \mathrm{c}\left(\mathrm{t}_{\mathrm{i}}, \mathrm{t}_{\mathrm{j}}\right)\right)$ over the time between intervals two and three use Equation 8.53 .

$$
\begin{array}{lr}
t_{i}:=1 & \text { begining time interval } \\
t_{j}:=3 & \text { ending time interval } \\
C_{\mathrm{CU}}:=2.2 & \text { ultimate creep coefficient Table } 2.11
\end{array}
$$

Use the modular ratio based on the concrete modulus at transfer $\left(\mathrm{n}_{\mathrm{p}} \mathrm{j}\right)$ since concrete will not have achieved full strength within 3 days. For later intervals use a modular ratio based on the concrete modulus based on the 28-day strength.

$$
\Delta \mathrm{f}_{\mathrm{pC} \_ \text {ti_t }}:=\mathrm{n}_{\mathrm{pi}} \mathrm{C}_{\mathrm{CU}} \cdot \mathrm{K}_{\mathrm{CH}} \cdot \mathrm{K}_{\mathrm{CA}} \cdot \mathrm{K}_{\mathrm{CS}} \cdot \mathrm{f}_{\mathrm{Cpg}_{-} 1} \cdot\left(\frac{\mathrm{t}_{\mathrm{j}}^{0.60}}{10+\mathrm{t}_{\mathrm{j}}^{0.60}}-\frac{\mathrm{t}_{\mathrm{i}}^{0.60}}{10+\mathrm{t}_{\mathrm{i}}^{0.06}}\right) \Delta \mathrm{f}_{\mathrm{pC} \mathrm{C}_{-} \mathrm{tij}_{\mathrm{tj}}}=1.80703 \mathrm{ksi}
$$


To estimate the prestressing losses due to shrinkage $\left(\Delta \mathrm{f}_{\mathrm{p}} \mathrm{s}\left(\mathrm{t}_{\mathrm{i}}, \mathrm{t}_{\mathrm{j}}\right)\right)$ over a time interval use Equation 8.42 . Continue with the assumption that the tie is steam cured.

$$
\begin{aligned}
& \mathrm{b}:=55 \\
& \varepsilon_{\mathrm{SU}}:=0.0005 \quad \text { ultimate shrinkage strain of concrete, see Section 3.1.4.3.3 of report } \\
& \Delta \mathrm{f}_{\mathrm{pS} \_t i \_t j}:=\mathrm{E}_{\mathrm{ps}} \cdot \varepsilon_{\mathrm{SU}} \cdot \mathrm{K}_{\mathrm{SH}} \cdot \mathrm{K}_{\mathrm{SS}} \cdot \frac{\mathrm{b} \cdot\left(\mathrm{t}_{\mathrm{j}}-\mathrm{t}_{\mathrm{i}}\right)}{\left(\mathrm{b}+\mathrm{t}_{\mathrm{i}}\right) \cdot\left(\mathrm{b}+\mathrm{t}_{\mathrm{j}}\right)} * \quad \Delta \mathrm{f}_{\mathrm{pS} \_\mathrm{ti}+\mathrm{tj}}=0.40621 \mathrm{ksi}
\end{aligned}
$$

To estimate the prestressing losses due to relaxation $\left(\Delta \mathrm{f}_{\mathrm{p}}\left(\mathrm{t}_{\mathrm{i}}, \mathrm{t}_{\mathrm{j}}\right)\right)$ over a time interval use Equation 8.33 . Continue with the assumption that prestressing is low relaxation.

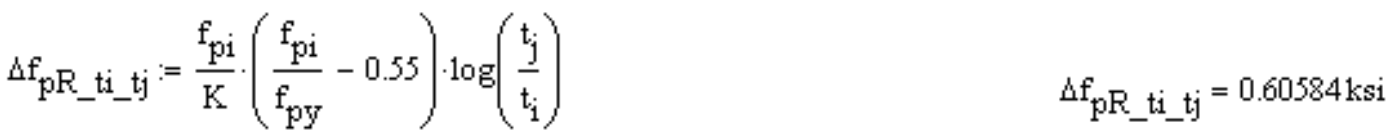

\begin{tabular}{|c|c|c|c|c|c|c|c|c|c|c|}
\hline \multicolumn{11}{|c|}{ Prestessing Losses Based on Rail Seat Section Properties } \\
\hline $\begin{array}{c}\text { Time } \\
\text { (days) }\end{array}$ & $\begin{array}{l}\Delta f_{g *::} \\
{[k s i]}\end{array}$ & $\begin{array}{l}\Delta f_{B=s} \\
{[k s i]}\end{array}$ & $\begin{array}{c}\mathrm{f}_{\mathrm{si}} \\
\text { (ksi) }\end{array}$ & $\begin{array}{l}\Delta f_{z}, \sigma_{2} \\
{[k s i]}\end{array}$ & $\begin{array}{l}\Delta f_{g s} \\
{[\mathrm{ksi}]}\end{array}$ & $\begin{array}{l}\Delta f_{g c} \\
\text { (ksi) } \\
\end{array}$ & $\begin{array}{c}f_{s .} \\
\text { (ksi) }\end{array}$ & $\begin{array}{l}\Delta \mathrm{f}_{8+0} \\
{[\mathrm{ksi}}\end{array}$ & $\begin{array}{c}\text { Total Lo55 } \\
\text { (ksi) }\end{array}$ & $\begin{array}{c}\text { Actual Prest re } 55 \\
\text { [ksi] }\end{array}$ \\
\hline 1 & 2.34 & 12.43 & 188.42 & 0.00 & 0.00 & 0.00 & $18 B .42$ & 0.00 & 14.78 & 188.42 \\
\hline 3 & 2.34 & 12.43 & $18 B .42$ & 0.61 & 0.41 & 1.81 & 185.60 & 2.82 & 17.59 & 185.60 \\
\hline 7 & 2.34 & 12.43 & 188.42 & 1.07 & 1.14 & 3.85 & 182.36 & 6.06 & 20.83 & 182.36 \\
\hline 28 & 2.34 & 12.43 & 188.42 & 1.81 & 3.83 & 7.48 & 175.30 & 13.12 & 27.90 & 175.30 \\
\hline 40 & 2.34 & 12.43 & 188.42 & 2.00 & 4.84 & 8.51 & 173.07 & 15.35 & 30.13 & 173.07 \\
\hline 365 & 2.34 & 12.43 & 188.42 & 3.17 & 10.21 & 14.30 & 160.74 & 27.68 & 42.45 & 160.74 \\
\hline 1825 & 2.34 & 12.43 & 188.42 & 4.00 & 11.43 & 16.66 & 156.33 & 32.09 & 46.86 & 156.33 \\
\hline 18250 & 2.34 & 12.43 & 188.42 & 5.16 & 11.74 & 18.00 & 153.51 & 34.91 & 49.68 & 153.51 \\
\hline
\end{tabular}

This procedure is continued for all time intervals assuming the stress in the prestressing at the begining of interval is taken equal that at the end of the preceding interval. The results for the remaining intervals are summarized in the table below. 


\section{Theoretical Prestress Loss at Center}

All humidity correction factors for creep and shrinkage are the same as those for the rail seat.

From Table 2.10 determine size and shape factors for creep and shrinkage based on the volume-to-surface ratio.

$$
\begin{aligned}
& \text { Perimeter_C }:=33.75 \mathrm{in} \\
& \text { Lateral_Surface_Per_Unit_Length_C }:=1 \cdot \text { in Perimeter_C }
\end{aligned}
$$

Use linear interpolation to calculate values corresponding to volume to-to-surface ratio.

Given

$$
\frac{1.04-\mathrm{K}_{\mathrm{SS}}}{1.04-0.96}=\frac{1 \text { in }-V_{-} \mathrm{S}}{1 \text { in }-2 \text { in }}
$$

$\mathrm{K}_{\mathrm{SS}}:=\operatorname{Find}\left(\mathrm{K}_{\mathrm{SS}}\right)$

$\mathrm{K}_{\mathrm{SS}}=0.98264$

Given

$$
\frac{1.05-\mathrm{K}_{\mathrm{CS}}}{1.05-0.96}=\frac{1 \text { in }-\mathrm{V}_{-} \mathrm{S}}{1 \text { in }-2 \text { in }}
$$

$\mathrm{K}_{\mathrm{CS}}:=\operatorname{Find}\left(\mathrm{K}_{\mathrm{CS}}\right)$

$\mathrm{K}_{\mathrm{CS}}=0.98547$

Losses before and during stress transfer:

The interval of time which these losses take place is $0-24$ hours ( 1 day). The stress at hour zero after jacking and anchorage set is the following:

$$
\mathrm{f}_{\mathrm{pj}}=203.19303 \mathrm{ksi}
$$

The relaxation losses during the inital curing period $\left(\Delta f_{\mathrm{pr}}\right)$ of 24 hours ( 1 day) according to Equation 8.17 is :

$$
\Delta f_{p r 1}:=\frac{\log \left(24 \cdot t_{A}\right)}{K} \cdot\left(\frac{f_{p j}}{f_{p y}}-0.55\right) \cdot f_{p j} * \quad \Delta f_{p r 1}=2.34062 k s i
$$


The losses due to elastic shortening is given by Equation 8.21 .

Self-weight moment acting on tie during elastic shortening period:

$\mathrm{L}:=8.5 \mathrm{ft}$

Tie_Weight $:=7351 b f$

$w_{\mathrm{G}}:=\frac{\text { Tie_Weight }}{\mathrm{L}}$

$\mathrm{w}_{\mathrm{G}}=86.47059 \mathrm{plf}$

$\mathrm{M}_{\mathrm{G}}:=\frac{\mathrm{w}_{\mathrm{G}} \cdot \mathrm{L}^{2}}{8} *$

$\mathrm{M}_{\mathrm{G}}=9.37125 \mathrm{in} \cdot \mathrm{kip}$

The stress in the concrete at the centroid of the prestressing steel due to the self-weight of the tie is:

$$
f_{\text {cgpG }}:=\frac{M_{G} \cdot e_{C}}{I_{x_{-} C}}
$$

$f_{\text {cgpG }}=-0.00659 \mathrm{ksi}$

Determine the stress in the concrete due to the prestressing force. The prestressing force including the losses due to the initial relaxation is:

$$
\begin{aligned}
& F_{i}:=\left(f_{p j}-\Delta f_{p r 1}\right) \cdot A_{p s} \\
& \mathrm{~F}_{\mathrm{i}}=138.38731 \mathrm{kip} \\
& f_{c_{g p p}}:=\frac{F_{i}}{A_{c_{-} C}}+\frac{F_{i} \cdot e_{C}{ }^{2}}{I_{x_{-} C}} \\
& f_{\text {cgpF }}=2.40679 \mathrm{ksi}
\end{aligned}
$$

The loss of prestressing force due to elastic shortening $\left(\Delta f_{\mathrm{PES}}\right)$ is:

$$
\begin{array}{ll}
\mathrm{n}_{\mathrm{pi}}:=\frac{\mathrm{E}_{\mathrm{ps}}}{\mathrm{E}_{\mathrm{ci}}} & \mathrm{n}_{\mathrm{pi}}=7.45356 \\
\Delta \mathrm{f}_{\mathrm{pES}}:=\mathrm{n}_{\mathrm{pi}} \cdot\left(\mathrm{f}_{\mathrm{cgpF}}-\mathrm{f}_{\mathrm{cgpG}}\right) & \Delta \mathrm{f}_{\mathrm{pES}}=17.98833 \mathrm{ksi}
\end{array}
$$

Therefore, the initial prestressing stress including all instantaneous losses is:

$$
\mathrm{f}_{\mathrm{pi}}:=\mathrm{f}_{\mathrm{pj}}-\Delta \mathrm{f}_{\mathrm{pr} 1}-\Delta \mathrm{f}_{\mathrm{pES}} \quad \mathrm{f}_{\mathrm{pi}}=182.86408 \mathrm{ksi}
$$

Time dependent losses after transfer:

The stress in the concrete at the centroid of the prestressing steel at the end of the first interval (1 day) is:

$$
f_{c p g \_1}:=\frac{f_{p i} A_{p s}}{A_{c_{-} C}}+\frac{f_{p i} A_{p s} \cdot e_{C}^{2}}{I_{x_{-} C}}-f_{c g p G}
$$

$$
\mathrm{f}_{\mathrm{cpg} \_1}=2.19784 \mathrm{ksi}
$$


To estimate the loss due to creep $\left(\Delta \mathrm{f}_{\mathrm{p}} \mathrm{c}\left(\mathrm{t}_{\mathrm{i}}, \mathrm{t}_{\mathrm{j}}\right)\right)$ over the time between intervals two and three use Equation 8.53 .

$$
\begin{array}{ll}
t_{i}:=1 & \text { begining time interval } \\
t_{j}:=3 & \text { ending time interval } \\
C_{C U}:=2.2 & \text { ultimate creep coefficient Table } 2.11
\end{array}
$$

$$
\Delta \mathrm{f}_{\mathrm{pC} \_t i \_t}:=\mathrm{n}_{\mathrm{pi}} \cdot \mathrm{C}_{\mathrm{CU}} \cdot \mathrm{K}_{\mathrm{CH}} \cdot \mathrm{K}_{\mathrm{CA}} \cdot \mathrm{K}_{\mathrm{CS}} \cdot \mathrm{f}_{\mathrm{cpg} \_} \cdot\left(\frac{t_{j}^{0.60}}{10+\mathrm{t}_{\mathrm{j}}^{0.60}}-\frac{\mathrm{t}_{\mathrm{i}}^{0.60}}{10+\mathrm{t}_{\mathrm{i}}^{0.06}}\right) \Delta \mathrm{f}_{\mathrm{pC} \_\mathrm{ti}+\mathrm{tj}}=2.66766 \mathrm{ksi}
$$

To estimate the prestressing losses due to shrinkage $\left(\Delta \mathrm{f}_{\mathrm{p}} \mathrm{s}\left(\mathrm{t}_{\mathrm{i}}, \mathrm{t}_{\mathrm{j}}\right)\right)$ over a time interval use Equation 8.42 . Continue with the assumption that the tie is steam cured.

$$
\begin{aligned}
& \mathrm{b}:=55 \\
& \varepsilon_{\mathrm{SU}}:=0.0005 \quad \text { ultimate shrinkage strain of concrete based on concrete compressive strength } \\
& \Delta \mathrm{f}_{\mathrm{pS} \_\mathrm{ti} \_\mathrm{tj}}:=\mathrm{E}_{\mathrm{ps}} \cdot \varepsilon_{\mathrm{SU}} \cdot \mathrm{K}_{\mathrm{SH}} \cdot \mathrm{K}_{\mathrm{SS}} \cdot \frac{\mathrm{b} \cdot\left(\mathrm{t}_{\mathrm{j}}-\mathrm{t}_{\mathrm{i}}\right)}{\left(\mathrm{b}+\mathrm{t}_{\mathrm{i}}\right) \cdot\left(\mathrm{b}+\mathrm{t}_{\mathrm{j}}\right)} * \quad \Delta \mathrm{f}_{\mathrm{pS} \_\mathrm{ti}+\mathrm{tj}}=0.4268 \mathrm{ksi}
\end{aligned}
$$

To estimate the prestressing losses due to relaxation $\left(\Delta \mathrm{f}_{\mathrm{P}}\left(\mathrm{t}_{\mathrm{i}}, \mathrm{t}_{\mathrm{j}}\right)\right)$ over a time interval use Equation 8.33 .

\begin{tabular}{|c|c|c|c|c|c|c|c|c|c|c|}
\hline \multicolumn{11}{|c|}{ Preste ssing Losses Based on Center Section Properties } \\
\hline $\begin{array}{l}\text { Time } \\
\text { (days) }\end{array}$ & $\begin{array}{l}\Delta f_{s=1} \\
(k s i)\end{array}$ & $\begin{array}{l}\Delta f_{s e s} \\
{[k s i]}\end{array}$ & $\begin{array}{r}f_{s i} \\
(k s i)\end{array}$ & $\begin{array}{l}\Delta f_{s=2} \\
(k \mathbf{s})\end{array}$ & $\begin{array}{l}\Delta f_{s s} \\
(\mathbf{k g})\end{array}$ & $\begin{array}{l}\Delta f_{s c} \\
\text { [ksi] }\end{array}$ & $\begin{array}{c}f_{s:} \\
\text { (ksi) }\end{array}$ & $\begin{array}{l}\Delta \mathrm{f}_{\text {sto }} \\
(\mathrm{ksi})\end{array}$ & \begin{tabular}{|c} 
Total Lo55 \\
(ksi)
\end{tabular} & $\begin{array}{c}\text { Actual P restress } \\
\text { [ksi] }\end{array}$ \\
\hline 1 & 2.34 & 17.89 & 182.96 & 0.00 & 0.00 & 0.00 & 182.96 & 0.00 & 20.23 & 182.96 \\
\hline 3 & 2.34 & 17.89 & 182.96 & 0.54 & 0.43 & 2.65 & 179.35 & 3.62 & 23.85 & 179.35 \\
\hline 7 & 2.34 & 17.89 & 182.96 & 0.95 & 1.20 & 5.64 & 175.18 & 7.78 & 28.02 & 175.18 \\
\hline 28 & 2.34 & 17.89 & 182.96 & 1.61 & 4.03 & 10.90 & 166.42 & 16.54 & 36.77 & 166.42 \\
\hline 40 & 2.34 & 17.89 & 182.96 & 1.78 & 5.08 & 12.39 & 163.71 & 19.25 & 39.48 & 163.71 \\
\hline 365 & 2.34 & 17.89 & 182.96 & 2.81 & 10.73 & 20.69 & 148.73 & 34.23 & 54.46 & 148.73 \\
\hline 1825 & 2.34 & 17.89 & 182.96 & 3.55 & 12.01 & 24.02 & 143.39 & 39.57 & 59.80 & 143.39 \\
\hline 18250 & 2.34 & 17.89 & 182.96 & 4.58 & 12.34 & 25.90 & 140.14 & 42.82 & 63.05 & 140.14 \\
\hline
\end{tabular}
Continue with the assumption that prestressing is low relaxation.

$$
\Delta f_{p R \_t i \_t j}:=\frac{f_{p i}}{K} \cdot\left(\frac{f_{p i}}{f_{p y}}-0.55\right) \cdot \log \left(\frac{t_{j}}{t_{i}}\right)
$$

$$
\Delta \mathrm{f}_{\mathrm{pR} \_ \text {ti_tj }}=0.5353 \mathrm{ksi}
$$

This procedure is continued for all time intervals assuming the stress in the prestressing at the begining of interval is taken equal that at the end of the preceding interval. The results for the remaining intervals are summarized in the table below. 
At a time of 40 days (approximately 1000 hours) the prestressing stress after losses according to theoretical methods are:

$$
\begin{aligned}
& \mathrm{f}_{\mathrm{pi} \_\mathrm{RS}}:=188.42 \mathrm{ksi} \\
& \mathrm{f}_{\mathrm{pi} \_\mathrm{C}}:=182.96 \mathrm{ksi} \\
& \mathrm{f}_{\mathrm{pe} \_\mathrm{RS}}:=173.07 \mathrm{ksi} \\
& \mathrm{f}_{\mathrm{pe} \_\mathrm{C}}:=163.71 \mathrm{ksi}
\end{aligned}
$$

The percentage of prestressing loss at the rail seat section is:

$$
\text { percent_loss_RS }:=100 \frac{f_{\mathrm{pj}}-f_{\mathrm{pe} \_R S}}{f_{\mathrm{pj}}}
$$

percent_loss_RS $=14.82484$

The percentage of prestressing loss at the rail seat section is:

$$
\text { percent_loss_C }:=100 \frac{f_{\mathrm{pj}}-f_{\mathrm{pe} \_\mathrm{C}}}{\mathrm{f}_{\mathrm{pj}}}
$$

\begin{tabular}{|c|c|c|c|}
\hline \multirow{2}{*}{$\begin{array}{c}\text { Critical } \\
\text { Section }\end{array}$} & \multicolumn{2}{|c|}{$\begin{array}{c}\text { Effective Prestressing Losses at } \\
1000 \text { hrs }\end{array}$} & $\begin{array}{c}\text { Percent Difference } \\
100 \text { (Lump Sum - Time-Step) } \\
\text { / Lump Sum }\end{array}$ \\
\cline { 2 - 3 } Rail Seat & $14.8 \%$ & $15.2 \%$ & $2.4 \%$ \\
\hline Center & $19.4 \%$ & $18.5 \%$ & $-5.0 \%$ \\
\hline
\end{tabular}

There is adequate correlation between experimental results of prestressing loss and theoretical values. Therefore, this method of estimating prestressing losses will be used for the remainder of the optimization study. 


\section{Allowable Concrete Stresses at Transfer}

The support condition at transfer is a simply supported configuration based on the camber of the tie in the form and the tie supported on cribbing during storage shortly after transfer. The self-weight will be modeled as a uniformly distributed loading over the enitre tie. The uniform loading will be the weight of the tie over its entire length. Since the actual geometry and therefore weight per unit length varies along the length of the tie, this is a conservative as sumption since the tie necks down in the middle third. Two loading configurations occur:

1. Upside down in the form,

2. Right side up in storage.

The figure below demonstrates the loading configurations and distances from the end of the tie to the critical sections, which is used in the self-weight moment calculations.

(1)

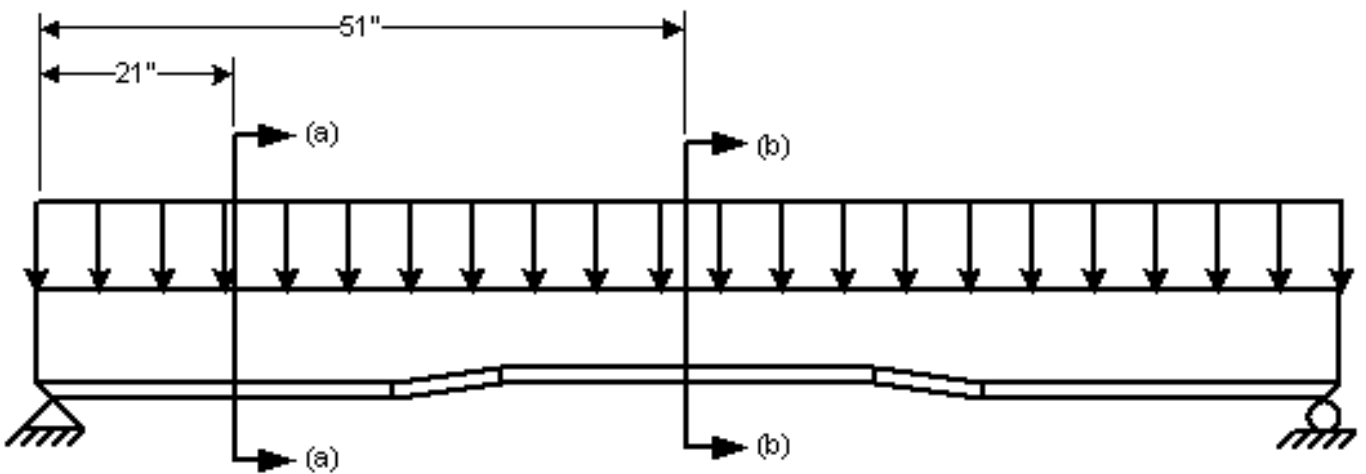

(2)

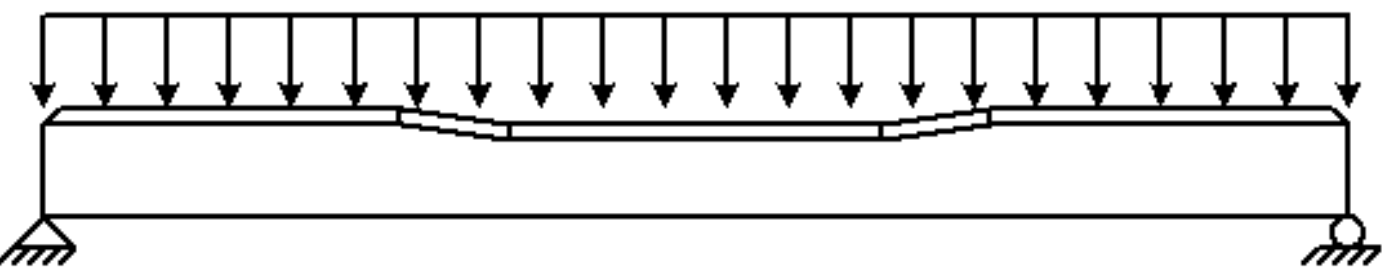

At transfer the allowable compression and tension concrete stresses are:

Extreme fiber stress in tension (d) transfer, ACI 318-08 18.4.1(b):

$$
\sigma_{\mathrm{ti}}:=-3 \cdot \sqrt{\mathrm{psi}} \cdot \sqrt{{ }^{\rho_{\mathrm{ci}}}}
$$

$\sigma_{\mathrm{ti}}=-201.24612 \mathrm{psi}$

Extreme fiber stress in compression (d) transfer, ACI 318-08 18.4.1 (a):

$$
\sigma_{\mathrm{ci}}:=0.6 \cdot \mathrm{P}_{\mathrm{ci}}
$$

$\sigma_{\mathrm{ci}}=2700 \mathrm{psi}$ 


\section{Rail Seat Section (a)}

$$
\begin{array}{ll}
\mathrm{x}:=\mathrm{L}-21.7 \mathrm{in} & \mathrm{x}=6.69167 \mathrm{ft} \\
\mathrm{M}_{0}:=\frac{\mathrm{w}_{\mathrm{G}} \cdot \mathrm{x}}{2} \cdot(\mathrm{L}-\mathrm{x}) & \mathrm{M}_{0}=6.27816 \mathrm{kip} \cdot \mathrm{in}
\end{array}
$$

Stresses at transfer are only due to self-weight and prestressing forces (use prestressing force derived using theoretical prestressing losses):

$$
\mathrm{F}_{\mathrm{i}}:=\mathrm{f}_{\mathrm{pi} \_\mathrm{RS}} \cdot \mathrm{A}_{\mathrm{ps}} \quad \mathrm{F}_{\mathrm{i}}=129.82138 \mathrm{kip}
$$

Concrete stresses at transfer in load configuration 1 (tie upside down in form):

$$
\begin{aligned}
& \sigma_{\text {top }}:=\frac{F_{i}}{A_{c_{-} R S}}+\frac{F_{i} \cdot e_{R S} \cdot y_{t \_} R S}{I_{x_{-} R S}}+\frac{M_{0} \cdot y_{t \_R S}}{I_{x_{-} R S}} \quad \sigma_{\text {top }}=2165.01356 \mathrm{psi} \quad \sigma_{\text {top }}<2700 \mathrm{psi} \quad 0 . K \text {. }
\end{aligned}
$$

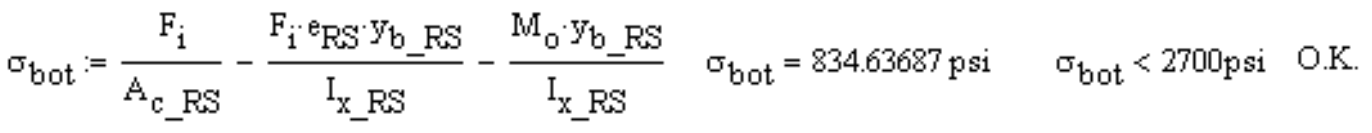

Concrete stresses at transfer in load configuration 2 (tie right side up in storage):

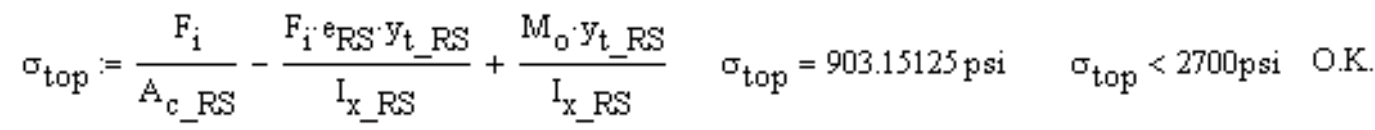

$$
\begin{aligned}
& \sigma_{\text {bot }}:=\frac{F_{i}}{A_{c_{-} R S}}+\frac{F_{i} \cdot e_{R S} \cdot y_{b} R S}{I_{x_{-}} R S}-\frac{M_{0} \cdot y_{b} R S}{I_{x_{-} R S}} \quad \sigma_{b o t}=2045.91821 \text { psi } \quad \sigma_{b o t}<2700 \mathrm{psi} \quad \text { O.K. }
\end{aligned}
$$




\section{Center Section (b)}

$$
\begin{array}{ll}
\mathrm{x}:=\frac{\mathrm{L}}{2} & \mathrm{x}=51 \text { in } \\
\mathrm{M}_{\mathrm{O}}:=\frac{\mathrm{w}_{\mathrm{G}} \cdot \mathrm{x}}{2} \cdot(\mathrm{L}-\mathrm{x}) * & \mathrm{M}_{\mathrm{O}}=9.37125 \mathrm{kip} \cdot \mathrm{in}
\end{array}
$$

Stresses at transfer are only due to self-weight and prestressing forces (use prestressing force derived using theoretical prestressiing losses):

$$
\mathrm{F}_{\mathrm{i}}:=\mathrm{f}_{\mathrm{pi} \_} \mathrm{C}_{\mathrm{ps}} \quad \mathrm{F}_{\mathrm{i}}=126.05944 \mathrm{kip}
$$

Concrete stresses at transfer in load configuration 1 (tie upside down in form):

$$
\begin{aligned}
& \sigma_{\text {top }}:=\frac{F_{i}}{A_{c_{-} C}}+\frac{F_{i} \cdot e_{C} \cdot y_{t} C}{I_{x_{-} C}}+\frac{M_{0} \cdot y_{t} C}{I_{x_{-} C}} * \quad \sigma_{\text {top }}=1969.48744 p s i \quad \sigma_{\text {top }}<2700 p s i \quad \text { O.K. } \\
& \sigma_{\text {bot }}:=\frac{F_{i}}{A_{c_{-} C}}-\frac{F_{i} \cdot e_{C} \cdot y_{b_{-}} C}{I_{x_{-} C}}-\frac{M_{o} \cdot y_{b_{-} C}}{I_{x_{-} C}} * \quad \sigma_{b o t}=2377.87326 \mathrm{psi} \quad \sigma_{b o t}<2700 \mathrm{psi} \quad \text { O.K. }
\end{aligned}
$$

Concrete stresses at transfer in load configuration 2 (tie right side up in storage):

$$
\begin{aligned}
& \sigma_{\text {top }}:=\frac{F_{i}}{A_{c_{-} C}}-\frac{F_{i} \cdot e_{C} \cdot y_{t} C}{I_{x_{-} C}}+\frac{M_{o} \cdot y_{t} C}{I_{x_{-} C}} * \quad \sigma_{\text {top }}=2640.13011 \text { psi } \quad \sigma_{\text {top }}<2700 \mathrm{psi} \quad \text { O.K. } \\
& \sigma_{b o t}:=\frac{F_{i}}{A_{c_{-} C}}+\frac{F_{i} \cdot e_{C} \cdot y_{b} C}{I_{x_{-} C}}-\frac{M_{0} \cdot y_{b_{-} C}}{I_{x_{-} C}} * \quad \sigma_{b o t}=1717.87571 \mathrm{psi} \quad \sigma_{b o t}<2700 \mathrm{psi} \quad O . K .
\end{aligned}
$$




\section{Moment Capacity Analysis Based on Allowable Concrete Stresses}

Concrete railroad tie failure and the corresponding capacity as defined by AREMA is dictated by cracking to the outer most layer of prestressing. Therefore, the moments required to initate cracking at the critical sections of the rail seat and center are of interest. To avoid working with cracked sections and determining the rate of crack propagation, the tie will assume to be failed when the stresses in the tie reach the allowable stresses at the extreme compression and tension fibers.

For this capacity analysis the final prestressing force $\left(f_{p e}\right)$ calculated with the theoretical method will be taken at 40 days with the corresponding losses to match the experimental data provided by the tie manufacturer. This is done to compare the analysis process used with experimental results. All other capacity analyses will be performed with the final prestressing force calculated at a time of 50 years, so that all prestressing losses are included. This will yield the smallest capacity which the tie will have over its service life.

For the following analysis the final prestressing force at 40 days is:

$$
\begin{array}{ll}
\mathrm{F}_{\mathrm{RS}}:=f_{\mathrm{pe} \_\mathrm{RS}} \cdot \mathrm{A}_{\mathrm{ps}} & \mathrm{F}_{\mathrm{RS}}=119.24523 \mathrm{kp} \\
\mathrm{F}_{\mathrm{C}}:=\mathrm{f}_{\mathrm{pe} \_}{ } \cdot \mathrm{A}_{\mathrm{ps}} & \mathrm{F}_{\mathrm{C}}=112.79619 \mathrm{kp}
\end{array}
$$

The moment due to self-weight is calculated based on the flexure test configurations used to obtain the experimental capacity results.

\section{Experimental Flexwral Test Results and Configurations}

The load capacity test configurations illustrated below come from AREMA 4.9.1 Design Test of Monoblock Ties. In addition the experimental flexural capacity results have been provided in the form of a point load (F) which corresponds to those shown in the figures. These tests were performed by the tie manufacturer and the average value for $P$ in each configuration is:

$$
\begin{aligned}
& \mathrm{P}_{\mathrm{RS}_{-} \mathrm{P}}:=64.8 \mathrm{kip} \\
& \mathrm{P}_{\mathrm{RS}_{-} \mathrm{N}}:=39.8 \mathrm{kip} \\
& \mathrm{P}_{\mathrm{C}_{-} \mathrm{P}}:=13.8 \mathrm{kip} \\
& \mathrm{P}_{\mathrm{C}_{-} \mathrm{V}}:=16.6 \mathrm{kip}
\end{aligned}
$$


The figure below displays the test set up for positive moment at the rail seat.

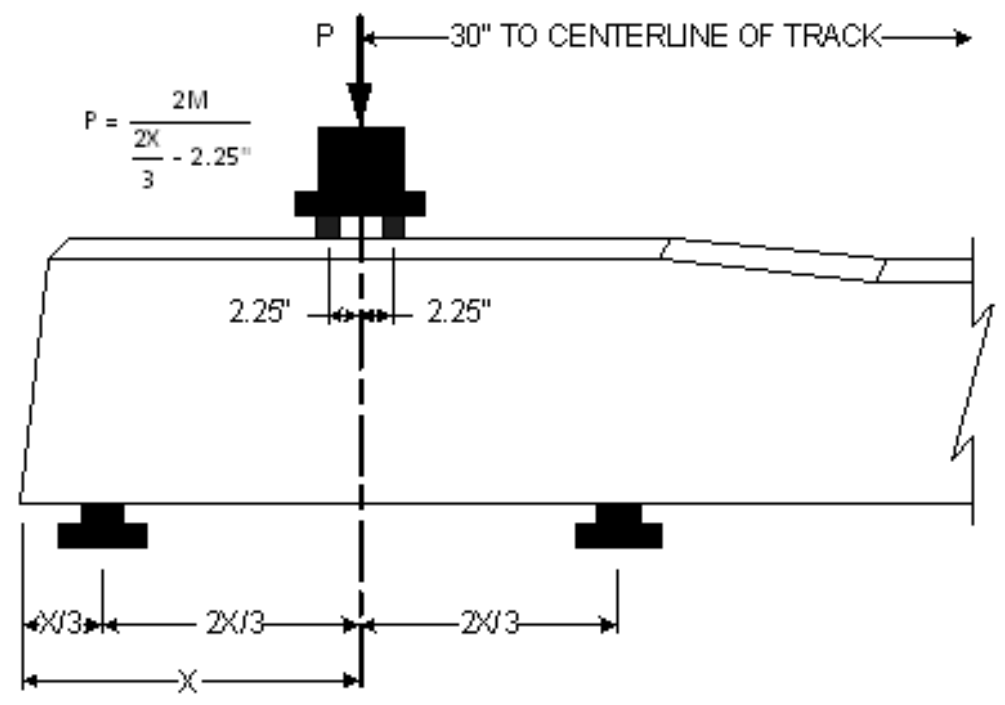

For the baseline tie the value of "X" according to this test configuration is (this value is constant for all design iterations):

$$
\mathrm{X}:=21.17 \mathrm{in}
$$

Rearraging the vertical load and moment equation from the diagram to solve for the corresponding cracking moment, the following is determined to be the positive cracking moment for the rail seat region.

$$
\mathrm{M}_{\mathrm{RS} \_\mathrm{P}}:=\frac{\mathrm{P}_{\mathrm{RS} \_\mathrm{P}}\left(\frac{2 \cdot \mathrm{X}}{3}-2.25 \mathrm{in}\right)}{2} * \quad \mathrm{M}_{\mathrm{RS} \_\mathrm{P}}=384.372 \mathrm{kip} \cdot \mathrm{in}
$$

The figure below displays the test set up for negative moment at the rail seat.

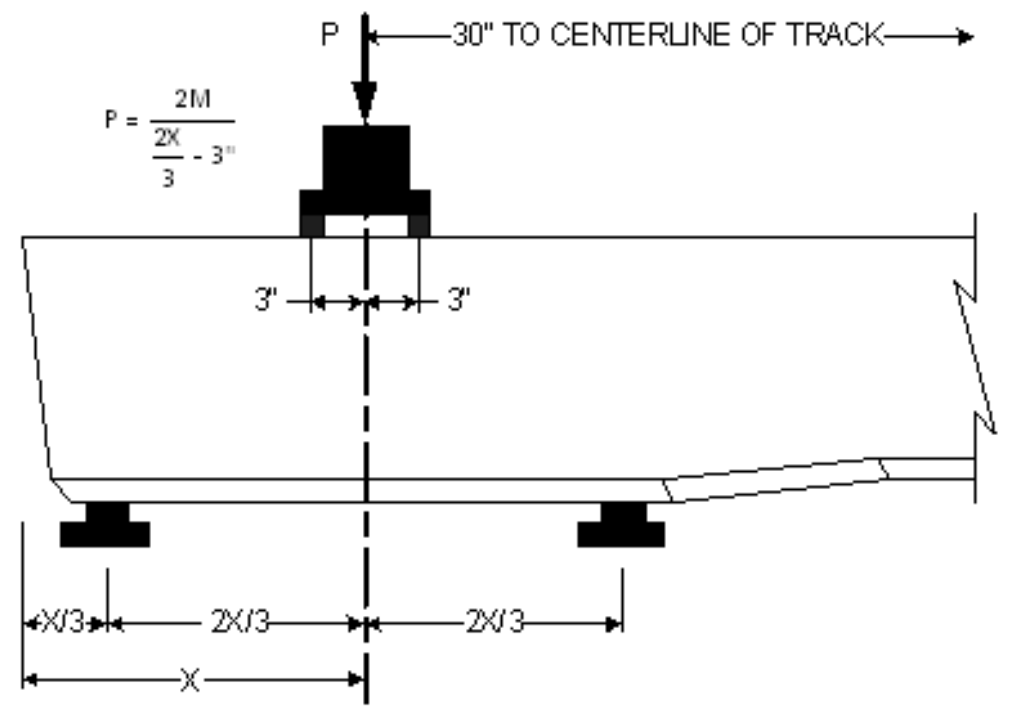


For the baseline tie the value of "X" according to this test configuration is (this value is constant for all design iterations):

$$
\mathrm{X}:=21.17 \mathrm{in}
$$

Rearraging the vertical load and moment equation from the diagram to solve for the corresponding cracking moment, the following is determined to be the negative cracking moment for the rail seat region.

$$
\mathrm{M}_{\mathrm{RS}_{-} \mathrm{N}}:=\frac{\mathrm{P}_{\mathrm{RS} \_\mathrm{N}} \cdot\left(\frac{2 \cdot \mathrm{X}}{3}-3 \mathrm{in}\right)}{2} * \quad \mathrm{M}_{\mathrm{RS} \_\mathrm{N}}=221.15533 \mathrm{kip} \cdot \mathrm{in}
$$

The figure below displays the test set up for positive moment at the center.

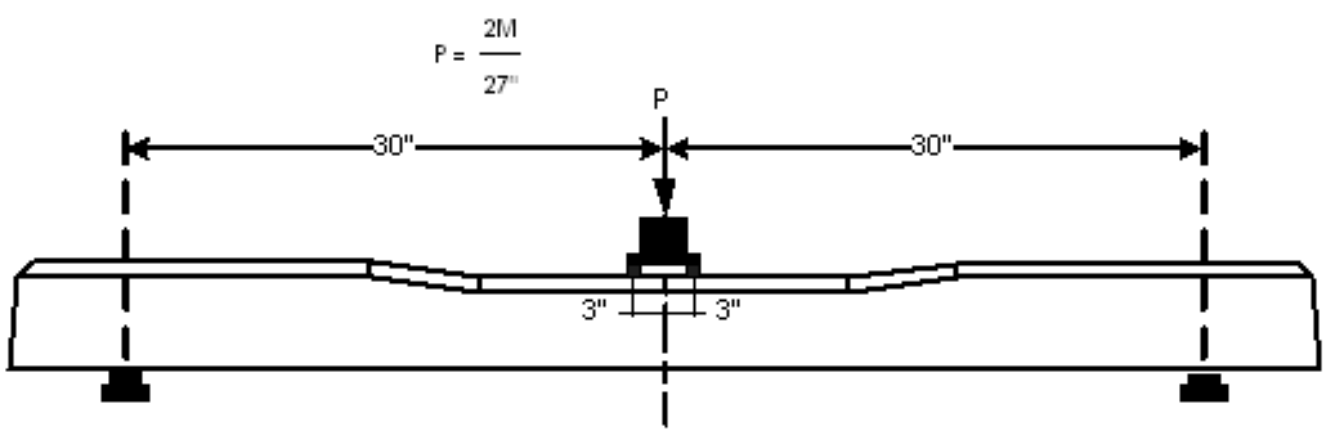

Rearraging the vertical load and moment equation from the diagram to solve for the corresponding cracking moment, the following is determined to be the positive cracking moment for the center region.

$$
\mathrm{M}_{\mathrm{C}_{-} \mathrm{P}}:=\frac{\mathrm{P}_{\mathrm{C}_{-} \mathrm{P}} \cdot 27 \mathrm{in}}{2} * \quad \quad \mathrm{M}_{\mathrm{C}_{-} \mathrm{P}}=186.3 \mathrm{kip} \cdot \text { in }
$$

The figure below displays the test set up for negative moment at the center.

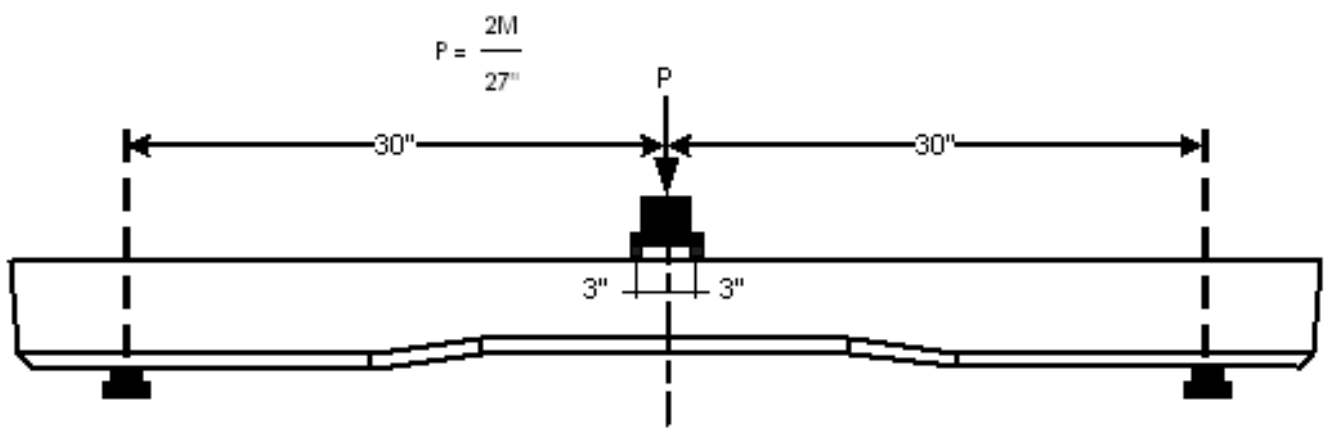

Rearraging the vertical load and moment equation from the diagram to solve for the corresponding cracking moment, the following is determined to be the negative cracking moment for the center region.

$$
\mathrm{M}_{\mathrm{C} \_\mathrm{N}}:=\frac{\mathrm{P}_{\mathrm{C} \_\mathrm{N}} \cdot 27 \mathrm{in}}{2} *
$$

$\mathrm{M}_{\mathrm{C} \_\mathrm{N}}=224.1 \mathrm{kp} \cdot \mathrm{in}$ 


\section{Calculation of Flexwral Capacities Using Theoretical Methods}

Based on the flexural test configurations from AREMA presented above, the moments due to self-weight at the rail seat and center sections are:

Rail Seat Section Test Configuration Moment Diagram w/Self-Weight:

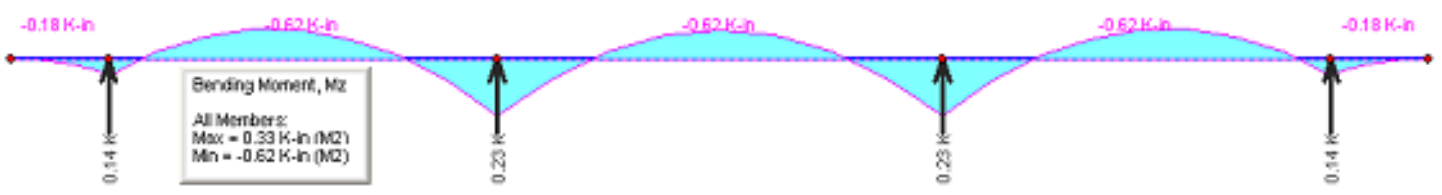

$\mathrm{M}_{\mathrm{O}_{-} \mathrm{RS}}:=0.3 \mathrm{in} \cdot \mathrm{kip}$

Center Section Test Configuration Moment Diagram w/ Self-Weight:

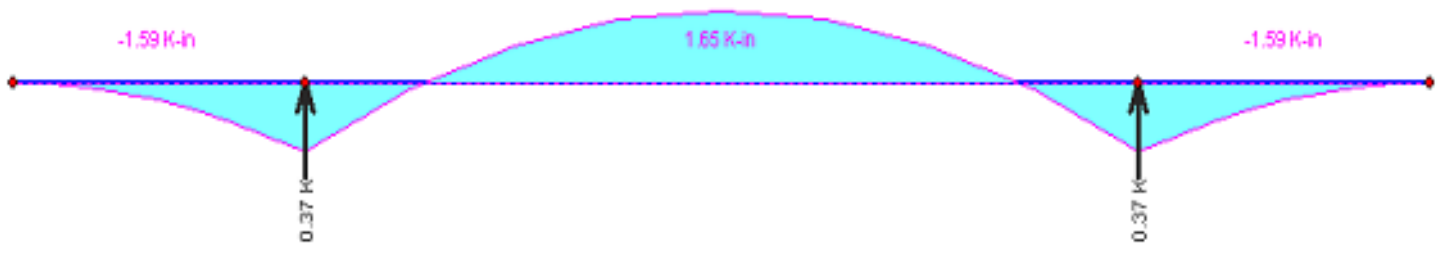

$\mathrm{M}_{\mathrm{o}_{-} \mathrm{C}}:=1.6 \mathrm{in} \cdot \mathrm{kip}$

Moment due to self weight is neglible compared to the live load moment required to cause failure, therefore it will be omitted from capacity analysis. 
Maximum positive moment based on allowable concrete stresses at the rail seat section:

Positive cracking moment (top stress):

$\mathrm{M}_{\mathrm{L}}:=350 \mathrm{in} \cdot \mathrm{kip} \quad$ Guess

Given

$\sigma_{\mathrm{cs} 2}=\frac{\mathrm{F}_{\mathrm{RS}}}{\mathrm{A}_{\mathrm{c}_{-} \mathrm{RS}}}-\frac{\mathrm{F}_{\mathrm{RS}} \cdot \mathrm{e}_{\mathrm{RS}} \cdot \mathrm{y}_{t_{-} \mathrm{RS}}}{\mathrm{I}_{\mathrm{x}_{-} \mathrm{RS}}}+\frac{\mathrm{M}_{\mathrm{L}} \cdot \mathrm{y}_{\mathrm{t}_{-} \mathrm{RS}}}{\mathrm{I}_{\mathrm{x}_{-} \mathrm{RS}}}$

$M_{L}:=\operatorname{Find}\left(M_{L}\right)$

$\mathrm{M}_{\mathrm{L}}=447.87554 \mathrm{kip} \cdot \mathrm{in}$

Positive cracking moment (bottom stress):

Given

$\sigma_{t s}=\frac{F_{R S}}{A_{c_{-}} R S}+\frac{F_{R S} \cdot e_{R S} \cdot y_{b} R S}{I_{x_{-} R S}}-\frac{M_{L} \cdot y_{b} R S}{I_{x_{-}} R S}$

$M_{L}:=\operatorname{Find}\left(M_{L}\right)$

$\mathrm{M}_{\mathrm{L}}=348.3139 \mathrm{kip} \cdot \mathrm{in}$

Maximum positive moment at the rail seat section is 348 kip-in controlled by allowable tension stress.

Maximum negative moment based on allowable concrete stresses at the rail seat section:

Negative cracking moment (top stress):

Given

$\sigma_{t s}=\frac{F_{R S}}{A_{c_{-} R S}}-\frac{F_{R S} \cdot e_{R S} \cdot y_{t \_R S}}{I_{x_{-} R S}}+\frac{M_{L} \cdot y_{t} R_{-}}{I_{x_{-} R S}}$

$M_{L}:=\operatorname{Find}\left(M_{L}\right)$

$\mathrm{M}_{\mathrm{L}}=-185.36145 \mathrm{kip} \cdot \mathrm{in}$

Negative cracking moment (bottom stress):

Given

$\sigma_{\mathrm{cs} 2}=\frac{F_{\mathrm{RS}}}{A_{c_{-} R S}}+\frac{F_{\mathrm{RS}} \cdot \mathrm{e}_{\mathrm{RS}} \cdot \mathrm{y}_{\mathrm{b} \_\mathrm{RS}}}{\mathrm{I}_{\mathrm{x}_{-} \mathrm{RS}}}-\frac{\mathrm{M}_{\mathrm{L}} \cdot \mathrm{y}_{\mathrm{b}} \mathrm{RS}}{\mathrm{I}_{\mathrm{x}_{-} \mathrm{RS}}}$

$M_{L}:=\operatorname{Find}\left(M_{L}\right)$

$\mathrm{M}_{\mathrm{L}}=-311.36595 \mathrm{kip} \cdot \mathrm{in}$

Maximum negative moment at the rail seat section is 185 kip-in controlled by allowable tension stress. 
Maximum positive moment based on allowable concrete stresses at the center section:

Positive cracking moment (top stress):

Given

$$
\sigma_{c s 2}=\frac{F_{C}}{A_{c_{-} C}}-\frac{F_{C} \cdot e_{C} \cdot y_{t} C}{I_{x_{-} C}}+\frac{M_{L} \cdot y_{t} C}{I_{x_{-} C}}
$$

$\mathrm{M}_{\mathrm{L}}:=\mathrm{Find}\left(\mathrm{M}_{\mathrm{L}}\right)$

$\mathrm{M}_{\mathrm{L}}=141.37175 \mathrm{kip} \cdot \mathrm{in}$

Positive cracking moment (bottom stress):

Given

$\sigma_{t s}=\frac{F_{C}}{A_{c_{-} C}}+\frac{F_{C} \cdot e_{C} \cdot y_{b_{-} C}}{I_{x_{-} C}}-\frac{M_{L} \cdot y_{b_{-} C}}{I_{x_{-} C}}$

$\mathrm{M}_{\mathrm{L}}:=\operatorname{Find}\left(\mathrm{M}_{\mathrm{L}}\right)$

$\mathrm{M}_{\mathrm{L}}=167.5609 \mathrm{kip} \cdot \mathrm{in}$

Maximum positive moment at the center section is 1412 kip-in controlled by allowable compression stress.

Maximum negative moment based on allowable concrete stresses at the center section:

Negative cracking moment (top stress):

Given

$\sigma_{t s}=\frac{F_{C}}{A_{c_{-} C}}-\frac{F_{C} \cdot e_{C} \cdot y_{t} C}{I_{x_{-} C}}+\frac{M_{L} \cdot y_{t} C}{I_{x_{-} C}}$

$\mathrm{M}_{\mathrm{L}}:=\operatorname{Find}\left(\mathrm{M}_{\mathrm{L}}\right)$

$\mathrm{M}_{\mathrm{L}}=-207.98308 \mathrm{kip} \cdot \mathrm{in}$

Negative cracking moment (bottom stress):

Given

$\sigma_{c s 2}=\frac{F_{C}}{A_{c_{-} C}}+\frac{F_{C} \cdot e_{C} \cdot y_{b_{-} C}}{I_{x_{-} C}}-\frac{M_{L_{L}} \cdot y_{b_{-} C}}{I_{x_{-} C}}$

$\mathrm{M}_{\mathrm{L}}:=\operatorname{Find}\left(\mathrm{M}_{\mathrm{L}}\right)$

$\mathrm{M}_{\mathrm{L}}=-187.42869 \mathrm{kip} \cdot \mathrm{in}$

Maximum negative moment is 187 kip-in controlled by allowable compression stress. 
A summary of the flexural capacities based on experimental and theoreticcal results is presented in the table below. These capacities are based on prestressing forces at 40 days. It should be expected that capacities will decrease over time as further losses occur.

\begin{tabular}{|c|c|c|c|}
\hline $\begin{array}{c}\text { Moment } \\
\text { Direction/Location }\end{array}$ & $\begin{array}{c}\text { Theoretical } \\
\text { Moment Capacity } \\
\text { (kip-in) }\end{array}$ & $\begin{array}{c}\text { Experimental } \\
\text { Moment Capacity } \\
\text { (kip-in) }\end{array}$ & $\begin{array}{c}\text { Percent Difference } \\
100 \text { (Exp. - Theo.) } \\
\text { / Exp. }\end{array}$ \\
\hline Positive/Rail Seat & 348 & 381 & $8.66 \%$ \\
\hline Negative/Rail Seat & 186 & 219 & $15.07 \%$ \\
\hline Positive/Center & 141 & 186 & $24.19 \%$ \\
\hline Negative/Center & 187 & 224 & $16.52 \%$ \\
\hline
\end{tabular}




\section{Nominal Capacity Using Strain Compatibility}

The flexural capacity in terms of typical structural prestressed concrete design, is higher than that determined in the previous section. Even though tie failure is defined as cracking of the tie section by AREMA, the nominal capacity as defined by ACI will be computed as well for comparison purposes with other numerical analysis methods.

For strain compatibility the total strain in the prestressing steel can be broken down into three components:

1. $\varepsilon_{1}$, the strain in the prestressing due to the effective prestress after all losses have been accounted for,

2. $\varepsilon_{2}$, the strain in the concrete at the level of each steel layer due to the prestressing force, for a reference point, this strain is set when the concrete surronding the lowest level of steel reaches decompression,

3. $\varepsilon_{3}$, the strain in the concrete at the level of each steel layer at ultimate.

Summing the components together the strain in each level of prestressing steel can be determined at utlimate. The figure below illustrates each strain component and their summation for the positive bending at the rail seat condition.

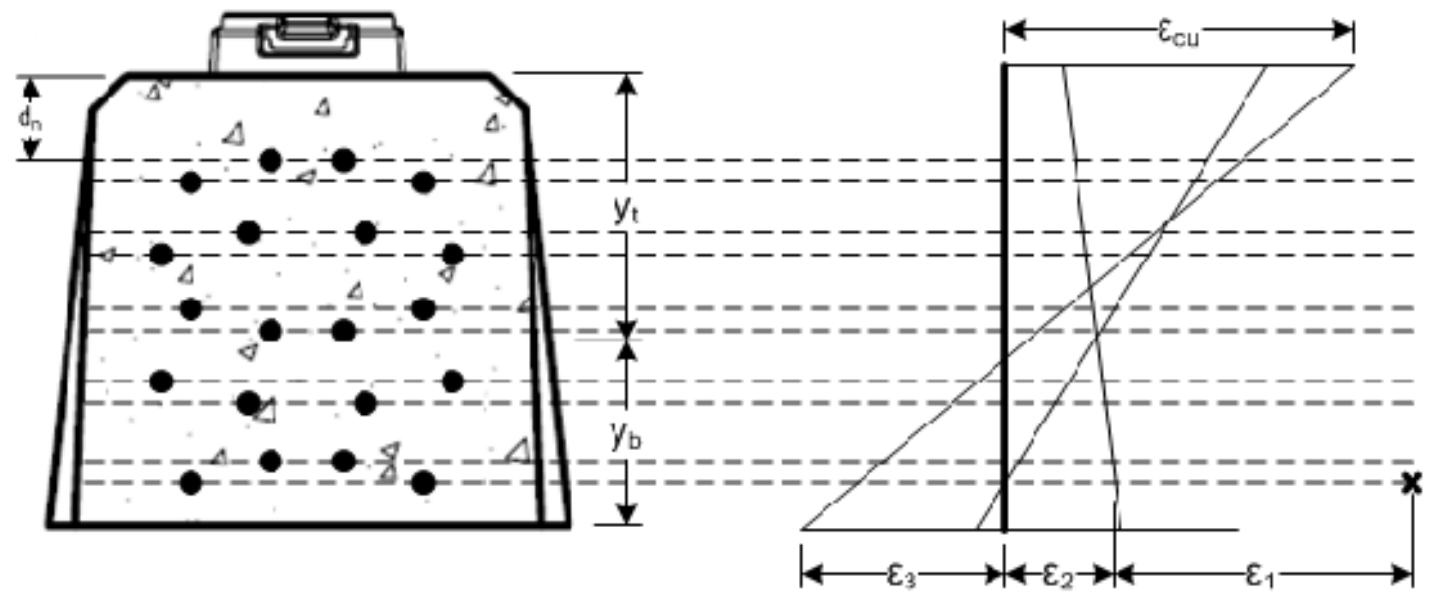

The strain in the prestressing due to the effective prestress after all losses have been accounted for $\left(\varepsilon_{1}\right)$ is constant for all prestressing layers within a cross-section since this is the strain of the prestressing steel, not the concrete. However, $\varepsilon_{1}$ does change depending on the cross-section, since different cross-sections containing the same prestressing tendons can have different prestressing losses. Therefore, the strain due to effective prestress is different for railseat and center sections. The strain in the rail seat and center sections is based upon the effective prestress including all calculated theoretical losses.

$$
\begin{aligned}
& \varepsilon_{1 \_\mathrm{RS}}:=\frac{\mathrm{f}_{\mathrm{pe} \_\mathrm{RS}}}{\mathrm{E}_{\mathrm{ps}}} * \\
& \varepsilon_{1 \_\mathrm{RS}}=0.00607 \\
& \varepsilon_{1 \_\mathrm{C}}:=\frac{\mathrm{f}_{\mathrm{pe} \_\mathrm{C}}}{\mathrm{E}_{\mathrm{ps}}} * \\
& \varepsilon_{1 \_\mathrm{C}}=0.00574
\end{aligned}
$$


$\varepsilon_{2}$ and $\varepsilon_{3}$ vary depending on the load configuration and the critical section. Since a portion of the prestressing steel may be within the compression zone of the concrete at ultimate, the strain at each layer of prestressing steel will be calculated rather than at the centroid of all prestressing. Due to this repitious calculation, the process is be demonstrated for a single layer of prestressing then completed in a spreadsheet for the remaining prestressing layers and load configurations.

\section{Positive Moment Ulimate Capacity Rail Seat}

To illustrate how the strain compatibility spreadsheets in Appendix D were obtained, an example of the strain compatibility process will be develped below for the first layer of prestressing in the rail seat section for positive rail seat bending. This process can then be transitioned to the other bending and critical section combinations.

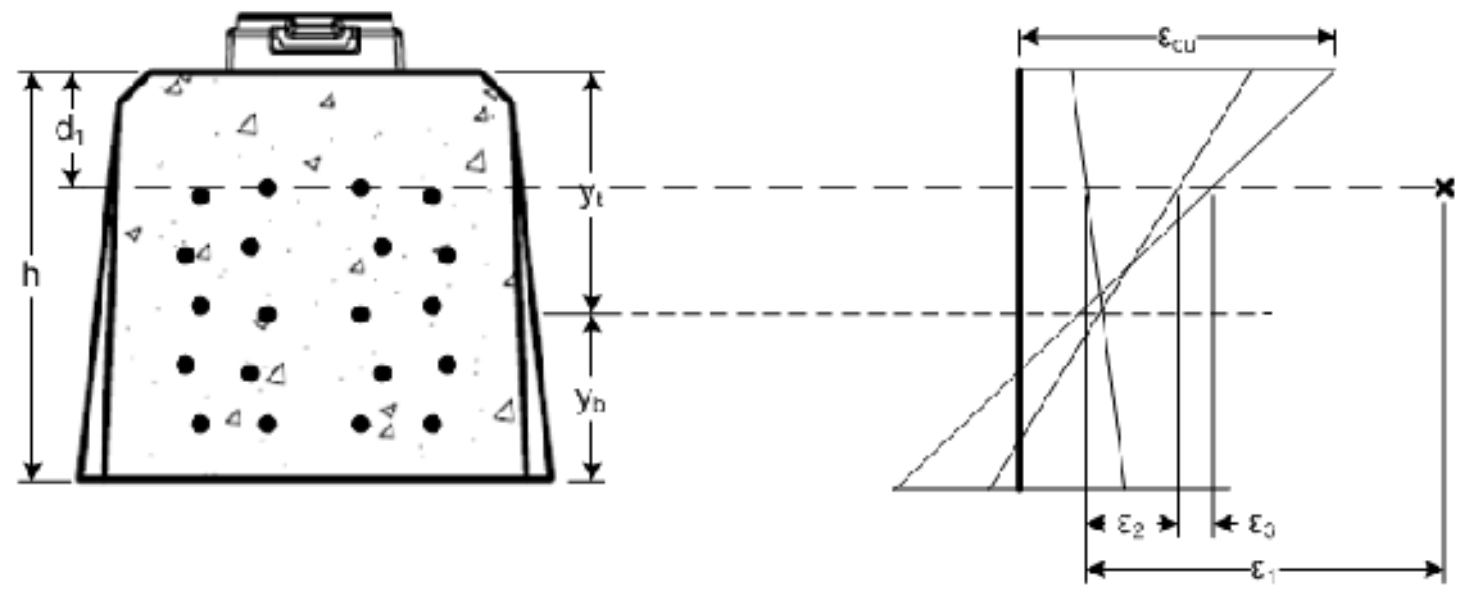

The first step is to guess a value for the depth to the neutral axis (c). This value will be used for the first iteration of strain calculations.

$$
c:=3.72 \mathrm{in}
$$

From the provided cross-section drawings, the area of prestressing steel in the first layer and the distance to the centroid of the layer from the extreme compression fiber is:

$$
\begin{aligned}
& A_{p s \_1}:=2 \cdot A_{\text {tendon }} \\
& A_{\text {ps_1 }}=0.0689 \text { in }^{2} \\
& d_{1}:=2.7275 \text { in }
\end{aligned}
$$

The strain in the concrete at the level of the steel layer due to the prestressing force when the concrete surronding the lowest level of steel reaches decompression is:

Strain in concrete at lowest level of prestressing steel at decompression is:

$$
\begin{aligned}
& \mathrm{d}_{\max }:=7.977 \sin \\
& \varepsilon_{\text {dmax }}:=\frac{f_{\mathrm{pe} \_\mathrm{RS}} \cdot \mathrm{A}_{\mathrm{ps}}}{\mathrm{E}_{\mathrm{c}}} \cdot\left[\frac{1}{\mathrm{~A}_{\mathrm{c} \_\mathrm{RS}}}+\frac{\left(\mathrm{d}_{\max }-\mathrm{y}_{\mathrm{t} \_\mathrm{RS}}\right)^{2}}{\mathrm{I}_{\mathrm{x} \_\mathrm{RS}}}\right] * \quad \varepsilon_{\mathrm{d} \max }=0.00071
\end{aligned}
$$


Use similar triangles to find the strain in the first layer of prestressing corresponding to decompresion. Assume the section remains uncracked at decompression, therefore curvature remains constant. Use the neutral axis (center of gravity for uncracked section) as reference point for determination of decompression increment $\left(\varepsilon_{2}\right)$.

$$
\varepsilon_{2 \_1}:=\frac{\varepsilon_{\text {dmax }} \cdot\left(y_{t \_R S}-d_{1}\right)}{d_{\max }-y_{t \_R S}}
$$$$
\varepsilon_{2 \_1}=0.00044
$$

Using the same process as above, the strains in the concrete surronding all the layers of prestressing at decompression are:
$\varepsilon_{2}{ }_{2}:=0.00039$
$\varepsilon_{2} 5:=0.00013$
$\varepsilon_{2} 8:=0.00045$
$\varepsilon_{2 \_}:=0.00018$
$z_{2 \_}=0.00019$
$z_{2} g:=0.00065$
$z_{2} 4:=0.00013$
$z_{2} z:=0.00039$
$z_{2} \_00.00071$

The last component of strain to be considered is that from decompression to ultimate. Based on the ultimate concrete strain ( $\varepsilon_{0}$ ) use similar triangles to determine the strain in the concrete at the first level of prestressing

$$
\begin{array}{ll}
\varepsilon_{\mathrm{cu}}:=0.003 & \text { maximum compressive concrete strain per ACI } 318 \\
\varepsilon_{3}:=\varepsilon_{\mathrm{cu}}\left(\frac{\mathrm{c}-\mathrm{d}_{1}}{\mathrm{c}}\right) * & \varepsilon_{3}{ }_{1}=0.0008
\end{array}
$$

Using the same process as above, the strains in the concrete surronding all the layers of prestressing at failure are:

$$
\begin{aligned}
& \varepsilon_{3}{ }_{2}:=0.00060 \\
& \varepsilon_{3}{ }_{5}:=0.00131 \\
& \varepsilon_{3}{ }_{8}:=0.00247 \\
& \varepsilon_{3}{ }_{3}:=0.00015 \\
& \varepsilon_{3 \_}:=0.00151 \\
& \varepsilon_{3 \_}:=0.00323 \\
& \varepsilon_{3 \_4}:=0.00036 \\
& \left.\varepsilon_{3}\right]:=0.00227 \\
& z_{3 \_10}:=0.00343
\end{aligned}
$$

Sumuing the strain components (careful attention must be payed to the direction of the stain components, when the steel layer is above the neutral axis in the compression zone of the concrete, the strain from decompression and ultimate reduces the total strain):

$$
\varepsilon_{\mathrm{ps} \_1}:=\varepsilon_{1 \_\mathrm{RS}}-\varepsilon_{2}{ }_{-}-\varepsilon_{3 \_} 1 \quad \varepsilon_{\mathrm{ps} \_1}=0.00483
$$


Using the same process as above, the total strains in all the layers of prestressing at failure are:

$$
\begin{aligned}
& \varepsilon_{\mathrm{ps} \_}:=z_{1} \_\mathrm{RS}-z_{2} 2_{2}-z_{3} 2 * \quad \varepsilon_{\mathrm{ps} \_}=0.00508 \\
& \varepsilon_{\mathrm{ps} 3}:=\varepsilon_{1} \mathrm{RS}-\varepsilon_{2 \_}+\varepsilon_{3 \_} * \quad \varepsilon_{\mathrm{ps} 3}=0.00604 \\
& \varepsilon_{\mathrm{ps} \_}:=\varepsilon_{1 \_R S}-\varepsilon_{2}{ }_{-}+z_{3 \_4} * \quad \varepsilon_{\mathrm{ps} \_4}=0.0063 \\
& \varepsilon_{\mathrm{ps} 5}:=\varepsilon_{1 \_\mathrm{RS}}+\varepsilon_{2 \_}+\varepsilon_{3 \_} * \quad \varepsilon_{\mathrm{ps} 5}=0.00751 \\
& \varepsilon_{\mathrm{ps} \_}:=\varepsilon_{1 \_\mathrm{RS}}+\varepsilon_{2 \_6}+\varepsilon_{3 \_} * \quad \varepsilon_{\mathrm{ps} \_}=0.00777
\end{aligned}
$$

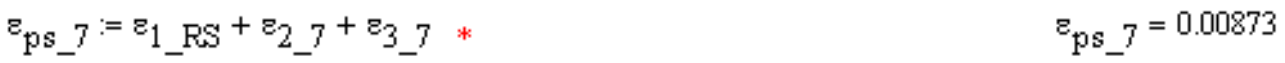

$$
\begin{aligned}
& \varepsilon_{\mathrm{ps} \_}:=\varepsilon_{1 \_\mathrm{RS}}+\varepsilon_{2 \_}+\varepsilon_{3 \_} * \quad \varepsilon_{\mathrm{ps} \_}=0.00899 \\
& \varepsilon_{\mathrm{ps} \_}:=\varepsilon_{1 \_\mathrm{RS}}+\varepsilon_{2 \_9}+\varepsilon_{3 \_} * * \varepsilon_{\mathrm{ps} 9}=0.00995 \\
& \varepsilon_{\mathrm{ps} \_10}:=\varepsilon_{1 \_\mathrm{RS}}+\varepsilon_{2 \_10}+\varepsilon_{3 \_10} * \quad \varepsilon_{\mathrm{ps} \_10}=0.01021
\end{aligned}
$$

The stress in the prestressing corresponding to the total strain at failure is (to approximate yield strain use curve equation for $250 \mathrm{ksi}$ strand out of PCI Handbook):

$$
f_{\mathrm{ps} \_1}:=\mid \begin{array}{ll}
\mathrm{E}_{\mathrm{ps}} \cdot \varepsilon_{\mathrm{ps} \_} \text {if } \varepsilon_{\mathrm{ps} \_1} \leq 0.0076 & \mathrm{f}_{\mathrm{ps} s_{-}}=137.7 \mathrm{ksi} \\
250 \mathrm{ksi}-\frac{0.04 \mathrm{ksi}}{\varepsilon_{\mathrm{ps} s_{-} 1}-0.0064} \text { if } \varepsilon_{\mathrm{ps} s_{-} 1}>0.0076 &
\end{array}
$$

Using the same equation relating stress and strain as above, the stresses in all the layers of prestressing at failure are:

$$
\begin{aligned}
& \mathrm{f}_{\mathrm{ps} \_}:=145 \mathrm{ksi} \quad \mathrm{f}_{\mathrm{ps}_{-} 5}:=214.3 \mathrm{ksi} \quad \mathrm{f}_{\mathrm{ps} \_} 8:=234.6 \mathrm{ksi} \\
& \mathrm{f}_{\mathrm{ps} \_}:=172.8 \mathrm{ksi} \quad \mathrm{f}_{\mathrm{ps} s_{-}}:=220.9 \mathrm{ksi} \quad \mathrm{f}_{\mathrm{ps} s_{-}}:=238.7 \mathrm{ksi} \\
& \mathrm{f}_{\mathrm{ps} \_}:=179.6 \mathrm{ksi} \quad \mathrm{f}_{\mathrm{ps} \_}:=232.9 \mathrm{ksi} \quad \mathrm{f}_{\mathrm{ps} \_10}:=239.5 \mathrm{ksi}
\end{aligned}
$$

Since this layer is located in the compression zone $(d<c)$ it is expected that the stress in the prestressing steel will decrease from the effective prestress to that at failure, which is the case here.

The force of the prestressing layer is the area of prestressing within the layer multiplied by the stress determine above:

$$
\mathrm{T}_{1}:=\mathrm{A}_{\mathrm{ps} \_} \cdot \mathrm{f}_{\mathrm{ps} \_} 1
$$


The force in all the layers of prestressing is:

$$
\begin{array}{lll}
\mathrm{T}_{2}:=10.0 \mathrm{kip} & \mathrm{T}_{5}:=14.8 \mathrm{kip} & \mathrm{T}_{8}:=16.2 \mathrm{kip} \\
\mathrm{T}_{3}:=11.9 \mathrm{kip} & \mathrm{T}_{6}:=15.2 \mathrm{kip} & \mathrm{T}_{9}:=16.4 \mathrm{kip} \\
\mathrm{T}_{4}:=12.4 \mathrm{kip} & \mathrm{T}_{7}:=16.0 \mathrm{kip} & \mathrm{T}_{10}:=16.5 \mathrm{kip}
\end{array}
$$

The moment produced by the layer of prestressing steel about the cross-section's center of gravity is (counter-clockwise is assumed to be positive):

$$
\mathrm{M}_{\mathrm{n} 1}:=-\mathrm{T}_{1} \cdot\left(\mathrm{y}_{\mathrm{t} \_\mathrm{RS}}-\mathrm{d}_{1}\right) \quad \mathrm{M}_{\mathrm{n} 1}=-19.09635 \mathrm{kip} \cdot \mathrm{in}
$$

The moment produced by all the layers of prestressing is:

$$
\begin{array}{lll}
\mathrm{M}_{\mathrm{n} 2}:=-17.6 \mathrm{kp} \cdot \mathrm{in} & \mathrm{M}_{\mathrm{n} 5}:=9.0 \mathrm{kp} \cdot \mathrm{in} & \mathrm{M}_{\mathrm{n} 8}:=33.1 \mathrm{kip} \cdot \mathrm{in} \\
\mathrm{M}_{\mathrm{n} 3}:=-9.8 \mathrm{kp} \cdot \mathrm{in} & \mathrm{M}_{\mathrm{n} 6}:=13.1 \mathrm{kp} \cdot \mathrm{in} & \mathrm{M}_{\mathrm{n} 9}:=49.1 \mathrm{kip} \cdot \mathrm{in} \\
\mathrm{M}_{\mathrm{n} 4}:=-7.1 \mathrm{kp} \cdot \mathrm{in} & \mathrm{M}_{\mathrm{n} 7}:=28.9 \mathrm{kp} \cdot \mathrm{in} & \mathrm{M}_{\mathrm{n} 10}:=53.4 \mathrm{kip} \cdot \mathrm{in}
\end{array}
$$

Using the value for the depth to the neutral axis, estimate the depth of the compression block:

Assume fully bonded tendons, therefore (ACI 318-08 10.2.7.1):

$$
\begin{aligned}
& \beta_{1}:=\mid \begin{array}{l}
0.85-0.05 \cdot\left(\frac{\mathrm{f}_{\mathrm{c}}-4000 \mathrm{psi}}{1000 \cdot \mathrm{psi}}\right) \\
0.65 \text { otherwise }
\end{array} \quad \beta_{1}=0.7 \\
& \mathrm{a}:=\beta_{1} \cdot \mathrm{c} \quad \mathrm{a}=2.604 \mathrm{in}
\end{aligned}
$$

The total area of the concrete in compression, based on the approximated depth of the compression block is:

$$
\mathrm{A}_{\mathrm{C}}:=\frac{2 \cdot 9.10 \mathrm{in}+(\mathrm{a}-0.71 \mathrm{in}) \cdot 0.0897}{2} \cdot(\mathrm{a}-0.71 \mathrm{in})+5.92 \mathrm{in}^{2} \quad \mathrm{~A}_{\mathrm{C}}=23.31629 \mathrm{in}^{2}
$$

The resultant force of the concrete in compression area is:

$$
\mathrm{C}:=0.85 \cdot \mathrm{f}_{\mathrm{c}} \cdot \mathrm{A}_{\mathrm{C}} \quad \mathrm{C}=138.73191 \mathrm{kip}
$$

Sum the forces of all the prestressing layers to determine the total tension force:

$$
\mathrm{T}:=\mathrm{T}_{1}+\mathrm{T}_{2}+\mathrm{T}_{3}+\mathrm{T}_{4}+\mathrm{T}_{5}+\mathrm{T}_{6}+\mathrm{T}_{7}+\mathrm{T}_{8}+\mathrm{T}_{9}+\mathrm{T}_{10} \quad \mathrm{~T}=138.88887 \mathrm{kpp}
$$

Once convergence of the resultant compresive force (C) and total prestressing forces from all layers ( $T$ ) has been achieved, the appropriate depth to the neutral axis (c) has been determined. 
In this iteration, since $\mathrm{T}=\mathrm{C}$ the correct depth to the neutral axis has been determined and the nominal moment capacity of the section can be calculated.

$$
\begin{aligned}
& M_{n}:=M_{n 1}+M_{n 2}+M_{n 3}+M_{n 4}+M_{n 5}+M_{n 6}+M_{n 7}+M_{n 8}+M_{n 9}+M_{n 10}+C \cdot\left(y_{t} R_{S}-\frac{a}{2}\right) \\
& M_{n}=609.96396 \mathrm{kip} \cdot \mathrm{in}
\end{aligned}
$$

The spreadsheet summarizing the process of determining the nominal moment capacity based on strain compatibility is located in the Appendix of this report. In the spreadheet the individual values for each prestresisng layer at each step of calculation are given as well as the nominal moment capacity for the corresponding section and load condition. This process is repeated for the remaining nominal moment capacity calculations for negitive bending at the rail seat, and positive and negative bending at the center sections. The processes for these conditions will be identical to the one shown above with the location of the extreme compression fiber changing from top to bottom, depending on the bending condition. The figures below illustrate the location of the compression fiber and the three strain increments for the remaining nominal moment conditions of interest.

\section{Megative Moment Ultimate Capacity Rail Seat}

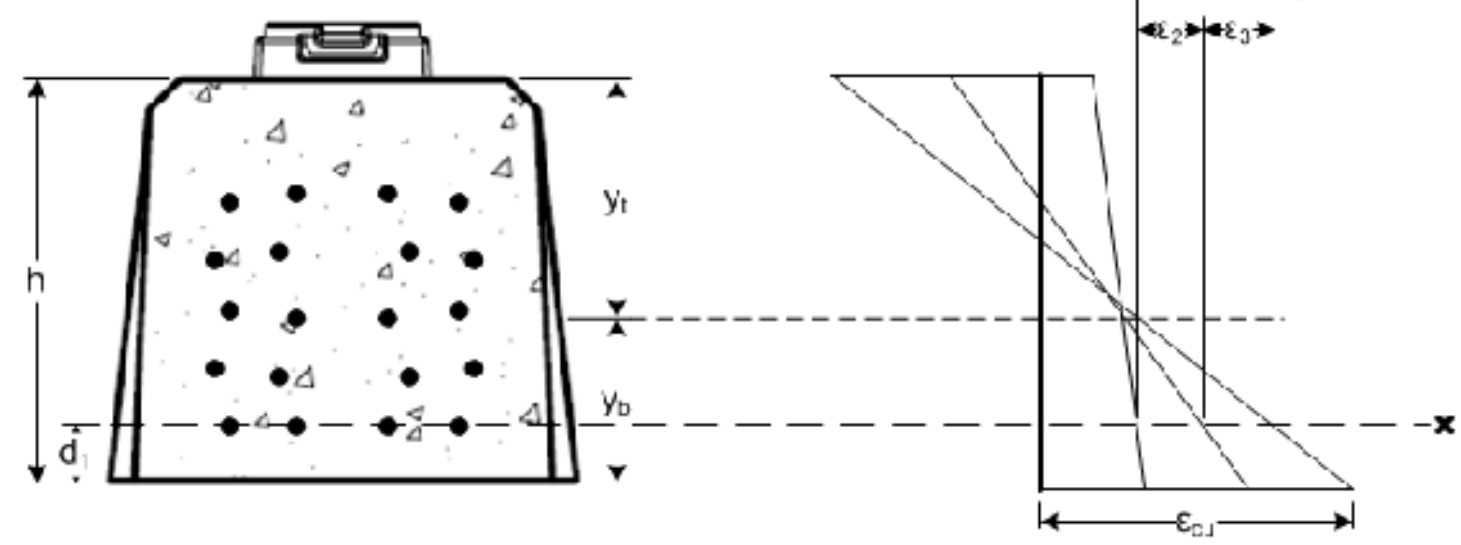

\section{Positive Moment Ultimate Capacity Center}

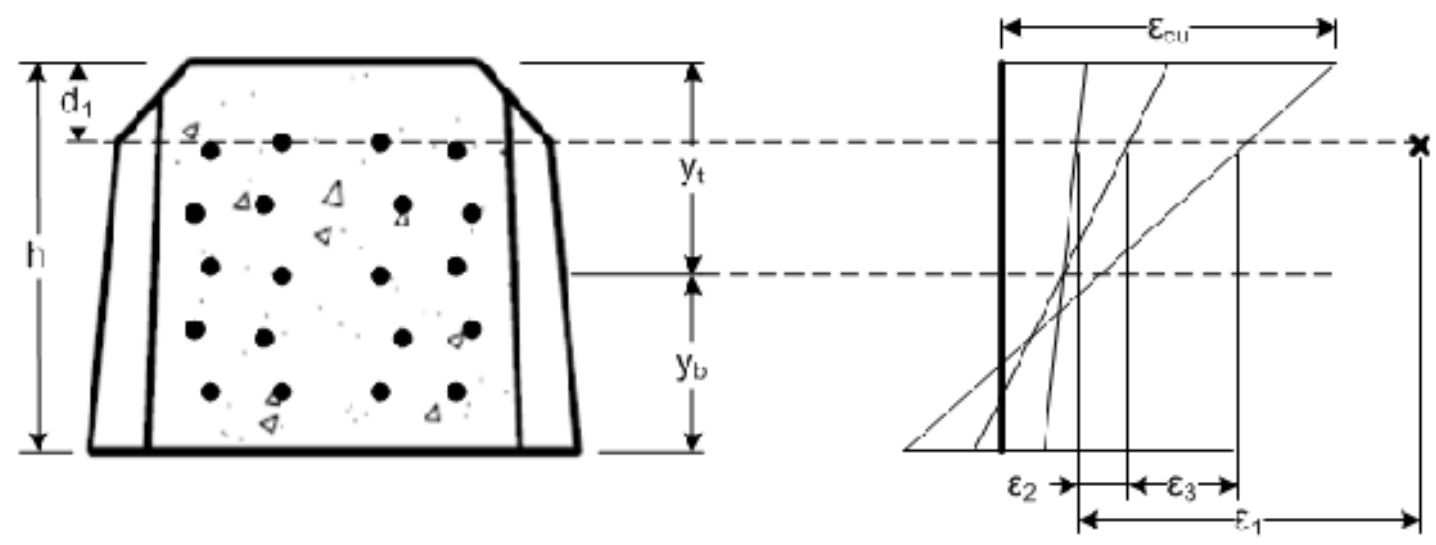


Negative Moment Ultimate Capacity Center

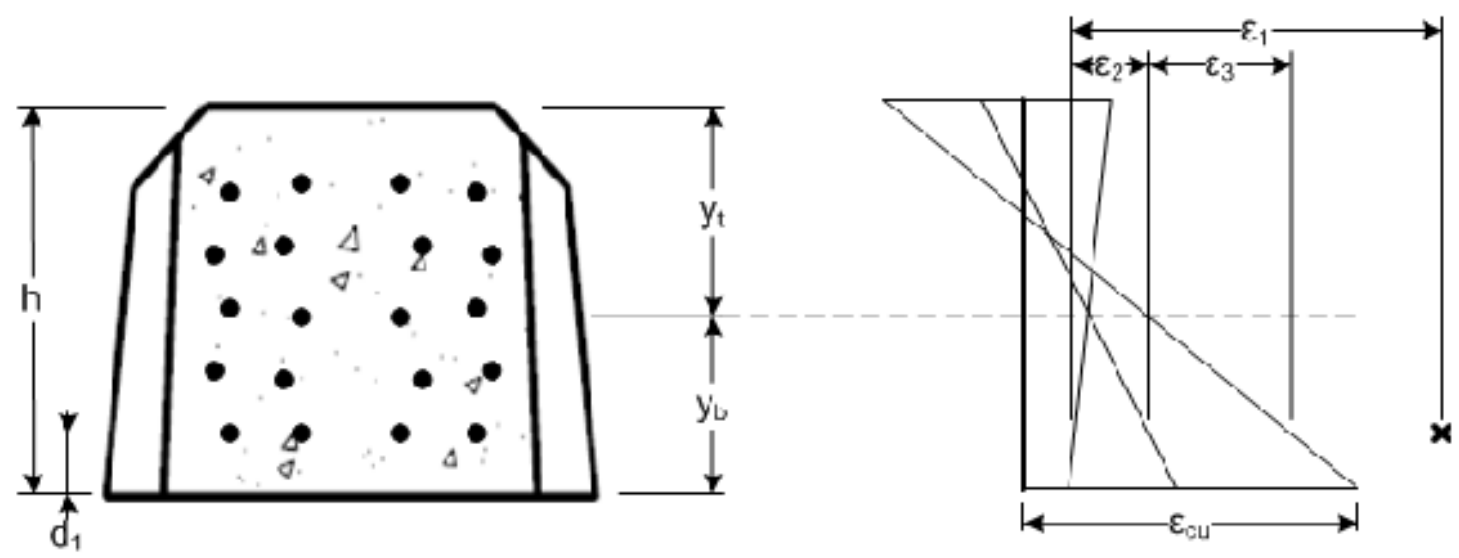

A nominal moment capacity summary for all four conditions is:

\begin{tabular}{|c|c|}
\hline Load Case/Critical Section & $\begin{array}{c}\text { Nominal Moment Capacity } \\
\mathbf{M}_{\mathbf{n}} \text { (kip-in) }\end{array}$ \\
\hline Positive Bending/Rail Seat & 610 \\
\hline Negaitive Bending/Rail Seat & 412 \\
\hline Positive Bending/Center & 334 \\
\hline Negaitive Bending/Center & 385 \\
\hline
\end{tabular}




\section{2.0 Baseline Tie Analysis (Spreadsheet)}

\begin{tabular}{|c|c|c|c|c|c|c|c|c|}
\hline \multicolumn{9}{|c|}{$\mathrm{I}_{\mathrm{x}}$ Center Section } \\
\hline Component & b & h & A & y & Ay & $I_{\text {bar }}$ & d & $I_{b a r}+A d^{2}$ \\
\hline $\mathrm{A}$ & 7.75 & 6.88 & 53.28 & 3.44 & 183.15 & 209.86 & 0.28 & 214.14 \\
\hline $\mathrm{B}$ & 0.31 & 6.88 & 0.11 & 2.29 & 0.24 & 2.80 & 1.43 & 3.02 \\
\hline C & 0.31 & 6.88 & 0.11 & 2.29 & 0.24 & 2.80 & 1.43 & 3.02 \\
\hline $\mathrm{D}$ & 6.50 & 0.63 & 4.06 & 7.19 & 29.20 & 0.13 & -3.47 & 48.96 \\
\hline $\mathrm{E}$ & 0.63 & 0.63 & 0.20 & 7.08 & 1.38 & 0.00 & -3.36 & 2.21 \\
\hline $\mathrm{F}$ & 0.63 & 0.63 & 0.20 & 7.08 & 1.38 & 0.00 & -3.36 & 2.21 \\
\hline Sum & & & 57.95 & & 215.61 & & & 273.55 \\
\hline$Y_{\text {bar }}$ & 3.72 & & & & & & & \\
\hline
\end{tabular}

\begin{tabular}{|c|c|c|c|c|c|c|c|c|}
\hline \multicolumn{9}{|c|}{$\mathrm{I}_{\mathrm{x}}$ Rail Seat Section } \\
\hline Component & b & h & A & y & Ay & $I_{\text {bar }}$ & d & $\mathrm{I}_{\mathrm{bar}}+A d^{2}$ \\
\hline$A$ & 9.10 & 8.59 & 78.12 & 4.29 & 335.35 & 479.82 & 0.26 & 485.12 \\
\hline$B$ & 0.39 & 8.59 & 1.65 & 2.86 & 4.73 & 6.77 & 1.69 & 11.49 \\
\hline $\mathrm{C}$ & 0.39 & 8.59 & 1.65 & 2.86 & 4.73 & 6.77 & 1.69 & 11.49 \\
\hline $\mathrm{D}$ & 7.69 & 0.71 & 5.42 & 8.94 & 48.45 & 0.22 & -4.38 & 104.46 \\
\hline $\mathrm{E}$ & 0.71 & 0.71 & 0.25 & 8.82 & 2.22 & 0.01 & -4.27 & 4.60 \\
\hline $\mathrm{F}$ & 0.71 & 0.71 & 0.25 & 8.82 & 2.22 & 0.01 & -4.27 & 4.60 \\
\hline Sum & & & 87.35 & & 397.70 & & & 621.76 \\
\hline$Y_{\text {bar }}$ & 4.55 & & & & & & & \\
\hline
\end{tabular}

Section Properties Summary

\begin{tabular}{|l|l|l|}
\hline Geometry Constant & Rail Seat & Center \\
\hline
\end{tabular}

\begin{tabular}{|c|c|c|}
\hline$A\left(\mathrm{in}^{2}\right)$ & 87.35 & 57.95 \\
\hline $\mathrm{I}\left(\mathrm{in}^{4}\right)$ & 621.76 & 273.55 \\
\hline $\mathrm{y}_{\mathrm{b}}(\mathrm{in})$ & 4.55 & 3.72 \\
\hline $\mathrm{y}_{\mathrm{t}}(\mathrm{in})$ & 4.74 & 3.78 \\
\hline
\end{tabular}




\begin{tabular}{|l|c|}
\hline \multicolumn{2}{|c|}{ Concrete Properties } \\
\hline$f^{\prime}{ }_{c}(p s i)$ & 7000 \\
\hline$E_{c}(k s i)$ & 4769 \\
\hline$f^{\prime}{ }_{c i}(p s i)$ & 4500 \\
\hline$E_{c i}(k s i)$ & 3824 \\
\hline$\sigma_{t i}(p s i)$ & -201 \\
\hline$\sigma_{c i}(p s i)$ & 2700 \\
\hline$\sigma_{t s}(p s i)$ & -627 \\
\hline$\sigma_{c s}(p s i)$ & 4200 \\
\hline
\end{tabular}

\begin{tabular}{|c|c|}
\hline \multicolumn{2}{|c|}{ Steel Properties } \\
\hline$f_{p u}(k s i)$ & 255.44 \\
\hline$f_{p y}(k s i)$ & 229.90 \\
\hline Jacking Force (Ibs) & 7000 \\
\hline$f_{p j 2}(k s i)$ & 203.19 \\
\hline$E_{p s}(k s i)$ & 28500 \\
\hline$f_{p j \_u}(k s i)$ & 204.35 \\
\hline$f_{p j \_y}(k s i)$ & 216.10 \\
\hline$f_{p i \_u}(k s i)$ & 189.03 \\
\hline$f_{p i \_y}(k s i)$ & 188.52 \\
\hline
\end{tabular}

\begin{tabular}{|l|l|}
\hline$n_{p i}$ & 7.45 \\
\hline$n_{p}$ & 5.98 \\
\hline
\end{tabular}




\begin{tabular}{|c|r|}
\hline \multicolumn{2}{|c|}{ Prestressing Size } \\
\hline $\mathrm{d}_{\text {tendon }}(\mathrm{in})$ & 0.21 \\
\hline $\mathrm{A}_{\text {tendon }}\left(\mathrm{in}^{2}\right)$ & 0.03445 \\
\hline
\end{tabular}

\begin{tabular}{|c|c|c|c|c|}
\hline \multicolumn{5}{|c|}{ Prestressing Centroid Calculator } \\
\hline Layer Number & $\begin{array}{c}\text { Number of } \\
\text { Tendons in Layer }\end{array}$ & $\begin{array}{c}\text { Area of Tendons } \\
\text { in Layer } \\
\text { (A) }\left(\mathrm{in}^{2}\right)\end{array}$ & $\begin{array}{l}\text { Distance of Layer } \\
\text { From Bottom } \\
\text { (y) (in.) }\end{array}$ & Ay \\
\hline 1 & 2 & 0.07 & 1.3125 & 0.090 \\
\hline 2 & 2 & 0.07 & 1.5625 & 0.108 \\
\hline 3 & 2 & 0.07 & 2.5 & 0.172 \\
\hline 4 & 2 & 0.07 & 2.75 & 0.189 \\
\hline 5 & 2 & 0.07 & 3.6875 & 0.254 \\
\hline 6 & 2 & 0.07 & 3.9375 & 0.271 \\
\hline 7 & 2 & 0.07 & 5.125 & 0.353 \\
\hline 8 & 2 & 0.07 & 5.375 & 0.370 \\
\hline 9 & 2 & 0.07 & 6.3125 & 0.435 \\
\hline 10 & 2 & 0.07 & 6.5625 & 0.452 \\
\hline 11 & 0 & 0.00 & 0 & 0.000 \\
\hline 12 & 0 & 0.00 & 0 & 0.000 \\
\hline 13 & 0 & 0.00 & 0 & 0.000 \\
\hline 14 & 0 & 0.00 & 0 & 0.000 \\
\hline 15 & 0 & 0.00 & 0 & 0.000 \\
\hline Totals & 20 & 0.69 & & 2.696 \\
\hline & & & Ysteel centroid $_{\text {(in.) }}$ & 3.913 \\
\hline
\end{tabular}

\begin{tabular}{|c|c|c|}
\hline \multicolumn{3}{|c|}{ Eccentricity Calculator } \\
\hline $\begin{array}{c}\text { Eccentricity } \\
\text { Location }\end{array}$ & $\begin{array}{c}y_{\text {concrete centroid }} \\
\text { (in.) }\end{array}$ & $\begin{array}{c}\text { Eccentricity } \\
\text { (in.) }\end{array}$ \\
\hline Rail Seat $\left(e_{\mathrm{RS}}\right)$ & 4.55 & 0.638 \\
\hline Center $\left(\mathrm{e}_{\mathrm{C}}\right)$ & 3.72 & -0.193 \\
\hline
\end{tabular}




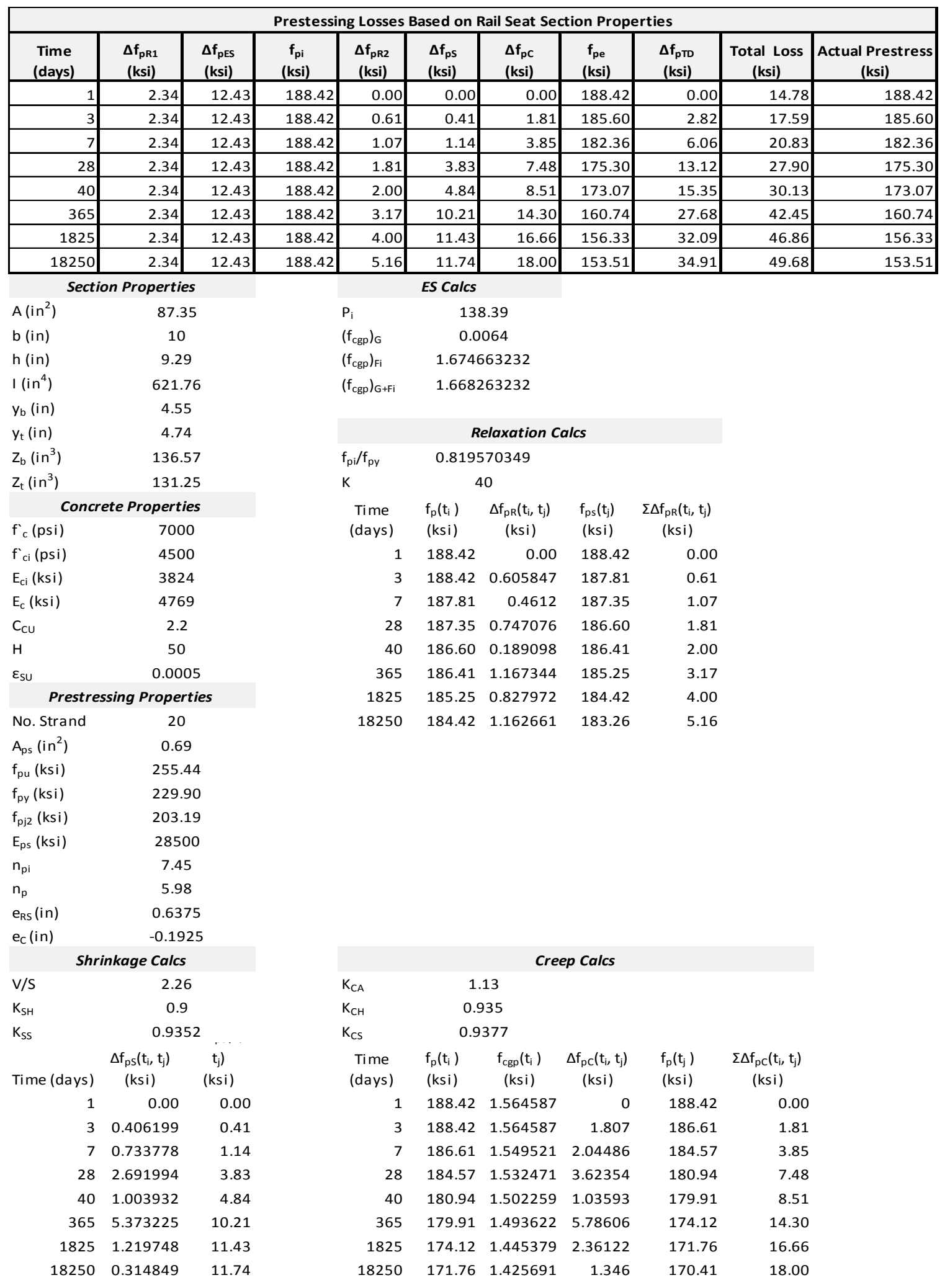




\begin{tabular}{|c|c|c|c|c|c|c|c|c|c|c|}
\hline \multicolumn{11}{|c|}{ Prestessing Losses Based on Center Section Properties } \\
\hline $\begin{array}{c}\text { Time } \\
\text { (days) }\end{array}$ & $\begin{array}{l}\Delta \mathrm{f}_{\mathrm{pR} 1} \\
(\mathrm{ksi})\end{array}$ & $\begin{array}{l}\Delta \mathrm{f}_{\mathrm{pES}} \\
(\mathrm{ksi})\end{array}$ & $\begin{array}{c}\mathbf{f}_{\mathrm{pi}} \\
(\mathbf{k s i})\end{array}$ & $\begin{array}{c}\Delta f_{p R 2} \\
(k s i)\end{array}$ & $\begin{array}{l}\Delta \mathrm{f}_{\mathrm{ps}} \\
(\mathrm{ksi})\end{array}$ & $\begin{array}{l}\Delta \mathrm{f}_{\mathrm{pc}} \\
(\mathrm{ksi})\end{array}$ & $\begin{array}{c}f_{p e} \\
\text { (ksi) }\end{array}$ & $\begin{array}{r}\Delta \mathbf{f}_{\mathrm{pTD}} \\
(\mathbf{k s i})\end{array}$ & $\begin{array}{c}\text { Total Loss } \\
\text { (ksi) }\end{array}$ & $\begin{array}{c}\text { Actual Prestress } \\
\text { (ksi) }\end{array}$ \\
\hline 1 & 2.34 & 17.89 & 182.96 & 0.00 & 0.00 & 0.00 & 182.96 & 0.00 & 20.23 & 182.96 \\
\hline 3 & 2.34 & 17.89 & 182.96 & 0.54 & 0.43 & 2.65 & 179.35 & 3.62 & 23.85 & 179.35 \\
\hline 7 & 2.34 & 17.89 & 182.96 & 0.95 & 1.20 & 5.64 & 175.18 & 7.78 & 28.02 & 175.18 \\
\hline 28 & 2.34 & 17.89 & 182.96 & 1.61 & 4.03 & 10.90 & 166.42 & 16.54 & 36.77 & 166.42 \\
\hline 40 & 2.34 & 17.89 & 182.96 & 1.78 & 5.08 & 12.39 & 163.71 & 19.25 & 39.48 & 163.71 \\
\hline 365 & 2.34 & 17.89 & 182.96 & 2.81 & 10.73 & 20.69 & 148.73 & 34.23 & 54.46 & 148.73 \\
\hline 1,825 & 2.34 & 17.89 & 182.96 & 3.55 & 12.01 & 24.02 & 143.39 & 39.57 & 59.80 & 143.39 \\
\hline 18,250 & 2.34 & 17.89 & 182.96 & 4.58 & 12.34 & 25.90 & 140.14 & 42.82 & 63.05 & 140.14 \\
\hline \multicolumn{3}{|c|}{ Section Properties } & \multicolumn{4}{|c|}{ ES Calcs } & & & & \\
\hline$A\left(i n^{2}\right)$ & \multicolumn{2}{|c|}{57.95} & & $\mathrm{P}_{\mathrm{i}}$ & \multicolumn{2}{|c|}{138.39} & & & & \\
\hline$b(\mathrm{in})$ & \multicolumn{2}{|c|}{7.75} & & $\left(f_{\mathrm{cgp}}\right)_{\mathrm{G}}$ & \multicolumn{2}{|c|}{0.0066} & & & & \\
\hline$h($ in) & \multicolumn{2}{|c|}{7.5} & & $\left(f_{\mathrm{cgp}}\right)_{\mathrm{Fi}}$ & \multicolumn{2}{|c|}{2.4068962} & & & & \\
\hline I $\left(\mathrm{in}^{4}\right)$ & \multicolumn{2}{|c|}{273.55} & & $\left(f_{c g p}\right)_{G+F i}$ & \multirow{2}{*}{\multicolumn{2}{|c|}{2.4002962}} & & & & \\
\hline$y_{b}($ in $)$ & & & & & & & & & \\
\hline$y_{t}(\mathrm{in})$ & \multicolumn{2}{|c|}{3.78} & & & \multicolumn{3}{|c|}{ Relaxation Calcs } & & & \\
\hline$Z_{b}\left(i n^{3}\right)$ & \multicolumn{2}{|c|}{73.52} & & $f_{p i} / f_{p y}$ & \multicolumn{3}{|c|}{0.795837033} & & & \\
\hline $\mathrm{Z}_{\mathrm{t}}\left(\mathrm{in}^{3}\right)$ & & .38 & & K & \multicolumn{2}{|c|}{40} & & & & \\
\hline \multicolumn{3}{|c|}{ Concrete Properties } & & Time & $f_{p}\left(t_{i}\right)$ & $\Delta \mathrm{f}_{\mathrm{pR}}\left(\mathrm{t}_{\mathrm{i}}, \mathrm{t}_{\mathrm{j}}\right)$ & $f_{p s}\left(t_{j}\right)$ & $\left.t_{j}\right)$ & & \\
\hline$f_{c}^{\prime}(p s i)$ & 70 & 00 & & (days) & (ksi) & (ksi) & (ksi) & (ksi) & & \\
\hline$f_{c i}^{\prime}(p s i)$ & 45 & 500 & & 1 & 182.96 & 0.00 & 182.96 & 0.00 & & \\
\hline$E_{c i}(k s i)$ & 38 & 324 & & 3 & 182.96 & 0.53651 & 182.43 & 0.54 & & \\
\hline$E_{c}(k s i)$ & 47 & 69 & & 7 & 182.43 & 0.40865 & 182.02 & 0.95 & & \\
\hline $\mathrm{c}_{\mathrm{cu}}$ & 2 & .2 & & 28 & 182.02 & 0.66224 & 181.35 & 1.61 & & \\
\hline $\mathrm{H}$ & 5 & 50 & & 40 & 181.35 & 0.16774 & 181.19 & 1.78 & & \\
\hline$\varepsilon_{\mathrm{su}}$ & 0.0 & 005 & & 365 & 181.19 & 1.03569 & 180.15 & 2.81 & & \\
\hline Prestre & essing Prop & erties & & 1825 & 180.15 & 0.73541 & 179.42 & 3.55 & & \\
\hline No. Strand & 2 & 20 & & 18250 & 179.42 & 1.03349 & 178.38 & 4.58 & & \\
\hline$A_{p s}\left(i n^{2}\right)$ & 0. & & & & & & & & & \\
\hline$f_{p u}(k s i)$ & 255 & 5.44 & & & & & & & & \\
\hline$f_{p y}(k s i)$ & 229 & 9.90 & & & & & & & & \\
\hline$f_{p j 2}(k s i)$ & 203 & 3.19 & & & & & & & & \\
\hline$E_{p s}(k s i)$ & 285 & 500 & & & & & & & & \\
\hline $\mathrm{n}_{\mathrm{pi}}$ & 7. & & & & & & & & & \\
\hline$n_{p}$ & 5. & & & & & & & & & \\
\hline$e_{R S}(i n)$ & 0.6 & 375 & & & & & & & & \\
\hline$e_{c}(i n)$ & -0.1 & 1925 & & & & & & & & \\
\hline Shr & rinkage Cal & & & & & Cree & ep Calcs & & & \\
\hline $\mathrm{V} / \mathrm{s}$ & 1. & 72 & & $\mathrm{~K}_{\mathrm{CA}}$ & 1. & 13 & & & & \\
\hline $\mathrm{K}_{\mathrm{SH}}$ & 0 & .9 & & $\mathrm{~K}_{\mathrm{CH}}$ & 0.9 & 935 & & & & \\
\hline $\mathrm{K}_{\mathrm{sS}}$ & $0.9 \varepsilon$ & 826 & & $\mathrm{~K}_{\mathrm{CS}}$ & 0.9 & 855 & & & & \\
\hline $\begin{array}{l}\text { Time } \\
\text { (days) }\end{array}$ & $\begin{array}{c}\Delta f_{p s}\left(t_{i}, t_{j}\right) \\
(k s i)\end{array}$ & $\begin{array}{c}\Sigma \Delta f_{p s}\left(t_{i}, t_{j}\right) \\
(k s i)\end{array}$ & & $\begin{array}{l}\text { Time } \\
\text { (days) }\end{array}$ & $\begin{array}{l}f_{p}\left(t_{i}\right) \\
(k s i)\end{array}$ & $\begin{array}{c}f_{\mathrm{cgp}}\left(t_{i}\right) \\
(\mathrm{ksi})\end{array}$ & $\begin{array}{c}\Delta \mathrm{f}_{\mathrm{pc}}\left(\mathrm{t}_{\mathrm{i}}, \mathrm{t}_{\mathrm{j}}\right) \\
(\mathrm{ksi})\end{array}$ & $\begin{array}{l}f_{p}\left(t_{j}\right) \\
(k s i)\end{array}$ & $\begin{array}{c}\Sigma \Delta f_{p c}\left(t_{i}, t_{j}\right) \\
(k s i)\end{array}$ & \\
\hline 1 & 0.00 & 0.00 & & 1 & 182.96 & 2.1859 & 0 & 182.96 & 0.00 & \\
\hline 3 & 0.426787 & 0.43 & & 3 & 182.96 & 2.1859 & 2.65327 & 180.31 & 2.65 & \\
\hline 7 & 0.770969 & 1.20 & & 7 & 180.31 & 2.15411 & 2.98763 & 177.32 & 5.64 & \\
\hline 28 & 2.828436 & 4.03 & & 28 & 177.32 & 2.11831 & 5.26408 & 172.06 & 10.90 & \\
\hline 40 & 1.054815 & 5.08 & & 40 & 172.06 & 2.05523 & 1.48948 & 170.57 & 12.39 & \\
\hline 365 & 5.645563 & 10.73 & & 365 & 170.57 & 2.03738 & 8.29481 & 162.27 & 20.69 & \\
\hline 1825 & 1.281571 & 12.01 & & 1825 & 162.27 & 1.93798 & 3.32733 & 158.95 & 24.02 & \\
\hline 18250 & 0.330807 & 12.34 & & 18250 & 158.95 & 1.8981 & 1.88335 & 157.06 & 25.90 & \\
\hline
\end{tabular}




\begin{tabular}{|c|c|}
\hline \multicolumn{2}{|c|}{ Self Weight Calculator } \\
\hline Tie Weight $(\mathrm{lb})$ & 735 \\
\hline Tie Length $(\mathrm{ft})$ & 102 \\
\hline $\mathrm{w}_{\mathrm{G}}(\mathrm{Ib} / \mathrm{in})$ & 7.21 \\
\hline
\end{tabular}

\begin{tabular}{|c|c|c|}
\hline Location & $\begin{array}{c}\text { Distance } \\
\text { From End (in) }\end{array}$ & $\begin{array}{c}\mathbf{M}_{\mathbf{0}} \\
\text { (kip-in) }\end{array}$ \\
\hline Rail Seat & 21.7 & 6.28 \\
\hline Center & 51 & 9.37 \\
\hline
\end{tabular}

\begin{tabular}{|c|c|}
\hline \multicolumn{2}{|c|}{ Initial Prestressing Force } \\
\hline$F_{\text {i_RS }}($ kip) & 129.82 \\
\hline$F_{\text {i_C }}($ kip) & 126.06 \\
\hline
\end{tabular}

\begin{tabular}{|c|c|c|c|}
\hline \multicolumn{4}{|c|}{ Rail Seat } \\
\hline Load Condition & Location & $\begin{array}{c}\text { Concrete Stress } \\
\text { (psi) }\end{array}$ & $\begin{array}{c}\text { Allowable } \\
\text { Check }\end{array}$ \\
\hline \multirow{2}{*}{1} & Top & 2165 & OK \\
\hline & Bottom & 834 & OK \\
\hline \multirow{2}{*}{2} & Top & 903 & OK \\
\hline & Bottom & 2046 & OK \\
\hline \multicolumn{4}{|c|}{ Center } \\
\hline Load Condition & Location & $\begin{array}{c}\text { Concrete Stress } \\
\text { (psi) }\end{array}$ & $\begin{array}{c}\text { Allowable } \\
\text { Check }\end{array}$ \\
\hline \multirow{2}{*}{1} & Top & 1970 & OK \\
\hline & Bottom & 2378 & OK \\
\hline \multirow{2}{*}{2} & Top & 2640 & OK \\
\hline & Bottom & 1718 & OK \\
\hline
\end{tabular}




\begin{tabular}{|l|r|}
\hline \multicolumn{2}{|c|}{ Effective Prestressing Force } \\
\hline$F_{\mathrm{RS}}$ (kip) & 119.24 \\
\hline $\mathrm{F}_{\mathrm{C}}$ (kip) & 112.80 \\
\hline
\end{tabular}

\begin{tabular}{|c|c|c|c|c|}
\hline \multicolumn{5}{|c|}{ Rail Seat } \\
\hline Load Condition & Location & $\begin{array}{c}\text { Live Load } \\
\text { Moment } \\
\text { (kip-in) }\end{array}$ & $\begin{array}{c}\text { Governing } \\
\text { Moment } \\
\text { (in-kip) } \\
\end{array}$ & $\begin{array}{c}\text { Governing } \\
\text { Stress } \\
\text { Condition } \\
\end{array}$ \\
\hline \multirow{2}{*}{ (+) Bending } & Top & 448 & \multirow{2}{*}{348} & \multirow{2}{*}{$\begin{array}{l}\text { Tension } \\
\text { Bottom }\end{array}$} \\
\hline & Bottom & 348 & & \\
\hline \multirow{2}{*}{ (-) Bending } & Top & 186 & \multirow{2}{*}{186} & \multirow{2}{*}{$\begin{array}{l}\text { Tension } \\
\text { Bottom }\end{array}$} \\
\hline & Bottom & 311 & & \\
\hline \multicolumn{5}{|c|}{ Center } \\
\hline Load Condition & Location & $\begin{array}{c}\text { Live Load } \\
\text { Moment } \\
\text { (kip-in) }\end{array}$ & $\begin{array}{c}\text { Governing } \\
\text { Moment } \\
\text { (in-kip) } \\
\end{array}$ & $\begin{array}{c}\text { Governing } \\
\text { Stress } \\
\text { Condition } \\
\end{array}$ \\
\hline \multirow{2}{*}{ (+) Bending } & Top & 141 & \multirow{2}{*}{141} & \multirow{2}{*}{$\begin{array}{c}\text { Compression } \\
\text { Top }\end{array}$} \\
\hline & Bottom & 168 & & \\
\hline \multirow{2}{*}{ (-) Bending } & Top & 208 & \multirow{2}{*}{187} & \multirow{2}{*}{$\begin{array}{l}\text { Compression } \\
\text { Bottom }\end{array}$} \\
\hline & Bottom & 187 & & \\
\hline
\end{tabular}




\begin{tabular}{|c|c|c|}
\hline \multicolumn{2}{|c|}{ Flexural Capacity } \\
\hline Load Case/Critical Section & $\begin{array}{c}\text { Nominal Moment Capacity } \\
\mathbf{M}_{\mathbf{n}} \text { (kip-in) }\end{array}$ & $\begin{array}{c}\text { Service Moment Capacity } \mathbf{M}_{\mathbf{L}} \\
\text { (kip-in) }\end{array}$ \\
\hline Positive Bending/Rail Seat & 610 & 348 \\
\hline Negaitive Bending/Rail Seat & 412 & 186 \\
\hline Positive Bending/Center & 334 & 141 \\
\hline Negaitive Bending/Center & 385 & 187 \\
\hline
\end{tabular}

\begin{tabular}{|c|c|c|}
\hline \multicolumn{2}{|c|}{ Prestressing Stresses Summary/Check } \\
\hline Load Case/Critical Section & Prestressing Stress (ksi) & Allowable Stress Check \\
\hline Jacking & 203.19 & OK \\
\hline Initial/Rail Seat & 188.42 & OK \\
\hline Initial/Center & 182.96 & OK \\
\hline Final/Rail Seat & 173.07 & N/A \\
\hline Final/Center & 163.71 & N/A \\
\hline
\end{tabular}

\begin{tabular}{|c|c|c|}
\hline \multicolumn{2}{|c|}{ Concrete Stresses @ TransferSummary/Check } \\
\hline Location/Critical Section & Concrete Stress (psi) & Allowable Stress Check \\
\hline Tie Top/Rail Seat & 903 & OK \\
\hline Tie Bottom/Rail Seat & 2165 & OK \\
\hline Tie Top/Center & 2640 & OK \\
\hline Tie Bottom/Rail Seat & 1970 & OK \\
\hline
\end{tabular}




\title{
Appendix E: Cross-sections of Optimized Designs
}

\author{
$W(P T)-0.21(P D)-7(C S)$
}

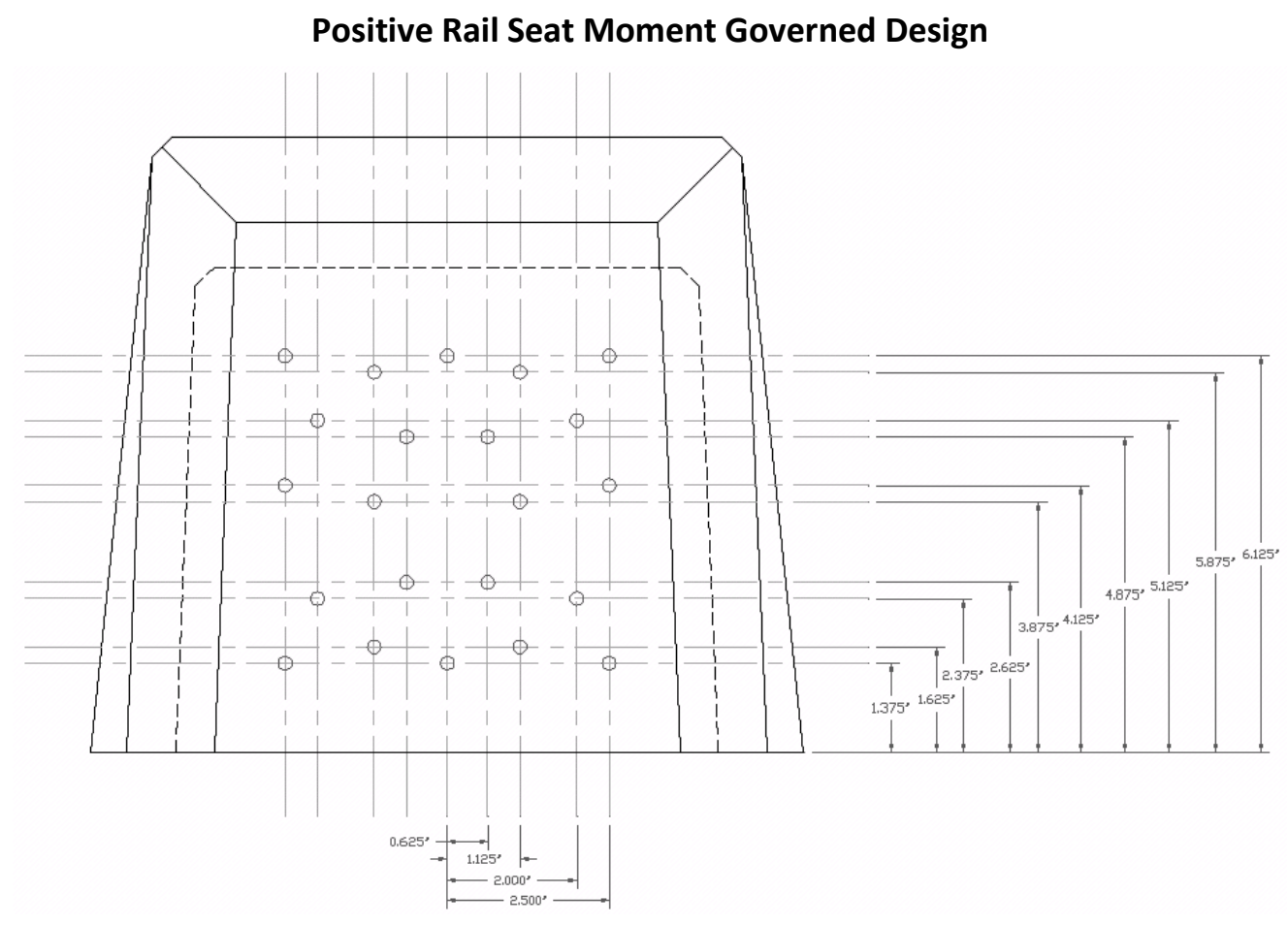

Negative Center Moment Governed Design

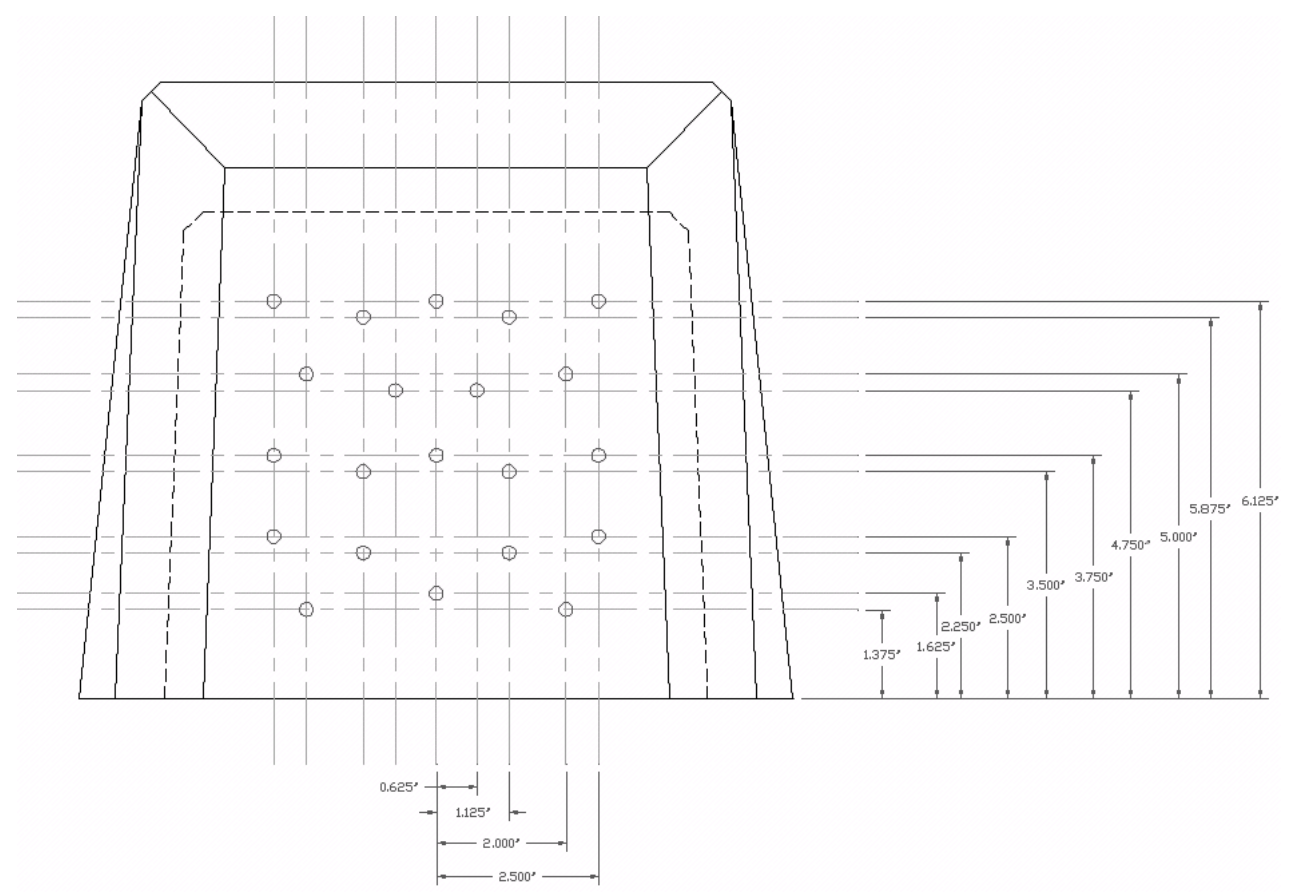


W(PT)-0.21(PD)-95(CS)

\section{Positive Rail Seat Moment Governed Design}

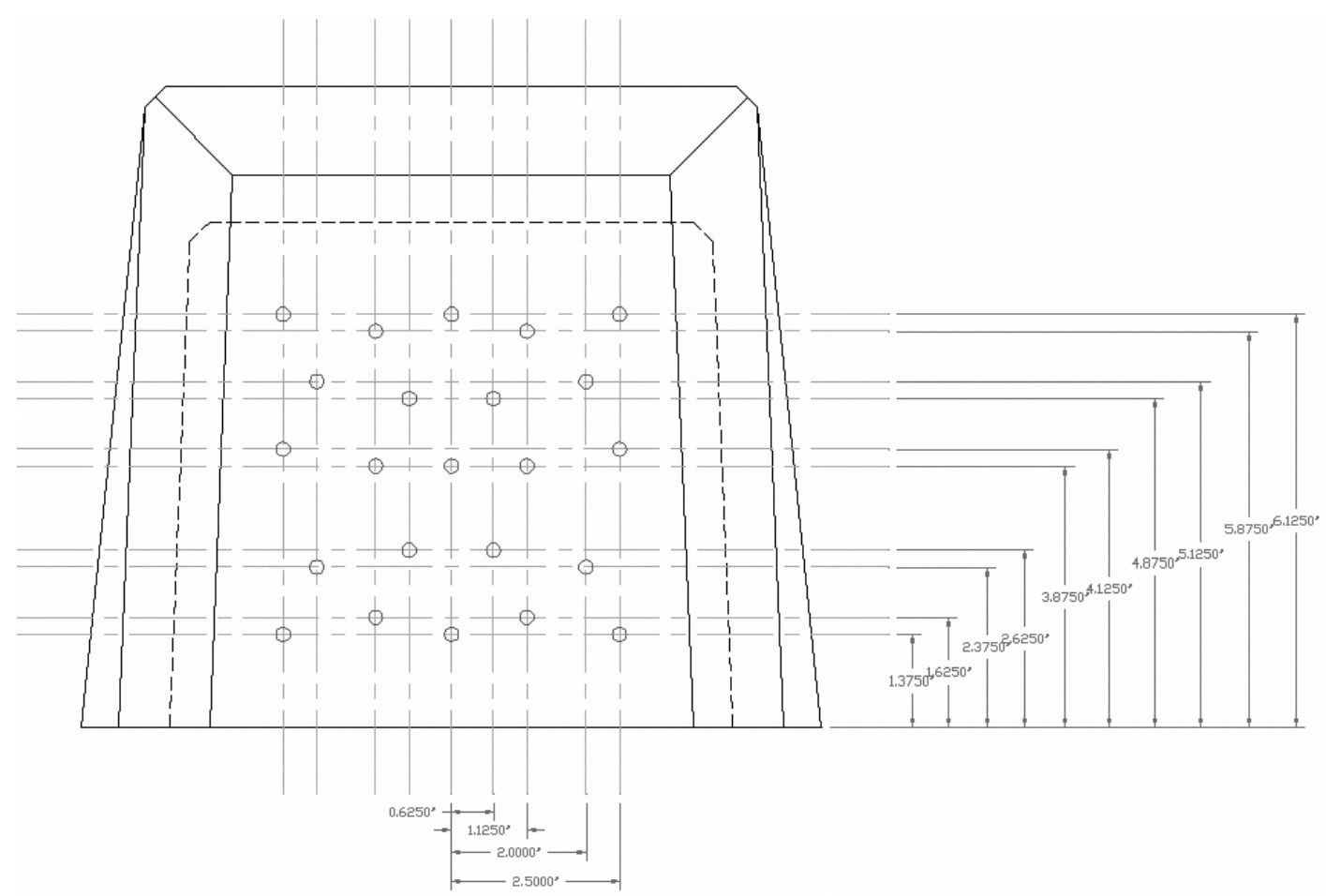

Negative Center Moment Governed Design

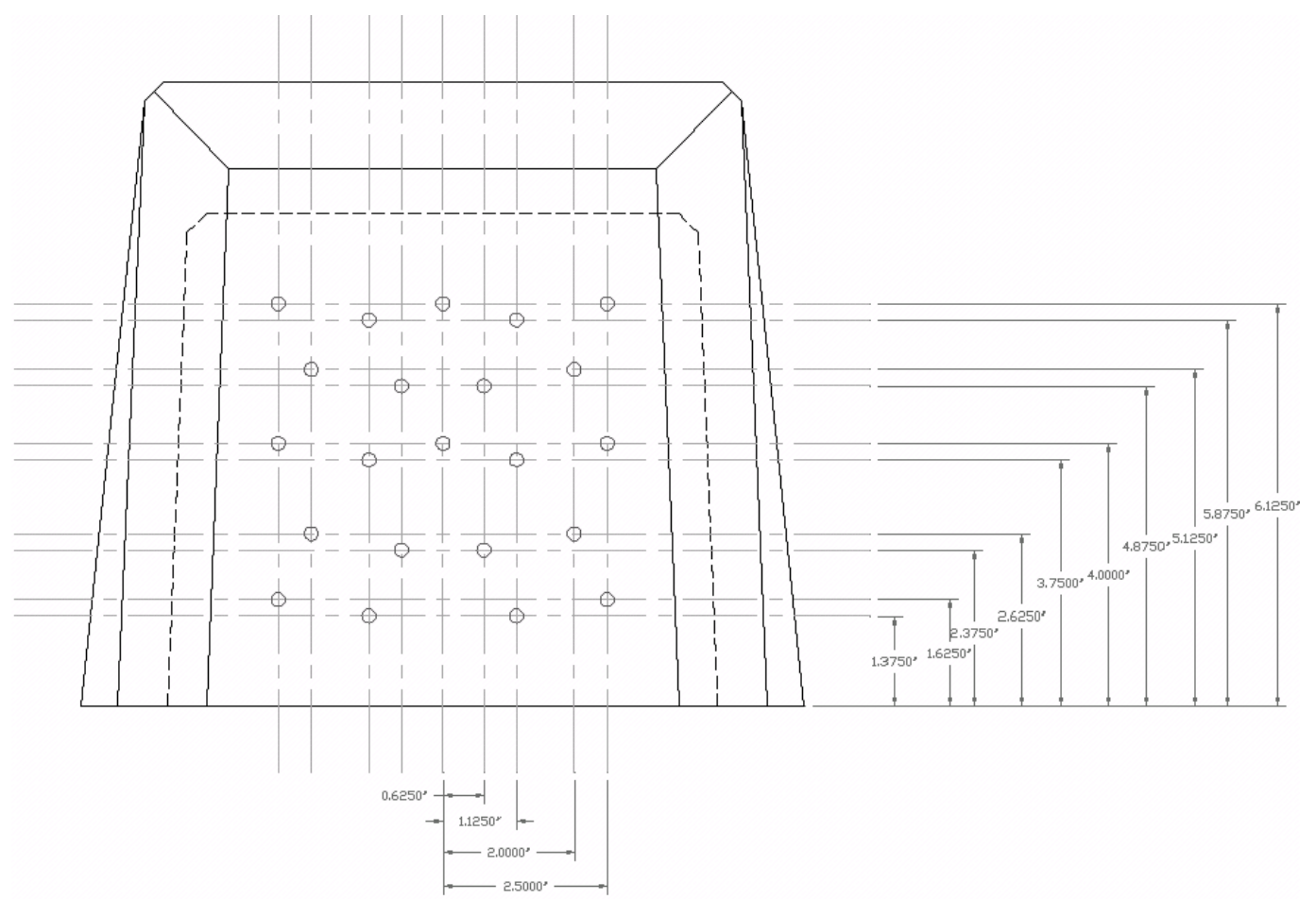


W(PT)-0.21(PD)-12(CS)

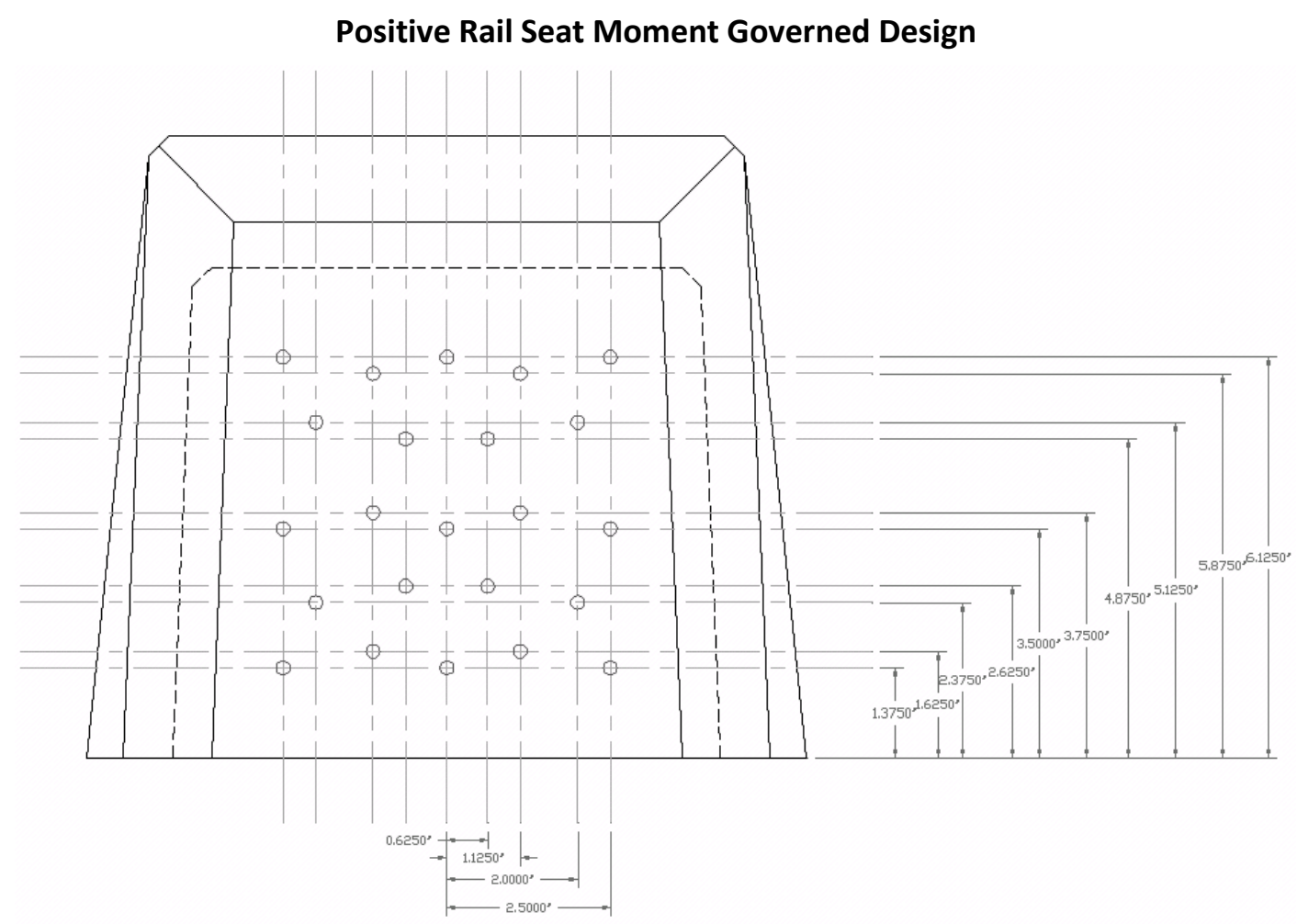

Negative Center Moment Governed Design

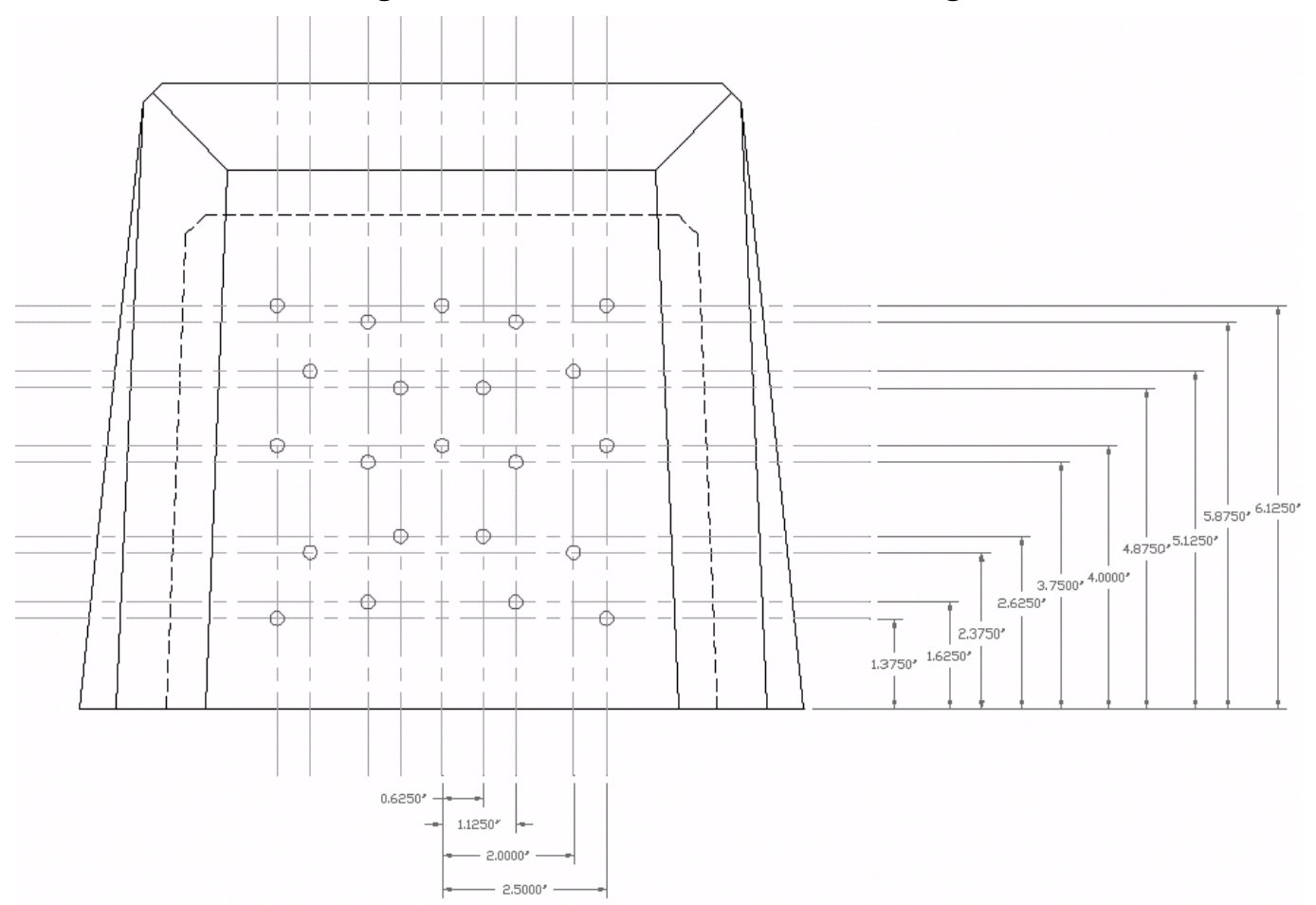




\section{W(PT)-0.21(PD)-15(CS)}

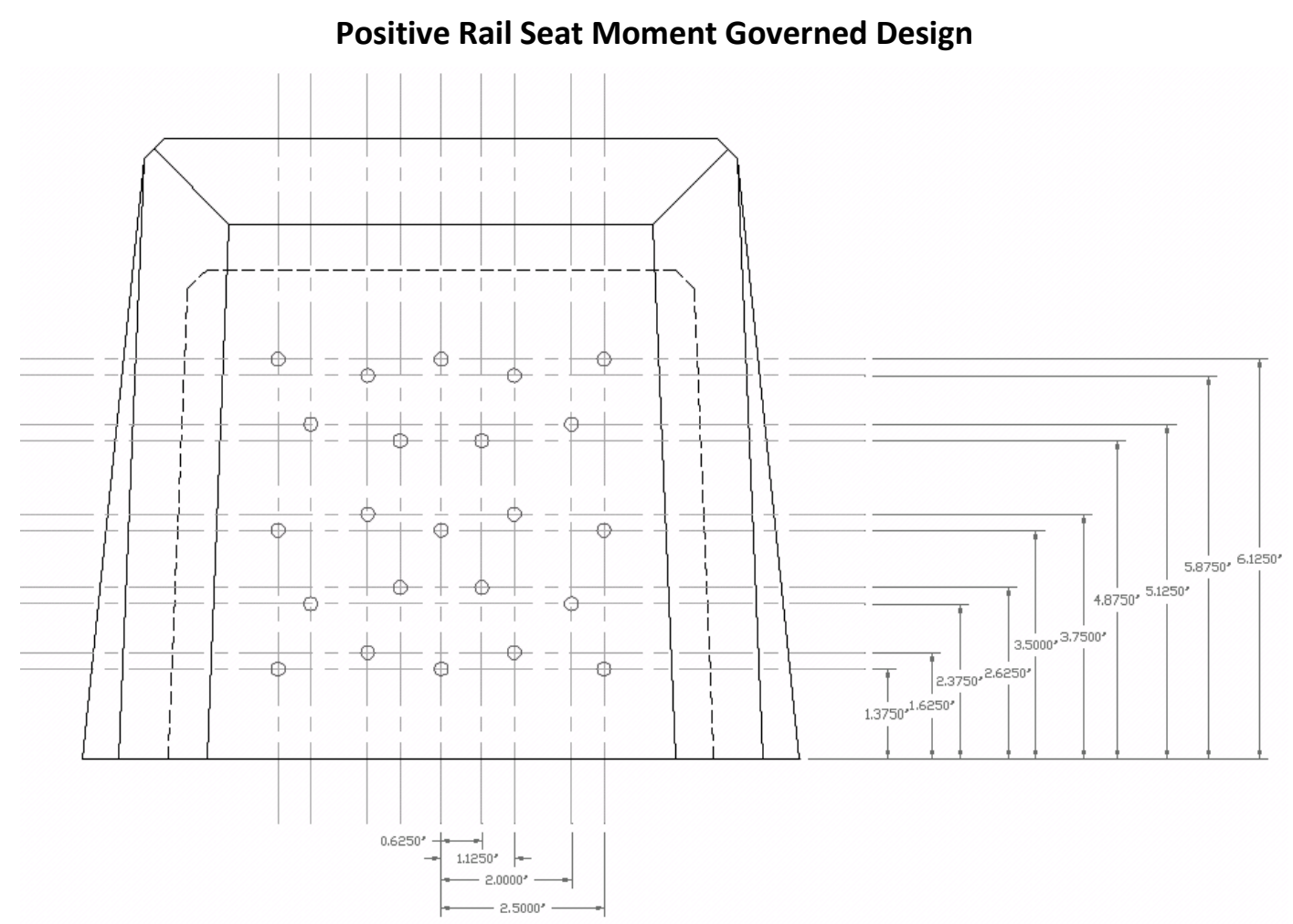

Negative Center Moment Governed Design

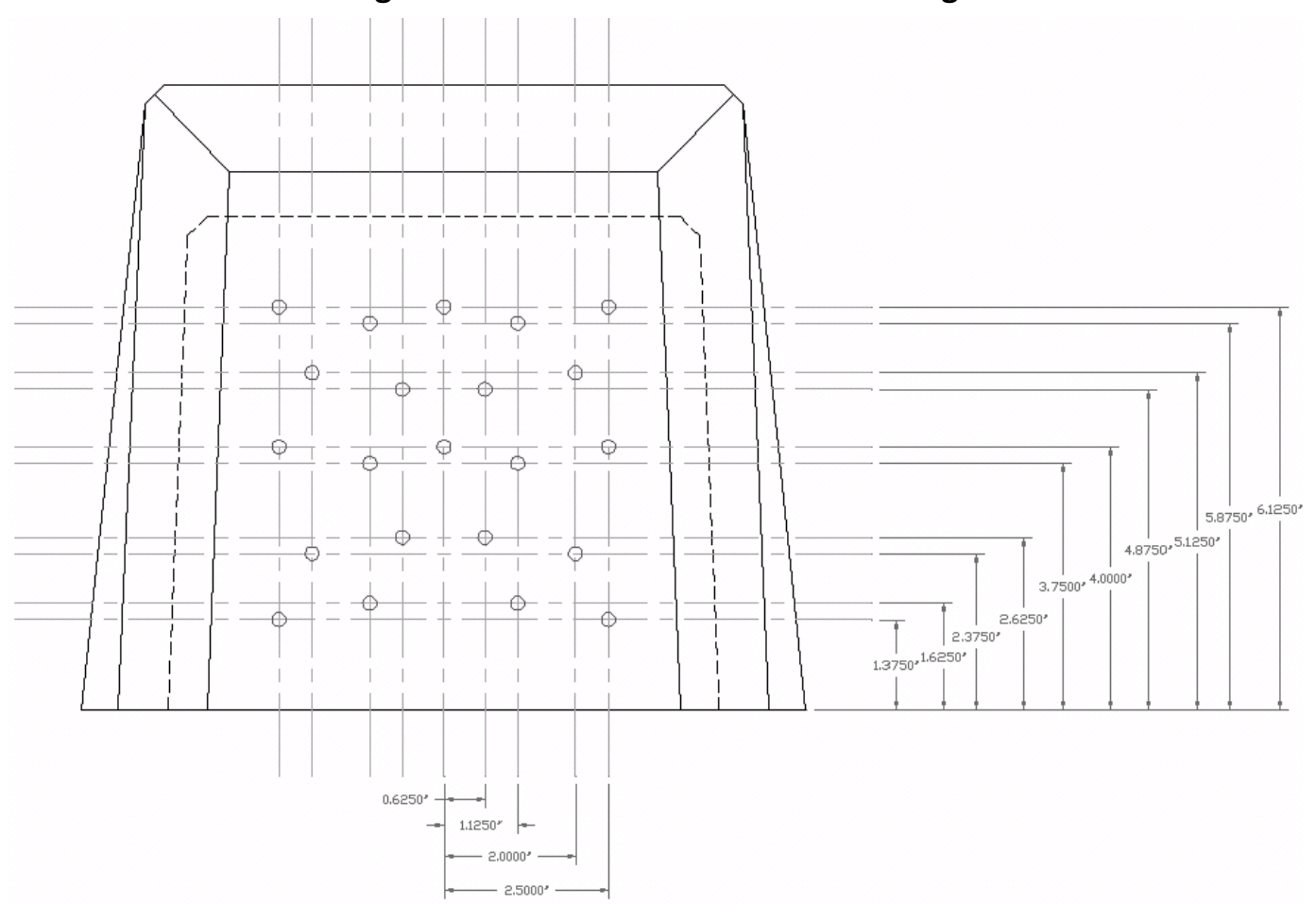




\section{S(PT)-0.25(PD)-7(CS)}

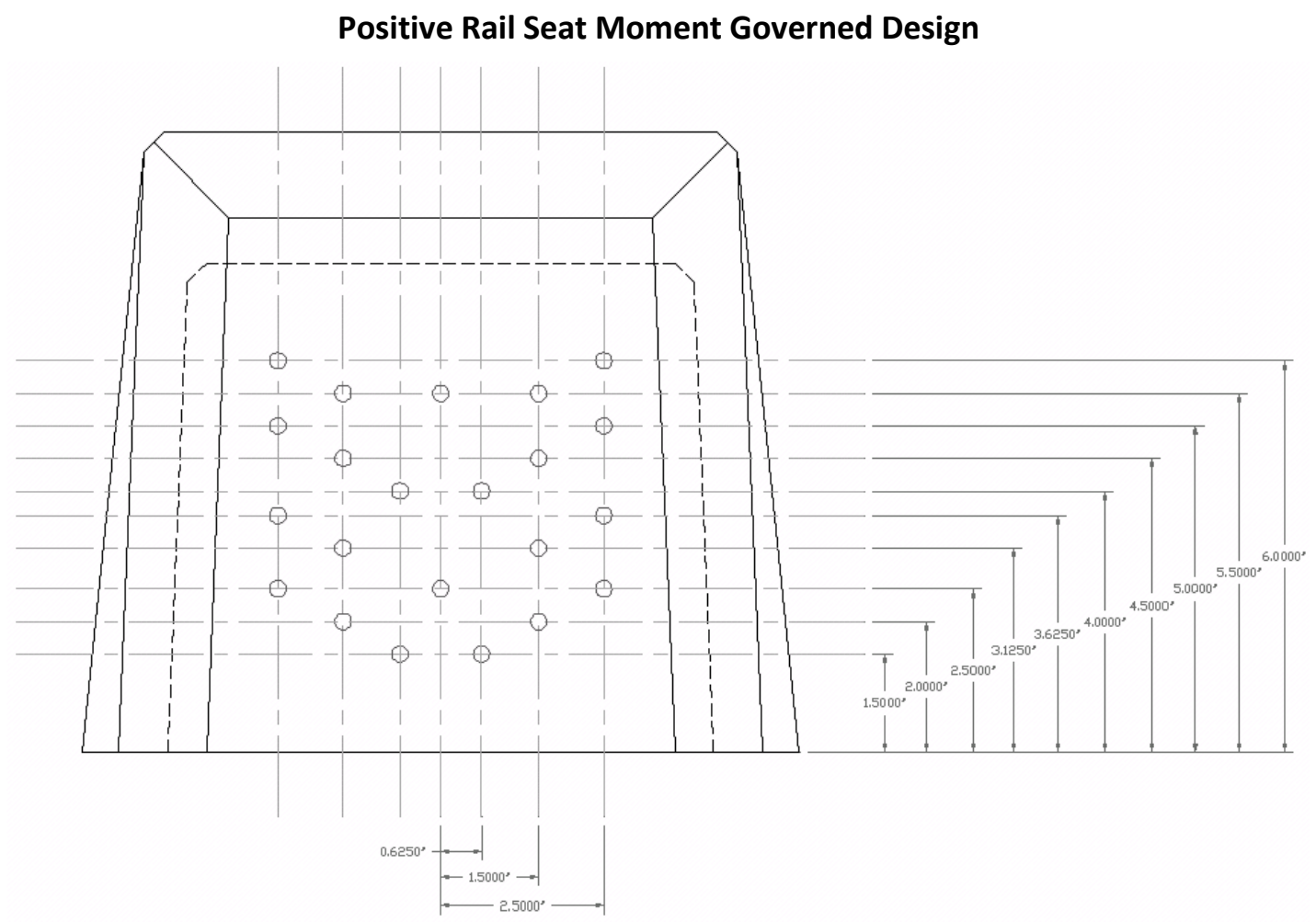

Negative Center Moment Governed Design

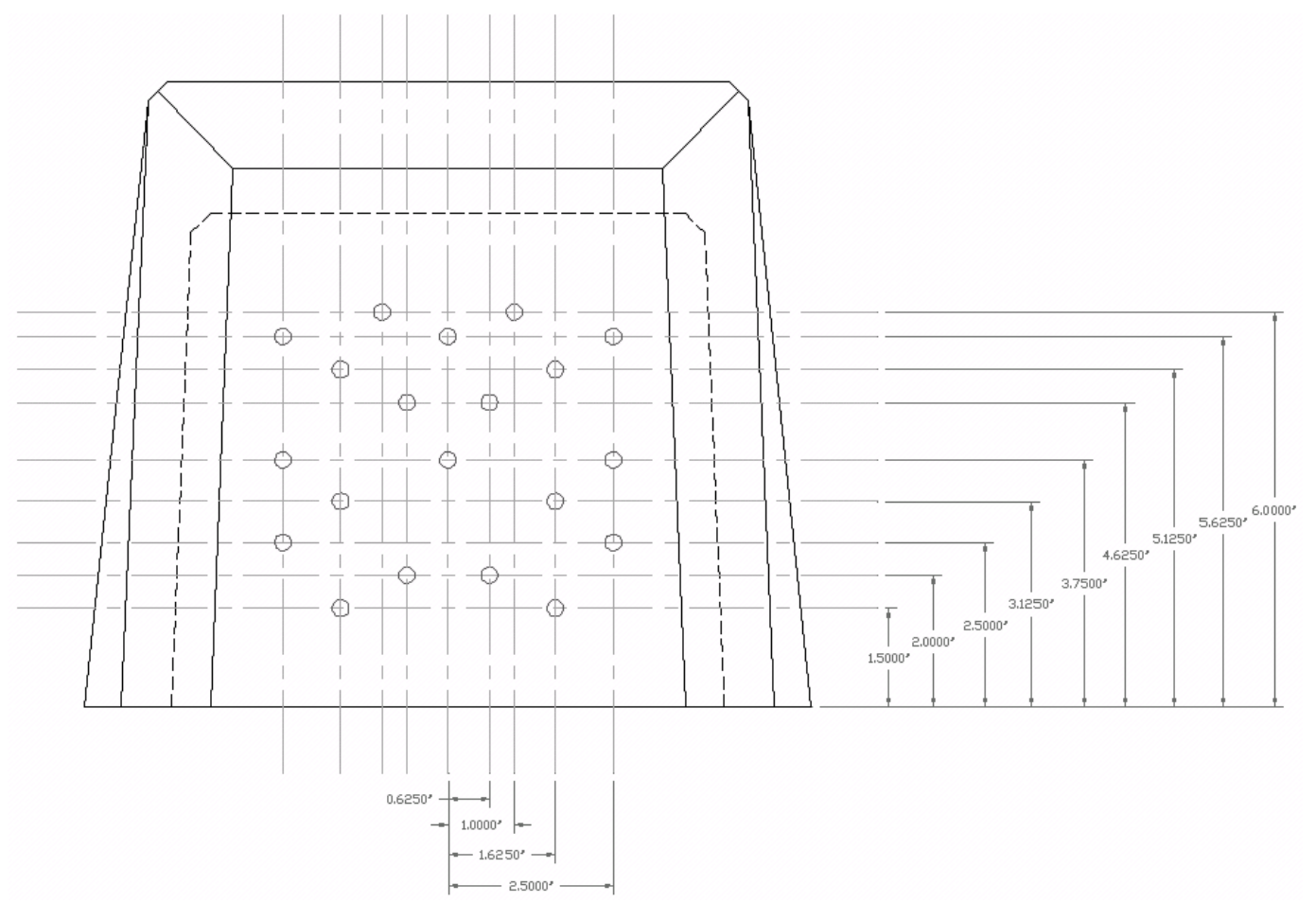




\section{S(PT)-0.25(PD)-95(CS)}

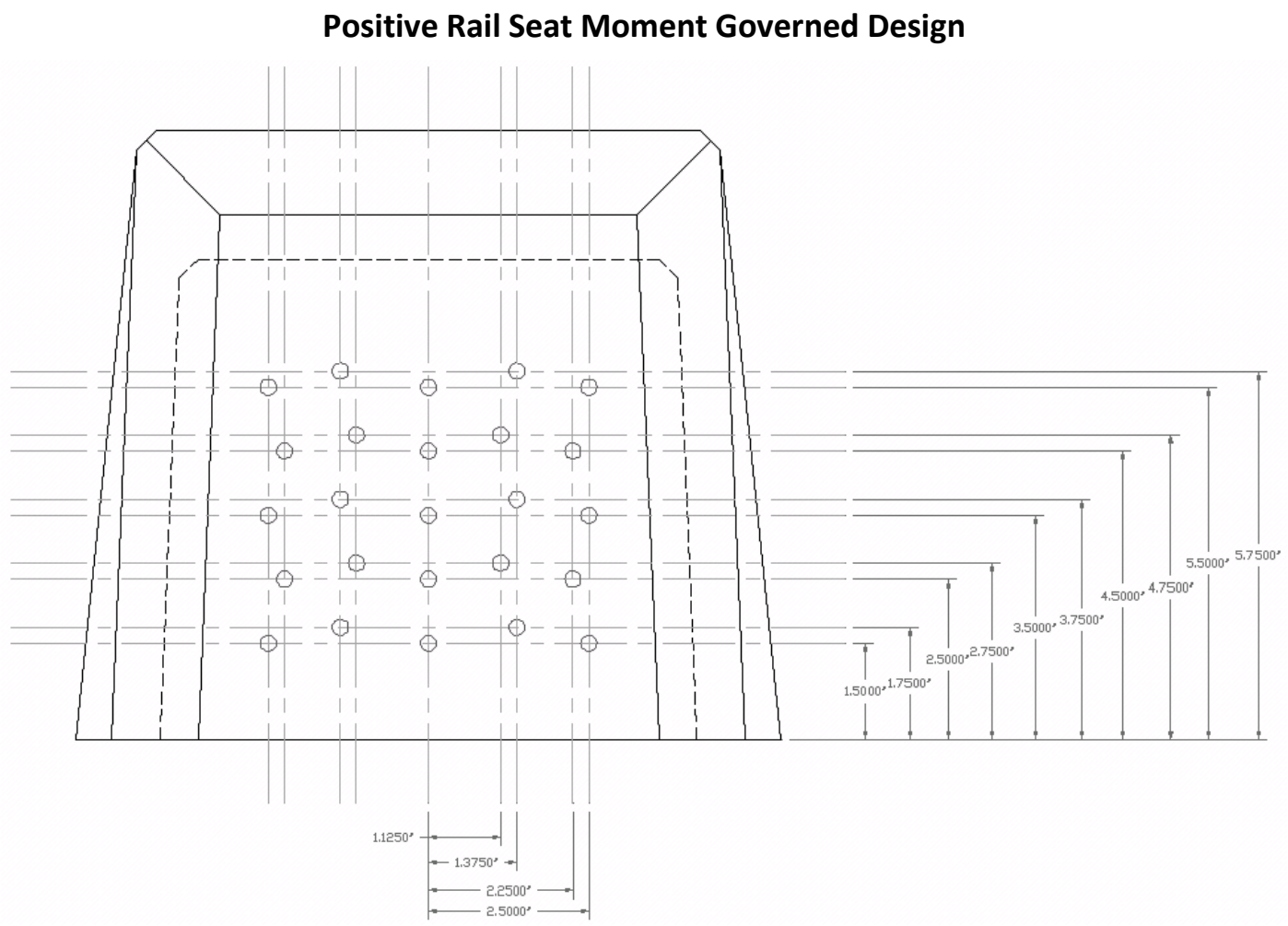

Negative Center Moment Governed Design

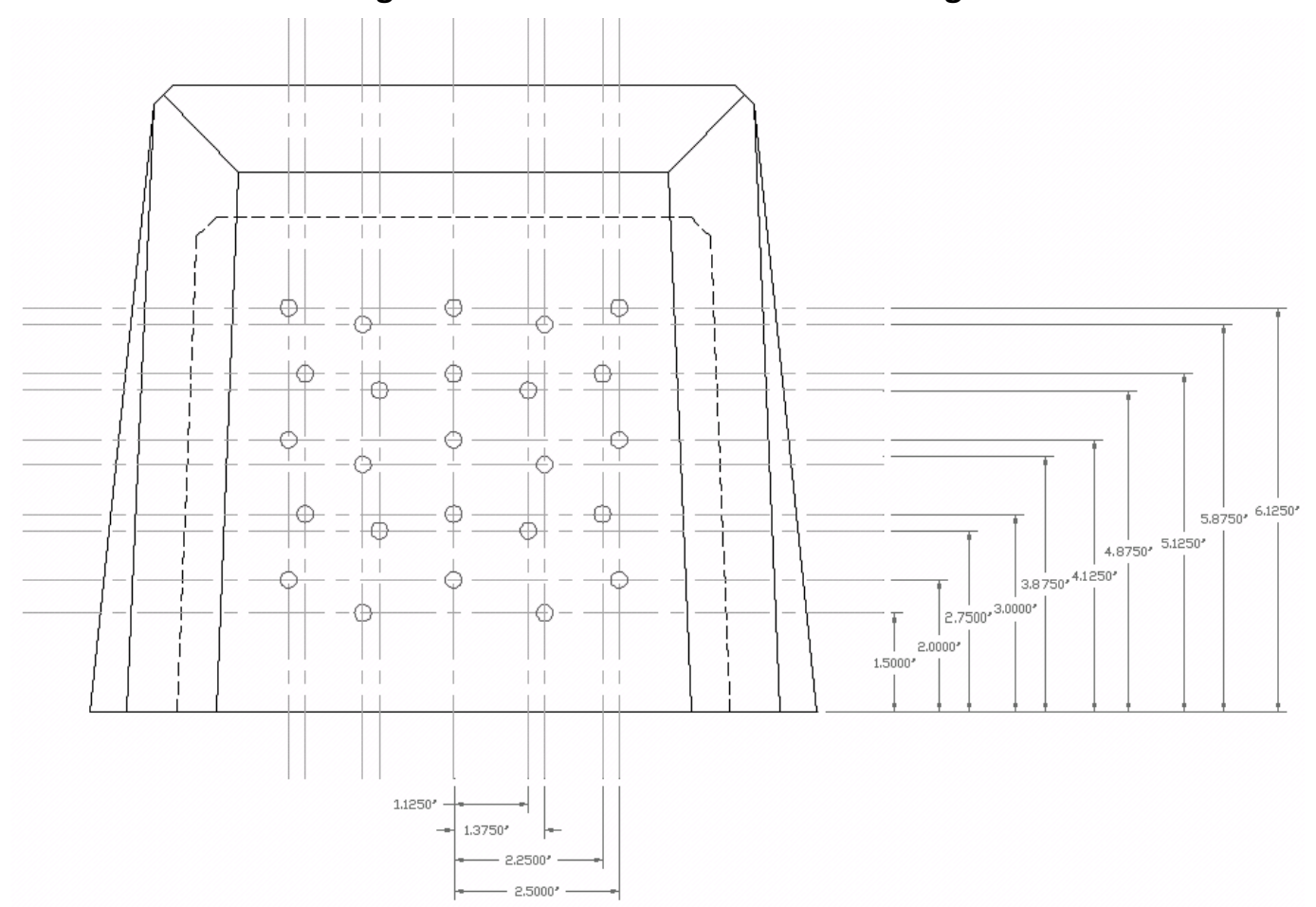




\section{$S(P T)-0.25(P D)-12(C S)$}

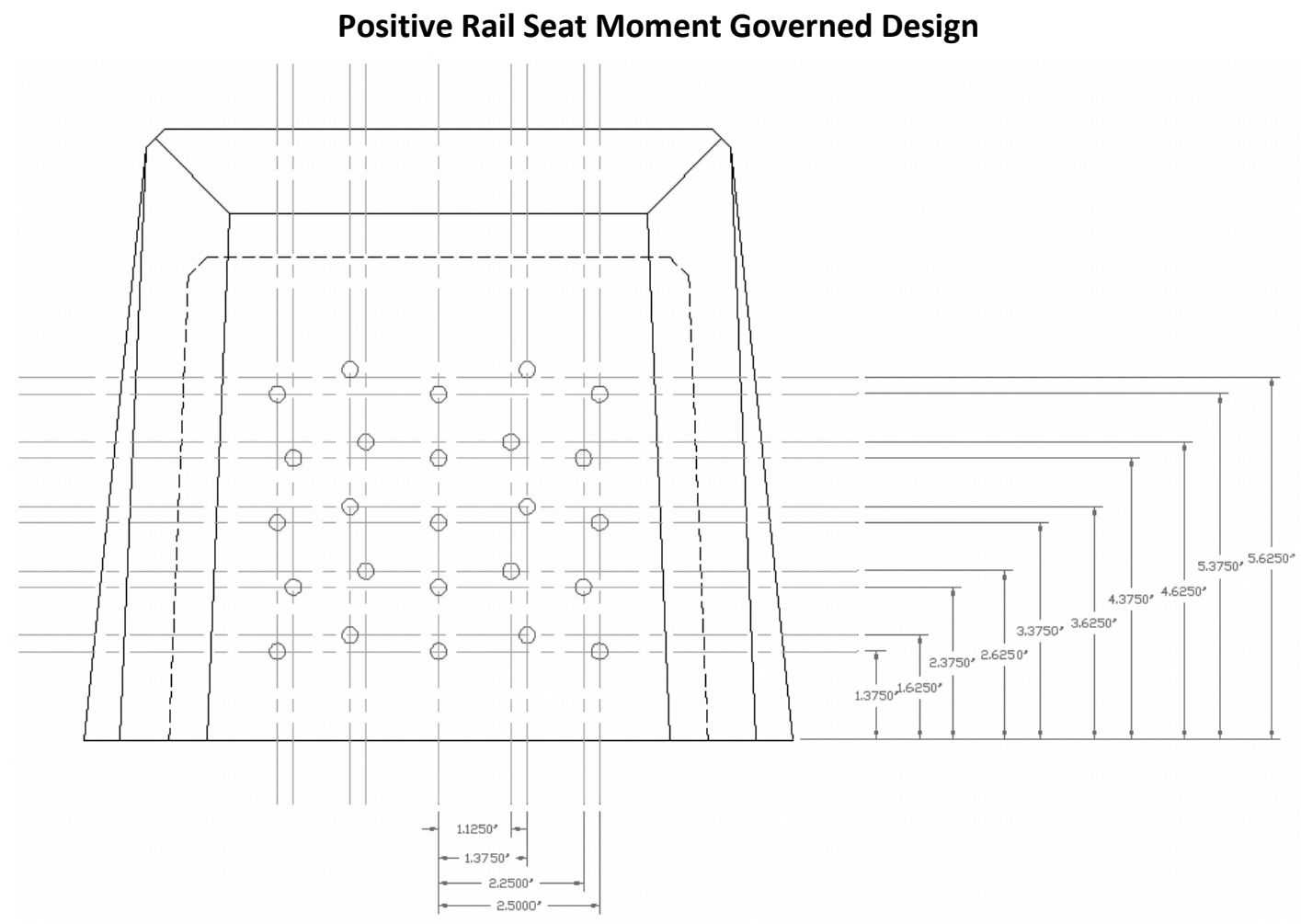

Negative Center Moment Governed Design

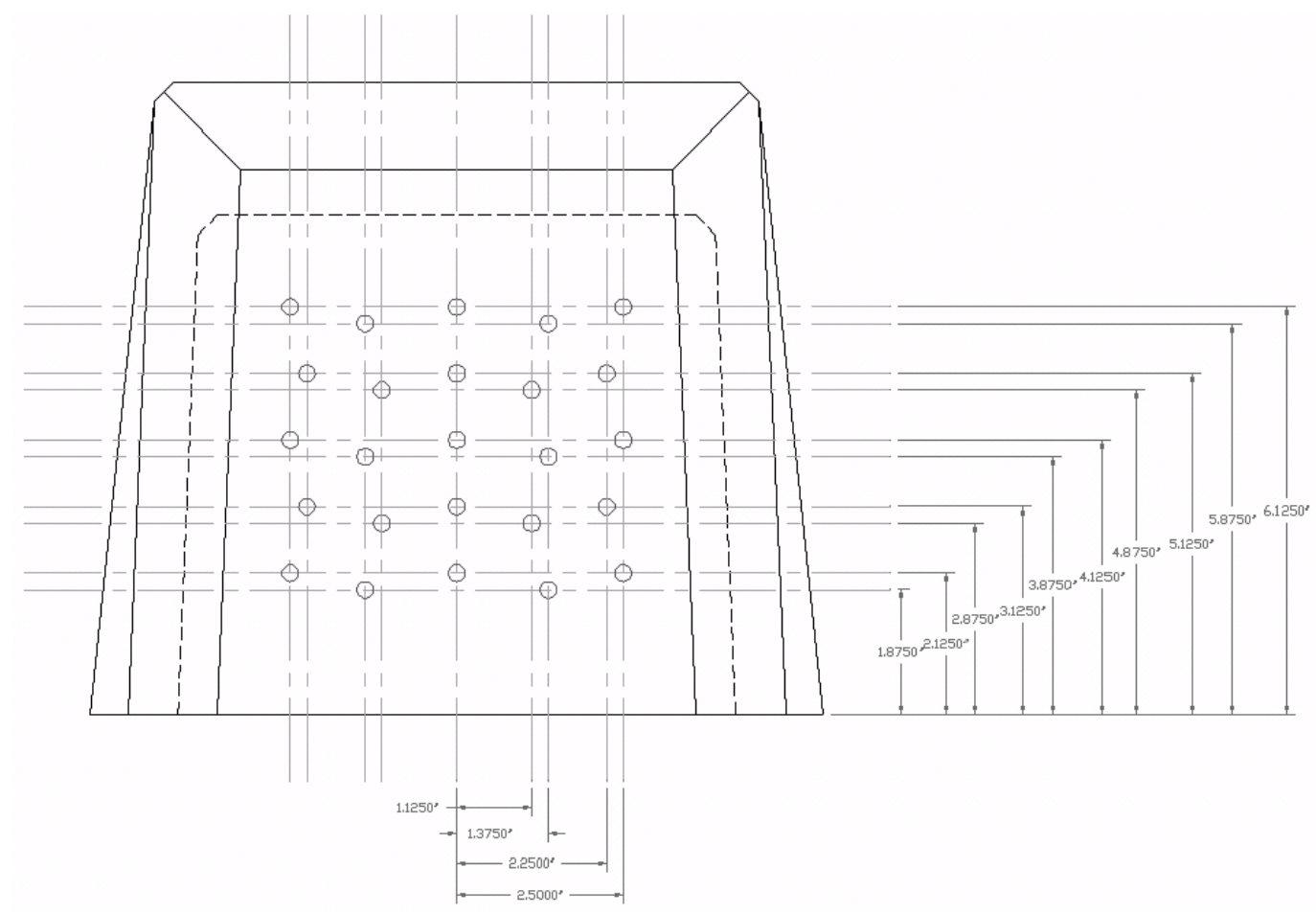




\section{$S(P T)-0.25(P D)-15(C S)$}

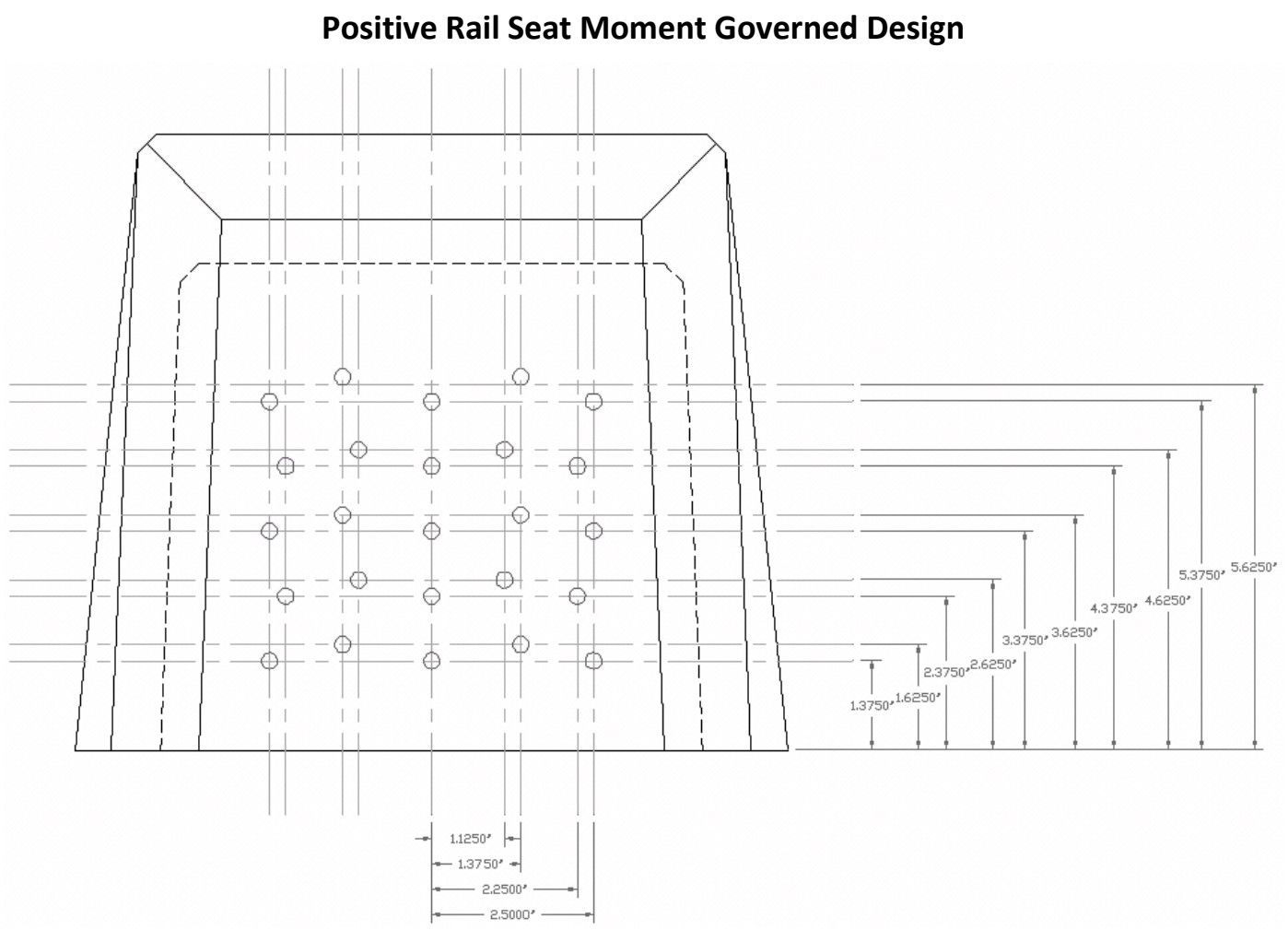

Negative Center Moment Governed Design

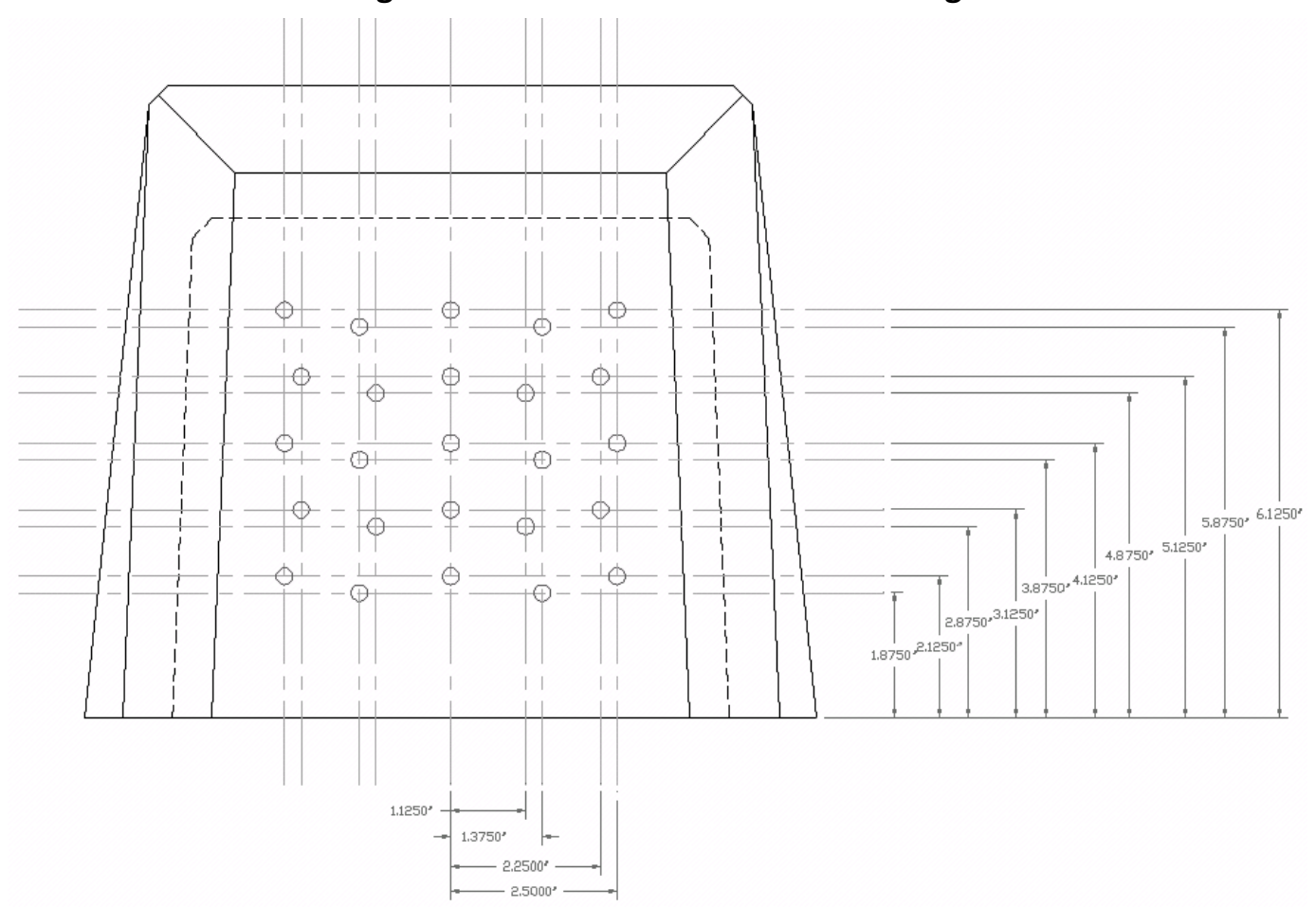




\section{S(PT)-0.3125(PD)-7(CS)}

Positive Rail Seat Moment Governed Design

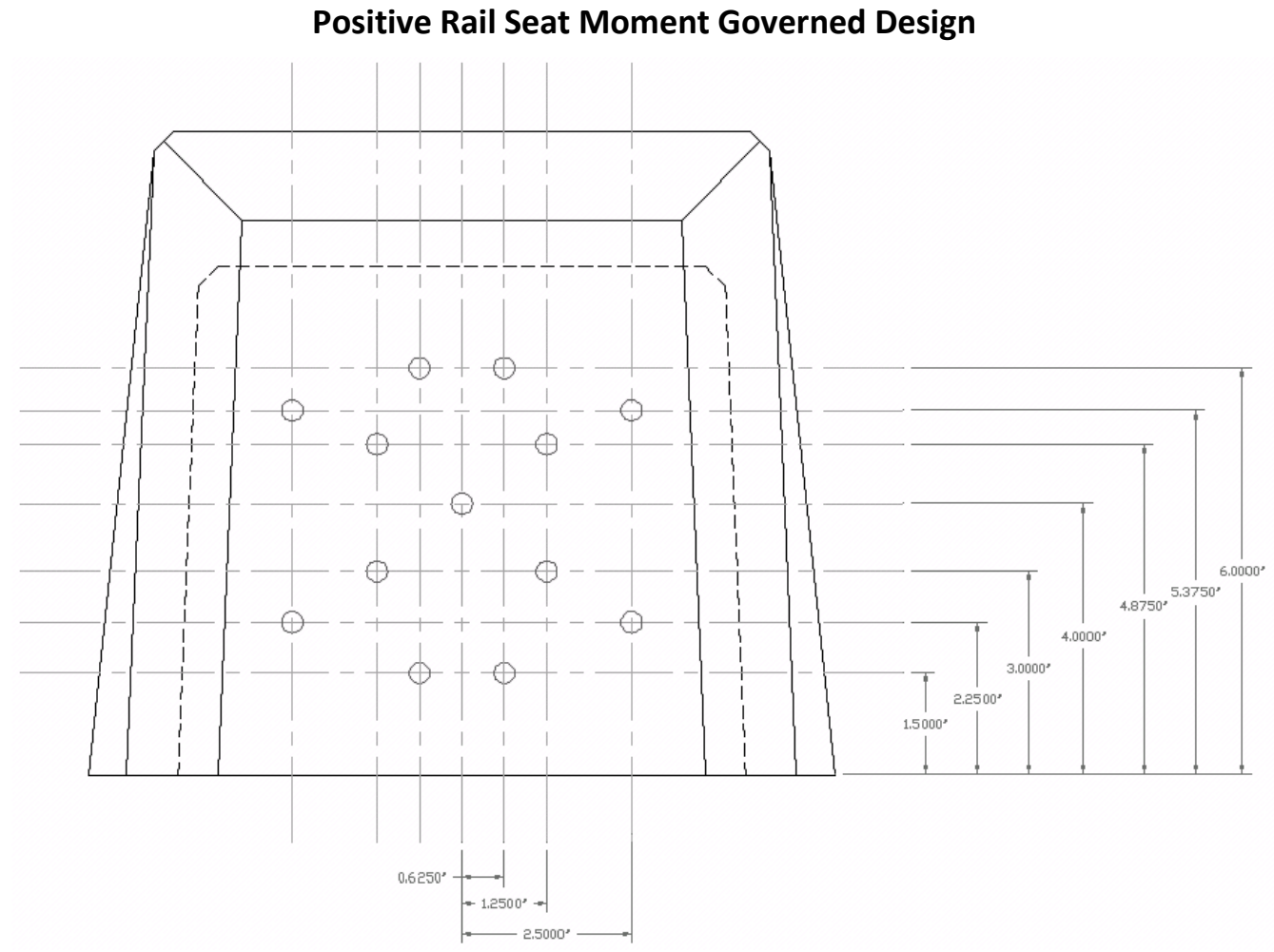

Negative Center Moment Governed Design

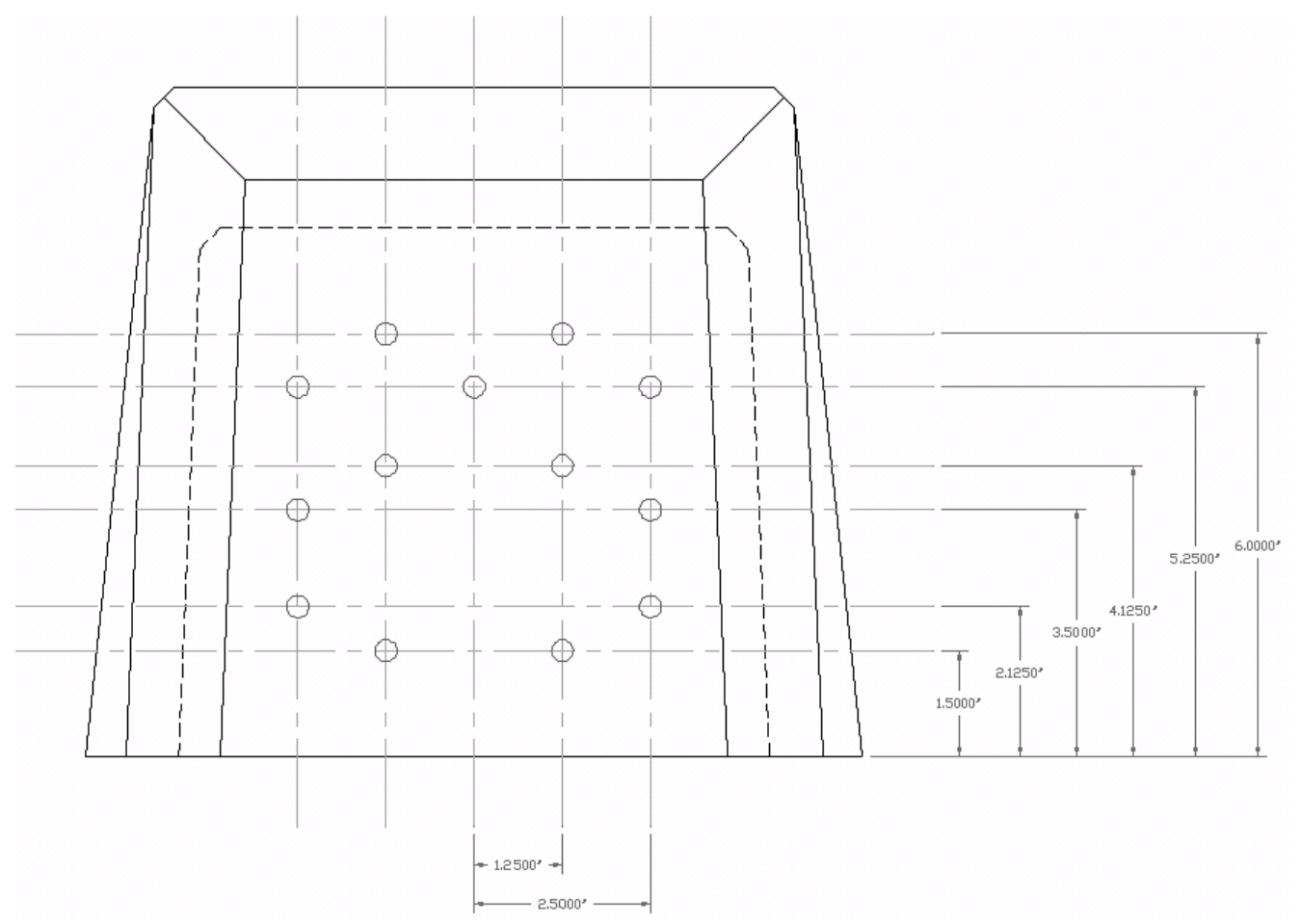


S(PT)-0.3125(PD)-95(CS)

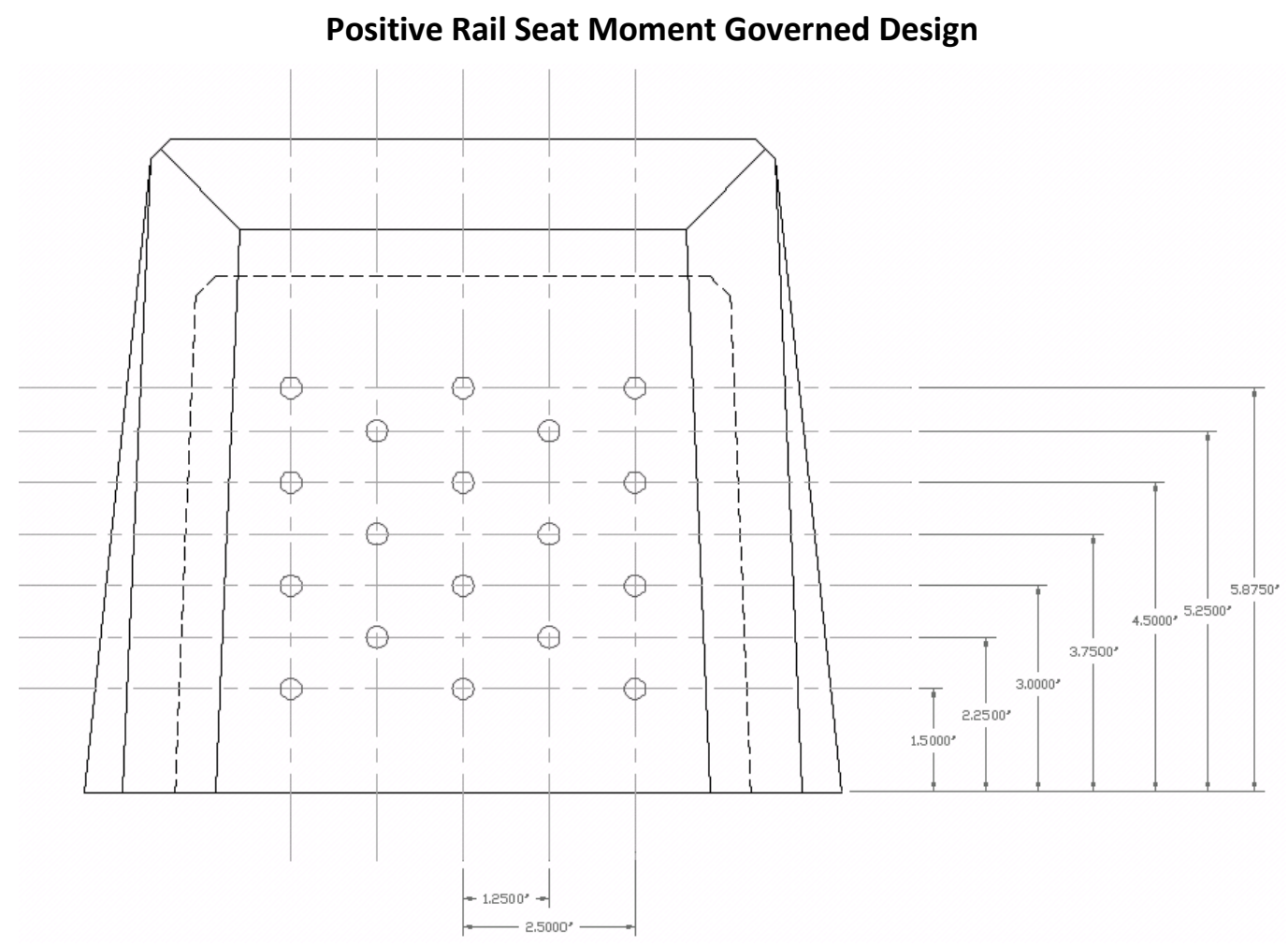

Negative Center Moment Governed Design

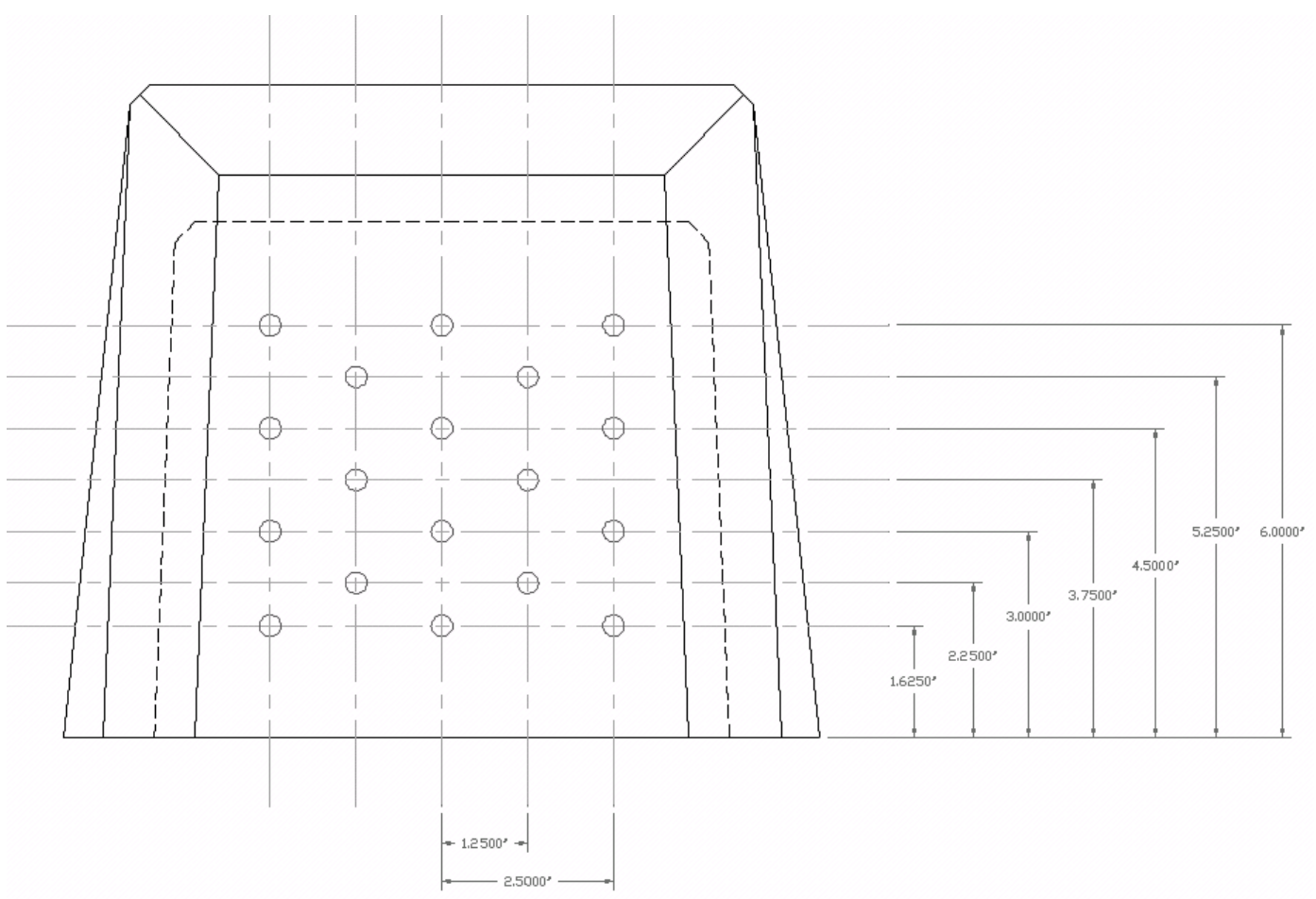


S(PT)-0.3125(PD)-12(CS)

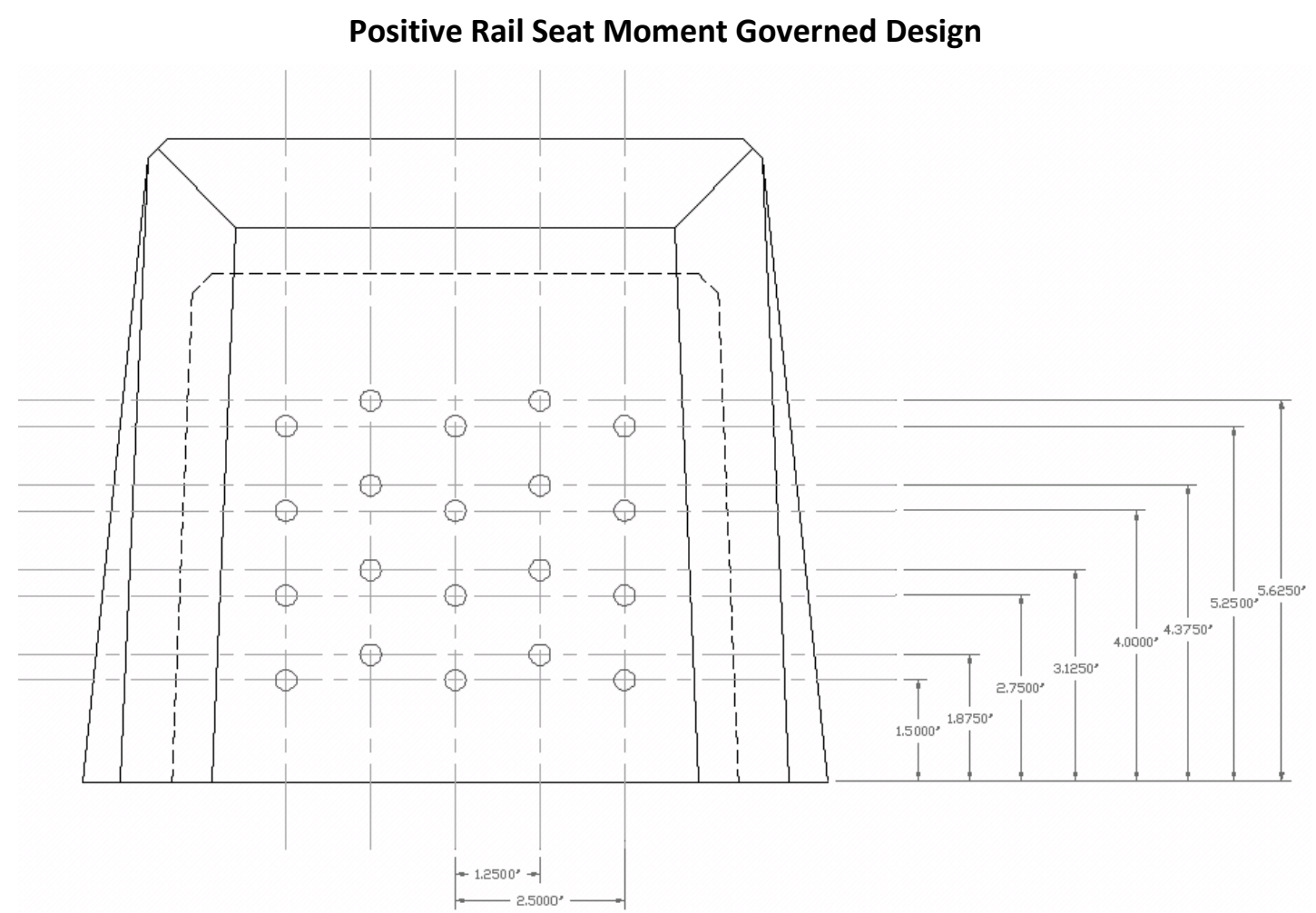

Negative Center Moment Governed Design

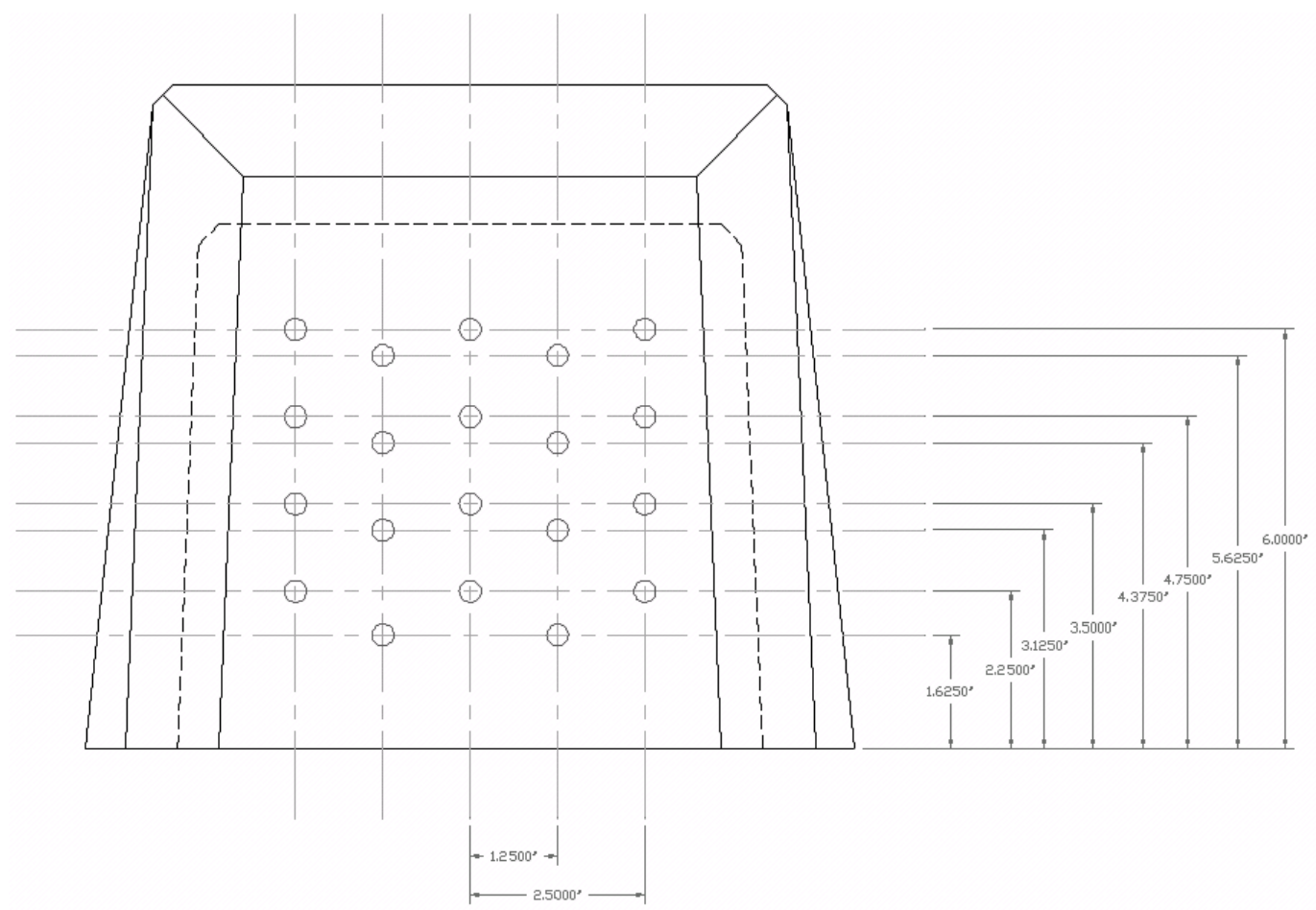


S(PT)-0.3125(PD)-15(CS)

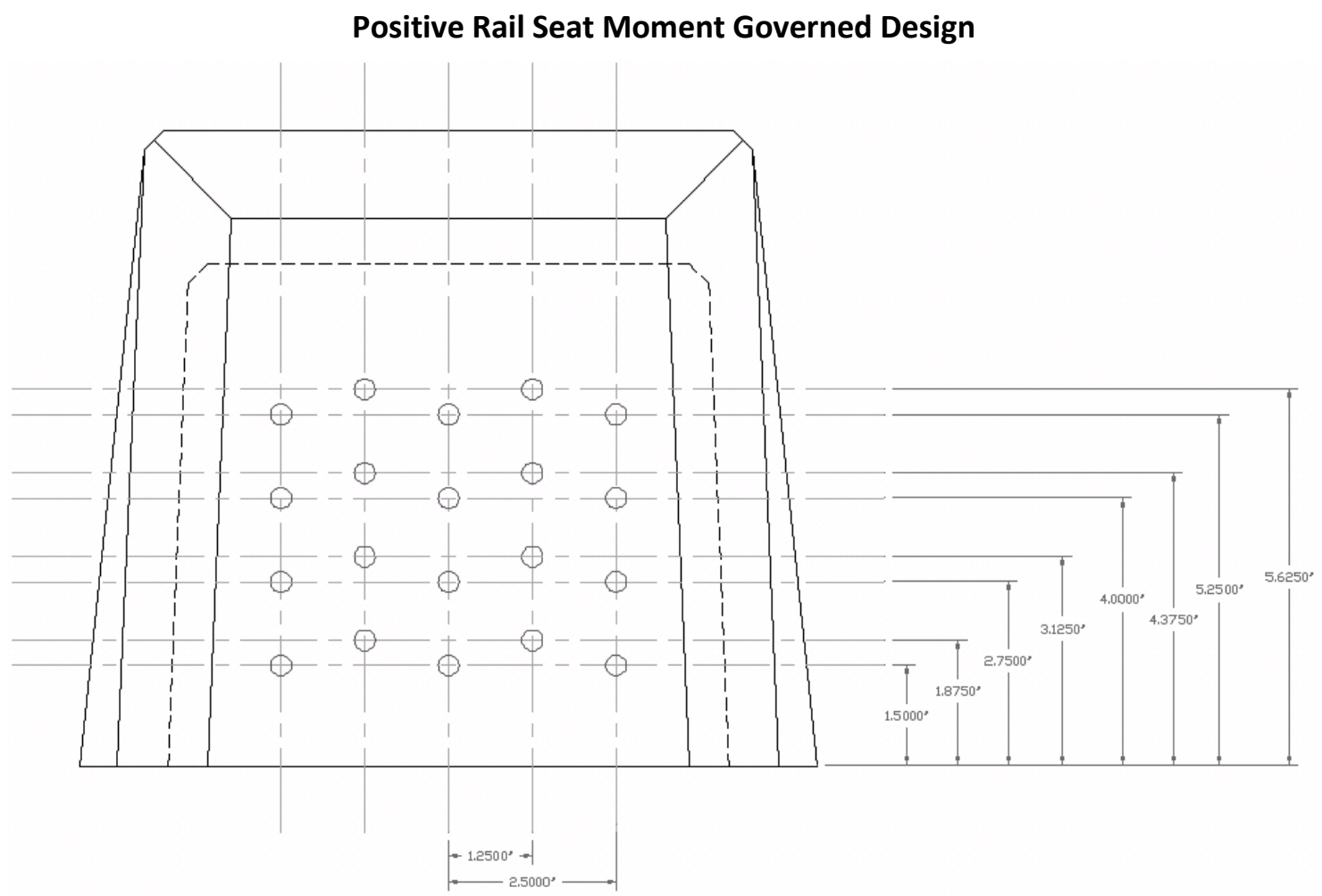

Negative Center Moment Governed Design

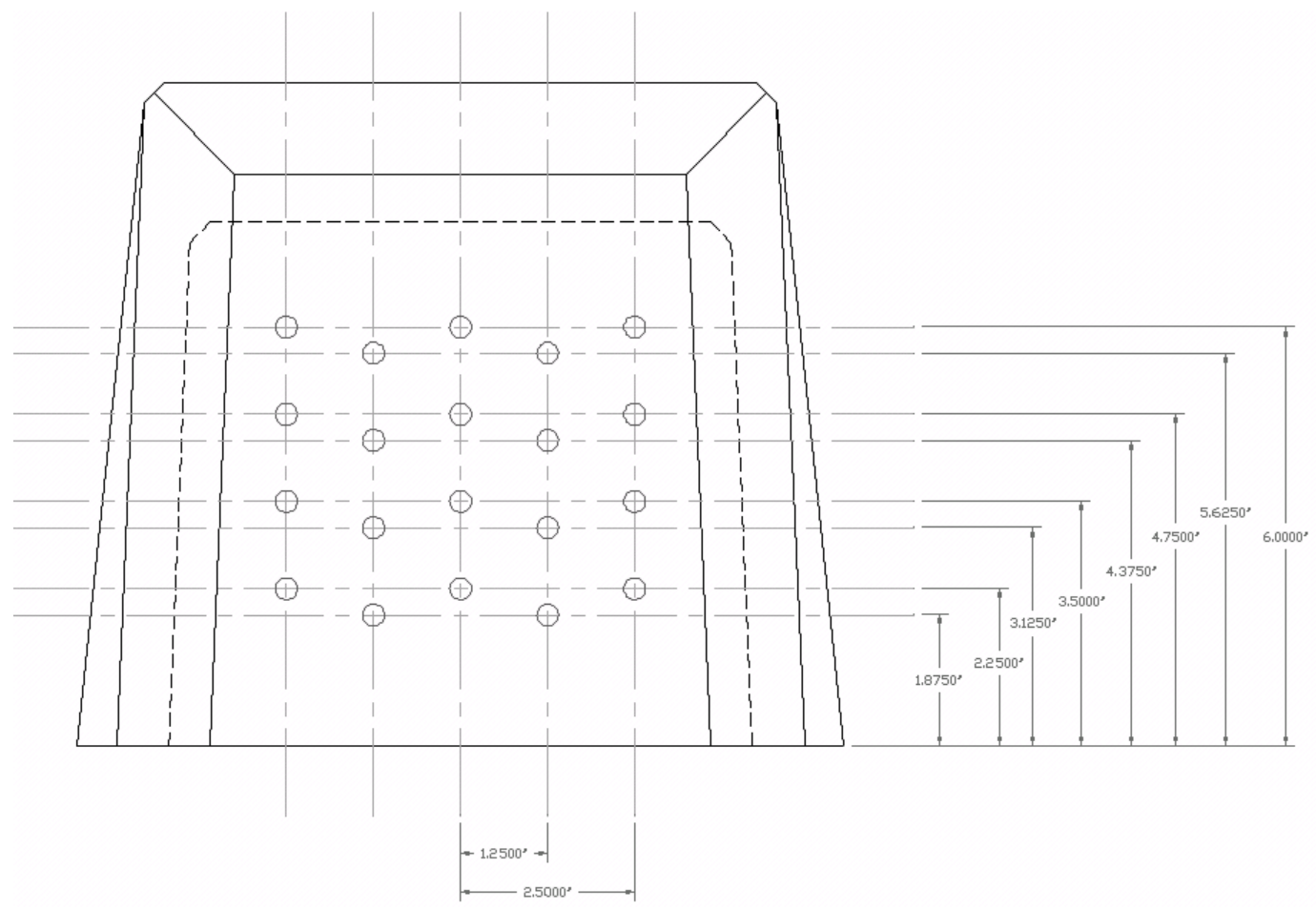


S(PT)-0.375(PD)-7(CS)

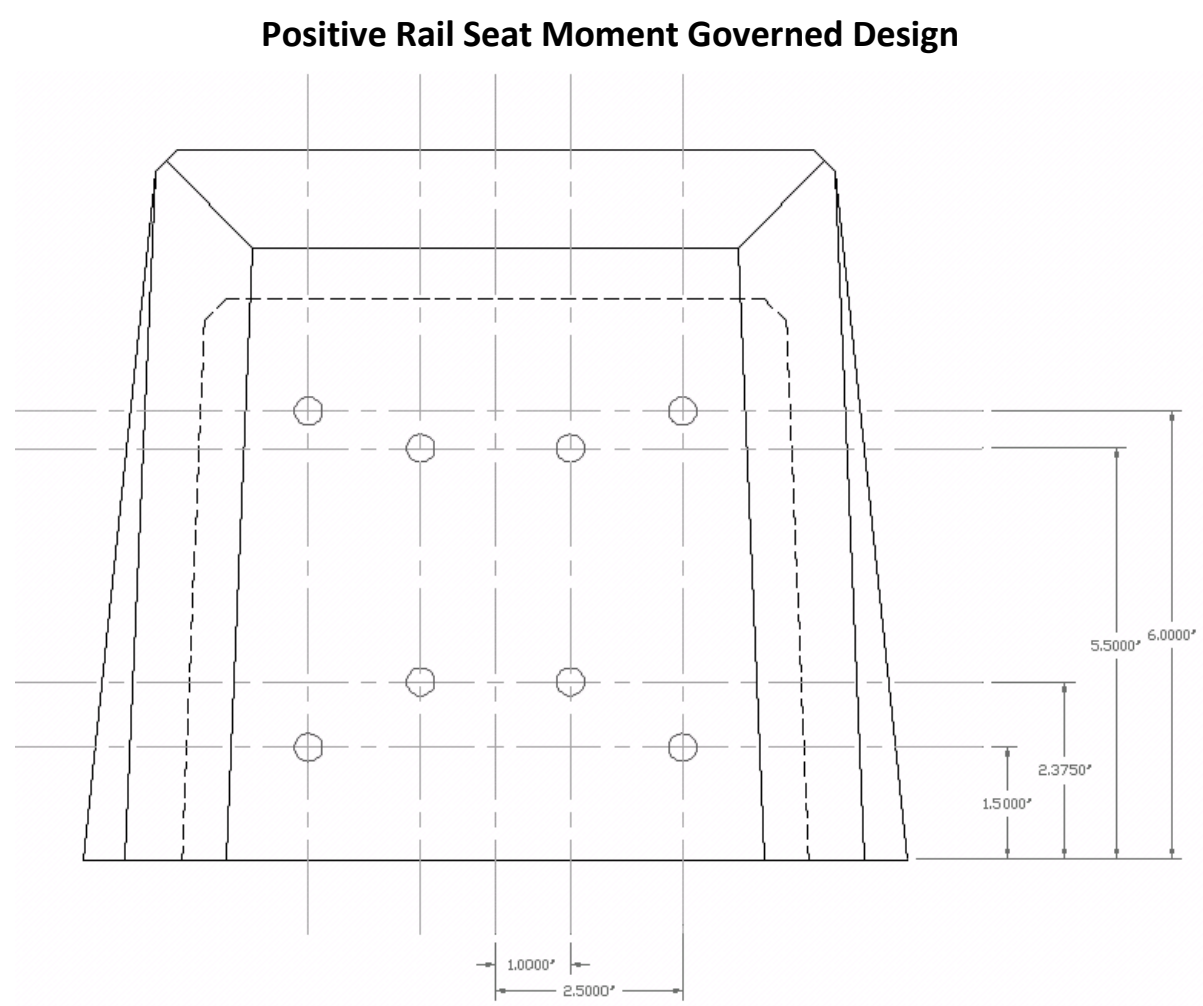

Negative Center Moment Governed Design

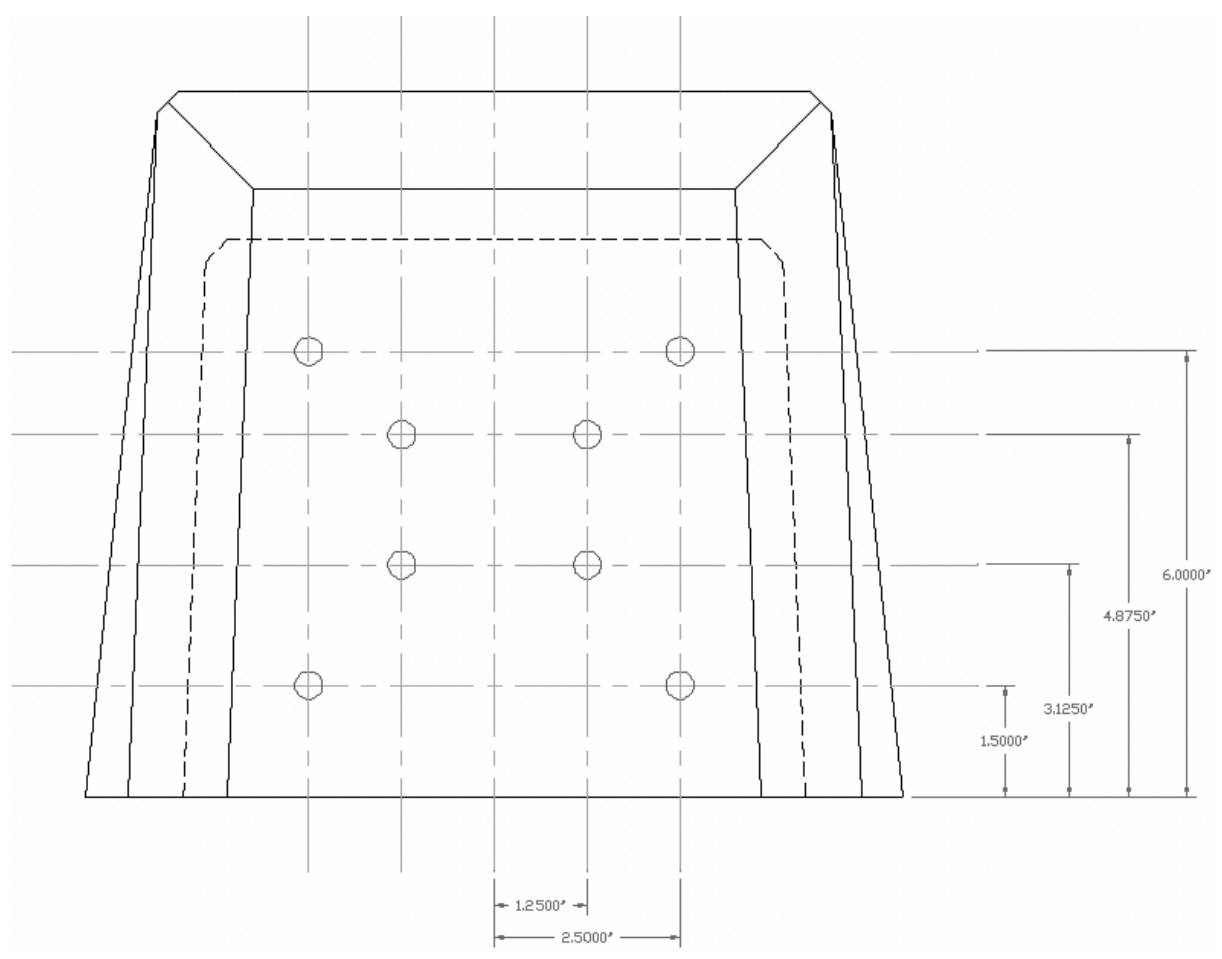


S(PT)-0.375(PD)-95(CS)

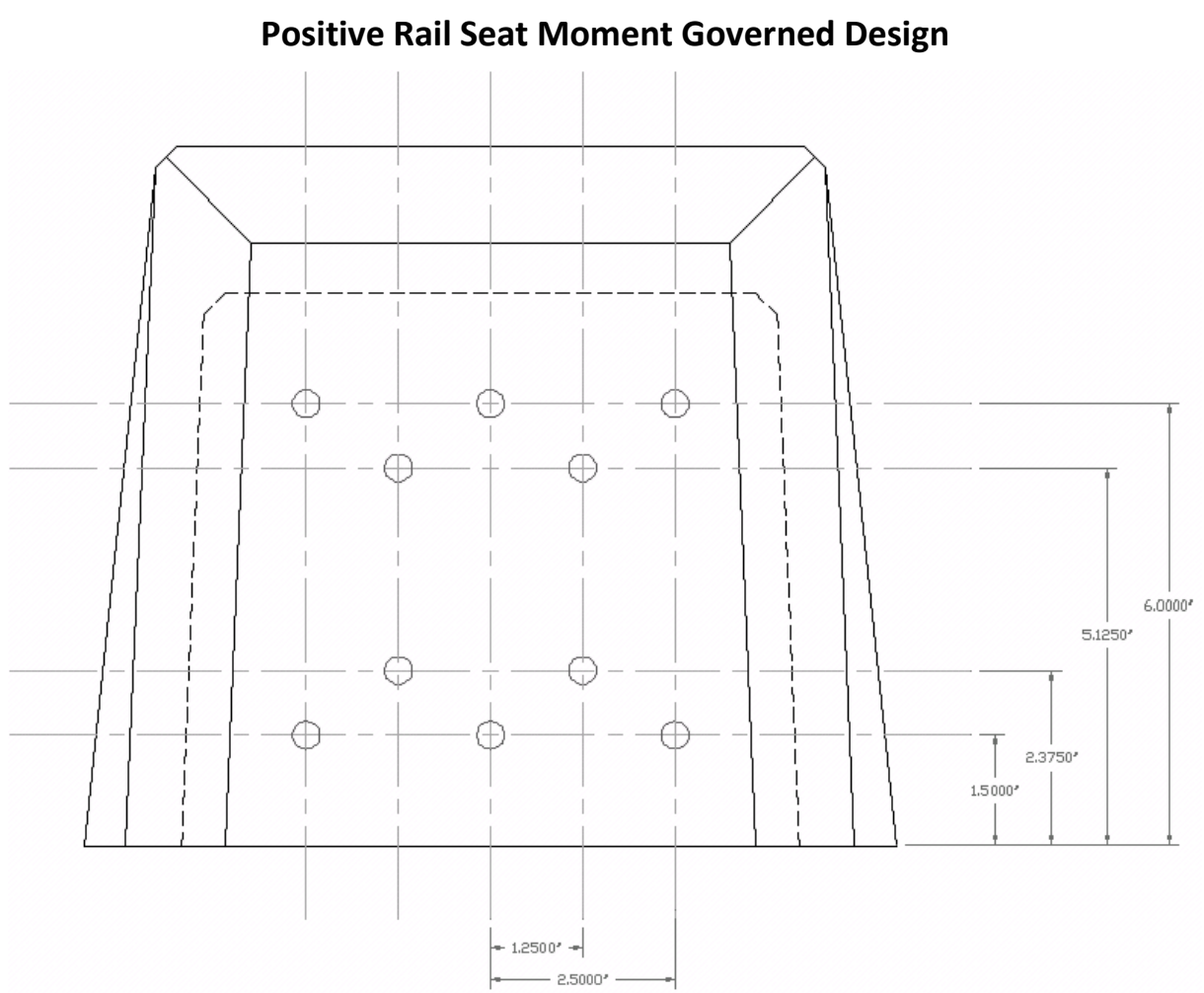

Negative Center Moment Governed Design

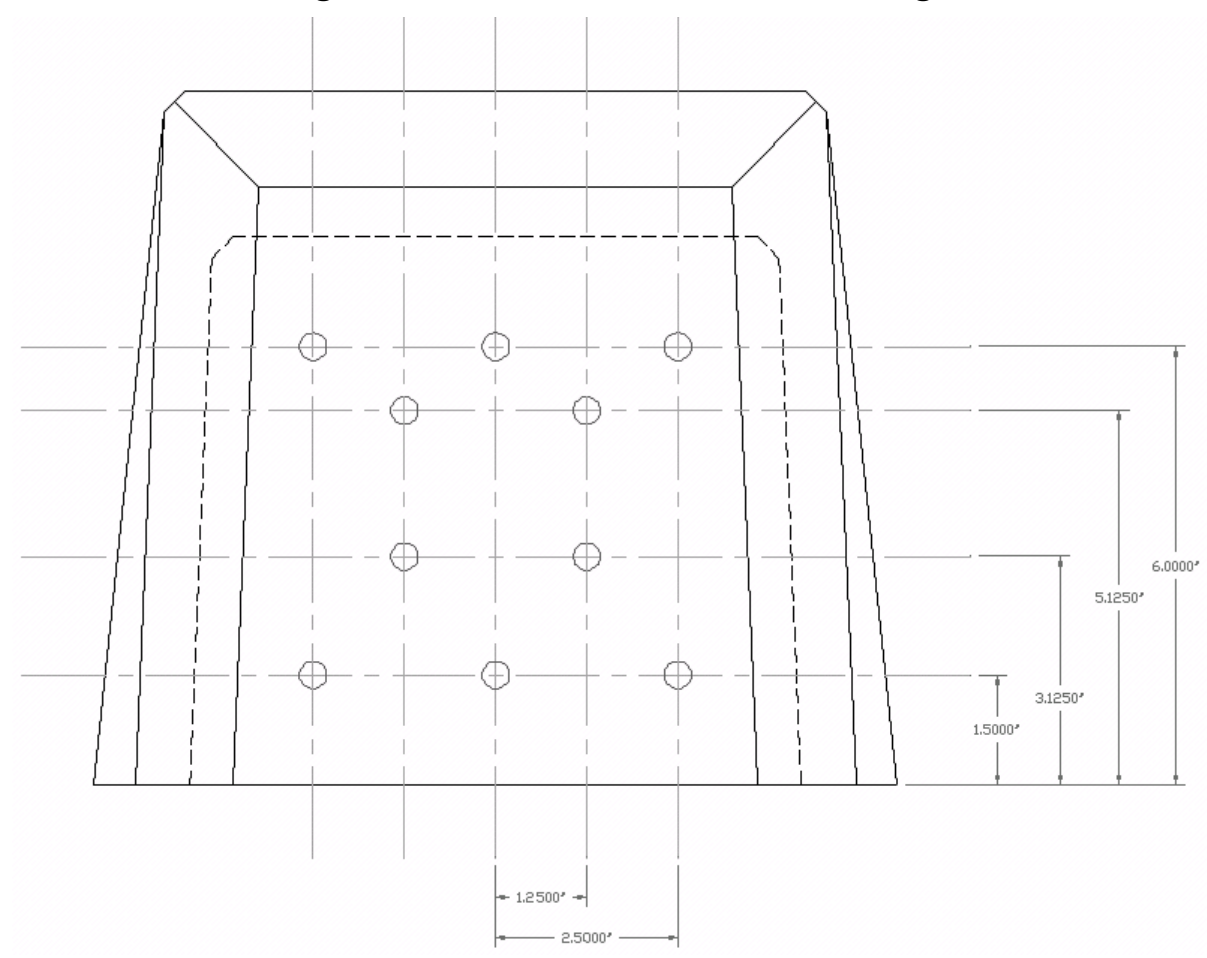




\section{S(PT)-0.375(PD)-12(CS)}

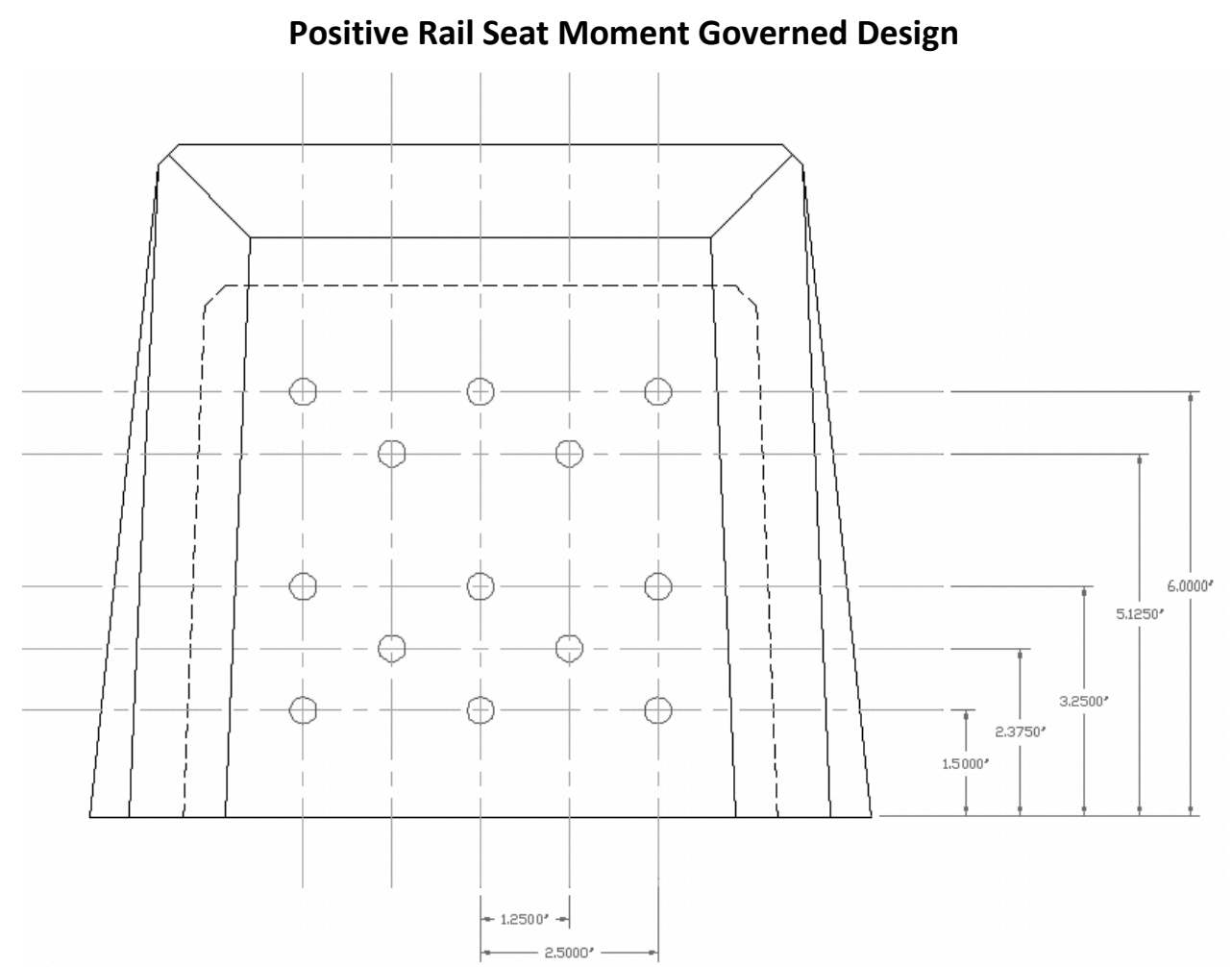

Negative Center Moment Governed Design

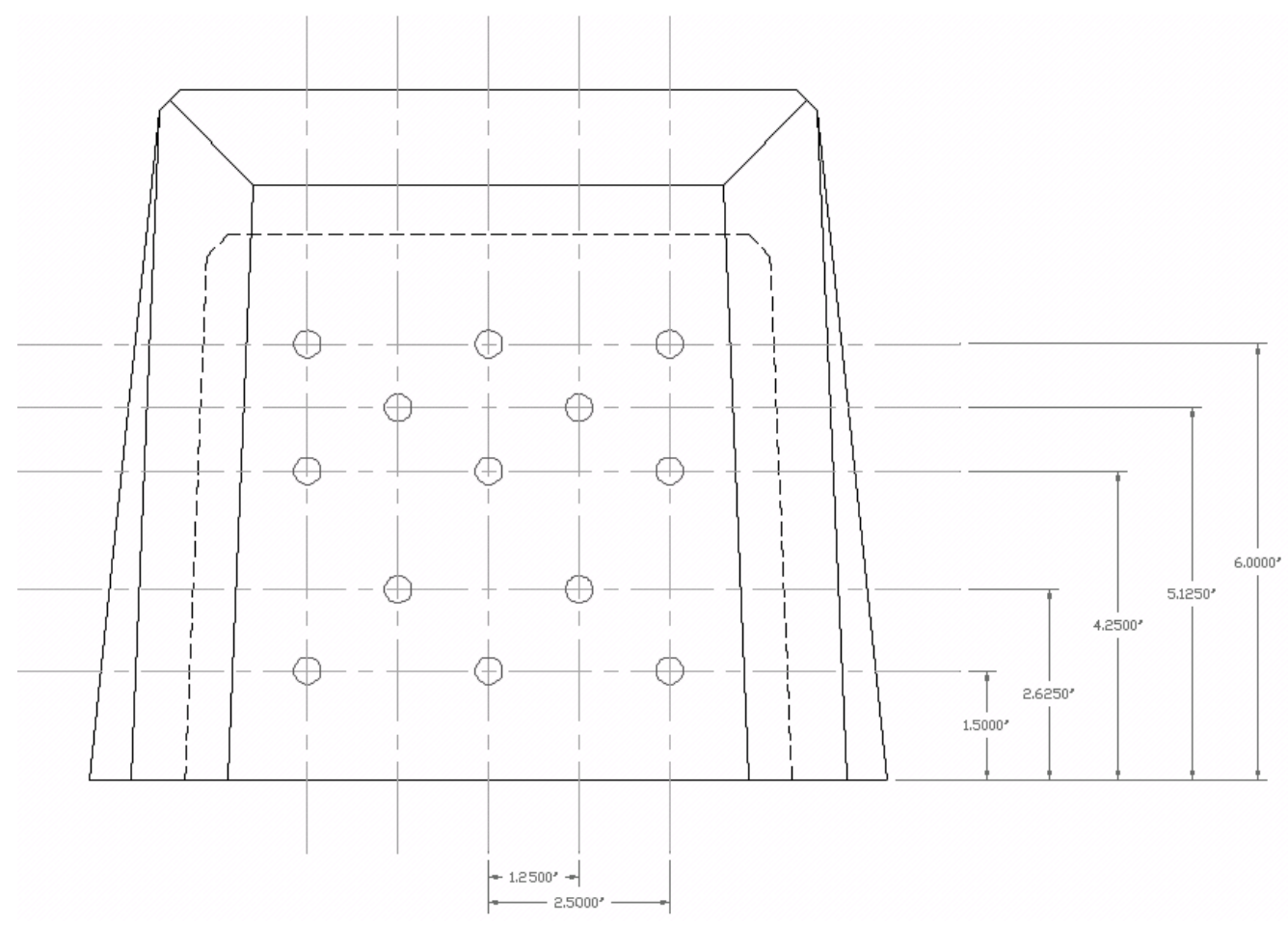




\section{S(PT)-0.375(PD)-15(CS)}

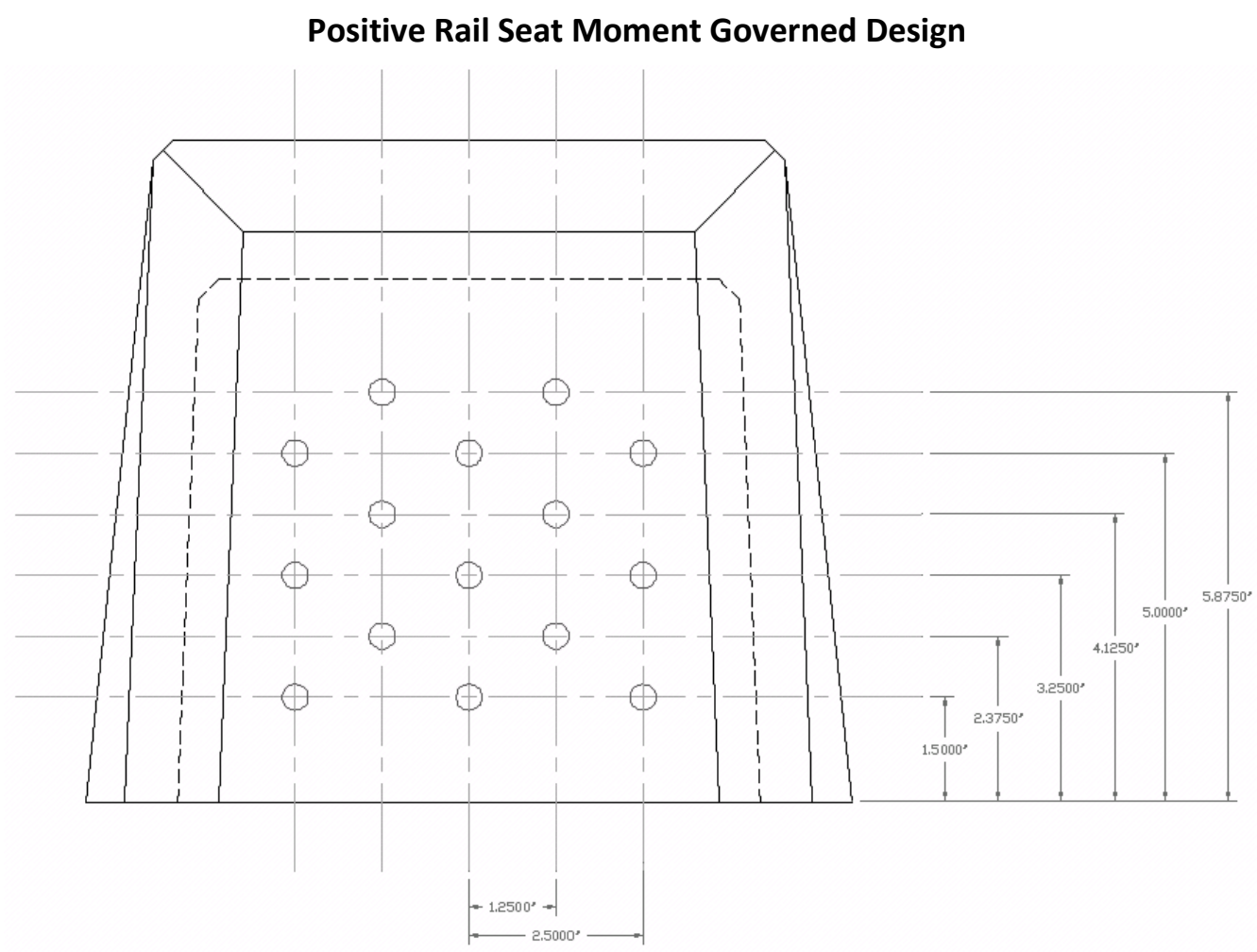

Negative Center Moment Governed Design

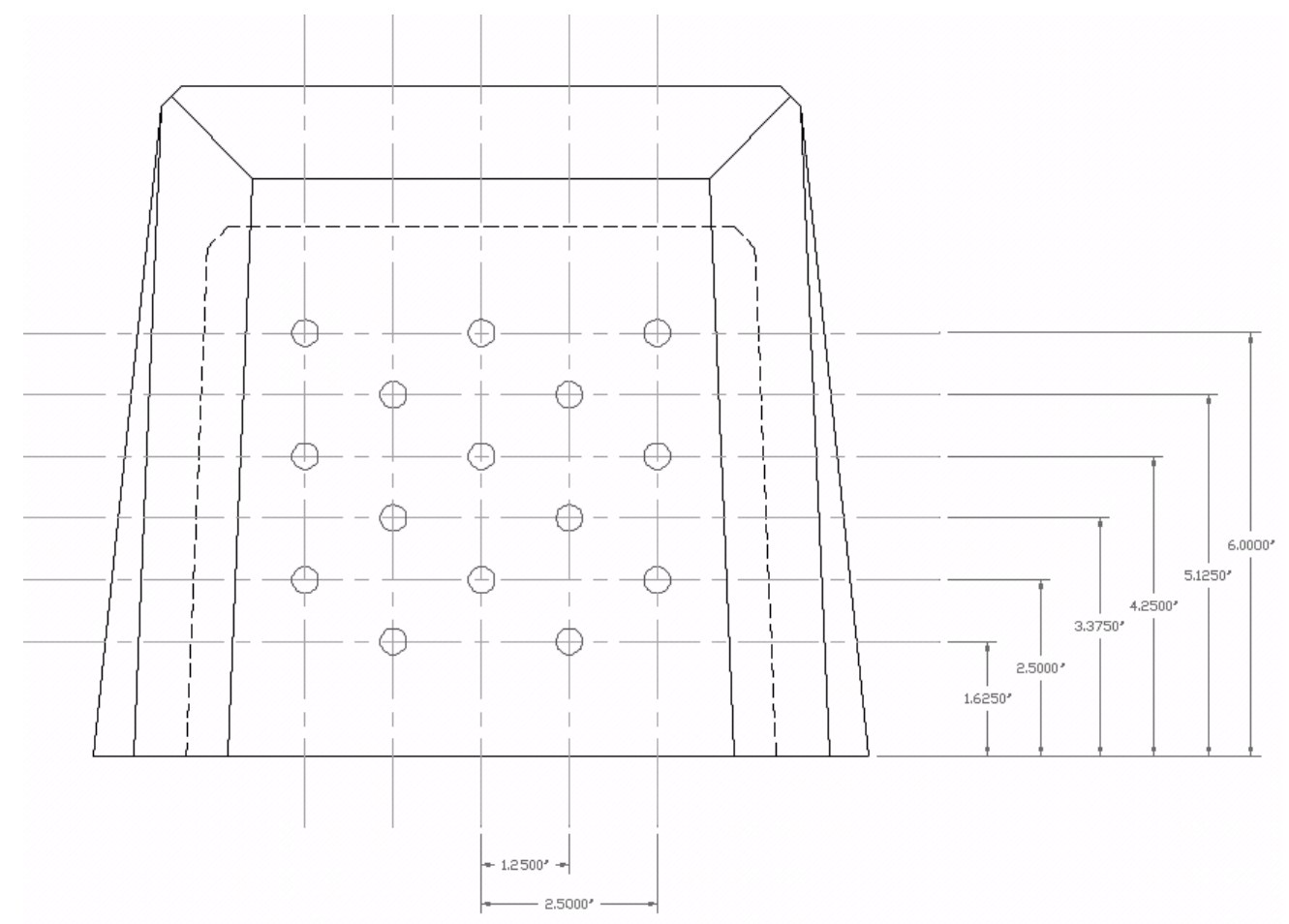




\section{FRP(PT)-0.25(PD)-7(CS)}

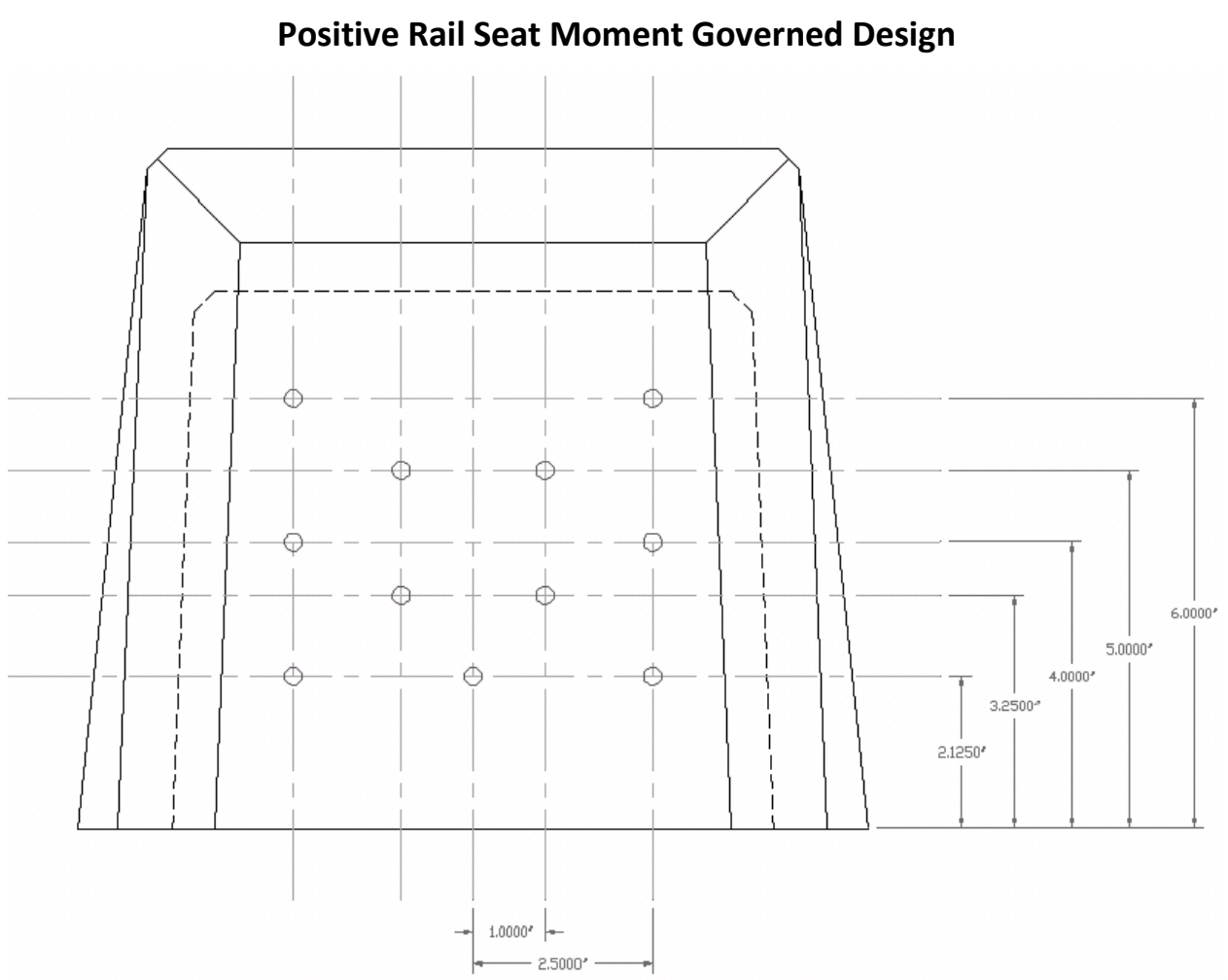

Negative Center Moment Governed Design

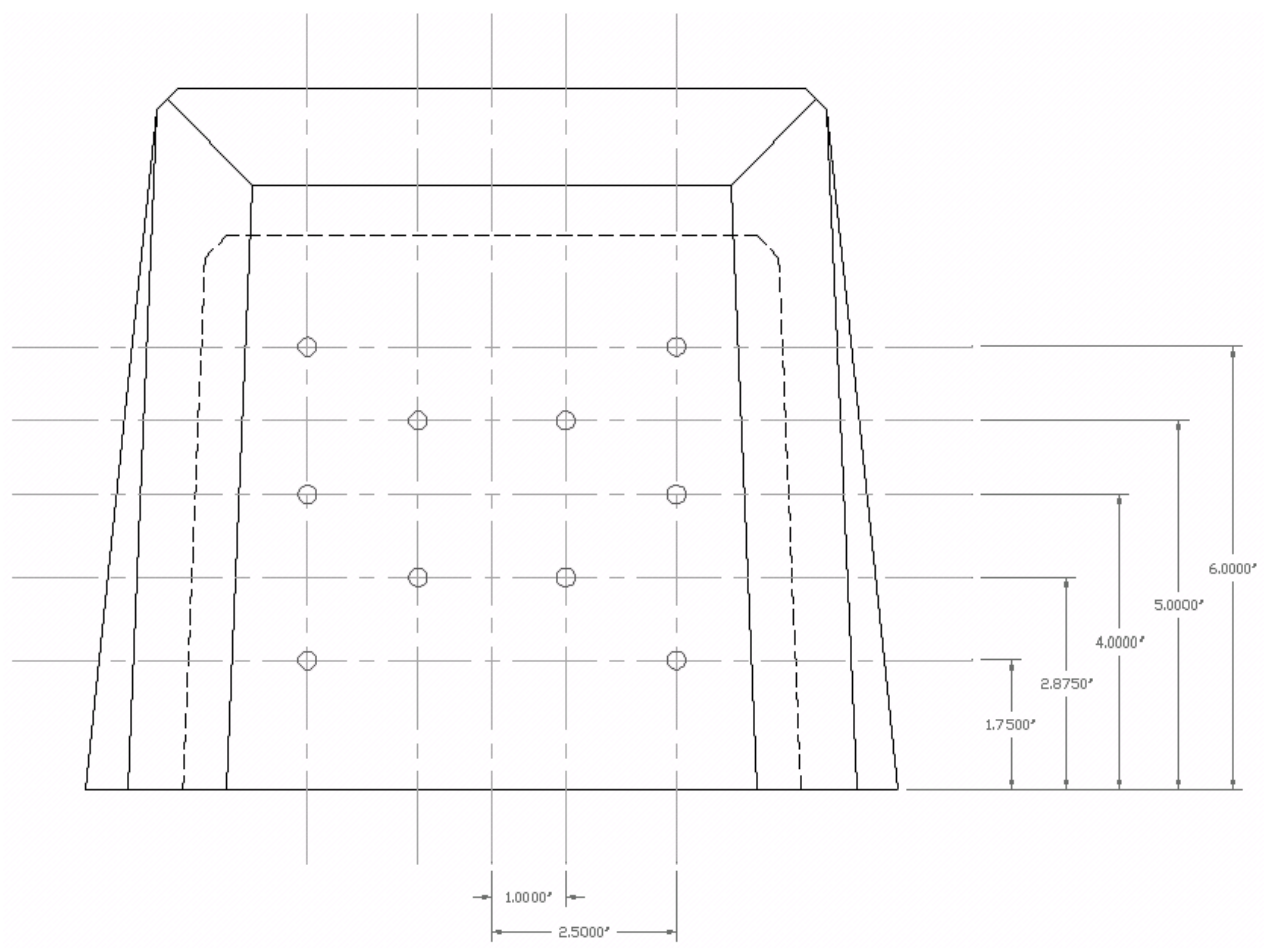


FRP(PT)-0.25(PD)-95(CS)

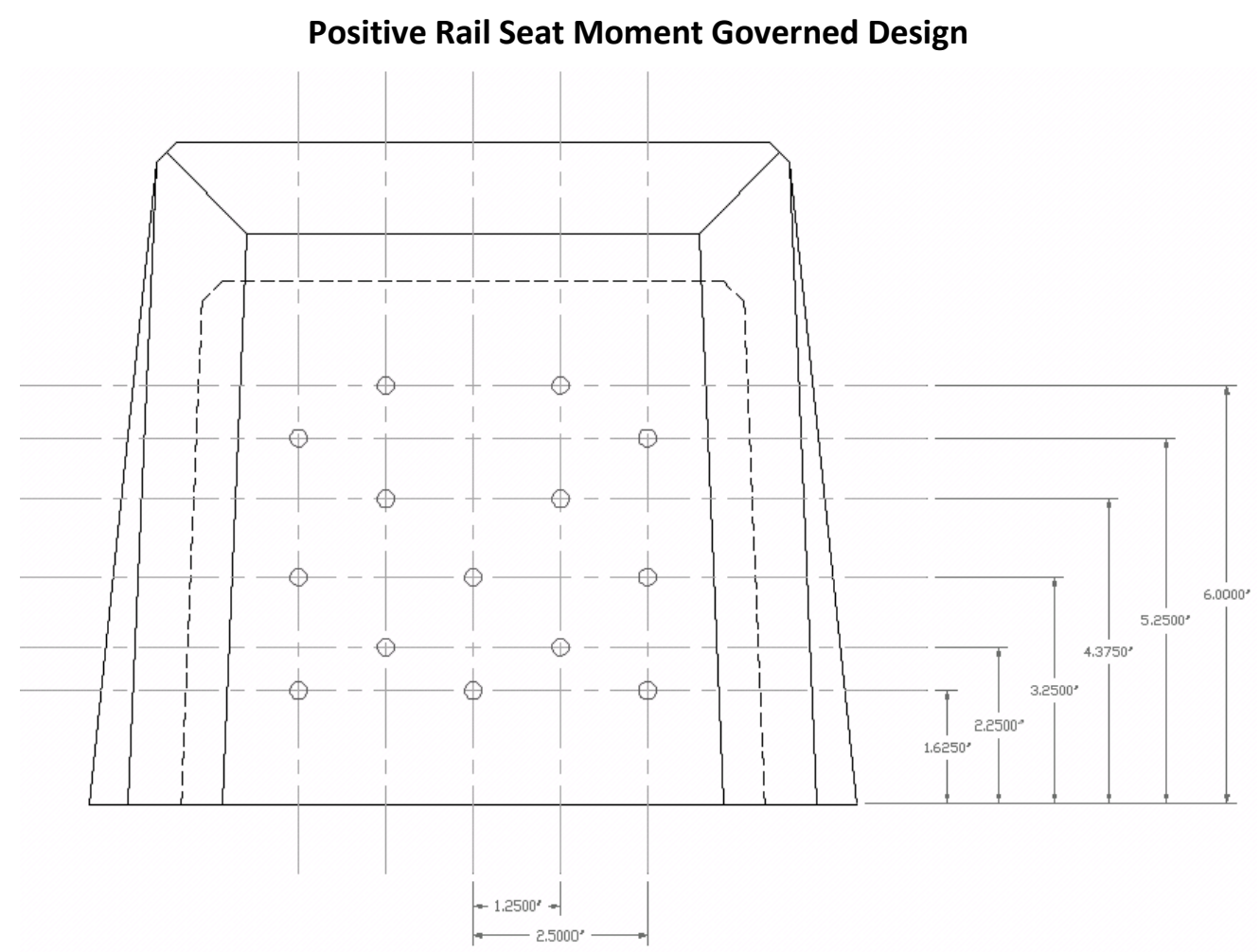

Negative Center Moment Governed Design

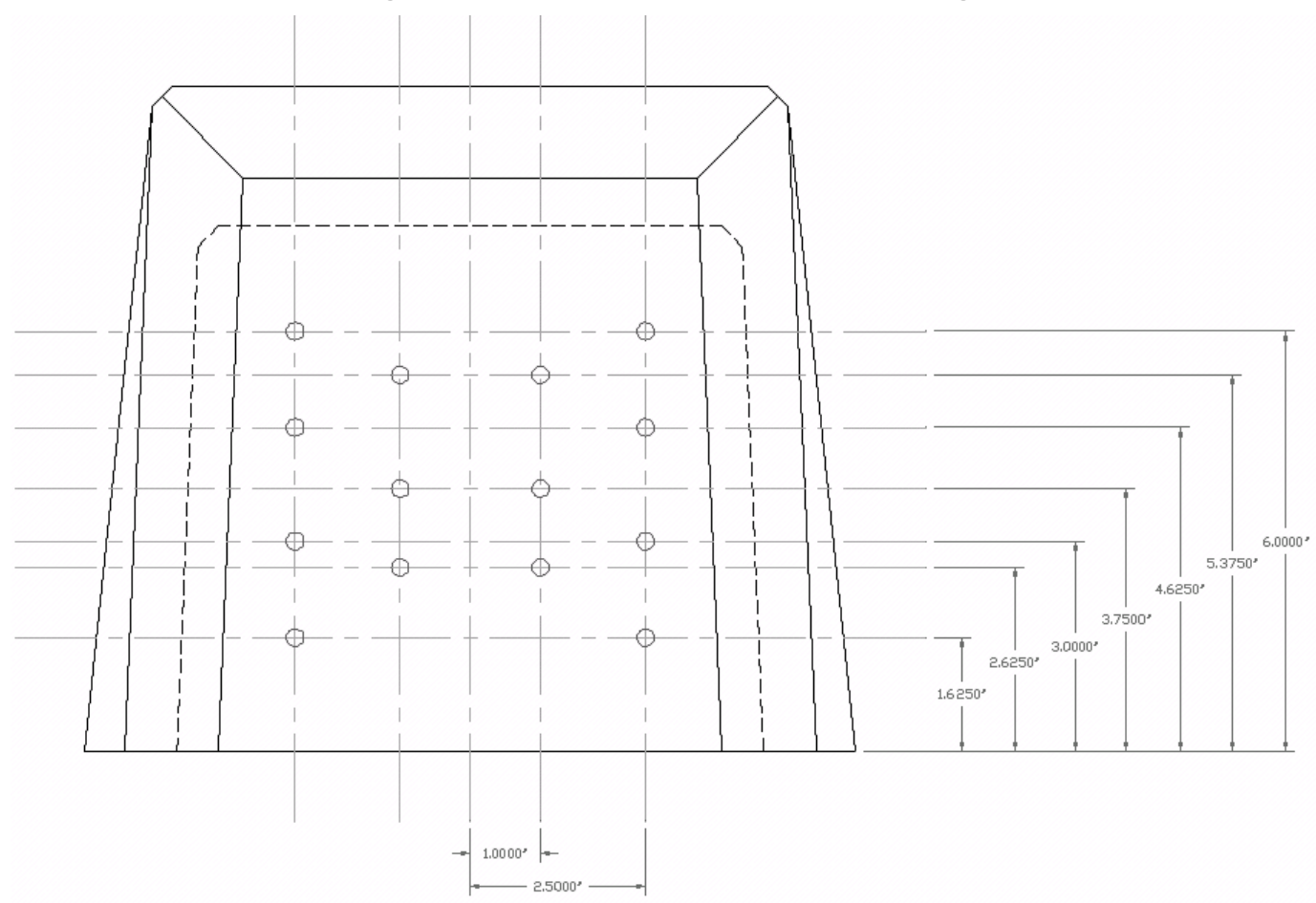


FRP(PT)-0.25(PD)-12(CS)

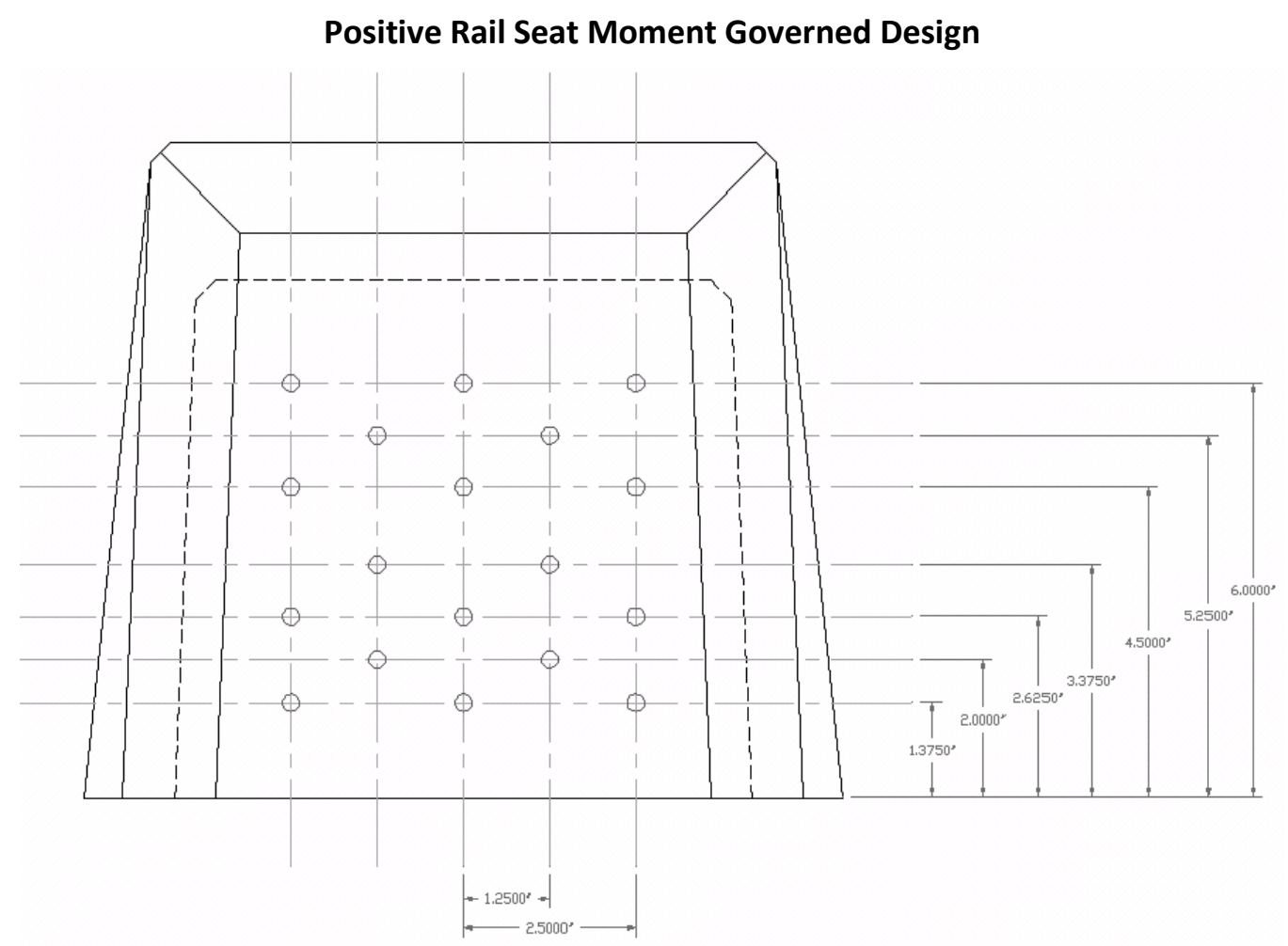

Negative Center Moment Governed Design

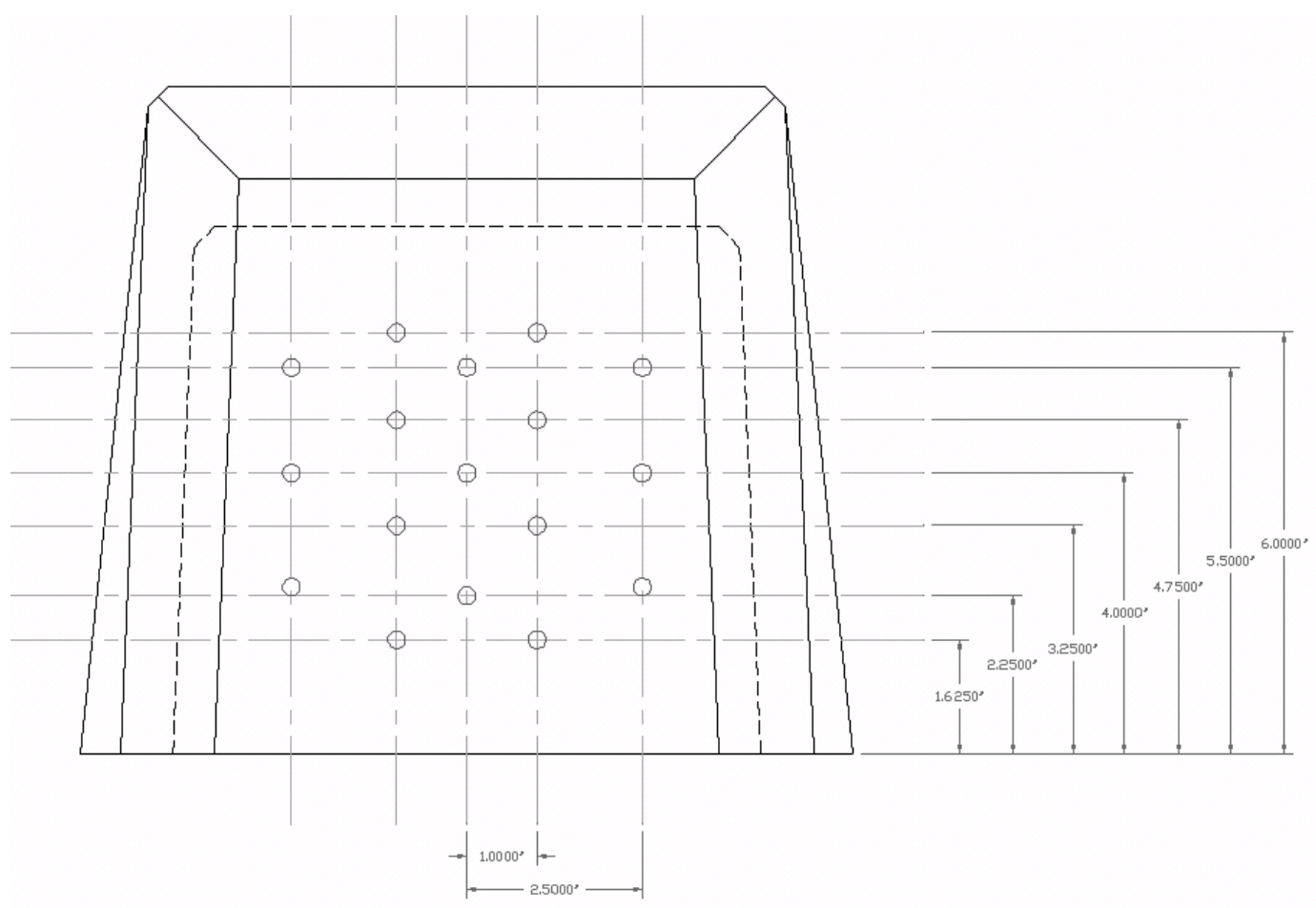


FRP(PT)-0.25(PD)-15(CS)

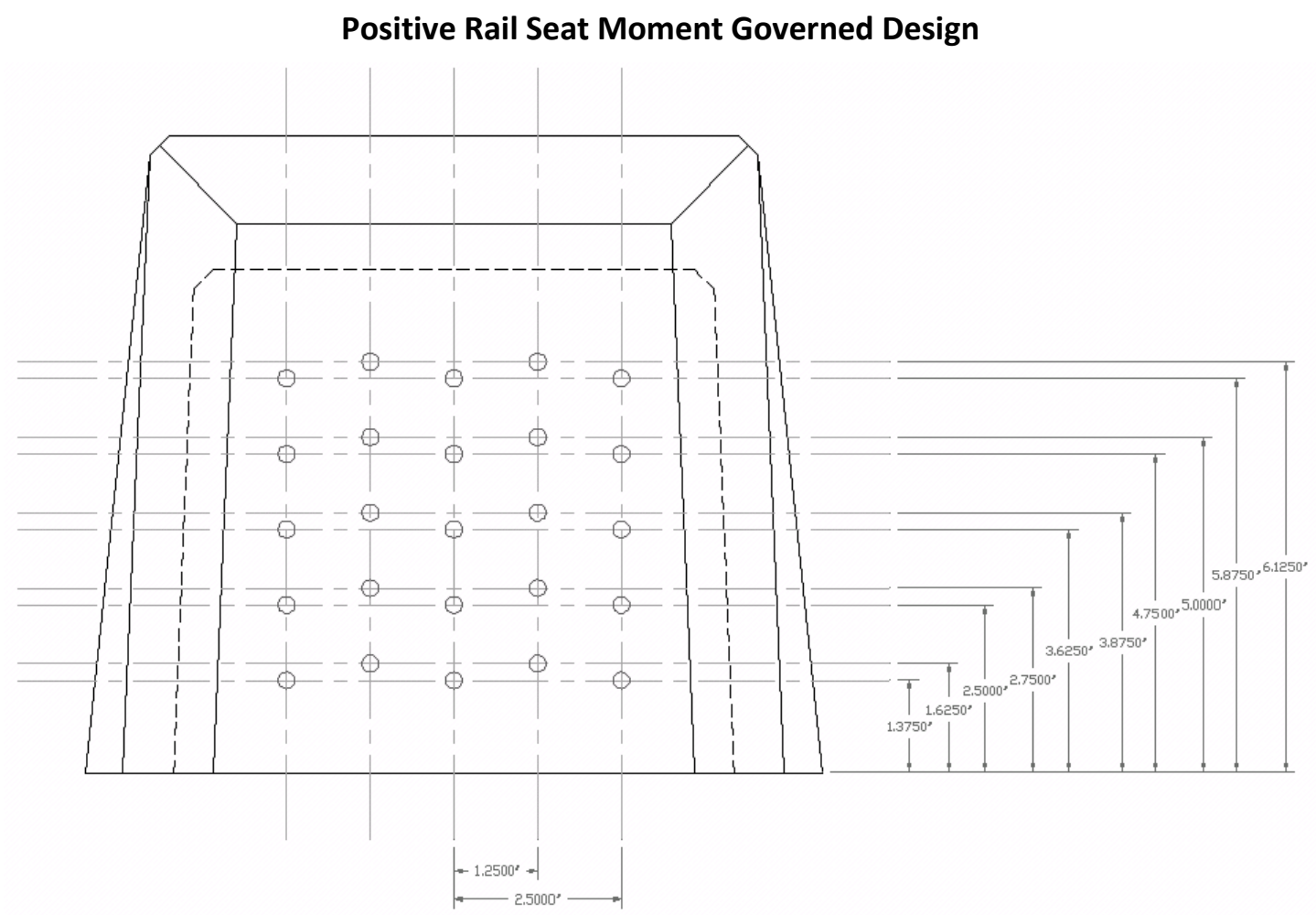

Negative Center Moment Governed Design

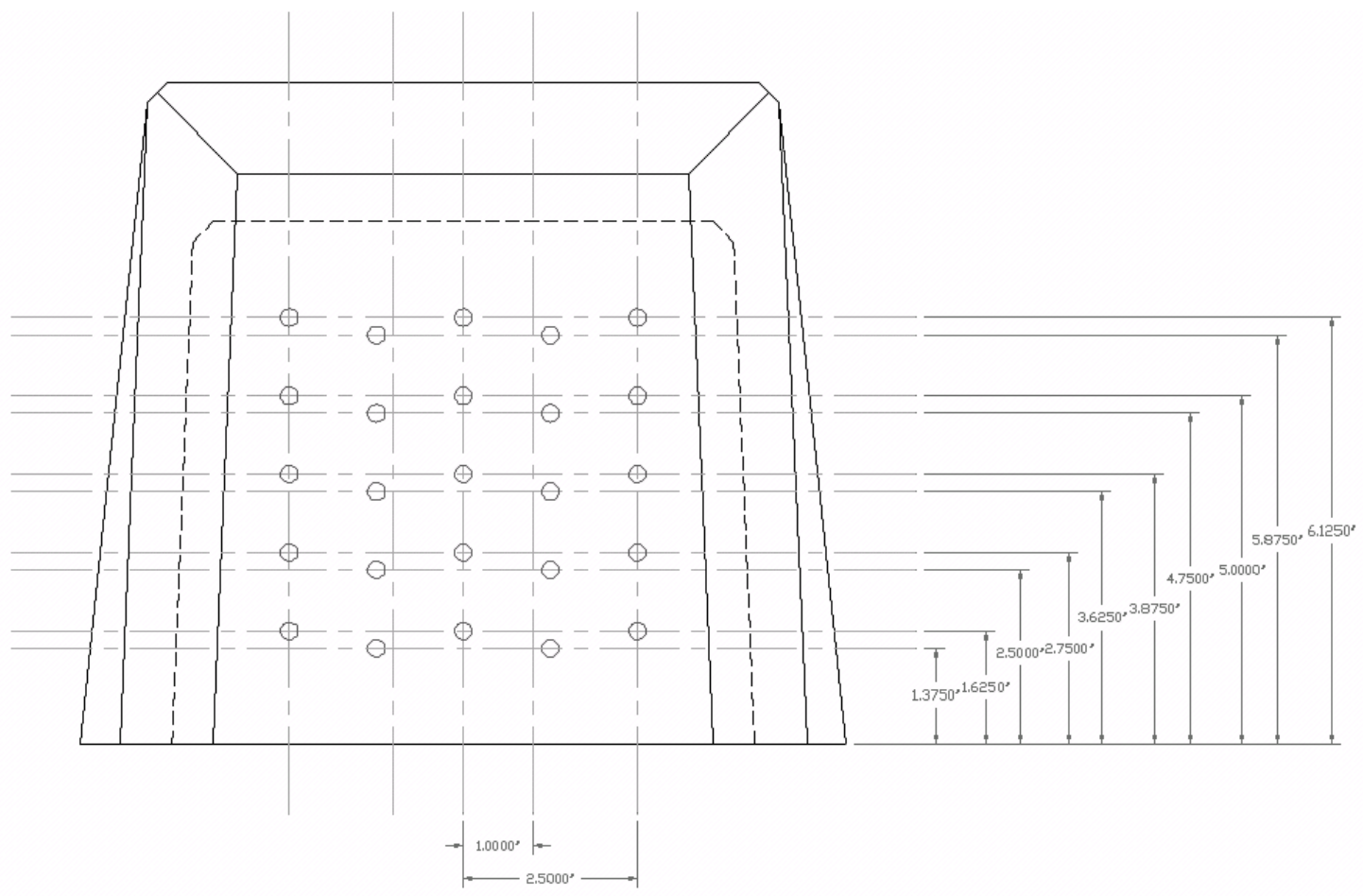


FRP(PT)-0.375(PD)-7(CS)

Positive Rail Seat Moment Governed Design

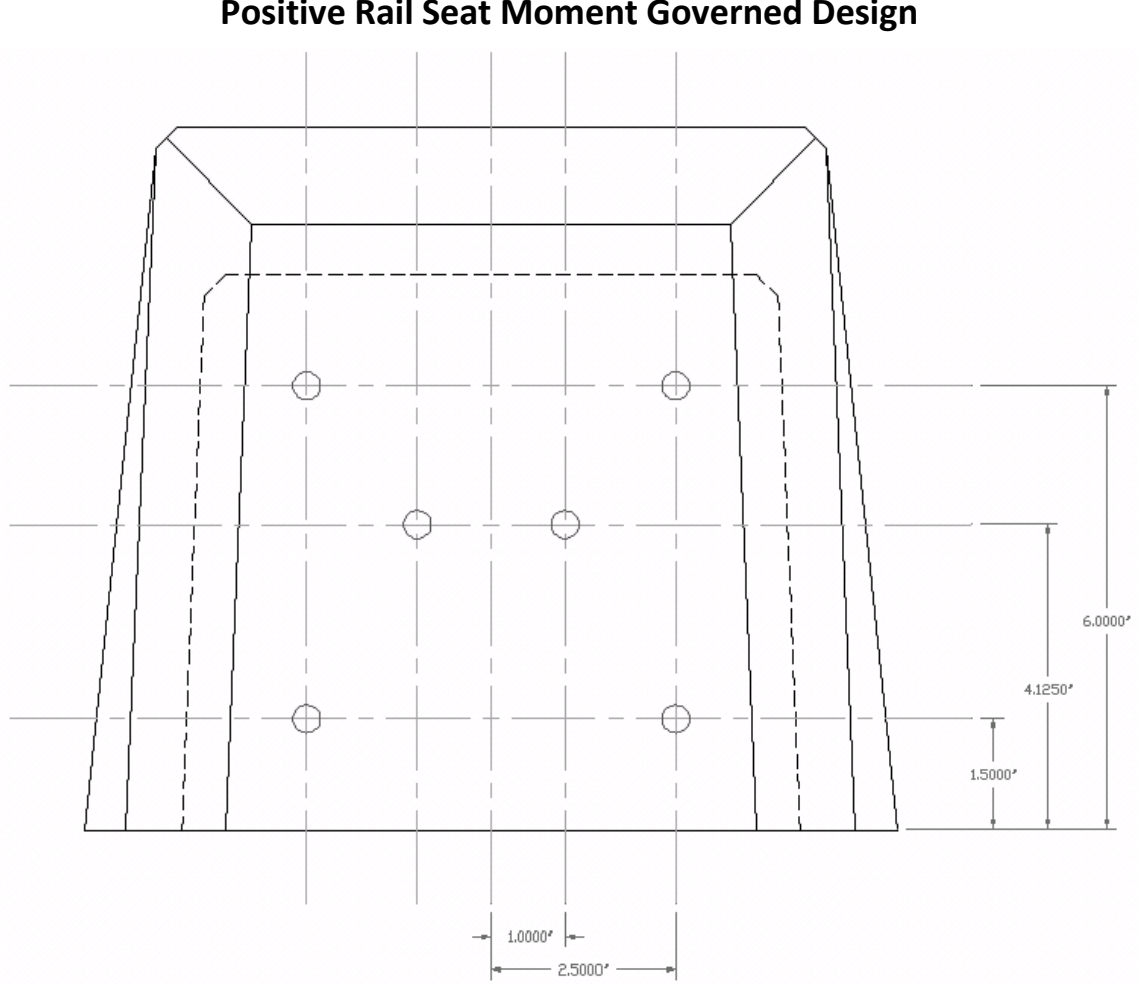

Negative Center Moment Governed Design

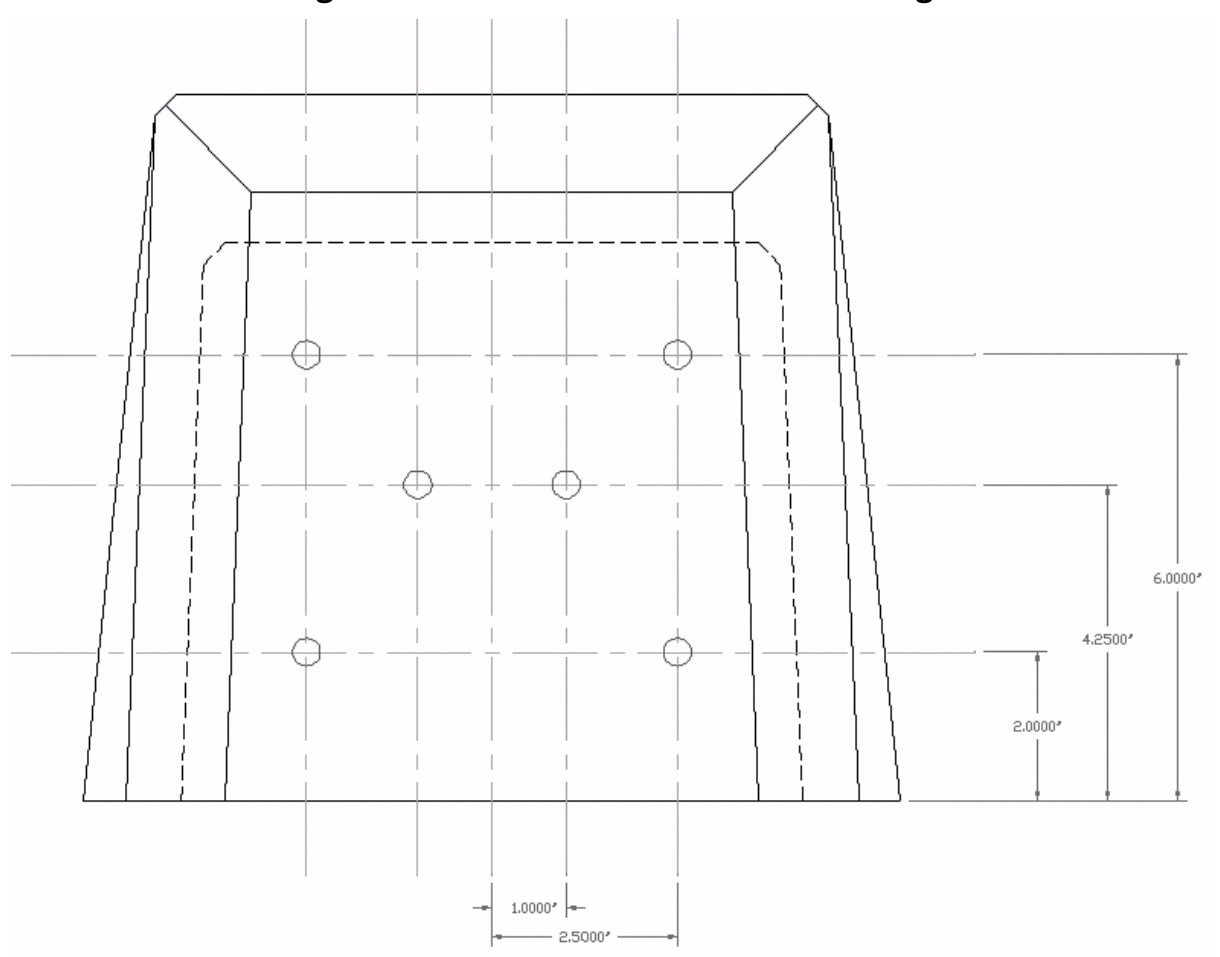


FRP(PT)-0.375(PD)-95(CS)

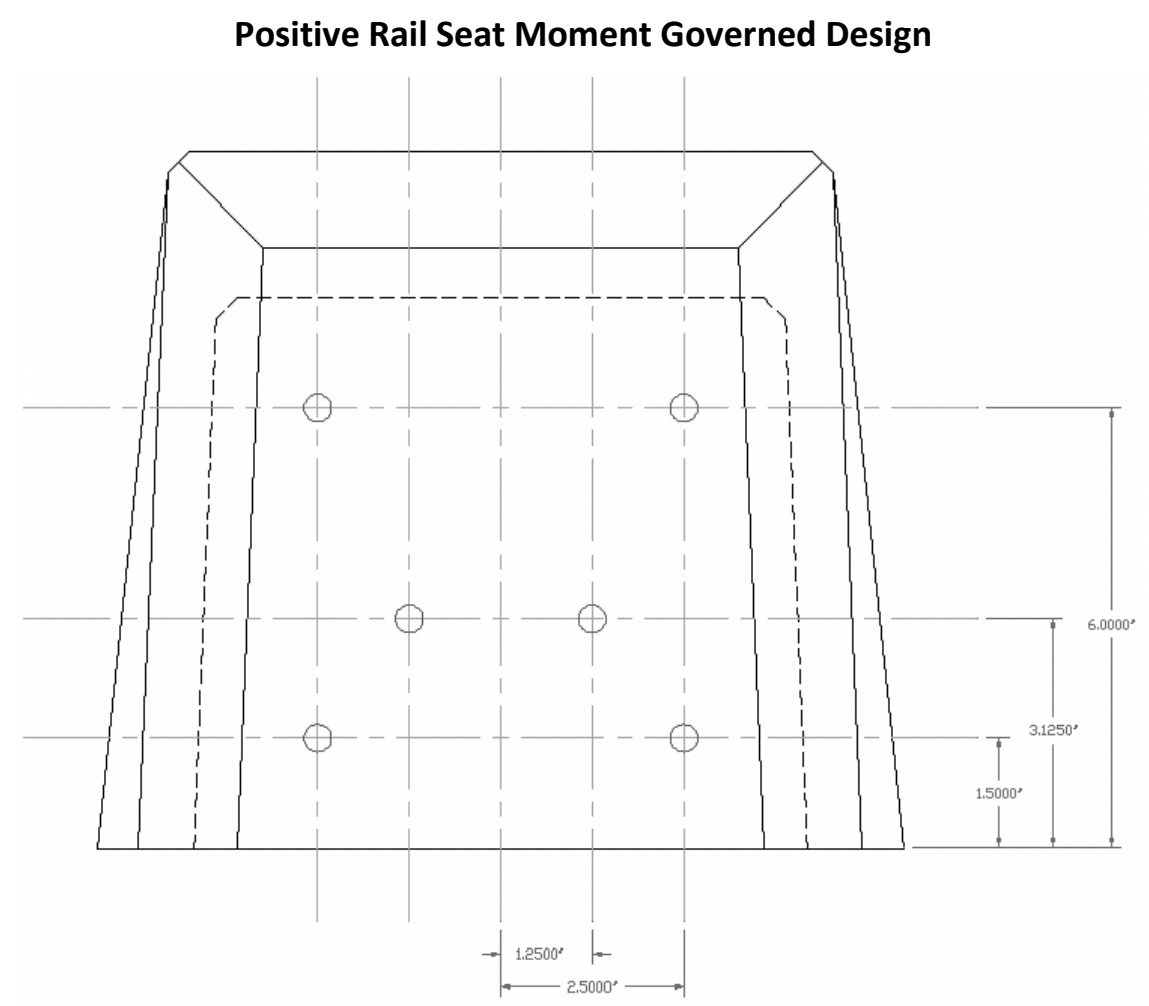

Negative Center Moment Governed Design

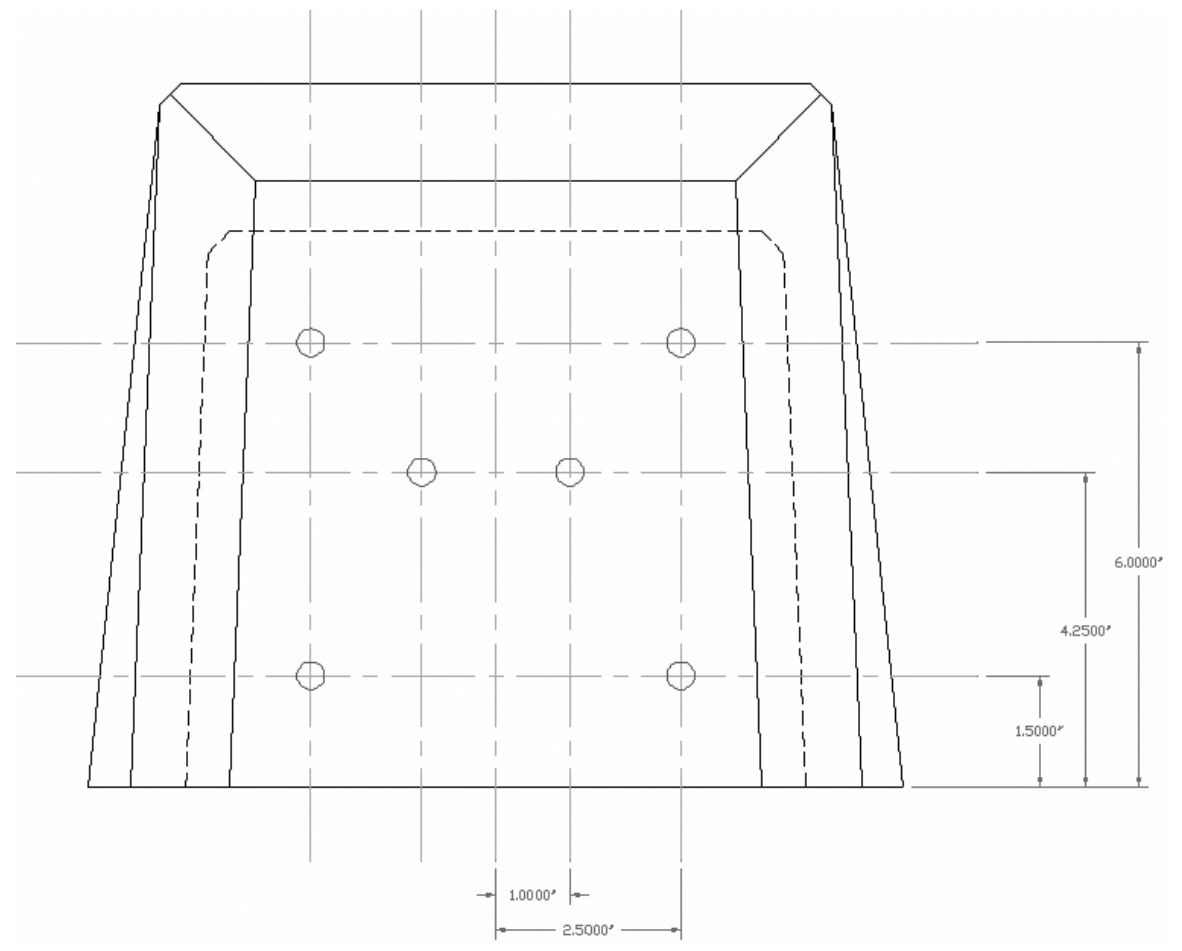


FRP(PT)-0.25(PD)-12(CS)

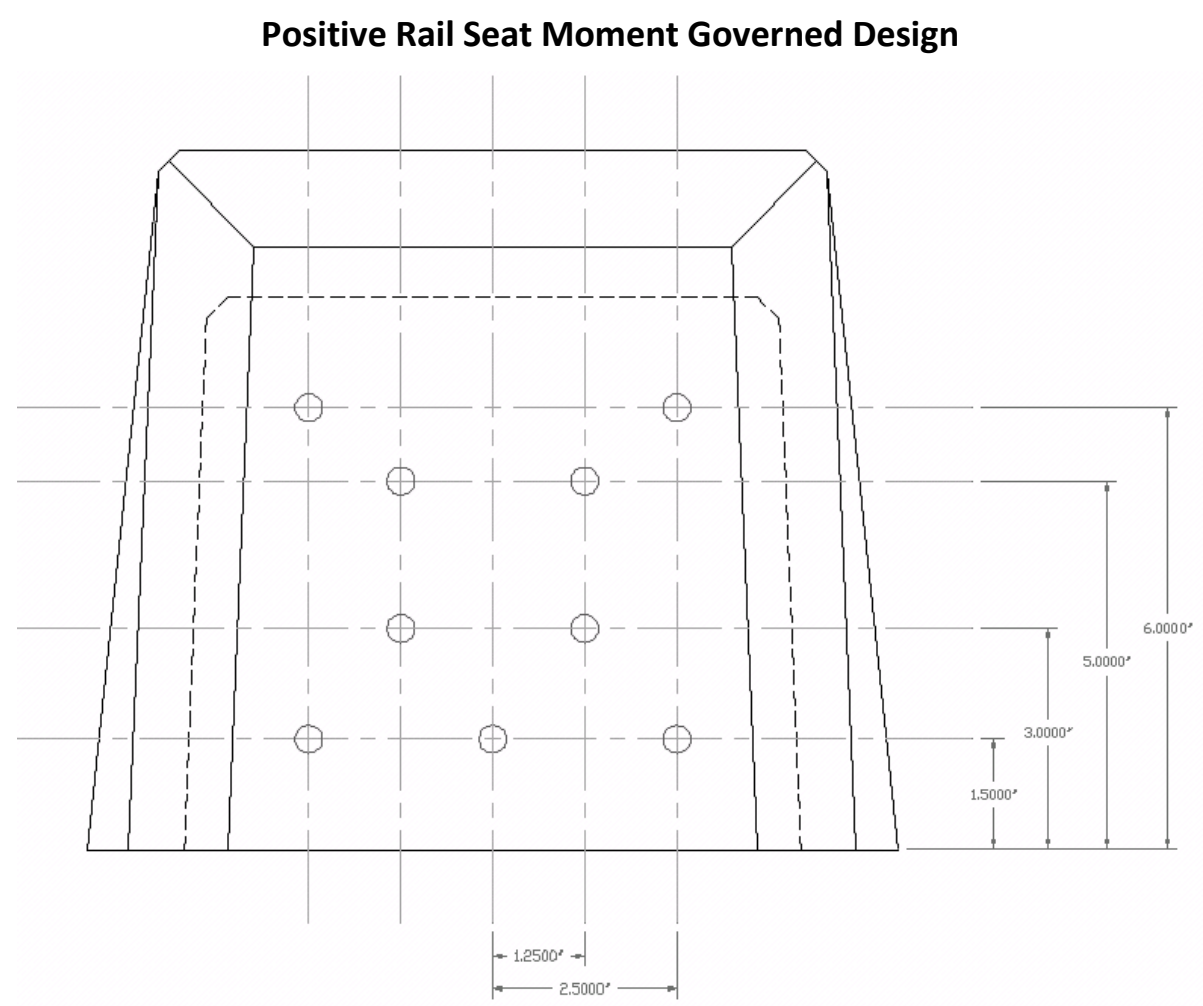

Negative Center Moment Governed Design

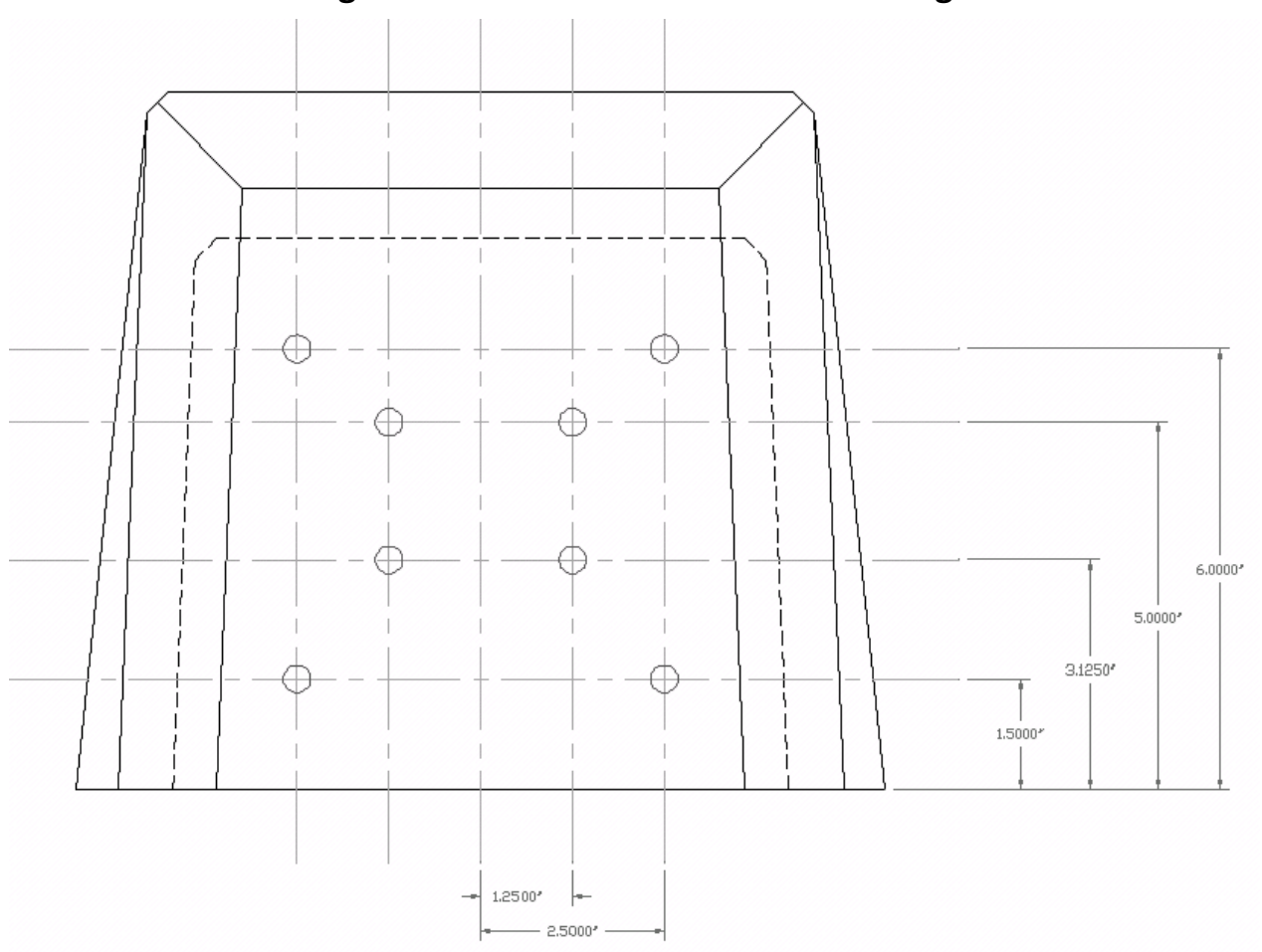


FRP(PT)-0.25(PD)-15(CS)

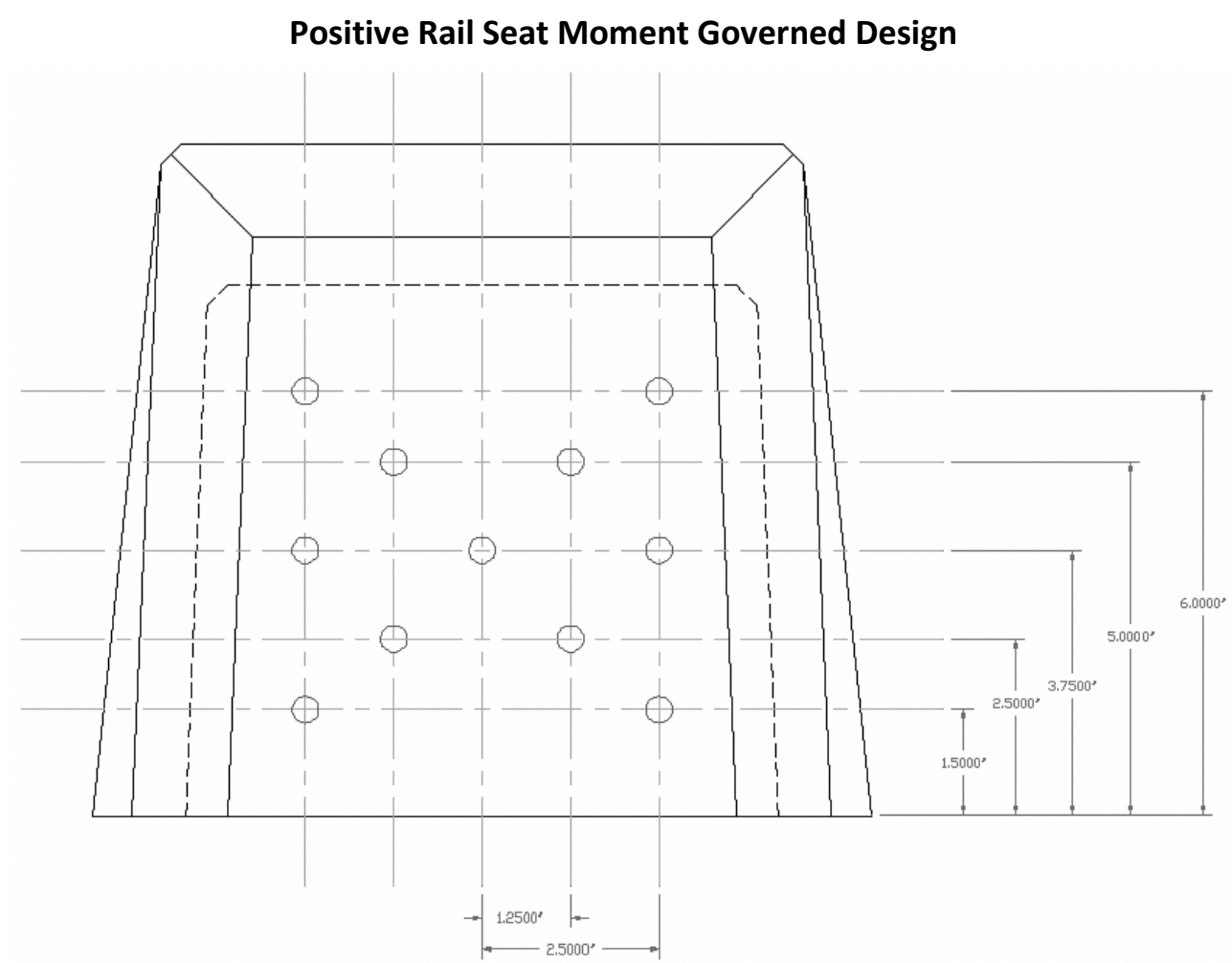

Negative Center Moment Governed Design

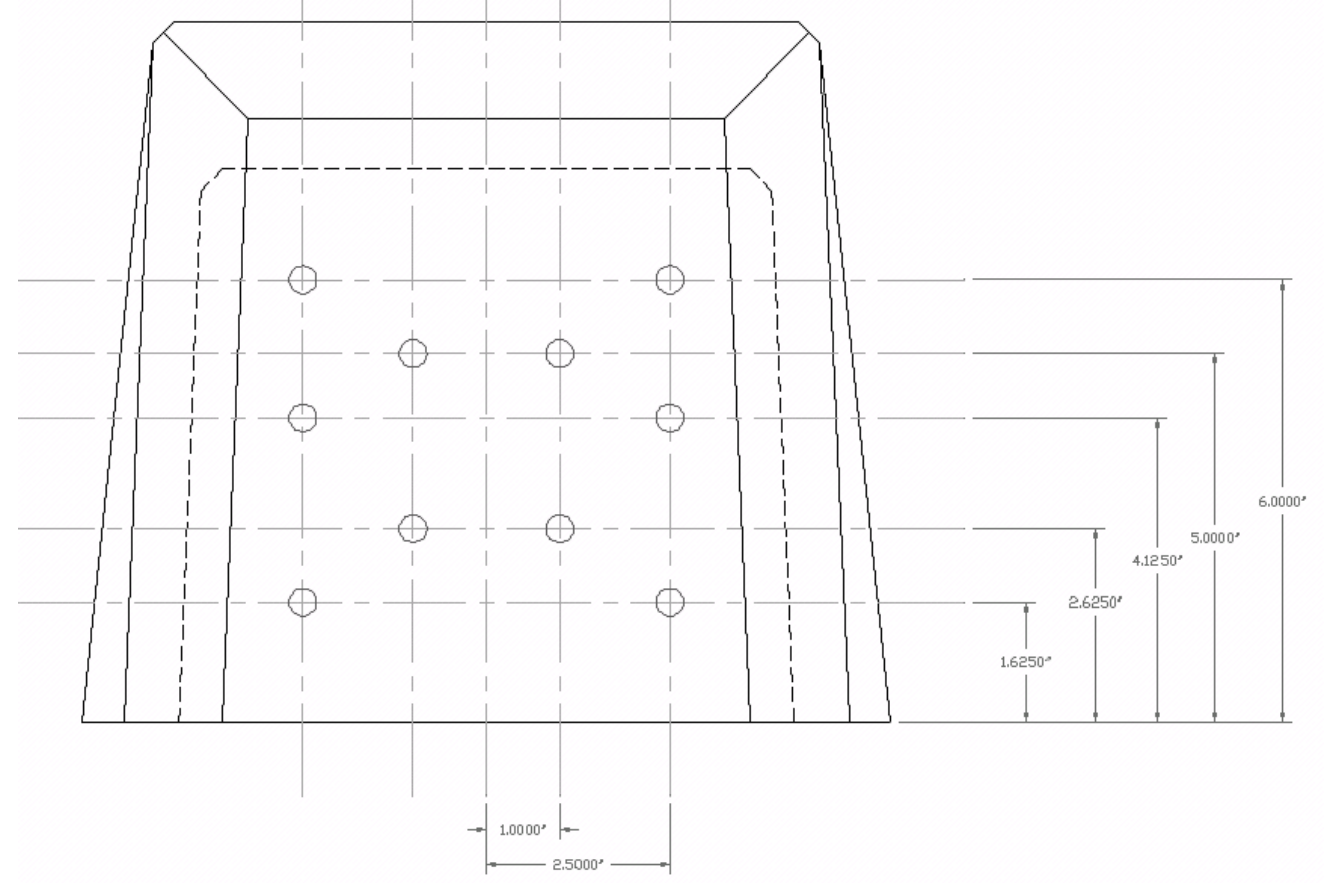




\section{Appendix F: FEA Modeling}

\section{F 1.0 Finite Element Analysis Modeling Work Plan}

Finite element analysis (FEA) is a powerful tool which can be applied to the design of irregular shaped members, whose geometry causes standard analysis to be difficult or more importantly inaccurate. For flexural members that are exposed to regions of high stress concentration or exhibit varying cross-sectional dimensions along their length, the application of FEA modeling techniques is a valued addition to the analysis process. It allows for the addition of sophisticated geometry which would have previously been simplified or neglected (Logan 2007). For the reasons discussed above, prestressed concrete railroad ties are an excellent candidate for analysis using FEA modeling methods. Using the FEA modeling techniques, an evaluation of the baseline tie and optimized tie designs can be completed. Reasons for modeling the tie designs include:

- Having a second numerical analysis technique to compare with experimental results,

- There are currently few examples of FEA analysis on prestressed concrete railroad ties,

- FEA analysis offers the ability to evaluate member behavior through the entire loading range to ultimate capacity,

- FEA analysis allows for the evaluation of many iterations with relatively little computational expense on the part of the user compared to other numerical methods such as those described in Chapter 4.

The following sections outline the application of FEA modeling to prestressed concrete railroad tie design. As stated in the future work section of this report, applying the methods of FEA to this analysis is the next logical step in the progression of this research.

\section{F 1.1 Baseline Tie Model}

To validate the application of FEA modeling to the analysis of prestressed concrete ties, a model of an existing tie design can be completed and compared to experimental results. Experimental results for the baseline tie design are available from the tie manufacturer and summarized on the design sheet included in Appendix B. The validation model would consist of the overall member geometry and the associated concrete and prestressing materials. Factors to be 
considered in the FEA model are material properties, prestressing force itself, transfer lengths, bond slip, loading stages and boundary conditions.

\section{F 1.2 Optimized Tie Design Model}

Similar to the modeling of the baseline tie, the optimized tie designs could be modeled to evaluate their behavior across the range of loading which ties are exposed to.

\section{F 2.0 Modeling Prestressed Concrete Ties Using Finite Element Analysis}

Due to the intricacies or irregularities present in a structure's design, analysis using a twodimensional model may be impossible or may simplify the actual structure to the point that it is no longer an accurate representation. In such cases finite element analysis (FEA) utilizing three dimensional modeling may be beneficial. However, three-dimensional FEA is tedious and impractical to perform by hand. This issue is further exacerbated by the incorporation of material properties and flow of loads throughout a structure. Computer software aids in resolving calculation problems but in order to produce a useful model proper procedures and modeling methods must be employed (Logan 2007).

FEA software has become a useful tool in the world of engineering, specifically structural engineering. However, FEA and its application to certain building methods such as reinforced and prestressed concrete can be substantially more difficult than say steel. The primary reason for the increased complexity is composite behavior which occurs in prestressed concrete between the concrete and steel (Nasreddin and Ergin 1991). Since structural concrete is one of the most widely utilized building materials in the world and with the structures it creates becoming more complex, the use of FEA is vital to the analysis and design of such structures.

This literature review will provide an introduction to the unique characteristics associated with modeling prestressed concrete such as nonlinear material behavior, heterogeneous materials, two stage behavior (cracked versus un-cracked) and bond slip between the steel and concrete elements. In addition, current modeling techniques will be presented.

\section{F 2.1 Introduction to the Application of FEA to Prestressed Concrete}

Over the last several decades the methods to analyze prestressed concrete using finite element analysis has advanced with respect to modeling and material behavior. This has occurred 
through the uses of innovative modeling techniques which utilize specialized elements and varying degrees of freedom. Considering these innovations three approaches are used in the modeling of a prestressed concrete members; discrete model, embedded model, and smeared model. Modeling prestressed concrete railroad ties would utilize one of these methods or a combination of them depending on the desired complexity and capability of the model (Nasreddin and Ergin 1991).

The first method and most straightforward in theory is the discrete model. The discrete model uses individual elements to construct the concrete and steel meshes separately. Typically solid elements and bar elements are used for the concrete and steel respectively (Figure 77). Fictitious spring elements model bond between the concrete and steel by connecting the separate nodes of the meshes. The various bond conditions existing between the limits of no bond and perfect bond can be applied by changing the spring stiffness. Large spring stiffness corresponds to perfect bond while low spring stiffness signifies a post-tensioned member absent of bond (Nasreddin and Ergin 1991). An advantage of the discrete model is that it allows for precise definition of material properties since two independent element types are used for the concrete and steel.

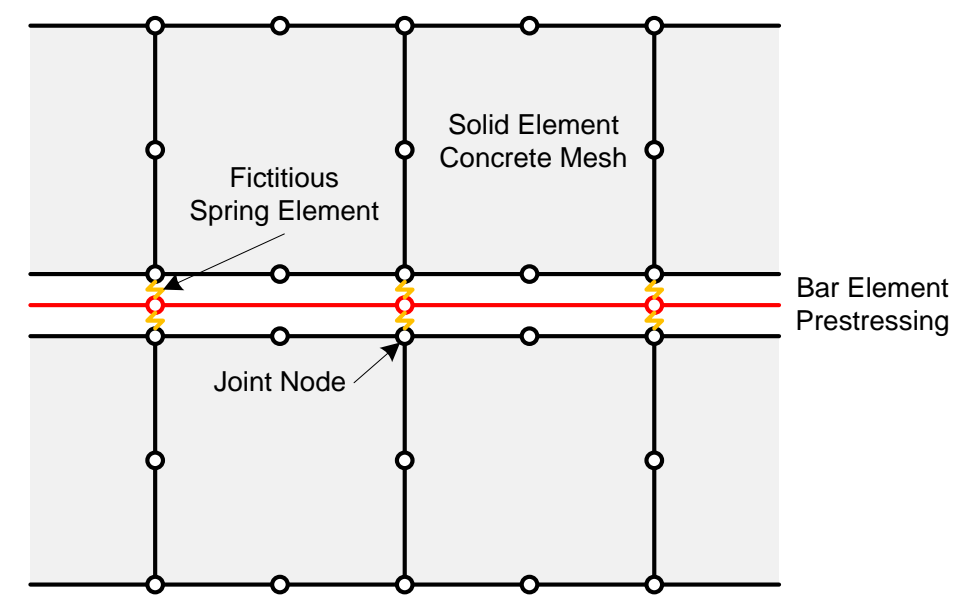

Figure 77: Two-dimensional demonstration of discrete model showing individual components

The only disadvantage to the discrete model is that meshing is restricted to the placement of prestressing. In order to have transfer of strain from the concrete to the steel and vice versa the 
individual nodes of the meshes must coincide to have the fictitious nodal connections representing bond. Therefore the equilibrium point between a uniformly very fine mesh and irregular mesh constrained to the position of reinforcement must be found (Nasreddin and Ergin 1991).

To surmount the issue of mesh dependency inherent in the discrete model, the embedded model formulation has been developed. The modeling process begins with setting the concrete mesh independent of the steel layout, refining as necessary. Once the steel and concrete elements have been placed the edge nodes of the concrete elements mid-side are moved to the intersections of the steel and concrete (Figure 78). Physically shifting the placement of the concrete edge nodes causes node mapping distortions (NMD) characterized by the change in the polynomials defining the parent element. To account for NMD the parent element must be augmented to allow for edge node movement. This is typically done automatically by most FEA software or alternate element types such as isoparametric elements with movable nodes may be used (Nasreddin and Ergin 1991).

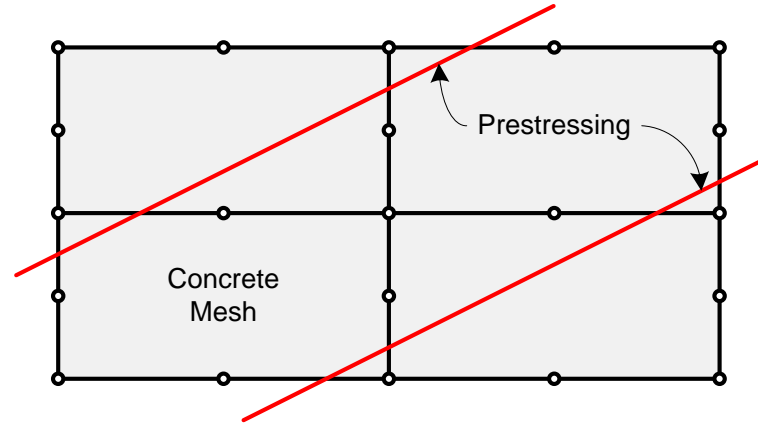

(a)

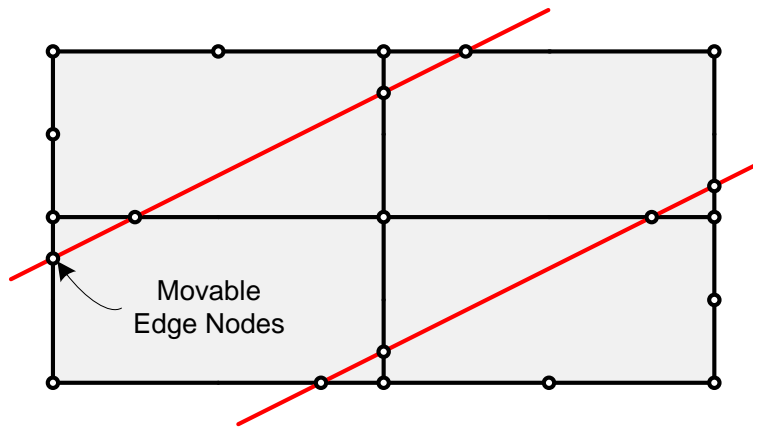

(b)

Figure 78: Steel elements in concrete mesh: (a) regular mesh (b) mesh with shifted edge nodes (Nasreddin and Ergin 1991)

Comparing discrete and embedded models, both allow for the use of separate steel and concrete elements, precision in terms of material property definition, while embedded models eliminate the mesh dependency characteristic of discrete models.

The final method called the smeared model is restricted to uniformly distributed reinforcement. In order to model prestressing or any other main reinforcement a discrete model is required. For the reinforcement modeled by the smear model perfect bond is assumed. For the 
aforementioned reasons the smear model is typically used in conjunction with discrete models to achieve the necessary material parameter options.

\section{F 2.2 Stress-Strain Relationships}

Similar to topics previously discussed simplifying assumptions about materials in terms of stressstrain behavior are made to perform standard prestressed concrete analysis. Typically it is assumed that stress-strain are linear relationships for both concrete and steel materials in the lower stress ranges and simplifying assumptions are made for their behavior in the upper regions of their stress-strain curves where the relationship become nonlinear ( $A C l$ 2005). However, with FEA software nonlinear analysis can be performed.

\section{F 2.2.1 Concrete}

The stress-strain curve for concrete contains both linear and non-linear portions. In order to model its behavior using FEA methods two alternative approaches are available. First the nonlinear curve portion can be approximated as a series of linear curves with set limits. Secondly, more complicated algorithms can be determined to match the curve. In either case the true nonlinear curve should be determined through laboratory testing. Approximations for concrete material properties do exist in the $\mathrm{ACl}$ code references previously discussed but for accurate model behavior laboratory data representative of the specific concrete mix is preferred (Lykidis and Spiliopoulos 2008).

\section{F 2.2.2 Steel}

Similar to concrete, high tensile steel, which is a characteristic of prestressed concrete, exhibits nonlinear behavior in the upper regions of its stress-strain curve near failure. To model the steel behavior the most common method is to use a multi-linear curve algorithm with set limits for the boundaries of the transitions. Steel manufacturers are typically able to provide the necessary information on the boundaries of the multi-linear curve (Mario et al. 1999).

\section{F 2.3 Two Stage Behavior}

Cracking is typically a term associated with failure, but in prestressed concrete this is not the case. Concrete members are unique in that they are permitted to crack under service design loads while remaining structurally sound and safe. In other words these members will crack prior to reaching their ultimate load. Therefore the model a designer uses must be capable of 
identifying when stresses in a member reach a specified cracking limit and adjust the model accordingly to continue being able to accurately simulate of the actual member behavior. A model may account for cracking by changing the section properties of the member and the flow of stresses within the model. Figure 79 illustrates a prestressed concrete beam which has cracked in the tension zone of the bottom flange, but is still capable of supporting load.

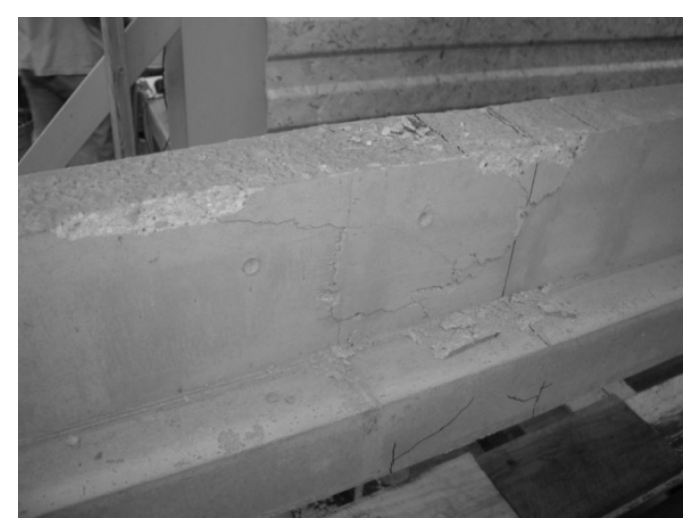

Figure 79: Cracking in bottom flange of beam outlined in black marker occurs prior to complete failure of beam

\section{F 2.4 Prestressing Transfer}

The mechanical relationship between steel and concrete is what generates the carrying capacity of the structural members which they compose. However, this relationship can be further complicated by stressing the steel in tension prior to service. The tensioned steel will in turn compress the surrounding concrete, ultimately making a more efficient design in terms of material. Through the use of prestressing longer spans and delayed crack initiation of the concrete can be achieved. When modeling a prestressed concrete member the transfer of the stress from the steel to the surrounding concrete element mesh is an issue which must be addressed.

Transfer of the prestressing stress begins from the free end of the prestressing steel where the initial strain is zero. As the prestressing moves inward from the ends of the member the initial strain and force are transferred into the surrounding concrete until the concrete has equivalent strain as the steel (Naaman 2004). The distance that is required for this equilibrium to take place is known as the transfer length. The distance required depends on the diameter of the prestressing steel, steel surface roughness, and the concrete mix design. 


\section{F 2.5 Prestressing Bond Slip}

For the mechanical relationship of prestressed concrete members to take place a bond between the steel and concrete occurs at the interface of the two materials. The bond consists of a mechanical interaction between concrete components and deformations along the surfaces of the prestressing. The strength of the bond depends on the strength of the concrete and the size and pattern of steel deformations. When the strength of this bond is exceeded slippage at the interface may occur. Cracking of the concrete to a depth of the steel at higher loads may increase slippage until yielding allows steel strains to more closely match those of the concrete (Figure 80) (Lykidis and Spiliopoulos 2008).

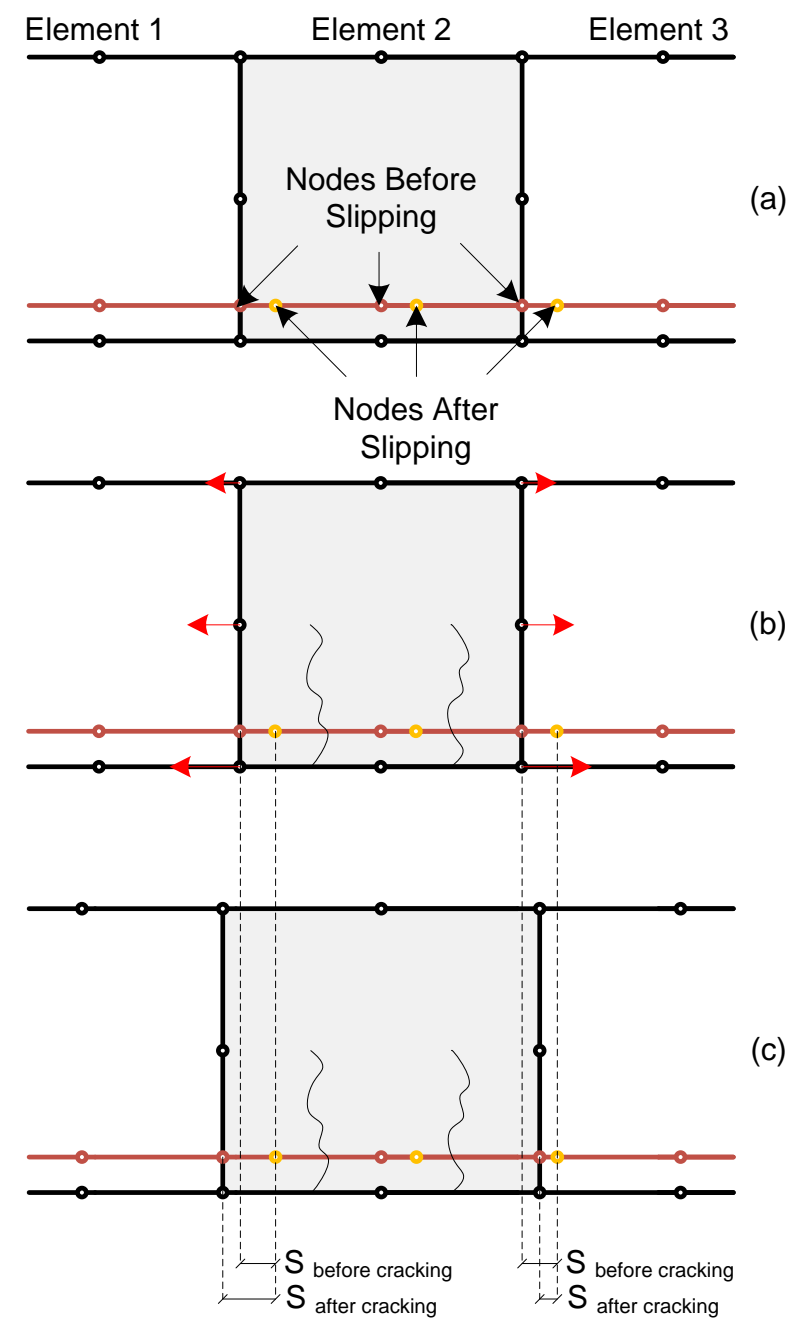

Figure 80: Effect of cracking at interface between steel and concrete (a) reinforcement slipping inside concrete prior to cracking (b) residual forces resulting from cracking act on un-cracked concrete to expand cracked region (c) steel elements deform from residual forces and bar slipping (Lykidis and Spiliopoulos 2008) 
Bond is typically ignored in design as compatibility is assumed. FEA provides the opportunity to account for the movement of steel and concrete elements with respect to one another. For models which intend on operating in the higher load regions of member failure, the inclusion of bond slip is essential for creating an accurate model. Modeling techniques for prestressing bond and slippage incorporation are discussed in the following sections.

\section{F 2.5.1 Perfect Bond Assumption}

The assumption of perfect bond is made for many models due to the added complexity which is associated with bond slip. Perfect bond is the assumption that the connection between the prestressing and concrete is infinitely strong. Therefore no movement will occur between the two elements throughout the loading sequence. The accuracy of this assumption depends on magnitude of the loading which the model is expected to perform through. If the model will operate within the initial linear region of the steel and during the uncracked section conditions then perfect bond assumptions are reasonable. However, if the prestressing is expected to yield and the concrete crack, this assumption will be unconservative in terms of ultimate capacity. Therefore it is generally suggested that models include bond slip parameters to accurately predict member behavior in the upper ranges of loading.

\section{F 2.5.2 Method I: Spring \& Concentrated Link Elements}

The first method of modeling bond at the interface and the most common in practice is the use of additional fictitious elements such as springs or concentrated links to connect the steel and concrete. Such connecting elements link the nodes of the respective steel bar elements and concrete matrix. Using this method the bond stresses are typically distributed linearly along the

element length. Connecting elements are also responsible for the transfer of prestressing force from steel element to concrete "host" element (Figure 77). Stiffness of the connecting elements is determined from experimental testing of bond. This process was discussed earlier and is often associated with the discrete model method (Lykidis and Spiliopoulos 2008).

\section{F 2.5.3 Method II: Element Subdivision}

To minimize the number of elements a method of subdividing the existing steel elements into sub-elements has been proposed. Each sub-element describes a single effect, such as inelastic behavior due to bending, shear behavior at the interface and bond slip behavior at higher loads. 
The interaction of the individual effects is achieved through the combination of the subelements (Lykidis and Spiliopoulos 2008).

\section{F 2.5.4 Method III: Additional Degrees of Freedom}

Similar to previous methods, steel modeling is done using bar elements. However, an additional degree of freedom is incorporated at each node expressing the relative slip between the steel and concrete. In this case the element represents both the steel and the bond at the interface. This additional degree of freedom is the relative slip displacement is defined as the difference between the steel and concrete displacements (Lykidis and Spiliopoulos 2008).

\section{F 2.6 Element Selection}

A variety of element types exists for both steel and concrete materials because the purpose and desired output may vary from model to model. The following section summarizes suggested elements for use in modeling prestressed concrete members. These recommendations are based on the commercially available software ANSYS.

\section{F 2.6.1 Solid Elements}

Characteristics of solid elements which are necessary for modeling concrete of concrete included; the ability to model the cracking and crushing of the solid matrix, user defined inelastic response. It is recommended that the user start with the SOLID65 three-dimensional reinforced concrete solid element which is defined by eight nodes with each having three degrees of freedom (Figure 81). This element must be used in association with the discrete model since edge nodes are not available. To obtain non planar surfaces associated with the tie geometry prism and tetrahedral options are available. The SOLID65 is capable of cracking tension and crushing in compression due to built in algorithms which are dependent on user input of material parameters.

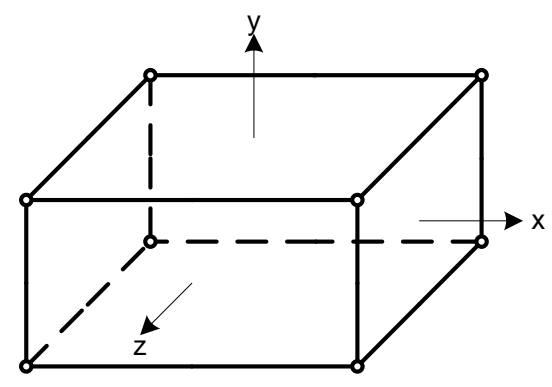

Figure 81: SOLID65 three-dimensional element 


\section{F 2.6.2 Bar Elements}

To model prestressing the two necessary element characteristics are the ability to perform inelastic behavior and define an initial strain. It is recommended starting with the LINK8 element (Figure 82). This is a truss element which is capable of compression and tension with three degrees of freedom at each node. Each end node is modeled as a pin connection so no bending of the element is considered. An advantage of the LINK8 element is the ability to specify an initial strain. This is useful for defining the initial prestressing force. In addition, prestressing transfer can be completed by simply varying the initial strain along the length of the steel mesh.

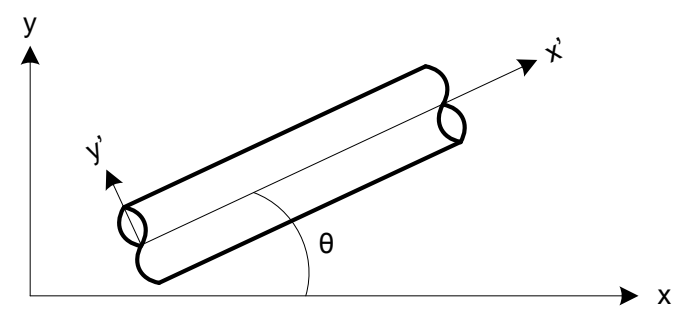

Figure 82: LINK8 bar element displayed with local and global axis

\section{F 3.0 Summary of FEA Related to Concrete Ties}

The three most important aspects of FEA modeling of a prestressed concrete railroad tie are the following:

- The model must be capable of differentiating when the elements have reached the allowable concrete stress conditions which correspond to failure.

- The model must be capable of operating within the nonlinear range of behavior to capture the ultimate capacity of the tie.

- The connection between the concrete and prestressing elements should be able to account for bond slip, transfer and development.

- Concrete railroad ties have variable boundary conditions due to the changing ballast support distributions. 


\section{Appendix G: Copyright Permissions}

From: Nigel.Peters@cn.ca

To: rhlutch@mtu.edu

Russell,

Thank you contacting me regarding the use of material from one of my papers. I have no objection to you using the photos or any other material in the paper as long as you acknowledge and cite the source.

Good luck with your paper and your seminar.

Nigel W. Peters, Ph.D., P.Eng

Assistant Chief Engineer

Bridges and Structures

CN Rail

Homewood, IL.

----- Original Message -----

From: Russell Lutch [rhlutch@mtu.edu]

Sent: 29/01/2009 05:15 PM EST

To: Nigel Peters

Subject: Permission for use of photographs, Russell Lutch-Michigan Tech University

Dr. Nigel Peters,

Hello, my name is Russell Lutch and I am a graduate student at Michigan Technological University. I am writing a conference paper called "Causes and Preventative Methods for Railseat Abrasion in North American Railroads" for the ASCE Cold Regions Engineering Conference. I am citing a report you wrote in collaboration with a Steven Mattson several years ago titled "CN 60E Concrete Tie Development". In the paper there are several excellent photographs depicting rail seat abrasion and the cast-in steel plates used in the CN 60E design. I would like your permission to use those photographs in my conference paper merely as examples. Please feel free to contact me with any questions, and I look forward to hearing your response.

Thank you,

Russell H. Lutch 